\title{
Using Concept MappingPattern Matching to Develop a Conceptual Framework for Successful Transition of First Year Saudi Students into Postsecondary Education
}

Atiyah A. Alghamdi

Follow this and additional works at: https://researchrepository.wvu.edu/etd

\section{Recommended Citation}

Alghamdi, Atiyah A., "Using Concept MappingPattern Matching to Develop a Conceptual Framework for Successful Transition of First Year Saudi Students into Postsecondary Education" (2017). Graduate Theses, Dissertations, and Problem Reports. 5062.

https://researchrepository.wvu.edu/etd/5062

This Dissertation is protected by copyright and/or related rights. It has been brought to you by the The Research Repository @ WVU with permission from the rights-holder(s). You are free to use this Dissertation in any way that is permitted by the copyright and related rights legislation that applies to your use. For other uses you must obtain permission from the rights-holder(s) directly, unless additional rights are indicated by a Creative Commons license in the record and/ or on the work itself. This Dissertation has been accepted for inclusion in WVU Graduate Theses, Dissertations, and Problem Reports collection by an authorized administrator of The Research Repository @ WVU.

For more information, please contact researchrepository@mail.wvu.edu. 
Using Concept Mapping/Pattern Matching to Develop a Conceptual Framework

for Successful Transition of First Year Saudi Students into Postsecondary Education

\author{
Atiyah A. Alghamdi \\ Dissertation submitted to the \\ College of Education and Human Services \\ at West Virginia University \\ in partial fulfillment of the requirements \\ for the degree of \\ Doctor of Philosophy \\ in Education \\ Educational Leadership and Policy Studies
}

Sam Stack, Ph.D., Chair

Sebastián R. Díaz, Ph.D., J.D.

Micah Fierstein, Ph.D.

Nathan M. Sorber, Ph.D.

Ugur Kale, Ph.D.

Department of Curriculum and Instruction, Educational Leadership, and Literacy Studies

Morgantown, West Virginia

2017

Keywords: Concept Mapping/Pattern Matching, Saudi Higher Education, King Saud University, Preparatory Year Program, First-Year Experience, First-Year Theory, First-Year Organizational

Structure and Design, First-Year Pedagogy

Copyright 2017 Atiyah A. Alghamdi 


\section{Abstract \\ Using Concept Mapping/Pattern Matching to Develop a Conceptual Framework for Successful Transition of First Year Saudi Students into Postsecondary Education Atiyah A. Alghamdi}

The Preparatory Year Program (PYP) considers a new phenomenon in Saudi higher education. This study identified the future ideal functions of PYP and developed a conceptual framework for the program at King Saud University. Four research questions were answered in this study including: 1) Using the Concept Mapping/Pattern Matching methodology, how do Saudi male and female postsecondary stakeholders conceptualize the future ideal functions of Preparatory Year Deanship to help students successfully transition into their first year of college/university?; 2) Does this Concept Mapping/Pattern Matching conceptualization compare and contrast with the current working model of the Preparatory Year Program at King Saud University?; 3) Does this Concept Mapping/Pattern Matching conceptualization compare and contrast with King Saud University's explicit strategic plan?; and 4) When conducting a Concept Mapping/Pattern Matching conceptualization, how do the results for males compare and contrast with the results for females?

The Concept Mapping/Pattern Matching methodology advanced by (Trochim 1989a, 1989b; Kane \& Trochim, 2007) utilized for data collection and analyzing. Fourteen male including 2-PYP students, 1-Medicine College Faculty, 1-Business Administration College Faculty, 1-Engineering College Faculty, 4-PYP Faculty, 1-Academic Advising Faculty at PYP, 1-Students Affairs Faculty at KSU, 1Students Affairs at PYP, and 2-Educational Company and nine female including 3-PYP' students, 1Pharmacy College Faculty, 2-PYP Faculty, 2-Parents, and 1-Educational Company participated in two separate brainstorming sessions. The male participants generated 48 statements and the female group generated 36 statements. The participants in each group sorted the generating statements individually into groups and rated them based on a five-point scale for relative importance and institutional efficacy.

For each group male/female the Multidimensional Scaling and Hierarchical Cluster Analysis were conducted to create various concept maps, the final one being a seven-cluster and six-cluster concept map for male and female, respectively, representing the stakeholders' conceptualization of the field being studied. Following the creation of the concept maps for each group, the resulting priorities and their conceptualization schema were both compared and contrasted to the current working model of PYP and the explicit strategic plan of KSU (KSU2030) for similarities and differences in a qualitative document analysis. The male and female perceptions were also compared and contrasted.

The study revealed three main dimensions for developing PYP at KSU including Organizational design and structure, Pedagogical functionality, and Student services. Further, seven foundational principles may be embraced to develop the three dimensions previously mentioned including: 1) adopting a talent philosophy to first meet student's needs and then the institution's mission; 2) a flexible PYP model to meet individual student's needs; (3) applying a pedagogical on theory-based; (4) reorganizing PYP's tasks and centralizing student's services; (5) involving KSU's colleges; (6) supporting nonfiltering program; and (7) adopting self-operation. The significance of this study for the educational policymaker, planner, and developer, is that the findings can be used as a model to make student's transition into postsecondary education successful. 


\section{Dedication}

I dedicate this dissertation to several people who have contributed and supported me on my knowledge journey. To my parents, Abdullah and Refaah Alghamdi, for their inspiration and encouragement. To my wife, Fatimah, for her sacrifices, fruition support, understanding, and patience. To my daughters and sons for their endurance and continued support. Additionally, to my sisters and their husbands and kids for all support. 


\section{Acknowledgments}

I would like to acknowledge Allah Almighty, the God for all things given to me in my life and for guiding and for providing me the strength, inspiration, motivation, and wisdom to achieve what I have done so far in my journey in life.

I would like to thank the Saudi Arabian government and King Saud University, in particular, for giving me a learning chance to study abroad in a great country of the United State of America at respectable university, West Virginia University.

This study could not have been conducted without the guidance of an outstanding dissertation committee, to which I be indebted thanks and gratitude. To Dr. Sam Stack, my advisor, for all the support and encouragement he provided to me. I would like to thank him further for facilitating and supporting me to overcome all challenges encountered during my study. I thank him for his fast responses to all my studying requests and inquiries.

I would sincerely like to give special thanks to Dr. Sebastián R. Díaz, my first advisor before he had to devote his time to other commitments. I would like to thank him for being my professor and for kindly agreeing to serve on my committee to complete what we started together in the dissertation. I would like to thank Dr. Sebastián for believing in me and for giving me the chance to be a student at WVU. I will not forget my first meeting with him when I was carrying my big dream and looking for someone to guide and direct me to achieve it. I also would like to thank him for introducing me to the Concept Mapping/Pattern Matching methodology that was

utilized in this study. Thank you Dr. Sebastián for all the minutes, hours, days, months, and years you dedicated to working with me, despite the distance between us.

I would also like to thank Dr. Micah Fierstein for his kind support. I will not forget the Leadership class that I took with him and how he taught me how leaders should be in the educational division. His words still touch my soul and settled on my heart when he said, "listen to others deeply and help them to find their voice". I will not forget his wisdom when he said, "as a leader be in the middle, do not dive in the depth of the ocean because you only will find sand".

Additionally, I would like to thank Dr. Nathan M. Sorber for his agreement to serve on the dissertation committee. I had several courses with Dr. Nathan, which expanded my knowledge, experience, and skills in higher education and policy studies. In addition, I appreciated his constructive comments and feedback on my dissertation. 
I am grateful to Dr. Ugur Kale for also kindly agreeing to serve on the dissertation committee. Dr. Kale is a supportive and kind person. His comments on my dissertation and direction helped to improve this study structure and outcomes.

I would also like to acknowledge the 14 male and 9 female participants who accepted the invitation to participate in the study. I really appreciate their time and patience to complete this study process. Their inputs and ideas made this study real and without their contributions this study would not have been conducted.

My thanks and appreciation is extended to Drs. Paul Chapman and Philip Ice for provisionally serving on the committee until they too had to dedicate their time to other commitments. Their time, advice, and feedback have been greatly valued. Furthermore, my gratitude is extended to the College of Education and Human Services family at WVU. To Dr.'s D.J. Hendricks, Miriam Douglas, Suzanne Hartman, Brandi Weekley, Reagan Curtis, Malayna Bernstein, and Mr. Michael Wilhelm, the former director of the International Office.

Finally, I would like to thank Dr. Nami Aljohani the Dean of the Preparatory Year Deanship at King Saud University on his permission to conduct this study at PY. Furthermore, to Dr. Fayez Alghamdi from King Saud University and Dr. Saad Yaaqeib from United Arab Emirates University for their help in the translation process of brainstorming sessions outcomes from Arabic-English-Arabic. Additionally, I would like to thank Drs. Misfer Alsaloly, Khitam Alqahtani, Khalid Alqarni, Alawiya Alali, and Hasan Sababeha from King Saud University for their support and help for organizing and conducting the brainstorming sessions at KSU. All thanks and gratitude for those who have a positive impact on my life and supported me in different ways but I did not include their names in this acknowledgment. 


\section{Table of Contents}

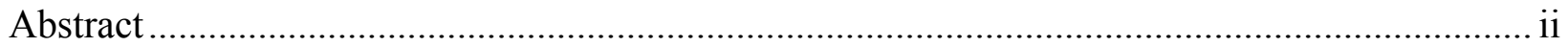

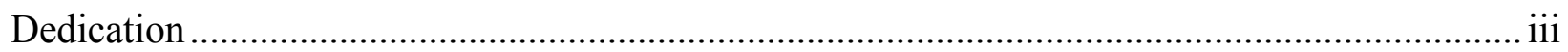

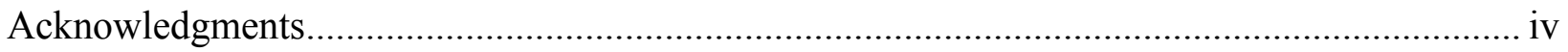

Table of Contents ........................................................................................................ vi

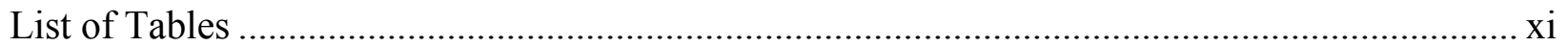

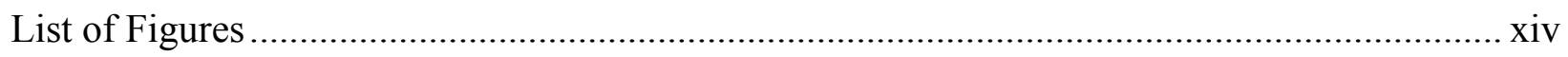

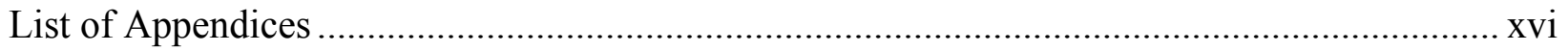

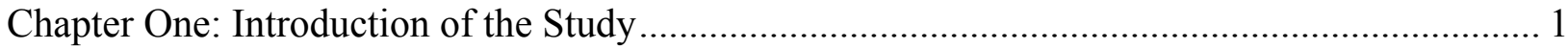

Brief History of Saudi Higher Education................................................................ 1

Saudi Higher Education Reform Movement.................................................................. 3

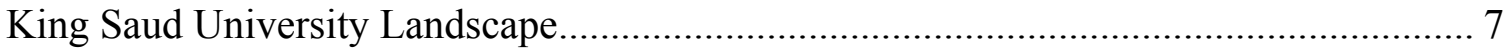

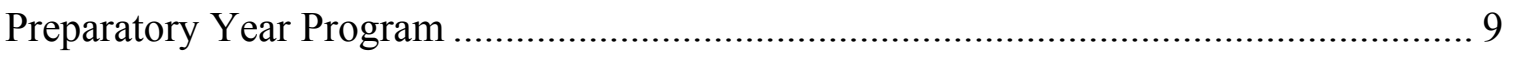

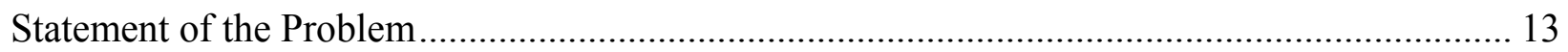

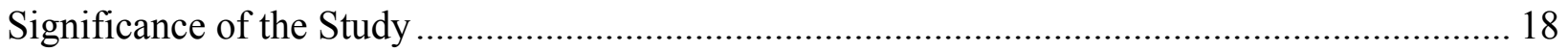

Purpose of Study and Research Questions........................................................................... 20

Definition of Terms in Alphabetical Order..................................................................... 22

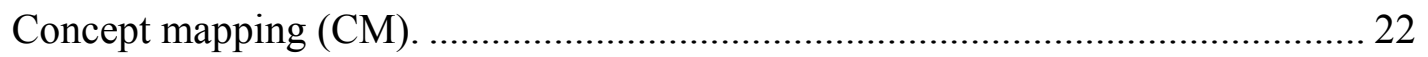

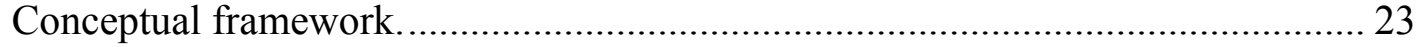

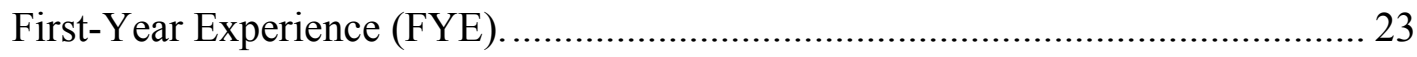

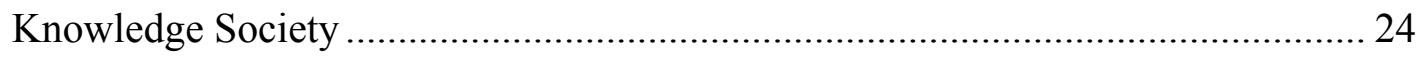

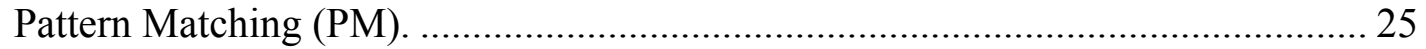

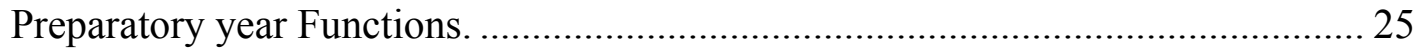

Preparatory Year Program (PYP) . ................................................................ 26

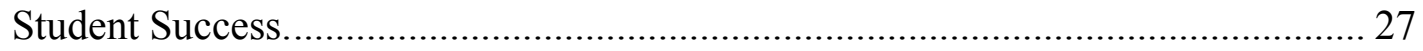

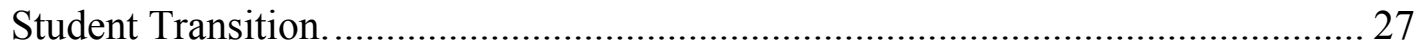




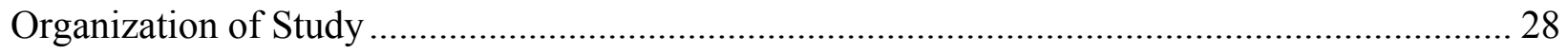

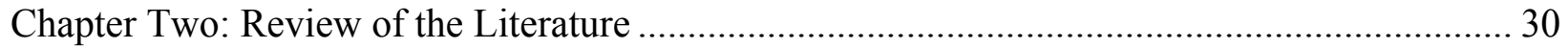

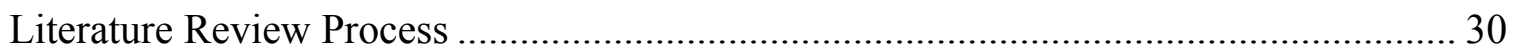

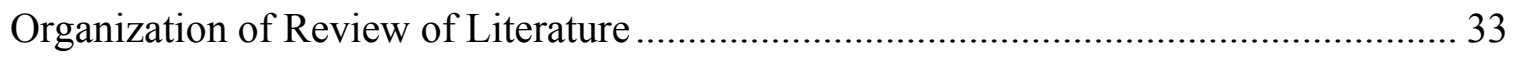

Theoretical Foundations of Student Development …..................................................... 34

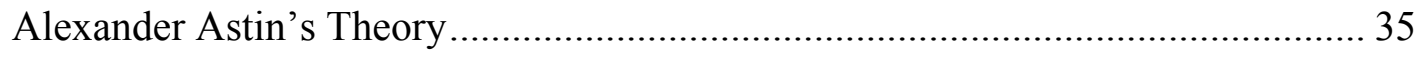

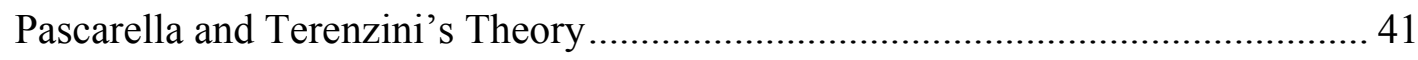

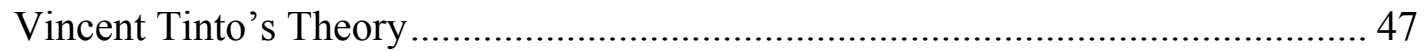

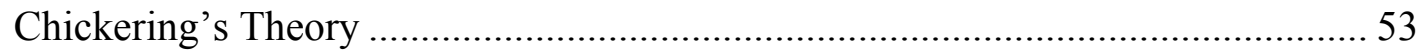

Schlossberg's Transition Theory …............................................................. 56

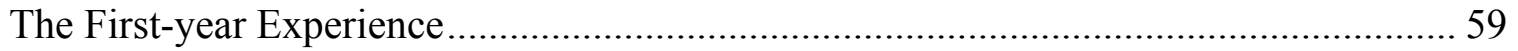

The History of the First-year Experience Concept ............................................ 61

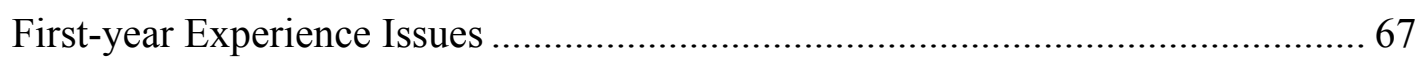

First-year Intervention Strategies, Functions, and Practices................................ 72

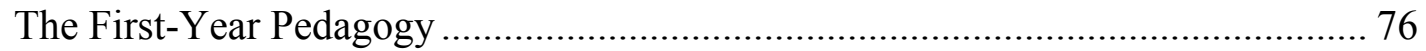

The First-Year Organizational Design and Structure ......................................... 77

The First-Year Experience: An International Perspective .................................. 82

First-year Experience in the Context of Saudi Postsecondary Education................ 84

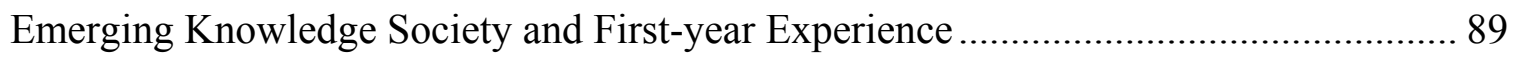

Knowledge Society and Knowledge-Based Economy Concepts Dilemma and

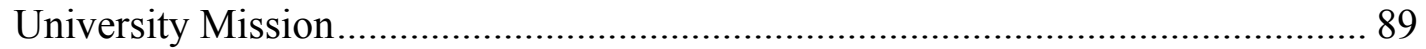

Knowledge Society Movement in Saudi Arabia................................................. 94

University Roles and Challenges in Emerging Knowledge Society...................... 97

Concept Mapping/Pattern Matching as a Developmental Methodology ....................... 104

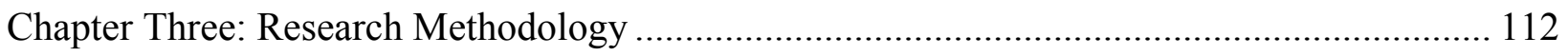

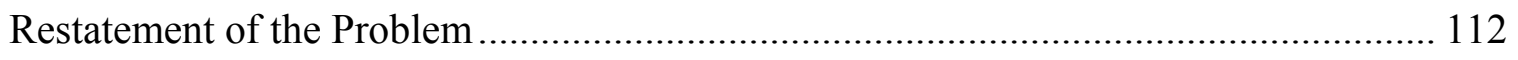

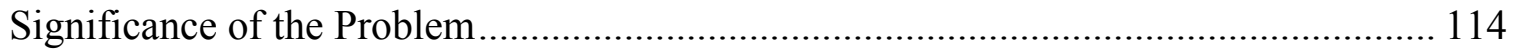

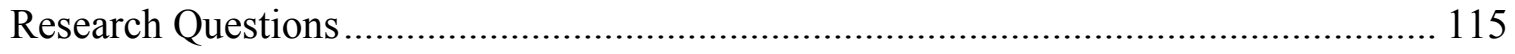

The Concept Mapping/Pattern Matching Methodology Utilized in this Study ............. 115

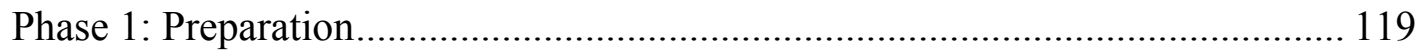


Phase 2: Generation of Statements 121

Phase 3: Structuring of Statements 122

Phase 4: Analysis and Representation of Statements 124

Phase 5: Interpretation of Maps 126

Phase 6: Utilization of Maps 127

Participants. 128

Data Collection 130

Treatment of the Data 130

Translation Process 131

Limitations of the Methodology 134

Chapter Four: Result 136

Purpose of the Study and Research Questions.......................................................... 136

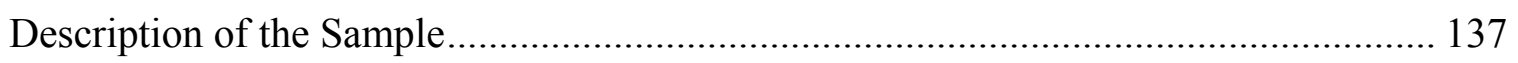

Implementation of the Concept Mapping/Pattern Matching Process .......................... 141

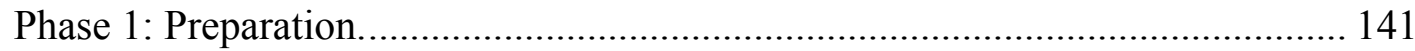

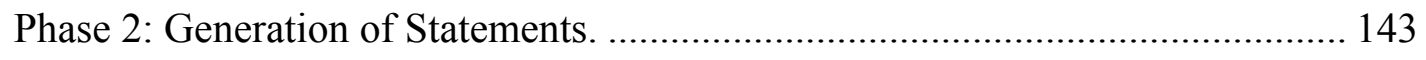

Phase 3: Structuring of Statements. .............................................................. 145

Data Analysis of the Results of the Concept Mapping/Pattern Matching Methodology 146

Phase 4: Representation of the Statements. ..................................................... 146

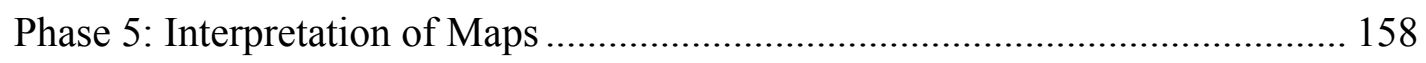

Applying the survey outcomes to the CM/PM finding (The Rating Task)............ 163

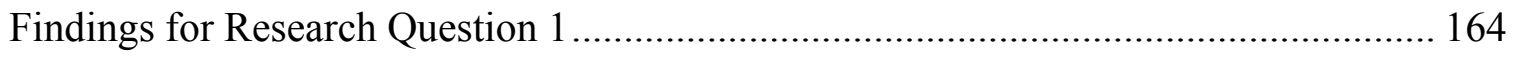

Male Group: Cluster 1: Program Regulation..................................................... 168

Male Group: Cluster 2: Program Assessment Mechanism \& Curriculum Structure.

Male Group: Cluster 3: Program Philosophy, Planning, \& Operational Mechanism.

Male Group: Cluster 4: Program Academic Design. ........................................ 175

Male Group: Cluster 5: Program Services: Prior to and During.......................... 177

Male Group: Cluster 6: Supporting Student Learning...................................... 179

Male Group: Cluster 7: Program Applications Policy .................................... 181 
The Total Importance and Efficacy Mean Scores for Each Cluster in the Male Group. 182

Female Group: Cluster 1: Program Assessment Mechanism and Curriculum

Structure 185

Female Group: Cluster 2: Program Academic Design. 187

Female Group: Cluster 3: Teaching Quality.... 190

Female Group: Cluster 4: Program Regulation. 191

Female Group: Cluster 5: Program Services: Prior to and During. 193

Female Group: Cluster 6: Promoting Student Learning. 194

The Total Importance and Efficacy Mean Scores for Each Cluster in the Female Group. 196

Finding for Research Question 1a. 198

Male Group: Document Analysis Results for Research Question 1a (Cluster Level)

Male Group: Document Analysis Results for Research Question 1a (Similarity Statements Level).

Male Group: Document Analysis Results for Research Question 1a (Differences -

Statements Level). 211

Female Group: Document Analysis Results for Research Question 1a (Cluster

Level) 214

Female Group: Document Analysis Results for Research Question 1a (Similarity -

Statements Level). 216

Female Group: Document Analysis Results for Research Question 1a (Differences -

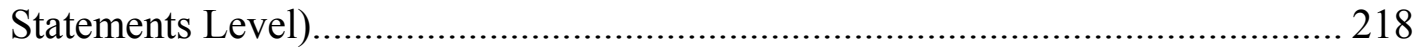

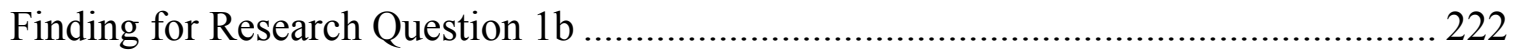

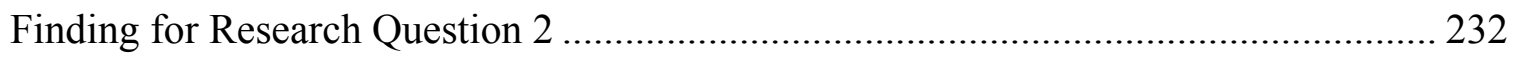

Results of Female Versus Male Perceptions..................................................... 232

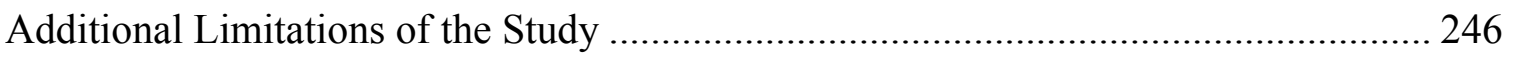

Chapter Five: Summary, Discussion, Implications, and Future Research............................ 252

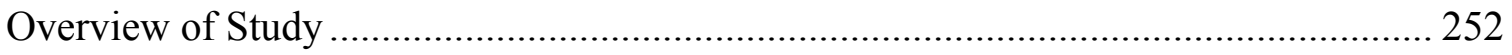

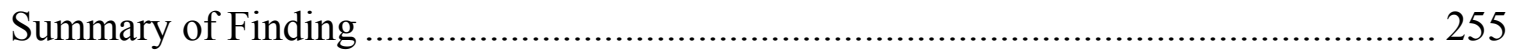


Summary of Results for Research Question 1.................................................. 255

Summary of Results for Research Question 1a. ............................................... 261

Summary of Results for Research Question 1b. ............................................... 265

Summary of Results for Research Question 2 ................................................ 269

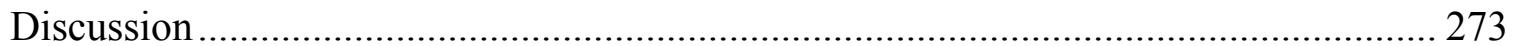

A Comprehensive Set to Develop a Conceptual Framework of the Preparatory Year

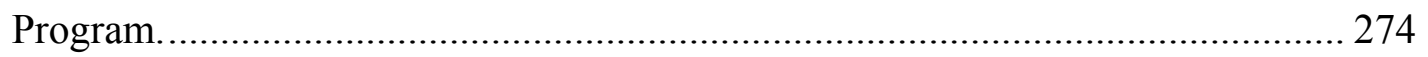

Relevance of CM/PM on the Organizational Design and Structure, Pedagogical Functionality, and Student Services themes to the First-Year Experience Theory.

Concerns regarding the Preparatory Year Program philosophy, pedagogy, and guiding theory.

Alignment of the CM/PM Outcomes and King Saud University's Vision and

Mission 295

Relevance of the CM/PM Outcomes from the Male and Female Groups ............. 300 Importance of Involving Stakeholder Group in Developing the Preparatory Year

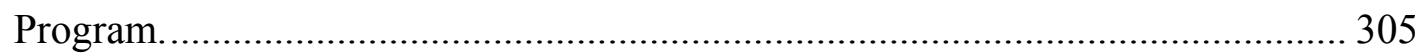

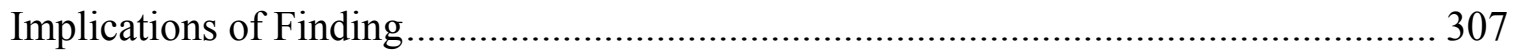

Implication to Develop the Preparatory Year Program: A Conceptual Framework

Proposed to the Policymakers at KSU ............................................................. 307

Implication to Raise the Benefit of the PYP Investment on the Program ............. 312

Implication to King Saud University Policymakers ....................................... 313

Implication for Educational Planning at Saudi Ministry of Education................. 314

Recommendations for Future Research .............................................................. 315

First: Recommendations Regarding the PYP's Conceptual Framework and CM/PM

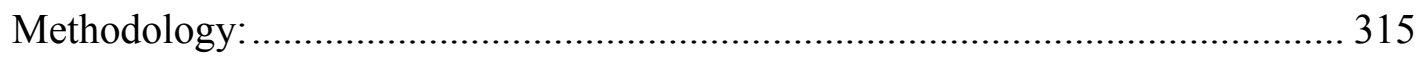

Second: Recommendations Regarding the First-Year Experience within Saudi

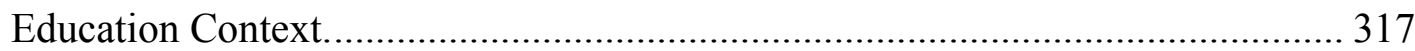

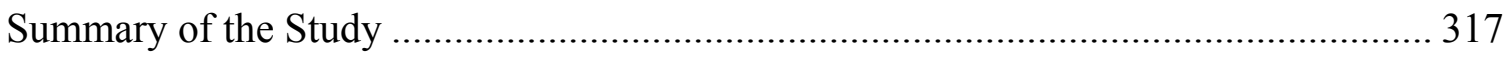

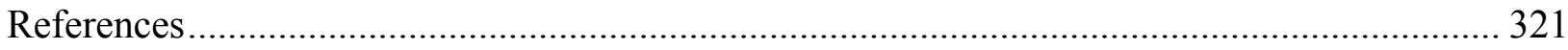

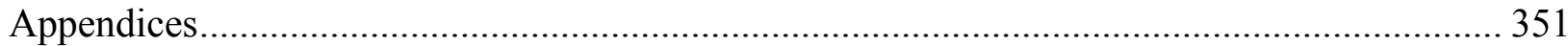




\section{List of Tables}

Table 1: Participants in the Concept Mapping/Pattern Matching Brainstorming Sessions and Statement Sorting and Rating Tasks by role

Table 2: Descriptive Analysis of Sorting Stage of CM/PM 148

Table 3: Displays of Similarity and Dissimilarity among Statements for the Male Group (Examples)

Table 4: Displays of Similarity and Dissimilarity among Statements for the Female Group

(Examples).

Table 5: Displays the comparison of selecting 7-cluster or 8-cluster solutions for the final decision

Table 6: Displays the list of 48 statements generated by the male focus group, Organized into Clusters using Hierarchical Cluster Analysis, and Labeled 158

Table 7: Displays the list of 36 statements generated by the female focus group, Organized into Clusters using Hierarchical Cluster Analysis, and Labeled 160

Table 8:List of Seven Clusters with Labels and Definitions Created by CM/PM for the Male Group 166

Table 9: List of Six Clusters with Labels and Definitions Created by CM/PM for the Female Group 167

Table 10: List of Statements in the Program Regulation Cluster and Their Mean Ratings for Importance and Efficacy

Table 11: List of Statements in the Program Assessment Mechanism \& Curriculum Structure Cluster and Their Mean Ratings for Importance and Efficacy. 172

Table 12: List of Statements in the Program Philosophy, Planning and Operational Mechanism Cluster and Their Mean Ratings for Importance and Efficacy.....

Table 13: List of Statements in the Program Academic Design Cluster and Their Mean Ratings for Importance and Efficacy..... 
Table 14: List of Statements in the Program Services: Prior to and During Cluster and Their Mean Ratings for Importance and Efficacy 179

Table 15: List of Statements in the Supporting Student Learning Cluster and Their Mean Ratings for Importance and Efficacy. 180

Table 16: List of Statements in the Program Applications Policy Cluster and Their Mean Ratings for Importance and Efficacy..... 182

Table 17: The Importance and Efficacy Mean Scores for Each Cluster in the Male Group ...... 184

Table 18: List of Statements in the Program Assessment Mechanism and Curriculum Structure Cluster and Their Mean Ratings for Importance and Efficacy..... 187

Table 19: List of Statements in the Program Academic Design Cluster and Their Mean Ratings for Importance and Efficacy. 189

Table 20: List of Statements in the Teaching Quality Cluster and Their Mean Ratings for Importance and Efficacy

Table 21: List of Statements in the Program Regulation Cluster and Their Mean Ratings for Importance and Efficacy

Table 22: List of Statements in the Program Services: Prior to and During Cluster and Their Mean Ratings for Importance and Efficacy

Table 23: List of Statements in the Promoting Student Learning Cluster and Their Mean Ratings for Importance and Efficacy.... 195

Table 24: The Importance and Efficacy Mean Scores for Each Cluster in Female Group ........ 197

Table 25: The Student's Guidebook Sections as appears in the Male and Female versions ...... 200

Table 26: The Percentage of Alignment of the Two Versions of the Student's Guidebook for Male and Female 204

Table 27: Comparison of the CM/PM Generated Clusters and the Student's Guidebook Chapters for the Male Group 206

Table 28: Similarity Comparison of the CM/PM Generated Statements and the PY's Student's Guidebook Chapters for the Male Group 209 
Table 29: Dissimilarity Comparison of the CM/PM Generated Statements and the Student's

Guidebook Chapters for the Male Group .

Table 30: Comparison of the CM/PM Generated Clusters and the Student's Guidebook Chapters for the Female Group 216

Table 31: Similarity Comparison of the CM/PM Generated Statements and the PY's the Student's Guidebook Chapters for the Female Group 218

Table 32: Dissimilarity Comparison of the CM/PM Generated Statements and the Student's

Guidebook Chapters for the Female Group 221

Table 33: Similarity Comparison of the CM/PM Generated Statements for the Male and Female Groups and KSU's Strategic Plan 230

Table 34: The Descending Order of Male Clusters vs Female Clusters Based on the Importance Mean. 236

Table 35: The Descending Order of Male Clusters vs Female Clusters Based on the Efficacy Mean 236

Table 36: Shows the List of the Most Important and Fewest Efficacies Statements in Male Group 238

Table 37: Shows the List of the Most Important and Fewest Efficacies Statements in the Female Group 241

Table 38: Shows the List of the Most Important Statements Female vs Male 243

Table 39: Shows the List of the Fewest Efficacies Statements Female vs Male..... 245 


\section{List of Figures}

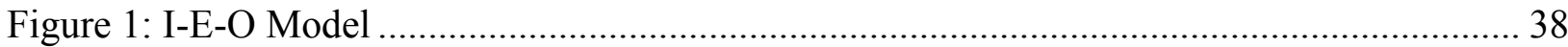

Figure 2: The General Model for Assessing Change............................................................ 45

Figure 3: A comprehensive model of influences on student learning and persistence............... 47

Figure 4: Tinto's longitudinal model of institutional departure............................................ 49

Figure 5: Point map with each point corresponding to one of the 48 statements generated by the male group.

Figure 6: Point map with each point corresponding to one of the 36 statements generated by the female group. 149

Figure 7: Numbered point map with each point corresponding to one of the 48 statements generated by the male group. 150

Figure 8: Numbered point map with each point corresponding to one of the 36 statements generated by the female group.

Figure 9: The Point Cluster Map for the maximum number of possible clusters solutions 10cluster for the 48 statements generated by the male group.

Figure 10: The Point Cluster Map for the maximum number of possible clusters solutions 10cluster for the 36 statements generated by the female group.

Figure 11: The Point Cluster Map with seven clusters generated by the male group.

Figure 12: The Point Cluster Map with six clusters generated by the female group. 158

Figure 13: The cluster map with the seven clusters named as generated by the male group. .... 162

Figure 14: The cluster map with the six clusters named as generated by the female group....... 163 Figure 15: Ladder graph displaying the mean ratings of importance and efficacy for each cluster from the male group. 185

Figure 16: Ladder Graph displaying the mean ratings of importance and efficacy for the female group clusters 198 
Figure 16: Similarities and differences between male vs female perceptions on the clusters level.

Figure 17: The most important and fewest efficacies statements in male group.................... 240

Figure 18: The most important and fewest efficacies statements in female group.................. 242

Figure 19: Final Map for the Male Group with Clusters Labels and Theoretical Interpretation.276

Figure 20: Final Map for the Female Group with Clusters Labels and Theoretical Interpretation.

Figure 21: The Main Dimensions of General Conceptualization Framework of the PYP as

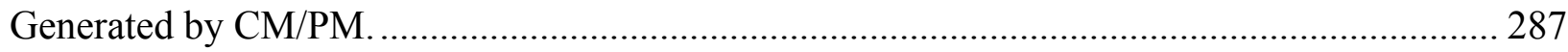

Figure 22: The Proposed Conceptual Framework Generated by the CM/PM........................ 311 


\section{List of Appendices}

Appendix A: PY's Dean Permission to Conduct the Study at PYP at KSU

351

Appendix B: List of 48 Outcomes Formatted for the Importance and Efficacy Rating Using

Qualtrics for Male Group 352

Appendix C: List of 36 Outcomes Formatted for the Importance and Efficacy Rating Using Qualtrics for Female Group 359

Appendix D: Dendrogram or Hierarchical Cluster Tree Acquired from the Hierarchical Cluster Analysis Showing Cluster Membership for Each Item in the Male Group . 365

Appendix E: Dendrogram or Hierarchical Cluster Tree Acquired from the Hierarchical Cluster Analysis Showing Cluster Membership for Each Item in the Female Group.......................... 366

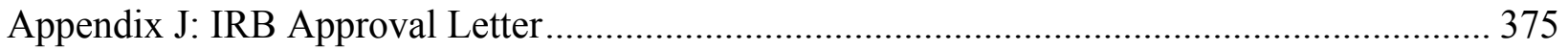

Appendix K: List of the 48 Outcomes with Mean Scores for Importance and Efficacy for Male Group 377

Appendix L: List of the 36 Outcomes with Mean Scores for Importance and Efficacy for Female

Group 379

Appendix M_1: Student's Guidebook Cover for Boys Section. 381

Appendix M_2: Student's Guidebook Cover for Girls Section........................................... 382

Appendix N: Student's King Saud University’s Strategic Plan (KSU2030) Cover .................. 383

Appendix O: The Comparison Matrix of KSU's Strategic Plan. 384 


\section{Chapter One \\ Introduction of the Study}

\section{Brief History of Saudi Higher Education}

On January 15, 1902, King Abdulaziz established the third Saudi country; naming this country the Kingdom of Saudi Arabia on September 23, 1932. Higher education began with the approval of King Abdulaziz, sending 14 students of various fields of specialization to Egypt in 1927. However, the actual beginning of institutional higher education in the Kingdom occurred in 1949, when the first College of Islamic Law (Shari'a), in Makkah was founded (Information, 2013).

The history of Saudi higher education can be divided into three phases: a) foundation (1949-1960); this phase contains the first blocks of higher education, which was the College of Islamic Law (Shari'a) in Makkah established in 1949, followed by the Teachers College in 1952. In 1953 and 1954, respectively, a second College of Islamic Law (Shari'a) and a College of Arabic were established in Riyadh, the capital city of Saudi Arabia. These two colleges in Riyadh were the nucleus of the establishment of the King Saud University in 1957, and were followed by additional colleges within the university such as Colleges of Arts, Science, Administrative Sciences, and Pharmacy; b) expansion (1961-1980); this phase involved an expansion in the establishment of universities on the country level in different provinces of the Kingdom. For example, the Islamic University in Medina in 1961, King Abdulaziz University in Jeddah in 1967, Imam Muhammad Ibn Saud Islamic University in Riyadh in 1974, King Fahd University of Petroleum and Minerals in Dhahran and King Faisal University in Al-Hassa in 1975, and finally Umm Al-Qura University in Makkah in 1980. These universities together consisted of 58 colleges of various disciplines. During that era, some of these universities had campuses in other provinces besides the main campuses. For example, King Saud University 
established branches at Abha, which is located in the south of the Kingdom, and Qassim, located in the middle of the Kingdom; similarly, the Imam Muhammad Ibn Saud Islamic University branch is at Al-Hassa in the east of the Kingdom; and the King Abdulaziz University branch is at Al-Medina in the west of the Kingdom. Moreover, this expansion phase is characterized by an increase in diversity of higher education specialists and establishing numerous teachers' colleges in different cities (Information, 2013, p. 19); and (c) comprehensiveness (1981-2012). The comprehensiveness phase can signify the mass education of Saudi Arabia when the country's government was clearly intending on spreading the institutions of higher education in all the provinces and districts of the Kingdom. The goal was to enable people in small cities, towns, and villages to pursue higher education without having to move to major cities such as Riyadh, Jeddah, and Dammam. Between 1957-2011, the number of universities grew rapidly from 8 in 2001 to 33 in 2011 (Information, 2013).

The Saudi higher education system is centralized, meaning the Ministry of Education plans and manages; while universities rely on the government for most funding and infrastructure. Currently, the government allows the private business sector to support public universities with funding and resources, especially for the research segment, including full funding for major endowment projects and the appointment of research chairs in different disciplines and universities (Al-Eisa \& Smith, 2013). Although endowments and philanthropic contributions are a relatively new phenomenon in Saudi higher education, it is important to note that these charitable gifts represent an essential part of Saudi religious practice. This charitable practice provides universities more autonomy to generate and make their own decisions about the allocation of such funding (Christensen, 2011) as cited in (Al-Eisa \& Smith, 2013). 
In sum, higher education in Saudi Arabia is a relatively modern phenomenon with the first university institution being established in 1957 (Al-Eisa \& Smith, 2013). Consequently, the Saudi government has been developing many regulations covering all aspects of higher education, including the "number of students to be enrolled, student admission procedures and personnel policies for faculty members" (Alkhazim, 2003) (e.g., salaries, promotion, reappointment, and retirement age) as cited in (Al-Eisa \& Smith, 2013).

\section{Saudi Higher Education Reform Movement}

In recent years, the Kingdom of Saudi Arabia has emphasized the educational sectors both secondary and postsecondary, to develop human capital and to increase the knowledge society. The transition from an oil-based economy to a knowledge society requires the population to develop its level of human capital (Corneo, 2011; Gallarotti, Filali \& Yahia 2013). Currently, Saudi Arabia supplies 60 percent of the world's oil, and policymakers in Saudi government are aware that decreasing the dependence on oil for the supply of energy is the priority of research and government policy (Smith \& Abouammoh, 2013).

Hence, the government's Ninth National Development Strategic Plan (2010-2014) states, "Knowledge has become a critical requirement for enhancing competitiveness of countries in the twenty first century" (Planning, 2010, p. 94). The ninth plan stresses the following:

To establish a learning pattern that develops analytical thinking, advances acquirement of practical skills, and promotes initiative and entrepreneurship, the system of education needs to address a set of issues ranging from curriculum development, lifelong learning, linking education with development, Arabization of knowledge, to privatization (Planning, 2010, p. 94). 
The ninth plan defines Arabization of knowledge as requiring that "knowledge and scientific and technical information should be in Arabic" and Privatization of education means “to maintain values, heritage and particularities of society, educational policies and objectives remain the responsibility of the State" (Planning, 2010, p. 95). Thus, the quest for educational reforms became part of the ninth-plan development. Such a strategic transition from the current oil-based economy to a knowledge society requires an enhanced effort to improve both cognitive and non-cognitive skills.

Consequently, in 2006, the Ministry of Higher Education launched its future strategic plan named AAFAQ2029 (translated to English: "Horizons2029") in alignment with the national strategic plan, which aims to shift toward a knowledge society and a more diverse economy. AAFAQ2029 adopts the government trend, launching its educational reform plan on the following basis: "Expansion of higher education in the Kingdom of Saudi Arabia with an integrated quality, excellence, and competing for global leadership to contribute effectively in building a knowledge society" (AAFAQ, 2013, p. 15).

AAFAQ2029 incorporates a comprehensive reform process for Saudi Arabia's postsecondary system for developing a long-term plan for the next 25 years (Al-Swailem \& Elliott, 2013). Due to Saudi Arabia's postsecondary system being a centralized system of control in terms of policy and educational support, the AAFAQ2029 project defines the mission and outcomes for the higher education system as a whole. The plan suggests a mechanism through which methods of strategic planning are to be adopted by all public universities in the country (Smith \& Abouammoh, 2013). To provide support to AAFAQ2029, the Ministry of Higher Education launched the complementary plan entitled Achieve Excellence in Science and Technology2025 (AEST2025). AEST2025 emphasizes various dimensions of educational reform. 
One of these dimensions is developing students' skills to prepare knowledge workers who could participate effectively in the nation's movement toward a knowledge society through merging necessary knowledge, hard and soft skills, and job market skills (Information, 2010).

The AEST2025 plan created new initiatives and programs for students' development, which aims to achieve the following goals:

- Developing basic student skills that are needed in the job market and society in general;

- Improving the students' ability to continue their education, find appropriate solutions to problems, and develop their thinking skills;

- Developing graduates' vocational, social, and personal skills, and;

- Enabling students to broaden their knowledge bases (Information, 2010, p. 26).

Further, the AEST2025 plan consolidates student skills and improves the quality of postsecondary graduates through two paths: 1) an academic knowledge path to prepare students to be qualified in a specific area of study, and 2) a professional skills path, which focuses on soft and hard skills, technology utilization, research skills, self-learning skills, and lifelong learning skills (Information, 2010). To support the higher education reform movement, the AEST2025 plan suggests programs that Saudi universities, either public or private, could apply to achieve the knowledge society, such as the Preparatory Year Program (PYP) and Centers of Developing and Improving Personal Skills. The new postsecondary policy allows universities to collaborate with the business sector such as educational companies to operate and provide educational service such as training and teaching on the required skills and knowledge (2010).

The higher education policy makers aware that such educational strategic reform should take into account the necessity of building human capital by instilling the values of work, commitment, lifelong learning skills, accountability, collaboration, creativity, and innovation to 
participate effectively in building a knowledge society. Therefore, universities are responsible to ensure that students who are transferred from secondary to postsecondary education will be ready with the essential knowledge, skills, and attitudes for a successful transition into postsecondary education (AAFAQ2029, 2013; Corneo, 201; Smith \& Abouammoh, 2013). Such plans and transitions should encounter some challenges. The Ministry of Higher Education report, The Current Status of Higher Education (2013), states that between 1999-2012, the number of new students who enrolled in first-year of college/university increased from 109,049 to 329,696 , or approximately (300\%). Similarly, from 2000-2012 the total of all students in all public universities increased from 404,094 to $1,116,230$ or $(250 \%)$. As in 2012 , the total number of graduates was 111,852 students. This number represents 66,860 females, or $(59.8 \%)$, and 44,992 males, (40.2\%). These percentages indicate higher participation of females in higher education (Information, 2013).

Despite the high percentage of female participation in postsecondary education, the gender segregation culture is still considered a challenge for the educational reform movement; which has a goal to achieve equality of educational opportunity for females and achieve the knowledge society (Jamjoom \& Kelly, 2013; Smith \& Abouammoh, 2013). For example, the curriculums that are used to teach male or female at these institutions are the same, with the exclusion of topics in physical education and home economics for females. In addition, in many cases male-only departments are responsible to plan and select curriculum materials and content without sharing it with female-only departments. Furthermore, establishing equality in terms of leadership positions, where some of the female departments are still managed through male departments remains a challenge, as well as equity matters concerning access to knowledge resources or highly qualified teachers (Jamjoom \& Kelly, 2013; Smith \& Abouammoh, 2013). 
Therefore, more attention is required to meet male and female prerequisites with respect to religion, culture and privacy, especially in programs such as Preparatory Year Program (PYP).

In responding to these needs and political trends, Saudi universities established a Preparatory Year Program (PYP) during the past ten years to support the First-Year students and to provide them with essential skills, knowledge, and attitudes to achieve success and excellence, especially for those who are not ready for college. The Preparatory Year Program attempts to fill the gap between secondary education outcomes and university requirements and also ensures students' readiness for the job market and knowledge society (Alatas, 2012; Alhosin, 2010; Bagazi, 2010; Dow \& Alnassar, 2013; Habib, 2010).

While internal evaluation reports addressing these aspects have yet to be released publicly, there do exist secondary journalistic accounts that provide evaluative insights into the Preparatory Year Program. However, because this study's focus is on King Saud University (KSU), specifically on their Preparatory Year Program, it is worthy to provide a brief description about KSU and its strategic plan and trend.

\section{King Saud University Landscape}

King Saud University is a research university that was established in 1957. It is considered the first and largest university in the Kingdom of Saudi Arabia. The university consists of 24 colleges and involves 49,896 students total in 2013 . The number of female students is 22,149 , or $(44.40 \%)$ of the student body, and 27,747 male, representing $(55.60 \%)$. Ninety percent of the student's total is undergraduates (Ministry, 2015).

In 2013, King Saud University admitted 11,234 students, which represents 3,578 females and 7,656 males. Male faculty number $n=4,083(64.6 \%)$, while female faculty number $n=2,239$ (35.4\%) (Ministry, 2015). Furthermore, in 2011, King Saud University officially launched its 
strategic plan KSU2030, although it actually began sixteen months prior to being officially announced (Resalah, 2011).

KSU2030 was in alignment with AAFAQ2029 and the ninth national strategic plan. In conjunction with the AAFAQ2029 and the national plan, KSU2030 aims to move toward a knowledge society, which states in its vision "to be a world class university and a leader in building the knowledge society" and its mission statement is "to provide distinctive education, produce creative research, serve society and contribute in building the knowledge economy and community through learning, creative thinking environment, the optimal use of technology and effective international partnership" (Plan, 2014, p. 14). Moreover, the KSU2030 plan has built on three stages: 1) compare and contrast the current site with its aspiration and best world practices; 2) develop strategic objectives; and 3) develop an implementation plan. Furthermore, KSU2030 addresses three important outputs: the institutional reputation, teaching effectiveness, and research effectiveness.

To establish on a strong base, the KSU2030 strategic plan received the benefit and advantage of some of the world's best practices in student learning and development. For example, the Tiered Model that is used in the California State Higher Education System, tailors its education to the quality of students and experience, and the Preparatory Schools Model that is used in the University of Southern California (USC) to increase its students qualification with more attention to the local society's needs such as raising the admission criteria (Plan, 2014).

According to the King Saud University strategic plan, KSU2030, soft skills involve time management, writing effectively, problem solving, self-assessment, decision making, oral presentations, teamwork, thinking critically, and leadership skills. Hard skills are described as English, Arabic, other languages, mathematics, and science (Plan, 2014, p. 102). Therefore, 
KSU has launched many initiatives to be a world-class university. One of its initiatives is the Preparatory Year Program (PYP). The program is a one-year program for all new students, or first-year students.

Currently, KSU applies the PYP in cooperation with educational private sectors. KSU universities plan, manage, and control the Preparatory Year Program while the business sector is taking the responsibility of teaching and operating PYP through agreements and business contracts consistent with the university's vision, mission, and policy.

\section{Preparatory Year Program}

In the fall of 2007, Preparatory Year Program (PYP) established a concentrated one-year training and learning program for first-year students (Preparatory Year Strategic Plan 2011-2016, 2011). At that time, the PYP objectives were preparing students for college and the job market, and its vision was to be the "pioneer in developing students' learning, academic and life skills in the region by 2016” (Preparatory Year Strategic Plan 2011-2016, 2011, p. 9). In 2014, PYP's vision was revised "to be excellent in preparing the knowledge generation" and its mission is to "offer advanced education through a stimulating environment of learning and creativity supported by ideal utilization of technology and distinguished partnerships" (Deanship, 2014, p. 12).

Although the Preparatory Year Program statements of vision, mission, objectives, priorities, and the high government financial support, the current working model of the program, including policy, functions, and academic and organization structure encounters a criticism from the academic and social segments. For example, 1) the PYP causes a financial bind on universities' budgets; 2) concerns related to learning and teaching quality have been raised; 3) the program requirements such as books and supplies cause financial pressure for students, 
especially those from low-income family backgrounds; and 4) in some cases due to the nature of preparatory year curriculums design and assessments methods, some students feel depressed or dropout of the program (Alaqeeli, 2014; Al Kathiri, 2014; Alkhazim, 2007; Alsalim, 2012; Alkhazim, 2013; Alhosini, 2012; Al-jarallah, 2014; Almaliki, 2011; Alsoltan, 2012; Marifh, 2013; Ministry, 2015). Thus, in March 2010, all public and private Saudi universities Vice Rectors of Academic Affairs met for two days to discuss the program experience, challenges, and development possibilities of the program. Several critical questions were raised in that meeting related to the program functions, practices, administration style, curriculums, and academic design.

For example, is it necessary to enroll all first-year students into the PYP or only students from specific disciplines such as science colleges, and may exclude the humanities colleges? What is the relationship between the preparatory year program admission policy and university policy? How will the Preparatory Year Program's GPA influence the students' future in terms of which college students will enter? Does the preparatory year functions and learning style based on a conceptual and theoretical framework? Does the program meet the actual needs of students, or does it only meet the university's desires and goals? Does the preparatory year program solve or reduce students' departure issue or does it improve students' retention and performance at universities? Does the preparatory year program faculty and administration staff members have the adequate skills to teach and treat first-year students? What is the identity of the Preparatory Year Program? Is it an academic college or support services deanship? What is the ideal structure and functions of the Preparatory Year Program? (Alqahtani, 2010; Mahmood, 2010; Alshamri, 2010; Alqassim University, 2010; Tabuk University, 2010; Jazan, 2010; Malawi, 2010). Some decisions made after this meeting included the necessity of embracing Humanity 
Colleges in the program, which resulted in expanding the Preparatory Year Program's capacity in terms of faculty numbers, operation budget, administration staff, and location. The Preparatory Year Program becomes the portal to university and all first-year students require studying in the program for one entire year (Deanship, 2014).

Today, more than five years after the expansion of Preparatory Year Program, most of the key questions about the efficacy, structure, and functions of the program still exist. Al-Dammam University called for the First National Conference for Preparatory Year in Saudi Universities that took place on April 22-23, 2015. The conference themes include: 1) Preparatory Year: the Concept, Establishment, Organizational Structures and Strategic Policies, 2) How to Achieve Quality in the Preparatory Year, 3) Administration of the Preparatory Year: Operation, Plans and Programs, 4) Evaluating the Preparatory Year Experience in Saudi Universities, and 5) The Future of the Preparatory Year in Saudi Universities (University of Dammam, n. d.). These themes appear to be a response to the gap between the current practices of the Preparatory Year Program and students' development theories specifically for first-year students.

Despite the academic and social critique on the program, the Preparatory Year Program represents a working model of consistency with several international practices in first-year programs in terms of the nature of study plan, curriculum content, and administration style with some differences in terms of faculty selection criteria or program application methods. In addition, the Preparatory Year Program tries to deliver essential skills and knowledge required for the job market. Additionally, the program provides an ideal learning environment with high technology that may help first-year students engage with new experiences within the university. Overall, the Preparatory Year Program is essential and important for all first-year students, but it needs to reform someway to meet students' and university's needs at the same time (Alhosin, 
2010; Bagazi, 2010). Although the necessity of the program for all first-year students at Saudi universities is to help them transition into postsecondary, and despite a certain amount of success, the Ministry of Higher Education has made a decision about the continuity of the Preparatory Year Program based on the current working model design at all public universities, including King Saud University.

In January 2015, during the annual meeting of Preparatory Year Deans, the Vice Minister of Higher Education announced that due to some issues related to the learning and teaching quality in the Preparatory Year Program, educational companies would no longer operate the program in the future. From this moment, Saudi universities are required to take responsibility to operate the program instead of business sectors, and find an appropriate way to operate it based on its capacity (Ministry, 2015).

This decision involves necessity of reforming the program and redesigning it functions and activities to achieve universities and national goals. Consequently, reformation or redesigning or developing the Preparatory Year Program functions is crucial. Determining Preparatory Year future functions will help to identify the weakest points and improve those aspects to make student's transition into college/university successful. In addition, due to the expected budget cuts, universities policymakers will need to identify how the Preparatory Year Program can continue its operation to achieve its mission. Thus, these educational and economic issues lead to a question: How can Preparatory Year be designed to optimally help Saudi universities successfully transition into postsecondary? This question is what the current research study intends to answer.

Overall, the Preparatory Year Program at King Saud University under the current design comprises of multiple tasks. The student's retention is not the focus point of the program, 
nonetheless PYP works as a filter to place students into their colleges based on his/her performance by the end of the program. The PYP focuses on improving students' skills and knowledge and prepare them for the university level. The tasks of the PYP are as follows:

1- Fill the knowledge and skills gap between high school and university requirements without consideration of gender differences.

2- It aims to make its students' transition into their colleges easy and effective in terms of meeting colleges' requirements.

3- Prepare its students for the job market to be a knowledgeable worker.

4- Raise the English competency for all students with more focus on soft/hard skills.

5- Finally, King Saud University must develop the Preparatory Year model based on two principles: ensure program quality to part ways with the business sectors from operating the program to meet university students' actual needs, and reduce program operational budget.

\section{Statement of the Problem}

As a response to higher education trends in developing first-year students, educational policymakers at King Saud University are interested in developing and re-structuring the Preparatory Year Program to improve student quality, to meet students' needs and institutional mission, to reduce program cost, and not to rely on the educational business sector to operate the program long-term.

The current model of for the Preparatory Year Program has four main challenges: a) the program's capability to meet students' actual needs and to prepare them to achieve the university vision and mission; b) learning and teaching quality concerns related to the business sector, which is currently responsible for operating the Preparatory Year Program; c) the economic 
problems related to the high operational budget of the program, which will cause instability of the program in the future; and d) lack of governing philosophy, theoretical, and pedagogical base of the program.

Further, the King Saud University community including policymakers, administrators, faculty, parents, students, and business market feel that the incoming students from high schools are extremely ill-prepared for college and they need more preparation in terms of the English language, soft/hard skills, math and science skills, writing and reading skills. Thus, a need exists for a comprehensive educational support system such as the Preparatory Year Program, to assist the university in reaching its goal to be a knowledge society university and to help its students successfully transition into postsecondary education. Consequently, developing Preparatory Year Program regulation, functions, policy, activities, services, and academic programs is critical.

The SWOT analysis of KSU2030 strategic plan (2014) and faculty survey reported that " $69 \%$ of King Saud University faculty think that the university students somewhat or not prepared for market place and 56\% alumni of university said they were not ready for job market" (p. 76). Thus, the university plan identifies the skill and knowledge gap in the following areas:

1. Soft skills such as problem solving (61\%), decision-making (52\%), time management $(68 \%)$, and written (65\%) and oral communication (50\%).

2. Hard skills revolving mostly around English (72\%) and mathematics (41\%) (Plan, 2014, p. 102).

These results conclude that with the current students' performance, King Saud University' students could not contribute in the national movement towards a knowledge society (KSU2030 strategic plan, 2014). Further, the KSU2030 strategic plan (2014) reported that the high school graduates who enroll in university encounter some academic and social difficulties 
such as: (a) poor mathematical and science skills, (b) lack of soft and technical skills, (c) disengagement in university experience and environment, dissatisfaction with career assistance and support, and (d) weakness of English competence and preparation prior to entering university.

Additionally, the KSU2030 plan admits that the skill gap will make students' transition into university a big challenge. Therefore, the university could not build its strategies on the current state of high school graduates' outcomes where graduates have a lack of qualification and readiness for university, and university graduates could not compete with other university students, nor find opportunity in the marketplace.

Regarding the economic problem, according to the Information Technology department (2014) report at Preparatory Year Program, the fulltime faculty members in the program was 989 total, 678 males and 311 females. As the number of students in the program in 2014 was 11,477 total, 7,686 males and 3,791 females. The actual operational budget of the Preparatory Year Program is not public information, but these numbers can indicate the high amount of expense to keep the program running. Alaqeeli, Abouammoh, and Alghamdi (2014) note that most Saudi public universities operated the Preparatory Year Program through the business sector, educational or training institutions, and this is considered unprecedented practice on the international level. These business sectors are new in the educational and training market in general, and in the first-year program operational domain in particular. In other words, these businesses sectors may not have enough experience to operate such programs or deal with firstyear students.

Additionally, Alaqeeli et.al note a lack of qualified faculty selected by the business sector to teach or deal with first-year students, which causes miscommunication between first-year 
students and university faculty. Besides, one disadvantage of relying on the business sector to operate the Preparatory Year Program is known as the "Commodification of Higher Education", which leads to learning and teaching quality problems. Schroeder (1998) advocates that collaboration with the business sector is considered the most challenging trend encounter in postsecondary institutions.

Although the Preparatory Year Program has been in existence for nine years at King Saud University, there is a lack of research and evaluation studies that can inform about the program status. Close examination of the first-year or Preparatory Year Program literature in Saudi universities proved very few studies were conducted individually about Preparatory Year in the Arabic or English language to evaluate specific aspects of the program. Most of the research was conducted for the English skills program. Despite the large size of Preparatory Year Deanship in Saudi universities in general and at King Saud University in particular, there is no evaluation or research unit to assess the Preparatory Year Program progression or research center for first-year experience.

Moreover, several questions were exposed regarding the current working model of PYP, for instance: (1) Do the Preparatory Year faculty, administrations, and students have a clear definition and understanding of the university's mission to knowledge society and its applications? (2) Does the current model of Preparatory Year have a theoretical base or pedagogical philosophy linked to the university's mission and objectives? (3) Does the current model of Preparatory Year have assessment tools that accurately describe the program status and capability to meet the student's needs and institution mission? This study helped to address some of these questions and told how the Preparatory Year's stakeholders encouraged the Preparatory Year to accomplish student's needs and King Saud University mission. Furthermore, the study 
also aided in understanding and establishing a theoretical and pedagogical base of the Preparatory Year Program. Furthermore, given the nature of separating the sexes in Saudi postsecondary education, this study utilized a two-pronged approach to correspondingly examine both sexes, while recognizing stakeholder perceptions about the future ideal functions of the Preparatory Year Program that could achieve the university's mission.

This study resulted in an integrative approach assuring lifelong learning skills, for example, extending the Preparatory Year Program beyond only a one-year program, to include specific study each consecutive year a student attends university. Such a resulting integrative approach will eventually modify the postsecondary curriculum to include lifelong learning skills or knowledge society skills in the Preparatory Year Program. Furthermore, this study attempted to address the issues mentioned earlier and add to the weak body of existing literature, especially in the Arabic culture, where the first-year practices and theories and student's development in general need more attention.

An underlying goal of this study was to identify whether the inclusion of more stakeholders representing other sectors of King Saud University, with interests in the Preparatory Year Program such as students, parents, members of the business sector, and administrators, and faculty from varying disciplines, would facilitate a better understanding of the importance of the Preparatory Year for all participants. Additionally, themes that were generated from two concept maps indicated to what extent these themes aligned with the current working model of PYP and with KSU2030 explicit strategic plan. Two separate concept maps for male and female perspectives about the future functions and activities of the Preparatory Year Program were merged and used to develop a conceptual framework for developing the Preparatory Year 
Program at King Saud University that may help to make first-year students successful in the transition into university.

Finally, it is important to distinguish this study from conventional first-year transition studies conducted in the United States. In the United States, affordability of postsecondary education can be a significant factor in preventing students' success in their first-year transition. In other words, if a student worries about the cost of college, that is a factor. In Saudi Arabia, however, postsecondary education is free to students. Therefore, the economic challenges to individual students is not a concern, as would be the case in the United States. Moreover, because the Kingdom invests heavily in fully subsidizing postsecondary education, their concerns about Return on Investment (ROI) are much different than US policymakers.

\section{Significance of the Study}

Research studies on first-year students agree that the first-year is critical for developing a foundation for successfully transitioning into college, and students' success is largely based on first-year experiences (Ben-Avie, Kennedy, Unson, Li, Riccardi \& Mugno, 2012; Clark, 2005; Frazier, 2007: Mutch, 2005; Tinto \& Pusser, 2006; Noel, Levitz, \& Saluri, 1985; Upcraft, Gardner \& Barefoot, 2004;). The new trend of postsecondary education policy and practice is to provide equal opportunity for all students, which is considered fundamental for building a knowledge based-economy or knowledge society. Bill mentioned that this trend toward a new economy provides an educational and organizational context for first-year experiences and students in transition (Johnston, 2010).

First-year experience $[$ sic $]$ are varied, therefore, and it may be better to think in terms of 'multiple', with nuanced transitions influenced by diverse backgrounds and contexts, rather than a unified one-size-fits-all format. To that extent the term first-year experience 
is perhaps best seen as a helpful shorthand for a complex and dynamic reality (Johnston, 2010, p. 3).

In this context, and due to the newness of the Preparatory Year Program at King Saud University, which just started in 2007; the Preparatory Year Program is considered a relatively new notion in most Saudi public universities with one expectation in King Fahd University. This study is significant because it identified the best future domains of the Preparatory Year Program that need development to help students successfully transition into college/university and to also support the university's mission. Further, this study represented significant research for several reasons.

First, this study responded to the call of the Saudi Higher Education Ministry to restructure the Preparatory Year Program to improve learning quality and reduce operational budget. In other words, this study has a learning and economic significance.

Second, due to the nature of the Saudi educational system in terms of male and female segregation, this study addressed the perceptions of both groups separately, which resulted in merged framework of the Preparatory Year Program for both groups.

Third, the current working model of the Preparatory Year has no documented theoretical and pedagogical base. This issue affects curriculum design, teaching methods, and student outcomes. In other words, "the preparatory year in Saudi universities lacks a Governing Concept philosophy” (Alaqeeli, 2014, p. 60). This study steps toward establishing a conceptual framework of the Preparatory Year Program that connected to theories and learning pedagogy instead of only relying on the best global practices.

Fourth, the groups of stakeholders participating in this study (faculty, students, parents, members of the business sector, and administrators) have given clear insights about their 
perceptions of the program's components, which was beneficial for the future program design. The current working model was designed for all students, male and female, meaning it is contrary to the fact that no one-size fits all. This study revealed that King Saud University may need to establish a centralized and fixable model to meet different students' needs.

Fifth, this study compared and contrasted King Saud University’s explicit strategic plan KSU2030 with perceptions identified through the Concept Mapping/Pattern Matching (CM/PM). The comparison helped to understand the questions of "how do we distinguish between wants and needs? How do we know if what we offer fits with entering students?" (Upcraft, 2005, p. 476). Identifying the future functions of the program has given an indicator about the Preparatory Year Program stakeholders, including male and female perceptions, and their understanding of knowledge society requirements.

Sixth, this study compares and contrasts male education versus and female education with the current working model of the program, which resulted in generating developmental domains utilized as a conceptual framework for the Preparatory Year Program.

Finally, this study was significant due to the research methodology that was utilized known as Concept Mapping/Pattern Matching (CM/PM). Based on accurate investigation in Arabic and English research databases, this is the first study in Saudi Arabia that utilized the CM/PM methodology that was advanced by William Trochim (1989a, 1989b, \& 2007). Therefore, this study contributed to expansion of this methodology and experience in Saudi universities.

\section{Purpose of Study and Research Questions}

The purpose of this study was to identify the future functions of the Preparatory Year Program that need to develop to help first-year students successfully transition into of 
college/university at King Saud University. To accomplish this goal, the researcher studied two groups of stakeholders: males and females. Each group consisted of KSU and PYP's faculty, students, parents, a representative of the business sector, student affairs, academic affairs, and KSU and PYP's administrators. These groups solicited to participate in two brainstorming sessions conducted separately using the Concept Mapping/Pattern Matching (CM/PM) methodology that was advanced by William Trochim (1989a, 1989b, 2007). As mentioned previously, this study's concern was not gender but to compare and contrast male education versus female education.

The first session with the male group was conducted face-to-face, and the second session with the female group was conducted distantly using video conferencing technology within the King Saud University campus. After the creation of the two concept maps, the conceptualization schema outcomes were compared to the current working model of the Preparatory Year Program, to the King Saud University's strategic plan, and finally to each other (female education versus male education). The comparisons were done in order to recognize similarities and dissimilarities between both groups and to examine how these outcomes of two maps reached a consensus or disagreement regarding the developmental conceptual framework of the Preparatory Year Program. Therefore, this study attempted to answer the following guiding research questions: RQ1: Using the Concept Mapping/Pattern Matching methodology, how do Saudi male and female postsecondary stakeholders conceptualize the future ideal functions of Preparatory Year Deanship to help students successfully transition into their first year of college/university? a: Does this Concept Mapping/Pattern Matching conceptualization compare and contrast with the current working model of the Preparatory Year Program at King Saud University? 
b: Does this Concept Mapping/Pattern Matching conceptualization compare and contrast with King Saud University's explicit strategic plan?

RQ2: When conducting a Concept Mapping/Pattern Matching conceptualization, how do the results for males compare and contrast with the results for females?

To answer these questions, the research study utilized the Concept Mapping/Pattern Matching (CM/PM) methodology, advanced by William Trochim (1989a, 1989b, \& 2007), for gathering and analyzing the data to identify a conceptual framework regarding the future ideal functions of the Preparatory Year Program based on female and male perceptions separately. While gender-based perspective was not the primary focus of this study, the CM/PM methodology conducted two separate brainstorming sessions to compare and contrast the male curriculum versus the female curriculum. However, the male and female segregation is a sociopolitical reality, not intellectual divide.

Following the creation of two conceptualization maps of stakeholders, the resulting priorities and their conceptualization schema compared to the King Saud University explicit strategic plan, KSU2030, and the current working model of the Preparatory Year Program. The research study outcomes assisted the educational policymakers to understand the required functions and pieces of the Preparatory Year Program that need to be further developed. The objective of this process was to develop the existing Preparatory Year Program's functions and practices based on the stakeholders' conceptualization of male and female as they related to the current Preparatory Year groups of stakeholders.

\section{Definition of Terms in Alphabetical Order}

Concept Mapping (CM). The definition of CM used in this study refers to William Trochim's (1989a) methodology in particular: 
Concept mapping is a type of structured conceptualization, which can be used by groups to develop a conceptual framework which can guide evaluation or planning. In the typical case, six steps are involved: 1) Preparation (including selection of participants and development of focus for the conceptualization); 2) the Generation of Statements; 3) the Structuring of Statements; 4) the Representation of Statements in the form of a concept map (using multidimensional scaling and cluster analysis); 5) the Interpretation of Maps; and, 6) the Utilization of Maps (Trochim, 2015, Concept Mapping website).

Conceptual Framework. Jabareen (2009) defined a conceptual framework "as a network, or 'a plane,' of interlinked concepts that together provide a comprehensive understanding of a phenomenon or phenomena" (p. 51).

First-Year Experience (FYE). In 1998, the concept of First-Year Experience and Students in Transition was introduced by the University of South Carolina's National Resource Center (Watts, n.d.). Upcraft, Gardner and Barefoot (2005) determined some practices to express the definition of First-Year Student Success, which states that students successfully in the firstyear are connected by two points: (a) completing courses registered in the first-year, and (b) persistent course registration for the second year. For the purpose of this study, the researcher used Upcraft et al. classifications of first-year success that the majority of postsecondary institutions use in general to achieve its goals:

- Developing academic and intellectual competence.

- Establishing and maintaining interpersonal relationships.

- Exploring identity development.

- Deciding on a career.

- Maintaining health and wellness. 
- Considering faith and the spiritual dimensions of life.

- Developing multicultural awareness.

- Developing civic responsibility (p. 7-9).

Knowledge Society. The UNESCO World Report of Towards Knowledge Societies (2005), advanced by Bindé and Matsuura, defined knowledge society as "a society that is nurtured by its diversity and its capacities" and stated that "the concept of knowledge societies encompasses much broader social, ethical and political dimensions" (p. 17).

The Saudi Ministry of Economy \& Planning (MOEP), and King Abdul Aziz City for Science and Technology (KACST), and Madar Research \& Development (MRD) in their report Transition to Knowledge Society in Saudi Arabia: Tracing the Rise of the Knowledge Economy in the Kingdom of Saudi Arabia (2014) defines knowledge society as "a society that generates, disseminates and invests in knowledge for the well-being of its members, and the advancement of the standard of living and quality of life" (p. 62).

In this context, the knowledge society concept is varied and overlaps with some other concepts such as knowledge economy and information society. Therefore, this study will utilize the knowledge society definition that was described by Saudi Ministry of Higher Education in its report Higher Education \& Building Knowledge Society, an International Evaluation Reports (2011; 2013). These reports define knowledge society as:

A knowledge-based society is every society where knowledge, rather than capital or labor force, is regarded as the primary source of production. This indicates the importance given by such a society to information, which, having been found and disseminated, is used to fulfill the welfare and prosperity of citizens. This type of society is characterized by the fact that knowledge is the main component of all its human activities. Whether 
economic, social, or cultural, all these activities rely on information and knowledge. In short, a knowledge society is one where knowledge is one of the forces of innovation and creativity (p. 10).

Pattern Matching (PM). The definition of PM employed in this study refers to Michalski (1999), "Pattern matching allows for the combination of any two measures aggregated at the cluster level to see to what degree the measures match or whether they disconnect" (Michalski, 1999, p. 108).

The definition of pattern matching employed in this study refers to Kane \& Trochim (2007), which states “pattern matching, pairwise comparisons of cluster ratings across criteria such as different stakeholder groups, rating variables, or points in time, using a ladder graph representation" (p. 13).

Preparatory Year Functions. In his study, Rethinking College Readiness; Conley (2008) suggests four dimensions for postsecondary institutional improvement to make students' transition into college successful. These dimensions express the first-year functions in college/university.

1. Key Cognitive Strategies: Conley (2003b) states "students arrive largely unprepared for the intellectual demands and expectations of postsecondary education" (Conley, 2008, p. 7). Therefore, building a foundation of key cognitive strategies will help students learn in any discipline. The key cognitive strategies involve:

a. Problem formulation and problem solving.

b. Research skills.

c. Reasoning, argumentation, and proof.

d. Analyzing and interpretation data or information. 
e. Precision and accuracy for tasks achievement (p. 7-8).

2. Academic Knowledge and Skills: associated with academic subjects (e. g., English, mathematics, science, social studies, world language, and the arts).

3. Academic Behaviors: this includes "self-awareness, self-monitoring, and self-control of processes and actions necessary for academic success... self-management skill...time management, stress management, task prioritizing, using information resources, taking class notes, and communicating with teachers and advisers" (p. 9-10).

4. Contextual Skills and Awareness: "the information students need to apply successfully to college, gain necessary financial aid, and then, subsequent to matriculation, understand how college operates as a system and culture" (p. 10-11).

Adding to these four dimensions, Evenbeck, Jackson, Smith, Ward, \& Associates (2010) illustrate that by linking faculty members, student affairs, student services, policies, and academic advisor's division, and then utilize the first-year programing such as first-year seminars, learning communities, etc. first-year experience is established in functions.

Overall, in this study the function word expresses all Preparatory Year Program domains including program purpose and philosophy, policy, regulation, organizational structure and design, curriculum, student's assessment methodology, student services, and co-curricular activities.

Preparatory Year Program (PYP). Preparatory Year Program is a one-year educational and training program, whereby KSU is providing students with foundation courses in essential soft and hard skills before entering their colleges. Students also have to complete all Preparatory Year Program requirements in one academic year (2 semesters + an exceptional summer semester) with a GPA no less than 3 out of 5 (Deanship, 2014). 
Student Success. Schreiner, Louis, and Nelson (2012) define student success as students who "move beyond the fundamental benchmarks of college completion rates and grades have emerged in recent years. Such expanded definitions have included learning gains, talent development, satisfaction and sense of belonging, and student engagement" (p. xix).

Kuh, Kinzie, Buckley, Bridges, and Hayek (2006), define student success as "academic achievement, engagement in educationally purposeful activities, satisfaction, acquisition of desired knowledge, skills and competencies, persistence, attainment of educational objectives, and post-college performance" (p.7).

Student success is more likely to be experienced and evidenced when students: (1) feel personally validated and they matter to the college, (2) believe that their effort matters and that they can influence or control the prospects for success, (3) develop a sense of purpose and perceive the college experience as being personally relevant, (4) become actively or engaged in the learning process and in the use of campus resources, (5) become socially integrated or connected with other members of the college community, (6) think reflectively about what they are learning and connect it to what they already know or have previously experienced, and (7) are self-aware and remain mindful of their learning styles, learning habits, and thinking patterns (Cuseo, n.d.).

Student Transition. Mutch (2005) states "transition is different from change. Change is external and visible. A transition is internal and less visible, the process you go through mentally when you face a big life change" (p. 144).

Bill (2010) describes the transition concept as a double-sided concept comprising:

- The student experience of change involved in joining the university. 
- The programmes $[$ sic] of academic and other activities, which the university provides to support and enhance student transition (p. 4).

In addition, Bill mentions that transition can describe leaving school or college, place changing, a change of financial situation, etc. as can occur in different ways such as academic, personal, etc.

In educational sector transition concept typically refers to the three major transitional points in the public-education system: when students move from elementary school to middle school, from middle school to high school, and from high school to college. While students experience other "transitions" during their educational journey—such as advancing from one grade level to the next - the three "major" transition points are a particular focus of educators and school reformers because transitioning students often experience significant academic, social, emotional, physical, or developmental changes that may adversely affect their educational performance. During these transitions, for example, students may move from a familiar school to an unfamiliar school, where they encounter new teachers, peers, academic expectations, social issues, and school configurations that increase the likelihood they will feel overwhelmed, anxious, frustrated, or insecure (Transition, 2015, March 17).

\section{Organization of Study}

The first chapter of this study began with the overview of the status of Saudi postsecondary education and trends. Next, the study stated the research problem and significance to postsecondary education with a historical brief about the first-year movement and its importance in Saudi context. 
The second chapter is divided into five sub-sections. The first section provided extensive review of the literature of Student Development theories including the leading theories in the field. The second section provided a wide explanation about First-Year Experience with a precise description of its concepts, issues, intervention strategies, practices, functions, and overview on the literature of first-year experience on the international level and within Saudi higher education. The third section was about the knowledge society concept and challenge within Saudi education context. The fourth segment provided a brief explanation about the Concept Mapping/Pattern Matching methodology used in this study. Finally, the fifth section provides an illustration about the potential contribution of this study to the literature of first-year experience and student development.

The third chapter of this study provided a detailed explanation for the research methodology that was utilized. This explanation involved the data collection and analyzing process and any limitations related to the research methodology.

The fourth chapter illustrated in detail the study procedures and results responding to the four research questions of this study. The research questions were answered separately for each group of stakeholders: male and female. The fifth chapter reported the research findings and conclusion, including a discussion of the study outcomes and implementations, followed by recommendations for future studies and a summary of the study. 


\section{Chapter Two \\ Review of the Literature}

\section{Literature Review Process}

A wide investigation on the concepts of the Preparatory Year Program (PYP) and FirstYear Experience was conducted by searching different databases and academic libraries to fulfill the current literature review prerequisites. First, through the West Virginia University (WVU) library, peer reviewed and scholarly academic research papers were collected electronically using library catalogs. Online search of EBSCOhost's Education Research Complete Database with the phrases 'Preparatory Year Program' and 'First-Year Experience' as a key search with no other limitations reported the retrieval of 7,359 citations, the oldest with a publication date of 1981. By limiting the search using the subject field higher education, the citations number decreased to 30 citations since 1998.

A similar search in EBSCOhost's Academic Search Complete Database with the phrases 'Preparatory Year Program' and 'First-Year Experience' with no other limitations resulted in 20,574 citations. The oldest had a publication date of 1924. By limiting the search results using the subject field higher education, 1,430 citations were retrieved. Both databases identified 15 research studies by using the Saudi Arabia and Arabic-language as limitations of the search.

A parallel search was done using the ProQuest Dissertations \& Theses (PQDT) Database, limiting to the phrases 'Preparatory Year Program' and 'First-Year Experience' to higher education, citation, and abstract, retrieved 34,400 English-language dissertations and theses published between 1914 and 2014. When combined with the phrase knowledge society and higher education, no results were revealed. 
Using Google Scholar as a search tool with the phrases 'Preparatory Year Program' and 'First-Year Experience' reported about 1,040,000 results. The quoted sentence: "The role of first-year experience in knowledge society" resulted in no matches found on Google search or Google Scholar, despite the large amount of scholarly research that investigated university roles in Knowledge Society as a general title. In addition, a search was completed on an Arabic database named Saudi Digital Library (http://sdl.edu.sa/SDLPortal/en/Publishers.aspx) and King Saud University Library using Arabic language as a limitation. This search resulted in ten studies conducted in the Arabic language; most of them to assess a specific aspect of the Preparatory Year Program such as an assessment of the English language program and academic accreditation of the program. Additionally, most of these studies represent master's or doctoral student research.

Moreover, an electronic copy of the Saudi Journal of Higher Education was referenced on Google search engine. This is a peer-reviewed, bi-annual journal published by the Center for Higher Education Research and Studies (CHERS) Ministry of Higher Education. Three articles related to the First-Year Experience were retrieved from issue No.11 - Rajab 1435 AH - May 2014. One of these articles is titled A History of the First-Year Experience in the United States during the Twentieth and Twenty-First centuries: Past Practices, Current Approaches, and Future Directions, written by Prof. Andrew K. Koch and Prof. John N. Gardner. Another database utilized was the National Resource Center for the First-Year Experience \& Students in Transition at the University of South Carolina. The National Resource Center specializes in the First-Year Experience program and students-in-transition issues, which "serves as the trusted expert, internationally recognized leader, and clearinghouse for scholarship, policy, and best practice for all postsecondary student transitions" ("About the Center", 2015). 
The National Resource Center has several publications in the First-Year Experience \& Students in Transition. One of its publications is the Journal of The First-Year Experience \& Students in Transition, which has published 26 volumes divided into 52 issues, beginning with the first volume in 1989 to the most recent volume in fall 2014. All these materials are available electronically (“About the Center”, 2015). Furthermore, numerous books and annotated bibliographies have been published about the First-Year Experience. Moreover, the National Resource Center has conducted 34 annual conferences discussing first-year issues and development (“About the Center”, 2015).

The last search was done using the International Journal of the First-Year in Higher Education (Int J FYHE), which is published by Queensland University of Technology in Australia. The Int J FYHE published its first volume in 2010. The most recent volume published is volume six in the beginning of 2015. The Int J FYHE "focuses on research and practice about enhancing the experience of commencing students" ("Int J FYHE”, 2015).

In addition, the search process took into account the type of research, including both positivist and post-positivist research for better understanding of first-year students' practices and functions. Consequently, in preparation for conducting this study, a systematic review of literature associated to the application of first-year experience practices and theories to postsecondary education and a Knowledge Society was performed. Expanding the literature review's domain of search allows for more understanding and provides a researcher with new information and experience regarding his/her topic, and elucidate the relationship between different subjects within a research problem (Boylan, Bonham \& White, 1999). 


\section{Organization of Review of Literature}

For this study, the literature review starts with an outline of the most common and leading cited documents associated with the First-Year Experience and Preparatory Year Program discipline that established the foundation for several theoretical, practical, and research publications in the most recent years. Thus, the literature review has been divided into four main sections attempting to cover all issues and topics related to the study's domains.

The first section provides an inclusive description of theoretical foundations of Student's Development Theories. This section discusses the most common theories inspiring the student's development and First-Year Experience Movement and its expansion in the literature. These theories include the Alexander Astin Theory, Pascarella and Terenzini Theory, Vincent Tinto Theory, Chickering's Theory, and Schlossberg's Transition Theory. Each theory has been discussed in detail, comprising its roots, development, issues, and critical analysis of the theory.

The second section illustrates First-Year Experience topics, including a wide review of first-year history development, First-Year Experience issues, first-year intervention strategies and functions, first-year organizational structures, First-Year Experience: an international perspective, and First-Year Experience in Saudi postsecondary education context.

The third section discusses Knowledge Society and First-Year Experience, distinguishing between a Knowledge Society and knowledge-based economy, and the Knowledge Society Movement in Saudi Arabia. This portion highlights the most serious challenges encountered by the Saudi postsecondary movement toward a Knowledge Society and university role in this movement.

Finally, the fourth section involves a brief history on Concepts Mapping/Pattern Matching (CM/PM) methodology as a developmental methodology and some examples for its 
uses, followed by a conclusion about how this study contributes to the literature of First-Year Experience in a different cultural context.

\section{Theoretical Foundations of Student Development}

Several research studies were conducted over the last four decades related to various issues associated with student development in general, and first-year students and transition topics. The earlier studies discussed general issues related to college students' success and the factors that impacted students' persistence and retention. Other studies established new concepts and definitions such as first-year students, students' success, retention, readiness, persistence, etc. In the last thirty years, new issues manifested such as diversity, gender, race, sex, economic situation, higher education trends, etc.

Student development theories became part of the first-year and student in transition movement, with numerous theories attempting to study students' success and transition issues within a theoretical perspective. "Intentionally using student development theory to develop and deliver new students programs is critical to ensure that the needs of diverse students populations are addressed" (Cubarrubia \& Schoen, 2010, p. 167). In other words, applying the best practices of first-year programs at postsecondary institutions is inadequate to ensure program quality and success if we ignore the foundational theories of student development.

Due to differences in student characteristics from one community to another, a wide range of research on student development has worked to establish new models or programs to meet students' needs and to fulfill the postsecondary mission. Therefore, an analysis of the most common student development theories is vital for the current study, a process which will give insights about the student development movement and its applications. This analysis will help us to understand stakeholders' perceptions and to conceptualize the future functions of the 
Preparatory Year Program in Saudi postsecondary education. In this context, this section will discuss five theories of student development based on to two criteria:

1. Relationship to student development theories in college/university.

2. Contribution to First-Year Experience literature according to the indicated theories citation in Google Scholar.

If we are to help freshmen succeed, we must know how various theories attempt to explain their development. To be sure, the theoretical underpinning of freshman development is a dynamic and constantly changing endeavor. The most recent challenges to include women, minorities, and older students in our theoretical concepts about student development will expand and make our thinking about students more valid. In spite of this continuing uncertainty about students-development theories, everything we do to enhance freshman success must be grounded in one or more of these theories. It is important that we take what we know about students from developmental theories and apply it to our teaching, counseling, advising, and programming for freshmen (Upcraft \& Gardner, 1989, p. 52). Therefore, a discussion of these theories will assist as a fundamental background when a developed Preparatory Year Program functions based on stakeholders' perceptions.

Alexander Astin's Theory. Astin has conducted numerous research studies, but the most important are published in his books, Four Critical Years: Effects of College on Beliefs, Attitudes, and Knowledge (1977), and What Matters in College? Four Critical Years (1993), which were cited by 2,145 academic studies, Astin's Student Involvement: A Developmental Theory for Higher Education (1984), which was cited by 2,767 studies; both research studies citations referred to Google Scholar. 
The purpose of What Matters in College? was to provide faculty, Student Affairs, educational policy makers, and professionals a better understanding of "how undergraduate students are affected by their college experiences" (Astin, 1993, p. xix). To assess how students are affected by their college experiences, Astin cited three major activities that are used in his study: 1) understanding the nature and meaning student change; 2) select or develop a model or theoretical or conceptual framework to study student performance; and 3) "designing the analyses of college impact" (p. 5).

In this regard, Astin $(1977,1993)$ argues that the majority of research studies on first-year experience measures students' change or growth academically rather than studying the impact of the college itself on students' experience. For example, some postsecondary institutions survey student's perceptions at the first day of college and at the end of year, or after four years of study. In this case, students' change in perception is assessed by comparing two measures. The weakness of this measurement approach refers to the weakness of this measure to predict a student's change if he/she attends different colleges, or does not attend a college. Astin states that a student's change occurs due to two major mechanisms: college impact and the outside environment of college.

To measure the impact of college activities, Astin's study (1993) utilized the Cooperative Institutional Research Program Survey (CIRP). CIRP involves several measurements, thus Astin developed a conceptual scheme to organize and guide these measurements. The "taxonomy of student outcomes" (p. 9) contains three dimensions: 1) type of outcomes, which involves cognitive outcomes (called intellective) such as mental process (e.g. reasoning and logic), and non-cognitive outcomes (called affective) such as attitudes, values, self-concept, aspirations, and everyday behavior; 2) type of data, which describes type of information collected to evaluate 
cognitive and non-cognitive outcomes; these data involve Psychological (e.g. attitude, values, etc.) and Behavioral (e.g. personal habits, occupations, citizenship, etc.); and 3) time dimension, which refers to two points of time during college and after college (e.g. satisfaction with college represents a point of time during college, and job satisfaction represents a point of time after college) (p. 9-11).

Furthermore, Astin's studies $(1977,1993)$ utilized some standardized tests to recognize Student Input Characteristics such as the Scholastic Aptitude Test (SAT), American College Test (ACT), and Graduate Record Examination (GRE). Moreover, for Environment Measures, Astin utilized 192 environmental measures, including 16 measures of institutional characteristics (e.g. size, control, type); 35 measures of student peer group characteristics (e.g. socioeconomic status, academic preparation, values, etc.); 34 measures of faculty characteristics (e.g. teaching methods, moral, etc.); 15 measures of the curriculum; 15 measures of financial aid; 16 measures of freshman major field choice; 4 measurements of place of residence; and 57 different measures of student involvement (p. 15). Essentially, the main difference between Astin's studies (1993) and (1977) is the number of environmental measures that were utilized in the 1993 study.

The 1977 study used longitudinal data with a sample size of more than 200,000 students and tested more than 80 different student outcomes. Moreover, it gave more attention to students' involvement applications. For example, "place of residence, honors programs, undergraduate research participation, social fraternities and sororities, academic involvement, student-faculty interaction, athletic involvement, and involvement in student government" (Astin, 1984, p. 524).

The data analysis of these studies involves two stages: 1) the data of each freshman is entering through multiple-regression techniques to get a predicted score on each outcome 
measure under study; and 2) compare predicted scores for each freshman characteristic in different college environments with the actual outcome measures. This study has one important limitation, that was this study has no separate analysis representing "gender, race, ability, socioeconomic status, or other key students' characteristics" variables (Astin, 1993, p. 29). In other words, the "studies focus on individual programmatic interventions" (Terenzini, 2005, p. 1). Astin (1993) developed the Input-Environment-Outcome Model (I-E-O) as a conceptual framework to study college student development.

Inputs refer to the characteristics of the student at the time of initial entry to the institution; environment refer to various programs, polices, faculty, peers, and educational experiences to which the student is exposed; and outcomes refers to the student's characteristics after exposure to the environment. Change or growth in the student during college is determined by comparing outcome characteristics with input characteristics... studying student development with the I-E-O model provides educators, students, and policy makers with a better basis for knowing how to achieve desired educational outcomes (Astin, 1993, p. 7).

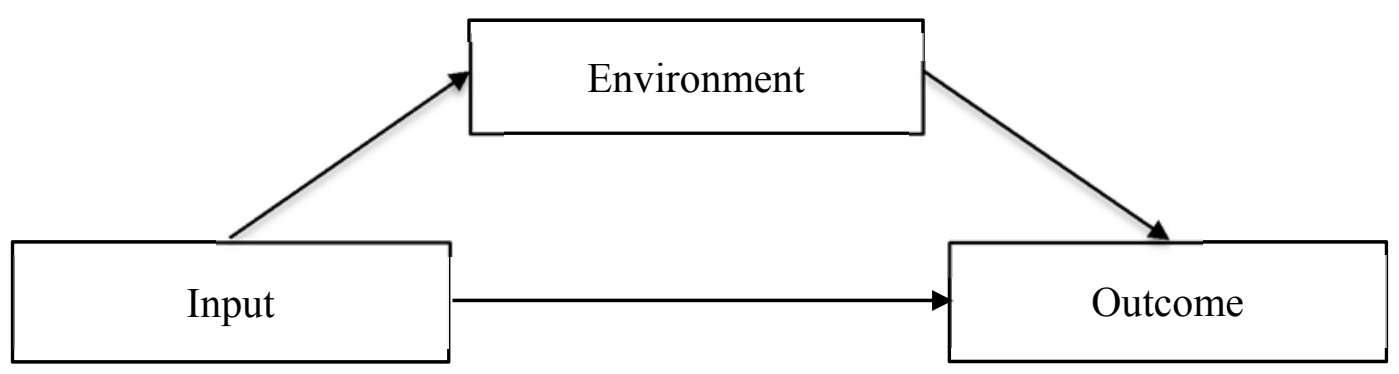

Figure 1: I-E-O Model. (Astin, 1993, p. 18)

Astin's study, Student Involvement: A Developmental Theory for Higher Education (1984), represented a development of his theory, the Theory of Student Involvement, which is found in student development research of postsecondary education during recent years. The 
theory dates back to a longitudinal study conducted by Astin in 1975, to identify the environmental factors impacting students' academic persistence (Astin, 1984). "Student involvement refers to the amount of physical and psychological energy that the student devotes to the academic experience" (p. 518). Astin provides some examples of involvement practices such as study hard, engage in campus activities and student organizations, and interact with faculty. On the other hand, uninvolved is a term used to represent the opposite practices.

Furthermore, Astin defines the involvement concept as an active term in the student development discipline, which expresses the following: attach oneself to, engage in, show enthusiasm for, take a fancy to, etc. In other words, he defines involvement as a behavioral practice. The involvement theory also has five basic postulates:

1. Student involvement requires investment of psychosocial and physical energy.

2. Involvement is continuous, and each student, as an individual, has a different amount of energy.

3. Involvement can be measured qualitatively or quantitatively.

4. The quality and quantity of involvement is related to the amount of learning acquired.

5. Policy effectiveness depends on its capacity to stimulate students' involvement (Astin, 1984, p. 519).

Astin's $(1977,1993, \&$ 1984) studies have provided postsecondary education with several practical applications. For example, develop students' peer group programs, which plays an important role in improving students' performance (Reason, 2009). Astin (1993) concludes, "Every aspect of the student's development - cognitive and affective, psychological and behavioral - is affected in some way by peer group characteristics, and usually by several peer characteristics" (p. 363). Moreover, "the student's peer group is the single most potent source of 
influence on growth and development during the undergraduate years" (Astin, 1993, p. 398). In real life, students tend to embrace the dominant beliefs or values structured by their peers, which Astin and Panos (1969) called progressive conformity.

In addition, Astin's model of Input-Environment-Outcomes (I-E-O) is used widely as a theoretical framework to study several issues related to first-year experience at postsecondary institutions. For example, the model is used to study students' retention, persistence, performance, and to design first-year initiatives such as seminar and orientation programs (Krahenbuhl, 2012). Kelly (1996) used the I-E-O model to identify relationships among inputs, environment, and student persistence as outcomes. This study found a statistically significant relationship between input and environment and students' persistence.

On the international level, Yanto, Mula, and Kavanagh (2011) used the I-E-O model for developing Students' Accounting Competencies (SAC). The study population was in Indonesian universities with a sample size of 7,500 students. Yanto et al., "utilized student motivation, student previous achievement, student demographic characteristics, learning facilities, and comfort of class size are educational inputs, and student engagement and sac are proxies for environment and outcome respectively" (p. 1). This study reported that all inputs are statistically significant for improving SAC, with one exception, student demographic characteristics. However, this study found the I-E-O model valid to analyze relationships among a single input, but less powerful among multiple inputs.

Using the I-E-O model, Norwani (2005) studied the relationships among inputs, environment, and students' learning based on a final Grade Point Average (GPA) and aptitude development in Australian universities. Norwani found that student input statistically can be used to predict the final GPA, while environmental factors impacted aptitude development. Moreover, 
Astin's (1993) I-E-O model reported that learning communities are considered a significant factor to students' success and involvement. Numerous research studies support Austin's point of view about the role of learning community in students' development in general, and in first-year in particular.

However, despite Astin's theory contributions in the first-year student experience research studies field, his I-E-O Theory has limitations. Despite its effectiveness as an assessment theoretical base to recognize the impact of student practices and behaviors, faculty, programs, and environmental components on student outcomes. Astin's Theory is limited in terms of assessing organizational components impacting students' outcomes, e.g., organization culture context impact (Terenzini, 2005). Furthermore, Astin's Theory as a social science theory places emphasis on how involvement makes a difference on students' outcomes, but does not clarify why involvement makes a difference, nor does it illustrate how to help students who are not involved (Torres \& LePeau, 2013).

In summary, Astin's (1977, 1993, \& 1984) studies conclude that students' involvement with their environment will lead to better learning. Designing educational programs with more focus on quality and quantity of involvement will lead to better learning. "The more students put in to an activity, the more they get out of it" (Barefoot, 1998, p. 3).

Pascarella and Terenzini's Theory. Pascarella and Terenzini have conducted a comprehensive analysis of student development research; How College Affects Students: Findings and Insights from Twenty Years of Research (1991), and How College Affects Students: A Third Decade of Research (2005), which were cited by 9,020 researchers, referring to Google Scholar. 
In a longitudinal analysis of how college affects students, Pascarella and Terenzini (1991, 2005) have conducted an exhaustive review of the literature on first-year students using variables such as GPA, retention, graduation and self-reported student satisfaction (Jamelske, 2009). The purpose of these studies is to answer the following questions, "Do students change in various ways during the college's year? To what extent are changes attributable to collegiate experience and not to other influences (like growing up)? And finally, what college characteristics and experiences tend to produce change?" (Pascarella and Terenzini, 1991, p. xvi-xvii). These studies attempted to answer six research questions:

1. What is the evidence that individuals change during the time in which they are attending college?

2. What evidence exists to indicate that change or development during college is the result of college attendance?

3. What is the evidence that different kinds of postsecondary institutions have a different influence on student change or development during college?

4. What evidence exists on the effect of different experiences within the same institution?

5. What evidence shows that the collegiate experience produces conditional, as opposed to general, effects on student change or development?

6. What are the long-term effects of college? (Pascarella \& Terenzini, 1991, p. 7-8). To answer these research questions, the Meta-Analysis methodology was utilized to synthesize research findings. In the first version of their study, Pascarella and Terenzini (1991) conducted a search covering an 11 year period, 1969-1980, by reviewing about 2,600 studies, representing 1,300 studies per decade. In their 2005 research, the number of studies increased to 2,400 studies during ten years in the 1990s (Pascarella, 2006). 
Pascarella and Terenzini's (1991) study, Theories and Models of Student Change in College helps to clarify the difference between change and development terminologies. "Change refers to alternations that occur over time in students' internal cognitive or affective characteristics" (p. 16). Moreover, change can be measured quantitatively or qualitatively. "Development on the other hand, has generated considerable philosophical and theoretical debate among psychologists, sociologists, and others for some time" (p. 16).

Pascarella and Terenzini $(1991,2005)$ classified two families of theories and models of student change and developed directed college impact studies in the last three decades. The first family category, Developmental Theories, involves psychological aspects of human growth, or in other words intra-individual development. The second family category, College Impact Models, regularly focus on "the environmental or sociological origins of student change" (p. 17). Some examples of this family of theories are Astin's (1985, 1993), Tinto's (1993), and Pascarella's (1985) models and theories.

The College Impact Models family category emphasizes environmental factors that change or develop one or more student aspect (e.g. academic aptitude, performance, socioeconomic, race, etc.) and on structural and organizational aspects (e.g. size, policy, administration, etc.) (Pascarella and Terenzini, 1991, 2005). In other words, "how does the environment of the college or university affect the student's development? How do the background and individual characteristics of the student foster or impede development?" (Long, 2012, p. 51). Pascarella and Terenzini $(1991,2005)$ identified four clusters of theories and models of student change in college:

1. Psychosocial theories (e.g. Erikson Theory, Arthur Checkering Theory, Cross's model of Black Identity Formation, etc.). 
2. Cognitive-structural theories (e.g. Jean Piaget Theory, Perry's Scheme of Intellectual and Ethical Development, Kohlberg's Theory of Moral Development, etc.).

3. Typological models (e.g. the Myers-Briggs typology, etc.).

4. Person-environment interaction models (e.g. Physical model, Human Aggregate model, Perceptual model. etc.).

In 1985, Pascarella suggested a general casual model to understand student change in college. The General Model for Assessing Change emphasized two dimensions for an institution's structural features/organizational characteristics and its environmental factors. In detail, Pascarella's model comprises five clusters for assessing college student change: 1) student background and precollege characteristics (e.g. aptitude, achievement, etc.); 2) organization structure and characteristics (e.g. selectivity, faculty-students ratio, etc.); 3) clusters one and two together shape cluster three, which consists of college environment; 4) the three clusters impact student interaction with campus components including peers, agents of socialization, etc.; and 5) cluster five is shaped by the quality of student effort, which is also shaped by student background and interaction with environment (Moon, Sullivan, Hershey, Walker, Bosangue, Filowitz, Fernandez, Unnikrishnan, \& Delgado, 2013). Pascarella's model assumes that student learning and cognitive development is impacted directly and indirectly by institutional characteristics and environment (Pascarella \& Terenzini, 1991, 2005). Despite the efforts to classify theories and models of student change in college, Pascarella and Terenzini (1991, 2005) admitted that "the important lesson is to understand what the constraints are on any approach and to bear in mind that reliance on developmental models may lead to misspecification of the origins of student change and growth" (p. 49-50). 
Finally, in their article: Studying College Students in the 21st Century: Meeting New Challenges, published in 1997, Pascarella and Terenzini state that "the knowledge base for How College Affects Students permitted us to draw conclusions about a population of students that no longer dominates American postsecondary education” (p. 2).

Ironically, just as analysis of the experiences of college students reached an apex in terms of quantitative technique and vigor," the population of interest began shifting. Now at the end of the 2 decades, our college campuses are no longer predominantly populated by the students described in this book (Educational Research, Stage 1993, p. 22) as cited in (Pascarella \& Terenzini, 1997, p. 2)

This conclusion gives an insight about the necessity of studying these theories and models in a different cultural context such as Saudi postsecondary education. Moreover, the fact of student change may make postsecondary institutions reconsider before transferring first-year programs or experiences from one culture to another under the best practices title without sufficient knowledge about students' needs. However, Pascarella and Terenzini statement supports the current study goals to recognize first-year students and other stakeholders' needs in the Preparatory Year Program.

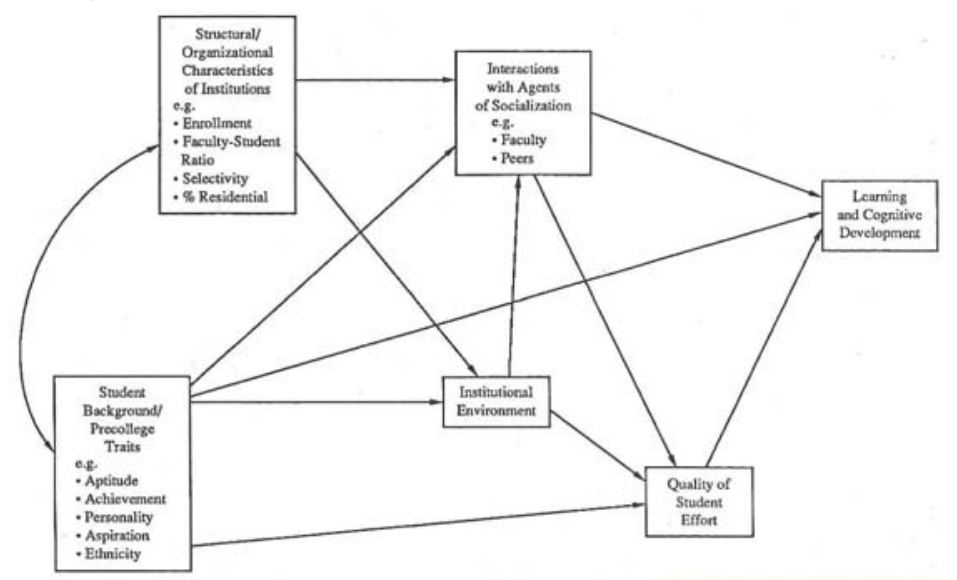

Figure 2: The General Model for Assessing Change. (Pascarella and Terenzini, 1991, p. 54). 
In 2005, Terenzini and Reason argued that most student development theories or models provide theoretical illustrations of student and faculty behaviors, attitudes, and cultures. However, it doesn't explain the influence of organizational structure and characteristics on student outcomes. One notable exception, Berger and Milem Model (2000), suggests that organizational structure and characteristics (Internal Organizational Features) impact students' college experiences directly or indirectly. Some examples are university/college curriculum structure, financial issues, educational policies, faculty recruiting, selectivity, etc.

Therefore, Terenzini and Reason (2005) proposed a new framework to identify the nature and dynamics of factors that impact first-year college experiences. The new framework is best classified in the second family of student development theories and models "college impact model" (p. 2), despite its diversity of components between psychology and social psychology theories, Cognitive Development Theory, and the Foundations of Excellence ${ }^{\circledR}$ of two years postsecondary institutions. Terenzini and Reason's (2005) model assumes that students come to college with diverse backgrounds, including experiences, knowledge and skills (academic and social background) that prepare him/her to become involved with the numerous formal and informal learning opportunities offered by his/her institution. Moreover, student interaction with the institution's environment will shape his/her experience and reflect on his/her learning.

The model has three main factors that impact student learning: college/university internal organization context, the peer environment, and student experiences. However, the Terenzini and Reason (2005) model relies on different theoretical components including Foundations of Excellence $^{\circledR}$ of two-year postsecondary institutions. Therefore, applying such a model to fouryear postsecondary institutions requires more study to check its validity in the research university. 


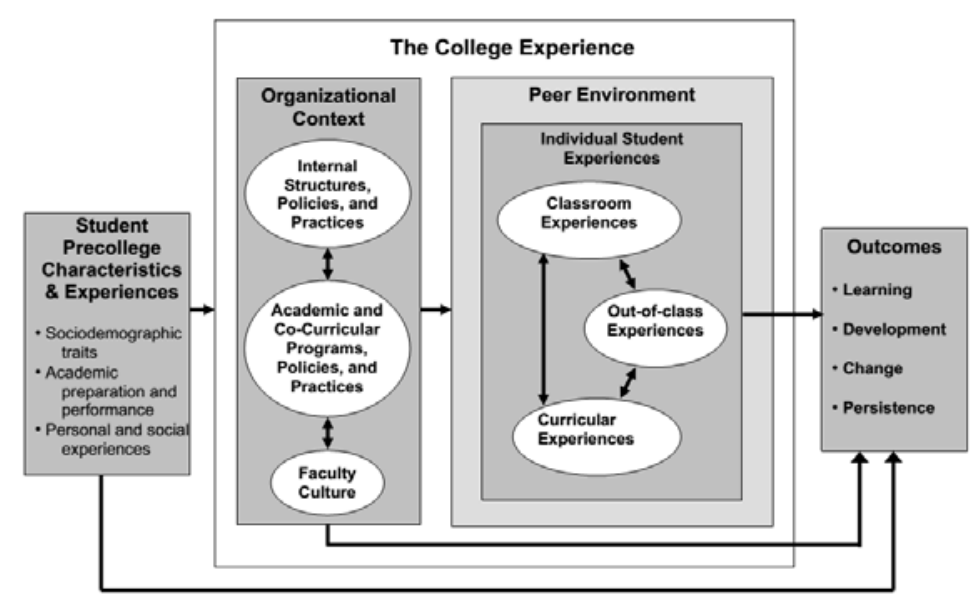

Figure 3: A comprehensive model of influences on student learning and persistence. (Terenzini and Reason, 2005, p. 21).

Vincent Tinto's Theory. Tinto authored a large number of studies in student development discipline. For example, Dropout from Higher Education: A Theoretical Synthesis of Recent Research (1975), which was cited by 4,994 researchers, based on Google Scholar statistics. Tinto also authored Leaving College: Rethinking the Causes and Cures of Student Attrition (1987,1993), which was cited by 8,289 researchers, based on Google Scholar. Tinto (1975, 1987, 1993) introduces the Theory of Student Departure dominant sociological viewpoint and the common referred model of student retention/dropout literature (Draper, 2005; Kuh, Kinzie, Buckley, Bridges, \& Hayek, 2006).

Tinto's Theory was based on the work of cultural anthropologist Arnold Van Gennep. Gennep focused on studying the movement of individuals from one group to another. Furthermore, Tinto's Theory is influenced by Durkheim's Theory of Suicide (1951) and Spady's work Dropout from Higher Education: Toward an Empirical Model (1971) (Tinto,1987, 1993, 1988). Additionally, Tinto (1993) highlighted egoistic suicide to justify his relying on Durkheim's Theory of Suicide, which states "the individual is unable to become integrated into society due to values which may deviate from society, or from insufficient personal affiliation 
between the individual and other persons in society" (p. 102). Tinto explains that the student who is not integrated into college/university academically and socially will be at risk of dropping out (Roos, 2012). The theory takes from the educational economy discipline concerning the costbenefit analysis of individual decisions regarding continuing/dropping out of his/her college (Tinto, 1975).

Tinto's longitudinal model aims to elucidate the college student attrition process, and is related to Astin's Involvement Theory (Pascarella \& Terenzini, 1991; Skipper, 2005). In addition, Tinto identifies two main paths of the theory of student departure: academic and social integration (Tinto, 1975, $1987 \&$ 1993). Academic integration means that students can meet college/university requirements and standards while embracing college values and beliefs. Social integration means that the student feels he/she is part of society beliefs and norms on campus (Comeaux \& Harrison, 2011; Skipper, 2005; Stuart, Rios-Aguilar \& Deil-Amen, 2014). The term integration describes the extent to which a student "shares normative attitudes and values of peers and faculty in institution and bides by the formal and informal structural requirements for membership in that community or in the subgroups of which the individual is a part" (Pascarella \& Terenzini, 1991, p. 52-53). The term integration can be defined as a negative or a positive connection between the student and academic or social system.

Tinto hypothesized three dimensions that influence student departure or retention: 1) preentry characteristics (e.g., family background, skills and abilities, prior educational experience); 2) goals and commitments; and 3) institutional experiences with academic systems (e.g. academic performance, faculty/staff interaction) and social system (e.g. extracurricular activities, peer interaction) (Tinto, 1975, $1987 \& 1993)$. The nature and power of integration determines 
departure decision. In other words, a student who could not achieve a level of academic or social integration is probable to leave college/university.

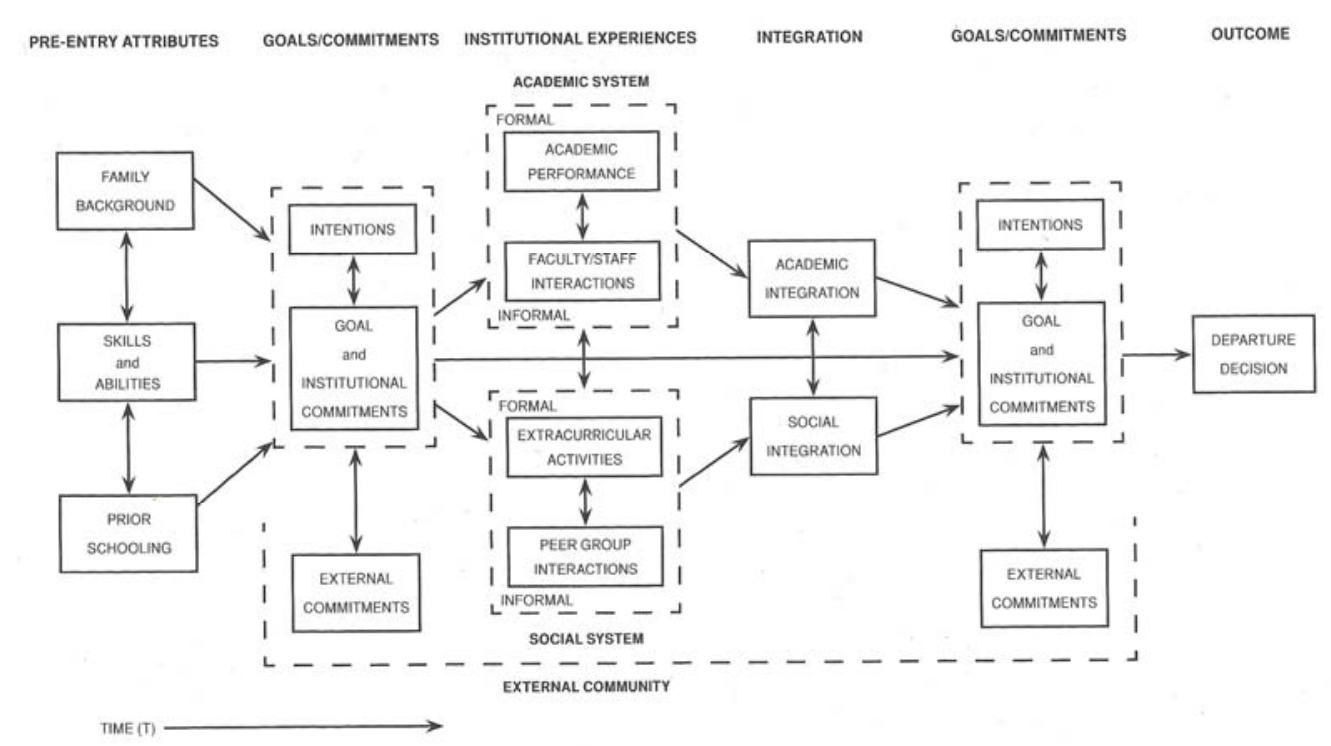

Figure 4: Tinto's longitudinal model of institutional departure. (Tinto, 1993, p. 114).

In 1988, Tinto introduced three stages of students' departure, Separation, Transition to College, and Incorporation in College. The Separation stage means that the student requires separating him/her self from the past community and becoming involved in a new community (university community). This stage contains a difficult process due to its nature and the relationship to the person's life, choices, belief, and attitude. The Transition stage consists of the period of movement between the old community to the new one. This stage requires the student to adapt and adjust him/her self with a new culture. Tinto (1988) stresses that, at this stage, the student has not yet acquired new community norms and patterns of behavior; therefore, more support, either academic, social, financial, etc., is required to help the student be involved in a new culture. The Incorporation stage means that the student is ready to become a part of a new community. In other words, the student moved away from the old norms and behavior pattern to a new one. 
Despite its popularity, Tinto's Theory of student departure has come under a critical or developmental review. Tinto's student integration model has changed over the last three decades from the original version. One change that has occurred is the addition of a new variable such as motivation (Demetriou \& Sciborski, 2011). Several studies reported other factors outside of Tinto's model causes students to leave their college, such as a student's inability to adjust, economic and financial difficulties, lack of family emotional and social support, and poor academic performance (Bogard, Helbig, Huff \& James, 2011; De Witz, Woosley, \& Walsh, 2009). For example, Tinto himself expanded the Theory of Student Departure to include classroom activities as a variable of student departure. His study utilizes a learning community practice as a tool to understand the relationship between classroom activities and retention. The study found that classroom activities, in general, and learning community practice especially, impact student's retention positively (Tinto, 2000).

To provide another example, in his book, Reworking the Student Departure Puzzle, Braxton (2000) dedicated two chapters for criticism of Tinto's Theory, which resulted in the development of a new theoretical path to recognize student departure factors. Braxton's framework suggests new variables that influence student departure such as socioeconomic and financial impact, and tuition. Further, Braxton suggests that the campus climate and learning methodology also influence student departure. Braxton also discusses issues related to student race, color, and identity, which can affect student behavior and persistence.

Pascarella and Chapman (1983) have studied Tinto's Theory validation in a multiinstitutional sample. Pascarella and Chapman illustrate three main problems related to the previous studies that tested Tinto's Theory validation as follows: 1) most of these studies focus on the operational variables of academic and social integration (e.g. studying the relationship 
between pre-college characteristics and student retention); 2) most of these studies were conducted in four-year residential institutions; therefore, more investigation regarding two-year institutions, or commuter institutions are required; and 3) these studies, in general, utilized a single sample in one large university, which produces a generalization limitation.

Pascarella and Chapman's (1983) study was conducted on four different types of institutions: residential universities, liberal arts colleges, two-year and four-year commuter institutions. In general, this study supported the predictive validity of Tinto's Theory with a comment that student characteristics have "the main-effects influence on persistence" (p. 25). However, Pascarella and Chapman use the concepts of persistence/withdrawal instead of the retention concept in their study, despite Tinto (2010) distinguishing between two concepts:

Retention refers to the perspective of the institution. Institutions seek to retain students and increase their rates of institutional retention. By extension the term student retention refers to that process that leads students to remain within the institution in which they enroll and earn a certificate or degree. By contrast, persistence refers to the perspective of the student. Students seek to persist even if it may lead to transfer to another institution. By extension, the term student persistence refers to that process that leads students to remain in higher education and complete their certificate or degree regardless of the institution from which the certificate or degree is earned (p. 53).

Moreover, Rendón, Jalomo, and Nora (2000) criticized Tinto's Theory due to the issue of the non-white students variable. The purpose of their study was to 1) provide a critical analysis of Tinto's Theory with a specific focus on the Separation and Transition stages mentioned earlier; 2) critique Tinto's concepts of academic and social integration; and 3) provide some 
recommendations to develop Tinto's Theory into a higher level of student development research (p. 131).

Rendón et al. (2000) sees the Separation stage of Tinto's Theory as utilizing a negative interpretation of a native culture, which requires a student to abandon his/her culture and embrace the new culture of an institution or community to be integrated socially or academically. Rendón et al. states "The assumption made is that an individual's values and beliefs rooted in his or her cultural background must be abandoned to successfully incorporate the values and beliefs not only of the institution but of the majority population upon which they are based" (p. 132).

To overcome this issue, Rendón et al. (2000) offer a concept of "Biculturalism” (p. 133) which says that students can move between two or more cultures that are separate and diverse. In fact, understanding a student's ability to fit between and within two cultures is important, especially for first-year students. Therefore, "culture translators, mediators, and role models become critical to the socialization process" (Skipper, 2005, p. 72). However, moving from a theoretical perspective to a practical action, Tinto (1993) suggests action principles for the development of retention programs:

1. Postsecondary institutes require providing adequate resources to develop intervention programs.

2. Postsecondary institutes are obligated to plan a long-term process to develop and adjust these programs based on students' needs and the institution's mission.

3. Postsecondary institution that plans such changes are required to identify and allocate tasks and responsibilities across the campus to implement that change.

4. Postsecondary institutions require coordinating efforts to insure a systematic campuswide approach to achieve the retention goal. 
5. Postsecondary institutes require insuring that faculty and administration staff members have the necessary skills to teach and assist students.

6. Postsecondary institutions require giving more attention to student retention issues.

7. Postsecondary institutes require focusing more on the assessment of its process and actions about retention programs for developmental purposes.

In summary, Tinto's Theory provides a wide understanding of student retention issues and includes suggestions to improve student retention. Moreover, Tinto's Theory provides a new perspective about factors and variables that can influence students' persistence and retention. For example, new perspectives emerged as a result of applying Tinto's Theory in different contexts such as economic, cultural, psychological, organizational, and social perspectives, especially for the first-year student. Furthermore, Tinto's Theory stresses that developing and implementing a comprehensive student retention program requires a commitment from university leaders, faculty, and staff.

Chickering's Theory. The first outline of Chickering's Theory was in his book, Education and Identity (1969), which focused on studying the college environment's impact on the development of students. In 1993, Chickering revised his theory by including new variables: 1) merging research findings on student development such as gender, race, etc.; 2) including new resources students have in their college such as specialists, finance aid, etc.; 3) adjusting the theory to fit student's age and to also include adult learners; and 4) introducing an alternative definition of seven vectors of his theory. Thus, Chickering and Linda Reisser (1993) revised the theory (Evans, Forney, \& Guido-DiBrito, 1998; Rode \& Cawthon, 2010). In fact, Chickering and Reisser's (1993) work relied on Pascarella and Terenzini's research (1991) mentioned earlier in this section (DeVilbiss, 2014). 
Chickering mentions that the big challenge encountered by college students is establishing their identity (Rode \& Cawthon, 2010). Chickering (1969) states "because each seems to have direction and magnitude...even though the direction may be expressed more appropriately by a spiral or by steps than by a straight line" (p. 8) as cited in (Rode \& Cawthon, 2010, p. 37-38). In this context, Chickering and Reisser (1993) illustrate that a person's environment, culture, and background impact the ways he or she will deal with future issues or tasks. Therefore, Chickering and Reisser (1993) introduce seven vectors or developmental tasks that contribute to build student identity. The vectors are described as "maps to help us determine where students are and which way they are headed" (p. 34). "Vectors built on each other, leading to greater complexity, stability, and integration" (Rode \& Cawthon, 2010, p. 14). In other words, each vector has its own direction and measure.

These seven vectors illustrated by scholars are as follows: 1) developing competence, which includes intellectual (e.g. knowledge and skills acquisition), interpersonal (e.g. communication, leadership, and teamwork skills), and physical (e.g. through athletic and recreational activities); 2) managing emotions (e.g. anxiety, depression, shame, caring, optimism, and inspiration); 3) moving through autonomy toward interdependence; 4) developing mature interpersonal relationships (e.g. tolerance, respect differences, empathy); 5) establishing identity (e.g. self-esteem, self-concept); 6) developing purpose (e.g. personal interest in future plans, committed behavior toward study or family); and 7) developing integrity (e.g. values and responsible behavior) (Chickering \& Reisser, 1993). The Chickering and Reisser argue that the educational environment has a high impact on student development. Chickering and Reisser proposed seven main educational factors that play an important role on students' transitions: 
1. Institutional goals. The clarity of university/college objectives will shape its policy, programs, and practices.

2. Institutional size. The number of students plays a crucial role on the amount of development that each student can receive.

3. Student-faculty relationship. Chickering and Reisser (1993) suggest that a student needs to deal faculty in different situations, which make student-faculty interaction effective and useful for student.

4. Curriculum. An appropriate curriculum is needed, which meets students' needs and differences.

5. Teaching. Timely feedback, an appropriate interaction between student-faculty, uses different teaching methods such as learning collaboration, etc.

6. Friendship and student communities. Involvement in community, either formal or informal, helps students develop personal skills such as collaboration, teamwork, confidence, etc.

7. Student development programs and services. Chickering and Reisser suggest a collaborative effort between academic and Student Affairs to design ideal services and programs to fit students' needs.

Some research studies have been conducted to check the validity of this theory. For example, on women's development, Taub and McEwen's (1991) study found that “women's development differs from men's, particularly regarding the importance of interpersonal relationships in fostering other aspects of development" as cited in (Evans, Forney \& GuidoDiBrito, 1998, p. 46). On the other hand, some studies demonstrate a critique for the theory. For example, Evans et al., (1998) sees the vectors definitions as quite general, and states "it lacks 
specificity and precision" (p. 51). Moreover, Rode and Cawthon (2010) suggest that it is better for researchers to focus on one or two vectors rather than all of the vectors in one study and use qualitative research methodology to test theory validation in terms of psychosocial development.

In summary, Chickering's Theory (Identity Development Theory) is often a favorite option of the Student Affairs community (DeVilbiss, 2014). The Seven Vectors of Theory can be used as categories for student development issues mentioned earlier in this chapter, especially the issues related to first-year students, or in other words, related to students in transition. Examples include: 1) developing competence; 2) managing emotions; and 3) moving through autonomy toward interdependence. These three vectors usually manifest in the first-year students as other studies showed earlier in this chapter (e.g. Tinto 1975, 1993; Pascarella and Terenzini, 1991; Upcraft \& Gardner, 1989; Gardner, \& Barefoot, 2005; Evans, Forney, \& Guido-DiBrito, 1998)

Schlossberg's Transition Theory. In 1984, Schlossberg felt there was a need to develop a framework to understand adults in transition and to help them manage their daily lives (Evans, Forney, \& Guido-DiBrito, 1998; Rode \& Cawthon, 2010). Schlossberg, Waters, and Goodman (1995) defined a transition as "any event, or not-event, that results in changed relationships, routines, assumptions, and roles" (p. 27). In other words, transition could happen suddenly, or may be anticipated or unanticipated, and its impact can be measured by the degree of change made in personal life. Moreover, transition must be attached to individual perception or experiences, either positive or negative, and these experiences are considered a chance for development (Schlossberg et al., 1995; Rode \& Cawthon, 2010).

Schlossberg et al. (1995) identified four key factors that impact an individual's ability to manage event transition. Schlossberg et al. named these four factors 'The $4 S$ 's: 
1. Situation: At this stage, an individual asks him/her self-questions to identify his/her condition, such as: is the transition anticipated and under control? Is there a responsibility or commitment related to transition? Is there previous experience, which could help in the current situation?

2. Self: How is the individual positioned in terms of demographic characteristics, gender, ethnicity, age, etc.?

3. Support: Schlossberg et al. identify four types of social support: close relationship, family support, friends-community, and institutional-community.

4. Strategies: How will the individual manage the transition issue? Does he/she have different strategies or just one response?

Evans, Forney and Guido-DiBrito (1998) see the Transition Theory as appropriate to support the postsecondary education adult learner. For example, using the transition process 4S's to develop a framework for services delivery. Rode and Cawthon (2010) suggest that the Transition Theory and its process is an appropriate framework for orientation program development. Utilizing the 4S's will provide the orientation program designer with logical steps and tools to move in or out using different strategies e.g. handbook, website, peer support, etc. to help students in transition fit with the new educational environment and make their transition experience positive.

However, Whittaker (2008) argues that approaches to supporting transition are linked to improving preparedness for higher education, easing integration into the university environment, both academically and socially, and encouraging the development of the independent learner. "By shifting the focus of transition from student retention and withdrawal to supporting the engagement and empowerment of all students, successful 
transitions can be measured not simply in terms of whether students continue on their programmes $[\mathrm{sic}]$, but whether in doing so they are provided with the opportunity to achieve their full potential (as cited in Johnston, 2010, p. 4).

The Transition Theory provides better understanding of the transition process and how first-year program designers can employ its applications to develop orientation programs. Moreover, it provides insights about a theoretical mechanism of structuring a first-year program. Overall, this section of the literature review discusses the most common student development theories that have a relationship to first-year student experience and how these theories can be applied to help to restructure of first-year programs. Astin's $(1977,1993)$ Involvement Theory or I-E-O model describes the importance of an interaction between the student and educational environment. Increased interaction will lead to more involvement and learning. Additionally, Astin suggests learning community as a perfect strategy to help first-year students become involved in the university/college environment. Pascarella and Terenzini's Theory $(1991,2005)$ discusses student change in college. They suggest that much interaction between the student and his/her university environment will lead to better learning. Furthermore, the theory is revised to align with the Foundations of Excellence ${ }^{\circledR}$ dimensions to be more practical.

Tinto's $(1975,1987,1993)$ Student Departure theory or the Retention Theory represents a new perspective about factors and variables that can influence students' persistence and retention. Tinto's Theory also examines factors that affect student learning in the first-year. His investigation found different variables that can impact student decisions about continuing or leaving their college. These variables include economic, cultural, psychological, organizational, and social perspectives. Tinto called for the necessity of implementing a comprehensive student retention program at colleges. 
Chickering's (1993) Theory, or the Identity Development Theory, is a practical tool for the Student Affairs division at any college, as it provides practical categories for student development transition issues through the Seven Vectors Theory. Schlossberg's (1984) Transition Theory provides insights about the transition process that postsecondary education is required to consider, especially with first-year students. The theory provides a practical process of change management named the $4 \mathrm{~S}$ 's, and suggests using these processes for development of the orientation program for first-year students and their parents.

Finally, we can observe that these theories and models attempt to understand how students change in college. In other words, how does college affect students? Each theory built on the previous one or on part of it. In addition, each theory could be utilized to deal with part of or all of the first-year challenges. Understanding these theories and their applications helped to understand and analyze this studies participants' perception about their conceptualization of the future ideal functions of the Preparatory Year Deanship at King Saud University.

\section{The First-year Experience}

The first-year is a critical period of transition into postsecondary education. Besides, the first student year is "not grade 13" (Hunter, 2006, p. 4) of high school. The events happening at this period will affect students' success positively or negatively in coming years (Gardner, 1998; Soldner \& Duby, 1999; Upcraft \& Gardner, 1989; Tinto, 1996; Upcraft \& Gardner, 1989; Raymond \& Napoli, 1998; Upcraft, Gardner, \& Barefoot, 2005). On the other hand, despite the postsecondary institutions commitment to support students to earn their degrees and achieve their goals, postsecondary institutions are a business, which have high interest in its graduate quality and retention rate (Curtis \& Harte, 1991; Johnston, 2010). In other words, universities strive to compete with other intuitions, especially in a Knowledge Society era. 
Upcraft and Gardner (1989) proposed that postsecondary institutions should embrace ten beliefs to help first-year students be successful. These beliefs are as follows: 1) institutions have an obligation to support and enhance the first-year students; 2) institutions can intentionally and successfully help first-year students to achieve their academic and personal goals; 3) involvement is the key to success of first-year students; 4) help first-year students to engage with others such as faculty, students, etc.; 5) institutions should take into account the diversity issues such as racial, cultural, ethnic, etc.; 6) dignity and respect is a basis of student treatment; 7) establishing deliberate goals for first-year students; 8) ensuring an institutional commitment to enhance first-year student success; 9) utilizing the Freshman Seminar to improve student success; and 10) necessity of faculty involvement (p. 4-5). In their first-year, students learn the language and culture of their institution, they develop minimally successful study skills, and they also develop certain attitudes towards faculty. A student's attitude towards faculty is an important indicator as to whether or not a student will be retained (Gardner, 2007).

In this context and for better understanding of first-year students, this section of the literature review illustrates first-year experience in detail to recognize first-year history, issues, first-year intervention strategies, functions and practices, the first-year pedagogy, the first-year organizational design and structure, the first-year experience: an international perspective, and first-year experience in the context of Saudi postsecondary education. Furthermore, an explanation about the Saudi higher education trend and movement toward a Knowledge Society is provided. Finally, an explanation regarding the research methodology utilized in this study, the Concept Mapping/Pattern Matching (CM/PM) was advanced. 
The History of the First-year Experience Concept. The concept of first-year has historical roots, beginning with the "freshman" concept, which has gradually been replaced by the term, "first-year student," at colleges and universities. In 1998, the concept of First-Year Experience and Students in Transition was introduced by the University of South Carolina's National Resource Center (Watts, n.d.).

Historically, the first use of the freshman concept dates back more than 800 years, when the first Italian young men went to Bologna in the twelfth century for study (Dwyer, 1989). Freshmen students were responsible for organizing the lecture and examinations schedule. In France, in the "renaissance" (p. 26) era, the famous liberal arts teachers tried to attract some freshmen to come to Paris. These students' parents encouraged their sons, especially boys who were between 13 and 16, to join the nearest universities. Dwyer noted that, the Renaissance Era created an undergraduate curriculum that was used until the middle of the nineteenth century in Western higher education.

During that time, students lived with the other first-year students in a dorm or "hall" (p. 26). The dorm was managed by freshmen students themselves, or by the oldest students, or by a master. In addition, students were required to attend some lectures and select courses as a prelude to choosing a teacher (Dwyer, 1989). At the beginning of their arrival at university, the older students looked at a freshman as a "victim" (p. 27) upon arrival, but then welcomed the freshman later. In addition, the university celebrated new students in a ceremony called “depositio" (p. 27) as a part of a semiofficial university function. This celebration was conducted to celebrate the new arrivals; however, freshmen "might be subject to discrimination" (p. 27).

In Europe during the fourteenth and fifteenth centuries, universities required students to register for some courses that helped them to adjust to university life and manage personal 
affairs. Freshmen could register for “Ars Dictaminis, or business Latin” (Dwyer, 1989, p. 28) courses to learn how to draft a letter or document. After completing these courses, each freshman started to study subject by subject with his master until the master determined the student's readiness for the next level of study. Dwyer (1989) points out that, at this phase of study, students can take notes, memorize and retrieve information, work in groups, and engage in public debate. When approved by the master, freshmen became eligible to be a "sophister" (p. 28), which means "sophomore, in English universities later" (p. 28).

In the sixteenth century, the new technology of printing increased the availability of books, especially for freshmen, which provided more opportunity for students to access printed educational resources. In 1550, the concept of first-year manifested in the English language to describe a new novice in any field of work, and in 1590 was used officially in English universities to describe new students (Dwyer, 1989, p. 28). In 1638, the new Harvard College in North America used the concept of freshmen for the first time (Dwyer, 1989). Since the students in 1638 were the first group of students at Harvard and there were no sophomore students, they struggled to adapt to their masters. Harvard also created the "freshmen counselors" (p. 30) positions, which established the first system to help students' transition into college.

Dwyer (1989) mentioned that Harvard empowered its freshmen to get grants for doing some work such as serving the college, taking care of the college bell, etc. These tasks paved the way to appoint the first "President's freshman" (p. 30). Ralph Waldo Emerson was the first appointed to this position in 1817. In 1655, Harvard College raised admission criteria for freshmen, whereby students were required to have Latin speaking, reading, and writing skills. The admission process was changed, with an entrance exam conducted by Harvard's president (Dwyer, 1989). 
In 1735, Harvard College invented "the College Customs" (Dwyer, 1989, p. 31), and assigned freshmen advisors. The College Customs document contained a series of ethical and educational statements, and sophomore students were required to read it publicly for freshmen. Later, Harvard's faculty opposed the College Customs because they thought it was unsuccessful and replaced it with the first protection record of freshmen, which outlined the freshmen students' rights and responsibilities (Higgins, 2010). Despite the spread of freshman culture and initiatives, Dwyer noted that some freshmen at some universities were still suffering for their rights. For example, at some universities, freshmen were responsible for cleaning rooms and building the fireplace, while in other universities, they were not permitted to use a library.

In the nineteenth century, an educational development movement unfolded in secondary and postsecondary education, which caused universities and secondary schools enrollment numbers to expand and the student bodies to become more diverse. During that era, admission policies and standards changed to be more "selective" (p. 32). Further, universities such as Harvard required pre-courses for their freshmen such as mathematics. The secondary schools tried to prepare students for college, especially after the movement to standardize curriculum and teaching. Dwyer noted that the most important feature of that era is faculty involvement with freshmen, through which they tried to improve freshmen life. For example, faculty arranged "freshmen week" (p. 33). Additionally, in 1889 Harvard established "A Board of Freshman Advisors" (p. 33), which was responsible for taking care of freshman affairs such as students' support out of the classroom, to provide an orientation plan for new students, arrange social events, and provide advice to help freshmen become more independent (1989).

The Board of Freshman Advisors realized that freshmen advising and orientation are necessary to help students transition into college because during the transition phase students 
encounter difficulties making correct decisions, understanding the campus environment, and are often missing required skills for college (Higgins, 2010). Higgins noted that the Board of Freshman Advisors at Harvard identified three main principles for freshmen orientation: 1) students need guidance rather than only specific instruction; 2) students need a support system regarding choices and skills to make correct decisions; and 3) students need more support from faculty to ensure success (2010).

One of the important features of nineteenth century education is that women newly participated in higher education as freshmen students, such as "the seven sisters" (Dwyer, 1989, p. 33) at Mount Holyoke College in 1837, which is considered the first group of women in postsecondary education in the United States. Furthermore, Dwyer says, "Freshman women there were more members of a city community than a college campus" (p. 34). In other words, freshmen women were not subject to campus restriction or specific rules or direction such as males.

In the twentieth century, higher education functions were changed due to changes in social culture, the Industrial Revolution, need for qualified laborers, and emergence of new variables, especially among freshmen diversity, identity, behavioral problems, technology revolution, etc. (Dwyer, 1989). Dwyer divided freshmen development during the first half of the twentieth century into two stages: 1) "the freshman as parishioner" (p. 35), in which freshman learned from directions that were outlined by the university. Freshman were also required to learn time management and some soft skills, and 2) the freshman under the "microscope" (p. 35), in which freshman studies concentrated on problems encountered by freshman such as identity, curriculum adjustment, financial problems, beliefs, culture, religion, and successfully transitioning into college. 
During the second half of the twenty century, freshman research studies evolved further with new methods invented to help freshman. For example, General Alarm was a new system utilized to indicate students' needs or problems at many universities. Universities developed a more involved role to better provide students required tools for adjustment (Higgins, 2010). Additionally, mid-century freshmen research studies indicated that freshman students have different problems and needs. For example, some need guidance, others need a counselor or social support, while some need information that helps with adjustment to university life (Dwyer, 1989). In summary, Dwyer identified two services that can help universities or colleges provide support to first-year students as they transition to postsecondary education: 1) consular system; and 2) orientation programs.

The expression "freshman" is gradually replaced by the term, "first-year student," at colleges and universities. In 1998, the concept of First-Year Experience and Students in Transition was introduced by the University of South Carolina's National Resource Center (Watts, n.d.). In the last twenty years, the first-year discipline received large-scale interest by scholars and postsecondary institutions. In their preface to Challenging and Supporting the FirstYear College Student, Upcraft, Gardner, and Barefoot (2005) highlighted the most important first-year accomplishments in the last twenty years. To illustrate a few examples, colleges and universities:

1. Increased campus-wide, national, and international conversation and action about the first-year of college.

2. Introduced more initiatives designed to help first-year students succeed, for instance, more flexible and varied first-year seminars, more comprehensive development educational programs, etc. 
3. Expanded research and scholarship on the first-year of college, for example, Pascarella and Terenzini (1991) How College Affect Students, Astin (1993) What Matters in College?, and Tinto (1993) Principles of Effective Retention. The contributions of these scholars and others provide better understanding of students' characteristics, assessment and development tools of first-year, and more approaches to help students to transition into colleges successfully.

4. Developed closer collaboration between academic affairs and Student Affairs.

5. Integrated technology into first-year initiatives.

6. Included diversity in first-year initiatives as a permanent feature of the first-year student landscape.

7. Made the classroom central to efforts to promote first-year students' success (p. 2-7). However, Upcraft, Gardner, and Barefoot (2005) mentioned some challenges encountering first-year experience movements. For instance:

- There is no consensus about a clear sense of purpose in the first-year.

- Building first-year initiatives that are responsive to today's increasingly diverse students is still a challenge.

- The link from research and assessment to policy and practice is still weak.

- Institutional efforts to help first-year students succeed are still not sufficiently integrated.

- Efforts to help first-year students succeed are too often focused on retention rather than students learning.

- First-year students' out-of-class experiences are still a double-edged sword (p. 2-7). Despite these developments in first-year, Skipper (2005) mentions "many institutions already design and deliver interventions that assist students in resolving these and other tasks in 
the first college year and beyond, but these programs are frequently divorced from the student's classroom experiences and intellectual development" (p. 5). Barefoot (2004) states "Campuses have lacked any systematic, valid definition of, or standards for, first-year excellence that go beyond a single best-practice program to a broader characterization of a campus's total approach to the first-year" (p. 5). Overall, this study identified the most important dimensions that the Preparatory Year Program at King Saud University needs to develop more in order to meet firstyear students' needs and the university's mission.

First-year Experience Issues. "Where am I now, what am I doing, what has my schooling prepared me to do?' (Johnston, 2010, p. 1). Comments and questions about students' first-year were shared at most postsecondary institutions. These questions and others required clear answers and support to make students transition into university/college successful. Thus, Johnston states that each student has his/her own perception of first-year transition, which can influence his/her academic future and life. Upcraft, Gardner, and Barefoot (2005) outlined some important issues encountered by students as they transfer from secondary to postsecondary education. For example, discovering identity, determining self-concept, making decisions about future careers, building interpersonal relationships, developing academic competency, and developing responsible behaviors, beliefs, and spirituality.

The positive common characteristics of new first-year students include high skills and knowledge to use technology, a trend toward social work and team activity, ability to access and acquire information, focus less on school work, and emphasize a future career plan, improve familial/parental involvement, and passion to learn more with high expectations (Keeling, 2003; Newton, 2000). However, several issues and challenges related to students' transition into postsecondary education still exist (e.g., Astin, Oseguera, Sax, \&Korn, 2002; Bauer \& Liang, 
2003; Crissman Ishler, 2005; Gordon \& Steele, 2003; Howe \& Strauss, 2000; Johnston, 2010;

Pryor, Hurtado, Saenz, Lindholm, Korn \& Mahoney, 2005). For example:

1. Cultural barrier: students move from high school or familiar cultural environment to university or a more diverse cultural environment. Furthermore, students' move from theoretical fields to professional fields.

2. Personal change: some students feel academic disengagement, decreased social activism, difficulty understanding his/her capacity (self-assessment), weak decision-making skills, especially about his/her major, and lack of some life skills. Personal change has a direct effect on performance of first-year students.

3. Increase in emotional and mental health disorders among new students, either male or female.

4. Family background, type of relationship between students and his/her parents, some come from divorced families, and some are first generation students.

5. Increase in university cost and decrease in financial aid.

6. Number of students with disabilities, who require more attention.

7. Gender differences involving different needs.

8. Finally, the trend of postsecondary institutions to develop specific employment-related skills, especially those which want to shift toward a Knowledge Society or knowledge based-economy. However, labor market experts such as Paul Barton at the Educational Testing Service (ETS) and Peter Cappelli at the Wharton School argue, "being prepared for college is not the same as being prepared for successful transition into the workforce" (Stone, Lewis, 2012, p. 14). 
Alexander, Garcia, Gonzalez, and Grimes (2007), conducted a study to identify barriers in the transfer process for Hispanic and Hispanic immigrant students. This study determined several barriers encounter by such students: 1) economic difficulties; 2) culture barrier on two levels: engagement with dominant white student bodies and norms that do not support women's higher education; 3) lack of family and student awareness about postsecondary education importance and values; 4) lack of or no English language or life skills; 5) no preparation courses prior to university enrollment; and 6) lack of or no support from faculty and administration staff for those students.

Erickson and Strommer (2005) conducted a study to recognize the issues that are encountered by first-year students inside the first-year classroom. Erickson and Strommer classify the most common problems in first-year classrooms into four categories:

1. Academic preparation, in which a number of high school graduates are not ready for college academically, especially in English, science, math, writing skills, etc. Moreover, most of those students have no experience about the nature of studying in college, in which students need to spend more time for studying and completing assignments. In addition, some academic skills such as taking notes, summarizing content, participating in classroom activities, etc. are missing.

2. Expectations and motivation for learning, in which some students have course expectations higher or lower than his/her capacity. These expectations are the result of his/her perception about college or coursework, correlated to his/her motivation to study. Thus, establishing a positive relationship with faculty or an academic adviser will help a student to recognize his/her aptitude and manage his/her expectations while improving his/her motivation to learn. 
3. Learning style. First-year classroom experience differs; for example, students come from high school with different backgrounds, and teachers are responsible to guide students to do tasks/assignments, based on specific steps. Furthermore, each student has a different learning style and he/she may prefer a specific way of teaching. Therefore, faculty is required to recognize student diversity and to design learning activities in a way that ensures that all students can participate and engage in the classroom community.

4. Stage of intellectual development. Erickson and Strommer state that "students also differ in their stage of intellectual development... with some significant differences for women" (246). This research fact suggests that teaching students who are in different stages of intellectual development require using various teaching methods.

Utilizing supplemental instruction or peer-assisted support programs, academic advising, learning community to share experiences, and participation in service learning to enhance civic responsibility will help to overcome these challenges and problems (Studdert, 2013). Other challenges and problems of first-year students are outside of the classroom. For example, firstyear residential environments must facilitate and develop an interaction between students themselves, between students and faculty, and students and the external community. Moreover, the learning environment such as the library should be comfortable and facilitate learning. Finally, there should be development of some social activity to promote student engagement in society, promote student diversity, and working part time on campus (Astin, 1993; Pascarella \& Terenzini, 1991).

Mullendore and Banahan (2005) see orientation programs for students and their families as an effective solution to overcome previous challenges. Moreover, Mullendore and Banahan provide several recommendations for an effective orientation program: 
1. Develop and support an orientation process that continues at least throughout the first semester.

2. Develop an orientation program that introduces and reflects the mission and goals of the institution.

3. Balance between technology utilization and person-person interaction.

4. Encourage collaboration between Student Affairs and Academic Affairs in the orientation program.

Some other issues are related to gender. Christensen (1990) found strong correlation between gender and retention (as cited in Ishler \& Upcraft, 2005). Hill and Sedlacek's (1995) study on male and female first-year students found that men are more interested in improving their academic skills than women. On the other hand, females are more interested in receiving counseling about educational vocational concerns and emotional/social issues. Perrine's (2001) study, College Stress and Persistence, focused on first-year students, found that females demonstrated more stress than males, and the attrition rate is higher as well. Perrine recommended that an intervention program is required at this stage of college before students become stressed.

This conclusion supports the need for developing first-year intervention programs with more attention to gender issues, taking into account that females have different needs than males. As Preparatory Year Deanship at King Saud University provides male and female students with one content program, this may require redesigning to fit everyone's needs. However, as mentioned in Chapter One, this study's concern was not gender, and two administration brainstorming sessions for data collection was due to different segregation protocols for two groups within the Saudi higher education context. The current study provided information 
regarding both male and female perceptions regarding the first-year program at King Saud University and both were combined to create the proposed conceptual framework of the Preparatory Year Program. Barefoot (2000) in her article: The first-year experience: Are we making it any better? stresses the necessity of continuing to recognize the new challenges that affects students' transition and enhance the first-year programs and initiatives with more focus on factors that influence students' future work during their first-year. Johnston (2010) suggested that postsecondary institutions need to create flexible solutions that can respond to the diversity of students to promote their learning, and to make their transition experience successful while improving persistence and retention through systemic efforts with an appropriate pedagogy fitting local culture and supporting international trends.

In summary, this section demonstrations the most important issues related to first-year students and mentions some solutions that can be utilized to overcome these issues or reduce their impact on students' development.

First-year Intervention Strategies, Functions, and Practices. As observed earlier in the theoretical foundation section, most research on first-year program stress the importance of developing initiatives that make students become involved academically and socially, easing their transition into postsecondary education. Some research studies give more attention to factors that can influence students' success in college/university such psychological factors (e.g. motivation, self-understanding, mental health, self-efficacy, lifelong learning skills, personal goals, etc.). Furthermore, some postsecondary institutions develop intervention programs that aim to improve student retention, performance, and graduation rate. In summary, each institute has unique requirements and specific students' needs. Thus, several different first-year intervention programs have been developed. 
A wide debate related to the benefit of first-year intervention programs has emerged. Some researchers reported usefulness of these programs and others reported limited benefits from them. For example, some studies reported a high impact of learning community practice as an intervention program benefiting student retention and performance (Bailey \& Alfonso, 2005; Blackhurst, Akey \& Bobilya, 2003; Commander, Crissman, 2001; Dillon, 2003; franklin, 2000; Gold \& Pribbenow, 2000; Johnson, 2000-01; Kutnowski, 2005; Tinto, 2000; Valeri-Gold, Darnell, 2004; Walker, 2003). In contrast, Baker, Meyer, Hunt (2005) and Barrows and Goodfellow (2005) reported no or limited effect of learning community practices over time on students' performance. They suggest some intervention practices such as improving communication between students-faculty to make students' transition into college successful, instead of using the learning community strategy.

Moreover, Pascarella and Terenzini (2005) observed a lack of assessment studies that explore the weakness and strengths of first-year intervention programs or the studies that evaluated some of these intervention programs did not mention program characteristics, which creates difficulties predicting if these programs can work in different environments. Despite such limitations, first-year intervention programs continue to play an important role in preparing students for college/university life (Upcraft, Gardner, \& Barefoot, 2005).

First-year interventions are classified into three main categories: curricular strategies, cocurricular strategies, and institutional strategies (Barefoot, 2005; Miller, 2011; Storey, 2010; Upcraft, Gardner, \& Barefoot, 2005). The curricular strategies include initial courses, seminars, counseling, service learning, faculty development, and supplemental instruction. Co-curricular strategies include learning communities, first-year experience programs, campus activities, membership in social clubs or academic association, etc. Finally, institutional strategies include 
curricular and co-curricular interventions, which can create opportunities for students or institutional decision-makers to make adjustments or changes in specific areas of first-year programs to ensure program effectiveness. For example, provide financial support for students from lower socioeconomic backgrounds (Upcraft, Gardner, \& Barefoot, 2005).

Furthermore, as mentioned in Chapter One in the terminology section, Conley (2008) suggests four dimensions for postsecondary institutional improvement to make students' transition into college successful. These dimensions express the first-year strategies and functions in college/university.

1. Key Cognitive Strategies, which include:

a. Problem formulation and problem solving.

b. Research skills.

c. Reasoning, argumentation, and proof.

d. Analyzing and interpreting data or information.

e. Precision and accuracy for tasks achievement (p. 7-8).

2. Academic Knowledge and Skills: associated with academic subjects (e.g. English, mathematics, science, social studies, world languages, and the arts).

3. Academic Behaviors: this includes "self-awareness, self-monitoring, and self-control of processes and actions necessary for academic success... self-management skills... time management, stress management, task prioritizing, using information resources, taking class notes, and communicating with teachers and advisers" (p. 9-10).

4. Contextual Skills and Awareness: "the information students need to apply successfully to college, gain necessary financial aid, and then, subsequent to matriculation, understand how college operates as a system and culture" (p. 10-11). 
Adding to these four dimensions, Evenbeck, Jackson, Smith, Ward, and Associates (2010) explain that first-year experience establishes its functions by linking faculty members, Student Affairs, Student Services, policies, and academic advising, and then utilizing the firstyear programing such as first-year seminars, learning communities, etc. Furthermore, Crosling, Thomas, and Heagney (2008) identify several functions of the first-year: 1) recruiting; 2) admissions selectivity; 3) financial aid; 4) orientation and academic advising; 5) teaching/learning; 6) academic support; 7) supplemental instruction; 8) academic enrichment; 9) residential living; 10) learning communities; 11) service learning; 12) counseling; 13) extracurricular activities; 14) underrepresented students/specialty sub-populations; 15) undecided students; 16) early alert; 17) policies/procedures; 18) faculty/staff development; 19) internal marketing programs; 20) first-year experience course; 21) sophomore strategies; 22) technology utilization; 23) students' engagement and satisfaction; 24) quality service; and 25) adult learning strategies.

In addition, Koch and Gardner (2014) divided the current practices, initiatives, and programs of first-year experience into three categories:

1- Pre-University Programs for First-Year Students: including (new student orientation programs, parent/family orientation programs, summer bridge programs, and summer or common reading programs).

2- First-Year Initiatives Focused on the Curriculum and/or the Faculty: including (academic advising, developmental education, distance education and online first-year courses, faculty development, first-year seminars, learning communities, service learning, and supplemental instruction). 
3- Structures, Services and Activities that Benefit First-Year Students: including (early alert/warning systems, learner analytics, first-year activities such as athletics, institutional policies, attendance and mid-term reporting, and living-learning communities/first-year living environments) (p. 23-33).

In conclusion, first-year intervention strategies and functions are wide-ranging between postsecondary institutions. Determining student's needs and institute requirements is essential to draw up first-year functions and intervention strategies. In other words, understanding students' needs, parental expectations, administrative staff perspectives, and institutional policy, mission, and trends about first-year functions will help to structure and develop first-year programs. This study aims to identify the future ideal functions of first-year programs depending on the key stakeholders of the first-year.

The First-Year Pedagogy. Developing "transition pedagogy is crucial to developing a holistic approach in first year experience initiatives” (Rogers, M., \& Stypka, 2013, p. 6). The transition pedagogy of first-year students is defined by Kift (2004) as "a guiding philosophy for intentional first-year curriculum design that carefully scaffolds and mediates the first-year learning experience for contemporary heterogeneous cohorts" as cited in (Kift, 2008, p.5).

Tinto (2002) states "universities must provide faculty with the pedagogical and assessment skills they need to establish conditions in their classrooms that promote student involvement, learning, and retention" (p. 7). Furthermore, Kift (2008) stresses the necessity of "ensuring that professional staff (both central and faculty based) are also provided with the staff development opportunities they need around the FYE and the nature of their particular role and contribution to student success and retention" (p. 6). Nelson, Creagh, Kift, and Clarke (2014) 
identified six principles behind the successful transition pedagogy of first-year: transition approaches, design, diversity, engagement, assessments, and evaluation and monitoring.

As this study's goal was not to identify the Preparatory Year Program implicit or explicit pedagogy, instead it aimed to identify if a program's pedagogy reported as a dimension of program development based on groups of stakeholders' perceptions. According to Alaqeeli (2014), the current teaching practices of preparatory year focuses on curriculum content and not on teaching approaches. This practice is due to unclear educational pedagogy in the program.

The First-Year Organizational Design and Structure. "How is the first-year different in institutions of varying type, size, and mission? Is there evidence that the first-year is being designed in ways that are consistent with exiting principles of good practices that promote learning and retention?" (Barefoot, 2005, p. 47). Further, "How can colleges and universities improve their first-year academic encounters? How can they enhance the impact of their programs upon student retention?" (Tinto, 1996, p. 1).

Several studies attempted to answer these questions regarding first-year organization design and structure. For example, Barefoot (2005), in her study Current Institutional Practices in the First-year, developed two separate surveys: the first-year curricular practices survey and the first-year co-curricular practices survey. The survey items investigated the ways that postsecondary institutions structured first-year programs. For instance, some items asked about institutional mission, resources, role, programs, student body size, location, student life, policy, structure, etc. The surveys were used for description purposes, not for diagnosing problems or recommending solutions. The surveys used a random sample of 621 postsecondary institutions. The directors of academic and Student Affairs were asked to fill out the surveys in each institute. The sample was stratified according to the Carnegie Classification. The response rate was 54\%. 
This study concluded that the first-year experience is "more than seminar course, orientation program, or learning community" (Barefoot, 2005, p. 62).

Barefoot (2005) suggested that developing the first-year experience as a whole program, including interacting components, is better than separate parts or initiatives. Moreover, the type, size, mission, student, internal and external environmental components are key factors for structuring the first-year experience. Furthermore, Barefoot mentioned important issues related to higher education trends in general, "to be transformed by market pressures, changing levels of external financial support, and the impact of technology" (p. 63).

These results are consistent with Braxton and McClendon's (2001-2) study outcomes, which suggest that students' success and retention in the first-year is a campus-wide responsibility, not only the task of one division department. Moreover, Studdert (2013) and Cuseo (n.d.) suggest that a comprehensive and centralized first-year program is more effective than decentralized or fractured programs.

However, Skipper (2005) states that "many institutions already design and deliver interventions that assist students in resolving these and other tasks in the first college year and beyond, but these programs are frequently divorced from the student's classroom experiences and intellectual development" (p. 5). Therefore, more attention has been devoted to the structure of first-year programs to help students overcome such challenges. For example, Hossler, Kuh, and Olsen (2001), in their research, Finding (more) fruit on the vines, introduce three strategies regarding first-year organization, design, and structure to foster first-year student success: 1) expanding collaboration between university diffusion, colleges, and departments regarding firstyear initiatives; 2) developing and integrating academic and social experiences; and 3) establishing strong academic foundation. 
Cubarrubia and Schoen (2010), in their study Creating a Developmental Framework for New Student Orientation to Address the Needs of Diverse Population, offer a framework for delivering first-year experience that can meet diverse students' developmental needs. They suggest two levels of program design: the assessment and planning level, and the implementation level. The assessment and planning level requires answering three main questions: "What do I know about my student population? What does current research say about my student population?, and What is the balance between creating programs for some students and creating programs for all students?” (p. 173-174). In the implementation level, three main questions need to be answered: "How does my program address challenges related to accessibility and affordability? How does my program address challenges related to inadequate preparation?, and How does my program address students' need for adequate support networks?” (p. 174-175). In their study, University College: Flexible Structure for Serving Undergraduate Students, Swing and Alexander-Hamilton (2010) described the five-category typology of firstyear organizational structures created by the staff of the Policy Center on the First-year of College, now John N. Gardner Institute for Excellence in Undergraduate Education. The typology is divided into two levels:

1. Single administrative unit structures comprise comprehensive and non-comprehensive structure. The comprehensive structure contains a campus-wide organizational chart, director/senior leader, and a recurring operational budget; the non-comprehensive single unit structure meets some of previous components, but not all.

2. Multiple unit administrative structures contain three types of structures: a) multiple units that are coordinated by a formal standing committee or official coordinating form; $b$ ) multiple units that intentionally but informally collaborate to provide first-year resources 
and services; and c) multiple units that operate separately with limited coordination (p. 12).

By relying on the research published over the past 30 years (e.g., Astin, 1977, 1993;

Pascarella \& Terenzini, 1991, 1998, 2005; Whitt \&Associates, 1991), on professional experience, and developmental theories, Barefoot, Gardner, and Swing utilized the typology as a resource for Foundations of Excellence ${ }^{\circledR}$ in the First College Year Institute (Miller, 2011).

The Foundations of Excellence ${ }^{\circledR}$ in the First College Year Institute (http://www.jngi.org), established the First-year Focus - Foundational Dimensions ${ }^{\circledR}$ for Four-Year Colleges.

Foundational Dimensions statements constitute a model that provides institutions with a means to evaluate and improve the first-year of college. As an evaluation tool, the model enables institutions both to confirm their strengths and to recognize the need for improvement. As an aspirational model, the Dimensions provide general guidelines for an intentional design of the first-year (“John N. Gardner Institute”, 2015).

The dimensions are normative statements representing the issues related to postsecondary institution cultures, policies, missions, structures, activities, and programs that shape student learning and success in the first-year (Terenzini, 2005).

1- Foundations Institutions approach the first-year in ways that are intentional and based on a philosophy/rationale of the first-year that informs relevant institutional policies and practices (Philosophy).

2- Foundations Institutions create organizational structures and policies that provide a comprehensive, integrated, and coordinated approach to the first-year (Organization).

3- Foundations Institutions deliver intentional curricular and co-curricular learning experiences that engage students in order to develop knowledge, skills, attitudes, and 
behaviors consistent with the desired outcomes of higher education and the institution's philosophy and mission (Learning).

4- Foundations Institutions make the first college year a high priority for the faculty (Faculty).

5- Foundations Institutions facilitate appropriate student transitions through policies and practices that are intentional and aligned with the institution's mission (Transitions).

6- Foundations Institutions serve all first-year students according to their varied needs (All Students).

7- Foundations Institutions ensure that all first-year students experience diverse ideas, worldviews, and cultures as a means of enhancing their learning and preparing them to become members of pluralistic communities (Diversity).

8- Foundations Institutions promote student understanding of the various roles and purposes of higher education, both for the individual and society (Roles and Purposes).

9- Foundations Institutions conduct assessment and maintain associations with other institutions and relevant professional organizations in order to achieve ongoing first-year improvement (Improvement) (“John N. Gardner Institute”, 2015).

These dimensions were developed for self-assessment and to assist postsecondary institutions in measuring performance and impact on student learning to compare on-campus programs and to improve the current structure of the program if needed. Moreover, the dimensions were "formulated in a general manner to enable academic institutions to articulate their own beliefs for the preparatory year within the institutional guidelines" (Alaqeeli, 2014, p. 47). 
In summary, the first-year experience organizational design and structure are different from one postsecondary institution to another, with specific factors controlling the style of each institution's structure. In other words, no single way exists to organize or structure first-year programs. The differences among institutions' size, mission, financial budget, students' needs and capacity, and institutional trends and goals are the keys to designing first-year initiatives. In addition, despite the necessity of sharing campus' members (e. g. faculty, students, administrations, etc.) responsibility to plan and create first-year programs; building a centralized system of first-year is the preference of most researchers. A centralized system allows effective management, continuing assessment, and quality improvement. Therefore, understanding stakeholders' perceptions about the program functions that need to develop as this study envisioned, will be helpful to redesign, restructure, and develop the Preparatory Year Program at King Saud University in the future.

The First-Year Experience: An International Perspective. Outside the United State of America, the topic of the first-year experience and students in transitionhas high interest (Nutt \& Calderon, 2009). In the United Kingdom, Yorke's (1999) research about the students' departure and postsecondary institutions roles in this phenomenon has significance in shaping first-year researches in the UK. In 2007, Yorke and Longden conducted a study across UK's postsecondary institutions to identify first-year initiatives and programs. These studies provided insights about the critical factors that influence first-year programs in the UK (Nutt \& Calderon, 2009).

In Australia, McInnis, James, and Hartley's (2000) study contributed positively to disseminate the first-year culture across the country. Moreover, it directed first-year research toward specific issues related to students transition, retention, persistence, and development of 
English aptitude of students who had such problems. Furthermore, Krause, Hartley, James, and McKinnis (2005) conducted a longitude study to explore first-year movement during 10 years in Australia. This study directed research studies toward specific issues of the first-year as well (Nutt \& Calderon, 2009).

In 2009, the European First-year Experience Conference took place in Groningen, Netherlands. Numerous researchers from several countries have participated in the conference e.g. Belgium, Denmark, the Netherlands, and Norway; the main theme of the conference was Researching the First-Year Experience. The conference discussed several issues related to the first-year experience such as "student support services collaborating with academic staff preentry work to better prepare students for their studies, skills development for students in the firstyear, institutional fist-year strategies, and fist-year assessment” (Nutt \& Calderon, 2009, p. 5).

In the Arabian postsecondary education context, in general, and in Saudi context, in particular, searching the literature for this study did not yield an organized research project to discuss first-year issues and trends. There was a limited number of individual research studies as mentioned at the beginning of this chapter. For example, Talafha's (2015) study at the University of Dammam, examined the level of psychographic using a survey and random sampling consisting of 209 Preparatory Year (PY's) students. This study has three main variables to examine including achievement motivation, self-efficacy, and leisure attitude. A significant correlation was reported among these three variables. The study's recommendation informed "university management to plan and organize programs geared towards developing positive attitude, increasing self-efficacy and motivation among the students" (p. 70).

Further, an assessment study at University of Dammam was conducted by WinitWatjana, Baraka, Mostafa and Aljaizani (2015) to evaluate the motivation, learning styles, and 
program selections of the preparatory year students. This study used a mix-methods approach including a survey and interview on sample size that included 74 pharmacy and 342 nonpharmacy students. Students reported a need for orientation and counseling meetings service to overcome some challenge in some course. The program caused stress for some students and they felt unhappy with the programs academic design. Some students complained that there was a lack of information about future colleges and academic program requirements to make a decision about a future study.

Finally, the first conference about first-year experience in Saudi Arabia and in the region was named the First National Conference for Prep Year in Saudi Arabia and was conducted at the University of Dammam on 22-23 April 2015 (http://prep1sa.ud.edu.sa). However, by observing the first-year movement and development globally compared to first-year movements in the context of Saudi higher education, more attention is required to develop and organize firstyear discipline in Saudi Arabia, and this study will be a step in the right direction.

First-year Experience in the Context of Saudi Postsecondary Education. In Saudi Arabia's postsecondary education system, universities utilize the term Preparatory Year Program (PYP) instead of First-year Experience. Despite the name difference, the practices are similar to a large extent. In Saudi higher education, launching PYP was to improve students' readiness for university. Saudi universities design PYP for all prospective students, to help them meet the appropriate levels for college in English, Mathematics, Chemistry, Physics, SelfDevelopment skills, etc.

The majority of Saudi universities launched the Preparatory Year Program in 2007 or later, with one exception at King Fahd University of Petroleum and Minerals (KFUPM). KFUPM is considered one of the few Saudi universities in which the official language of study is 
English. Since KFUPM's establishment in 1963, new students have been required to complete a one-year intensive preparatory program studying mathematics and English courses before entering their colleges (Yushau \& Omar, 2007).

In Saudi Arabia, every year thousands of secondary Saudi students enter universities. In 2013, the total for high school graduates was 380,000 students. About 376,000 of them were admitted to all higher education institutions (Al awsat, 2013). As this study focuses on the Preparatory Year Program (PYP) at King Saud University (KSU), more details about the program are provided. The PYP at KSU was established in the fall of 2007. The first regiment of students admitted into the program in 2007 was 1,600 students. In the next three years, student enrollment in the program increased to 8,000 students and to approximately 12,000 students in 2014.

The prospective students were distributed onto three tracks: Health track, Science/Engineering track, and Humanities track. The organization structure of the PYP contained five Vice-Deanships as follows: (1) Vice-Dean for Academic Affairs; (2) Vice-Dean for Student Services; (3) Vice-Dean for Development and Quality; (4) Vice-Dean for Technical Affaires; and (5) Vice-Dean for Female Students. As well as several academic departments and units: (a) English Language Skills Department; (b) Basic Sciences Department, which offers Mathematics and Statistic courses; (c) Self-Development Skills Department, which offers Learning, Thinking and Research Skills, Communication Skills, Arabic Writing Skills, Introduction to Entrepreneurship, Health and Fitness, and Computer Skills courses; (d) Student Affairs and Counseling units; (e) Self-learning unit; (f) IT and technical unit; and (g) Quality unit (Preparatory Year Strategic Plan 2011-2016, 2011; PYP's website). 
The Preparatory Year Program model utilized some international benchmarks such as: 1) ARAMCO’s College Preparatory Program; 2) Bilkent University’s English Language Preparatory Program; 3) The University of Edinburgh's International Foundation Program; 4) The University of Sydney’s Foundation Program; and 5) University of Toronto's International Foundation Program (Preparatory Year Strategic Plan 2011-2016, 2011, p. 5).

In 2013, the Preparatory Year Program made some changes to the program's structure, vision, objectives, policy, and programs content. Additionally, the Preparatory Year Program's vision joined the Knowledge Society culture at King Saud University mentioned earlier, by stating the goal of "excellence in preparing of knowledge generation" (Deanship, 2014, p. 12). The Preparatory Year's strategic objectives consist of seven areas:

1. Raising awareness and responsibility.

2. Developing and maintaining excellent human resources.

3. Fostering creativity and innovation while enhancing students' capabilities.

4. Adopting a rigorous system for student assessment.

5. Creating a knowledge stimulating environment.

6. Improving quality control practices.

7. Building distinguished partnerships (Student's Guidebook, 2016, p. 12) in Arabic. Moreover, the Preparatory Year Program has four priorities:

1. Discipline and seriousness.

2. Learning enjoyment.

3. Mastering the essential skills.

4. Developing personal skills (Student's Guidebook, 2016, p. 12) in Arabic. 
Further, the Preparatory Year Program applies one model for males and females in terms of planning, academic services, students' assessment, teaching, and curriculums. The model consists of a one-year educational and training program whereby King Saud University is providing students with foundation courses in essential soft and hard skills before allowing entrance into their colleges. Students also have to complete all preparatory year requirements in one academic year ( 2 semesters plus an exceptional summer semester) with a GPA no less than 3 out of 5 (Deanship, 2014).

In terms of the program's admission policy, new students are admitted in one of three paths of study: 1) Medical Track that involves the colleges of Medicine, Dentistry, Pharmacology, Applied Medical Sciences, Nursing and Emergency Medicine; 2) Engineering and Scientific Track that includes the colleges of Engineering, Information Technology and Computer Sciences, Architecture and Planning, Business Administration, and Agriculture and Nutrition Sciences; and 3) Humanities Track, which includes the colleges of Arts, Education, Laws and Political Sciences, Tourism and Archaeology, Languages and Translation, and Teachers College (Deanship, 2014).

The national tests (General Aptitude Test, Educational Attainment Test for Science Colleges - Males, Educational Attainment Test - Females) and Students GPA are utilized to determine what path students will be enrolled in. Despite the difference between the female and male Educational Attainment Tests, both male and female students will study a similar Preparatory Year Program later (Deanship, 2014). In addition, Preparatory Year Deanship has a comprehensive academic system, which involves a study plan, placement test for the English program, courses' drop or withdrawal policy, and transfer rules between paths. For example, this system is used when a student transfers from the Science path to the Humanity path. 
Additionally, a students' assessment system exists for each course, e.g. quizzes, mid-term exam, and final exam. Student GPA also plays an important role in future study. Final GPA can allow a student a choice for his/her path or may transfer the student to another path of study depending on his/her performance.

Furthermore, students average 20-30 hours of studying per week, with about 15 hours counted for the transcript per-semester depending on the study path (Deanship, 2014). Moreover, the Preparatory Year Model involves some supportive units, such as Self-Learning Department, Students Clubs, volunteer works or society service unit, Gifted Students, and Guidance and Counseling units, which offers numerous advising services e.g. academic support, social and health care, outstanding students program, Psychological guidance, and a program for students with disabilities (Deanship, 2014). Furthermore, since its establishment in 2007, the Preparatory Year Program was positioned under the authority of the university rector; since 2013, it has been under the authority of the Vice-Rector of Academic Affairs (Deanship, 2014). According to Alexander-Hamilton (2010) classification typology, the Preparatory Year Program is considered a single administrative unit with comprehensive structures, including organization charts, Deans, Vice Deans, department directors, a budget, separate buildings, policies, supportive units, and recruitment system for faculty and administration staff.

As mentioned earlier, the current structure encounters several challenges such as economic, learning quality, and lack of a theoretical and philosophy base. These challenges made the educational policy makers to decide restructuring the program and its function. The current study contributed to achieve this goal, using the Concept Mapping/Pattern Matching assisted to identify the future ideal function of Preparatory Year from stakeholders' perceptions that needs to develop. 


\section{Emerging Knowledge Society and First-year Experience}

Writing this section is complex due to the paucity of information about the role of firstyear experiences in the emerging Knowledge Society. However, valuable information about the role of university/college in a Knowledge Society is available.

In this study, the literature review search found one reference written by Johnston (2010) in his book, The First-year at University: Teaching Students in Transition: Teaching Students in Transition, which mentions the importance of first-year experience in a Knowledge Society or knowledge-based economy. Johnston argues that a new trend of higher education policy and practice is to provide equal opportunity for all students. Equal opportunity is considered fundamental for building a knowledge based-economy or Knowledge Society. Johnston's work provides an educational and organizational context for Preparatory Year Experiences and students in transition. However, Johnston did not provide information about the type or nature of the educational and organizational context mentioned. In this context, several issues related to a Knowledge Society and postsecondary education will be discussed, considering the first-year experience as a part of university functions.

\section{Knowledge Society and Knowledge-Based Economy Concepts Dilemma and}

University Mission. Historically, knowledge has been defined as a power and each "society has its own knowledge assets" (Bakry \& Al-Ghamdi, 2008; Bindé \& Matsuura, 2005). In the last three decades, several new concepts have emerged from business and industrial sectors such as Information Society and Knowledge Society that have mainly been developed by academics from the United States of America, Japan, and Europe, with the concept of Knowledge-Based Economy proposed later by international organizations such as the Organization for Economic Cooperation and Development (OECD) (Hornidge, 2011; Kearns, 2004; Sörlin \& Vessuri, 2007). 
However, despite the differences between the meaning of these concepts and their application, the terms are "often used interchangeably" (Hornidge, 2011, p. 3).

For the Knowledge Society concept, numerous definitions of the term have been offered from the 1960s to the 1980s (Hornidge, 2011).

In 1966, Lane stated "a first approximation to a definition" which says:

The knowledge society is one in which, more than in other societies, its members: (a) inquire into the basis of their beliefs about man, nature, and society; (b) are guided (perhaps unconsciously) by objective standards of veridical truth, and, at the upper levels of education, follow scientific rules of evidence and inference in inquiry; (c) devote considerable resources to this inquiry and thus have a large store of knowledge; (d) collect, organize, and interpret their knowledge in a constant effort to extract further meaning from it for the purposes at hand; (e) employ this knowledge to illuminate (and perhaps modify) their values and goals as well as to advance them (Lane, 1966, p. 650). In 1950s, the economic scientist Peter Drucker defined Knowledge Society as an “employee society." Ten years later, he coined the terms "knowledge work" and "knowledge worker" (Drucker, 1994, p. 6; Drucker, 2010, p. 157).

In 1969, in his book The Age of Discontinuity: Guidelines to our Changing Society, Drucker uses the term of Knowledge Society and states "knowledge as central to our society and as the foundation of economy and social action" (p. 349). Moreover, he mentions that knowledge "has become the foundation of the modern economy" as we have shifted from an "economy of goods" to a "knowledge economy" (p. 265). Later, Drucker defines Knowledge Society as “a society of organizations in which practically every single task is being performed in and through 
an organization" (Drucker, 1994, p. 159). In addition, Drucker "pointed to the development of ICTs which embody a new economic reality" (Hornidge, 2011, p. 12).

At the same time, Daniel Bell uses the concept of Knowledge Society interchangeably with post-industrial society. He justified his use of the two concepts in an equivalent manner because he considers "knowledge is a fundamental resource" of post-industrial society (as cited in Stehr, 1994, p. 6). Peter (2007) associated the Knowledge Society concept with other concepts such as knowledge economy, information society, and learning society (established by sociologists, economists, and educators). Despite the historical background of these concepts, no direct connection between them exists in the academia sector. Hornidge (2011) states that “conceptual and terminological overlaps of the notions 'knowledge society', 'information society' and 'knowledge-based economy', the terms 'information society' and 'knowledge-based economy' entered the political sphere more rapidly than the more academic term 'knowledge society"' (p. 20). However, governments worldwide adopted the general idea of a Knowledge Society as well as the manifold terminology originating from the scientific community (Hornidge, 2011).

Sorlin and Vessuri (2007) have distinguished between a Knowledge Society and a knowledge economy, according to the methods that knowledge shapes society, mentioning that both concepts have a different vision:

Knowledge-based economies are growing all around us, but they do so without always acknowledging the democratic, ethical, and normative dimensions of science and scientific institutions. Knowledge economy is market-driven and performance based on the market ideology, which stands in a problematic but not necessarily conflicting relation to the norms and ideals of the knowledge society (p. 2). 
The United Nations (2005) in its published report Understanding Knowledge Societies: In Twenty Questions and Answers with the Index of Knowledge Societies, states that:

To be a Smart Knowledge Society... it is not enough to be rich in main assets and to take care of their development. A new sense of direction in development and a commitment to this new direction must assure high levels of quality and safety of life. Mass production of the knowledge "to do," piling up technological innovations, and converting them into products and services in the framework of the Knowledge Economy managed by the currently existing market does not by itself assure high levels of quality and safety of life for all people everywhere (p. xii).

Moreover, the King Abdulaziz City for Science and Technology (2014) report, Transition to Knowledge Society in Saudi Arabia: Tracing the Rise of the Knowledge Economy in the Kingdom of Saudi Arabia in 2014 (KACST), utilized three concepts: Knowledge Society, Knowledge-based Economy, and Knowledge Economy. The report provides three definitions to a large extent compatible with Sorlin and Vessuri (2007) and the United Nation (2005), as follows:

1. Knowledge Society: "A society that generates, disseminates, and invests in knowledge for the wellbeing of its members, and the advancement of the standard of living and quality of life".

2. Knowledge-based Economy: "An economy where the generation of, and investment in knowledge contribute substantially to economic growth and wealth creation; and where human capital rests at the core of the economy due to man's capacity to create and innovate, generate and invest in new ideas, use technology, and learn and perform new skills in all economic sectors". 
3. Knowledge Economy: It is part of a knowledge-based economy, where knowledge is turned into products and services, and information and communications technology (ICT) is the main platform and tool. This includes, for instance, creative industries in their four spheres as classified by the United Nations Conference on Trade and Development (UNCTAD):

1. Heritage: Includes activities such as crafts, traditional cultural expressions, and festivals and celebrations.

2. Arts: Visual arts - paintings, sculpture, photography, antiques; performing arts - live music, theatre, circus, puppetry, and traditional dance.

3. Media: Audio-visual activities - television, radio, film, and other broadcasting; publishing and printed media - books, press and other publications.

4. Functional Creations: Design - interior, graphic, fashion, jewelry, and new media digitalized creative content, software, video games, animation; creative services advertising, architectural, cultural and recreational, and creative R\&D (Alani, Mrayati, Al Kamil, \& M. Alghamdi, 2014, p. 62).

In the context of Saudi postsecondary education, the Ministry of Higher Education in its reports, Higher Education and Building Knowledge Society, an International Evaluation Reports (2011; 2013), defines Knowledge Society as:

A knowledge-based society is every society where knowledge, rather than capital or labor force, is regarded as the primary source of production. This indicates the importance given by such a society to information, which, having been found and disseminated, is used to fulfill the welfare and prosperity of citizens. This type of society is characterized by the fact that knowledge is the main component of all its human activities. Whether 
economic, social, or cultural, all these activities rely on information and knowledge. In short, a knowledge society is one where knowledge is one of the forces of innovation and creativity (p. 10).

These differences of concepts and definitions support the idea of each concept having its own cultural context, dimensions, and applications. In the educational sector, specifically in postsecondary education, understanding these differences will shape our educational reform plans, policy, curriculum, and practices. In this context, and in case we accept these distinctions among a Knowledge Society and knowledge-based economy and knowledge economy, we cannot use these concepts interchangeably because preparing students for a Knowledge Society is different from preparing them to only be knowledge workers on the production lines of a knowledge-based economy.

Several questions arose regarding this issue: 1) What type of teaching, curriculum, educational policy, infrastructure, and assessment system does a Knowledge Society require?; 2) What are the student characteristics that can be measured or observed to tell if we have a Knowledge Society citizen?; 3) How do we know if we become a Knowledge Society? Which qualitative and quantitative indicators can make the distinction?; 4) Is there a consistency among educators, educational policy makers, and society about the Knowledge Society definition and its practices?; 5) Which skills/knowledge and programs are required for first-year students at college/university, and how can these be designed to be appropriate for a Knowledge Society?; and 6) How should the first-year program be structured, organizationally, to achieve a Knowledge Society?

Knowledge Society Movement in Saudi Arabia. According to the King Abdulaziz City for Science and Technology (2014) report, "Saudi Arabia has achieved excellent progress on 
almost all ICT/business indicators published by international think tanks and organizations" (p. 24). In the educational sector, the Ministry of Higher Education in particular has launched numerous initiatives to develop the intellectual capital of its citizens, and encourage and facilitate inventions in science and technology (General Department for Planning Statistics, 2013).

In addition, the international reports (2013) such as the Global Competiveness Index (GCI), World International Property Organization (WIPO), the Global Information Technology Report (GITR), and the Report of Cultural Development in the Arab World, state that Saudi Arabia has managed to have strong global and regional positions in various fields of a Knowledge Society. For example, innovation is possible, as well as technological readiness, and higher education competences (General Department for Planning Statistics, 2013). Saudi Arabia has "laid down the foundation of the 21 st century economy to establish itself as a research, learning, and industrial center in the region, focusing on nanotechnology, biotechnology, and information and communication technology, which are the basic elements of knowledge-based industries" (General Department for Planning Statistics, 2013, p. 9). In terms of the Knowledge Society initiatives in higher education, Saudi Arabia has launched several projects. For example, enhancing the learning environment through establishing new public and private universities across the country, which increased the number of universities from eight universities in 2001 to thirty-three in 2011 (General Department for Planning Statistics, 2013).

Meanwhile, more attention has been devoted to preparing and developing faculty members' ability to teach, and to research as well. For example, each university has established a new deanship, Skill and Academic Development Deanship, which is responsible for training and developing faculty competency. In addition, the Incentive System has been created to retain faculty who might otherwise go to the private sector. For example, "guarantee psychological 
stability, encourage improved academic performance, create an atmosphere of competitiveness, and give great support to higher education outputs.... the system provides for an excellence reward of $10 \%$ salary increase for a member who receives a local award, $20 \%$ in the case of a regional award, $30 \%$ for a receiver of an international award, and $40 \%$ for a member who receives an invention patent” (General Department for Planning Statistics, 2013, p. 17). In addition, some initiatives have been created for postsecondary students. For example, the Preparatory Year Program and student skills development programs, which consists of two tracks: academic track and practical track, concentrate on communication, technological, and personal skills (General Department for Planning Statistics, 2013).

Regarding the second task of university research, Saudi universities administer 1,167 research laboratories and 89 specialized research centers. Moreover, the Ministry of Higher Education allows universities to establish Research Excellence Centers at Universities, Cooperative Research Centers, Science Parks and Technology Incubators, The Research Chair Program, and The Nanotechnology Program in specific universities (General Department for Planning Statistics, 2013). The Ministry of Higher Education (2013) statistics reported that in 2012, the total of government spending on Research and Development was 15.2 billion Saudi Riyal, representing $0.56 \%$ of Gross Domestic Product (GDP) (http://www.mohe.gov.sa/en/default.aspx).

For quality assurance, the Ministry of Higher Education established several initiatives to ensure the quality of research, learning, and service in Saudi universities. For example, establishing the National Commission for Assessment and Academic Accreditation (NCAAA), which is responsible for accreditation issues, the National Center for Assessment in Higher Education, which is accountable to create educational standards and measurements regarding 
learning issues, and the National Center for E-learning and Distance Education, responsible for e-learning development (General Department for Planning Statistics, 2013). In terms of Saudi Higher Education Internationalization, other initiatives have been established. For example:

1. Opening university admission to students of other nationalities and from other cultural environments (46,566 international students in Saudi universities).

2. Faculty member diversity.

3. Research cooperation and cooperation agreements with outstanding universities for knowledge exchange.

4. Granting scholarships to Saudi students to study abroad (190,506 students, 62,984 female and 141,223 male) (Information, 2013).

Moreover, numerous Saudi universities have been competing with international universities around the world. For example, the U.S. News and World Report Ranking (2012) ranked King Saud University $197^{\text {th }}$ and King Fahad University was ranked $208^{\text {th }}$ (Information, 2013).

University Roles and Challenges in Emerging Knowledge Society. In the Knowledge Society era, university plays important roles in developing knowledge, skills and competencies that lead to building the human capital of society (Suciu, Drăgulănescu, Ghiţiu-Brătescu, Picioruş, Imbrişcă, Şerbu, \& Grigore, 2011). University leaders, faculty, and administration staff need to understand the change in their roles of teaching, learning, and preparing students for a Knowledge Society (Rowley, 2000).

In the Knowledge Society era, university is seen as a business investment, a place where faculty members are working as service providers and students as clients (Amaral \& Magalhães, 2002; Jacob and Hellström, 2000). Consequently, the new Knowledge Society culture forces 
universities to compete by improving their educational systems, including selecting appropriate curriculum and implementing teaching methods that strengthen graduates.

The UNESCO World (2005) report, states that in a Knowledge Society the relevance of higher education means:

1. Being politically responsive: higher education does not fulfill its role when it neglects its function of being watchful and awakening minds, or fails to analyze social issues;

2. Being responsive to the world of work: it is vital that higher education should gear itself to changes in the world of work, without sacrificing its own identity and priorities, which concern the long-term needs of society;

3. Being responsive to other levels of the education system: the initial training of teachers and many social workers is, with few exceptions, the task of higher education. The priorities of university research should also include analysis and evaluation of the different levels of the education system in close relationship with the world of work (without, however, subordinating itself to it) and with a genuine social project;

4. Being responsive to culture and cultures: culture is not a given, but is constructed in space and time. Higher education should help to construct culture in its universal dimension and should accordingly be responsive to the diversity of cultures;

5. Being responsive to all: appropriate strategies should be implemented to increase the participation of disadvantaged groups, notably women;

6. Being responsive everywhere and all the time: the promotion of lifelong education calls for greater flexibility and greater diversification of training provision in higher education;

7. Being responsive to students and teachers: institutions of higher education should be conceived and managed not as mere training establishments but as educational facilities, 
implying better management of teaching careers and the active participation of students not only in teaching activities but also in the management and life of institutions of higher education (p. 97).

In his book, Education and The Knowledge Society, Weert (2004) outlines the eight principles of transforming educational institutions toward a Knowledge Society, which were originally developed by Buetner et al. (2004).

1. Vision;

2. Philosophy of learning and pedagogy;

3. Development plans and policies;

4. Facilities and resources;

5. Understanding the curriculum;

6. Professional development of institution staff;

7. Communities;

8. Assessment (p. 23).

Weert (2004) suggests that the founding philosophy of learning and pedagogy is the key component of success in developing the university mission toward a Knowledge Society. In this context, university roles in Knowledge Society's require flexible structure, which can respond to economic, societal, and individual needs. Flexibility involves policy change, faculty and curriculum continuous development, and the ability to redesign programs according to market needs. In contrast, universities with firm structures will encounter some challenges in a Knowledge Society in the future causing isolation from the world. Moreover, founding a philosophy of learning and pedagogy is essential to develop an appropriate educational content and programs for students. Despite success in the movement toward a Knowledge Society, some 
challenges remain in the Saudi higher education system regarding progress towards a Knowledge Society. The five main challenges encountered by the Saudi higher education system today are:

1. The tension between academic vision and cultural norms.

2. The lack of an appropriate governance model for Saudi universities.

3. Developing and sustaining international credibility.

4. Maximizing opportunities and achievements for women in higher education.

5. The tension between traditional Saudi approaches to teaching, learning, and student assessment and the needs of a global knowledge economy (Smith \& Abouammoh, 2013, p. 181).

To further clarify, the tension is between academic vision and dominant culture.

In the Saudi context, the cultural and religious norms are playing an important role in shaping government and public policy and practices. Shifting towards world-class universities or a Knowledge Society requires supporting professional autonomy for universities. Moreover, this shift requires high levels of collaboration and an open exchange of information with the global network of universities and academics (Smith \& Abouammoh, 2013). However, current "traditional Saudi culture and religious teachings are based on adherence to standards and norms, centralized systems of governance, structured lifestyles and work environments, rote learning of key information and a reluctance to engage strongly in open collaboration and exchange of ideas with the outside world" (Smith \& Abouammoh, 2013, p. 182). Thus, Saudi higher education works hard to overcome this challenge and find an ideal balance between a future Knowledge Society vision and a religious-based culture shaping the everyday life of Saudi society.

Moreover, the main challenge of the trend toward a self-government model of university management, as mentioned earlier regarding Saudi higher education, is a centralized system. The 
educational reform initiative AAFAQ or (Horizons) emphasized that to create world-class universities it is crucial to increase university autonomy. For example, give more authority to universities to make their decisions about their budget and strategic plan. Therefore, the development of a suitable and sustainable governance model for Saudi universities is critical if the Saudi higher education system is to reach its goal of world-class universities or Knowledge Society. The idea of self-governance of university and promoting institutional autonomy could be helped to overcome such a challenge. At the same time, the application of such a solution, university self-government, could cause a new crisis related to finding suitable leadership that can work independently (Smith \& Abouammoh, 2013).

Regarding developing rigorous research standards, Saudi universities require building a strong academic research reputation in particular to create a world-class university system. Thus, it is important to improve the quality of academic research, which also requires a degree of openness. To achieve this, Saudi higher education needs to establish a rigorous research-training infrastructure, either at the systemic or institutional level (Smith \& Abouammoh, 2013).

Currently, Saudi universities have many programs to enhance international credibility of research. For example, the visiting professor program where each university has authority to contact and sign a contract with any professor from any university around the world to conduct research in a specific field. The visiting program is to some extent a success; however, the program causes a new challenge whereby some departments or universities strive only to get a high citation ranking instead of research experience transfer to Saudi university or improvement of research quality (General Department for Planning and Statistics, 2013).

Concerning opportunities for women in higher education, as mentioned previously, the Saudi culture of gender segregation is considered a big challenge for higher education to achieve 
equality of opportunity for women. The Saudi higher education requires taking into account issues related to gender. For example, providing equal access to library materials and online research facilities for both women and men, where in some cases the libraries provide services to males only. Further, in many cases male departments are responsible to plan and select curriculum materials and content without sharing information with the female departments (Jamjoom \& Kelly, 2013).

The final issue is equality in terms of leadership positions, whereby some female departments continue to be managed through male departments. For example, at the Preparatory Year Program all departments' chairs are males. In the female section, there are coordinators or vice-chairman. To address the challenges between traditional Saudi approaches of teaching, learning, and Knowledge Society requirements, Saudi higher education and its universities and schools are sharing one vision: to be part of a knowledge based-economy or a Knowledge Society. Such a goal requires different models of assessment, teaching, curriculum, and policy. The traditional ways of teaching and planning will not achieve the goal of a Knowledge Society. Some Saudi universities established special deanships for professional development of faculty to improve their skills to match a Knowledge Society's needs. Moreover, some research centers have been established to develop Knowledge Society curricula and teaching methods at university levels. These centers also try to develop courses that match market needs. For example, an entrepreneurship course becomes a major requirement for all university students in any discipline. Universities are also merging high critical thinking skills in curriculum content to improve students' skills and prepare them for marketing those skills (Smith \& Abouammoh, 2013). 
In summary, higher education in Saudi Arabia is a modern system with a short history in comparison to other educational systems either in North America or Europe, or in the Arabic World. Despite this, Saudi higher education has achieved many initiatives especially in terms of infrastructure, expansion of education in all provinces, and quality of education to some extent. Currently, the Saudi government's aim is transitioning to a Knowledge Society and then reducing the dependence on oil as the basis of the economy. Due to the government's desire to shift toward a Knowledge Society or knowledge based-economy, higher education encounters different challenges. The big challenge is cultural norms. Creating an appropriate model of education with high attention to these two factors is a difficult but possible task (Smith \& Abouammoh (2013). Thus, at this point, we think that with a generous budget and social/governmental support, Saudi higher education can achieve the Knowledge Society goal through applying some recommendations such as involving international experts (e.g. research partners and academic mentors), stimulating the growth of private universities based on high quality standards, developing appropriate programs for females that enable them to contribute in building a Knowledge Society, and enhancing educational policy that supports international collaboration among higher education institutions.

Finally, Saudi higher education created the AAFAQ strategic plan in order to develop the Knowledge Society in Saudi Arabia, but we conclude that due to cultural differences and differences of operational efficiency between Saudi universities, not all universities are qualified at this time to be world-class universities. Therefore, more focus is required to divide these universities between research institutions and universities for teaching until the higher education ministry can establish strong accountability systems to manage these institutions. 


\section{Concept Mapping/Pattern Matching as a Developmental Methodology}

Joseph D. Novak who expanded upon Ausubel's Assimilation Theory (1968) invented the term of Concept Mapping in 1972 (Novak and Cañas, 2006, 2008). The Assimilation Theory of Learning states, "the learner is the center of meaning making" (Fraser. 1993). Novak concluded that "meaningful learning was the most important factor in building powerful knowledge structures, and by contrast, learning by rote contributed little to building individual's knowledge structures, nor does rote learning result in the remediation of misconceptions held by learners" and "the use of concept maps could help students learn how to learn meaningfully" (Novak and Cañas, 2006, 2008, p. 7). In other words, Novak translated Ausubel's Theory into the modern concept map structure made up of central issues (concepts) and links to (phrases or comments) to illustrate the relationship between them. Since that time, numerous studies have been conducted utilizing the concept mapping approach in different methods. During the late 1980s, Concept Mapping/Pattern Matching (CM/PM) was further developed by William Trochim at Cornell University.

In his article, Pattern Matching, Validity, and Conceptualization in Program Evaluation, Trochim (1985) discusses the utility of conceptualization methods and pattern matching to assess program implementation, validity of measure, and causal hypothesis. Trochim argues that to evaluate a program and its relationship to a theory, the researcher or evaluator needs to expand the theory through stakeholders' insights and perceptions. For example, to evaluate an educational program, it is useful to ask program administrators, customers, representatives, and interest groups their perceptions to gain better understanding. To accomplish the conceptualization stage, three major steps are required: 1) generate statements through the stakeholders; 2) determine the relationship between these statements using a sorting statements 
task; and 3) utilize statistical methods such as multidimensional scaling and cluster analysis to produce the concepts map. Trochim concluded with a call to "develop a taxonomy of conceptualization methods that can help facilitate this task" (p. 602).

Trochim (1989a, 1989b) introduced two articles titled, An Introduction to Concept Mapping for Planning and Evaluation and Concept Mapping Soft Science or Hard Art? Published in the journal Evaluation and Program Planning, to revise the Concept Mapping/Pattern Matching approach to six steps, which can be used by interest groups to develop a conceptual framework to guide evaluation or planning. The Concept Mapping is a "type of structured conceptualization" (Trochim, 1989a, p. 1) that uses a process by which "ideas are represented in the form of a picture or map" (p. 1) to define the relationship between theory and practice.

From the outset, it was important to establish: 1) that the concept mapping process provided an accurate representation of what people were thinking (i.e. reliability and validity); and 2) that the concept maps could be integrated into scientific theory-building and experimentation (Trochim, 1989b, p. 105-106).

Furthermore, Kane \& Trochim (2007) state in their book, Concept Mapping for Planning and Evaluation, that Concept Mapping/Pattern Matching has been created to be a useful tool in strategic planning and evaluation. Trochim (1989a) defined the concept map as "a pictorial representation of the group's thinking which displays all of the ideas of the group relative to the topic at hand, shows how these ideas are related to each other and, optionally, shows which ideas are more relevant, important, or appropriate" (p. 2). Furthermore, the concept mapping process “combines qualitative and quantitative research techniques to produce a map representing ideas, usually produced in a focus-group brainstorming session" (Streeter, Franklin, Kim, \& Tripodi, 
2011, p. 198). Concept mapping depends on interaction between diverse groups of stakeholders to discuss specific ideas using a brainstorming technique, which is considered a qualitative method, and then represents the session outcomes in visual results (e.g. maps, pattern matches, and value plots) that report stakeholders' knowledge about the issue under investigation and the degree of agreement between them (Kane \& Trochim, 2007).

Kane and Trochim, (2007) clarify the difference between the concept mapping approach and "less sophisticated" (p. 1) methods such as focus groups. For example:

1. The concept mapping process involves integrated steps in specific sequence starting with a brainstorming session, sorting, and rating tasks; and then analyzing data quantitatively by multivariate statistical method.

2. The visual analysis of idea (statements) can be used directly to develop planning goals or evaluation process.

3. Diverse data sources can be used for generating ideas. For example, document analysis, remote brainstorming session, or any other setting and geographical limitation.

4. Concept mapping has no requirement regarding stakeholders' group size. Concept mapping could be done with a small group of no less than eight, or with hundreds of diverse stakeholders by using technology (remote session).

5. In concept mapping, stakeholders themselves drive the session content and interpretation process instead of a facilitator or researcher. Concept mapping outcomes could be used to "measure any number of variables of interest such as the importance or feasibility of participant ideas and display these as patterns on the map. Ideas can then be compared via two or more patterns in the aggregate, and in detail, using pattern matching to look at consensus and consistency over time, along with bivariate 
displays known as "go zones," to identify the potential courses of action or types of measurement” (Kane \& Trochim, 2007, p. 2).

The advantages of concept mapping helped to achieve this study's goals to compare and contrast stakeholders' perceptions about first-year future ideal functions and also to develop a conceptual framework of the Preparatory Year Program at King Saud University based on groups of stakeholders' perceptions. The six steps of CM/PM used for this study include: 1) preparation; 2) generation of statements; 3) structuring of statements; 4) representation of statements; 5) interpretation of maps; and 6) utilization of maps (Kane \& Trochim, 2007; Streeter, Franklin, Kim, \& Tripodi, 2011; Trochim, 1989a; Trochim, 1989b). More details about these six steps are provided in Chapter Three. Furthermore, the Concept Mapping/Pattern Matching approach developed by Trochim has been used among researchers and graduate students. For example:

1- The Use of Concept Mapping/Pattern Matching to Determine the Content Domain for Information Literacy in Baccalaureate Education by Eleanor M. Messman-Mandicott (2012).

2- Conceptualizing Doctoral Advising from Professors' and Doctoral Students' Perspectives using Concept Mapping by Philip Kontor Adu (2011).

3- Using Concept Mapping to Identify Action Steps for Physical Activity Promotion in Cancer Treatment by Sean J. Fitzpatrick (2012).

4- The Use of Concept Mapping/Pattern Matching to Conceptualize the Desired Domain of Student Learning in the First Year of College by Jacob B. Sanwidi (2015). Additionally, Kane \& Trochim (2007) also listed numbers of dissertations that utilized Concept Mapping/Pattern Matching as a research methodology. These studies covered different 
aspects of social science, for example: 1) studies related to social issues (e.g. people's

perceptions toward work, housing, and school); 2) studies focusing on theoretical framework or instrument or organization structure development; 3) studies emphasizing assessment issues (e.g. learning, cognitive, skills, attitude); and 4) studies to test Concept Mapping/Pattern Matching validity in different settings.

Joseph (2004) conducted one of these studies, Hispanic Dropouts Speak Out: A Study of Hispanic Youth and Their Experiences in the Public-School System. We are selecting this study specifically due to two reasons: 1) this study is linked to the current study domain, whereby it discussed student departure issues and used Tinto's Theory as a theoretical framework; and 2) it used a complex research design, which employed a mixed method as a research methodology, and used concept mapping as a stage in the study process.

The purpose of this study was "an attempt [was] made to discover Hispanic dropout's perceptions of their interactions and experiences at school" (Joseph, 2004, p. 18). Moreover, this study involved three research questions:

1- What are Hispanic dropouts' perceptions of the internal and/or external factors contributing to their decision to leave school?

2- What are Hispanic dropouts' perceptions of the institutional factors contributing to their decision to leave school?

3- How useful and applicable is Tinto's Theory on student departure to the interactions and experiences Hispanic dropouts had within the public school? (p. 19).

The aforementioned study is the first to utilize a concept mapping process that had not been previously used in such a study. The study's design was based on the Sequential Exploratory of Mixed Method. Sequential Exploratory was conducted in two phases. The first 
phase was qualitative; involving interviews with eleven students, and was followed by a quantitative phase, which contained three focus group sessions to generate ideas, statement structures, and to interpret maps through five participations in this process (Joseph, 2004).

Joseph's (2004) brainstorming question was "Generate statements that describe one specific thing that happened in school that caused you to withdraw from school" (p. 69). The brainstorming sessions generated 80 statements. The Concept Systems ${ }^{\circledR}$ software developed by Trochim was utilized for data analysis. The participants were asked to sort and rate statements based on concept mapping criteria. The rating stage was based on an Ordinal scale in which $1=$ relatively unimportant, $2=$ somewhat important, $3=$ important, $4=$ very important, and $5=$ extremely important; and participants sorted the statements (Joseph, 2004).

The Concept Systems ${ }^{\circledR}$ software produced twenty clusters. Joseph (2004) reduced the cluster numbers to six according to his criteria as follows: 1) programs for teen cluster; 2) home and family problems cluster; 3) the lack of administrative support cluster; 4) the personal reasons cluster; 5) lack of school support cluster; and 6) lack of positive support from peers. Joseph (2004) added to the concept mapping process, the tests of reliability, validity, and trustworthiness, and study outcomes were merged in the data interpretation stage. The study has several limitations, such as no comparison groups were reported; for example, "between Hispanic dropouts and Hispanic students who remain in school" (p. 22). This study has a unique design, which concept mapping utilized as a step in a complex process of mixed method research.

A second study of interest was conducted in 1996 by Ludwig titled Abused Women's Experience with the Justice System: Concept Mapping. The purpose of this study was to "gain a better understanding of the experiences abused women have with the justice system in Alberta, 
and how they coped" (p. 2). The research questions of this study are: 1) what issues/experiences do abused women experience with the justice system?; 2) how do they cope with their experiences with the justice system?; and 3) what is the prevalence of these experiences in a larger sample of abused women? (p. 2). In this study, the uniqueness of using concept mapping was to give women, as themselves, a voice to describe their experience individually within an interest group. Also, this study used three ways for generating statements: 1) responses in writing for those who were too shy to talk; 2) interview; and 3) focus group. There were two focus group prompts: "Please describe an issue or experience you have had with the justice system or officials (police, lawyers, judges, social workers, or anyone else involved with the justice system) that had to do with family violence; and how did you cope with your experience with the justice system?" (Ludwig, 1996, p. 44).

Regarding women's experiences, the focus prompt produced 105 statements, which were reduced to 98 . Sixty-three different ways were reported to manage these issues and then were reduced to 59 statements. The concept map of coping has five clusters reflecting issues and experiences with the justice system. Ludwig's study reported that women have special needs and experiences, regarding issues under investigation (Ludwig, 1996). This conclusion supports the current study's goal to give women a chance to express their needs about the first-year program in separate focus group sessions. However, both previously mentioned studies utilized different approaches for generating statements. The researchers concern about stakeholders experience regarding issue/s under study made them eager to use an interview, document analysis, etc. to ensure statements are covering study aspects.

In general, using concept mapping in this current study achieved the following: 1) better and more reliable understanding to the dilemma being studied, because stakeholders perceptions 
would be directly linked to the problem; 2) visualizing the problem being studied assisted to understand the relationship among its components and determine the dominant or the important part/s of the problem, which need intervention or development; 3 ) the concept mapping process, especially ideas generated gave stakeholders a chance to express their opinion individually and within the group; and 4) through one question (focus prompt), concept mapping generated valuable data regarding the issue under study. 


\section{Chapter Three}

\section{Research Methodology}

The purpose of this study was to develop a conceptual framework for the future ideal functions of the Preparatory Year Program (PYP) at King Saud University (KSU).

\section{Restatement of the Problem}

The Preparatory Year Program (PYP) plays an important role in making student transitions into postsecondary education successful at Saudi Arabian universities (Alaqeeli, 2014; Al Kathiri, 2014). In 2012, King Saud University conducted a comprehensive assessment study of the Preparatory Year Program. "The study has used the multi pattern assessment model as an organizational frame including the following phases: context, inputs, operations, and outputs" (Al Kathiri, 2014, p. 66).

The publicly released section of the study reported that the PYP is a positive initiative at King Saud University, contributing positively in improving student performance, with $74.9 \%$ of the program's goals accomplished. Moreover, the study recommended revising specific aspects of the program such as the English language program and the scientific programs in order to meet students' needs and future major needs. The study also mentioned some challenges encountering the PYP, such as faculty selection and selecting the administrative and academic staff (Al Kathiri, 2014).

The study determines three major aspects that need improvement: 1) The English language curriculum; 2) The scientific curriculum (e.g. for all health, scientific, and humanitarian courses to cope with the needs of the universities); 3) The general curriculum (Al Kathiri, 2014, p. 96-70). These three recommendations are focusing on the overall improvement of the curriculum. However, the publicly released section of the report did not mention the current 
PYP's organizational structure, functions, policy, philosophy and pedagogy, teaching

effectiveness, and student's assessment methodology. In addition, the public section of the study did not mention females education as a variable that effects the study's outcomes. The current practices of the PYP at KSU are concentrated on preparing students academically (e.g. in math, languages, and business administration), socially, and improving their hard/soft skills (A1 Kathiri, 2014). However, the PYP at KSU will also be required to focus on "non-cognitive or non-academic skills" (Alaqeeli, 2014, p. 62). For example, "educational commitment, campus engagement, self-efficacy, appreciating creativity, seriousness, teamwork, and discipline” (p. $62)$.

Furthermore, the PYP is operated through the business sector, which causes several issues related to learning quality and university expense. Furthermore, operating the PYP through the business sector causes a lack of interaction between students and the academic culture. Additionally, the business sector has no previous experience in the operation of such a program (Alaqeeli, 2014). Although KSU and the PYP administrators control the program in terms of planning, curriculum content selection, assessment, and funding, controlling the program and teaching quality and educational practices are considered as challenges.

Despite the new trend in PYP in the United States of America and some other countries, which focuses on supporting students during all years of their undergraduate study, the current working model of PYP at KSU only focuses on preparing students for their first-year. In addition, the current teaching practices of PYP only focus on curriculum content, not teaching approaches. This practice is due to unclear educational pedagogy in the program (Alaqeeli, 2014). "The preparatory year in Saudi universities lacks a governing concept philosophy" (p. 
60). Lack of a governing concept philosophy may result in neglecting the theoretical base and establishment of a practically structured vision based on pedagogy and measurable goals.

Overall, the current model of preparatory year has several problems regarding: 1) learning quality; 2) economic issues; 3) operational difficulties; and 4) no clear theoretical base or pedagogical philosophy in the program.

\section{Significance of the Problem}

"It is time to apply the lessons of the past to the present and, in the process of doing so, make necessary structural, policy, curricular, and pedagogical changes to better meet the needs of our students so that they have fuller and richer futures" (Koch and Gardner, 2014, p. 35).

In this context, Saudi universities apply the Preparatory Year Program (PYP) as one of the best practices to help first-year student success in college/university. Koch and Gardner (2014) state that to create a successful preparatory year model, it is important to link program policy, structure, and practices with the university's mission. Therefore, postsecondary institutions "should work collectively to develop a research-based, comprehensive model of the first-year that is attainable and immediately usable to increase student learning, success, and retention" (p. 36).

Developing such a conceptual framework could be tied to the accreditation process, student learning and performance, and assessment strategies. Among these development and operational issues, developing a conceptual framework of the PYP to include the future ideal functions of the program is significant. As this study's purpose was in development, the use of Concept Mapping/Pattern Matching (CM/PM) allowed recognizing stakeholders' perceptions about the PYP's development aspects and assisted the establishment for future dimensions of the program that need more attention and improvements. "This concept mapping approach is 
effective when a group of people wants to develop a conceptual framework for evaluation or planning." (Kane \& Trochim, 2007, p. 7). Two separate groups of stakeholders were engaged in two brainstorming sessions to generate the developmental statements used for the PYP's conceptual framework. Finally, the literature search reported that no previous studies have been conducted that have utilized Concept Mapping/Pattern Matching (CM/PM) to develop a conceptual framework of first-year experience within a Saudi educational context.

\section{Research Questions}

This study attempted to answer the following research questions:

RQ1: Using the Concept Mapping/Pattern Matching methodology, how do Saudi male and female postsecondary stakeholders conceptualize the future ideal functions of the Preparatory Year Deanship to help students successfully transition into the first year of college/university?

a: Does this Concept Mapping/Pattern Matching conceptualization compare and contrast with the current working model of the Preparatory Year Program at King Saud University?

b: Does this Concept Mapping/Pattern Matching conceptualization compare and contrast with King Saud University’s explicit strategic plan?

RQ2: When conducting a Concept Mapping/Pattern Matching conceptualization, how do the results for males compare and contrast with results for females?

\section{The Concept Mapping/Pattern Matching Methodology Utilized in this Study}

The purpose of this study is to develop a conceptual framework for the future ideal functions of the Preparatory Year Program (PYP) at King Saud University (KSU). A close examination of the available research methods that can be used to develop a conceptual theoretical framework of the ideal function of the PYP at KSU shows that one approach to 
conduct research is through conducting a survey. Messman-Mandicott (2012) states that surveying people will make them respond just to specific items that might describe the current situation or what they wish in the future. In other words, a survey will limit participants' opportunity to express or share their perspective about the crucial issues of the PYP that needs to be developed.

Moreover, Messman-Mandicott (2012) states that using qualitative methods such as an interview "may not supply the quantifiable data that would validate the resulting consensus of objectives" (p. 71). In other words, some studies could use interviews or pen-ended survey questions, but the coding of participants' answers can be problematic and subjective. In addition, using these methodologies (survey, interview, etc.) may not provide the assessable data that would achieve the objectives of this study. Therefore, this study used Concept Mapping/Pattern Matching (CM/PM) as the methodology for collecting and analyzing the research data.

The use of CM/PM allows people to describe and share their experiences and beliefs individually and within a group of stakeholders at the same time (Chomey, 1994). In her study, Conceptualizing Feminism: Clarifying Social Science Concepts, Linton (1989) mentioned that concept mapping is a powerful methodology that allows miscellaneous perspectives of people to be heard. Besides, CM/PM is a useful tool for connecting ideas to create new knowledge. Linton states that using concept mapping with females provided an opportunity for women to express their needs without judgments or limitations, ensuring that the method provided valid and more valuable statistical results.

In $\mathrm{CM} / \mathrm{PM}$, the results of each participant's sorting and rating statements have equal significance, so participants can retain their individual perceptions throughout the CM/PM process. The idea of $\mathrm{CM} / \mathrm{PM}$ is to select a group of stakeholders in order to generate a number of 
statements/ideas related to the research or evaluation topic throughout a brainstorming session.

The statements will be sorted and rated so that they can be classified into piles based on similarity in either wording or ideas. Further, CM/PM is a "type of structured conceptualization" (Trochim, 1989a, p. 1) that uses a process by which "ideas are represented in the form of a picture or map" (p. 1) to define the relationship between theory and practice.

From the outset, it was important to establish: 1) that the concept mapping process provided an accurate representation of what people were thinking (i.e. reliability and validity); and 2) that the concept maps could be integrated into scientific theory building and experimentation (Trochim, 1989b, p. 105-106).

Furthermore, Kane \& Trochim (2007) in their book, Concept Mapping for Planning and Evaluation, elucidates that Concept Mapping/Pattern Matching has been a useful tool in strategic planning and evaluation. Trochim (1989a) defined the concept map as:

A pictorial representation of the group's thinking which displays all of the ideas of the group relative to the topic at hand, shows how these ideas are related to each other and, optionally, shows which ideas are more relevant, important, or appropriate (p. 2).

In other words, using $\mathrm{CM} / \mathrm{PM}$ is beneficial when looking at consensus and consistency over time among stakeholders. The use of $\mathrm{CM} / \mathrm{PM}$ as a research methodology in planning or evaluating is advantageous because (Trochim, 1989b):

First, it encourages the participant group to stay on task and to lay out relatively quickly a framework for a planning or evaluation study. Second, it expresses the conceptual framework in the language of the participants rather than in terms of the evaluator or planner's language or the language of social science theorizing. Third, it results in a graphic representation, which at a glance shows all of the major ideas and their 
interrelationships. Fourth, this graphic product is comprehensible to all of the participants and can be presented to other audiences relatively easily. Finally, we have observed over many concept mapping projects that one of the major effects of the process is that it appears to increase group cohesiveness and morale. Especially in groups which have previously tried to accomplish conceptualizing through committee discussions, we have found that they readily appreciate the structure of the process and the ease with which it produces an interpretable starting point for subsequent evaluation or planning work (p. 19-20).

For the purposes of this study CM/PM, has been selected to develop a conceptual framework of the future ideal functions of the PYP at KSU for several reasons:

1- $\mathrm{CM} / \mathrm{PM}$ allowed stakeholders, both male and female, to describe their experiences, needs, and perception about the Preparatory Year Program without limitations or judgment of their ideas.

2- The outcomes of the CM/PM process, especially the phase of sorting and rating statements, resulted in a list of statements that were used for developing an Ordinal-type survey, which was used to identify the development dimensions of the PYP at KSU and may be used in a different context in Saudi universities in the future.

3- The outcomes of CM/PM provided a report to policymakers about the stakeholders' perceptions and needs, not only what the university seeks to achieve with students.

4- Using CM/PM increased the validation of the study's outcomes.

5- Besides the validity of the CM/PM approach as a research tool to conduct this study, this study is considered the first one in Saudi educational context to use the CM/PM process and also using the Arabic language for generating statements. Using the CM/PM 
methodology in the Arabic language was a challenge, where the researcher made immense efforts to ensure the methodology's quality and validity in different contexts. Further, the translation process mentioned later in this chapter was time consuming but will help other researchers use the CM/PM methodology in an Arabic context in the future.

The six phases of the CM/PM methodology below aimed to obtain inputs from the groups of stakeholders including: the PYP and KSU's faculty, PYP's students, parents, members of the business sector, representative for the PYP and KSU's students and academic affairs, and PYP's administrators, because they all have an interest in the Preparatory Year Program.

Phase 1: Preparation. The Preparation Phase is considered the most important phase in the CM/PM process (Kane \& Trochim, 2007). This phase has two major activities: selecting the participants for both groups of stakeholders, male and female, and defining the research problem and the focus prompt for brainstorming sessions (1989b). The Preparation Phase is also "driven by the goals and desired outcomes" (Kane \& Trochim, 2007, p. 27). As the purpose of this study was to develop a conceptual framework of the Preparatory Year Program, which includes the future ideal functions of the program that can make students' transition into postsecondary education successful. The guiding question used for brainstorming sessions was 'What programs, services, and activities should guide the functions of the Preparatory Year Program?' This guiding question deliberately avoided limiting responses to participants' outcomes. The reason was that while participants' outcomes can help develop the PYP's functions, they do not demand that participants discuss $H O W$ these developmental statements are manifested. For that reason, this guiding question focuses on how the Preparatory Year Program can be developed. 
As this study was conducted at Preparatory Year Program at King Saud University, the researcher communicated with the PYP's dean and got his permission to conduct the study (see Appendix A) and is also considered as preretirement for the Institutional Review Board (IRB) to apply for its approval. For participants' selection, Trochim (1989b) states, "the scenario with which concept mapping is applied assumes that there is an identifiable group responsible for guiding the evaluation or planning effort" (p. 2). Two separate groups, female and male, made up the stakeholder/participants' groups, which vary widely, were invited to participate in the brainstorming sessions and each group consisted of KSU and PYP's faculty, students, parents, representative of the business sector, student affairs, academic affairs, and KSU and PYP's administrators. There were 20 females and 20 males asked to participate in the brainstorming sessions and the number of participants identified were based on participants' responses to a formal invitation and to what extent they were willing to participate in the study. More details will be provided about participants later in this chapter.

Besides the statement generating activity in the brainstorming sessions, the participants were asked to sort all generated statements into piles based on similarity from their perceptions. Additionally, they were asked to rate each statement based on importance and efficacy levels. "It is essential that the focus for both the brainstorming and the ratings be worded as statements which give the specific instruction intended so that all of the participants can agree in advance" (Trochim, 1989b, p. 5). For the male group, the brainstorming session was conducted face-toface, and for the female group, the session was conducted remotely through videoconference technology within King Saud University's network. "With the advent of better communications technology and the Internet, it has become possible and often desirable for stakeholders to generate ideas remotely as part of a concept mapping process (Kane \& Trochim, 2007, p. 54). 
However, the researcher took into account that "unlike on-site brainstorming, which facilitates high levels of participation, remote brainstorming is generally subject to a much lower response rate" (p. 54).

The two brainstorming sessions were conducted on two different days; the male session took place on October 27, 2015 and the female session was on October 28, 2015. However, the researcher developed a communication plan with the stakeholder groups using their emails to inform and explain the research project and its goals, and to obtain their agreement in advance. Along with selecting comfortable locations, an appropriate time for all stakeholders to participate was scheduled.

Phase 2: Generation of Statements. Phase two of CM/PM was a crucial part of the study, due to the participants meeting to generate statements/ideas. The guiding question mentioned in Phase 1 was used to prompt both groups for statement generation. This phase also requires professional management where the researcher needs to clarify that participants can express their ideas without fear of criticism or questions regarding the relevance to the topic, especially students who participated alongside faculty and administrations staff members, to avoid any potential power dynamics in statement generating (Trochim, 1989a; Kane \& Trochim, 2007).

Two facilitators one male and one female, helped to manage the process of statement generation. The researcher identified specific roles for them and did not exceed on printing statements on the computer and showed them on the screen for all participants. Supplies, refreshments, and snacks were provided to the participants as needed. The facilitators did not engage in discussions or statement judging. Kane and Trochim (2007) recommended that the researcher "assign people to coordinate the remote brainstorming process" (p. 55). Since the 
female session was conducted remotely, the researcher assigned a female facilitator to ensure a successful session. For both facilitators, the researcher provided short training about the CM/PM and study process, along with providing written tasks.

Moreover, the researcher provided participants with instructions with clear justification of the importance of the procedure and informed both groups about the number of statements limit, which would be a maximum of one 100 statements/ideas regarding the Preparatory Year Program development. As "theoretically, there is no limit to the number of statements that can be processed" (Kane \& Trochim, 2007, p. 11). For a final set of statements, selecting 100 statements as a maximum was based on Kane and Trochim's suggestion, “On the basis of our experience, we typically limit the final set of statements to 100 or fewer. This enables breadth of representation of contributed ideas while providing sorting and rating participants with manageable tasks to complete" (p. 11).

Finally, the researcher managed the session to keep the discussion on the track and keep participants focused on the focus prompt to ensure that the sessions progress was maintained. The researcher and facilitators recorded each statement as it was produced; with the last statement generated, the whole group made the final revision of statements/ideas for clarification and understanding (Trochim 1989b). Respectively, the males created 48 statements and the females created 36 statements.

Phase 3: Structuring of Statements. In this phase, each statement was printed out on a separate card and assigned a specific number, and each participant received a copy of all the revised statements. For the male group, each participant received a complete set of 48 cards and the female group received 36 cards. The participants also completed the second activity, statements sorting, which included placing statements/ideas in piles depending on sorting criteria 
and similarity "in a way that makes sense to you" (Trochim, 1989b, p. 7). The participants sorted their sets of statements/ideas individually and independently, which informed how these statements/ideas were interrelated. In addition, some instruction was provided, such as "all statements cannot be put into a single pile and each statement can be placed in only one pile" (Kane \& Trochim, 2007, p. 72). By the end of this activity, each participant had a unique set of data as a result of his/her activity.

Next, participants were asked to record their sorting on a recording sheet that was provided to them at the session. The results of the individual sorting were recorded on a "binary symmetric similarity matrix" (Kane \& Trochim, 2007, p. 91) to demonstrate an assortment of statements for each member's group and to a "combined group similarity matrix" (p. 92). "This final similarity matrix is considered the relational structure of the conceptual domain because it provides information about how the participants grouped the statements" (Trochim, 1989b, p. 8). In other words, the similarity matrix exposed how many participants recorded a pair of statements/ideas in the same pile/cluster.

A week after the sorting activity, the researcher administered the last activity in the Structuring of Statements Phase. Two separate emails were sent to each group of participants including a link to an online survey on Qualtrics Survey, an Internet-based data collection tool, showing the list of statements using an Ordinal 1-5 scale (see Appendixes B \& C). The purpose of this activity was to measures: 1) the relative importance of each statements; and 2) the degree of its efficacy to the Preparatory Year Program at King Saud University (Kane \& Trochim, 2007). The rating activity is important because the arithmetic mean of the ratings results provides a valuable statistical information regarding each statement that used later for Pattern Matching analysis (Kane \& Trochim, 2007; Trochim, 1989b). 
Phase 4: Analysis and Representation of Statements. The Analysis Phase began with data collected from the Structuring of Statements Phase and ended with a set of materials such as listing of statements, CM/PM points maps, and pattern matching for comparison. The Analysis Phase implements "three steps in the core analysis to compute maps for the conceptual domain:

1. Create similarity matrix from sort data.

2. Multidimensional Scaling [MDS].

3. Hierarchical cluster analysis of the Multidimensional Scaling [x,y] coordinates to partition the point [statements] on this map into groups" (Kane \& Trochim, 2007, p. 87). The analyzing process was conducted separately for each group, female and male. The analyzing process used advanced statistical techniques to answer research questions. Each statement was numbered and placed on the point maps using Multidimensional Scaling Analysis (MDS) nonmetric, "a general technique that represents any similarity or dissimilarity matrix in any number of dimensions as distances between the original items in the matrix" (Kane \& Trochim, 2007, p. 93). The MDS of the similarity matrix was used "to locate each statement as a separate point on a two-dimensional (X,Y) map" (p. 87). On an X,Y axes, statements that are similarly organized into one group create a cluster due to their close proximity, while statements that are not similar are located further away from each other. However, "In concept mapping, we are typically more interested in the map not for its dimensions but for its relationality—its ability to portray the relationships among the statements in terms of distance or proximity." (p. 96). Therefore, the two-dimensional $(\mathrm{X}, \mathrm{Y})$ was used to create the point map.

The point map created by MDS was converted to a clusters map using the Hierarchical Cluster Analysis (HCA) with Ward's method as Kane and Trochim (2007) recommended, and "simply consists of dots representing the statements, each of which is identified by its 
corresponding number." (p. 96). The HCA analysis used the process of dividing "groups individual statements on the point map into clusters of statements that aggregate to reflect similar concepts" (Kane \& Trochim, 2007, p. 98). Further, the HCA analysis revealed several possible clusters solutions that ranged between 3 to 10 clusters. A close examination to all these possible solutions and its statements, and by using the cluster point map and its Dendogram Tree (see Appendixes D \& E) the researcher and the CM/PM expert who served as a committee member of the dissertation, selected the final clusters numbers for this study for each group.

Determining the final clusters numbers involved both subjective and objective aspects because the researcher used the statistical approach to identify clusters ranges and a subjective perception to select and justify the final number of clusters used in the study. The clusters points map and Dendogram presented the relationships between brainstormed ideas/statements based on Multidimensional Scaling place statements. The clusters map also shows how statements are grouped by the cluster analysis (Kane \& Trochim, 2007).

Furthermore, Trochim (1989b) and Kane and Trochim (2007) recommended the utilization of Pattern Matching as a measurement tool to compare and contrast clusters or individual statements. Pattern Matches uses "Graphs [in] comparing the absolute or relative cluster ratings, between rating variables, demographic groups, or points in time" (Kane and Trochim, 2007, p. 116). Pattern Matching "generally uses what is known as a ladder graph representation, showing lines connecting cluster rating values on a pair of absolute or relative scales" (p. 126). However, for the purpose of this study the Pattern Matches used to compare and contrast the importance and efficacy of each cluster is based on the results of stakeholders' ratings. 
As each cluster contains a different set of features, programs, and activities, this comparison helped to understand how stakeholders conceptualize future ideal functions of the Preparatory Year and which function they see as the most important in their point of view. The Pattern Matching analysis was conducted through collecting the mean of each cluster based on each participants rating based on a 5-point Ordinal scale (Kane \& Trochim, 2007).

Phase 5: Interpretation of Maps. "The purpose of creating maps is to create insight to present ideas within a conceptual framework that clarifies the views of the group as a whole and enables them to use these results in ways that will change or measure something of interest to them" (Kane \& Trochim, 2007, p. 111). The primary concept mapping materials needed for the interpretation session contains six products:

1. The Statement List. The original list of brainstormed statements, each of which is shown with an identifying number.

2. The Cluster List. A listing of the statements as they were grouped into clusters by the cluster analysis.

3. The Point Map. The numbered point map, which shows how Multidimensional Scaling (MDS) placed statements.

4. The Cluster Map. The cluster map, which shows how the cluster analysis grouped statements.

5. The Point Rating Map. The numbered point map with average statement ratings overlaid.

6. The Cluster Rating Map. The cluster map with average cluster ratings overlaid (Kane \& Trochim, 2007, p. 115).

Trochim (1989b) and Kane and Trochim (2007) identify several steps to complete this task of CM/PM. The researcher should provide some supplies such as envelops, pens, papers, 
etc. also, each participant was given a copy of all statements generated in the brainstorming session. Then, they were given a copy of the clusters list that was resulted from the sorting task that was applied in Phase 3 of CM/PM statements structure. In the next step, each participant was asked to review each statement within the clusters list and suggest a name or label that they could use to express cluster components, this task could be done within group discussion to make a consensus about the final name of the cluster. After determining all the clusters names, a copy of the point map and cluster map was provided and participants wrote the agreeable name on each cluster. "This final named cluster map constitutes the conceptual framework and the basic result of the concept mapping process" (Kane \& Trochim, 2007, p. 122).

Finally, Kane and Trochim (2007) suggest several solutions for the Interpretation Phase including Pattern Matches, Go Zone, and Stress Point. For this study, the interpretation was limited to the CM/PM maps and Pattern Matching technique, which allowed for "a comparison of average cluster ratings between two variables" (Kane \& Trochim, 2007, p. 19).

Phase 6: Utilization of Maps. At this phase of CM/PM, the researcher and participants are responsible to identify "how the final concept map might be used to enhance either the planning or evaluation effort" (Trochim, 1989a, p. 12)". Kane and Trochim (2007) state:

For planning, these results might be used for structuring the subsequent planning effort or as the framework for an outline of a planning report. In evaluation, the concept map, pattern matching, and go-zones can act as an organizing device for operationalizing and implementing the program, as a guide for measurement development, or as a framework for examining patterns of outcomes (p. 14).

The $\mathrm{CM} / \mathrm{PM}$ could be used for evaluative or planning purposes depending on the research determination. However, Kane and Trochim (2007) identify four uses of CM/PM for planning: 
(1) for organizing for action or program planning; (2) for organizing needs assessment; (3) for organizing report writing; and (4) for organizing data synthesis and presentation (p. 155). For the purpose of this study, in particular, the CM/PM outcomes are used for the purposes of planning or development.

This study focused on how the key stakeholders conceptualized the future ideal functions of the Preparatory Year at King Saud University. This study showed how the conceptualization of the functions that were generated through the $\mathrm{CM} / \mathrm{PM}$, male or female, compared and contrasted with the KSU strategic plan and the current practices of the PYP. This study's goal was to develop a conceptual framework of the future ideal functions of the Preparatory Year Program. Due to the nature of this research project, the utilization of the CM/PM maps, reported with the discussion and recommendation section in Chapter 5, were used to develop the conceptual framework of the PYP that was based on the outcomes and stakeholders' conceptualizations.

\section{Participants}

"Identifying the participants in a concept mapping process is one of the most important tasks" (Kane \& Trochim, 2007, p. 10). The key stakeholders' selection is related to the study's goals and desired outcomes. Kane and Trochim state, "a conceptualization is best when it includes a wide variety of relevant people" (p. 35). For example, in the current study, the relevant groups consisted of participants who have interests revolving around the future functions of the Preparatory Year Program at King Saud University including KSU's and the PYP's faculty, students, parents, representative of the business sector, student's affair, academic affairs, and KSU and PYP's administrators either male or female. 
Heterogeneous participation helps to ensure the consideration of a wide variety of viewpoints; provides more information for the statistical analyses, thus improving the clarity and resolution of the maps; and encourages a broader range of people to "buy into" the resulting conceptual framework. (Kane \& Trochim, 2007, p. 35)

The number of participants in Concept Mapping/Pattern Matching approach is open. In other words, there is "no strict limit on the number of people who can participate in concept mapping” (Kane \& Trochim, 2007, p. 36). Further, Kane and Trochim suggest 40 or fewer participants with a minimum of 10 participants in the brainstorming session, in some research projects, small groups of 8 to 15 participants is enough to conduct CM/PM.

For the current study, the researcher created two separate groups of stakeholders, male and female. The suggested number of participants in each group is 20 participants. The researcher will make an effort to ensure similarity of participants' characteristics in both groups. For example, having an interest or responsibility in the Preparatory Year Program, educational background, etc.

The composition of each group was 20 participants were invited as follows: four Preparatory Year students, two parents, six Preparatory Year administrators and faculty, one faculty from the Medicine College, one faculty from the Engineering College, one faculty from the Humanity College, one faculty from the community college, one representative of the business sector, one representative of educational companies operating Preparatory Year, one representative of the university's student affairs, and one representative of the university's academic affairs. Only 14 males and 9 females agreed to participate in the study, but this number was enough to conduct this study (Kane \& Trochim, 2007). 


\section{Data Collection}

For this study, the data collection process followed Trochim's (1989b) and Kane and Trochim's (2007) six steps of Concept Mapping/Pattern Matching explained previously in this chapter. The researcher developed a communication plan using an email list and phone numbers to communicate with participants and to explain the study's process and objectives.

In addition, the researcher hired two facilitators, male and female, to help manage the process of data collection during the brainstorming sessions and identified their roles. For each group of participants, the researcher reserved a meeting room in a comfortable environment while taking privacy into account for the female group. For the male group, the room was in the main building of the Preparatory Year Deanship and the room included tables, data-show, computers, refreshments, and all supplies needed. The female room was in the Preparatory Year Deanship-female section. Also, all facilitation required was provided (Kane \& Trochim, 2007; Trochim, 1989a).

Furthermore, the videoconference within the King Saud University network was used to manage the females brainstorming session. Moreover, office supplies such computers, projector, papers, pens, etc. were provided. Since the brainstorming sessions and sorting sessions took approximately 3 hours, refreshments and snacks were also provided. One week later, the researcher emailed each group of participants a specific link including a survey created on Qualtrics an Internet-based survey to rate generated statements based on a 5-point Ordinal scale.

\section{Treatment of the Data}

Kane and Trochim (2007) and Trochim (1989a, 1989b) suggested some options that could be used for data treatment. The first option was a Concept System software that was 
designed by Trochim and associated purposefully for the CM/PM, in particular. The system designs were based on the six phases of CM/PM. The system requires a license to use.

The second option was suggested by Kane and Trochim (2007) and Trochim (1989a, 1989b), to use a widely available software such as Microsoft Word, Microsoft Excel, WordPerfect, SAS, and SPSS. For this study, the researcher preferred option two due the affordability, availability, and accessibility of these software. For statements generated through the brainstorming session, Microsoft Word and Microsoft Excel were used to edit, organize, and prepare sorting data for the next step of data analysis on the SAS software. The SAS (version 9.3) statistical software was used to generate a Multidimensional Scaling (MDS) and to create a group similarity matrix for each group independently. Finally, the SPSS Statistics (version 23) was used to run a Hierarchical Cluster Analysis (HCA) for each group of participants, male and female, separately. More details regarding these software results are provided in Chapter 4.

\section{Translation Process}

The brainstorming sessions were conducted in the participants' native Arabic language. The literature provides several techniques to translate text among different languages from or to English. Squires et al. (2013) state that:

Researchers generally tend to focus on the technical aspects of language translation and use only forward and back translation... Brislin's (1970) decentering method is perhaps the best known translation method. It emphasizes the semantics and technical aspects of translation during the forward and back translation process. (p. 2)

Therefore, the researcher decided to use the cross-culture, forward-backward translation process developed by Brislin (1970) with subjective, objective, and pilot assessment tests, which were utilized to ensure the quality of the process and measurement in terms of validation and the 
functional correspondence between the English and Arabic versions of Concept Mapping/Pattern Matching Outcomes.

To reduce the discrepancies between the original version of $\mathrm{CM} / \mathrm{PM}$ generated statements developed in the Arabic language and the new version created in the English language, essential main steps that the researcher should take into his/her account to ensure translation quality area as follows: (a) A bilingual person has a knowledge or experience about a topic understudy to perform translation from the source language document (Arabic version) into the target language (English version); (b) a second bilingual person has no information about the original document (Arabic version) to perform translation from target language (English version) to the original language (Arabic version); (c) comparing and contrasting both versions; and (d) in case of indispensable differences appear between the two versions, Arabic and English, correction and another round of translation should be repeated to reduce the discrepancies (Behling \& Law, 2000).

For this study, two bilingual persons fluent in the Arabic and English languages were used to help with the translation process. One is faculty member at King Saud University in the Linguistic College located in the English Department. The other translator is an international Ph.D. graduate student from the University of Missouri in the Education Department. The Ph.D. graduate is also a certified translator between Arabic-English-Arabic. The common factor between the two chosen translators is their native language of Arabic and that they are both working in higher education at universities (see Appendix F). The researcher applied several steps to translate the $\mathrm{CM} / \mathrm{PM}$ generated statements from the Arabic to English language as following: 
1- All Arabic statements were transcribed verbatim into the computer. Each statement took the same number allocated during the Sorting Phase of CM/PM. Two separate sheets on Microsoft Excel software, one for male and one for female, were created.

2- The list of all statements translated from Arabic to English by the researcher was created, and this was the first version of translation from Arabic to English.

3- The only English version of translation (Arabic) for both sheets female/male was sent to two bilingual persons to confirm the accuracy of translation to English. The original Arabic source was excluded where the researcher did not send it to the interpreters. Then, both interpreters were asked to translate the English version back into Arabic and make any necessary corrections on the English version.

4- The interpreters sent their version from English-Arabic including their feedback. All highlights and edits on the English version were also received. The interpreters also asked questions to clarify issues regarding terminology in the Arabic version and its consensus with the English version.

5- The researcher matched the interpreters' versions (Arabic version) with the original Arabic version. Some differences were observed, and discussion occurred to improve translation.

6- The researcher met one of the committee members who was a specialist in higher education to discuss terminologies, and also to clarify its meaning in English and to conform it correspondence to the Arabic language. For example, students' academic placement translation from Arabic to English or vice versa may give different meanings and the researcher does not understand the accurate meaning for the terminology in both languages. 
7- A new English version of the translation was created and included all comments and notes.

8- The interpreters were asked to match and confirm the accuracy of the original Arabic version with the last English version developed. Several rounds of correspondence were done until all parties reached a consensus between the Arabic and English versions for all 48 statements from the male group and 36 statements from the female group.

9- To enhance the validity of the last version of the English translation, two faculty members from the group of stakeholders who participated in the brainstorming session, one male and one female, were asked to double check the translation to ensure translation quality, clarity, and accuracy.

Although the forward-backward translation process used in this study was time consuming to complete for 84 total statements, it was worth it (see Appendixes $\mathrm{G} \& \mathrm{H}$ ).

\section{Limitations of the Methodology}

1- $\mathrm{CM} / \mathrm{PM}$ literature exposed several general limitations regarding CM/PM methodology illustrated by Kolb and Shepherd (1997) in their study: Concept Mapping Organizational Cultures. Four main themes may cause limitations for CM/PM reporting: (1) concern about reliability of CM/PM outcomes in case of repeating the study with different stakeholder groups; (2) validity of CM/PM for theory test or for comparative studies; (3) as $\mathrm{CM} / \mathrm{PM}$ has several processes, the Sorting and Rating Phases may cause confuse for participants; and (4) arranging CM/PM process particularly the brainstorming session, sorting, rating, and interpretation phases are considered a challenge, especially with a large sample size. However, Michalskia and Cousins (2000) state that "from a wider perspective none of these limitations should be construed as fatal flaws". 
2- There is a potential power dynamic at play in the brainstorming portion of the methodology. Students may feel reluctant to speak candidly in the presence of high-level officials. Employees may feel reluctant to speak candidly in the presence of supervisors, etc. However, to reduce this limitation affect: (a) in the brainstorming session, the researcher prompted all participants to speak up with no fear or criticism; (b) the prompt is not designed to elicit criticisms, but instead to elicit ideal characteristics; and (c) the sorting and rating is done individually by each participant. Therefore, at this stage each individual participant has an equal opportunity to anonymously influence the study's outcomes. 


\section{Chapter Four}

\section{Result}

The purpose of this chapter is to report the results of data collection and analysis for both groups of stakeholders who participated in the study. Results for females and males are addressed separately as they relate to the research questions.

This chapter contains eight sections, starting with a brief review of the purpose of the study and research questions. The second section describes the population employed in the study. The third section addresses the first three steps of CM/PM, namely preparation, generating statements, and structuring the statements. In the fourth section, data analysis of the $\mathrm{CM} / \mathrm{PM}$ process is reviewed, including representation of the statements and interpreting the maps, and applying the survey results to the $\mathrm{CM} / \mathrm{PM}$ results. The fifth section analyses how the results inform research question 1 . The sixth section explores document analysis results as they relate to research questions $1 \mathrm{a}$ and $1 \mathrm{~b}$. In the seventh section, comparison and contrasts are made for the results of $\mathrm{CM} / \mathrm{PM}$ for males and females. The final section clarifies the limitations of the study.

\section{Purpose of the Study and Research Questions}

The purpose of this study was to identify the future functions of the Preparatory Year Program (PYP) needed to help first-year students successfully transition into college/university at King Saud University (KSU).

To accomplish this goal, the researcher studied two groups of stakeholders, males and females, separately. Each group included KSU and PYP's faculty, students, parents, representatives of the business sector, Student Affairs, Academic Affairs, and KSU and PYP administrators. Studying two separate groups of stakeholders was due to the segregation protocols for female and male education within Saudi higher education. It is important to note, 
however, that gender issues were not the primary focus of this study. Instead, gender separation defines the context of how Saudi postsecondary education occurs.

These two groups were solicited to participate in two separate brainstorming sessions using the Concept Mapping/Pattern Matching (CM/PM) methodology advanced by William Trochim (1989a, 1989b, 2007). Following the creation of the two concept maps by the study's participants, the resulting priorities and their conceptualization schemas were compared and contrasted with: 1) the current working model of the Preparatory Year Program at King Saud University; 2) with King Saud University’s explicit strategic plan, KSU2030; and 3) with female and male perceptions. This study answered the follow questions:

RQ1: Using the Concept Mapping/Pattern Matching methodology, how do Saudi male and female postsecondary stakeholders conceptualize the future ideal functions of the Preparatory Year Deanship to help students successfully transition into their first year of college/university?

a: Does this Concept Mapping/Pattern Matching conceptualization compare and contrast with the current working model of the Preparatory Year Program at King Saud University?

b: Does this Concept Mapping/Pattern Matching conceptualization compare and contrast with King Saud University’s explicit strategic plan?

RQ2: When conducting a Concept Mapping/Pattern Matching conceptualization, how do the results for males compare and contrast with the results for females?

\section{Description of the Sample}

"Identifying the participants in a concept mapping process is one of the most important tasks" (Kane \& Trochim, 2007, p. 10). The key stakeholders' selection was related to the study's goals and desired outcomes. Kane and Trochim state, "a conceptualization is best when it 
includes a wide variety of relevant people" (p. 35). In this study, the relevant groups consisted of participants who have interests in the future functions of the Preparatory Year Program at King Saud University and have experience with the current working model of the program. These include KSU and PYP's faculty, students, parents, representatives of the business sector, Student Affairs, Academic Affairs, and KSU and PYP's administrators, either for the male or female stakeholders populations.

Heterogeneous participation helps to ensure the consideration of a wide variety of viewpoints; provides more information for the statistical analyses, thus improving the clarity and resolution of the maps; and encourages a broader range of people to "buy into" the resulting conceptual framework. (Kane \& Trochim, 2007, p. 35)

The number of participants in the Concept Mapping/Pattern Matching approach is open to a range of possibilities. In other words, there is "no strict limit on the number of people who can participate in concept mapping" (Kane \& Trochim, 2007, p. 36). Kane and Trochim suggest 40 or fewer participants with a minimum of 10 participants in the brainstorming session or in some research projects, small groups of 8 to 15 participants is enough to conduct CM/PM like this study.

For the purpose of this study, the researcher created two separate groups of stakeholders, male and female. The researcher planned to employee 20 participants for each group. A large effort was made to ensure the similarity of participants' characteristics in terms of: (a) having an interest or responsibility in the Preparatory Year Program at King Saud University; (b) working in the program or with its students; (c) desiring to participate in the study; and (d) having insights in developing the program. 
The researcher made an effort to involve participants from different backgrounds in the program including the PYP's students, parents, administrators and faculty, faculty from the Medicine College, Engineering College, Humanity College, and community college, representatives of the business sector, representatives of educational companies operating the Preparatory Year, representatives of University Student Affairs, and representatives of University Academic Affairs. Furthermore, all faculties from KSU's colleges who participated in the brainstorming session had a responsibility with First-Year students or worked as coordinators for the PYP at their colleges. In general, all groups of participants have experience with the PYP at King Saud University.

The researcher initially identified 40 individuals affiliated with the PYP at KSU, 20 male and 20 female, based on the criteria presented above. An official invitation letter was sent to all participants in both the Arabic and English languages (see Appendix I) in the fall semester of 2015 for their permission to participate in the study. Participants were contacted via phone, email, or in person. The result of communication with participants resulted in a list of 20 females and 20 males, including KSU and PYP's faculty, students, parents, representatives of the business sector, Student Affair, Academic Affairs, and KSU and PYP's administrators. Out of the 40 volunteers, 9 females and 14 males were able to attend the brainstorming sessions. Some of the participants who did not attend provided an excuse due to their personal circumstances while others did not justify their absences.

However, 9 female and 14 male participants completed the sorting task during the two sessions, as well as completing the rating task a week later. The group of females included one Pharmacy College faculty, two Preparatory Year Program faculty, two Parents, one Educational Company, and three PYP students. The male group consisted of one Medicine College faculty, 
one Business Administration College faculty, one Engineering College faculty, four Preparatory Year Program faculty, one Academic Advising at PYP, one Student Affairs personnel at KSU faculty, one Student Affairs personnel within the PYP faculty, two Educational Company representatives, and two PYP students. The CM/PM can be done with a small sample size, and considering the typical number of participants recommended for CM/PM mentioned earlier, the number of participants was representative and acceptable by the researcher in this study (Kane \&Trochim, 2007; Trochim, 1989a, 1989b).

Moreover, since the nature of this study was to use the CM/PM methodology for development purposes, this sample size was enough (Kane and Trochim, 2007). A nonrandom and purposive sampling process was utilized in this research. The purposive sampling "can provide the best information to achieve the objectives of your study. You as a researcher only go to those people who in your opinion are likely to have the required information and be willing to share it with you" (Kumar, 2005, p. 189). Furthermore, "Purposeful sampling is widely used in qualitative research for the identification and selection of information-rich cases related to the phenomenon of interest" (Palinkas, Horwitz, Green, Wisdom, Duan, \& Hoagwood, 2015, p. 1). The purposive sampling used in this study made participants' insights meaningfully related to the topic under study. Table 1 shows the number of participants in each group according to their role.

Table 1

Participants in the Concept Mapping/Pattern Matching Brainstorming Sessions and Statement Sorting and Rating Tasks by role

\begin{tabular}{cclcc}
\hline Group & Number & Participant Role & Percent (100\%) & Total \\
\hline \multirow{4}{*}{ Male } & 2 & PYP students & 14.29 & \\
& 1 & Medicine College Faculty & 7.14 & 14 \\
& 1 & Business Administration College Faculty & 7.14 & \\
& 1 & Engineering College Faculty & 7.14 &
\end{tabular}




\begin{tabular}{|c|c|c|c|c|}
\hline & 4 & PYP Faculty & \multicolumn{2}{|l|}{28.57} \\
\hline & 1 & Academic Advising Faculty at PYP & \multicolumn{2}{|l|}{7.14} \\
\hline & 1 & Student Affairs Faculty at KSU & \multicolumn{2}{|l|}{7.14} \\
\hline & 1 & Student Affairs at PYP & \multicolumn{2}{|l|}{7.14} \\
\hline & 2 & Educational Company & \multicolumn{2}{|l|}{14.29} \\
\hline \multirow{5}{*}{ Female } & 3 & PYP students & 33.33 & \multirow{5}{*}{9} \\
\hline & 1 & Pharmacy College Faculty & 11.11 & \\
\hline & 2 & PYP Faculty & 22.22 & \\
\hline & 2 & Parents & 22.22 & \\
\hline & 1 & Educational Company & 11.11 & \\
\hline
\end{tabular}

\section{Implementation of the Concept Mapping/Pattern Matching Process}

Phase 1: Preparation. Preparation was the first step in the process of developing CM/PM (Kane \& Trochim, 2007; Trochim, 1989b). This step consisted of two main activities: selecting the participants and developing the focus prompt question that was used in the brainstorming sessions.

As mentioned in the sample selection section, the researcher selected participants based on specific criteria: 1) she/he has a responsibility with the Preparatory Year Program (PYP) at King Saud University (KSU) such as PYP's faculty, administrators, and students or as coordinators for the PYP at different colleges at KSU; and2) have an interest in the program such as private sector, parents, and KSU's staff. After identifying the 40 potential male and female participants, official invitations were sent using email and with some cases email plus telephone. The invitation was developed in both the Arabic and English languages (see Appendix I). The cover letter (invitation) was approved by the Institutional Review Board (IRB) (see Appendix J).

Furthermore, the researcher developed a communication plane to communicate regularly with participants using email to explain the study's purpose, procedures, and their roles as participants in the research process. After getting their approval, five separate emails were sent to each participant: 1) the researcher introduced himself to the participant and defined the research 
problem and purpose and to schedule a meeting time for the brainstorming sessions; 2) described the study's procedures, potential outcomes, and the participants' roles in the research; 3) participants were notified about their right to freely participate in the study and withdraw from the study at any point without any repercussions, with no risk that would affect their status as a student or faculty at King Saud University, also the researcher informed them that their identity would not be exposed without previous approval; 4) to the researcher asked participants to complete the rating phase; and 5) letters of thanks were sent to all participants after they completed their tasks.

Furthermore, the researcher asked participants to suggest some times that fit with their schedules and some locations to meet in. One challenge that the researcher encountered was finding an appropriate time and location for the female group due to a distance between their work locations and their daily responsibilities at their colleges. Additional communication with the female sector of the university helped to overcome this challenge.

For the focus prompt question, the researcher used the following questions to guide the phase for generating statements: What programs, services, and activities should guide the functions of the Preparatory Year Program? This focus question was translated into the Arabic language and printed out on a large sized poster in both languages and displayed for participants throughout the brainstorming sessions in different locations of the meeting rooms, and was also shown on an electronic screen using a projector. Finally, by the end of the brainstorming sessions the researcher discussed the rating task and its schema, which is described later in this chapter, with the participants.

In addition, two facilitators who were faculty members from the Preparatory Year Program were identified to assist the researcher during the brainstorming sessions. The 
researcher provided short training for the facilitators to explain the CM/PM process and educate them about their roles in the brainstorming sessions. However, the facilitators' roles did not exceed beyond helping to organize the sorting tasks, printing statements on the computer, and providing necessary supplies and refreshments. Both facilitators had no roles in leading the discussion or administrating the research process. Additionally, because the female sessions were conducted remotely, the researcher made an extra effort to explain the CM/PM process and to identify her exact role with female groups facilitator. Again, both facilitators were experienced in PYP and were working within the PYP.

Lastly, two rooms were reserved for brainstorming sessions. The necessary supplies, food, and refreshments were provided for all participants to ensure their comfort. Additionally, the researcher used a Video Conference setting within King Saud University's network to communicate with the female group at the Preparatory Year's female building, since their session was conducted remotely. "Sorting and rating activities are particularly well suited to remote implementation, because they are inherently solitary activities — participants sort and rate depending on their own views and opinions of the aggregated set of ideas, so, strictly speaking, interaction with others is not necessary" (Kane and Trochim, 2007, p. 78). The researcher tested and practiced this technology two days before the session to ensure it would be appropriate.

Phase 2: Generation of Statements. This was the second phase of CM/PM. After coordinating the brainstorming sessions for two groups, male and female, the focus question, "What programs, services and activities should guide the functions of the Preparatory Year program?" was used to generate ideas and statements. "The participants generate a set of statements that, ideally, will represent the entire conceptual domain for the topic of interest." (Kane \& Trochim, 2007, p. 11). These sessions took place on two different days: the male 
session was facilitated on October 27, 2015 from 10AM to 1PM in the male section of the Preparatory Year Deanship. The female session was conducted remotely on October 28, 2015 from 10AM to 1PM in the female section of the Preparatory Year Deanship. Both locations included the necessary equipment and provided a comfortable environment in which to work. The researcher made efforts to ensure that the atmosphere was relaxing to encourage collaborative efforts among all participants.

Upon their arrival to the meeting room, the researcher welcomed and thanked the attendees for participating in the brainstorming sessions. Each participant also received another copy of the consent cover letter (see Appendix I) with a brief description about the study's purpose, the procedures, and the participants' rights. The researcher reminded the participants that anyone can withdraw at any time with no consequences on his/her situation at King Saud University. Moreover, using a projector and screen, the researcher showed a schedule for the brainstorming session procedure and a timeline for its activities.

All participants agreed on the timeline of the session and seemed to understand the directions of discussion as recommended by Kane and Trochim (2007) and Trochim (1989b). These directions involved: 1) respect each idea generated by any member of group; 2) encourage participants to express their ideas with no fear of criticism or judgment; 3) focus on the study's topic; 4) encourage questions for clarification purposes, explanation of the rules of statements recording and reviewing; and 5) understand a pre-determined maximum number of items for each group, $(n=100)$.

Using a computer and projector, the researcher and facilitators recorded and displayed each statement verbatim as the participants generated them (Kane \& Trochim, 2007). In some cases, some statements were modified slightly by participants to clarify ideas or concepts. The 
timeline for each group of participants was 2.5 hours for the generation task and a half hour for the sorting task. There was a 15-minute break after the statement generation task. As an important part of the data collection and analysis process, each statement was assigned a reference number. Before the sorting task, the researcher and group members designated some time to review and edit any statement. After revision, there were a total of 48 statements generated by the male group and 36 statements by the female group. Following the half hour break, the researcher and facilitator began the next step of CM/PM.

Phase 3: Structuring of Statements. This phase is the third step of the CM/PM process. Each participant worked independently to sort the similar statements from his/her perception together based on his/her assessment. For each group of participants, each statement was printed on a separate card, including the reference number specified for it, and each participant received a complete set of cards (i.e. 48 cards for each participant in the male group and 36 cards for each participant in the female group).

Further, each participant received a pen and two different sized envelopes: a small size10 envelope and a large packet envelope. The researcher asked each participant to sort the cards into piles "in a way that makes sense to you" (Kane \& Trochim, 2007, p. 12). Moreover, the researcher provided participants instructions for the sorting task that included: 1) each participant works independently; 2) statements could not be sorted into one pile of all items, or multiple piles of single items; and 3) each statement was to be used one time. Once the cards were sorted, the participant was asked to put each pile in separate small size-10 envelope and seal it, and record their name on it. The title the participant placed on the envelope served as a descriptor for that group of items. Next, each participant placed all small size-10 envelopes in the larger envelope, sealed it, and recorded his/her name on it. The researcher then reminded participants 
that they would be sent an email after one week that included a link to an online survey. Once again, these steps and activities were done separately for each group, male and female.

One week later, the researcher created two surveys, one for the males and one for the females. Participants in each group were asked to rate each statement they generated according to its importance and efficacy using a 5-point Ordinal Scale. Finally, the researcher thanked all the participants for their contribution to the study. The rating task was important to identify the arithmetic mean for each statement separately and for each pile. The participants were asked to rate each item on an Ordinal Scale using two questions:

1. How important is this program, service, or activity for first-year students at King Saud University? (Very Unimportant; Unimportant; Neutral; Important; Very Important).

2. Overall, how effectively does King Saud University's Preparatory Year Program facilitate this program, service, or activity? (Very Ineffective; Ineffective; Neutral; Effective; Very Effective).

The researcher could administer the survey following the brainstorming session immediately (Kane \& Trochim, 2007; Trochim, 1989b) but for this study the researcher preferred to administer the survey a week later to allow time to develop a Qualtrics Survey. After one week, 5 out of the 9 females and 8 out of the 14 males responded to the surveys. The researcher sent a reminder to all participants and gave one more week for those who did not respond in the first period. After two weeks, the total response rate was $100 \%$ for females and males. All participants rated all items fully.

\section{Data Analysis of the Results of the Concept Mapping/Pattern Matching Methodology}

Phase 4: Representation of the Statements. After receiving sorting packages from all participants in each group, the researcher created two separate files on Microsoft Excel and 
manually entered data for each group onto a spreadsheet. The file structure included four columns: 1) participant name; 2) affiliation; 3) pile name; and 4) and statement numbers. To avoid any mistakes, the researcher worked on each statement package for each participant individually. The researcher opened only one package of envelopes at a time and only worked on one small envelope size-10 to enter its items sequentially on one row including the pile name as the participant named it. To ensure there was no repetition or missing data, the researcher counted the number of statements for each participant individually and used Excel features to ensure the data entry's accuracy. For the male group, each participant should reach a total 48 statements and 36 statements for each participant in the female group.

In addition, the researcher used a mathematical technique on Microsoft Excel developed by Sanwidi (2015) to ensure correctness of data input through the sum of all items for each group. This formula was $(1+\mathrm{N}) *(\mathrm{~N} / 2)$. The $\mathrm{N}$ expressed the items number for each group, which should be a sum of 1176 for the male group and 666 for the female group. After entering each small envelope size-10 data, the researcher sealed the envelope and returned it to the large envelop and sealed it as well.

The data set of this step of CM/PM contained 69 rows, which represented the number of piles created by male participants; the large pile consisted of 27 statements and the small one consisted of two items, and the data matrix contained 69 rows and 27 columns for 14 participants. For the female group, the data matrix contained 47 rows and 23 columns for nine participants.

Note: across all this document (S) means (Statement). 
Table 2

Descriptive Analysis of Sorting Stage of CM/PM

\begin{tabular}{cccccc}
\hline Group & Participants & Items Total & Rows Total & Column Total & $\begin{array}{c}\text { Sum all Number for Each } \\
\text { Participant }(1+\mathrm{N}) *(\mathrm{~N} / 2)\end{array}$ \\
\hline Male & 14 & 48 & 69 & 27 & 1176 \\
Female & 9 & 36 & 47 & 23 & 666 \\
\hline
\end{tabular}

The data for each group, male or female, was loaded into SAS (version 9.3) statistical software. Syntax was used to create a matrix for females and males. This matrix specified how often items appeared together. Multidimensional Scaling (MDS) was then used to create a group similarity matrix for each group independently. Two similarity matrixes were created. For the male matrix, the number of rows was 48 and columns was 48 as the number of statements in this group. Similarly, the female group had 36 rows and 36 columns, which represented the number of statements. The similarity matrix value was represented by how many participants placed particular statements together in the same pile.

Multidimensional Scaling was created for each item on an X and Y coordinate. When combined with other items, the resulting 2 dimensional maps illustrate, via Euclidean distances, the relative similarity of two items as reflected by their distance from one another. The following plots, generated using IBM SPSS version 23, illustrates this for males and females (see Figures 5 \& 6). 


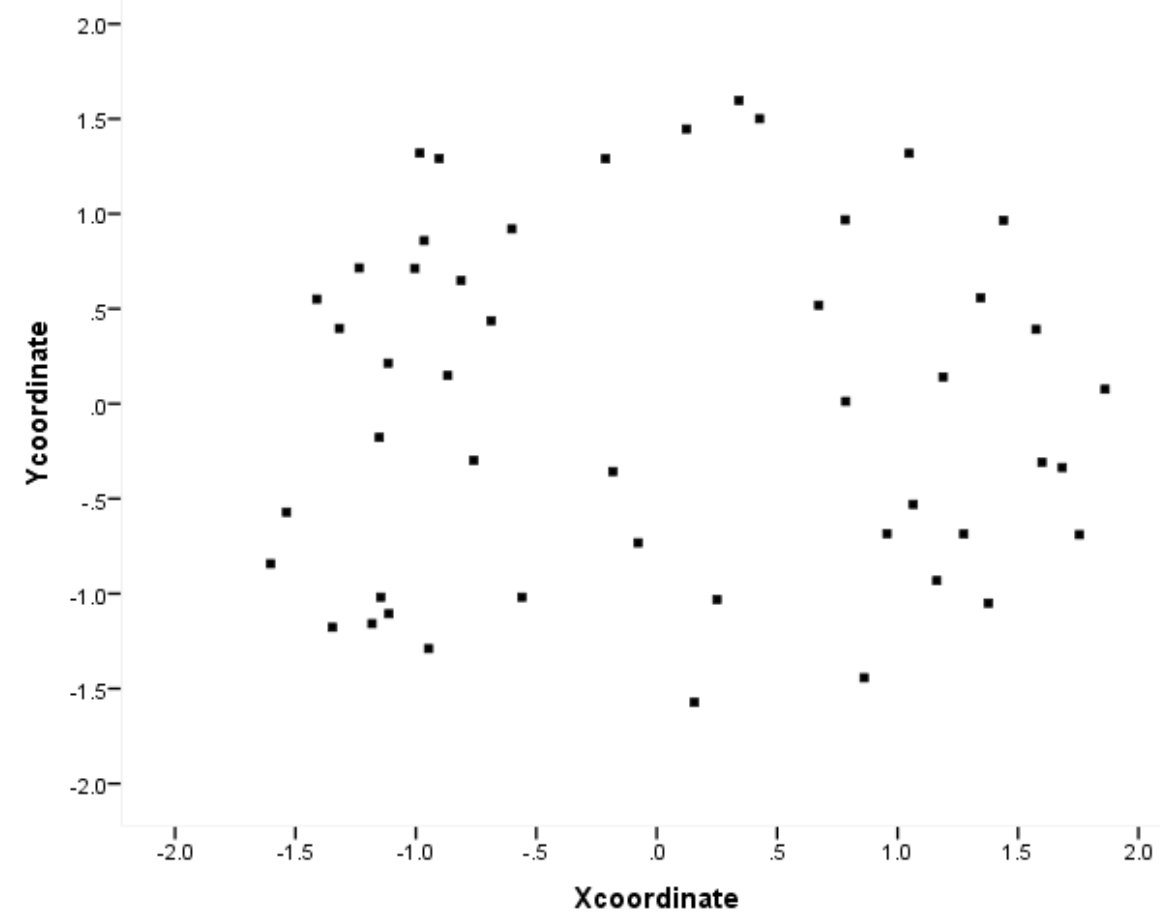

Figure 5: Point map with each point corresponding to one of the 48 statements generated by the male group.

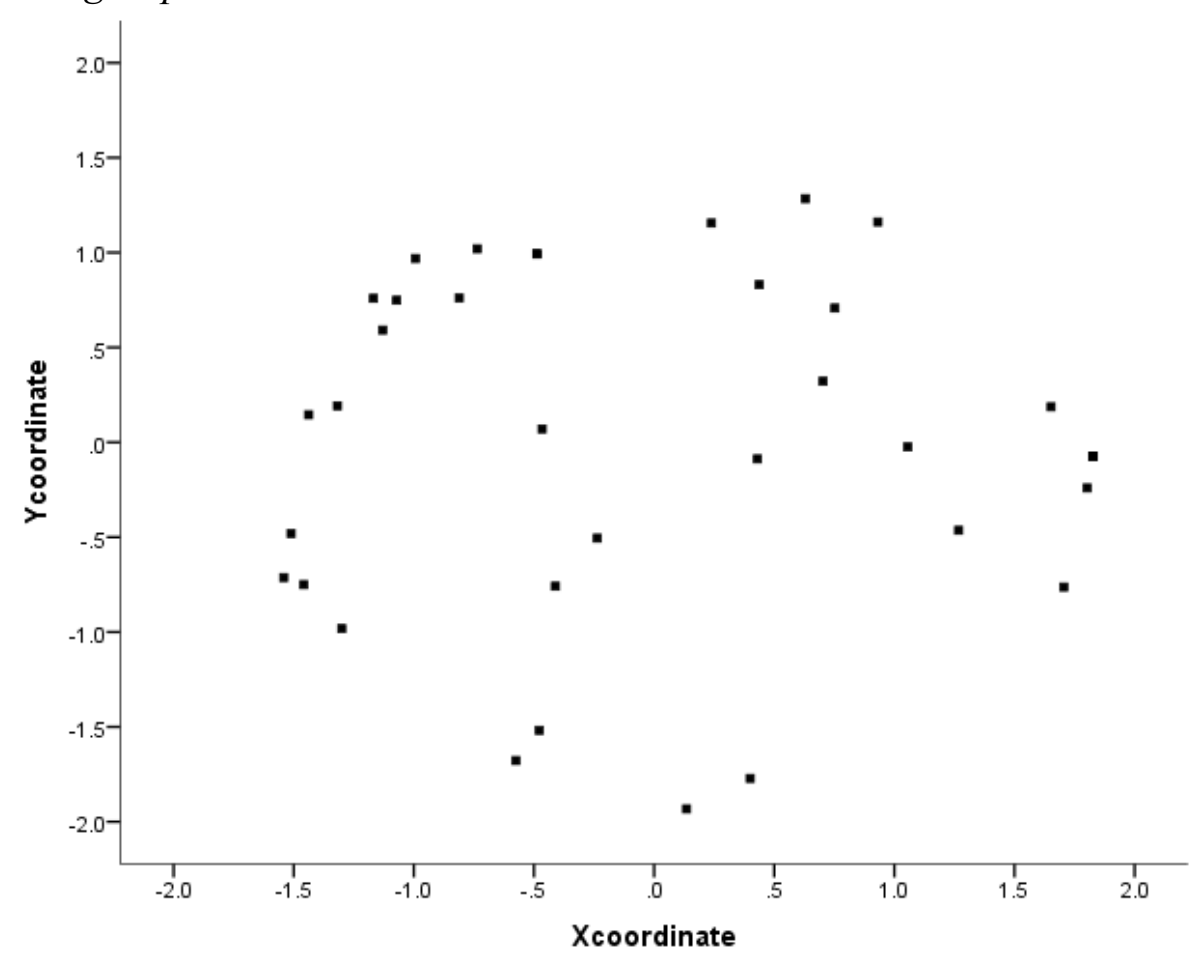

Figure 6: Point map with each point corresponding to one of the 36 statements generated by the female group. 
For the point map generated by Multidimensional Scaling (MDS), less distance between statements indicates that participants more frequently sorted these two particular items into the same pile. Statements less frequently placed into the same pile show a larger distance between them. Figures 7 and 8 display the placement of each statement and its referent number for each group, male and female.

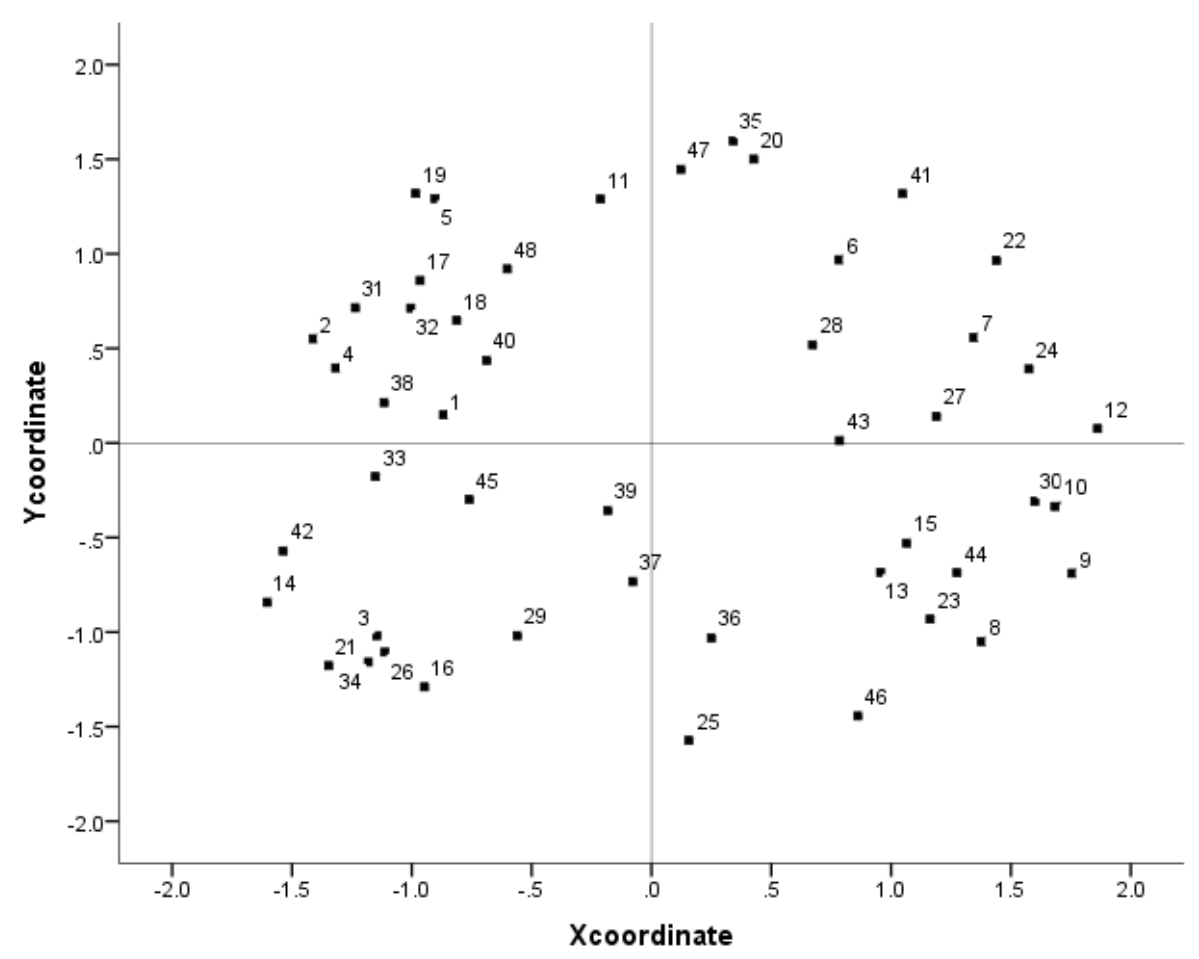

Figure 7: Numbered point map with each point corresponding to one of the 48 statements generated by the male group. 


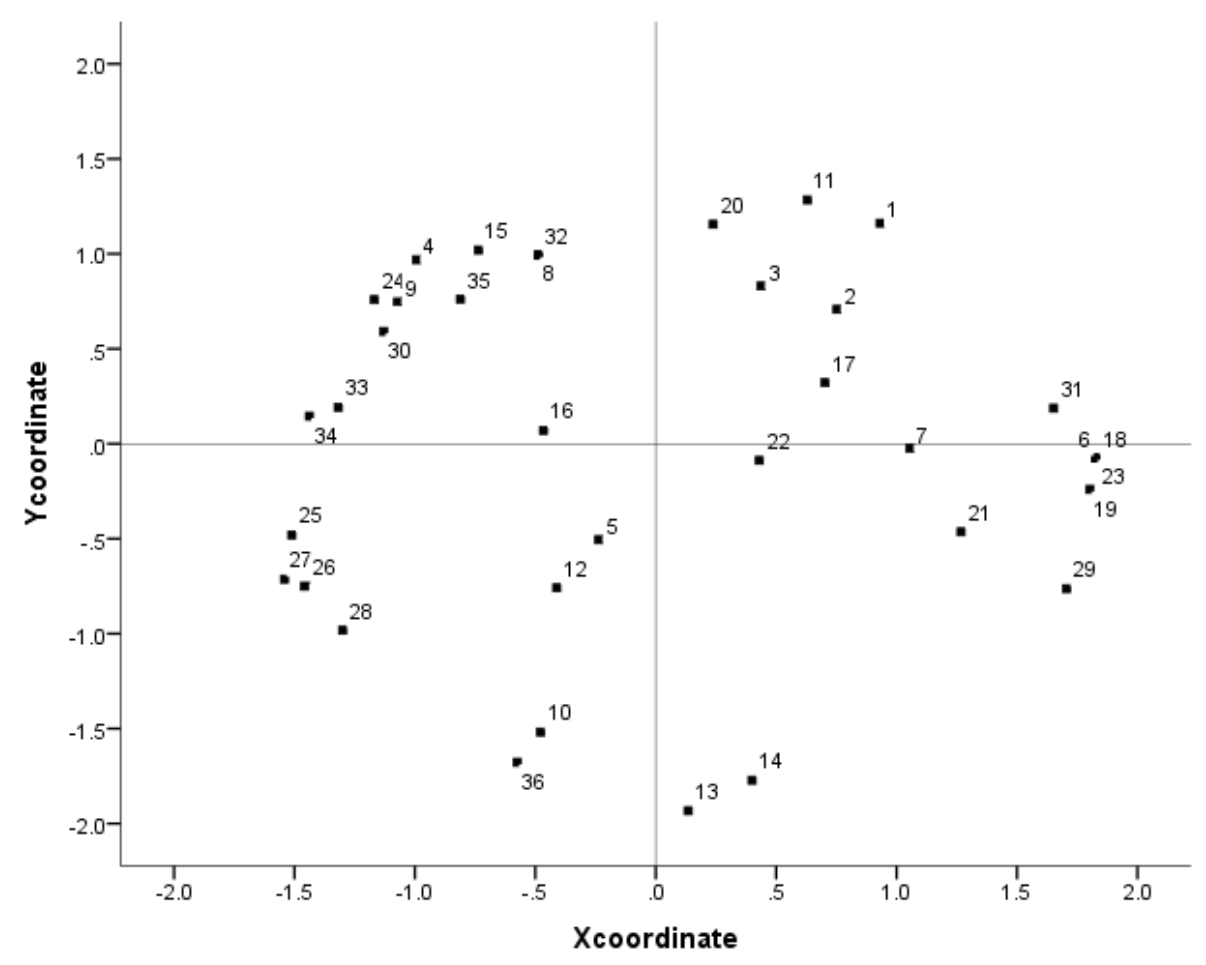

Figure 8: Numbered point map with each point corresponding to one of the 36 statements generated by the female group.

A couple examples help clarify this principle. In the male group, the lower left quadrant of Figure 7 shows how S3, S14, and S16 were grouped together frequently by the male participants. In other words, most male participants sorted together the following items: S3, Reformulating and defining the preparatory year's objectives, S14, Involving all preparatory year beneficiaries/stakeholders in the development of its plan, and S16, Hiring faculty members from colleges who have experience in teaching first-year university students. Note how these three statements refer to the Program Philosophy, Planning, and Operational Mechanism cluster. However, the point map for the male group (see Figure 7) also illustrates that S30, Providing academic counseling services for high school students before the preparatory year, in the lower right quadrant, and S32, Developing student assessment methods, in the upper left quadrant are not similar; therefore, they are located so far apart on the two-dimensional graph. 
In the female group, S25, S26, S27, and S28 are grouped together by most of the female participants, as illustrated in the lower left quadrant of Figure 8. S25, Organizing academic trips for distinguished students to study English language courses in international institutes, S26, Engaging students in international conferences to gain experience and contact with elites, S27, Publishing the outstanding research and media produced by students, and S28, Partnering with leading universities in adopting outstanding students, all refer to the cluster of Promoting Student Learning. Note that for the female group, S1, Developing an instrument to measure student level, for example, English language skills, is in the upper right quadrant and refers to the Program Application Policy and Assessment Mechanism cluster. S36, Increasing student awareness about university laws and regulations through a specialist department whenever they need advice, appears in the lower left quadrant and refers to the Program Services cluster. These two statements are different in terms of meaning and issues that are discussed. Therefore, female participants tend to sort these into the same pile very infrequently.

Table 3

Displays of Similarity and Dissimilarity among Statements for the Male Group (Examples)

\begin{tabular}{|c|c|c|c|c|}
\hline \multirow{4}{*}{ 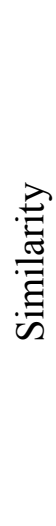 } & $\begin{array}{l}\text { Statements } \\
\text { number }\end{array}$ & X Coordinates & Y Coordinates & Statement \\
\hline & 3 & -1.1463 & -1.0183 & $\begin{array}{l}\text { Reformulating and defining the Preparatory } \\
\text { Year's objectives. }\end{array}$ \\
\hline & 14 & -1.6034 & -0.8426 & $\begin{array}{l}\text { Involving all Preparatory Year } \\
\text { beneficiaries/stakeholders in the development } \\
\text { of its plan. }\end{array}$ \\
\hline & 16 & -0.9475 & -1.2895 & $\begin{array}{l}\text { Hiring faculty members from colleges who } \\
\text { have experience in teaching first-year } \\
\text { university students. }\end{array}$ \\
\hline \multirow{2}{*}{ 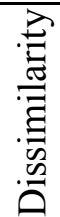 } & 30 & 1.59942 & -0.3081 & $\begin{array}{l}\text { Providing academic counseling services for } \\
\text { high school students before the Preparatory } \\
\text { Year. }\end{array}$ \\
\hline & 32 & -1.0046 & 0.71319 & Developing student assessment methods. \\
\hline
\end{tabular}


Table 4

Displays of Similarity and Dissimilarity among Statements for the Female Group (Examples)

\begin{tabular}{|c|c|c|c|c|}
\hline \multirow{5}{*}{ 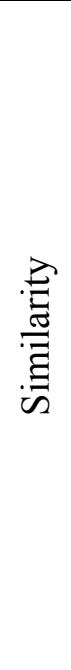 } & $\begin{array}{c}\text { Statements } \\
\text { number }\end{array}$ & X Coordinates & Y Coordinates & Statement \\
\hline & 25 & -1.511 & -0.4805 & $\begin{array}{l}\text { Organizing academic trips for distinguished } \\
\text { students to study English language courses in } \\
\text { international institutes. }\end{array}$ \\
\hline & 26 & -1.4584 & -0.7503 & $\begin{array}{l}\text { Engaging students in international } \\
\text { conferences to gain experience and contact } \\
\text { with elites. }\end{array}$ \\
\hline & 27 & -1.5416 & -0.7128 & $\begin{array}{l}\text { Publishing the outstanding research and media } \\
\text { produced by students. }\end{array}$ \\
\hline & 28 & -1.3002 & -0.9819 & $\begin{array}{l}\text { Partnering with leading universities in } \\
\text { adopting outstanding students. }\end{array}$ \\
\hline \multirow{2}{*}{ 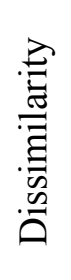 } & 1 & 0.93123 & 1.16147 & $\begin{array}{l}\text { Developing an instrument to measure student } \\
\text { level, for example, English language skills. }\end{array}$ \\
\hline & 36 & -0.5753 & -1.6776 & $\begin{array}{l}\text { Increasing student awareness about university } \\
\text { laws and regulations through a specialist } \\
\text { department whenever they need advice. }\end{array}$ \\
\hline
\end{tabular}

In the next phase of data analysis, Hierarchical Cluster Analysis (HCA) was conducted using IBM SPSS Statistics version 23 for each group. The benefit of HCA is to gather "groups individual statements on the point map into clusters of statements that aggregate to reflect similar concepts" (Kane \& Trochim, 2007, p. 98). The purpose of HCA is to begin to arrange the items from the point map into meaningful clusters. Kane and Trochim (2007) and Trochim (1989b) recommended Ward's algorithm method for HCA because it "gave more reasonable and interpretable solutions than other approaches such as single linkage or centroid methods" (p. 99). Additionally, "Ward's algorithm was especially appealing in the concept mapping context because it makes sense with distance-based data" (p. 99). The output of HCA is termed Hierarchical Cluster Tree (HCT) or a Dendogram (see Appendices D \& E). The HCT arranged the statements into clusters, visualized as a Dendogram, based on their similarity based on the 
point map. The researcher should determine in advance the minimum and maximum number of clusters to consider (Kane \& Trochim, 2007). Kane and Trochim did not specify a particular number for how many clusters are ideal. However, they mentioned that too few or too many clusters may make data interpretation difficult. Therefore, the researcher determined the number of clusters for each group of participants, whether male or female, to be three clusters minimum and ten clusters maximum. In other words, the HCA analysis divided the 48 statements generated by the male group between three and ten clusters and also the 36 statements for the female group between three and ten clusters. Figures 9 and 10 show the Point Cluster Map including the maximum number of possible cluster solutions for each group.

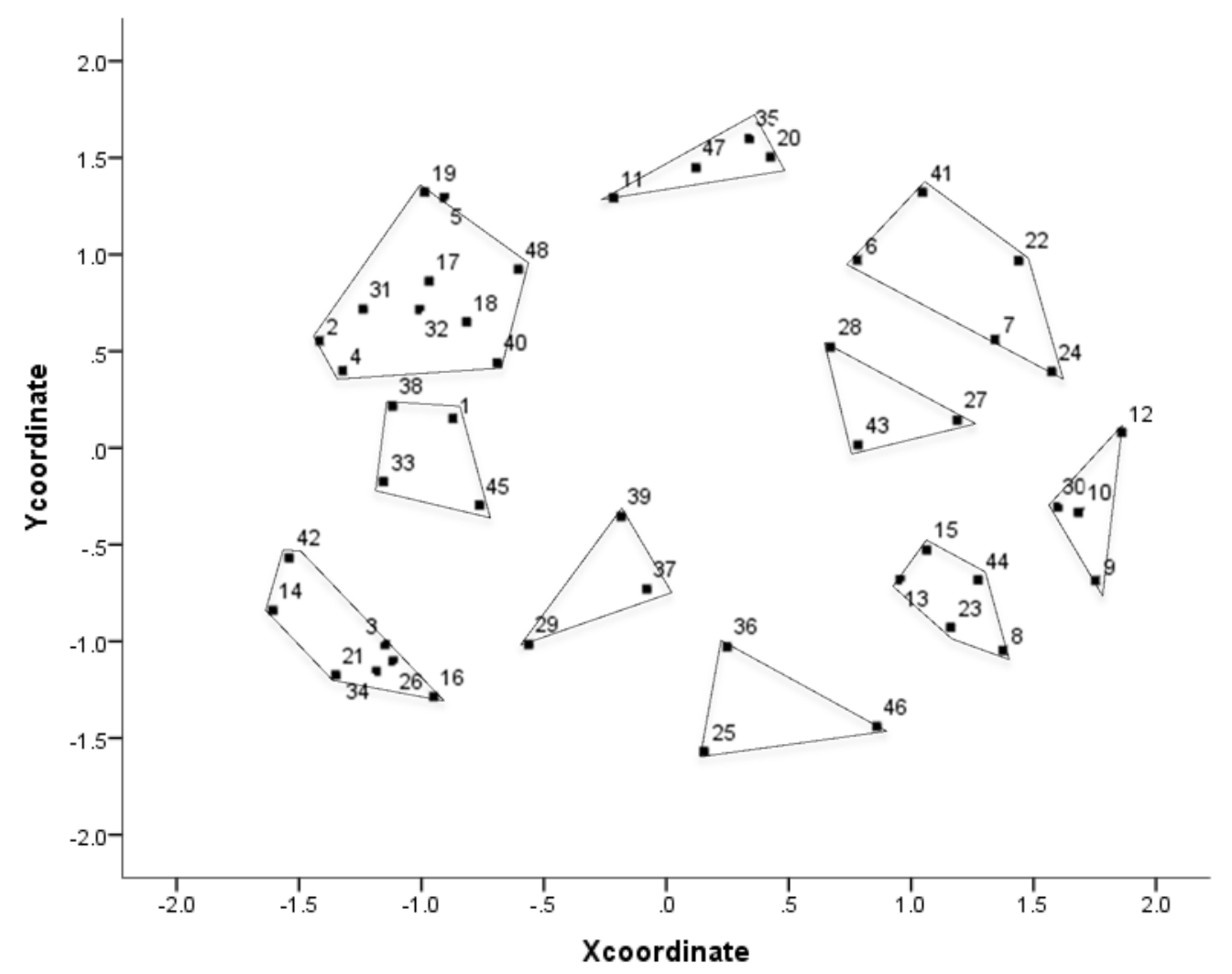

Figure 9: The Point Cluster Map for the maximum number of possible clusters solutions 10cluster for the 48 statements generated by the male group. 


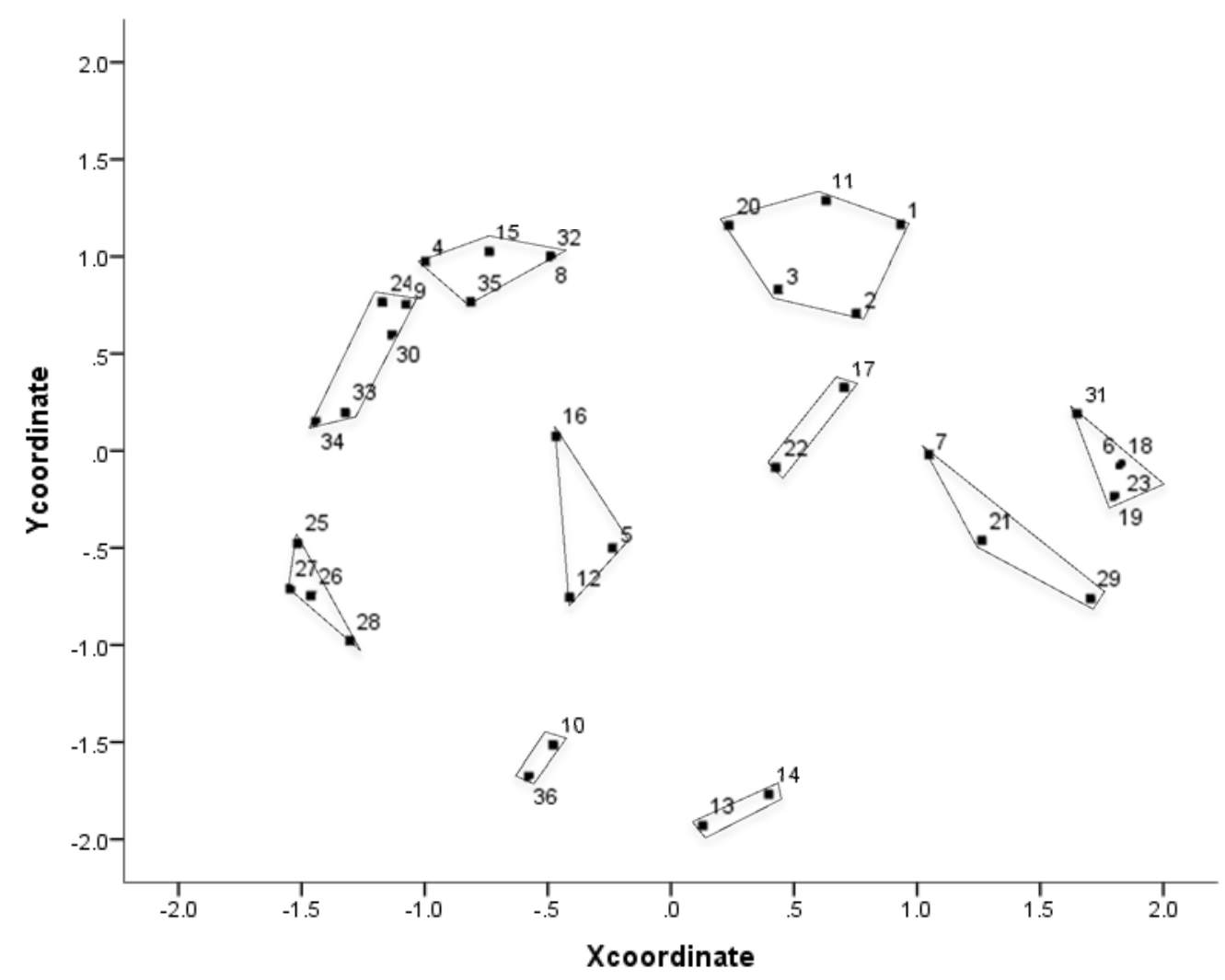

Figure 10: The Point Cluster Map for the maximum number of possible clusters solutions 10cluster for the 36 statements generated by the female group.

Next, the researcher decided about the final number of clusters selected for the data interpretation phase. The researcher combined quantitative and qualitative methods to decide the final clusters number for each group of participants (Kane \& Trochim, 2007). In this study, the quantitative method is represented by advanced objective statistical reasoning including Multidimensional Scaling (MDS) and Hierarchal Clustering Analysis (HCA). The qualitative method is represented by the choice of number of clusters that demands subjective judgment of each of the possible cluster solutions (ranging from 3 to 10) separately, and also for content analysis of documents used in research questions 2 and 3. The researcher also consulted a Concept Mapping/Pattern Matching (CM/PM) expert, who served as a member on the dissertation committee. 
In addition, as the brainstorming session had been facilitated in the Arabic language, the researcher carefully reviewed and considered the original lists of items to help ensure that translations to English were considered for nuances. Finally, the researcher made a final review for each cluster using the Dendogram to justify his selection. For the male group, the researcher and CM/PM consultant discussed the logical number of clusters, and considered solutions of either seven or eight clusters. The researcher carefully compared and contrasted these two options. Cluster 7 included S25, S36, S46, S29, S37, and S39. By dividing Cluster 7 into two clusters, Cluster 7 maintained S25, S36, and S46, while S29, S37, and S39 were transferred to Cluster 8 . The comparison of Clusters 7 and 8 statements showed a certain interrelationship that clarified why they were grouped together in the 7-cluster arrangement. In other words, the similarity among these statements justifies why the researcher and consultant agreed on the decision about the final number of clusters (see Table 5).

Table 5

Displays the comparison of selecting 7-cluster or 8-cluster solutions for the final decision

\begin{tabular}{|c|c|c|c|}
\hline $\begin{array}{c}\text { Item } \\
\text { number }\end{array}$ & Statement & 7 Cluster & 8 Cluster \\
\hline 25 & $\begin{array}{l}\text { Coordinating with beneficiary colleges to choose the } \\
\text { knowledge topics and skills that serve their majors. }\end{array}$ & 7 & 7 \\
\hline 36 & Preparing students for subsequent university study. & 7 & 7 \\
\hline 46 & $\begin{array}{l}\text { Developing a partnership with charitable and voluntary } \\
\text { organizations and invite them to be present and represented in } \\
\text { the Preparatory Year. }\end{array}$ & 7 & 7 \\
\hline 29 & $\begin{array}{l}\text { Implementing the Preparatory Year Program within colleges in } \\
\text { accordance with major tracks. }\end{array}$ & 7 & 8 \\
\hline 37 & $\begin{array}{l}\text { Setting clear and specific options in advance for students who } \\
\text { do not pass the Preparatory Year. }\end{array}$ & 7 & 8 \\
\hline 39 & $\begin{array}{l}\text { Developing programs to address student dropout in the } \\
\text { Preparatory Year or beyond. }\end{array}$ & 7 & 8 \\
\hline
\end{tabular}


For the female group, the decision about the final cluster solution was easier in part due to the number of statements being fewer as compared to males. Regardless, the final number of clusters chosen was seven for the male group (7-clusters) and six for the female group (6clusters). Figures 11 and 12 show the 7-clusters for the male group and 6-clusters for the female group respectively on the final Point Cluster Map.

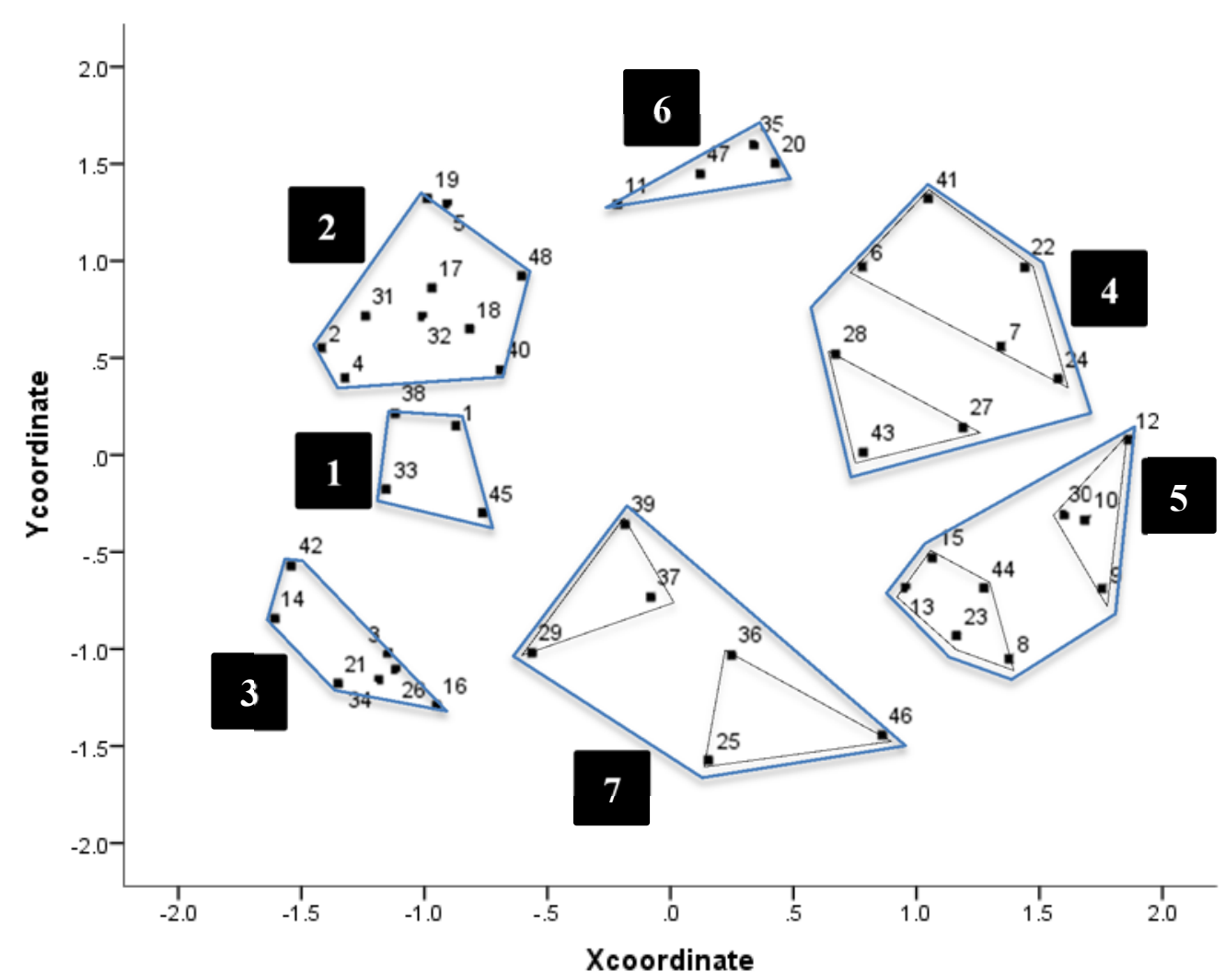

Figure 11: The Point Cluster Map with seven clusters generated by the male group. 


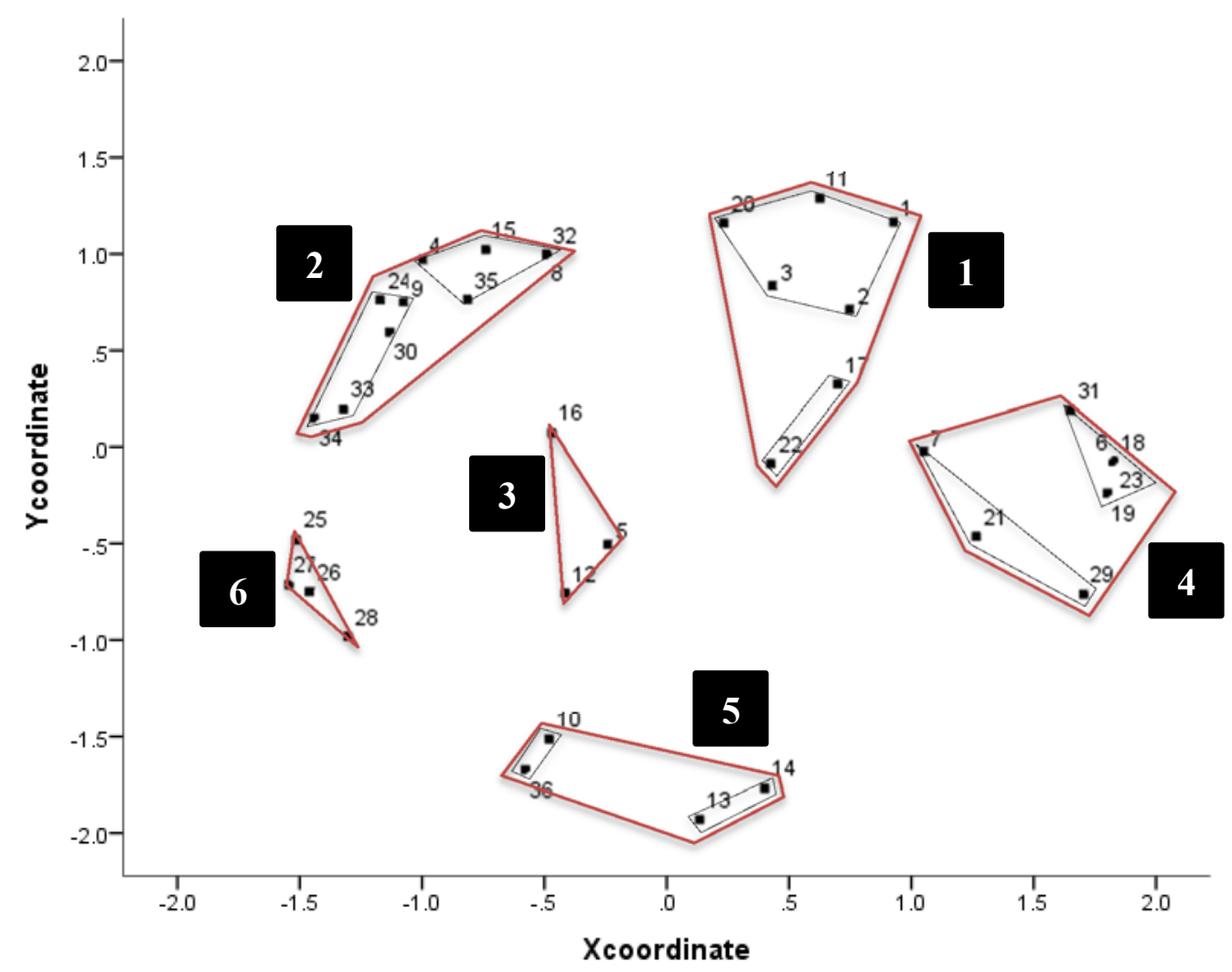

Figure 12: The Point Cluster Map with six clusters generated by the female group.

Phase 5: Interpretation of Maps. The fifth phase of the CM/PM process is to interpret the list of statements as sorted by clusters and label each cluster with a name (phrase/term/concept) that expresses and describes the cluster's contents (Kane \& Trochim, 2007). The researcher also consulted the focus group members, either male or female, and the $\mathrm{CM} / \mathrm{PM}$ expert, who served as a member in the dissertation committee about clusters names. The outcomes of this step identified 7-clusters names for the male group and 6-clusters names for the female group (see Table $6 \& 7$ ).

Table 6

Displays the list of 48 statements generated by the male focus group, Organized into Clusters using Hierarchical Cluster Analysis, and Labeled

\begin{tabular}{c|lccc}
\hline $\begin{array}{c}\text { Item } \\
\text { Number }\end{array}$ & \multicolumn{1}{c}{ Outcomes Generated by Male Focus Group } & $\begin{array}{c}\text { Cluster } \\
\text { Number }\end{array}$ & Cluster Label \\
\hline 1 & $\begin{array}{l}\text { Enabling students in fulfilling certain criteria to enroll in major- } \\
\text { specific courses. }\end{array}$ & 1 & Program Regulation \\
\end{tabular}




\begin{tabular}{|c|c|c|c|}
\hline 33 & $\begin{array}{l}\text { Reviewing the performance of faculty members in the Preparatory } \\
\text { Year. }\end{array}$ & & \\
\hline 38 & $\begin{array}{l}\text { Granting a certificate for students who pass the Preparatory Year } \\
\text { Program. }\end{array}$ & & \\
\hline 45 & $\begin{array}{l}\text { Introducing the Preparatory Year Program as a university program in } \\
\text { which students take responsibility for their learning and become self- } \\
\text { reliant. }\end{array}$ & & \\
\hline 2 & Availability of mechanisms for course acceleration/promotion. & \multirow{10}{*}{2} & \multirow{10}{*}{$\begin{array}{l}\text { Program Assessmen } \\
\text { Mechanism \& } \\
\text { Curriculum Structure }\end{array}$} \\
\hline 4 & $\begin{array}{l}\text { Reviewing student assessment mechanisms (student's } \\
\text { acceleration/promotion) during the program for all courses. }\end{array}$ & & \\
\hline 5 & $\begin{array}{l}\text { Merging some of the PY's similar courses after reviewing their } \\
\text { syllabi. }\end{array}$ & & \\
\hline 17 & Reconsidering the students' timetables and credit hours. & & \\
\hline 18 & Reviewing the medical track's study plan. & & \\
\hline 19 & $\begin{array}{l}\text { Reconsider reducing and refining course content or eliminating some } \\
\text { courses. }\end{array}$ & & \\
\hline 31 & Conducting continuous review of the Preparatory Year curriculum. & & \\
\hline 32 & Developing student assessment methods. & & \\
\hline 40 & $\begin{array}{l}\text { Developing the Preparatory Year to become a package of educational } \\
\text { and skills programs and then colleges and departments dictate the } \\
\text { programs that are required for their students. }\end{array}$ & & \\
\hline 48 & Intensifying/Enhancing the English language program. & & \\
\hline 3 & Reformulating and redefining the Preparatory Year's objectives. & \multirow{7}{*}{3} & \multirow{7}{*}{$\begin{array}{c}\text { Program Philosophy } \\
\text { Planning, \& } \\
\text { Operational } \\
\text { Mechanism }\end{array}$} \\
\hline 14 & $\begin{array}{l}\text { Involving all Preparatory Year beneficiaries/stakeholders in the } \\
\text { development of its plan. }\end{array}$ & & \\
\hline 16 & $\begin{array}{l}\text { Hiring faculty members from colleges who have experience in } \\
\text { teaching first-year university students. }\end{array}$ & & \\
\hline 21 & Reviewing the philosophy of the Preparatory Year and its purpose. & & \\
\hline 26 & Not linking the PY with academic/college placement. & & \\
\hline 34 & $\begin{array}{l}\text { Developing the Preparatory Year's self-operation mechanisms and } \\
\text { phasing out of outsourcing to private companies. }\end{array}$ & & \\
\hline 42 & $\begin{array}{l}\text { Developing and improving study halls/classrooms and the learning } \\
\text { environment. }\end{array}$ & & \\
\hline 6 & Developing note-taking skills during the lecture. & \multirow{8}{*}{4} & \multirow{8}{*}{$\begin{array}{l}\text { Program Academic } \\
\text { Design }\end{array}$} \\
\hline 7 & $\begin{array}{l}\text { Teaching students the basics of professional ethics and linking them } \\
\text { to Islamic values. }\end{array}$ & & \\
\hline 22 & Developing the skills of responsible autonomy. & & \\
\hline 24 & $\begin{array}{l}\text { Providing activities that encourage students to participate in } \\
\text { community service. }\end{array}$ & & \\
\hline 41 & $\begin{array}{l}\text { Assessing students' knowledge and skills before and after the } \\
\text { Preparatory Year Program. }\end{array}$ & & \\
\hline 27 & $\begin{array}{l}\text { Including activities into the Preparatory Year Program that are not } \\
\text { offered by other colleges (Not providing extracurricular activities } \\
\text { that will be offered after the Preparatory Year in colleges). }\end{array}$ & & \\
\hline 28 & $\begin{array}{l}\text { Avoid overwhelming students with activities offered by other } \\
\text { colleges. }\end{array}$ & & \\
\hline 43 & $\begin{array}{l}\text { Including gifted students' programs within the Preparatory Year } \\
\text { Program (to discover and take care of them). }\end{array}$ & & \\
\hline 8 & Educating students about the university's regulations and their rights. & \multirow{4}{*}{5} & \multirow{4}{*}{$\begin{array}{l}\text { Program Services: } \\
\text { Prior to \& During }\end{array}$} \\
\hline 13 & Educating students about majors' requirements. & & \\
\hline 15 & $\begin{array}{l}\text { Organizing workshops for high school students to identify and } \\
\text { address weaknesses of the Preparatory Year students. }\end{array}$ & & \\
\hline 23 & $\begin{array}{l}\text { Providing services needed by students through workshops and } \\
\text { through the cooperation between colleges and the Preparatory Year } \\
\text { Deanship. }\end{array}$ & & \\
\hline
\end{tabular}




\begin{tabular}{|c|c|c|c|}
\hline 44 & $\begin{array}{l}\text { Assigning students to visit their future colleges in coordination with } \\
\text { them to learn closely about the offered majors. }\end{array}$ & & \\
\hline 9 & $\begin{array}{l}\text { Introducing the university's facilities and services to students to take } \\
\text { advantage of them (orientation program). }\end{array}$ & & \\
\hline 10 & Educating students about libraries and research resources. & & \\
\hline 12 & $\begin{array}{l}\text { Adding activities and guidance programs that help students choose } \\
\text { their majors. }\end{array}$ & & \\
\hline 30 & $\begin{array}{l}\text { Providing academic counseling services for high school students } \\
\text { before the Preparatory Year. }\end{array}$ & & \\
\hline 11 & $\begin{array}{l}\text { Adding course activities that promote and motivate students' } \\
\text { learning. }\end{array}$ & \multirow{4}{*}{6} & \multirow{4}{*}{$\begin{array}{l}\text { Supporting Student } \\
\text { Learning }\end{array}$} \\
\hline 20 & $\begin{array}{l}\text { Providing extra training hours that do not conflict with current study } \\
\text { hours. }\end{array}$ & & \\
\hline 35 & Emphasizing critical thinking skills and creativity. & & \\
\hline 47 & Developing tutoring programs according to students' needs. & & \\
\hline 25 & $\begin{array}{l}\text { Coordinating with beneficiary colleges to choose the knowledge } \\
\text { topics and skills that serve their majors. }\end{array}$ & \multirow{6}{*}{7} & \multirow{6}{*}{$\begin{array}{l}\text { Program Applications } \\
\text { Policy }\end{array}$} \\
\hline 36 & Preparing students for subsequent university study. & & \\
\hline 46 & $\begin{array}{l}\text { Developing a partnership with charitable and voluntary organizations } \\
\text { and invite them to be present and represented in the Preparatory } \\
\text { Year. }\end{array}$ & & \\
\hline 29 & $\begin{array}{l}\text { Implementing the Preparatory Year Program within colleges in } \\
\text { accordance with major tracks. }\end{array}$ & & \\
\hline 37 & $\begin{array}{l}\text { Setting clear and specific options in advance for students who do not } \\
\text { pass the Preparatory Year. }\end{array}$ & & \\
\hline 39 & $\begin{array}{l}\text { Developing programs to address student dropout in the Preparatory } \\
\text { Year or beyond. }\end{array}$ & & \\
\hline
\end{tabular}

\section{Table 7}

Displays the list of 36 statements generated by the female focus group, Organized into Clusters using Hierarchical Cluster Analysis, and Labeled

\begin{tabular}{|c|c|c|c|}
\hline $\begin{array}{c}\text { Item } \\
\text { Number }\end{array}$ & Outcomes Generated by Male Focus Group & $\begin{array}{l}\text { Cluster } \\
\text { Number }\end{array}$ & Cluster Label \\
\hline 1 & $\begin{array}{l}\text { Developing an instrument to measure student's level, for example, } \\
\text { English language skills. }\end{array}$ & \multirow{7}{*}{1} & \multirow{7}{*}{$\begin{array}{l}\text { Program Assessment } \\
\text { Mechanism \& } \\
\text { Curriculum Structure }\end{array}$} \\
\hline 2 & $\begin{array}{l}\text { Reassessing the importance of teaching (some) courses in the } \\
\text { Preparatory Year, for example, health and fitness courses. }\end{array}$ & & \\
\hline 3 & Passing the placement tests for Preparatory Year courses. & & \\
\hline 11 & Students can pass some of the Preparatory Year courses directly. & & \\
\hline 20 & Determining the course timeline based on students' needs. & & \\
\hline 17 & $\begin{array}{l}\text { Reviewing the Preparatory Year curriculum and } \\
\text { comparing/contrasting them with public education curriculum. }\end{array}$ & & \\
\hline 22 & The inclusion of some courses for all study tracks, such as English. & & \\
\hline 4 & $\begin{array}{l}\text { Reducing theoretical hours for the courses that require practical } \\
\text { application, such as communication and computer skills. }\end{array}$ & \multirow{5}{*}{2} & \multirow{5}{*}{$\begin{array}{l}\text { Program Academic } \\
\text { Design }\end{array}$} \\
\hline 8 & $\begin{array}{l}\text { Canceling some of the redundant courses or merging them into a } \\
\text { single course, for example, math skills. }\end{array}$ & & \\
\hline 15 & $\begin{array}{l}\text { All offered skills are important and should not be specific for the } \\
\text { Preparatory Year. }\end{array}$ & & \\
\hline 32 & $\begin{array}{l}\text { Merging some courses together such as research skills and } \\
\text { communication skills under one course, named the skills course. }\end{array}$ & & \\
\hline 35 & $\begin{array}{l}\text { Integrating some skills, such as speech and scientific research, during } \\
\text { the study of language. }\end{array}$ & & \\
\hline
\end{tabular}




\begin{tabular}{|c|c|c|c|}
\hline 9 & $\begin{array}{l}\text { Emphasizing practical, applied, and skill aspects not just a } \\
\text { compilation of grades for academic placement. }\end{array}$ & & \\
\hline 24 & $\begin{array}{l}\text { Focusing on the practical aspects that ensure students will maintain } \\
\text { skills, such as the English language. }\end{array}$ & & \\
\hline 30 & Implementing independent learning more than lectures. & & \\
\hline 33 & $\begin{array}{l}\text { Self-development skills can be acquired during study through } \\
\text { workshops and courses that are offered by the Deanship of Student } \\
\text { Affairs. }\end{array}$ & & \\
\hline 34 & $\begin{array}{l}\text { Extra-curricular activities play an important role in the refinement of } \\
\text { students' skills. }\end{array}$ & & \\
\hline 5 & $\begin{array}{l}\text { Assigning a stable educational entity to run the courses (with low } \\
\text { possibility of management change). }\end{array}$ & \multirow{3}{*}{3} & \multirow{3}{*}{ Teaching Quality } \\
\hline 12 & $\begin{array}{l}\text { Ensuring that faculty members have the necessary capability to deal } \\
\text { with students at this age. }\end{array}$ & & \\
\hline 16 & Diversifying teaching strategies to shorten time. & & \\
\hline 6 & $\begin{array}{l}\text { Applying the academic/college placement at the beginning of the } \\
\text { Preparatory Year. }\end{array}$ & \multirow{8}{*}{4} & \multirow{8}{*}{ Program Regulation } \\
\hline 18 & Students' academic placement to be before the Preparatory Year. & & \\
\hline 19 & Identifying academic track/major from the first day of study. & & \\
\hline 23 & $\begin{array}{l}\text { Applying academic placement for all students before entering the } \\
\text { Preparatory Year to make students focus more on academic } \\
\text { achievement. }\end{array}$ & & \\
\hline 31 & Implementing academic placement from the beginning. & & \\
\hline 7 & $\begin{array}{l}\text { Achieving the most benefit from the Preparatory Year (skills) by } \\
\text { abolishing the academic placement policy after the Preparatory Year. }\end{array}$ & & \\
\hline 21 & $\begin{array}{l}\text { The Preparatory Year's GPA should not affect choosing the future } \\
\text { college of study. }\end{array}$ & & \\
\hline 29 & To be a Preparatory Program not a Preparatory Year. & & \\
\hline 10 & $\begin{array}{l}\text { The Preparatory Year regulations should be issued by the Vice Dean } \\
\text { of the Preparatory Year. }\end{array}$ & \multirow{4}{*}{5} & \multirow{4}{*}{$\begin{array}{l}\text { Program Services: } \\
\text { Prior \& During }\end{array}$} \\
\hline 36 & $\begin{array}{l}\text { Increasing student awareness about the university's laws and } \\
\text { regulations through a specialist department whenever they need } \\
\text { advice. }\end{array}$ & & \\
\hline 13 & The necessity of educating students about their rights and duties. & & \\
\hline 14 & $\begin{array}{l}\text { The importance of the orientation program for students before } \\
\text { starting the study plan. }\end{array}$ & & \\
\hline 25 & $\begin{array}{l}\text { Organizing academic trips for distinguished students to study English } \\
\text { language courses in international institutes. }\end{array}$ & \multirow{4}{*}{6} & \multirow{4}{*}{$\begin{array}{l}\text { Promoting Student } \\
\text { Learning }\end{array}$} \\
\hline 26 & $\begin{array}{l}\text { Engaging students in international conferences to gain experience } \\
\text { and contact with elites. }\end{array}$ & & \\
\hline 27 & Publishing outstanding research and media produced by students. & & \\
\hline 28 & Partnering with leading universities in adopting outstanding students. & & \\
\hline
\end{tabular}

Further, as a part of Kane and Trochim's (2007) process of CM/PM, Figures $13 \& 14$

display the clusters map on a two-dimensional map labeled with specific names that describe the overall statements contained therein. "This final named cluster map constitutes the conceptual framework and the basic result of the concept mapping process" (p. 122). Moreover, in the discussion section of Chapter 5 of this dissertation, the researcher used the two-dimensional 
clusters maps as seen in Figures 13 and 14 to link similar clusters within regions to develop the PYP's conceptual framework for this study and also to direct future research.

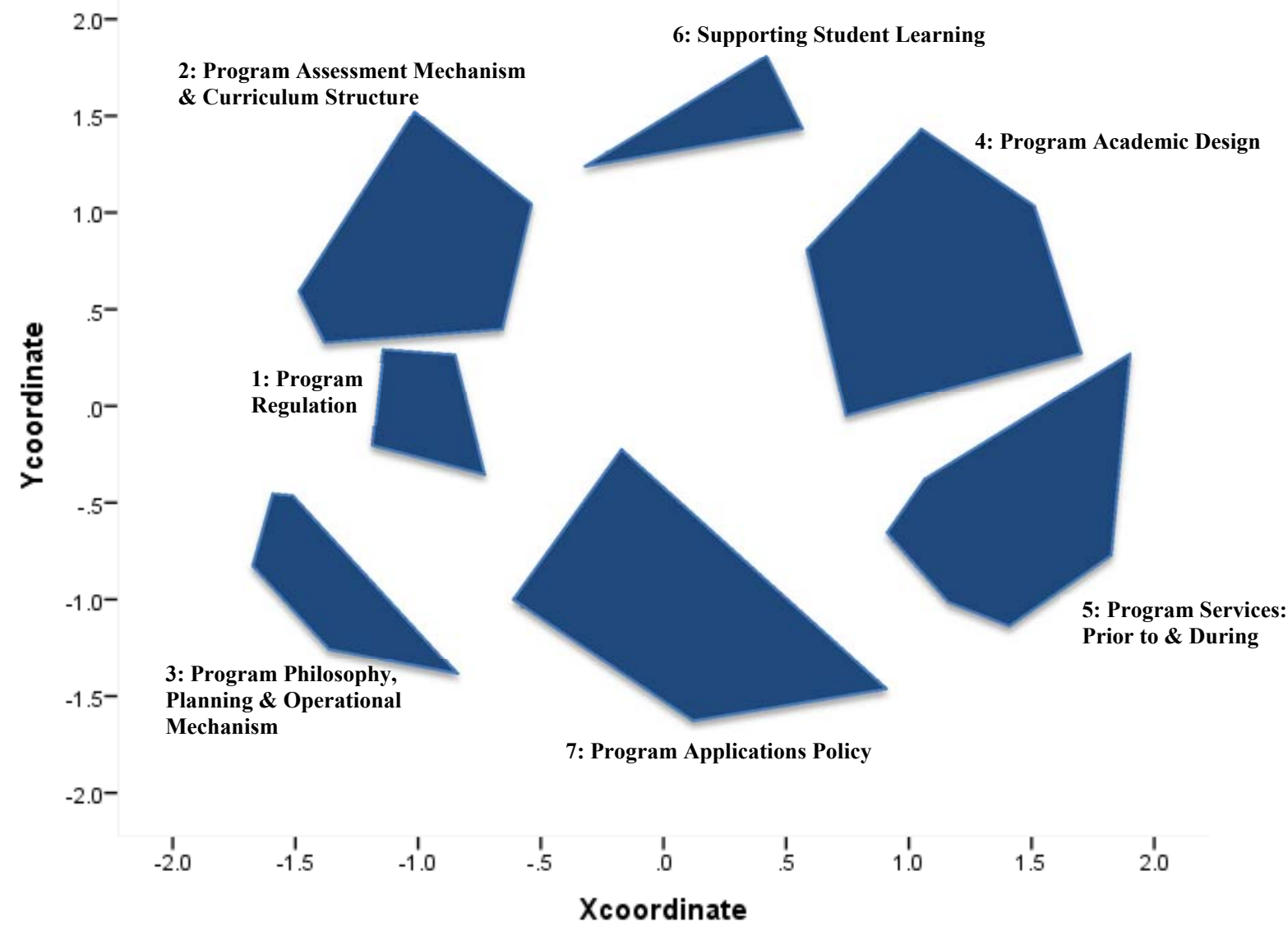

Figure 13: The cluster map with the seven clusters named as generated by the male group. 


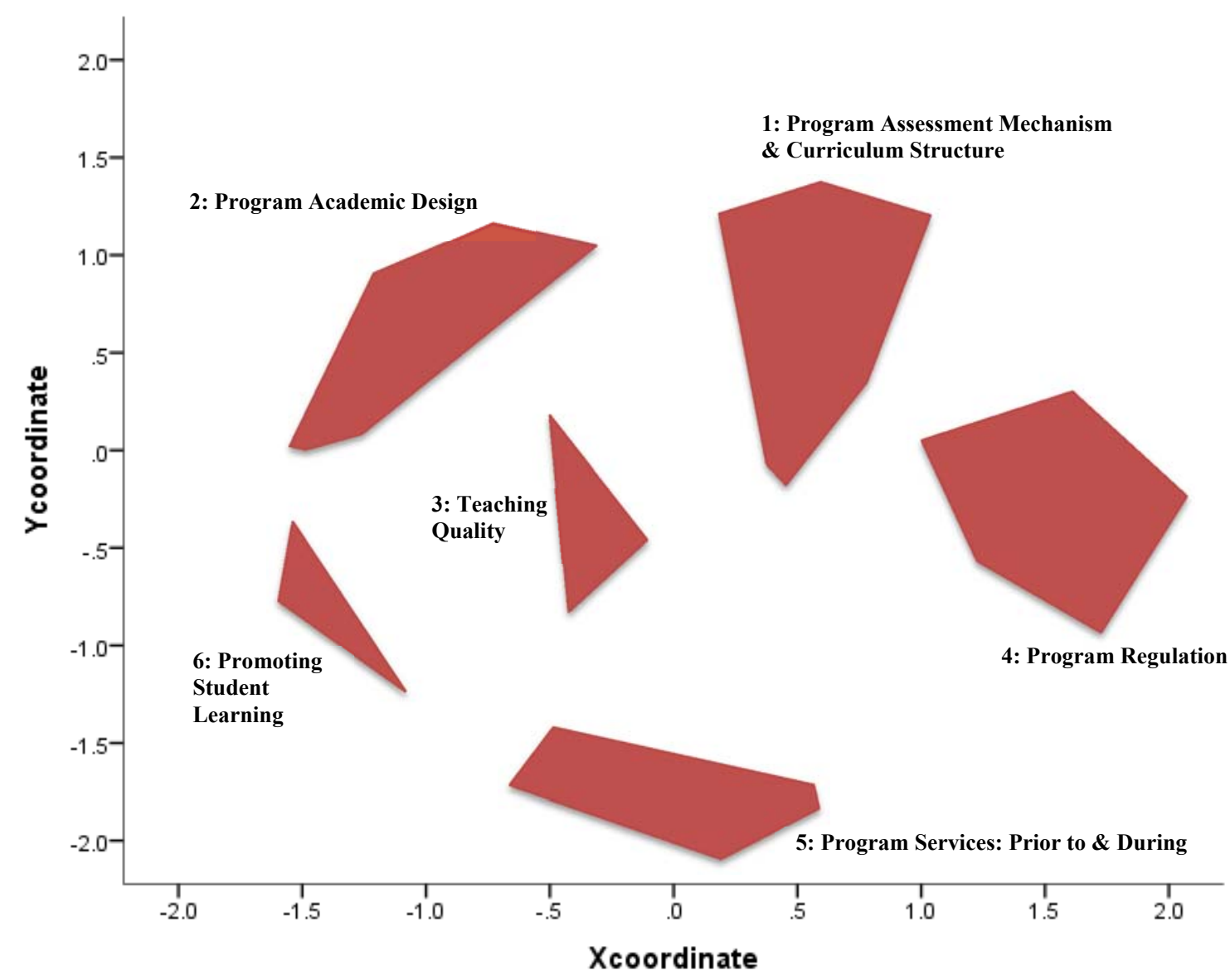

Figure 14: The cluster map with the six clusters named as generated by the female group.

\section{Applying the survey outcomes to the CM/PM finding (The Rating Task).}

As mentioned in Chapter 3, Phase 3: Structuring of Statements, 14 out of 14 males responded to the survey to rate 48 statements, and 9 out of 9 females rated the 36 statements based on a 5-point Ordinal Scale. Each statement was rated twice by respondents for importance and efficacy at the Preparatory Year Program (PYP) at King Saud University (KSU). Two questions were asked:

1. How important is this program, service, or activity for first-year students at King Saud University? 5 = Very Unimportant; 4 = Unimportant; 3 = Neutral; 2 = Important; $1=$ Very Important. 
2. Overall, how effectively does King Saud University's Preparatory Year Program facilitate this program, service, or activity? $5=$ Very Ineffective; $4=$ Ineffective; $3=$ Neutral; 2 = Effective; 1 = Very Effective.

The researcher used a Qualtrics survey, an Internet-based data collection tool, to send the surveys to all the participants. After all the responses were received, the data was analyzed by IBM SPSS Statistics Software (version 23) to calculate the arithmetic mean for each statement, as well as the aggregate mean for the cluster to which that item belonged (see Appendixes K \& L). This step reported participants' conceptualization of the field of study to explore the importance of each statement and to examine the extent of effectiveness King Saud University has in helping Preparatory Year students accomplish the expressed result.

\section{Findings for Research Question 1}

This study consisted of two central research questions and two sub-questions:

RQ1: Using the Concept Mapping/Pattern Matching methodology, how do Saudi male and female postsecondary stakeholders conceptualize the future ideal functions of the Preparatory Year Deanship to help students successfully transition into their first year of college/university?

a: Does this Concept Mapping/Pattern Matching conceptualization compare and contrast with the current working model of the Preparatory Year Program at King Saud University?

b: Does this Concept Mapping/Pattern Matching conceptualization compare and contrast with King Saud University's explicit strategic plan?

RQ2: When conducting a Concept Mapping/Pattern Matching conceptualization, how do the results for males compare and contrast with the results for females? 
For the first research question, "Using the Concept Mapping/Pattern Matching methodology, how do Saudi male and female postsecondary stakeholders conceptualize the future ideal functions of the Preparatory Year Deanship to help students successfully transition into their first year of college/university?", the data was generated through the two brainstorming sessions and concluded by the sorting and rating tasks completed by 14 male and 9 female stakeholders independently.

The participants in both groups were asked the same focus prompt question to petition their ideas or insights regarding the PYP's future development. The focus question was, "What programs, services, and activities should guide the functions of the Preparatory Year Program?”, the outcomes of the two brainstorming sessions was 84,48 by the males and 36 from the females. Each statement was given a sequential number, the male group ranged from 1-48, and the female group from 1-36.

Following the sorting tasks and after the objective statistical reasoning Multidimensional Scaling (MDS), Hierarchal Clustering Analysis (HCA), and subjective review done by the researcher and $\mathrm{CM} / \mathrm{PM}$ expert, who served on the dissertation committee, the statements were grouped into 7-clusters for the male group and 6-clusters for the female group. The statements for each group represented the stakeholders' perceptions regarding the future ideal functions of the Preparatory Year Program (PYP) at King Saud University (KSU). As we observed, some of these statements are similar to a large extent and some were different. This result promoted the terms and concepts that were used to name and define each cluster and made these names and definitions more suitable to describe each clusters components. Moreover, these definitions represented the future ideal functions of the PYP that may help policy makers to develop program functions in the future. Tables 8 and 9 represent the label or descriptor allocated to each 
cluster and the definition created by the researcher to summarize the main concepts that were established from grouping the statements into clusters.

Table 8

List of Seven Clusters with Labels and Definitions Created by CM/PM for the Male Group

Cluster Label Definition

Cluster 1 Program Regulation Developing program rules for more flexibility for the

PY's student to make decisions about course

registration, granting PYP certification, and review

faculty performance and capacity to teach first-year students.

Cluster 2 Program Assessment

Mechanism and

Curriculum Structure

Cluster 3 Program Philosophy, Planning, and Operational Mechanism

Cluster 4 Program Academic Design

Cluster 5 Program Services: Prior to and During
Developing students' learning assessment methods to foster student's movement to higher levels of study, and restructuring curriculums' content, syllabus, and applications through coordination with the university's colleges to meet their academic requirements and prospective students' needs.

Developing the PY's philosophy, purpose, goals, and application concurrently with improving the overall learning environments and starting self-operation for the program.

Identifying, developing, and organizing the essential skills that first-year student's need with more concentration on note taking, professional ethics, values, volunteer work, and responsible autonomy skills.

Providing prospective students services prior to and during the first-year to connect students with the university environment and help them to engage in the learning process through an orientation program, counseling services, cooperation with beneficiary, colleges, and high schools, and conducting awareness 
Cluster 6 Supporting Student Learning

Cluster 7 Program Applications Policy programs and workshops.

Developing extra academic programs and services to foster student learning and to improve critical thinking skills and creativity.

Developing a program policy and design to be part of colleges academic programs, to support students who cannot pass the PYP, and to address student's departure issue during or after the PYP.

Table 9

List of Six Clusters with Labels and Definitions Created by CM/PM for the Female Group

\begin{tabular}{|c|c|c|}
\hline Cluster & Label & Definition \\
\hline Cluster 1 & $\begin{array}{l}\text { Program Assessment } \\
\text { Mechanism and } \\
\text { Curriculum Structure }\end{array}$ & $\begin{array}{l}\text { Developing students' learning assessment approaches to } \\
\text { foster student's learning, restructuring the PYP's curriculum } \\
\text { content, syllabus, and comparing/contrasting with public } \\
\text { education curriculums. }\end{array}$ \\
\hline Cluster 2 & $\begin{array}{l}\text { Program Academic } \\
\text { Design }\end{array}$ & $\begin{array}{l}\text { Identifying, developing, organizing, and emerging some of } \\
\text { the program courses with concentrating on practices, extra- } \\
\text { curricular, and applied skills more than theory. }\end{array}$ \\
\hline Cluster 3 & Teaching Quality & $\begin{array}{l}\text { Ensuring the quality and capability of faculty at the PYP to } \\
\text { deal with first-year students. }\end{array}$ \\
\hline Cluster 4 & Program Regulation & $\begin{array}{l}\text { Developing program rules to make the academic/college } \\
\text { placement for all students on specific track/major before the } \\
\text { PYP rather than after the PY's completion, and do not count } \\
\text { the PYP's GPA to determine the future college or major. }\end{array}$ \\
\hline Cluster 5 & $\begin{array}{l}\text { Program Services: } \\
\text { Prior to and During }\end{array}$ & $\begin{array}{l}\text { Developing the orientation program and counseling services } \\
\text { to educate first-year students about their rights and duties } \\
\text { and the university's regulations. }\end{array}$ \\
\hline Cluster 6 & $\begin{array}{l}\text { Promoting Student } \\
\text { Learning }\end{array}$ & $\begin{array}{l}\text { Developing activities and academic programs that promote } \\
\text { and stimulate student learning and raise student's } \\
\text { engagement in the local and global contexts. }\end{array}$ \\
\hline
\end{tabular}


The importance and efficacy for each cluster in each group of participants was calculated. Using importance and efficacy means allowed for a deeper examination of each statement and cluster, and clarification on how statements in each cluster were similar or dissimilar. As mentioned in Chapters 3 and 4, each group of participants involved stakeholders from different backgrounds and experiences (KSU and PYP's faculty, students, parents, representative of the business sector, Student Affairs, Academic Affairs, and KSU and PYP's administrators), which demonstrated why some statements appeared different from others in the same group or seem to not belong in the cluster that it was placed into. This result may be due to the participant's interpretation and understanding of each statement's meaning. In the following section, the researcher started with the male group that included 7-clusters and 48 statements. For each cluster, the statements were sorted in precedence from highest to lowest according to the mean scores for the importance rating.

\section{Male Group: Cluster 1: Program Regulation. The Program Regulation Cluster} involved four statements depending on the cluster analysis. The researcher named this cluster "Program Regulation" due to the nature of statements that were involved in the cluster that represented different issues regarding program regulation. For example, S1, Enabling students in fulfilling certain criteria to enroll in major-specific courses, or S38, Granting a certificate for students who pass the Preparatory Year Program. The given definition for this cluster was “Developing program rules for more flexibility for the PY's student to make decisions about course registration, granting PYP certification, and review faculty performance and capacity to teach first-year students".

Overall, all four statements in this cluster yielded importance mean of 4.36 or above on a 5-point Ordinal Scale, which is considered relatively highly important from participants' 
perceptions to develop the Preparatory Year Program (PYP) functions in the future. On the other hand, the efficacy rating for these four statements yielded mean scores between 2.86 and 3.93, which indicted that King Saud University is ineffective on these dimensions and may need to develop the PYP's regulation to enhance program performance. In this cluster, the group of participants considered faculty performance at PYP the most important dimension; S33, Reviewing the performance of faculty members in the Preparatory Year $(\mathrm{M}=4.57)$. However, as the PYP's operational mechanism relies on outsourcing through the educational companies, this may justify participants' perspective in this regard.

Further, participants suggested S45, Introducing the Preparatory Year Program as a university program in which students take responsibility for their learning and become selfreliant $(\mathrm{M}=4.57)$. In other words, developing a program pedagogy to make students more selfreliant. Participants also proposed S1, Enabling students in fulfilling certain criteria to enroll in major-specific courses $(\mathrm{M}=4.43)$ or enhancing registration regulations to be more flexible for students.

The last statement in this cluster was S38, Granting a certificate for students who pass the Preparatory Year Program $(M=4.36$ importance $\& M=2.86$ efficacy). This statement suggested a new idea that would provide all PYP graduates a certificate that may help them to find a job during their next study year or specifically for those who depart from the university. A discussion around this idea was done in the brainstorming session and was clarified that the participants believed that after one year in the PYP and many hours of study in different disciplines such as English, mathematics, self-development, etc. students may be qualified to work in some places using the PYP's certification. From the researcher's perspective, all these statements related to the program's regulation fit objectively into this cluster and its definition. 
Table 10 shows the list of statements in the Program Regulation Cluster and their mean ratings for importance and efficacy.

Table 10

List of Statements in the Program Regulation Cluster and Their Mean Ratings for Importance and Efficacy

\begin{tabular}{|c|c|c|c|c|}
\hline \multirow[b]{2}{*}{$\begin{array}{l}\text { Item } \\
\text { number }\end{array}$} & \multirow[b]{2}{*}{ Statement } & \multirow[b]{2}{*}{$\mathrm{N}$} & \multicolumn{2}{|c|}{ Rating } \\
\hline & & & $\begin{array}{c}\text { Importance } \\
(M=4.48)\end{array}$ & $\begin{array}{l}\text { Efficacy } \\
(M=3.39)\end{array}$ \\
\hline 33 & $\begin{array}{l}\text { Reviewing the performance of faculty members in the } \\
\text { Preparatory Year. }\end{array}$ & 14 & 4.57 & 3.93 \\
\hline 45 & $\begin{array}{l}\text { Introducing the Preparatory Year Program as a } \\
\text { university program in which students take responsibility } \\
\text { for their learning and become self-reliant. }\end{array}$ & 14 & 4.57 & 3.79 \\
\hline 1 & $\begin{array}{l}\text { Enabling students in fulfilling certain criteria to enroll in } \\
\text { major-specific courses. }\end{array}$ & 14 & 4.43 & 3.00 \\
\hline 38 & $\begin{array}{l}\text { Granting a certificate for students who pass the } \\
\text { Preparatory Year Program. }\end{array}$ & 14 & 4.36 & 2.86 \\
\hline
\end{tabular}

Male Group: Cluster 2: Program Assessment Mechanism \& Curriculum Structure.

The Program Assessment Mechanism and Curriculum Structure Cluster is the largest one in the male group, which consists of ten statements. The items in this cluster revolve around curriculum and assessment issues of the Preparatory Year Program (PYP) at King Saud University.

The definition for this cluster was 'Developing students' learning assessment methods to foster student's movement to higher levels of study, and restructuring curriculums' content, syllabus, and applications through coordination with the university's colleges to meet their academic requirements and prospective students' needs". Eight out of ten statements focused on the PYP's curriculum reform such as merging similar courses, refining/reducing/eliminating some courses, developing course acceleration mechanisms, and developing course assessment instruments. These eight statements recorded importance means above 4.00: S2 (M=4.43), S5 $(\mathrm{M}=4.29), \mathrm{S} 17(\mathrm{M}=4.21), \mathrm{S} 19(\mathrm{M}=4.43), \mathrm{S} 31(\mathrm{M}=4.64), \mathrm{S} 40(\mathrm{M}=4.57), \mathrm{S} 48(\mathrm{M}=4.36)$, and $\mathrm{S} 18$ 
$(\mathrm{M}=3.93)$. The highest mean was for S31 that illustrated the significance of "Conducting continuous review of the Preparatory Year curriculum”. One statement, S18, Reviewing the medical track's study plan, recorded $(\mathrm{M}=3.93)$ which is lower than 4.00.This mean score may be low because this statement was only important for specific participants who represented the perception of the Medicine College and this may not interest other participants.

The last two statements in this cluster S4 $(\mathrm{M}=4.21)$ and S32 $(\mathrm{M}=4.50)$, straightly revealed the importance of developing an assessment approach for student's learning. Regarding S32, Developing student assessment methods. The participants' expressions were broad. In other words, the male stakeholder group saw the assessment development as generally important for the PYP with no determination, in which the assessment aspects need to improve within the PYP functions. This statement ranks on the third level of importance in this cluster. On the other hand, S4, Student assessment mechanisms (student's acceleration/promotion) during the program for all courses, specified exactly where the PYP needs to develop the assessment method.

Regarding the efficacy rating, eight of the ten statements yielded an efficacy mean lower than 4.00 and above 3.00. Only S31 recorded a mean efficacy at $(M=4.00)$. Additionally, S2, Availability of mechanisms for course acceleration/promotion, yielded an efficacy score at $(M=2.79)$, which is the only mean lower than 3.00 in this cluster. This outcome consensuses with the result of S4 since it revealed the importance of developing the PYP's course assessment and acceleration methods. In general, this result for Cluster 2 was acceptable from the researcher's perspective and all these statements content matching the cluster name "Program Assessment Mechanism and Curriculum Structure" and the assigned definition. Table 11 shows the list of statements in the Program Assessment Mechanism \& Curriculum Structure Cluster and their mean ratings for importance and efficacy. 
Table 11

List of Statements in the Program Assessment Mechanism \& Curriculum Structure Cluster and Their Mean Ratings for Importance and Efficacy

\begin{tabular}{|c|c|c|c|c|}
\hline \multirow{2}{*}{$\begin{array}{l}\text { Item } \\
\text { number }\end{array}$} & \multirow[b]{2}{*}{ Statement } & \multirow[b]{2}{*}{$\mathrm{N}$} & \multicolumn{2}{|c|}{ Rating } \\
\hline & & & $\begin{array}{c}\text { Importance } \\
(M=4.357)\end{array}$ & $\begin{array}{c}\text { Efficacy } \\
(M=3.3786)\end{array}$ \\
\hline 31 & $\begin{array}{l}\text { Conducting continuous review of the Preparatory } \\
\text { Year curriculum. }\end{array}$ & 14 & 4.64 & 4.00 \\
\hline 40 & $\begin{array}{l}\text { Developing the Preparatory Year to become a package } \\
\text { of educational and skills programs and then colleges } \\
\text { and departments dictate the programs that are required } \\
\text { from their students. }\end{array}$ & 14 & 4.57 & 3.50 \\
\hline 32 & Developing student assessment methods. & 14 & 4.50 & 3.64 \\
\hline 2 & $\begin{array}{l}\text { Availability of mechanisms for course } \\
\text { acceleration/promotion. }\end{array}$ & 14 & 4.43 & 2.79 \\
\hline 19 & $\begin{array}{l}\text { Reconsider reducing and refining course content or } \\
\text { eliminating some courses. }\end{array}$ & 14 & 4.43 & 3.29 \\
\hline 48 & Intensifying/Enhancing the English language program. & 14 & 4.36 & 3.93 \\
\hline 5 & $\begin{array}{l}\text { Merging some of PY's similar courses after reviewing } \\
\text { their syllabi. }\end{array}$ & 14 & 4.29 & 3.00 \\
\hline 4 & $\begin{array}{l}\text { Reviewing student assessment mechanisms (student's } \\
\text { acceleration/promotion) during the program for all } \\
\text { courses. }\end{array}$ & 14 & 4.21 & 3.14 \\
\hline 17 & $\begin{array}{l}\text { Reconsidering the students' timetables and credit } \\
\text { hours. }\end{array}$ & 14 & 4.21 & 3.00 \\
\hline 18 & Reviewing the medical track's study plan. & 14 & 3.93 & 3.50 \\
\hline
\end{tabular}

Male Group: Cluster 3: Program Philosophy, Planning, \& Operational Mechanism.

The Program Philosophy, Planning, and Operational Mechanism cluster consisted of seven statements. The statements highlighted on the necessity for developing the Preparatory Year Program's (PYP) philosophy, objectives, and operational methods or in short, a program pedagogy. The group of stakeholders suggested involving all the PYP's beneficiaries to plan and develop the program due to their feeling that the program did not fulfill the needs of either the students, parents, and/or colleges. 
Additionally, the cluster revealed three main issues: 1) selecting qualified faculty to teach first-year students; 2) not using the PYP's GPA to place students in their college; and 3) finally enhancing the overall learning environment. The differences among these themes are found in the Sorting Stage, where the participants combined all three of these issues in one cluster. This may be due to the lack of experience the participants have with the concept mapping process, so this is considered the first involvement for them in the chosen research methodology.

The definition for this cluster was "Developing the PY's philosophy, purpose, goals, and application concurrently with improving the overall learning environment and starting selfoperation for the program." A close examination on the survey outcomes exposed that the importance mean scores for six out of the seven statements in this cluster recorded a score above 4.00; this included S21 (M=4.36), S14 (M=4.29), S26 (M=4.29), S3 (M=4.21), S34 (M=4.21), and S42 $(M=4.14)$, while S16 $(M=3.86)$ fell between 4.00 and 3.00 .

In this cluster, a majority of the statements including S21, S14, S26, S3, and S16 recorded efficacy scores above 3.0 and less than 4.00, while S34, Developing the Preparatory Year self-operation mechanisms and phasing out of outsourcing to private companies, yielded efficacy score $(M=2.93)$, which is considered the lowest mean in this cluster. This result supported the fact stated in Chapter 1 about a challenge encountered by the PYP due to the reliance on the educational private sector to operate the academic program. Further, a close examination on the cluster outcomes revealed that statement S42, Developing and improving study halls/classrooms and the learning environment, is the only one in all 48 statements in the male group that yielded importance mean $(M=4.14)$, lower than its efficacy mean score $(\mathrm{M}=4.21)$. This result may reflect the participants' understanding about the definition of 'learning environment', which usually refers to the availability of infrastructure, technology, and 
supplies. Thus, participants rating this statement indicated that KSU performed effectively in providing an appropriate learning environment to develop student learning.

An observation on S26, Not linking the PY with academic/college placement $(\mathrm{M}=4.29)$, seemed to not belong to this cluster. The researcher believes that this statement could be better placed into the Program Applications Policy Cluster. On the Point Cluster Map (see Figure 11), S26 is closely located to the Program Applications Policy Cluster. Also, S16, Hiring faculty members from colleges who have experience in teaching first-year university students $(\mathrm{M}=3.86)$ appeared to fit in the Program Regulation Cluster despite the far distance between the two clusters. Similarly, from the researcher's perspective, S33, Reviewing the performance offaculty members in the Preparatory Year, that belonged to the Program Regulation Cluster (Cluster 1) is similar to statement S16, Hiring faculty members from colleges who have experience in teaching first-year university students, which is in the Program Philosophy, Planning, \& Operational Mechanism Cluster (Cluster 3). However, the researcher cannot disregard the Hierarchical Cluster Analysis (HCA) outcomes that was generated by the participants by making any changes in data sorting or rating.

Furthermore, S21, Reviewing the philosophy of the Preparatory Year and its purpose, reported the highest mean score in this cluster $(\mathrm{M}=4.36)$ and became the second lowest level of efficacy $(M=3.07)$. This conclusion revealed the importance of developing the program's philosophy and purpose, which may require King Saud University to take action addressing this issue in the future. Overall, the researcher considers the majority of statements in this cluster to fit well with the given definition. Table 12 shows the list of statements that belong to the Program Philosophy, Planning, and Operational Mechanism Cluster and their mean ratings for importance and efficacy. 
Table 12

List of Statements in the Program Philosophy, Planning and Operational Mechanism Cluster and Their Mean Ratings for Importance and Efficacy

\begin{tabular}{|c|c|c|c|c|}
\hline \multirow{2}{*}{$\begin{array}{l}\text { Item } \\
\text { number }\end{array}$} & \multirow[b]{2}{*}{ Statement } & \multirow[b]{2}{*}{$\mathrm{N}$} & \multicolumn{2}{|c|}{ Rating } \\
\hline & & & $\begin{array}{l}\text { Importance } \\
(M=4.1939)\end{array}$ & $\begin{array}{c}\text { Efficacy } \\
(M=3.357)\end{array}$ \\
\hline 21 & $\begin{array}{l}\text { Reviewing the philosophy of the Preparatory Year } \\
\text { and its purpose. }\end{array}$ & 14 & 4.36 & 3.07 \\
\hline 14 & $\begin{array}{l}\text { Involving all Preparatory Year } \\
\text { beneficiaries/stakeholders in the development of its } \\
\text { plan. }\end{array}$ & 14 & 4.29 & 3.14 \\
\hline 26 & Not linking the PY with academic/college placement. & 14 & 4.29 & 3.21 \\
\hline 3 & $\begin{array}{l}\text { Reformulating and redefining the Preparatory Year's } \\
\text { objectives. }\end{array}$ & 14 & 4.21 & 3.86 \\
\hline 34 & $\begin{array}{l}\text { Developing the Preparatory Year's self-operation } \\
\text { mechanisms and phasing out of outsourcing to private } \\
\text { companies. }\end{array}$ & 14 & 4.21 & 2.93 \\
\hline 42 & $\begin{array}{l}\text { Developing and improving study halls/classrooms } \\
\text { and the learning environment. }\end{array}$ & 14 & 4.14 & 4.21 \\
\hline 16 & $\begin{array}{l}\text { Hiring faculty members from colleges who have } \\
\text { experience in teaching first-year university students. }\end{array}$ & 14 & 3.86 & 3.07 \\
\hline
\end{tabular}

Male Group: Cluster 4: Program Academic Design. With eight statements, the Program Academic Design Cluster has the third highest number of items. This cluster is defined as “Identifying, developing, and organizing the essential skills that first-year student's need with more concentration on note taking, professional ethics, values, volunteer work, and responsible autonomy skills." This cluster addresses skills, activities, and values. The term 'skills' appeared in three statements, S22, S41, and S6. The word 'activities' was also seen in four statements, S28, S27, S24, and S43. The term 'values' that manifested in S7 suggests, Teaching students the basics of professional ethics and linking them to Islamic values.

Rating results revealed that all eight statements had a mean importance rating at or above 4.00. The highest rated statement was S43, Including gifted students' programs within the 
Preparatory Year Program (to discover and take care of them) (M=4.50). The lowest mean recorded was for S24, Providing activities that encourage students to participate in community service $(\mathrm{M}=4.00)$. For efficacy rating, statement $\mathrm{S} 43$ also reported the highest mean score at $(\mathrm{M}=4.00)$, and the lowest mean score was for statement S6, Developing note-taking skills during the lecture $(\mathrm{M}=3.00)$. In general, all eight statements in this cluster fell at or above a 3.00 score for efficacy rating.

A close investigation of these statements occurred, S41, Assessing students' knowledge and skills before and after the Preparatory Year Program, represented a theme may that may fit better in the Program Assessment Mechanism and Curriculum Structure Cluster (Cluster 4), which involves an assessment theme that appeared in the brainstorming session and the sorting task. However, on the Point Cluster Map (see Figure 11), S41's location was on the outer boundary of Cluster 4. As mentioned previously, the researcher cannot make any changes in the Hierarchical Cluster Analysis (HCA) outcomes that were generated by the participants' sorting data.

Furthermore, S27, Including activities into the Preparatory Year Program that are not offered by other colleges (Not providing extracurricular activities that will be offered after the Preparatory Year in colleges), is considered an organizational issue, which may encourage the PYP to redesign its program tasks and solve the overlap with university's colleges in terms of activities in the future. However, before deciding the final clusters number, S27 was placed in a separate cluster with S28 and S43 (see Figure 11). Due to the similarity among these statements in terms of its purpose and domains, the researcher and Concept Mapping/Pattern Matching $(\mathrm{CM} / \mathrm{PM})$ expert made a decision to combine the two clusters into one after referring to the Dendogram graph to support their decision (see Appendixes D). 
Overall, the participants did not mention a wide range of skills or activities or values, but they believe that more attention is required to develop and organize these essential aspects of the PYP mentioned in Cluster 4. Table 13 shows the list of statements in the Program Academic Design Cluster and their mean ratings for importance and efficacy.

Table 13

List of Statements in the Program Academic Design Cluster and Their Mean Ratings for Importance and Efficacy

\begin{tabular}{|c|c|c|c|c|}
\hline \multirow[b]{2}{*}{$\begin{array}{c}\text { Item } \\
\text { number }\end{array}$} & \multirow[b]{2}{*}{ Statement } & \multirow[b]{2}{*}{$\mathrm{N}$} & \multicolumn{2}{|c|}{ Rating } \\
\hline & & & $\begin{array}{l}\text { Importance } \\
(M=4.2054)\end{array}$ & $\begin{array}{c}\text { Efficacy } \\
(M=3.4554)\end{array}$ \\
\hline 43 & $\begin{array}{l}\text { Including gifted students' programs within the } \\
\text { Preparatory Year Program (to discover and take care } \\
\text { of them). }\end{array}$ & 14 & 4.50 & 4.00 \\
\hline 7 & $\begin{array}{l}\text { Teaching students the basics of professional ethics } \\
\text { and linking them to Islamic values. }\end{array}$ & 14 & 4.36 & 3.50 \\
\hline 22 & Developing the skills of responsible autonomy. & 14 & 4.21 & 3.36 \\
\hline 28 & $\begin{array}{l}\text { Avoiding overwhelming students with activities } \\
\text { offered by other colleges. }\end{array}$ & 14 & 4.21 & 3.36 \\
\hline 41 & $\begin{array}{l}\text { Assessing students' knowledge and skills before and } \\
\text { after the Preparatory Year Program. }\end{array}$ & 14 & 4.14 & 3.07 \\
\hline 27 & $\begin{array}{l}\text { Including activities into the Preparatory Year } \\
\text { Program that are not offered by other colleges (Not } \\
\text { providing extracurricular activities that will be } \\
\text { offered after the Preparatory Year in colleges). }\end{array}$ & 14 & 4.14 & 3.50 \\
\hline 6 & Developing note-taking skills during the lecture. & 14 & 4.07 & 3.00 \\
\hline 24 & $\begin{array}{l}\text { Providing activities that encourage students to } \\
\text { participate in community service. }\end{array}$ & 14 & 4.00 & 3.86 \\
\hline
\end{tabular}

Male Group: Cluster 5: Program Services: Prior to and During. With nine statements, the Program Services: Prior to and During Cluster is placed as the second largest cluster in the male group. This cluster is defined as "Providing prospective students services prior to and during the first-year to connect students with the university environment and help them to engage in the learning process through an orientation program, counseling services, 
cooperation with beneficiary, colleges, and high schools, and conducting awareness programs and workshops." The cluster definition concentrated on the PYP's future services and functions that connected to students rather than themes of administration or application or policy or academia.

Eight statements in this cluster were rated above 4.00 for importance: S9, S10, S8, S13, $\mathrm{S} 12$, S44, S30, and S23, while S15 recorded $(\mathrm{M}=3.79)$, which is considered the only mean below 4.00. Furthermore, for the efficacy rating, the same eight statements rated above 3.00, while statement S15, Organizing workshops for high school students to identify and address weaknesses of the Preparatory Year students, was still below 3.00 (M=2.93). The result for S15 indicated that the participants support the idea of educating high school students about the PYP, and also supported the idea of addressing the weaknesses of the PY students at the same time. This statement may have two different ideas, however, the group of stakeholders placed it into one statement.

A close examination for cluster statements revealed that statement $\mathrm{S} 9$, Introducing the university's facilities and services to students to take advantage of them (orientation program), and S10, Educating students about libraries and research resources, are the highest means in the importance rating $(\mathrm{M}=4.57)$. Furthermore, S44, Assigning students to visit their future colleges in coordination with them to learn closely about the offered majors, and S30, Providing academic counseling services for high school students before the Preparatory Year, yielded an importance mean at $(\mathrm{M}=4.29)$.

The nine statements reveal the necessity of developing academic services and university's facilities before and during the students first-year of college, which may make their transition easier and successful by establishing a bridge between their experiences at high school 
and their first-year university experiences. Additionally, such practice could help them to engage in the learning process easily in the future. Table 14 shows the list of statements in the Program Services: Prior to and During Cluster and their mean ratings for importance and efficacy.

Table 14

List of Statements in the Program Services: Prior to and During Cluster and Their Mean Ratings for Importance and Efficacy

\begin{tabular}{|c|c|c|c|c|}
\hline \multirow{2}{*}{$\begin{array}{l}\text { Item } \\
\text { number }\end{array}$} & \multirow[b]{2}{*}{ Statement } & \multirow[b]{2}{*}{$\mathrm{N}$} & \multicolumn{2}{|c|}{ Rating } \\
\hline & & & $\begin{array}{l}\text { Importance } \\
(M=4.3333)\end{array}$ & $\begin{array}{c}\text { Efficacy } \\
(M=3.5079)\end{array}$ \\
\hline 9 & $\begin{array}{l}\text { Introducing the university's facilities and services to } \\
\text { students to take advantage of them (orientation } \\
\text { program). }\end{array}$ & 14 & 4.57 & 3.71 \\
\hline 10 & $\begin{array}{l}\text { Educating students about libraries and research } \\
\text { resources. }\end{array}$ & 14 & 4.57 & 3.57 \\
\hline 8 & $\begin{array}{l}\text { Educating students about the university's regulations } \\
\text { and their rights. }\end{array}$ & 14 & 4.50 & 3.86 \\
\hline 13 & Educating students about majors' requirements. & 14 & 4.43 & 3.50 \\
\hline 12 & $\begin{array}{l}\text { Adding activities and guidance programs that help } \\
\text { students choose their majors. }\end{array}$ & 14 & 4.43 & 3.71 \\
\hline 44 & $\begin{array}{l}\text { Assigning students to visit their future colleges in } \\
\text { coordination with them to learn closely about the } \\
\text { offered majors. }\end{array}$ & 14 & 4.29 & 3.50 \\
\hline 30 & $\begin{array}{l}\text { Providing academic counseling services for high } \\
\text { school students before the Preparatory Year. }\end{array}$ & 14 & 4.29 & 3.36 \\
\hline 23 & $\begin{array}{l}\text { Providing services needed by students through } \\
\text { workshops and through the cooperation between } \\
\text { colleges and the Preparatory Year Deanship. }\end{array}$ & 14 & 4.14 & 3.43 \\
\hline 15 & $\begin{array}{l}\text { Organizing workshops for high school students to } \\
\text { identify and address weaknesses of Preparatory Year } \\
\text { students. }\end{array}$ & 14 & 3.79 & 2.93 \\
\hline
\end{tabular}

Male Group: Cluster 6: Supporting Student Learning. With four statements, the Supporting Student Learning Cluster is the second smallest cluster in the male group in terms of number of statements. This cluster is defined as "Developing extra academic programs and services to foster student learning and to improve critical thinking skills and creativity." This 
cluster revealed the importance of supporting student learning, especially developing critical thinking and creativity skills.

Two statements in this cluster were rated between 3.00 and 4.00; S47, Developing tutoring programs according to students' needs $(\mathrm{M}=3.86)$, and $\mathrm{S} 20$, Providing extra training hours that do not conflict with current study hours $(\mathrm{M}=3.79)$. The other two statements were above 4.00; S11, Adding course activities that promote and motivate students' learning $(\mathrm{M}=4.29)$, and $\mathrm{S} 35$, Emphasizing critical thinking skills and creativity $(\mathrm{M}=4.21)$. A close examination for each statement revealed that S11 and S35 are considered essential by participants' perceptions and are related to the academic and learning aspects, while S47 and S20 are measured as less important, because they may lean more towards being an administration issue than academic matter.

For the efficacy rating, all four statements yielded scores between 3.00 and 4.00. Further, S47 reported the second highest rating next to S42 in Cluster 3 across all seven clusters in the male group with an efficacy rating higher than the importance rating as follows: S47's importance was $(M=3.86)$ and efficacy was $(M=3.93)$. This result indicated that the Preparatory Year Program (PYP) at King Saud University (KSU) performed effectively to provide students extra educational support, such as tutoring. Overall, four statements in this cluster share a common feature and fit well in the cluster. Table 15 shows the list of statements in the Supporting Student Learning Cluster and their mean ratings for importance and efficacy. Table 15

List of Statements in the Supporting Student Learning Cluster and Their Mean Ratings for Importance and Efficacy

\begin{tabular}{ccccc}
\hline \multirow{2}{*}{$\begin{array}{c}\text { Item } \\
\text { number }\end{array}$} & Statement & $\mathrm{N}$ & \multicolumn{2}{c}{ Rating } \\
\cline { 4 - 5 } & & & $\begin{array}{c}\text { Importance } \\
(M=4.0357)\end{array}$ & $\begin{array}{c}\text { Efficacy } \\
(M=3.7857)\end{array}$ \\
\hline 11 & Adding course activities that promote and motivate & 14 & 4.29 & 3.86
\end{tabular}


students' learning.

35 Emphasizing critical thinking skills and creativity. $\quad 14 \quad 4.21 \quad 3.71$

47 Developing tutoring programs according to students' $14 \quad 3.86 \quad 3.93$ needs.

20 Providing extra training hours that do not conflict $\quad \begin{array}{lll}14 & 3.79 & 3.64\end{array}$ with the current study hours.

Male Group: Cluster 7: Program Applications Policy. Like Clusters 4 and 5, Cluster 7 consisted of two clusters before the combination decision. The assigned definition for this cluster was "Developing a program policy and design to be part of colleges academic programs, to support students who cannot pass the PYP, and to address student's departure issue during or after the PYP." This cluster consisted of six statements that revolved around the issues of developing a program application policy in a way that may completely change the Preparatory Year Program's (PYP) current working model at King Saud University (KSU).

For example, S29, Implementing the Preparatory Year Program within colleges in accordance with major tracks; this statement suggested that applying to PYP should occur within the academic programs of KSU's Colleges, not in a separate deanship like the current working model. Further, S39, Developing programs to address student dropout in the Preparatory Year or beyond, which suggests expanding the current mission of the PYP from focusing on developing student's skills or filtering them based on their academic performance to study student's retention and dropout issues. In other words, developing the program on theory-base not only on best practices-base. Further, S37, Setting clear and specific options in advance for students who do not pass the Preparatory Year, exposed a critical issue regarding the equality in education for those who did not pass the PYP. This statement was recommended to the PYP's policymaker to set and provide some options for those students in advance to treat their situation and ensure that they will get a chance to complete their study. This statement yielded efficacy scores of 
$(\mathrm{M}=3.07)$ and has the second lowest rating in this cluster, which indicates that KSU performed ineffectively on this dimension.

Overall, the six statements recording importance rating was at or above 4.00: S36 and $\mathrm{S} 37(\mathrm{M}=4.57), \mathrm{S} 25$ and S39 $(\mathrm{M}=4.50), \mathrm{S} 46(\mathrm{M}=4.36)$, and $\mathrm{S} 29(\mathrm{M}=4.00)$. For the efficacy rating, S36, S37, S25, S39, and S46 yielded mean scores above 3.00, while S29 was the only reported rating that fell below 3.00 at $(\mathrm{M}=2.46)$, which means that KSU was ineffective to address the issue of implementing PYP within colleges and their majors. The six statements fit in this cluster and match its definition well from the researcher's perspective. Table 16 shows the list of statements in the Program Applications Policy Cluster and their mean ratings for importance and efficacy.

Table 16

List of Statements in the Program Applications Policy Cluster and Their Mean Ratings for Importance and Efficacy

\begin{tabular}{|c|c|c|c|c|}
\hline \multirow[b]{2}{*}{$\begin{array}{c}\text { Item } \\
\text { number }\end{array}$} & \multirow[b]{2}{*}{ Statement } & \multirow[b]{2}{*}{$\mathrm{N}$} & \multicolumn{2}{|c|}{ Rating } \\
\hline & & & $\begin{array}{l}\text { Importance } \\
(\mathrm{M}=4.4167)\end{array}$ & $\begin{array}{c}\text { Efficacy } \\
(\mathrm{M}=3.2262)\end{array}$ \\
\hline 36 & Preparing students for subsequent university study. & 14 & 4.57 & 3.36 \\
\hline 37 & $\begin{array}{l}\text { Setting clear and specific options in advance for } \\
\text { students who do not pass the Preparatory Year. }\end{array}$ & 14 & 4.57 & 3.07 \\
\hline 25 & $\begin{array}{l}\text { Coordinating with beneficiary colleges to choose the } \\
\text { knowledge topics and skills that serve their majors. }\end{array}$ & 14 & 4.50 & 3.29 \\
\hline 39 & $\begin{array}{l}\text { Developing programs to address student dropout in } \\
\text { the Preparatory Year or beyond. }\end{array}$ & 14 & 4.50 & 3.21 \\
\hline 46 & $\begin{array}{l}\text { Developing a partnership with charitable and } \\
\text { voluntary organizations and invite them to be } \\
\text { present and represented in the Preparatory Year. }\end{array}$ & 14 & 4.36 & 3.79 \\
\hline 29 & $\begin{array}{l}\text { Implementing the Preparatory Year Program within } \\
\text { colleges in accordance with major tracks. }\end{array}$ & 14 & 4.00 & 2.46 \\
\hline
\end{tabular}

\section{The Total Importance and Efficacy Mean Scores for Each Cluster in the Male}

Group. The stakeholder's responses to the survey for 48 statements were calculated and 
averaged to reveal the mean scores for the importance and efficacy for each cluster. The rated tasks exposed participants' perceptions regarding the importance of the suggestions for the future ideal functions of the Preparatory Year Program (PYP) at King Saud University (KSU). The suggestions were generated in the brainstorming sessions and revealed the effectiveness of the current working model of the PYP at KSU to implement these 48 outcomes.

All seven clusters recorded important rating mean scores above 4.00 on a 5-point Ordinal Scale. The Program Regulation Cluster rated the highest $(M=4.48)$ followed by the Program Applications Policy Cluster (M=4.42). In the third level of importance the Program Assessment Mechanism and Curriculum Structure Cluster rated $(M=4.36)$ and the Program Services: Prior to and During rated $(\mathrm{M}=4.33)$. The Program Academic Design Cluster, and the Program Philosophy, Planning, and Operational Mechanism Cluster rated (M=4.21) and $(\mathrm{M}=4.19)$ respectively. In the lowest level of importance, the Supporting Student Learning Cluster rated $(\mathrm{M}=4.04)$.

Overall, the participants reached a consensus about the importance of the seven clusters and its themes to develop the PYP Conceptual Framework for Successful Transition of FirstYear Saudi Students into Postsecondary Education at KSU.

In terms of efficacy rating, all seven clusters rating fell between 3.00 and 4.00 on a 5point Ordinal Scale. The lowest efficacy rating was for Cluster 7, the Program Applications Policy Cluster, which rated at $(M=3.23)$. The highest efficacy rating was Cluster 6 , the Supporting Student Learning Cluster at $(\mathrm{M}=3.79)$. On closer examination for the Program Regulation Cluster (M=3.39), the Program Assessment Mechanism and Curriculum Structure Cluster (M=3.38), and the Program Philosophy, Planning, and Operational Mechanism Cluster $(M=3.36)$, the survey analysis revealed that all three clusters ratings were close to each other. 
Although, all clusters' efficacy ratings were above the midpoint on a 5-point Ordinal Scale, the participants' perceptions acknowledge that King Saud University (KSU) may need to improve, develop, change some of the current practices of the PYP. For example, changing the program application policy in terms of student's academic placement regulation. Table 17 displays the important and efficacy rating for the seven clusters in the male group.

Table 17

The Importance and Efficacy Mean Scores for Each Cluster in the Male Group

\begin{tabular}{cllcc}
\hline \multirow{2}{*}{ Cluster } & \multicolumn{1}{c}{ Label } & $\mathrm{N}$ & \multicolumn{2}{c}{ Rating } \\
\cline { 4 - 5 } & & & Importance & Efficacy \\
\hline 1 & Program Regulation & 14 & 4.48 & 3.39 \\
2 & $\begin{array}{l}\text { Program Assessment Mechanism and Curriculum } \\
\text { Structure }\end{array}$ & 14 & 4.36 & 3.38 \\
3 & Program Philosophy, Planning, and Operational & 14 & 4.19 & 3.36 \\
4 & Mechanism & & & \\
5 & Program Academic Design & 14 & 4.21 & 3.46 \\
6 & Program Services: Prior to and During & 14 & 4.33 & 3.51 \\
7 & Program Applications Policy & 14 & 4.04 & 3.79 \\
\hline
\end{tabular}

A visual representation of the Pattern Matching was performed at the cluster level for importance and efficacy ratings as shown in Figure 15. For specific clusters, the perfect match between the values of important and efficacy ratings manifested as a straight horizontal line connecting the important and efficacy values (Kane \& Trochim, 2007). The ladder graph in Figure 15 demonstrations that there are differences in the stakeholders' perceptions regarding the importance of outcomes versus their perceptions concerning the efficacy at KSU in developing the PYP functions. As mentioned earlier, the ladder graph indicated that KSU is ineffective to address these issues in the PYP despite its importance. 


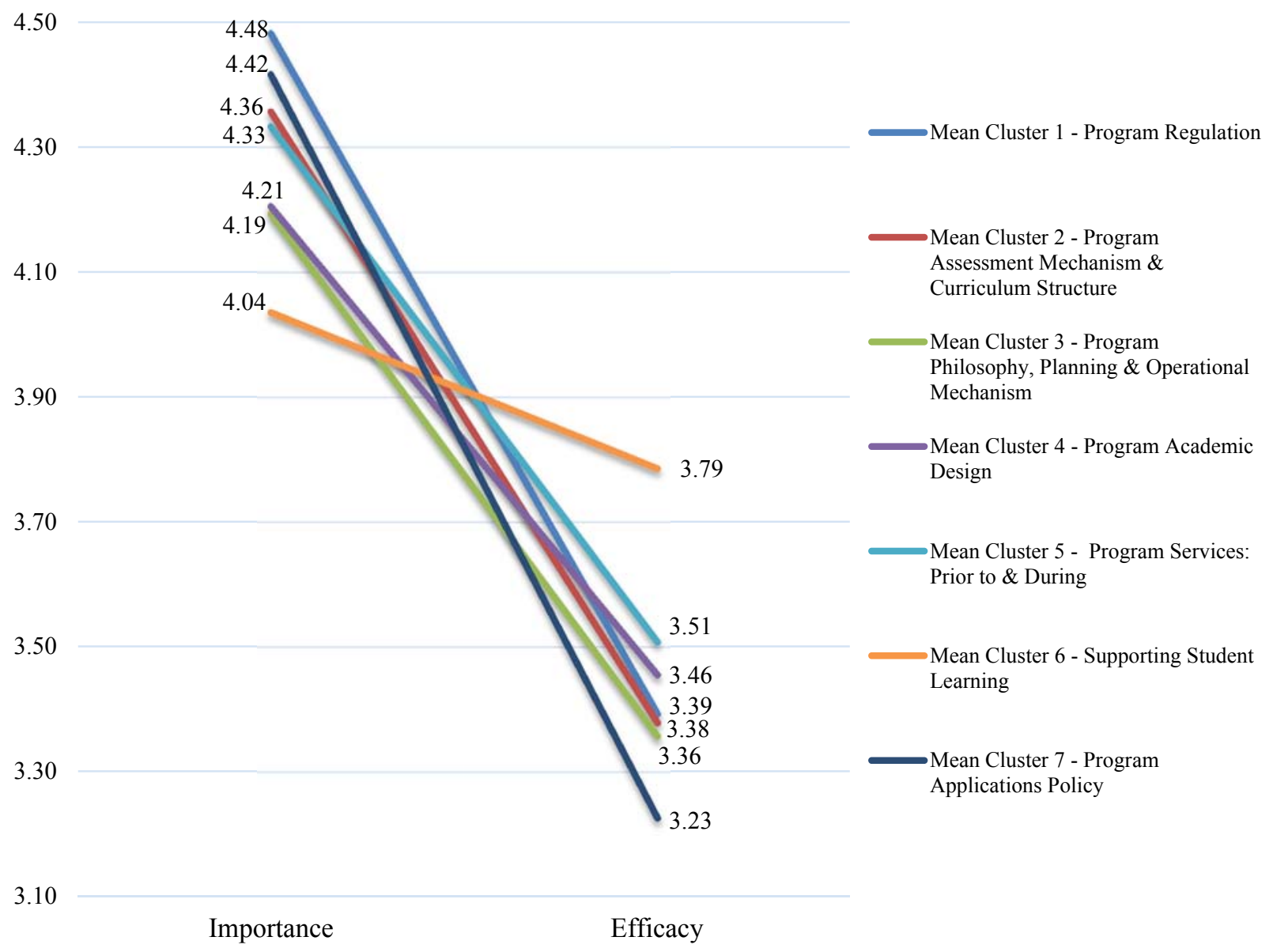

Figure 15: Ladder graph displaying the mean ratings of importance and efficacy for each cluster from the male group.

In the following section, the researcher is still continuing to answer the first research question: "Using the Concept Mapping/Pattern Matching methodology, how do Saudi male and female postsecondary stakeholders conceptualize the future ideal functions of the Preparatory Year Deanship to help students successfully transition into their first-year of college/university?" For each cluster, the statements are sorted in order from highest to lowest, according to the mean scores for the importance of the result.

\section{Female Group: Cluster 1: Program Assessment Mechanism and Curriculum}

Structure. The Program Assessment Mechanism and Curriculum Structure Cluster involves 
seven statements that revolve around the assessment of student learning and curriculum's structure. It is important to note that when determining the number of clusters for females, the researcher carefully considered whether to consider this a single intact cluster or two separate clusters. The majority of statements exposed the importance of developing assessment strategies to identify actual student's needs and provide appropriate curriculums to help students succeed. The given definition for this cluster is 'Developing students' learning assessment approaches to foster student's learning, restructuring the Preparatory Year Program (PYP) curriculums content, syllabus, and comparing/contrasting with public education curriculums”.

The seven statements rated at 4.00 or above on a 5-point Ordinal Scale. As observed this cluster is the only one, from both the male and female clusters, to have a reported mean of 5.00 for importance among all statements: S17, Reviewing the Preparatory Year curriculum and comparing/contrasting them with public education curriculum $(\mathrm{M}=5.00)$. Two statements were rated at (M=4.00) as follows: $\mathrm{S} 2$, Reassessing the importance of teaching (some) courses in the Preparatory Year, for example, health and fitness courses, and S22, The inclusion of some courses for all study tracks such as English, which are considered to be of the lowest importance level in this cluster. S3 and S20 rated at (M=4.44), while statement S1, Developing an instrument to measure student's level, for example, English language skills, rated the second highest level in the cluster at $(M=4.78)$. Finally $\mathrm{S} 11$ rated at $(\mathrm{M}=4.56)$. Generally, the group of participants seemed more interested in developing the PYP's curriculum and assessment approaches based on student's needs not only on the institute's vision-based.

For efficacy, the group of participants rated six statements above 3.00. The highest efficacy score was for $\mathrm{S} 1$ at $(\mathrm{M}=3.78)$. The lowest score of efficacy was for $\mathrm{S} 2(\mathrm{M}=2.87)$, this statement also reported the lowest importance score in the cluster. This result expressed female 
concern about specific courses that may be considered unimportant for them e. g. health and fitness courses, thus making King Saud University (KSU) seem ineffective to address this concern. However, for all seven statements, the group of participants' perceptions revealed that KSU is ineffective to address these challenges and develop the PYP functions based on student's actual needs, either male or female. Overall, from the researcher's perspective, all seven statements fit well in this cluster and the given definition is suitable to describe the cluster's ideas and concerns. Table 18 shows the list of statements in the Program Assessment Mechanism and Curriculum Structure Cluster and their mean ratings for importance and efficacy.

Table 18

List of Statements in the Program Assessment Mechanism and Curriculum Structure Cluster and Their Mean Ratings for Importance and Efficacy

\begin{tabular}{|c|c|c|c|c|}
\hline \multirow{2}{*}{$\begin{array}{l}\text { Item } \\
\text { number }\end{array}$} & \multirow[b]{2}{*}{ Statement } & \multirow[b]{2}{*}{$\mathrm{N}$} & \multicolumn{2}{|c|}{ Rating } \\
\hline & & & $\begin{array}{l}\text { Importance } \\
(M=4.4603)\end{array}$ & $\begin{array}{c}\text { Efficacy } \\
(M=3.3651)\end{array}$ \\
\hline 17 & $\begin{array}{l}\text { Reviewing the Preparatory Year curriculum and } \\
\text { comparing/contrasting them with public education } \\
\text { curriculum. }\end{array}$ & 9 & 5.00 & 3.33 \\
\hline 1 & $\begin{array}{l}\text { Developing an instrument to measure student's } \\
\text { level, for example, English language skills. }\end{array}$ & 9 & 4.78 & 3.78 \\
\hline 11 & $\begin{array}{l}\text { Students can pass some of the Preparatory Year } \\
\text { courses directly. }\end{array}$ & 9 & 4.56 & 3.22 \\
\hline 3 & $\begin{array}{l}\text { Passing the placement tests for the Preparatory Year } \\
\text { courses. }\end{array}$ & 9 & 4.44 & 3.11 \\
\hline 20 & $\begin{array}{l}\text { Determining the course timeline based on students' } \\
\text { needs. }\end{array}$ & 9 & 4.44 & 3.67 \\
\hline 2 & $\begin{array}{l}\text { Reassessing the importance of teaching (some) } \\
\text { courses in the Preparatory Year, for example, health } \\
\text { and fitness courses. }\end{array}$ & 9 & 4.00 & 2.87 \\
\hline 22 & $\begin{array}{l}\text { The inclusion of some courses for all study tracks } \\
\text { such as English. }\end{array}$ & 9 & 4.00 & 3.67 \\
\hline
\end{tabular}

Female Group: Cluster 2: Program Academic Design. With 10 total statements, this cluster is considered the largest one in the female group. This cluster consisted of two clusters before the combination decision. As mentioned in Cluster 1, the group of participants suggested 
assessing student's needs before developing curriculum, so that it is based on student's needs; this cluster provided some ideas and solutions to develop the PYP's academic design for the future. For example, S32 suggested that: Merging some courses together such as research skills and communication skills under one course, named the skills course. Thus, the majority of statements in this cluster revealed the importance of redesigning the academic program, curriculum, activities, and focus from theory to practice. The cluster's definition is "Identifying, developing, organizing, and emerging some of the program courses with concentrating on practices, extra-curricular, and applied skills more than theory".

For the importance rating, all eight statements yielded mean scores above 4.00 and fell between 3.00 and 4.00 on a 5-point Ordinal Scale. The highest importance score was for S24 $(\mathrm{M}=4.89)$ and the lowest score was assigned to S33, Self-development skills can be acquired during the study through workshops and courses that are offered by the Deanship of Student Affairs $(\mathrm{M}=3.33)$. A close examination on this cluster's statements, S24, S9, S4, and S30 reported the highest scores of importance as follows:

- S24: Focusing on the practical aspects that ensure students will maintain skills such as the English language $(\mathrm{M}=4.89)$;

- S9: Emphasizing practical, applied, and skills aspects not just a compilation of grades for academic placement $(\mathrm{M}=4.78)$;

- S4: Reducing theoretical hours for the courses that require practical application such as communication and computer skills $(\mathrm{M}=4.67)$;

- S30: Implementing independent learning more than lectures $(\mathrm{M}=4.56)$.

To a large extent, these four statements focused on developing curriculum design to be more practical than just providing knowledge and theories. For the efficacy rating, the result 
revealed that all 10 statements yielded mean scores above the mid-point on a 5-point Ordinal Scale. The highest efficacy score was for S34, Extra-curricular activities play an important role in the refinement of students' skills $(\mathrm{M}=4.22)$, which means that participants perceive KSU to be performing effectively in providing its students extra-curricular activities. The result of the mean importance score for this statement was $(M=4.44)$, which is higher than effective score. Further, statements S24, S9, S4, S30, (S8), and (S15) yielded efficacy scores that fell between 3.00 and 4.00. Three statements, $\mathrm{S} 32(\mathrm{M}=2.56), \mathrm{S} 35(\mathrm{M}=2.89)$, and $\mathrm{S} 33(\mathrm{M}=2.56)$ yielded mean efficacy scores below 3.00. The three statements suggest redesigning some of the PYP's courses and curriculums.

Overall, KSU may need to pay more attention to redesigning the PYP's academic program. From the researcher's perception, all statements are acceptable to be in this cluster and matched the assigned definition. Table 19 shows the list of statements in the Program Academic Design Cluster and their mean ratings for importance and efficacy.

Table 19

List of Statements in the Program Academic Design Cluster and Their Mean Ratings for Importance and Efficacy

\begin{tabular}{clccc}
\hline \multirow{2}{*}{$\begin{array}{c}\text { Item } \\
\text { number }\end{array}$} & \multicolumn{1}{c}{ Statement } & \multicolumn{2}{c}{ Rating } \\
\cline { 3 - 4 } & & $\mathrm{N}$ & $\begin{array}{c}\text { Importance } \\
(M=4.2889)\end{array}$ & $\begin{array}{c}\text { Efficacy } \\
(M=3.1889)\end{array}$ \\
\hline 24 & $\begin{array}{l}\text { Focusing on the practical aspects that ensure } \\
\text { students will maintain skills such as the English } \\
\text { language. }\end{array}$ & 9.89 & 3.44 \\
9 & $\begin{array}{l}\text { Emphasizing practical, applied, and skills aspects } \\
\text { not just a compilation of grades for academic } \\
\text { placement. }\end{array}$ & 9 & 4.78 & 3.22 \\
4 & $\begin{array}{l}\text { Reducing theoretical hours for the courses that } \\
\text { require practical application such as communication } \\
\text { and computer skills. }\end{array}$ & 9 & 4.67 & 3.22 \\
30 & $\begin{array}{l}\text { Implementing independent learning more than } \\
\text { lectures. }\end{array}$ & 9 & 4.56 & 3.22 \\
$\begin{array}{l}\text { Extra-curricular activities play an important role in } \\
\text { the refinement of students' skills. }\end{array}$ & 9 & 4.44 & 4.22
\end{tabular}


8 Canceling some of the redundant courses or merging
them into a single course, for example, math skills.

\begin{tabular}{|c|c|c|c|}
\hline 15 & $\begin{array}{l}\text { All offered skills are important and should not be } \\
\text { specific for the Preparatory Year. }\end{array}$ & 9 & 4.11 \\
\hline & $\begin{array}{l}\text { Merging some courses together, such as research } \\
\text { skills and communication skills, under one course, } \\
\text { named the skills course. }\end{array}$ & 9 & 4.00 \\
\hline & $\begin{array}{l}\text { Integrating some skills, such as speech and scientific } \\
\text { research, during the study of language. }\end{array}$ & 9 & 3.89 \\
\hline & $\begin{array}{l}\text { Self-development skills can be acquired during the } \\
\text { study through workshops and courses that are } \\
\text { offered by the Deanship of Student Affairs. }\end{array}$ & 9 & 3.33 \\
\hline
\end{tabular}

Female Group: Cluster 3: Teaching Quality. With three statements total, this cluster had the fewest number of items for the female group. The three statements in this cluster revealed a concern regarding the teaching practices at PYP. This cluster's definition is "Ensuring the quality and capability of faculty at the PYP to deal with first-year students." The three statements rated above 4.00 on a 5-point Ordinal Scale. The highest mean score was for S16, Diversifying teaching strategies to shorten time $(M=4.67)$.

For efficacy rating, the lowest mean score recorded was for S5, Assigning a stable educational entity to run the courses (with low possibility of management change) $(\mathrm{M}=3.00)$. Furthermore, S12, Ensuring that faculty members have the necessary capability to deal with students at this age, recorded the highest efficacy rating in this cluster $(\mathrm{M}=4.00)$.

In summary, this cluster concentrated on the teaching quality of first-year female students. The result exposed that KSU seemed ineffective to address teaching quality concerns in the female section at the PYP. Finally, the three statements are connected to each other in terms of meaning and similarity, and matched the definition allocated for this cluster. Table 20 shows the list of statements in the Teaching Quality Cluster and their mean ratings for importance and efficacy.

Table 20 
List of Statements in the Teaching Quality Cluster and Their Mean Ratings for Importance and Efficacy

\begin{tabular}{cllcc}
\hline \multirow{2}{*}{$\begin{array}{c}\text { Item } \\
\text { number }\end{array}$} & \multicolumn{1}{c}{ Statement } & $\mathrm{N}$ & \multicolumn{2}{c}{ Rating } \\
\cline { 4 - 5 } & & & $\begin{array}{c}\text { Importance } \\
(M=4.5185)\end{array}$ & $\begin{array}{c}\text { Efficacy } \\
(M=3.6296)\end{array}$ \\
\hline 16 & Diversifying teaching strategies to shorten time. & 9 & 4.67 & 3.89 \\
12 & $\begin{array}{l}\text { Ensuring that faculty members have the necessary } \\
\text { capability to deal with students at this age. }\end{array}$ & 9 & 4.56 & 4.00 \\
5 & $\begin{array}{l}\text { Assigning a stable educational entity to run the } \\
\text { courses (with low possibility of management } \\
\text { change). }\end{array}$ & 9 & 4.33 & 3.00 \\
\hline
\end{tabular}

Female Group: Cluster 4: Program Regulation. This cluster consisted of eight statements; the second highest for the female group. Seven of the eight statements concentrated and presented one issue that related to the student academic placement rule at the PYP. The definition assigned for this cluster is "Developing program rules to make the academic/college placement for all students on specific track/major before the PYP rather than after the PY's completion, and do not count the PYP's GPA to determine the future college or major."

For importance rating seven statements rated above 4.00 and only one statement received a mean score between 3.00 and 4.00 on a 5-point Ordinal Scale. Further, S6, Applying the academic/college placement at the beginning of the Preparatory Year, S19, Identifying academic track/major from the first day of study, S23, Applying academic placement for all students before entering the Preparatory Year to make students focus more on academic achievement, and S31, Implementing academic placement from the beginning, recorded similar mean scores and fell as the highest in the cluster at $(M=4.78)$. In fact, these four statements content is similar and express one idea before the cluster combination decision; these four statements were grouped in one cluster (see Figure 12). Additionally, only one statement rated below 4.00 for importance, S29, To be a Preparatory Program not a Preparatory Year $(\mathrm{M}=3.78)$. This statement actually appears to be an anomaly when compared to the others. A close examination of the Point Cluster Map 
(Figure 12), S29 is placed at a distance from other statements; but as mentioned earlier, the researcher cannot make any changes in the Hierarchical Cluster Analysis (HCA) outcomes that were generated by the participants' sorting data.

The efficacy rating results reported poor mean scores, where seven statements yielded mean scores below 3.00. One statement, S19, rated as the highest in this cluster at $(\mathrm{M}=3.33)$. Three statements S31, S7, and S21 scored at $(\mathrm{M}=2.89)$. Two statements, S6 and S18 reported $(M=2.78) . S 23$ was at $(M=2.67)$, and S29 was $(M=2.56)$, which is considered the lowest level of efficacy in this cluster, and this supports the pervious conclusion about this statement deliberation.

Overall, the participants' ratings for this cluster suggests King Saud University (KSU) ineffective to address the issues regarding student's academic placement and this regulation may need to be adjusted in the future. The ratings of importance for this cluster received the highest mean scores among all six clusters in the female group at $(\mathrm{M}=4.54)$, which indicated that the female group has a serious concern about the PYP regulation in the current working model, from the researcher's perception, all statements in this cluster fit well and match the cluster name and definition. Table 21 shows the list of statements in the Program Regulation Cluster and their mean ratings for importance and efficacy.

Table 21

List of Statements in the Program Regulation Cluster and Their Mean Ratings for Importance and Efficacy

\begin{tabular}{|c|c|c|c|c|}
\hline \multirow[b]{2}{*}{$\begin{array}{l}\text { Item } \\
\text { number }\end{array}$} & \multirow[b]{2}{*}{ Statement } & \multirow[b]{2}{*}{$\mathrm{N}$} & \multicolumn{2}{|c|}{ Rating } \\
\hline & & & $\begin{array}{l}\text { Importance } \\
(M=4.5417)\end{array}$ & $\begin{array}{c}\text { Efficacy } \\
(M=2.8472)\end{array}$ \\
\hline 6 & $\begin{array}{l}\text { Applying the academic/college placement at the } \\
\text { beginning of the Preparatory Year. }\end{array}$ & 9 & 4.78 & 2.78 \\
\hline 19 & $\begin{array}{l}\text { Identifying academic track/major from the first day } \\
\text { of study. }\end{array}$ & 9 & 4.78 & 3.33 \\
\hline 23 & Applying academic placement for all students before & 9 & 4.78 & 2.67 \\
\hline
\end{tabular}


entering the Preparatory Year to make students

focus more on academic achievement.

31 Implementing academic placement from the beginning.

18 Students' academic placement to be before the Preparatory Year.

$7 \quad$ Achieving the most benefit from the Preparatory Year (skills) by abolishing the academic placement policy after the Preparatory Year.

21 The Preparatory Year's GPA should not affect

$9 \quad 4.78$

$9 \quad 4.67$

$9 \quad 4.44$ choosing the future college of study.

To be a Preparatory Program not a Preparatory Year.

Female Group: Cluster 5: Program Services: Prior to and During. This cluster consists of four statements. The main theme in the cluster was to educate first-year students about university laws, regulation, and services. This cluster consisted of two clusters before the combination decision, since each had two statements. The group of stakeholders indicated that the orientation program was the main instrument to achieve this goal. The definition assigned for this cluster is "Developing the orientation program and counseling services to educate first-year students about their rights and duties, and the university's regulations”.

Three statements rated above 4.00 and one fell between 3.00 and 4.00 on a 5-point Ordinal Scale. S13, The necessity of educating students about their rights and duties, and S14, The importance of the orientation program for students before starting the study plan, rated at $(\mathrm{M}=4.56)$, which is considered the highest mean score in this cluster. S36, Increasing student awareness about university laws and regulations through a specialist department whenever they need advice, reported $(\mathrm{M}=4.33)$. The lowest mean score recorded was for $\mathrm{S} 10$, The Preparatory Year regulations should be issued by the Vice Dean of the Preparatory Year at (M=3.89). S10 seemed an anomaly due to its content stating an issue related to the administration authority system at the female section in the PYP. However, the group of participants and the Hierarchical Cluster Analysis (HCA) outcomes placed the statement within this group. 
For the efficacy ratings, the three statements, S13, S14, and S36, rated above 4.00, and $\mathrm{S} 10$ rated at $(\mathrm{M}=3.56)$. Although the data indicated that the importance rating is still higher than efficacy rating at KSU for this dimension, the group of stakeholders' perception may see King Saud University (KSU) performing effectively in the Program Services dimension.

Overall, the four statements are appropriate for this cluster and the definition assigned for the cluster matches the main theme from the researcher's standpoint. Table 22 shows the list of statements in the Program Services: Prior to and During Cluster and their mean ratings for importance and efficacy

Table 22

List of Statements in the Program Services: Prior to and During Cluster and Their Mean Ratings for Importance and Efficacy

\begin{tabular}{clccc}
\hline \multirow{2}{*}{$\begin{array}{c}\text { Item } \\
\text { number }\end{array}$} & \multicolumn{1}{c}{ Statement } & $\mathrm{N}$ & \multicolumn{2}{c}{ Rating } \\
\cline { 3 - 5 } & & $\begin{array}{l}\text { Importance } \\
(M=4.3333)\end{array}$ & $\begin{array}{c}\text { Efficacy } \\
(M=3.9722)\end{array}$ \\
\hline 13 & $\begin{array}{l}\text { The necessity of educating students about their } \\
\text { rights and duties. } \\
14\end{array}$ & 9 & 4.56 & 4.00 \\
& $\begin{array}{l}\text { The importance of the orientation program for } \\
\text { students before starting the study plan }\end{array}$ & 9.56 & 4.33 \\
$\begin{array}{l}\text { Increasing student awareness about university laws } \\
\text { and regulations through a specialist department } \\
\text { whenever they need advice. } \\
10\end{array}$ & 9 & 4.33 & 4.00 \\
$\begin{array}{l}\text { The Preparatory Year regulations should be issued } \\
\text { by the Vice Dean of the Preparatory Year. }\end{array}$ & 9 & 3.89 & 3.56 \\
\hline
\end{tabular}

Female Group: Cluster 6: Promoting Student Learning. This cluster is the last one in the female group and seemed similar to the previous one in terms of statement numbers, four. The main idea in this cluster is to promote student learning, in other words, raising the importance of female students and giving them more opportunities for participating and engaging in the global educational society. For example, S26, S28, and S25 suggested giving female students a chance to engage in international conferences, twining with lead universities in the world in some academic programs, and studying the English language abroad in short training 
programs. The definition assigned for this cluster is "Developing activities and academic programs that promote and stimulate student learning and raise student's engagement in the local and global contexts".

Three statements rated above 4.00 on a 5-point Ordinal Scale. The highest mean score was S27 at $(M=4.44)$, Publishing the outstanding research and media produced by students. S26 and S28 were recorded with the same mean score of $(M=4.433)$. S25, Organizing academic trips for distinguished students to study English language courses in international institutes, rated $(\mathrm{M}=3.78)$, which is important but lower than the others. Four statements rated above 3.00 for efficacy. S27 and S26 rated at $(M=3.78), S 28$ recorded $(M=3.22)$ and $(S 25)$ at $(M=3.00)$. In general, the efficacy rating was the least important rating for all four statements, which indicates that King Saud University (KSU) may need to be more effective in developing these dimensions in the future for the female section.

Overall, the homogeneity among these statements were high and all fit well together in the cluster. Furthermore, consulting the Point Cluster Map (see Figure 12), the proximity among these statements was very close due to the participants sorting. Table 23 shows the list of statements in the Promoting Student Learning Cluster and their mean ratings for importance and efficacy.

Table 23

List of Statements in the Promoting Student Learning Cluster and Their Mean Ratings for Importance and Efficacy

\begin{tabular}{|c|c|c|c|c|}
\hline \multirow[b]{2}{*}{$\begin{array}{c}\text { Item } \\
\text { number }\end{array}$} & \multirow[b]{2}{*}{ Statement } & \multirow[b]{2}{*}{$\mathrm{N}$} & \multicolumn{2}{|c|}{ Rating } \\
\hline & & & $\begin{array}{l}\text { Importance } \\
(M=4.2222)\end{array}$ & $\begin{array}{c}\text { Efficacy } \\
(M=3.4444)\end{array}$ \\
\hline 27 & $\begin{array}{l}\text { Publishing outstanding research and media produced } \\
\text { by students. }\end{array}$ & 9 & 4.44 & 3.78 \\
\hline 26 & $\begin{array}{l}\text { Engaging students in international conferences to } \\
\text { gain experience and contact with elites. }\end{array}$ & 9 & 4.33 & 3.78 \\
\hline 28 & Partnering with leading universities in adopting & 9 & 4.33 & 3.22 \\
\hline
\end{tabular}


outstanding students.
$\begin{array}{llll}25 & \text { Organizing academic trips for distinguished students } & 9 & 3.78\end{array}$ to study English language courses in international institutes.

\section{The Total Importance and Efficacy Mean Scores for Each Cluster in the Female}

Group. The responses of the stakeholders survey for 36 statements were calculated and averaged to reveal the mean scores for the importance and efficacy for each cluster. The rating exposed the participants' perceptions regarding the future ideal function of the Preparatory Year Program (PYP) at King Saud University (KSU) and disclosed the effectiveness of the current working model of the PYP to apply these outcomes. All six clusters recorded important ratings above 4.00 on a 5-point Ordinal Scale. The Program Regulation Cluster rated the highest at $(\mathrm{M}=4.4 .54)$ followed by the Teaching Quality Cluster $(\mathrm{M}=4.52)$. In the third level of importance, the Program Assessment Mechanism and Curriculum Structure Cluster rated at $(\mathrm{M}=4.46)$ and the Program Services: Prior to and During at $(M=4.33)$. The Program Academic Design Cluster recorded $(\mathrm{M}=4.29)$. In the lowest level of importance, the Promoting Student Learning cluster rated at $(\mathrm{M}=4.22)$. Overall, the participants reached a consensus about the importance of the six clusters and their themes to develop a Conceptual Framework for Successful Transition of FirstYear Saudi Students into Postsecondary Education at KSU.

For the efficacy rating, with one exception for Cluster 4, rated below 3.00, while the remaining five clusters rated above 3.00 on a 5-point Ordinal Scale. The lowest efficacy rating was for Cluster 4, the Program Regulation Cluster $(M=3.23)$. The highest cluster rated for efficacy rating was Cluster 5, the Program Services: Prior to and During Cluster $(\mathrm{M}=3.97)$. The Teaching Quality Cluster was rated the second highest level of efficacy $(\mathrm{M}=3.63)$, followed by the Promoting Student Learning Cluster $(M=3.44)$. For Clusters 1 and 2, the survey rating results recorded $(M=3.37)$ and $(M=3.19)$, which fell to the lowest second and third levels of efficacy 
correspondingly. The participants' perceptions acknowledge that King Saud University (KSU)

may need to give more attention to developing the Preparatory Year Program (PYP) functions in the female student's section. For example, improving teaching quality. Table 24 displays the importance and efficacy rating for the six clusters in the female group.

Table 24

The Importance and Efficacy Mean Scores for Each Cluster in Female Group

\begin{tabular}{|c|c|c|c|c|}
\hline \multirow{2}{*}{ Cluster } & \multirow{2}{*}{ Label } & \multirow{2}{*}{$\mathrm{N}$} & \multicolumn{2}{|c|}{ Rating } \\
\hline & & & Importance & Efficacy \\
\hline 1 & Program Assessment Mechanism \& Curriculum Structure & 9 & 4.46 & 3.37 \\
\hline 2 & Program Academic Design & 9 & 4.29 & 3.19 \\
\hline 3 & Teaching Quality & 9 & 4.52 & 3.63 \\
\hline 4 & Program Regulation & 9 & 4.54 & 2.85 \\
\hline 5 & Program Services: Prior to and During & 9 & 4.33 & 3.97 \\
\hline 6 & Promoting Student Learning & 9 & 4.22 & 3.44 \\
\hline
\end{tabular}

A visual representation of the Pattern Matching that was performed at the cluster level for importance and efficacy is shown in Figure 16 below. As mentioned previously in this chapter, the typical match between the values of important and efficacy ratings manifested as a straight horizontal line connecting the important and efficacy values (Kane and Trochim, 2007). The Ladder Graph in Figure 16 demonstrations that there are differences in the perceptions of stakeholders' for the female group regarding the importance of outcomes versus perceptions of efficacy at KSU, and that indicated KSU ineffective to address these concerns in the PYP despite its importance. 


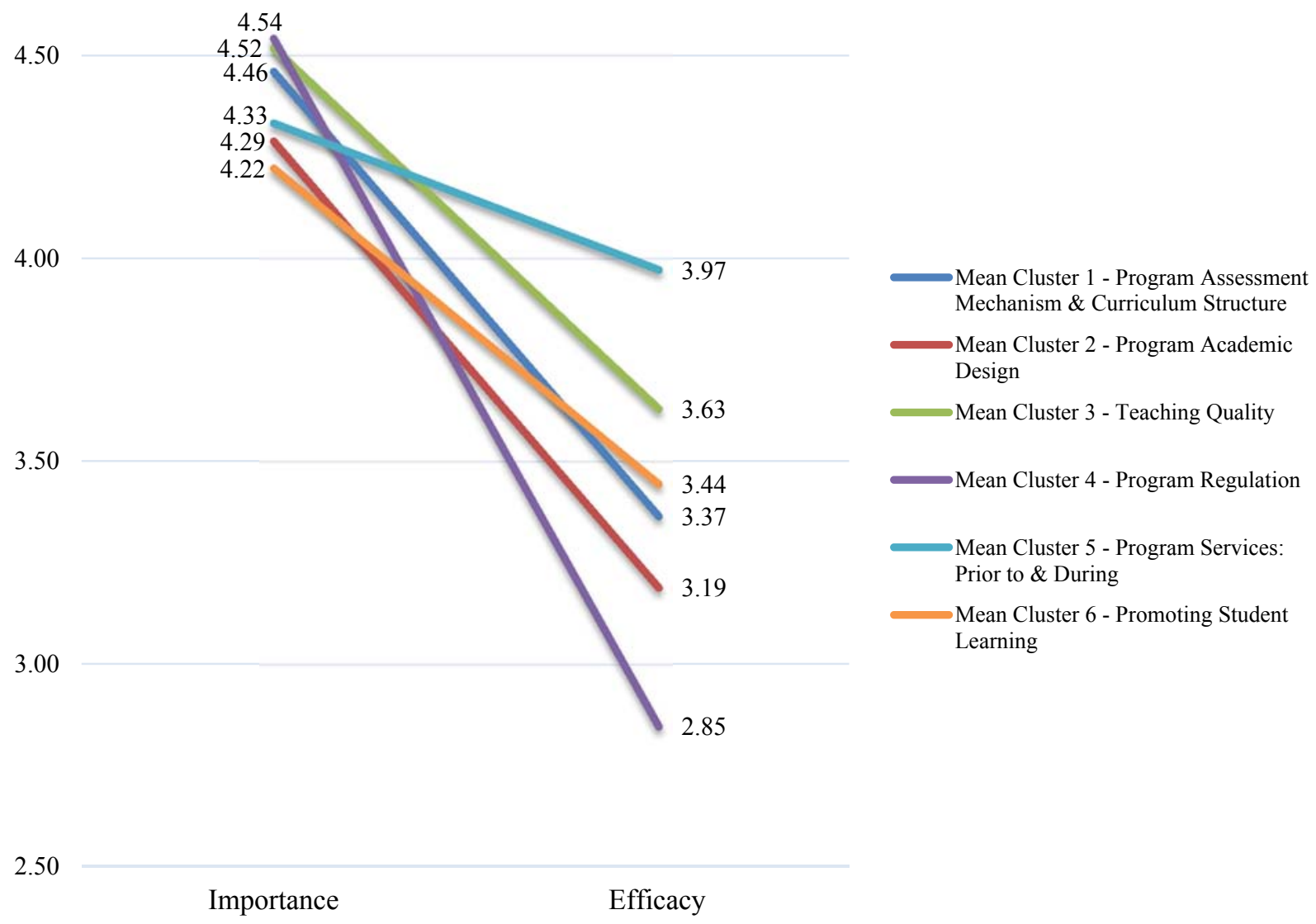

Figure 16: Ladder Graph displaying the mean ratings of importance and efficacy for the female group clusters

\section{Finding for Research Question 1a (Document Analysis)}

The first sub-question in this study was "Does this Concept Mapping/Pattern Matching $(\mathrm{CM} / \mathrm{PM})$ conceptualization compare and contrast with the current working model of the Preparatory Year Program at King Saud University?" To answer this question, the researcher performed a document analysis to compare and contrast the outcomes exposed by the CM/PM for male and female groups separately with the current working model of the Preparatory Year Program (PYP) at King Saud University (KSU). The comparison involved the 48 statements placed into 7-clusters for the male group and the 36 statements placed into 6-clusters for the female group. The researcher made a wide search and consulted the PYP's deanship, 
administrations, and faculty to inspect the availability of artifacts that describe the PYP's model and could be used to make the comparison. The search resulted in two official sources that can be used to portray the current working model of the PYP.

The primary source was the official Student's Guidebook developed by the Preparatory Year Deanship at KSU in 2016. This document is offered in two versions, one for males and the other for females (see Appendix M). The secondary source was the PY's official website, which the researcher used only to check and confirm some of the information provided by the Student's Guidebook, and to ensure the quality of translation from Arabic to English for some parts of the Student's Guidebook.

The researcher decided to use the Student's Guidebook because it is considered the only official description of the PYP's vision, mission, goals, policy, academic aspects, student services, and functions. The document is high-value in terms of providing details that could be used to examine the alignment of the current working model of the PYP with the CM/PM results generated by the stakeholder groups. Further, the document was prepared by a team of experts, including the PY Dean, Vice Deans, and representatives from all academic departments in the PYP with coordination with KSU's Academic Affairs and Student Affairs.

Additionally, the PYP deanship revises the document every year to ensure consistency of its content with KSU's policy and PY's regulations; therefore, the version used for this study was the most recently produced 2016 version. The Student's Guidebook was created based on university regulation and academic policy to achieve specific goals that match the university's strategic goals, this made it a vigorous tool to explore the PYP model. The document also provides a practical explanation for students, parents, faculty, and stakeholders about the PYP's mission, goals, academic policy, activities, services, curriculum instruction, and student 
assessment approaches that are used in the program. In other words, the Student's Guidebook is considered an applied document more than a theoretical document. Table 25 displays all 14 chapters as manifested in the Student's Guidebook with a brief explanation of its content.

Table 25

The Student's Guidebook Sections as appears in the Male and Female versions

\begin{tabular}{lll}
\hline \multirow{2}{*}{ Chapter } & $\begin{array}{l}\text { Student's } \\
\text { Guidebook Label }\end{array}$ \\
\end{tabular}

Vision:

To achieve leadership and excellence in providing a knowledge generation.

Mission:

To provide quality education in an environment with an incentive to learning and creativity, that is supported by optimal utilization of state-of-the-art technologies and excellent partnerships.

$1 \quad$ PY's Strategic Objectives:

Plan 1- Raising awareness and responsibility

2- Developing and maintaining excellent human resources

3- Fostering creativity and innovation while enhancing students' capabilities

4- Adopting a rigorous system for student assessment

5- Creating a knowledge stimulating environment

6- Improving quality control practices

7- Building distinguished partnerships

$2 \quad$ Academic Terminology

This chapter defines numerous concepts and terminology used in the PYP, e.g. PYP concept, study plan, courses, grades, tests, GPA, and academic warning.

This chapter contained a direction about academic system, course registration,

3 Academic System English placement test system, dropping, transferring and withdrawing, reenrollment after withdrawal, student transfer, attendance and denial, and passing a course.

This chapter involved a description about the PYP's curriculum, study plans, and student placement regulation after completing the PYP for all three academic tracks in the PY as follows:

- Health Colleges Track: It includes the colleges of Medicine, Dentistry, Pharmacy, Applied Medical Sciences, Nursing, and Prince Sultan College for

Curriculum and

4 Student's Emergency Medical Services;

- Engineering and Science Colleges Track: It includes the colleges of

Placement Engineering, College of Computer and Information Sciences, Architecture and Planning, Business Administration, and Food and Agriculture Sciences;

- Humanities Colleges Track: It includes the colleges of Arts, Education, Law and Political Science, Tourism and Antiquities, Languages, and Translation.

Further, the chapter includes information about the PYP's academic department and the courses offered.

$5 \quad$ Student's This chapter describes student assessment approaches that are comprised of: 1) 
Assessment

6

\section{Learning}

Resources

$7 \quad$ Student Affairs

\section{Student}

8 Enterprise

Initiative

9 continued assessment during the semester, e.g. quizzes, projects, and papers; and 2) tests that include a mid-term test and a final test for each course. Additionally, the chapter provides details about the grading policy for all courses and the method of calculating the cumulative GPA.

This chapter describes the learning resources that can support student's learning, e.g. libraries, e-learning tools and courses, and learning resource centers that provides computers, software, electronic journals and books, science movies, etc.

This chapter explains the Student Affairs mission at the PYP that includes:

- "Solving registration problems that students face in the beginning of each academic year;

- Coordinating timetables to the students best interest within regulations and availability;

- Providing the academic departments with students' lists and study timetables;

- Preparing the lists of denied students and entry marks;

- Processing students' transactions, such as re-registration, dropping and withdrawing, dropping a semester, make-up exams, removing students from the denied list, transfer of credits, discipline committee affairs, and student rights affairs, etc.

- Orienting students with academic departments, university regulations, study systems, and the PY by-laws;

- Organizing meetings for orienting the PY staff with the PY rules and regulations;

- Providing students with services, such as issuing university cards, issuing identification letters, travel vouchers, letters to health institutions, and printing timetables and academic records" (Student Affairs, n. d.).

This initiative only existed in the male section. This project considers a student initiative aims to develop student's skills and knowledge to plan, manage, and launch activities, enterprises, and volunteer work based on administration principles and quality. The project is established and managed by students themselves.

This unit provides several activities and clubs for students. For example, the science club, culture and arts club, social responsibility club, etc. This unit works to achieve numerous goals:

- "Providing a congenial environment for creativity, innovation, and selfdevelopment;

- Enhancing leadership skills, self-confidence, and instilling a sense of responsibility and initiative;

- Realizing life-long learning and building a society that fosters continuous learning;

- Encouraging students to play constructive and positive roles in learning;

- Assisting students to optimize university life;

- Building learning outcomes that can help students compete for excellent job opportunities" (Student Activities Unit, n. d.). 


\section{Student}

10 Counseling

Service

11 Student Services

12

This unit "seeks to engage excellent capabilities among students in the decision-making process, assuming responsibility, and contributing to the development of the educational, academic, and service process with a view to supporting the PY mission and achieving its objectives" (Student counseling Unit, n. d.). The unit involves several advising programs to help students succeed in the PYP. The objectives of this section are:

- "Providing a platform for communication between the PY Deanship and students in a way that improves the educational, academic, and service process in the university;

- Seeking students' views vis-à-vis the PY services, academic and extracurricular activities;

- Offering advice to the PY Dean in the fields of interest to students;

- Showing cooperation to make the PY the ideal place for gaining knowledge, and the congenial environment for absorbing ethics and values where cordial relations among the staff prevail;

- Engaging students to participate in university activities;

- Clarifying details of the measures that students may fail to understand..etc." (Student counseling Unit, n. d.).

This unit provides and facilitates amenities for students that help them acclimate during their study. For example, loan programs, dorm service, discounts and coupons, facilitate communication with the PY's academic department, faculty, and units. Moreover, providing and managing the PY's website and student's emails, parking service, and entertainment programs.

This document provides a full explanation for student's rights and duties either on the academic or general level. Students are responsible for reading and understanding his/her rights and duties, and recognizing legal ways to solve issues that are encountered.

This document is considered a contract between the PYP and the student. All students are required to sign this document at the beginning of year. This

13 PY's Charter document contains six sections: 1) Academic Behavior; 2) Personal Behavior; 3) Student Rights; 4) Infractions; 5) Disciplinary Actions; and 6) Communication with the PY's Dean.

PY's This section involves information about the PY's staffs' names, emails, offices 14 Communication locations and numbers.

Guide

Note: Adapted from the Student's Guidebook Developed by the Preparatory Year Deanship at King Saud University (2016).

The researcher performed a careful examination of both versions, male and female, of the Student Guidebook to identify the similarities and differences between them before conducting document analysis and comparison with the CM/PM outcomes. Two criteria were set by researcher and used them to compare both versions of the document and to identify to what 
extent the two versions corresponded: 1) the alignment of text and meaning despite the differences in some words that pertain to gender, either male or female; and 2) the alignment of projects, initiative, activities, and curriculums placed under each chapter in both documents.

The two versions were matched page to page to identify similarities and differences between them. The researcher found that language played an important role for the two versions of the document, which in the Arabic language, addressing a female is different from a male. For example, in the English language, the expression "student" is used for males and females at the same time with no adjustment, while in the Arabic language, the expression "student" is different between male and female. However, the outcomes of comparing the two versions of the Student's Guidebook revealed that the two versions were (94.5\%) aligned in terms of text, content, services, activities, policy, curriculum, and functions (see Table 26). The (5.55\%) of differences between the two versions referred to the presence of an extra chapter, Chapter 8, in the male version titled, "Student Enterprise Initiative", which made the male version contain 14 chapters and the female version 13 chapters.

A closer examination of Chapter 8 showed that the chapter presented an initiative created by students themselves in the male section; as the PYP deanship adopted the initiative, it was assigned a chapter to encourage student's involvement. In general, the extra chapter did not affect the comparison process because its content is considered an anomaly from the researcher's perception, although its important as a student's initiative from the PYP's administration perception; therefore, the researcher decided to remove the chapter from the comparison. Thus, the $(94.45 \%)$ of similarity was enough from the researcher's perspective to use the document for the purpose of this study. 
Further, Chapter 2 Academic Terminology and Chapter 13 PY's Contact Information Guide provided general information, which is considered trivial for the purpose of comparison. The researcher decided to remove these two chapters from the comparison stage. The final comparison list that was used in this study includes 11 chapters as displayed in Table 26.

Table 26

The Percentage of Alignment of the Two Versions of the Student's Guidebook for Male and Female

\begin{tabular}{clcl}
\hline Ch & Chapter label & Alignment \% & Differences \\
\hline 1 & PY's Strategic Plan & 100.00 & \\
2 & Academic System & 100.00 & \\
3 & Curriculum and Student's & 100.00 & \\
& Placement & 100.00 & \\
4 & Student's Assessment & 66.70 & No library reported in the female section \\
5 & Learning Resources & 100.00 & \\
6 & Student's Affairs & 100.00 & Language differences on the names, e.g. \\
7 & Student's Activities & & scouting term for male and ambassador \\
& & 92.30 & term for female \\
& & & Some programs are not applicable for \\
8 & Student Counseling & 80.00 & No dorm service and smoking cessation \\
& Service & & clinic for females \\
9 & Student Services & 100.00 & \\
& & & \\
10 & Student's Rights and & 100.00 & \\
& Duties & $94.45 \%$ & \\
\hline 11 & PY's Charter & Total &
\end{tabular}

Note: Adapted from the Student's Guidebook Developed by the Preparatory Year Deanship at King Saud University (2016).

The comparison between the CM/PM outcomes and the Student's Guidebook performed on two separate main levels, clusters level and statements level. Further, the statements level has two sub-levels of comparisons, similarity level and differences level. The purpose of the first level, the cluster level, was to explore an option of a relationship between themes generated by the CM/PM (clusters) and the Student's Guidebook chapters. In the second level of comparison, 
the statements level, the researcher paired each statement generated by the group of stakeholders with specific chapters from the Student's Guidebook. Pairing 48 statements from the male group and 36 statements inform the female group with the 11 chapters of Student's Guidebook provided deep insights about the associated CM/PM outcomes with the current working model of the PYP.

However, the researcher set two criteria to compare and contrast the CM/PM results with the Student's Guidebook to ensure the validity and integrity of the comparison process: 1) each statement must be paired with only one chapter in the Student's Guidebook that aligns conceptually in the meaning or function; and 2) the document analysis be performed based on the researcher's subjective perception of the conceptual sense of each cluster/statement, either in the male or female group. Therefore, the researcher was aware that another researcher performing documents analysis may result in different outcomes.

Finally, as these two versions of the Student's Guidebook were released only in the Arabic language, the researcher performed the cross-culture, forward-backward translation process developed by Brislin (1970) with subjective, objective, and pilot assessment test, to ensure the quality of process and measurement in terms of validity, and the functional correspondence between English and Arabic. This process was performed only for sections that were necessary to achieve the study's goals.

\section{Male Group: Document Analysis Results for Research Question 1a (Cluster Level).} As previously mentioned, the purpose of this extra comparison step was to explore the extent of the alignment of the Student's Guidebook themes, chapters, and clusters generated by the groups of stakeholders. The researcher paired one chapter or more with one cluster according to its title, general purpose of the chapter, and the definition assigned for the cluster. This step gave general 
insights about the harmony of the Student's Guidebook chapters with the seven clusters in the male group and the six clusters in the female group. As a researcher, be aware that the Student's Guidebook chapters describe the current working model of the PYP and the clusters generated by groups of stakeholders explicated the future functions of the PYP. This means that the context of the Student's Guidebook and clusters are varied, despite the similarity of some themes and chapters, in terms of titles or practices involved.

For the male group, all the Student's Guidebook chapters are paired with the clusters generated by the CM/PM. Clusters 1, Program Regulation, and 7, Program Applications Policy, did not match any chapter in the Student's Guidebook. The reason behind this was that the general purpose of the two clusters was to show the difference from the Student's Guidebook chapters' purpose that did not meet one of the criteria sets to make a comparison.

Cluster 5, Program Services: Prior to and During aligned with Chapters 6, 8, 9, 10, and 11, which represented (45.45\%) alignment. This result may express that the PYP currently appears as a service program more than an academic program. Cluster 2, Program Assessment Mechanism and Curriculum Structure, is paired with Chapters 2, 3, and 4. Cluster 3 is paired with Chapter 1 PY's Strategic Plan. Clusters 4 and 6 respectively align with Chapter 7 Student's Activities and Chapter 5 Learning Resources. The variance of clusters context generated by the $\mathrm{CM} / \mathrm{PM}$ and the Student's Guidebook's chapters context, despite the similarity of its titles and the general purpose, reflected the necessity of developing the PYP's function from the participants' perceptions. Table 27 shows the matching of the CM/PM clusters with the Student's Guidebook.

Table 27

Comparison of the CM/PM Generated Clusters and the Student's Guidebook Chapters for the Male Group 
Cluster 1 - Program Regulation: Developing program rules for

more flexibility for the PY's student to make decisions about course registration, granting $P Y P$ certification, and review faculty performance and capacity to teach first-year students.

Cluster 2 - Program Assessment Mechanism \& Curriculum Structure: Developing students' learning assessment methods to foster student's movement to higher levels of study, and restructuring curriculums' content, syllabus, and applications through coordination with the university's colleges to meet their academic requirements and prospective students' needs.

Cluster 3 - Program Philosophy, Planning, and Operational Mechanism: Developing the PY's philosophy, purpose, goals, and application concurrently with improving the overall learning environments and starting self-operation for the program.

Cluster 4 - Program Academic Design: Identifying, developing, and organizing the essential skills that first-year student's need with more concentration on note taking, professional ethics, values, volunteer work, and responsible autonomy skills.

Cluster 5 - Program Services: Prior to and During: Providing prospective students services prior to and during the first-year to connect students with the university environment and help them to engage in the learning process through an orientation program, counseling services, cooperation with beneficiary, colleges, and high schools, and conducting awareness programs and workshops.

Cluster 6 - Supporting Student Learning: Developing extra academic programs and services to foster student learning and to improve critical thinking skills and creativity.

Cluster 7 - Program Applications Policy: Developing a program policy and design to be part of colleges academic programs, to support students who cannot pass the PYP, and to address student's departure issue during or after the PYP.
Chapter 2: Academic System

Chapter 3: Curriculum and Student's Placement

Chapter 4: Student's Assessment

Chapter 1: PY's Strategic Plan

Chapter 7: Student's Activities

Chapter 6: Students Affairs

Chapter 8: Student Counseling Service Chapter 9: Student Services

Chapter 10: Student's Rights and Duties

Chapter 11: PY's Charter

Chapter 5: Learning Resources

\section{Male Group: Document Analysis Results for Research Question 1a (Similarity -}

Statements Level). The researcher conducted an in-deep examination for each statement to explore its alignment or disagreement with the current working model of the PYP as manifested in the Student's Guidebook. The researcher used a printed copy of the Student's Guidebook and highlighted the similar parts between both documents CM/PM statements and Student's Guidebook using a green color and different parts with a yellow color. The examination required 
an accurate reading for the document to match each of the 48 statements with an appropriate chapter. The analysis revealed that 19 statements $(39.58 \%)$ were aligned with specific chapters of the Student's Guidebook. The similarity means that the statement/s aligned with the Student's Guidebook and is applicable in the current working model of the PYP.

Five out of 19 statements (26.32\%) aligned with Chapter 7 Student's Activities. These five statements: 6, 7, 22, 24, and 43, belong to Cluster 4 Program Academic Design that originally consisted of 8 statements. As illustrated earlier in this chapter, this cluster was placed in the fifth level of importance $(M=4.21)$ and the third level of efficacy $(M=3.46)$ among the seven clusters in the male group. The result indicated that the PYP is performing effectively in developing student's activities and the participants' perceptions are compatible to a large extent with the context of Chapter 7.

Chapter 3 Curriculum and Student's Placement involved 4 statements (21.05\%). These statements belonged to different clusters: S31 and S48 to Cluster 2 Program Assessment Mechanism and Curriculum Structure, S13 to Cluster 5 Program Services: Prior to and During, and S36 to Cluster 7 Program Applications Policy. These outcomes showed that Chapter 3 is comprised of complex functions that revolve around program policy, services, curriculum, and assessment issues. Additionally, Clusters 2, 5, and 7 consisted of 20 total statements, which means only $20 \%$ of these statements are represented in Chapter 3.

Chapter 8 Student Counseling Service recorded three statements to belong to different clusters. S20 and S47 to Cluster 6 Supporting Student Learning, and S12 to Cluster 5 Program Services: Prior to and During. Chapters 1, 5, and 9 recorded two statements in each chapter as follows: Chapter 1 PY's Strategic Plan has S35 that belongs to Cluster 6 Supporting Student Learning, and S46 to Cluster 7 Program Applications Policy. Chapter 5 Learning Resources 
recorded S10 and S42 that belong to Cluster 5 Program Services: Prior to and During, and Cluster 3 Program Philosophy, Planning, and Operational Mechanism respectively. Finally, Chapters 6, 9, and 10 recorded one statement for each and S8, S9, and S44 belong to Cluster 5 Program Services: Prior to and During respectively.

A close examination of this consequence revealed that the statements of Cluster 5 Program Services: Prior to and During appeared frequently in Chapters 3, 5, 6, 8, 9, and 10 with 6 of 9 statements (S8, S9, S10, S12, S13, and S44). Cluster 5 had an importance rating of $(M=4.33)$ and efficacy $(M=3.51)$, this cluster placed in the fourth level of importance and second level of efficacy based on the Multidimensional Scaling (MDS) and the Hierarchical Cluster Analysis (HCA). Furthermore, Cluster 6 Supporting Student Learning originally had four statements; three statements (75\%) aligned with the Student's Guidebook chapters, which means that the PYP is effectively supporting student's learning. These results concluded that the PYP performed effectively in terms of student's services, activities, and learning resources availability than regulation, policy, curriculum, and assessment methodology. Table 28 displays the similarity comparison list between the CM/PM outcomes on and the Student's Guidebook of the PY on the statements level.

Table 28

Similarity Comparison of the CM/PM Generated Statements and the PY's Student's Guidebook Chapters for the Male Group

\begin{tabular}{clll}
\hline S-No & \multicolumn{1}{c}{ Statement } & Student's Guidebook & \multicolumn{1}{c}{ Cluster Label } \\
\hline 35 & $\begin{array}{l}\text { Emphasizing critical thinking } \\
\text { skills and creativity. }\end{array}$ & $\begin{array}{l}\text { Cl 6: Supporting Student } \\
\text { Learning }\end{array}$ \\
46 & $\begin{array}{l}\text { Developing a partnership with } \\
\text { charitable and voluntary } \\
\text { organizations and invite them to } \\
\text { be present and represented in the }\end{array}$ & Ch 1: PY's Strategic & $\begin{array}{l}\text { Cl 7: Program Applications } \\
\text { Policy }\end{array}$ \\
Preparatory Year. & $\begin{array}{l}\text { Educating students about majors' } \\
\text { requirements. }\end{array}$ & Ch 3: Curriculum and & $\begin{array}{l}\text { Cl 5: Program Services: } \\
\text { Prior to and During }\end{array}$
\end{tabular}


31 Conducting continuous review of the Preparatory Year curriculum.

36 Preparing students for subsequent university study.

48 Intensifying/Enhancing the English language program.

10 Educating students about libraries and research resources.

42 Developing and improving study halls/classrooms and the learning environment.

44 Assigning students to visit their future colleges in coordination with them to learn closely about the offered majors.

6 Developing note-taking skills during the lecture.

7 Teaching students the basics of professional ethics and linking them to Islamic values.

22 Developing the skills of responsible autonomy.

24 Providing activities that encourage students to participate in community service.

43 Including gifted students' programs within the Preparatory Year Program (to discover and take care of them).

12 Adding activities and guidance programs that help students choose their majors.

20 Providing extra training hours that do not conflict with current study hours.

47 Developing tutoring programs according to students' needs.

9 Introducing the university's facilities and services to students to take advantage of them (orientation program).

8 Educating students about the university's regulations and their rights.
Student's Placement

Ch 5: Learning

Resources

Ch 6: Student's

Affairs

Ch 7: Student's

activities

8-Ch: Student

counseling service

Cl 5: Program Services: Pre \& During

6-Cl: Supporting Student

Learning

6-Cl: Supporting Student Learning

9-Ch: Student services 5-Cl: Program Services: Pre \& During

Cl 5: Program Services: Prior to and During
Cl 2: Program Assessment Mechanism \& Curriculum Cl 7: Program Applications Policy

Cl 2: Program Assessment Mechanism \& Curriculum Structure Cl 5: Program Services: Prior to and During Cl 3: Program Philosophy, Planning, \& Operational Mechanism Cl 5: Program Services: Prior to and During

Cl 4: Program Academic Design Cl 4: Program Academic Cl 4: Program Academic Design Cl 4: Program Academic Design

Cl 4: Program Academic Design
Ch 10: Student's Rights and Duties 
Note. $\mathrm{S}-\mathrm{No}=$ Statement Number; $\mathrm{Ch}=$ ACRL Chapter; $\mathrm{Cl}=$ Cluster.

\section{Male Group: Document Analysis Results for Research Question 1a (Differences -}

Statements Level). The document analysis left 29 statements $(60.42 \%)$ that do not align with any chapter of the Student's Guidebook. This result was expected due to the nature of this study, where the prompt question used in the brainstorming session was asking about the future ideal functions of the PYP, “What programs, services and activities should guide the functions of the Preparatory Year program?", which is focusing on improvement rather than assessing the current situation at the PYP. The group of participants expressed their desire in developing the PYP in the future more than describing the current reality, despite the similarity reported in the previous section.

However, all four statements (100\%) in Cluster 1 Program Regulation have nonalignment with any chapter in the Student's Guidebook. A close examination to this cluster's statements revealed that two statements, S33, Reviewing the performance of faculty members in the Preparatory Year, and S45, Introducing the Preparatory Year Program as a university program in which students take responsibility for their learning and become self-reliant, recorded the same importance mean $(\mathrm{M}=4.57)$ and fell in the second level of importance among all 48 statements. Also, the other two statements, S1, Enabling students in fulfilling certain criteria to enroll in major-specific courses $(\mathrm{M}=4.43)$, and $\mathrm{S} 38$, Granting a certificate for students who pass the Preparatory Year Program $(\mathrm{M}=4.36)$ recorded means above 4.00, which is considered high. The four statements appear to bring four different developmental ideas regarding program regulation that do not apply at the PYP within the current working model.

Furthermore, Cluster 3 Program Philosophy, Planning, and Operational Mechanism, documented 6 statements $(85.71 \%)$ with nonalignment with the Student's Guidebook. S21, 
Reviewing the philosophy of the Preparatory Year and its purpose, yielded an importance rate of $(\mathrm{M}=4.36)$, which is considered the highest in this cluster. This outcome indicated an actual need to develop the PYP's purpose, vision, and mission to meet the stakeholders' needs. Moreover, S3, Reformulating and redefining the Preparatory Year's objectives, and S34, Developing the Preparatory Year self-operation mechanisms and phasing out of outsourcing to private companies, yielded an importance mean at $(\mathrm{M}=4.21)$, which is consider high. This result indicated that the current working model's objectives might need to be developed to meet the PY's students' needs, it may also indicate that the current working model of the PYP may have a vague purpose as the participant's state from their opinion. Additionally, both statements suggest that the PYP may need to not relay on the private sector to operate the program long-term.

Cluster 2 Program Assessment Mechanism and Curriculum Structure was positioned in the third level of nonalignment where 8 statements $(80 \%)$ were in nonalignment with the Student's Guidebook. For example, S40, Developing the Preparatory Year to become a package of educational and skills programs and then colleges and departments dictate the programs that are required from their students, rated at $(\mathrm{M}=4.57)$ for importance that became the second level of importance among all 48 statements. Furthermore, S32, Developing student assessment methods, reported an importance rating of $(\mathrm{M}=4.50)$, which is considered high as well. S2, Availability of mechanisms for course acceleration/promotion, and S19, Reconsidering reducing and refining course content or eliminating some courses, both recorded a similar importance mean of $(\mathrm{M}=4.43)$. These results revealed that developing the PYP assessment methodology and curriculum is essential in the PYP's future development.

Cluster 7 Program Applications Policy placed in the fourth level of dissimilarity, which recorded 4 statements (66.67\%) that did align with the Student's Guidebook. For instance, S25, 
Coordinating with beneficiary colleges to choose the knowledge topics and skills that serve their majors, and S39, Developing programs to address student dropout in the Preparatory Year or beyond, yielded an importance mean of $(\mathrm{M}=4.50)$. This cluster mentioned a vital issue that did not appear before in the other clusters, addressing student's dropout at the PYP or beyond. The group of participants suggested some ideas to increase the program's effectiveness, e.g. sharing with university's schools and colleges their needs and preparing curriculum that can help colleges achieve their learning goals.

Clusters 4 Program Academic Design, Cluster 5 Program Services: Prior to and During, and Cluster 6 Supporting Student Learning were recorded at the lowest level of alignment with the Student's Guidebook, below (50\%). Overall, this result indicated that the difference in some of the statements in these clusters, the majority of its 29 statements $(60.42 \%)$, contain nonalignment with the current working model of the PYP. Table 29 shows the dissimilarity statements generated by the CM/PM with the current working model of the PYP.

Table 29

Dissimilarity Comparison of the CM/PM Generated Statements and the Student's Guidebook Chapters for the Male Group

\begin{tabular}{|c|c|c|c|c|}
\hline $\begin{array}{c}\text { Item } \\
\text { Number }\end{array}$ & Outcomes Generated by the Male Focus Group & $\begin{array}{l}\text { Cluster } \\
\text { Number }\end{array}$ & Cluster Label & $\begin{array}{l}\text { Dissimilarity } \\
\text { Ratio }\end{array}$ \\
\hline 1 & $\begin{array}{l}\text { Enabling students in fulfilling certain criteria to enroll } \\
\text { in major-specific courses. }\end{array}$ & \multirow{4}{*}{1} & \multirow{4}{*}{$\begin{array}{l}\text { Program } \\
\text { Regulation }\end{array}$} & \multirow{4}{*}{$100 \%$} \\
\hline 33 & $\begin{array}{l}\text { Reviewing the performance of faculty members in the } \\
\text { Preparatory Year. }\end{array}$ & & & \\
\hline 38 & $\begin{array}{l}\text { Granting a certificate for students who pass the } \\
\text { Preparatory Year Program. }\end{array}$ & & & \\
\hline 45 & $\begin{array}{l}\text { Introducing the Preparatory Year Program as a } \\
\text { university program in which students take } \\
\text { responsibility for their learning and become self- } \\
\text { reliant. }\end{array}$ & & & \\
\hline 2 & $\begin{array}{l}\text { Availability of mechanisms for course } \\
\text { acceleration/promotion. }\end{array}$ & \multirow{4}{*}{2} & \multirow{4}{*}{$\begin{array}{c}\text { Program } \\
\text { Assessment } \\
\text { Mechanism and } \\
\text { Curriculum } \\
\text { Structure }\end{array}$} & \multirow{4}{*}{$80 \%$} \\
\hline 4 & $\begin{array}{l}\text { Reviewing student assessment mechanisms (students } \\
\text { acceleration/promotion) during the program for all } \\
\text { courses. }\end{array}$ & & & \\
\hline 5 & $\begin{array}{l}\text { Merging some of the PY's similar courses after } \\
\text { reviewing their syllabi. }\end{array}$ & & & \\
\hline 17 & Reconsidering the students' timetables and credit & & & \\
\hline
\end{tabular}




\begin{tabular}{|c|c|c|c|c|}
\hline & hours. & & & \\
\hline 18 & Reviewing the medical track's study plan. & & & \\
\hline 19 & $\begin{array}{l}\text { Reconsider reducing and refining course content or } \\
\text { eliminating some courses. }\end{array}$ & & & \\
\hline 32 & Developing student assessment methods. & & & \\
\hline 40 & $\begin{array}{l}\text { Developing the Preparatory Year to become a package } \\
\text { of educational and skills programs and then colleges } \\
\text { and departments dictate the programs that are required } \\
\text { from their students. }\end{array}$ & & & \\
\hline 3 & $\begin{array}{l}\text { Reformulating and defining the Preparatory Year's } \\
\text { objectives. }\end{array}$ & \multirow{6}{*}{3} & \multirow{6}{*}{$\begin{array}{l}\text { Program } \\
\text { Philosophy, } \\
\text { Planning, and } \\
\text { Operational } \\
\text { Mechanism }\end{array}$} & \multirow{6}{*}{$85.71 \%$} \\
\hline 14 & $\begin{array}{l}\text { Involving all Preparatory Year } \\
\text { beneficiaries/stakeholders in the development of its } \\
\text { plan. }\end{array}$ & & & \\
\hline 16 & $\begin{array}{l}\text { Hiring faculty members from colleges who have } \\
\text { experience in teaching first-year university students. }\end{array}$ & & & \\
\hline 21 & $\begin{array}{l}\text { Reviewing the philosophy of the Preparatory Year and } \\
\text { its purpose. }\end{array}$ & & & \\
\hline 26 & Not linking the PY with academic/college placement. & & & \\
\hline 34 & $\begin{array}{l}\text { Developing the Preparatory Year self-operation } \\
\text { mechanisms and phasing out of outsourcing to private } \\
\text { companies. }\end{array}$ & & & \\
\hline 41 & $\begin{array}{l}\text { Assessing students' knowledge and skills before and } \\
\text { after the Preparatory Year Program. }\end{array}$ & \multirow{3}{*}{4} & \multirow{3}{*}{$\begin{array}{l}\text { Program Academic } \\
\text { Design }\end{array}$} & \multirow{3}{*}{$37.5 \%$} \\
\hline 27 & $\begin{array}{l}\text { Including activities into the Preparatory Year Program } \\
\text { that are not offered by other colleges (Not providing } \\
\text { extracurricular activities that will be offered after the } \\
\text { Preparatory Year in colleges). }\end{array}$ & & & \\
\hline 28 & $\begin{array}{l}\text { Avoiding overwhelming students with activities } \\
\text { offered by other colleges. }\end{array}$ & & & \\
\hline 15 & $\begin{array}{l}\text { Organizing workshops for high school students to } \\
\text { identify and address weaknesses of Preparatory Year } \\
\text { students. }\end{array}$ & \multirow{3}{*}{5} & \multirow{3}{*}{$\begin{array}{l}\text { Program Services: } \\
\text { Prior to and } \\
\text { During }\end{array}$} & \multirow{3}{*}{$33.33 \%$} \\
\hline 23 & $\begin{array}{l}\text { Providing services needed by students through } \\
\text { workshops and through the cooperation between } \\
\text { colleges and Preparatory Year Deanship }\end{array}$ & & & \\
\hline 30 & $\begin{array}{l}\text { Providing academic counseling services for high } \\
\text { school students before the Preparatory Year. }\end{array}$ & & & \\
\hline 11 & $\begin{array}{l}\text { Adding course activities that promote and motivate } \\
\text { students' learning. }\end{array}$ & 6 & $\begin{array}{l}\text { Supporting Student } \\
\text { Learning }\end{array}$ & $25 \%$ \\
\hline 25 & $\begin{array}{l}\text { Coordinating with beneficiary colleges to choose the } \\
\text { knowledge topics and skills that serve their majors. }\end{array}$ & \multirow{4}{*}{7} & \multirow{4}{*}{$\begin{array}{l}\text { Program } \\
\text { Applications } \\
\text { Policy }\end{array}$} & \multirow{4}{*}{$66.67 \%$} \\
\hline 29 & $\begin{array}{l}\text { Implementing the Preparatory Year Program within } \\
\text { colleges in accordance with major tracks. }\end{array}$ & & & \\
\hline 37 & $\begin{array}{l}\text { Setting clear and specific options in advance for } \\
\text { students who do not pass the Preparatory Year. }\end{array}$ & & & \\
\hline 39 & $\begin{array}{l}\text { Developing programs to address student dropout in the } \\
\text { Preparatory Year or beyond. }\end{array}$ & & & \\
\hline
\end{tabular}

\section{Female Group: Document Analysis Results for Research Question 1a (Cluster}

Level). Much as with the data for males, the purpose of this step was to explore the extent of the 
compatibility between the Student's Guidebook chapter and cluster themes generated by the group of stakeholders. The researcher paired one chapter or more with one cluster according to its title, general purpose of the chapter, and the definition assigned for the cluster. The researcher took into account the limitations previously mentioned that stated the Student's Guidebook chapters, and describes the current working model of the PYP, and the clusters generated by the group of stakeholders that explicate the future ideal functions of the PYP.

With one exception for Chapter 1 PY's Strategic Plan, the other 10 chapters were paired with one cluster in the female group that consisted of six clusters. Further, Cluster 4 Program Regulation, and Cluster 3 Teaching Quality did not match any chapter in the Student's Guidebook, which indicated that the current working model of the PYP is ineffective in terms of mentoring and developing faculty performance.

Cluster 1 Program Assessment Mechanism and Curriculum Structure aligned with Chapter 4 Student's Assessment, although the similarity between the two and the Student's Guidebook is on the cluster level, the comparison done on the statements level revealed important differences that are mentioned later in this chapter. Cluster 2 Program Academic Design paired with Chapters 2 and 3. Furthermore, similar to the male group, Cluster 5 Program Services: Prior to and During aligned with Chapters 6, 8, 9, 10, and 11 that represented (45.45\%) of alignment, which is considered the highest degree of compatibility between clusters and the Student's Guidebook chapters. Finally, Cluster 6 Promoting Student Learning paired with two chapters, 5 and 7. The researcher observed that the Program Services: Prior to and During Cluster still reports the highest degree of similarity on the cluster level between both documents, which indicates that the PYP performed more effectively on the student's services than teaching quality, assessment, academic, and program regulation. In other words, the current model of the 
PYP focuses on student's services than academic dimensions. Table 30 shows the alignment of the CM/PM clusters with the Student's Guidebook.

Table 30

Comparison of the CM/PM Generated Clusters and the Student's Guidebook Chapters for the Female Group

\begin{tabular}{ll}
\hline Female Group Cluster Definition & Student's Guidebook Label \\
\hline Cluster 1 - Program Assessment Mechanism \& Curriculum & Chapter 4: Student's Assessment \\
Structure: Developing students' learning assessment & \\
approaches to foster student's learning, restructuring the PYP's & \\
curriculum content, syllabus, and comparing/contrasting with & \\
public education curriculums. &
\end{tabular}

Cluster 2 - Program Academic Design: Identifying, developing, organizing, and emerging some of the program courses with concentrating on practices, extra-curricular, and applied skills more than theory.

Cluster 3 - Teaching Quality: Ensuring the quality and capability of faculty at the PYP to deal with first-year students.

Cluster 4 - Program Regulation: Developing program rules to make the academic/college placement for all students on specific track/major before the PYP rather than after the PY'S completion, and do not count the PYP's GPA to determine the future college or major.

Cluster 5 - Program Services: Prior to and During: Developing the orientation program and counseling services to educate first-year students about their rights and duties and the university's regulations.

Cluster 6 - Promoting Student Learning: Developing activities and academic programs that promote and stimulate student learning and raise student's engagement in the local and global context.
Chapter 2: Academic System

Chapter 3: Curriculum and Student's Placement

Chapter 6: Student's Affairs

Chapter 8: Student Counseling Service

Chapter 9: Student Services

Chapter 10: Student's Rights and Duties

Chapter 11: PY's Charter

Chapter 5: Learning Resources

Chapter 7: Student's Activities

\section{Female Group: Document Analysis Results for Research Question 1a (Similarity -}

Statements Level). As mentioned in the male section, the researcher used a printed copy of the Student's Guidebook and highlighted the similar parts between documents, the CM/PM statements and the Student's Guidebook, with a green color and different parts with a yellow color. The researcher read each statement carefully and conducted an in-depth examination to 
explore its similarity or dissimilarity with the current working model of the PYP as manifested in the Student's Guidebook. This analysis revealed that only 5 statements $(13.89 \%)$ out of the 36 statements aligned with a specific chapter, while 31 statements $(86.11 \%)$ represented new ideas or suggestions for the PYP's future. To refresh, the similarity means that the statement/s aligned with the Student's Guidebook and are applicable in the current working model of the PYP.

Chapter 3 Curriculum and Student's Placement involved one statement that relates back to Cluster 1 Program Assessment Mechanism and Curriculum Structure, S22, The inclusion of some courses for all study tracks such as English. The current working model of the PYP already applies English courses for all tracks and majors, including the Humanity Track.

Chapter 6 Student's Affairs was paired with S13, The necessity of educating students about their rights and duties. This statement belonged to Cluster 5 Program Services: Prior to and During, because Cluster 5 appeared as a common factor in the comparison process between the Student's Guidebook and the CM/PM outcomes.

Chapter 7 Student's Activities involved two aligned statements, S27, Publishing the outstanding research and media produced by students, that belonged to Cluster 6 Promoting Student Learning, and S34, Extra-curricular activities play an important role in the refinement of students' skills, that belonged to Cluster 2 Program Academic Design, Activities, and Skills. Finally, Chapter 10 Student's Rights and Duties, aligned with S36, Increasing student awareness about university's laws and regulations through a specialist department whenever they need advice, that belonged to Cluster 5 .

In summary, these outcomes revealed that two statements belonged to Cluster 5 and the other the three statements were divided between Clusters 1, 2, and 6. Further, these statements aligned with Chapters 3,6,7, and 10, which may mean that there were seven chapters that did 
not match any statements. Three chapters, 6,7 , and 10, out of the four chapters represented in the Student's Services Cluster and one chapter linked to the academic aspect that is presented in Chapter 3 Curriculum and Student's Placement. This conclusion supports the idea of the current working model of the PYP that tends to be a service model than an academic model for first-year students. In other words, the PYP focuses more on Student's Services than academic dimensions. Table 31 displays the similarity comparison list between the CM/PM outcomes and the Student's Guidebook of the PY on the statements level.

Table 31

Similarity Comparison of the CM/PM Generated Statements and the PY's the Student's Guidebook Chapters for the Female Group

\begin{tabular}{|c|c|c|c|}
\hline S-No & Statement & Student's Guidebook & Cluster Label \\
\hline 22 & $\begin{array}{l}\text { The inclusion of some courses } \\
\text { for all study tracks, such as } \\
\text { English. }\end{array}$ & $\begin{array}{l}\text { Ch 3: Curriculum and } \\
\text { Student's Placement }\end{array}$ & $\begin{array}{l}\text { Cl 1: Program Assessment } \\
\text { Mechanism \& Curriculum } \\
\text { Structure }\end{array}$ \\
\hline 13 & $\begin{array}{l}\text { The necessity of educating } \\
\text { students about their rights and } \\
\text { duties. }\end{array}$ & $\begin{array}{l}\text { Ch 6: Student's } \\
\text { Affairs }\end{array}$ & $\begin{array}{l}\mathrm{Cl} \text { 5: Program Services: } \\
\text { Prior to and During }\end{array}$ \\
\hline 27 & $\begin{array}{l}\text { Publishing the outstanding } \\
\text { research and media produced by } \\
\text { students. }\end{array}$ & Ch 7: Student's & $\begin{array}{l}\mathrm{Cl} \text { 6: Promoting Student } \\
\text { Learning }\end{array}$ \\
\hline 34 & $\begin{array}{l}\text { Extra-curricular activities play } \\
\text { an important role in the } \\
\text { refinement of students' skills. }\end{array}$ & Activities & $\begin{array}{l}\text { Cl 2: Program Academic } \\
\text { Design }\end{array}$ \\
\hline 36 & $\begin{array}{l}\text { Increasing student awareness } \\
\text { about the university's laws and } \\
\text { regulations through a specialist } \\
\text { department whenever they need } \\
\text { advice. }\end{array}$ & $\begin{array}{l}\text { Ch 10: Student's } \\
\text { Rights and Duties }\end{array}$ & $\begin{array}{l}\mathrm{Cl} \text { 5: Program Services: } \\
\text { Prior to and During }\end{array}$ \\
\hline
\end{tabular}

Note. S-No = Statement Number; $\mathrm{Ch}=\mathrm{ACRL}$ Chapter; $\mathrm{Cl}=$ Cluster.

\section{Female Group: Document Analysis Results for Research Question 1a (Differences -}

Statements Level). The document analysis of the Student's Guidebook and 36 statements generated by CM/PM left 31 statements $(86.11 \%)$ of nonalignment with any parts in the current working model of the PYP. As mentioned earlier in the male comparison section, this result was 
expected due to the nature of this study that focused on the development not on the assessment of the PYP.

A close examination of the document analysis outcomes revealed that Cluster 3 Teaching Quality and Cluster 4 Program Regulation statements had nonalignment with any part of the current working model of the PYP. In other words, the stakeholders' perceptions regarding teaching and regulation of the PYP did not meet any of the Student's Guidebook dimensions. Cluster 3 Teaching Quality consisted of three statements, 5, 12, and 16. S16, Diversifying teaching strategies to shorten time, recorded a high mean at $(\mathrm{M}=4.67)$. The other three statements focused on improving teaching practices in the female section and asked to ensure the quality and capability of faculty at the PYP's female section. It is worthy to mention that this cluster has an importance rate of $(\mathrm{M}=4.52)$, which is considered the second most important cluster rate in the female group.

Cluster 4 Program Regulation has eight statements. S6, S19, S23, and S31 yielded an importance mean of $(M=4.78)$, which represents the third level of importance on this cluster. Further, S29, To be a Preparatory Program not a Preparatory Year, was rated on the second lowest level of importance in this cluster at $(\mathrm{M}=3.78)$. The main theme in this cluster involved a high recommendation to change student's academic placement regulation at the PYP.

The group of participants believed that the current regulation effects student's performance and may cause problems, such as student dropout or withdrawal from the PYP. The group of participants suggested that constructing the PYP as a short program to prepare first-year students for university may be better, and not design the program to last one year. This result matched the CM/PM outcomes that rated Cluster 4 Program Regulation on the highest level of importance $(M=4.54)$ and the lowest level of efficacy at $(M=2.85)$ in the female group. 
Nine statements (88.89\%) in Cluster 2 Program Academic Design did align with parts of the Student's Guidebook. This cluster concentrated on developing the academic design of the program to be more practical than theoretical, e.g. S24, Focusing on the practical aspects that ensure students will maintain skills, such as the English language $(\mathrm{M}=4.89)$. This statement was recorded at the second highest level of importance among the 36 statements in the female group. Moreover, S33, Self-development skills can be acquired during study through workshops and courses that are offered by the Deanship of Student Affairs, rated at (M=3.33), which was placed on the lowest level of importance among all 36 statements. Although this is considered the lowest level of rating, embracing such a suggest means completely restructuring the PYP model because the current model has an academic department named Self-Development Skills. This department is responsible for providing first-year students all the essential skills that may make his/her transition to postsecondary education successful. (Student's Guidebook, 2016)

Cluster 1 Program Assessment Mechanism and Curriculum Structure recorded six statements $(85.71 \%)$ of nonalignment with the Student's Guidebook. S17, Reviewing the Preparatory Year curriculum and comparing/contrasting them with public education curriculum, rated at $(M=5.00)$, which is considered the highest level of importance among all 36 statements. This statement illustrated the importance of linking public education or high-school curriculums with the PY's curriculum, which may support educational policymaker's endeavor to make student's transition successfully into higher education. Furthermore, the group of participants seemed interested in developing an assessment mechanism to foster student's moving from one class to another or from one level of study to another.

Cluster 6 Promoting Student Learning, has three statements (75\%) of nonalignment with the Student's Guidebook. For example, S26, Engaging students in international conferences to 
gain experience and contact with elites, and S28, Partnering with leading universities in

adopting outstanding students, were both recorded at $(\mathrm{M}=4.33)$. The researcher observed that the main theme in this cluster is to endorse students in the female section to engage in the local and global educational context.

Cluster 5 Program Services: Prior to and During recorded (50\%) of differences between the Student's Guidebook and the CM/PM outcomes. This cluster recorded high similarity and low differences in the female group, as well as in the male group. This conclusion stresses the fact that the current working model of the PYP performed more effectively on the student's services dimension than the academic aspects. Table 32 shows the dissimilarity statements generated by the CM/PM with the current working model of the PYP.

Table 32

Dissimilarity Comparison of the CM/PM Generated Statements and the Student's Guidebook Chapters for the Female Group

\begin{tabular}{|c|c|c|c|c|}
\hline $\begin{array}{c}\text { Item } \\
\text { Number }\end{array}$ & Outcomes Generated by Male Focus Group & $\begin{array}{l}\text { Cluster } \\
\text { Number }\end{array}$ & Cluster Label & $\begin{array}{l}\text { Dissimilarity } \\
\text { Ratio }\end{array}$ \\
\hline 1 & $\begin{array}{l}\text { Developing an instrument to measure student's level, } \\
\text { for example, English language skills. }\end{array}$ & \multirow{6}{*}{1} & \multirow{6}{*}{$\begin{array}{c}\text { Program } \\
\text { Assessment } \\
\text { Mechanism \& } \\
\text { Curriculum } \\
\text { Structure }\end{array}$} & \multirow{6}{*}{$85.71 \%$} \\
\hline 2 & $\begin{array}{l}\text { Reassessing the importance of teaching (some) } \\
\text { courses in the Preparatory Year, for example, health } \\
\text { and fitness courses. }\end{array}$ & & & \\
\hline 3 & $\begin{array}{l}\text { Passing the placement tests for the Preparatory Year } \\
\text { courses. }\end{array}$ & & & \\
\hline 11 & $\begin{array}{l}\text { Students can pass some of the Preparatory Year } \\
\text { courses directly. }\end{array}$ & & & \\
\hline 20 & $\begin{array}{l}\text { Determining the course timeline based on students' } \\
\text { needs. }\end{array}$ & & & \\
\hline 17 & $\begin{array}{l}\text { Reviewing the Preparatory Year curriculum and } \\
\text { comparing/contrasting them with public education } \\
\text { curriculum. }\end{array}$ & & & \\
\hline 4 & $\begin{array}{l}\text { Reducing theoretical hours for the courses that require } \\
\text { practical application, such as communication and } \\
\text { computer skills. }\end{array}$ & \multirow{5}{*}{2} & \multirow{5}{*}{$\begin{array}{l}\text { Program } \\
\text { Academic Design }\end{array}$} & \multirow{5}{*}{$88.89 \%$} \\
\hline 8 & $\begin{array}{l}\text { Canceling some of the redundant courses or merging } \\
\text { them into a single course, for example, math skills. }\end{array}$ & & & \\
\hline 15 & $\begin{array}{l}\text { All offered skills are important and should not be } \\
\text { specific for the Preparatory Year. }\end{array}$ & & & \\
\hline 32 & $\begin{array}{l}\text { Merging some courses together, such as research skills } \\
\text { and communication skills, under one course, named } \\
\text { the skills course. }\end{array}$ & & & \\
\hline 35 & Integrating some skills, such as speech and scientific & & & \\
\hline
\end{tabular}




\begin{tabular}{|c|c|c|c|c|}
\hline & research, during the study of language. & & & \\
\hline 9 & $\begin{array}{l}\text { Emphasizing practical, applied, and skill aspects not } \\
\text { just a compilation of grades for academic placement. }\end{array}$ & & & \\
\hline 24 & $\begin{array}{l}\text { Focusing on the practical aspects that ensure students } \\
\text { will maintain skills, such as the English language. }\end{array}$ & & & \\
\hline 30 & $\begin{array}{l}\text { Implementing independent learning more than } \\
\text { lectures. }\end{array}$ & & & \\
\hline 33 & $\begin{array}{l}\text { Self-development skills can be acquired during study } \\
\text { through workshops and courses that are offered by the } \\
\text { Deanship of Student Affairs. }\end{array}$ & & & \\
\hline 5 & $\begin{array}{l}\text { Assigning a stable educational entity to run the } \\
\text { courses (with low possibility of management change) }\end{array}$ & \multirow{3}{*}{3} & \multirow{3}{*}{ Teaching Quality } & \multirow{3}{*}{$100 \%$} \\
\hline 12 & $\begin{array}{l}\text { Ensuring that faculty members have the necessary } \\
\text { capability to deal with students at this age. }\end{array}$ & & & \\
\hline 16 & Diversifying teaching strategies to shorten time. & & & \\
\hline 6 & $\begin{array}{l}\text { Applying the academic/college placement at the } \\
\text { beginning of the Preparatory Year. }\end{array}$ & \multirow{8}{*}{4} & \multirow{8}{*}{$\begin{array}{l}\text { Program } \\
\text { Regulation }\end{array}$} & \multirow{8}{*}{$100 \%$} \\
\hline 18 & $\begin{array}{l}\text { Students' academic placement to be before the } \\
\text { Preparatory Year. }\end{array}$ & & & \\
\hline 19 & $\begin{array}{l}\text { Identifying academic track/major from the first day of } \\
\text { study. }\end{array}$ & & & \\
\hline 23 & $\begin{array}{l}\text { Applying academic placement for all students before } \\
\text { entering the Preparatory Year to make students focus } \\
\text { more on academic achievement. }\end{array}$ & & & \\
\hline 31 & $\begin{array}{l}\text { Implementing academic placement from the } \\
\text { beginning. }\end{array}$ & & & \\
\hline 7 & $\begin{array}{l}\text { Achieving the most benefit from the Preparatory Year } \\
\text { (skills) by abolishing the academic placement policy } \\
\text { after the Preparatory Year. }\end{array}$ & & & \\
\hline 21 & $\begin{array}{l}\text { The Preparatory Year's GPA should not affect } \\
\text { choosing the future college of study. }\end{array}$ & & & \\
\hline 29 & To be a Preparatory Program not a Preparatory Year. & & & \\
\hline 10 & $\begin{array}{l}\text { The Preparatory Year regulations should be issued by } \\
\text { the Vice Dean of the Preparatory Year. }\end{array}$ & \multirow[b]{2}{*}{5} & \multirow{2}{*}{$\begin{array}{l}\text { Program Services: } \\
\text { Prior to and } \\
\text { During }\end{array}$} & \multirow{2}{*}{$50 \%$} \\
\hline 14 & $\begin{array}{l}\text { The importance of the orientation program for } \\
\text { students before starting the study plan. }\end{array}$ & & & \\
\hline 25 & $\begin{array}{l}\text { Organizing academic trips for distinguished students } \\
\text { to study English language courses in international } \\
\text { institutes. }\end{array}$ & \multirow{3}{*}{6} & \multirow{3}{*}{$\begin{array}{l}\text { Promoting Student } \\
\text { Learning }\end{array}$} & \multirow{3}{*}{$75 \%$} \\
\hline 26 & $\begin{array}{l}\text { Engaging students in international conferences to gain } \\
\text { experience and contact with elites. }\end{array}$ & & & \\
\hline 28 & $\begin{array}{l}\text { Partnering with leading universities in adopting } \\
\text { outstanding students. }\end{array}$ & & & \\
\hline
\end{tabular}

\section{Finding for Research Question 1b (Document Analysis)}

The second sub-question in this study was "Does this Concept Mapping/Pattern Matching conceptualization compare and contrast with King Saud University's explicit strategic plan?" To answer this question, the researcher performed a document analysis to compare and contrast the 
outcomes generated by the Concept Mapping/Pattern Matching (CM/PM) separately for male and female groups, with the explicit strategic plan of King Saud University (KSU).

The researcher used the released document titled "KSU Strategic Plan 2030-Version-2" that was produced in 2014 in the English language to make a comparison (see Appendix N). KSU's strategic plan was created to develop university at all levels; the researcher consulted with a member of the dissertation committee to design a matrix for comparison purposes.

The purpose of this step was not to evaluate KSU's strategic plan but to exam to what extent the $\mathrm{CM} / \mathrm{PM}$ outcomes for both groups of stakeholders compare and contrast with the university's plan. However, recently, the Saudi government launched a new strategic plan for 2030 that is titled, "Saudi Vision 2030”. King Saud University is part of the Saudi government sectors, it is working to develop or adjust its strategic plan, KSU2030, to meet Saudi Vision 2030 plan; therefore, this study's outcomes may assist KSU's policymakers and the educational planners at the PYP to develop the program toward new horizons. The researcher decided to include KSU's vision, mission, values, strategic objectives, and any sections that mention the Preparatory Year Program and considered primary resources to the comparison matrix (see Appendix O). For example, the document mentioned the PY's location within KSU's organization structure; this part was excluded because it did not provide relevant information for this study's purpose.

The researcher read the document and made an accurate review to identify these sections and highlighted them using a green color. The document mentioned the "Preparatory Year" phrase 11 times. The researcher designed the matrix based on two levels of importance (primary and secondary) and classified all included items accordingly (see Appendix O). The decision was made to include the primary items in the final matrix set for the comparison purpose that 
consisted of nine main themes, as shown in Table 33 below. Additionally, the pilot test to compare and contrast the strategic plan based on cluster levels did not reveal valuable information that can inform educational policymakers about the future development of the PYP forcing the researcher to decide on comparing the statement levels for more accuracy.

Furthermore, the document analysis performed was based on the researcher's subjective perception of the conceptual sense of each statement. The researcher was aware that another researcher performing documents analysis may result in different outcomes. The comparison involved the 48 statements from the male group and the 36 statements from the female group, and KSU's strategic plan matrix of comparison that includes nine main themes (see Table 33). The strategic plan of KSU was building based on a broad framework for all King Saud University's colleges, schools, human resources, etc., thus providing the PYP gained interest in the plan, since it is mentioned 11 times throughout the document. Through close examination of these themes, the researcher observed that the plan states "the Preparatory year program seeks to strengthen the effectiveness and build capabilities in H.R., infrastructure, students etc. This would include review of Preparatory year program capabilities such a H.R., system, faculty, curriculum, infrastructure, collaboration with industry, NGO’s, private sector" (Plan, 2014, p. 222). In fact, this declaration may include all 48 and 36 statements generated by the stakeholder groups, either male or female, because all of these statements consider a development in nature and could fit well underneath this theme.

Furthermore, the researcher found that some of the 36 female and 48 male statements could be placed under different themes in the plan. For example, in the male group, S6, Developing note taking skills during the lecture, as this statement considers as a type of "soft skill" that was mentioned in the strategic plan, the researcher may place this statement within 
three different locations on the comparison table as follows: 1) could be placed with the fourth strategic goal; 2) with the introduction about the PYP on page 103; or 3) with the strategic implication for KSU on page 106. Thus, the researcher decided to place the statement under the closest theme based on his subjective perception. The document analysis revealed that 19 statements (39.58\%) for the male group and 10 statements (27.78\%) aligned with KSU's strategic plan.

On further examination of the male group statements, two statements, S24 and S35, aligned with KSU's mission. S24, Providing activities that encourage students to participate in community service, yielded an importance mean of $(M=4.00)$ and efficacy at $(M=3.86)$, and belonged to Cluster 4 Program Academic Design that was rated at $(\mathrm{M}=4.21)$ for importance and at $(\mathrm{M}=3.46)$ for efficacy. S35, Emphasizing critical thinking skills and creativity, was rated at $(M=4.21)$ for importance and $(M=3.71)$ for efficacy. This statement belonged to Cluster 6 Supporting Student Learning that rated at the lowest level of importance at $(M=4.04)$ and at the highest level of efficacy at $(M=3.79)$. Although these results imply a high importance mean for both statements and its clusters, the result indicated that the PYP performed ineffectively to achieve KSU's mission.

S22, Developing the skills of responsible autonomy, and S45, Introducing the Preparatory Year Program as a university program in which students take responsibility for their learning and become self-reliant, yielded an importance mean above 4.00 and efficacy less than 4.00. S22 belonged to Cluster 4 Program Academic Design and S45 belonged to Cluster 1 Program Regulation that recorded the highest importance mean at $(M=4.48)$. These statements appeared under the Leadership and Teamwork theme that belonged to KSU's value. In addition, S7, Teaching students the basics of professional ethics and linking them to Islamic values, 
aligned with KSU's Fairness and Integrity value. These results indicate that though the similarity, the PYP may need to pay more attention to raising student's values in some aspects as the stakeholder groups stated. S16, Hiring faculty members from colleges who have experience in teaching first-year university students, and S33, Reviewing the performance of faculty members in the Preparatory Year, agree with the second strategic objective of KSU that states, “Distinctive faculty (Attract and develop distinctive faculty)". Regardless of the similarity, the result indicates a concern regarding the teaching quality in the PYP. Both statements yielded an importance mean above 4.00, but an efficacy mean below 4.00, which means that the PYP performed ineffectively in developing teaching quality in the program.

S6, Developing note taking skills during the lecture was one of the statements that could fit under several themes; the researcher decided to place it under the fourth strategic objective. S23 and S25 were placed under the fifth strategic objective that states, "Building bridges (Build bridges among KSU constituencies and externally with local and international groups)" the stakeholders' perceptions revealed that more coordination between KSU's colleges, services deanships, and the PYP is essential to develop the program and to select appropriate academic content that could meet colleges and students, and to avoid any overlapping among KSU's colleges and academic departments. Additionally, S25 belonged to Cluster 7 Program Applications Policy that was recorded in the second highest level of importance at $(\mathrm{M}=4.42)$ and the lowest level of efficacy at $(M=3.23)$. This result indicated the requirement of more attention to this issue before developing the program in the future.

S42 aligned with the sixth strategic objective of KSU that states, "Supportive learning environment" and S36, Preparing students for subsequent university study paired with the PYP's task that was established by KSU, "KSU's recent introduction of the preparatory year (whereby 
students are given foundation courses in core hard and soft skills before beginning their university-level studies)". S48, Intensifying/Enhancing the English language program paired with KSU's strategic implication that suggests more concentration on English courses at the PYP. This implication indicates the importance of developing comprehensive teaching and learning plans with concentration on English language skills (Plan, 2014). S3, S4, S18, S19, S21, and S31 aligned with KSU's recommendation to continuously develop the PYP.

In general, the majority of statements that aligned with KSU's strategic plan belonged to Cluster 2 Program Assessment Mechanism and Curriculum Structure with five statements, Cluster 3 Program Philosophy, Planning, and Operational Mechanism with four statements, and Cluster 7 Program Applications Policy with three statements. With these results, the stakeholders' perceptions suggested that the PYP may require effective performance in order to develop three domains of the PYP: 1) assessment methodology; 2) program philosophy and purpose; and 3) program application policy, where this conclusion raised concern regarding the capability of the PYP on achieving KSU's strategic plan mission, objectives, and recommendations.

For the female group, as mentioned above, 10 statements $(27.78 \%)$ aligned with KSU's strategic plan. S26, Engaging students in international conferences to gain experience and contact with elites", and S28, Partnering with leading universities in adopting outstanding students, recorded similar importance means at $(\mathrm{M}=4.33)$ and efficacy means at $(\mathrm{M}=3.78)$ for S26 and $(M=3.22)$ for S28. These statements belonged to Cluster 6 Promoting Student Learning that was placed on the third level of efficacy $(\mathrm{M}=3.44)$. The result indicated that the PYP may need to give more chances for female students to engage in the global educational context. This suggestion is paired with KSU's Fairness and Integrity value that mentions "Equal Opportunity”. 
S9, Emphasizing practical, applied, and skill aspects not just a compilation of grades for academic placement, S15, All offered skills are important and should not be specific for the Preparatory Year, S24 Focusing on the practical aspects that ensure students will maintain skills, such as the English language, and S30, Implementing independent learning more than lectures focused on applied skills more than theoretical knowledge. In other words, developing students' skills that can benefit them and help them to succeed during university life and in their future career. These statements align with KSU's Lifelong Learning value. The result indicated that the PYP's academic approach tended to be more theoretical than practical for the female section. The PYP may require finding a solution to help students maintain skills long-term, not just during the program. S12, Ensuring that faculty members have the necessary capability to deal with students at this age brought concern about the teaching quality in the female section. This statement paired with the second strategic objective, "Distinctive faculty (Attract and develop distinctive faculty)". S22, The inclusion of some courses for all study tracks, such as English paired with KSU's strategic implication that suggests intensifying the English program for all students.

S2 and S17 exposed the need for comparing the PYP's curriculum with public education curriculum, and assessing some of the PYP's courses that offer a female section, such as health and fitness courses. Both statements aligned with KSU's strategic implication that suggests developing comprehensive teaching and a learning plan with concentration on curriculum development to meet student's needs. The majority of statements in this comparison belonged to Cluster 2 Program Academic Design with four statements and Cluster 1 Program Assessment Mechanism and Curriculum with three statements. The two clusters were placed in the fourth and fifth levels of efficacy respectively, which is considered a low level of efficacy despite its 
level of importance. These results may provoke the educational policymaker to explore the extent of appropriateness of the current design of the PYP to promote female's learning.

For dissimilarity, as mentioned formerly, KSU's strategic plan states “The Preparatory year program seeks to strengthen the effectiveness and build capabilities in H.R., infrastructure, students etc. This would include review of Preparatory year program capabilities such a H.R., system, faculty, curriculum, infrastructure, collaboration with industry, NGO's, private sector" (Plan, 2014, p. 222). The researcher thought all statements could align with this recommendation due to the nature of the 36 and 48 developmental statements generated by the stakeholder groups. However, 29 statements $(60.42 \%)$ from the male group and 26 statements $(72.22 \%)$ from the female group had nonalignment with any theme in the KSU strategic plan, which indicates that KSU may need to assess the PYP to explore its capability to achieve KSU's mission.

The majority of statements from the male group that were not paired with KSU's plan belonged to Cluster 5 Program Services: Prior to and During, Cluster 4 Program Academic Design, and Cluster 2 Program Assessment Mechanism and Curriculum Structure. Furthermore, the majority of statements from the female group that were not paired with KSU's plan belonged to Cluster 2 Program Academic Design, Cluster 3 Teaching Quality, Cluster 4 Program Regulation, and Cluster 5 Program Services: Prior to and During. Clusters 4 and 5 statements have no matching with KSU's strategic plan, and Cluster 4 statements, in particular, work the opposite of KSU's regulation completely, which suggests that making student's academic placement before the PYP, not after the completion of the PYP as the program currently performs. This conclusion exposed two questions about the PYP and KSU's strategic plan: 1) To what extent do both plans respond to the actual needs of stakeholders for both groups, male and female?; and 2) Does the current model of the PYP make an actual difference on first-year 
students' learning? Table 33 displays the similarity comparison of the CM/PM statements and

KSU's strategic plan.

Table 33

Similarity Comparison of the CM/PM Generated Statements for the Male and Female Groups and KSU's Strategic Plan

\begin{tabular}{|c|c|c|c|}
\hline No & $\begin{array}{c}\text { Male Group } \\
\text { Statements (S) }\end{array}$ & Item & $\begin{array}{l}\text { Female Group } \\
\text { Statements (S) }\end{array}$ \\
\hline 1 & $\begin{array}{l}\text { S24, } \\
\text { S35 }\end{array}$ & $\begin{array}{l}\text { Mission: To provide distinctive education, produce creative } \\
\text { research, serve society and contribute in building the knowledge } \\
\text { economy and community through learning, creative thinking } \\
\text { environment, the optimal use of technology and effective } \\
\text { international partnership (p. 14). }\end{array}$ & \\
\hline 2 & & $\begin{array}{l}\text { Vision: To be a world-class university and a leader in building } \\
\text { the knowledge society (p. 14). }\end{array}$ & \\
\hline \multirow[t]{5}{*}{3} & & $\begin{array}{l}\text { Value: } \\
\text { 1- Quality and excellence: We measure ourselves according to } \\
\text { challenging criteria, honoring high ambitions and the pursuit } \\
\text { of distinctiveness through our commitment to the highest } \\
\text { intellectual standards in teaching, learning and innovation }\end{array}$ & \\
\hline & $\mathrm{S} 22, \mathrm{~S} 45$ & $\begin{array}{l}\text { 2- Leadership and teamwork: We remain committed to } \\
\text { promoting individual and institutional leadership roles that } \\
\text { drive social development, upholding professionalism, } \\
\text { responsibility, and innovation. } \\
\text { 3- Freedom of inquiry: Rigorous and honest intellectual } \\
\text { exploration is dimensions of our scholarly activities. }\end{array}$ & \\
\hline & S7 & $\begin{array}{l}\text { 4- Fairness and integrity: We abide by the principles of social } \\
\text { justice, equal opportunity and cultural diversity, consequently } \\
\text { holding the members of our community to the highest } \\
\text { standards of honesty, respect, and professional ethics. }\end{array}$ & S26, S28 \\
\hline & & $\begin{array}{l}\text { 5- Transparency and accountability: We remain committed to } \\
\text { expose our thinking and ideas for society and scholars to } \\
\text { judge our contributions to global knowledge, and we hold } \\
\text { accountable everybody in our community for respecting and } \\
\text { upholding our values in all forms of their scholarly activities. }\end{array}$ & \\
\hline & & $\begin{array}{l}\text { 6- Lifelong learning: We are committed to lifelong learning } \\
\text { inside and outside the KSU community, enhancing continued } \\
\text { intellectual growth and welfare of the society (p. 14-15). }\end{array}$ & $\begin{array}{l}\text { S9, S15, S24, } \\
\text { S30 }\end{array}$ \\
\hline 4 & & $\begin{array}{l}\text { Strategic objective: } \\
\text { 1- Good everywhere; Great in focus areas (Strengthen our } \\
\quad \text { comprehensive university with academic areas of research }\end{array}$ & \\
\hline
\end{tabular}


and teaching excellence).

S16, S33 2- Distinctive faculty (Attract and develop distinctive faculty).

3- Less is more (Reduce KSU's volume, increase the share of graduate students and raise entry requirements).

S6 4- Stronger graduates (Enable KSU students to learn hard and soft skills throughout their academic life).

S23, S25 5- Building bridges (Build bridges among KSU constituencies and externally with local and international groups).

S42 6- Supportive learning environment (Create an engaging environment at KSU for faculty, students, and staff)

7- Sustainable future (Build KSU's endowment and diversify sources of funding).

8- Flexibility and Accountability (Create a performance contract between KSU and the government).

9- Organizing for purpose (Establishing an organization and governance model that support KSU's mission) (p. 156-159).

5

$6 \quad$ S36

7

8

S48
Placement exam after preparatory year (The medical school admissions criteria) (p. 98).

KSU's recent introduction of the preparatory year (whereby students are given foundation courses in core hard and soft skills before beginning their university-level studies) (p. 103).

Strategic implication for KSU: KSU should create a 3-track preparatory year program, with a mandatory placement exam for entering undergraduate school (p. 104).

Strategic implication for KSU: KSU should ensure that the skills taught during the preparatory year (English, soft skills) are developed further through the curriculum of all its academic programs. The accreditation further recommends the development of a comprehensive learning and teaching plan to support transition points for students, and skill-building for faculty (p. 106).

9 S3, S4, S18, Recommendation 4.1: Strengthen preparatory year capabilities: S19, S21, S31 all students who take admission in KSU have to choose a track e.g. humanities track, Science \& Engineering, Health track etc. The installation of PY Tracks has been a huge success at the university. It is equally important to have a lasting effect on students as their one-year is invested in their capabilities. The Preparatory year program seeks to strengthen the effectiveness and build capabilities in H.R., infrastructure, students etc. This would include review of Preparatory year program capabilities such a H.R., system, faculty, curriculum, infrastructure, collaboration with industry, NGO's, private sector (p. 222). 


\section{Finding for Research Question 2 (Compare and Contrast Male and Female Perceptions)}

The second research question was "When conducting a Concept Mapping/Pattern Matching conceptualization, how do the results for males compare and contrast with the results for females?" The outcomes of the CM/PM for both stakeholder groups were used for comparison. As mentioned in Chapters 1, 3, and 4, the gender segregation is a sociopolitical reality, not an intellectual divide, and gender was not the main focus of this study. In other words, the comparison purpose was to explore male-only educational context versus female-only educational context at the Preparatory Year Program (PYP) at King Saud University (KSU).

Again, King Saud University applies one model of the Preparatory Year Program for male and female students including policy, regulation, curriculums, activities, and one strategic plan for the program despite different perceptions. Thus, the researcher made the comparison on two levels: the cluster level and the statements level. The similarity and differences were reported between two groups.

Results of Female versus Male Perceptions. The CM/PM perceptions produced 36 and 48 statements for the female and the male group respectively. Two separate brainstorming sessions were conducted and two different datasets were created for each group. The outcomes of the Concept Mapping/Pattern Matching (CM/PM) resulted in six clusters for the female group and seven clusters for the male group. 9 females participated in the female brainstorming session and constructed 36 statements, while 14 males created 48 statements in the male brainstorming session. The percentage of participants' contribution in generating these statements was 3.43 statements for each male and 4 statements for each female. Despite the differences between the two groups in terms of statement's content, ideas, and issues presented; four clusters from the male group aligned with four clusters from the female group according to the names and themes 
involved. The similarity means that these clusters have similar themes/ideas/insights, although they differ in phrasing or context. For example, Cluster 1 Program Regulation in the male group has a topic connected to the program rules, e.g. S38, Granting a certificate for students who pass the reparatory Year Program, this idea did not appear in the female group but it is linked to program regulation. On the other hand, the female group showed different ideas, e.g. S18, Students academic placement to be before the Preparatory Year, this statement did not appear in the male group but is also connected to program regulation.

A close examination of the CM/PM results revealed that the Program Regulation title aligned with Cluster 1 in the male group and Cluster 4 in the female group. Cluster 1 involves four statements, while Cluster 4 has eight statements, and both were assigned to the highest importance mean in the two groups as follows: Cluster $1(\mathrm{M}=4.48)$ and Cluster $4(\mathrm{M}=4.54)$. Furthermore, Cluster 1 was placed on the fourth level of efficacy for the males at $(M=3.39)$, which is considered a moderate efficacy, and reported at the lowest level of efficacy at $(\mathrm{M}=2.85)$ for the females. In fact, Cluster 4 in the female group is the only one cluster among all the clusters, either male or female, that was rated below 3.00 for efficacy. The main themes that appeared in both clusters suggest that the student academic placement regulation should take place before the PYP, not after. The stakeholders group suggested granting a PYP certification for those who could not complete PYP to help them engage in the labor market. The two groups of stakeholders stated concern about program regulation and this is considered the most important domain for KSU to develop in the future before developing the program academically.

Cluster 2 in the male group and Cluster 1 in the female group were named similarly, Program Assessment Mechanism and Curriculum Structure. Cluster 2 has 10 statements as the largest in the male group and Cluster 1 has seven statements. Both clusters were rated in the third 
level of importance with different means: Cluster $2(\mathrm{M}=4.36)$ and Cluster $1(\mathrm{M}=4.46)$. The efficacy means scores were very closes to each other at $(\mathrm{M}=3.38)$ for Cluster 2 and at $(\mathrm{M}=3.37)$ and for Cluster 1. The main themes raised in both clusters were developing assessment methodology to identify student's learning progression and inform curriculum developers and policymakers about the programs performance. Regardless of the high importance and moderate efficacy reported for each cluster, the group of stakeholders' perceptions thought that KSU performed ineffectively to develop student's assessment methodology and curriculum.

The title, Program Services: Prior to and During was assigned for both groups' Clusters 5. Both clusters yielded similar importance mean scores at $(\mathrm{M}=4.33)$ and rated in the fourth level of importance. In the male group, the cluster has nine statements and the female group contains five statements. For the efficacy rating, both clusters recorded high mean scores at the second level for the male group at $(M=3.51)$ and the first level for the female group at $(M=3.97)$. However, the efficacy rating is still lower than importance, which means statistically, KSU performed ineffectively on these clusters. The result also indicates that the PYP concentrated more on developing infrastructure and student's services than academic domains.

Cluster 4 in the male group and Cluster 2 in the female group were titled, Program Academic Design. Both groups shared some main themes, such as identifying, developing, organizing, and emerging student's skills and activities in new academic design, which takes into account the coordination with KSU's colleges and academic departments to avoid an overlap among these departments. Cluster 4 has eight statements and rated at importance $(\mathrm{M}=4.21)$, while Cluster 2 has 10 statements as the largest cluster in the female group and rated at $(\mathrm{M}=4.29)$ for importance. Both were placed on the fifth level of importance. For efficacy, Cluster 4 was recorded at $(\mathrm{M}=3.46)$ and Cluster 2 at $(\mathrm{M}=3.19)$. However, these results indicate that both 
groups' perceptions concentrated on developing student's skills, activities, and redesigning the academic program and restructuring its curriculum, e.g. merging some courses.

The remaining clusters, either male or female, represented new themes about the PYP's future. For the male group, Cluster 3 Program Philosophy, Planning, and Operational Mechanism, and Cluster 7 Program Applications Policy recorded an average importance mean above 4.00 on a 5-point Ordinal Scale, both clusters were placed on the lowest level of efficacy at $(M=3.36)$ and $(M=3.23)$ respectively. Cluster 3 has seven statements and Cluster 7 has six statements. The result indicated that the stakeholders' thought that the PYP's purpose and philosophy are ambiguous. On the other hand, the female group mentioned a vital subject regarding Teaching Quality, Cluster 2, in the PYP. Cluster 2 was rated in the second level of importance, which indicates to the need for improving faculty performance in the female section.

Finally, Cluster 6 Supporting Student Learning in male group, and Cluster 6 Promoting Student Learning in the female group have four statements each. In the male group, supporting student's learning through activities, opportunities, and participation in community services, etc. was rated on the highest level of efficacy at $(\mathrm{M}=3.79)$, which indicates that the PYP gives priority to facilitate student's learning through services and extra-curriculum. The researcher used the term "promoting" for the female group to describe female perceptions that focused on giving them more opportunities to participate in local or international educational activities. Tables 34 and 35 display the comparison of male and female clusters based on importance and efficacy ratings, and Figure 16 displays the similarities and differences between male and female perceptions on the clusters. 
Table 34

The Descending Order of Male Clusters vs Female Clusters Based on the Importance Mean

\begin{tabular}{lclc}
\hline \multicolumn{1}{c}{ Male Group } & \multicolumn{1}{c}{ Female Group } \\
\hline \multicolumn{1}{c}{ Cluster Label } & Importance & \multicolumn{1}{c}{ Cluster Label } & Importance \\
\hline 1-Program Regulation & 4.48 & 4-Program Regulation & 4.54 \\
7-Program Applications Policy & 4.42 & 3-Teaching Quality & 4.52 \\
& 4.36 & 1-Program Assessment & 4.46 \\
2-Program Assessment Mechanism & & Mechanism and Curriculum \\
and Curriculum Structure & & Structure \\
5-Program Services: Prior to and & 4.33 & 5-Program Services: Prior to & 4.33 \\
During & & and During & \\
4- Program Academic Design & 4.21 & 2-Program Academic Design & 4.29 \\
3-Program Philosophy, Planning, & 4.19 & 6-Promoting Student Learning & 4.22 \\
and Operational Mechanism & & & \\
6-Supporting Student Learning & 4.04 & & \\
\hline
\end{tabular}

Table 35

The Descending Order of Male Clusters vs Female Clusters Based on the Efficacy Mean

\begin{tabular}{|c|c|c|c|}
\hline \multicolumn{2}{|l|}{ Male Group } & \multicolumn{2}{|l|}{ Female Group } \\
\hline Cluster Label & Efficacy & Cluster Label & Efficacy \\
\hline 6-Supporting Student Learning & 3.79 & $\begin{array}{l}\text { 5-Program Services: Prior to and } \\
\text { During }\end{array}$ & 3.97 \\
\hline $\begin{array}{l}\text { 5-Program Services: Prior to and } \\
\text { During }\end{array}$ & 3.51 & 3-Teaching Quality & 3.63 \\
\hline 4- Program Academic Design & 3.46 & 6-Promoting Student Learning & 3.44 \\
\hline 1-Program Regulation & 3.39 & $\begin{array}{l}\text { 1-Program Assessment Mechanism } \\
\text { and Curriculum Structure }\end{array}$ & 3.37 \\
\hline $\begin{array}{l}\text { 2-Program Assessment Mechanism } \\
\text { and Curriculum Structure }\end{array}$ & 3.38 & 2- Program Academic Design & 3.19 \\
\hline $\begin{array}{l}\text { 3-Program Philosophy, Planning, } \\
\text { and Operational Mechanism }\end{array}$ & 3.36 & 4-Program Regulation & 2.85 \\
\hline 7-Program Applications Policy & 3.23 & & \\
\hline
\end{tabular}




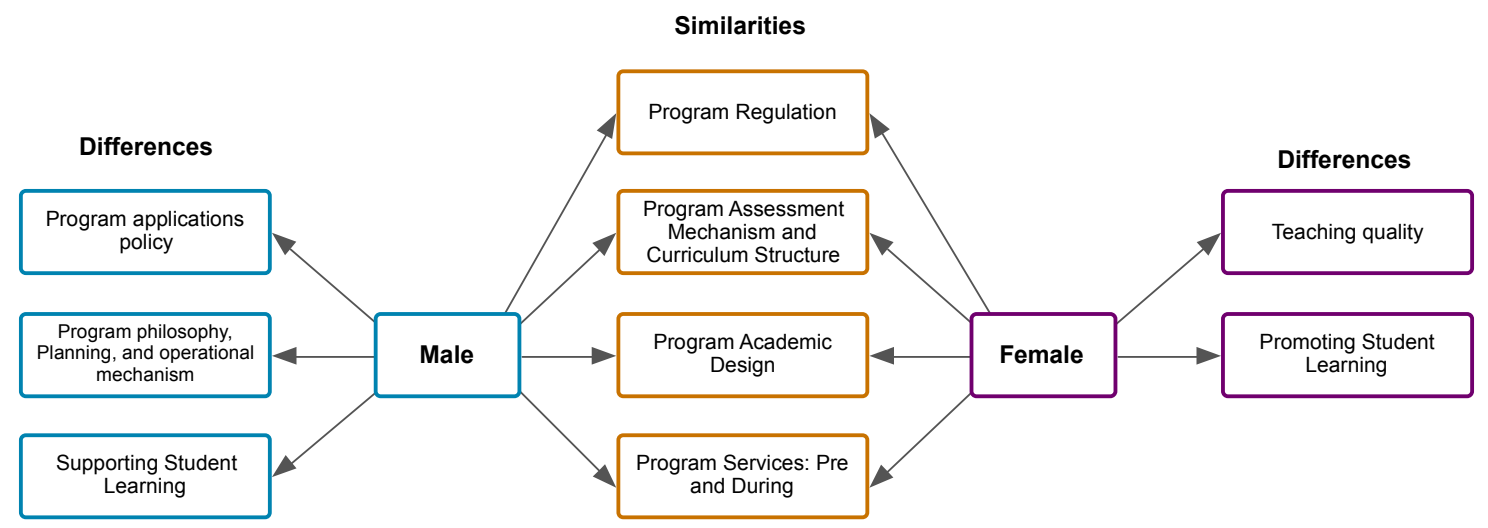

Figure 16: Similarities and differences between male vs female perceptions on the clusters level.

On the statements level, the male group has 48 statements. 43 statements $(89.58 \%)$ yielded importance mean scores above 4.00, and 5 statements $(10.42 \%)$ rated between 3.00 to 4.00. For efficacy, three statements (6.25\%) yielded efficacy mean scores at or above 4.00, while 40 statements $(83.33 \%)$ ranked between 3.00 and 4.00 , and five statements $(10.42 \%)$ rated below 3.00 on a 5-point Ordinal Scale.

The female group has 36 statements. One statement $(2.78 \%)$ recorded the highest score among all statements in both groups at 5.00 for importance. Thirty statements $(83.33 \%)$ yielded importance mean scores at 4.00 or below 5.00, and finally, five statements $(13.89 \%)$ rated below 3.00. For efficacy rating, five statements $(13.89 \%)$ rated at or above $4.00 .20(55.56 \%)$ statements rated between 3.00 and 4.00 . Finally, 11 statements $(30.56 \%)$ rated below 3.00 on a 5-point Ordinal Scale. As observed for both groups, the majority of statements yielded mean scores above 4.00 for importance and below 4.00 for efficacy. The researcher set criterion to compare male and female perceptions based on statements level. The criterion was that the statements included for comparison were the only statements that recorded the highest importance mean scores and that recorded the lowest efficacy rate in both groups. All statements that yielded importance means at 4.50 or above were selected for comparison purposes. All 
statements that yielded efficacy means at 3.00 or below were selected for comparison. The reason for this criterion was to limit the number of statements and to explore the development trend in both groups.

For the male group, 13 statements $(27.08 \%)$ yielded importance means at or above 4.50 . One statement was rated at $(M=4.64)$, seven statements at $(M=4.57)$, and five statements at $(\mathrm{M}=4.50)$. In details, $\mathrm{S} 31$ at $(\mathrm{M}=4.64), \mathrm{S} 37, \mathrm{~S} 9, \mathrm{~S} 10, \mathrm{~S} 33, \mathrm{~S} 36, \mathrm{~S} 40$, and $\mathrm{S} 45$ at $(\mathrm{M}=4.57)$, and $\mathrm{S} 8, \mathrm{~S} 25, \mathrm{~S} 32, \mathrm{~S} 39$, and S43 at $(\mathrm{M}=4.50)$. Furthermore, S25, S36, S37, and S39 belonged to Cluster 7 Program Applications Policy. S8, S9, and S10 fitted into Cluster 5 Program Services: Prior to and During; S31, S32, and S40 tailored to Cluster 2 Program Assessment Mechanism and Curriculum Structure. S33 and S45 belonged to Cluster 1 Program Regulation, and S43 fitted into Cluster 4 Program Academic Design. No statements were aligned with Cluster 3 Program Philosophy, Planning \& Operational Mechanism, and Cluster 6 Supporting Student Learning for importance.

For efficacy in the male group, nine statements $(18.75 \%)$ rated at 3.00 or below were selected. S1, S17, S6, and S5 rated at $(\mathrm{M}=3.00), \mathrm{S} 15$ and $\mathrm{S} 34$ at $(\mathrm{M}=2.93), \mathrm{S} 38$ at $(\mathrm{M}=2.86), \mathrm{S} 2$ at $(\mathrm{M}=2.79)$, and $\mathrm{S} 29$ at $(\mathrm{M}=2.64)$. The matching revealed that $\mathrm{S} 2, \mathrm{~S} 5$, and $\mathrm{S} 17$ belonged to Cluster 2, S1 and S38 belonged to Cluster 1, S34 to Cluster 3, S6 to Cluster 4, S15 to Cluster 5, S29 to Cluster 7, and finally, no statements paired with Cluster 6. Table 36 shows the most important and fewest efficacies statements.

Table 36

Shows the List of the Most Important and Fewest Efficacies Statements in Male Group

\begin{tabular}{|c|c|c|c|c|c|}
\hline $\mathrm{S}$ & Statement & $\operatorname{Imp}$ & $\mathrm{S}$ & Statement & Effi \\
\hline 31 & $\begin{array}{l}\text { Conducting continuous review of the } \\
\text { Preparatory Year curriculum. }\end{array}$ & 4.64 & 1 & $\begin{array}{l}\text { Enabling students in fulfilling certain } \\
\text { criteria to enroll in major-specific courses. }\end{array}$ & 3.00 \\
\hline 37 & $\begin{array}{l}\text { Setting clear and specific options in advance } \\
\text { for students who do not pass the Preparatory } \\
\text { Year. }\end{array}$ & 4.57 & 17 & $\begin{array}{l}\text { Reconsidering the students' timetables and } \\
\text { credit hours. }\end{array}$ & 3.00 \\
\hline 9 & Introducing the university's facilities and & 4.57 & 6 & Developing note-taking skills during the & 3.00 \\
\hline
\end{tabular}


services to students to take advantage of them (orientation program).

10 Educating students about libraries and research resources.

33 Reviewing the performance of faculty members in the Preparatory Year.

36 Preparing students for subsequent university study.

40 Developing the Preparatory Year to become a package of educational and skills programs and then colleges and departments dictate the programs that are required from their students.

45 Introducing the Preparatory Year Program as a university program in which students take responsibility for their learning and become self-reliant.

8 Educating students about the university's regulations and their rights.

25 Coordinating with beneficiary colleges to choose the knowledge topics and skills that serve their majors.

32 Developing student assessment methods.

39 Developing programs to address student dropout in the Preparatory Year or beyond.

43 Including gifted students' programs within the Preparatory Year Program (to discover and take care of them). lecture.

4.57 5 Merging some of the PY's similar courses $\quad 3.00$ after reviewing their syllabi.

$4.57 \quad 15$ Organizing workshops for high school $\quad 2.93$ students to identify and address weaknesses of Preparatory Year students.

4.5734 Developing the Preparatory Year selfoperation mechanisms and phasing out of outsourcing to private companies.

$\begin{array}{lll}4.57 & 38 & \text { Granting a certificate for students who } \quad 2.86\end{array}$ pass the Preparatory Year Program.

$\begin{array}{lll}4.57 & 2 & \text { Availability of mechanisms for course } \quad 2.79\end{array}$ acceleration/promotion.

4.5029 Implementing the Preparatory Year Program within colleges in accordance with major tracks.

Moreover, the results exposed that Cluster 7 Program Applications Policy and its statements have the majority of importance impact, while the majority of Cluster 2 Program Assessment Mechanism and Curriculum Structure statements fell in the lowest level of efficacy. Figure 17 displays all statements that are rated as most important and as fewest efficacies for the male group. 


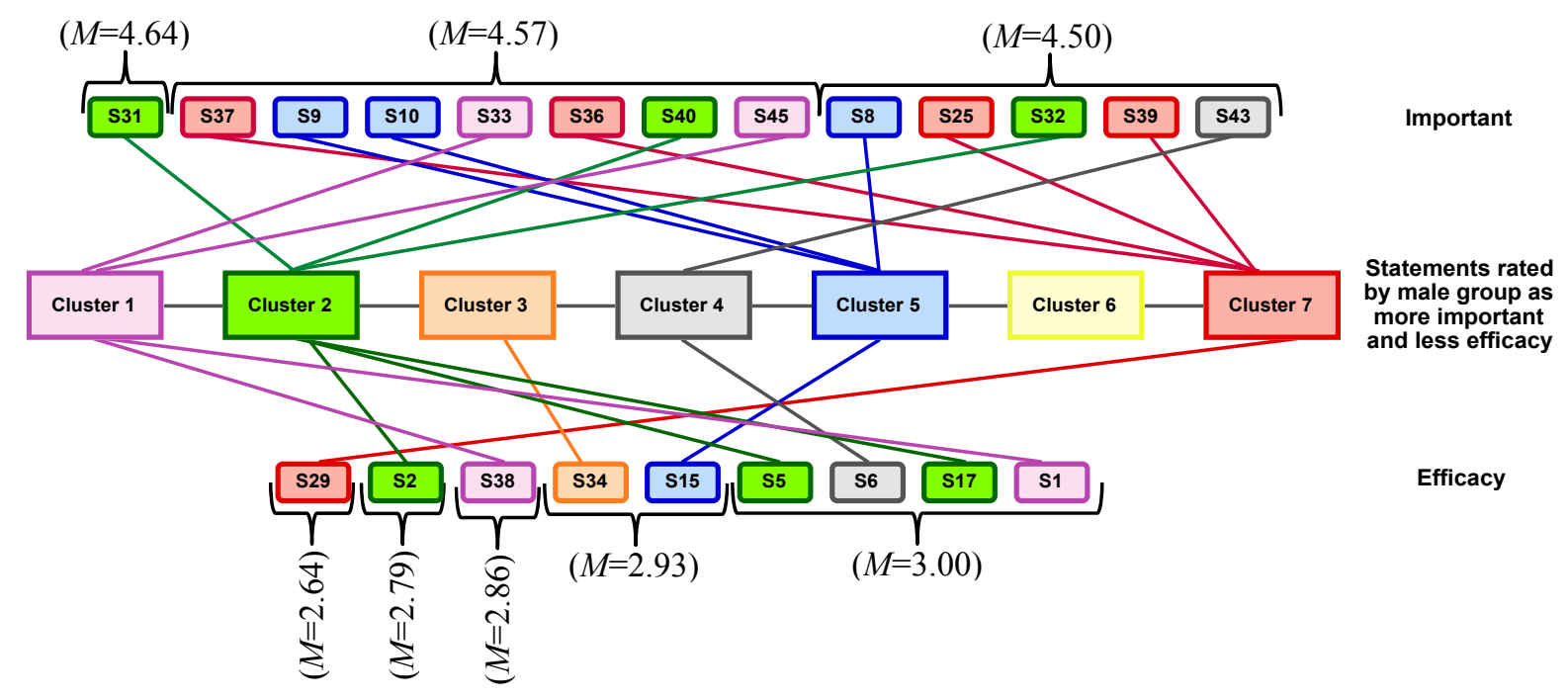

Figure 17: The most important and fewest efficacies statements in male group.

For the female group, 16 statements $(44.44 \%)$ yielded an importance mean at 4.50 or above. $\mathrm{S} 17$ rated at $(\mathrm{M}=5.00), \mathrm{S} 24$ at $(\mathrm{M}=4.89) ; \mathrm{S} 1, \mathrm{~S} 6, \mathrm{~S} 9, \mathrm{~S} 19, \mathrm{~S} 23$, and $\mathrm{S} 31$ at $(\mathrm{M}=4.78)$; 4 , $\mathrm{S} 16$, and $\mathrm{S} 18$ at $(M=4.67) ; \mathrm{S} 11, \mathrm{~S} 12, \mathrm{~S} 13, \mathrm{~S} 14$, and $\mathrm{S} 30$ at $(\mathrm{M}=4.56)$.

S1, S11, and S17 belonged to Cluster 1 Program Assessment Mechanism and Curriculum Structure. S4 S9, S30, and S24 fitted in Cluster 2 Program Academic Design. S12 and S16 aligned with Cluster 3 Teaching Quality. S18, S19, S23, and S31 fitted into Cluster 4 Program Regulation. S13 and S14 aligned with Cluster 5 Program Services: Prior to and During. Finally, Cluster 6 Promoting Student Learning did not pair with any statements in this comparison.

Thirteen statements $(36.11 \%)$ yielded efficacy mean scores at 3.00 or below in the female group. S5 and S25 rated at (M=3.00); S7, S21, S31, and S35 at (M=2.89); S2, S6, and S18 at $(M=2.78)$; $S 23$ rated at $(M=2.67)$; and $S 29, S 32$, and $S 33$ at $(M=2.56)$. Furthermore, S6, S7, S18, S21, S23, S29, and S31 belonged to Cluster 4; S32, S33, and S35 fitted into Cluster 2), S2 to Cluster 1, S5 to Cluster 3, S25 to Cluster 6, and Cluster 5 has no matching. Table 37 shows the most important and fewest efficacies statements. 
Table 37

Shows the List of the Most Important and Fewest Efficacies Statements in the Female Group

\begin{tabular}{|c|c|c|c|c|c|}
\hline $\mathrm{S}$ & Statement & Imp & $\mathrm{S}$ & Statement & Effi \\
\hline 17 & $\begin{array}{l}\text { Reviewing the Preparatory Year curriculum } \\
\text { and comparing/contrasting them with public } \\
\text { education curriculum. }\end{array}$ & 5.00 & 5 & $\begin{array}{l}\text { Assigning a stable educational entity to run } \\
\text { the courses (with low possibility of } \\
\text { management change) }\end{array}$ & 3.00 \\
\hline 24 & $\begin{array}{l}\text { Focusing on the practical aspects that ensure } \\
\text { students will maintain skills, such as the } \\
\text { English language. }\end{array}$ & 4.89 & 25 & $\begin{array}{l}\text { Organizing academic trips for } \\
\text { distinguished students to study English } \\
\text { language courses in international institutes. }\end{array}$ & 3.00 \\
\hline 1 & $\begin{array}{l}\text { Developing an instrument to measure student } \\
\text { level, for example, English language skills. }\end{array}$ & 4.78 & 7 & $\begin{array}{l}\text { Achieving the most benefit from the } \\
\text { Preparatory Year (skills) by abolishing the } \\
\text { academic placement policy after the } \\
\text { Preparatory Year. }\end{array}$ & 3.00 \\
\hline 6 & $\begin{array}{l}\text { Applying the academic/college placement at } \\
\text { the beginning of the Preparatory Year. }\end{array}$ & 4.78 & 21 & $\begin{array}{l}\text { The Preparatory Year's GPA should not } \\
\text { affect choosing the future college of study. }\end{array}$ & 3.00 \\
\hline 9 & $\begin{array}{l}\text { Emphasizing practical, applied, and skill } \\
\text { aspects not just a compilation of grades for } \\
\text { academic placement. }\end{array}$ & 4.78 & 31 & $\begin{array}{l}\text { Implementing academic placement from } \\
\text { the beginning. }\end{array}$ & 2.93 \\
\hline 19 & $\begin{array}{l}\text { Identifying academic track/major from the } \\
\text { first day of study. }\end{array}$ & 4.78 & 35 & $\begin{array}{l}\text { Integrating some skills, such as speech } \\
\text { skill and scientific research, during the } \\
\text { study of language. }\end{array}$ & 2.93 \\
\hline 23 & $\begin{array}{l}\text { Applying academic placement for all students } \\
\text { before entering the Preparatory Year to make } \\
\text { students focus more on academic } \\
\text { achievement. }\end{array}$ & 4.78 & 2 & $\begin{array}{l}\text { Reassessing the importance of teaching } \\
\text { (some) courses in the Preparatory Year, for } \\
\text { example, health and fitness courses. }\end{array}$ & 2.86 \\
\hline 31 & $\begin{array}{l}\text { Implementing academic placement from the } \\
\text { beginning. }\end{array}$ & 4.78 & 6 & $\begin{array}{l}\text { Applying the academic/college placement } \\
\text { at the beginning of the Preparatory Year. }\end{array}$ & 2.79 \\
\hline 4 & $\begin{array}{l}\text { Reducing theoretical hours for the courses } \\
\text { that require practical application, such as } \\
\text { communication and computer skills. }\end{array}$ & 4.67 & 18 & $\begin{array}{l}\text { Students' academic placement to be before } \\
\text { the Preparatory Year. }\end{array}$ & 2.64 \\
\hline 16 & $\begin{array}{l}\text { Diversifying teaching strategies to shorten } \\
\text { time. }\end{array}$ & 4.67 & 23 & $\begin{array}{l}\text { Applying academic placement for all } \\
\text { students before entering the Preparatory } \\
\text { Year to make students focus more on } \\
\text { academic achievement. }\end{array}$ & 2.67 \\
\hline 18 & $\begin{array}{l}\text { Students' academic placement to be before } \\
\text { the Preparatory Year. }\end{array}$ & 4.67 & 29 & $\begin{array}{l}\text { To be a Preparatory Program not a } \\
\text { Preparatory Year. }\end{array}$ & 2.56 \\
\hline 11 & $\begin{array}{l}\text { Students can pass some of the Preparatory } \\
\text { Year courses directly. }\end{array}$ & 4.56 & 32 & $\begin{array}{l}\text { Merging some courses together, such as } \\
\text { research and communication, under one } \\
\text { course, named the skills course. }\end{array}$ & 2.56 \\
\hline 12 & $\begin{array}{l}\text { Ensuring that faculty members have the } \\
\text { necessary capability to deal with students at } \\
\text { this age. }\end{array}$ & 4.56 & 33 & $\begin{array}{l}\text { Self-development skills can be acquired } \\
\text { during study through workshops and } \\
\text { courses that are offered by the Deanship of } \\
\text { Student Affairs. }\end{array}$ & 2.56 \\
\hline 13 & $\begin{array}{l}\text { The necessity of educating students about } \\
\text { their rights and duties. }\end{array}$ & 4.56 & & & \\
\hline 14 & $\begin{array}{l}\text { The importance of the orientation program for } \\
\text { students before starting the study plan }\end{array}$ & 4.56 & & & \\
\hline 30 & $\begin{array}{l}\text { Implementing independent learning more than } \\
\text { lectures. }\end{array}$ & 4.56 & & & \\
\hline
\end{tabular}

Furthermore, results showed that Cluster 4 Program Regulation and its statements have the majority of importance with five statements and also the majority of lowest efficacy 
statements with seven statements. Figure 18 displays the statements that were rated as most important and fewest efficacies for the female group.

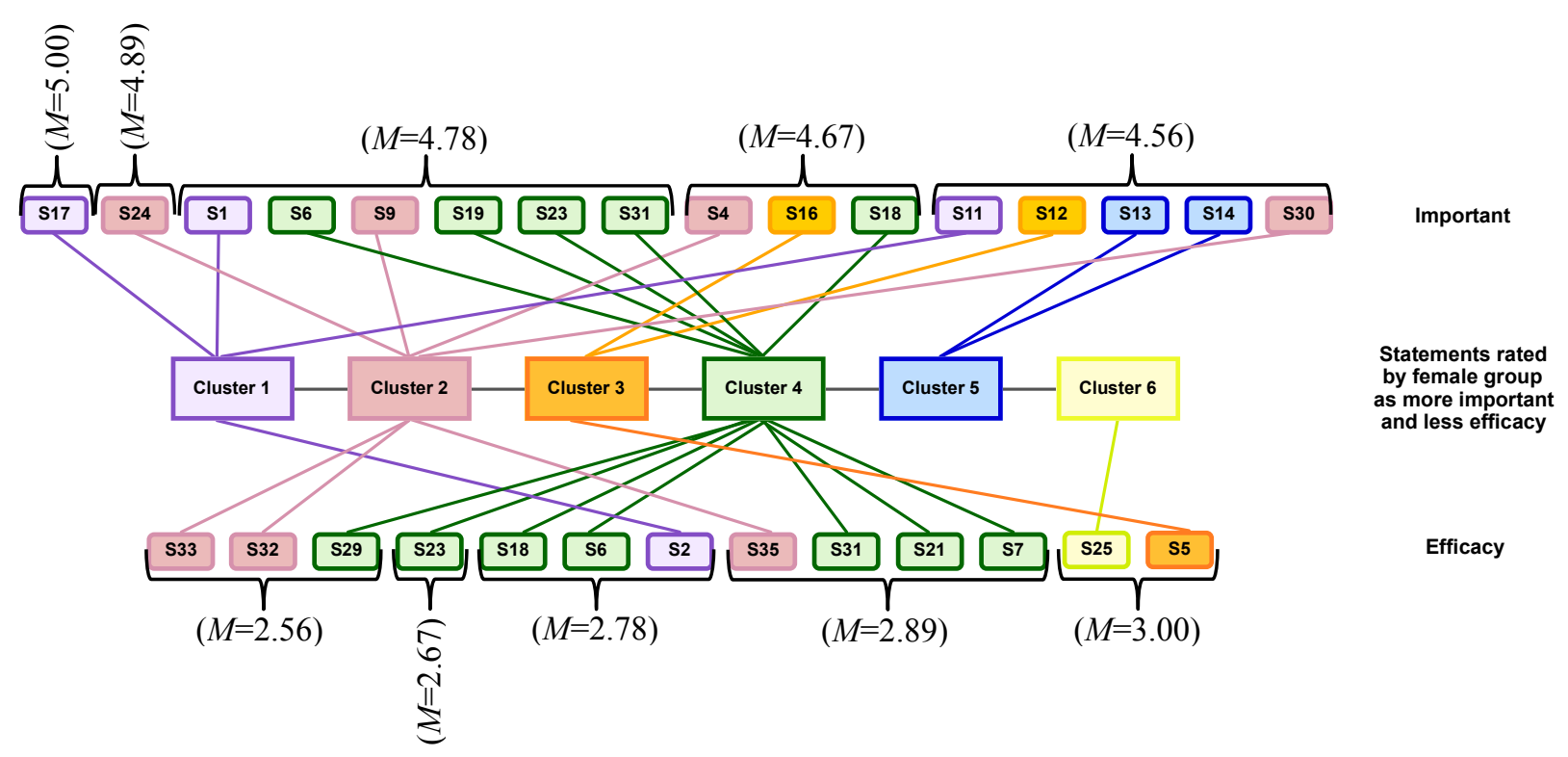

Figure 18: The most important and fewest efficacies statements in female group.

In-depth examination for similarities and differences between the most important and fewest efficacies statements in both groups was performed subjectively. As mentioned at the beginning of this section, the similarity means statements illustrated a similar theme or context that the researcher concluded was for the most important statements in both groups, $16(100 \%)$ of the most important statements in the female group aligned with 11 statements $(84.62 \%)$ of 13 in the male group. In detail, S17, S24, S9, S4, and S30 from the female group aligned with S31, $\mathrm{S} 36, \mathrm{~S} 40, \mathrm{~S} 45, \mathrm{~S} 25$, and S43 in the male group. The main theme that appeared in all these statements was about the academic and curriculum design issues in the PYP.

Upon further analysis, S1, S6, S19, S23, S31, S18, and S11 in the female group aligned with S32 in the male group that emphasized on student's learning assessment issues. S16 and S12 in the female group aligned with S33 of the male group that was concerned about teaching quality and methods. The last similarity reported between the two groups was for S13 and S14 in 
the female group aligned with S8, S9, and S10 in the male group, and all represented a theme regarding the orientation program and its components such as student's rights, duties, and educating them about the university's facilities, libraries, etc.

For the differences between both groups on the level of most important statements, as all female importance statements included in the similarity comparison mentioned above, there were two remaining statements from the male group that were not aligned with any in the female group; S37, Setting clear and specific options in advance for students who do not pass the Preparatory ear, and S39, Developing programs to address student dropout in the Preparatory Year or beyond; both provided new ideas about the PYP's development, especially the issue of researching students who dropout from the PYP or KSU. Table 38 displays female versus male perceptions for the most important statements.

Table 38

Shows the List of the Most Important Statements Female vs Male

\begin{tabular}{|c|c|c|c|c|c|}
\hline $\mathrm{S}$ & Female/Statement & $\operatorname{Imp}$ & $\mathrm{S}$ & Male/Statement & $\operatorname{Imp}$ \\
\hline 17 & $\begin{array}{l}\text { Reviewing the Preparatory Year curriculum } \\
\text { and comparing/contrasting them with public } \\
\text { education curriculum. }\end{array}$ & 5.00 & 31 & $\begin{array}{l}\text { Conducting continuous review of the } \\
\text { Preparatory Year curriculum. }\end{array}$ & 4.64 \\
\hline 24 & $\begin{array}{l}\text { Focusing on the practical aspects that ensure } \\
\text { students will maintain skills, such as the } \\
\text { English language. }\end{array}$ & 4.89 & 37 & $\begin{array}{l}\text { Setting clear and specific options in } \\
\text { advance for students who do not pass the } \\
\text { Preparatory Year. }\end{array}$ & 4.57 \\
\hline 1 & $\begin{array}{l}\text { Developing an instrument to measure student } \\
\text { level, for example, English language skills. }\end{array}$ & 4.78 & 9 & $\begin{array}{l}\text { Introducing the university's facilities and } \\
\text { services to students to take advantage of } \\
\text { them (orientation program). }\end{array}$ & 4.57 \\
\hline 6 & $\begin{array}{l}\text { Applying the academic/college placement at } \\
\text { the beginning of the Preparatory Year. }\end{array}$ & 4.78 & 10 & $\begin{array}{l}\text { Educating students about libraries and } \\
\text { research resources. }\end{array}$ & 4.57 \\
\hline 9 & $\begin{array}{l}\text { Emphasizing practical, applied, and skill } \\
\text { aspects not just a compilation of grades for } \\
\text { academic placement. }\end{array}$ & 4.78 & 33 & $\begin{array}{l}\text { Reviewing the performance of faculty } \\
\text { members in the Preparatory Year. }\end{array}$ & 4.57 \\
\hline 19 & $\begin{array}{l}\text { Identifying academic track/major from the } \\
\text { first day of study. }\end{array}$ & 4.78 & 36 & $\begin{array}{l}\text { Preparing students for subsequent } \\
\text { university study. }\end{array}$ & 4.57 \\
\hline 23 & $\begin{array}{l}\text { Applying academic placement for all students } \\
\text { before entering the Preparatory Year to make } \\
\text { students focus more on academic } \\
\text { achievement. }\end{array}$ & 4.78 & 40 & $\begin{array}{l}\text { Developing the Preparatory Year to } \\
\text { become a package of educational and skills } \\
\text { programs and then colleges and } \\
\text { departments dictate the programs that are } \\
\text { required from their students. }\end{array}$ & 4.57 \\
\hline 31 & $\begin{array}{l}\text { Implementing academic placement from the } \\
\text { beginning. }\end{array}$ & 4.78 & 45 & $\begin{array}{l}\text { Introducing the Preparatory Year Program } \\
\text { as a university program in which students } \\
\text { take responsibility for their learning and } \\
\text { become self-reliant. }\end{array}$ & 4.57 \\
\hline 4 & Reducing theoretical hours for the courses & 4.67 & 8 & Educating students about the university & 4.50 \\
\hline
\end{tabular}


that require practical application, such as communication and computer skills.

16 Diversifying teaching strategies to shorten time.

18 Students' academic placement to be before the Preparatory Year.

11 Students can pass some of the Preparatory Year courses directly.

12 Ensuring that faculty members have the necessary capability to deal with students at this age.

13 The necessity of educating students about their rights and duties.

14 The importance of the orientation program for 4.56 students before starting the study plan

30 Implementing independent learning more than 4.56 lectures. regulations and their rights.

4.6725 Coordinating with beneficiary colleges to choose the knowledge topics and skills that

4.50 serve their majors.

4.67 32 Developing student assessment methods. $\quad 4.50$

4.5639 Developing programs to address student $\quad 4.50$ dropout in the Preparatory Year or beyond.

4.5643 Including gifted students' programs within the Preparatory Year Program (to discover and take care of them).

Note: S: Statement. Imp: Important

Moreover, the researcher compared the fewest efficacies statements in both groups to explore similarities and differences. 12 statements $(92.31 \%)$ of the fewest efficacies statements in the female group aligned with 7 statements $(77.78 \%)$ out of 9 in the male group. In details, S5 in the female group aligned with S34 in the male group. Both statements main theme regarded the PYP's operational mechanism. Furthermore, S18, S21, S7, S23, S6, and S31 in the female group aligned with $\mathrm{S} 1$ and $\mathrm{S} 2$ in the male group. The main theme was about students learning assessment development. Also, S35, S2, S32, and S33 in the female group aligned with S17, S5, and S6 in the male group and highlighted academic and curriculum designs in the PYP. The last similarity was between S29 and S29 in both groups, which suggested ideas regarding the PYP implementation methods.

For differences between both groups on the level of the fewest efficacies statements, the female group retaining S25, Organizing academic trips for distinguished students to study English language courses in international institutes, and for the male group, two statements were retained involving S15, Organizing workshops for high school students to identify and address weaknesses of Preparatory Year students, and S38, Granting a certificate for students who pass 
the Preparatory Year Program, as these ideas may represent administration and organization

issues regarding the program that may be addressed in the future development of the program.

Table 39 displays the female versus male perceptions for the fewest efficacies statements.

Table 39

Shows the List of the Fewest Efficacies Statements Female vs Male

\begin{tabular}{|c|c|c|c|c|c|}
\hline $\mathrm{S}$ & Female/Statement & Effi & $\mathrm{S}$ & Male/Statement & Effi \\
\hline 5 & $\begin{array}{l}\text { Assigning a stable educational entity to run } \\
\text { the courses (with low possibility of } \\
\text { management change) }\end{array}$ & 3.00 & 1 & $\begin{array}{l}\text { Enabling students fulfilling certain criteria } \\
\text { to enroll in major-specific courses. }\end{array}$ & 3.00 \\
\hline 25 & $\begin{array}{l}\text { Organizing academic trips for distinguished } \\
\text { students to study English language courses in } \\
\text { international institutes. }\end{array}$ & 3.00 & 17 & $\begin{array}{l}\text { Reconsidering the students' timetables and } \\
\text { credit hours. }\end{array}$ & 3.00 \\
\hline 7 & $\begin{array}{l}\text { Achieving the most benefit from the } \\
\text { Preparatory Year (skills) by abolishing the } \\
\text { academic placement policy after the } \\
\text { Preparatory Year. }\end{array}$ & 3.00 & 6 & $\begin{array}{l}\text { Developing note-taking skills during the } \\
\text { lecture. }\end{array}$ & 3.00 \\
\hline 21 & $\begin{array}{l}\text { The Preparatory Year's GPA should not affect } \\
\text { choosing the future college of study. }\end{array}$ & 3.00 & 5 & $\begin{array}{l}\text { Merging some of the PY's similar courses } \\
\text { after reviewing their syllabi. }\end{array}$ & 3.00 \\
\hline 31 & $\begin{array}{l}\text { Implementing academic placement from the } \\
\text { beginning. }\end{array}$ & 2.93 & 15 & $\begin{array}{l}\text { Organizing workshops for high school } \\
\text { students to identify and address } \\
\text { weaknesses of Preparatory Year students. }\end{array}$ & 2.93 \\
\hline 35 & $\begin{array}{l}\text { Integrating some skills, such as speech and } \\
\text { scientific research, during the study of } \\
\text { language. }\end{array}$ & 2.93 & 34 & $\begin{array}{l}\text { Developing the Preparatory Year self- } \\
\text { operation mechanisms and phasing out of } \\
\text { outsourcing to private companies. }\end{array}$ & 2.93 \\
\hline 2 & $\begin{array}{l}\text { Reassessing the importance of teaching } \\
\text { (some) courses in the Preparatory Year, for } \\
\text { example, health and fitness courses. }\end{array}$ & 2.86 & 38 & $\begin{array}{l}\text { Granting a certificate for students who } \\
\text { pass the Preparatory Year Program. }\end{array}$ & 2.86 \\
\hline 6 & $\begin{array}{l}\text { Applying the academic/college placement at } \\
\text { the beginning of the Preparatory Year. }\end{array}$ & 2.79 & 2 & $\begin{array}{l}\text { Availability of mechanisms for course } \\
\text { acceleration/promotion. }\end{array}$ & 2.79 \\
\hline 18 & $\begin{array}{l}\text { Students' academic placement to be before } \\
\text { the Preparatory Year. }\end{array}$ & 2.64 & 29 & $\begin{array}{l}\text { Implementing the Preparatory Year } \\
\text { Program within colleges in accordance } \\
\text { with major tracks. }\end{array}$ & 2.64 \\
\hline 23 & $\begin{array}{l}\text { Applying academic placement for all students } \\
\text { before entering the Preparatory Year to make } \\
\text { students focus more on academic } \\
\text { achievement. }\end{array}$ & 2.67 & & & \\
\hline 29 & $\begin{array}{l}\text { To be a Preparatory Program not a } \\
\text { Preparatory Year. }\end{array}$ & 2.56 & & & \\
\hline 32 & $\begin{array}{l}\text { Merging some courses together, such as } \\
\text { research and communication skills, under one } \\
\text { course, named the skills course. }\end{array}$ & 2.56 & & & \\
\hline 33 & $\begin{array}{l}\text { Self-development skills can be acquired } \\
\text { during study through workshops and courses } \\
\text { that are offered by the Deanship of Student } \\
\text { Affairs. }\end{array}$ & 2.56 & & & \\
\hline
\end{tabular}

Note: S: Statement. Effi: Efficacy 


\section{Additional Limitations of the Study}

This study has some potential limitations for two main reasons: 1) the nature of the Concept Mapping/Pattern Matching (CM/PM) methodology itself; and 2) the variety of real-life obstacles that were encountered by the researcher during the process of conducting the research.

1. Although the Concept Mapping/Pattern Matching is used broadly in western research studies, this study was applied in an Arabic cultural context using the Arabic language for some of the study's phases, particularly for the brainstorming sessions, including the sorting and rating tasks for both stakeholder groups, male and female. Additionally, any document that was written in Arabic, such as the Students' Guidebook, may be considered a limitation, although the researcher used a cross-culture, forward-backward translation process developed by Brislin (1970) with a subjective, objective, and pilot assessment test to translate all text from Arabic to English in order to ensure the integrity of the data and results.

2. Usually in the $\mathrm{CM} / \mathrm{PM}$ empirical studies, the researcher compares and contrasts the stakeholders' perceptions for one dataset. In other words, one list of statements/ideas is used for comparison purposes between stakeholder groups, e.g. male versus female or student versus faculty. This study, however, has two lists of statements and different conceptualization maps, which may have made comparison of the two lists limited to results articulation rather than making a direct statistical comparison, e.g. studying a correlation or association between variables. However, this study's purpose was developmental in nature, and that is what made the stakeholders' perceptions valuable.

3. This study sample consisted only of people who were involved in the Preparatory Year Program (PYP) at King Saud University (KSU), or stakeholders. The sample was 
purposely selected from the population of students, faculty, administrators, parents, and representatives of the private sector at KSU. The final lists of participants who engaged in the brainstorming sessions for male or female may not have represented all groups of stakeholders at the university. In other words, the participants did not consist of a random sample of stakeholders and may not represent all sub-groups of KSU's community. All these factors are possible limitations. In addition, the study did not include any other universities in Saudi Arabia, which may be considered a limitation to generalizing the study outcomes to other institutions in Saudi higher education. More research would have to be done with other institutions included before any generalizations could be made.

4. This study used a focus group technique for data generation, but slightly different settings were used for male and female participants. The male session was accomplished face-toface, while the female session was administered remotely using video-conferencing technology; this may be considered a limitation. However, the researcher exerted maximum effort to reduce the effect of this limitation. He assigned a facilitator to help him coordinate the remote conferencing sessions. The researcher provided the facilitator with all necessary information, materials, and directions, which made the session more productive.

5. Furthermore, the use of remote brainstorming as a technique to gather data may be considered a limitation: "remote brainstorming is generally subject to a much lower response rate" (Kane \& Trochim, 2007. p. 54) when compared with face-to-face brainstorming. To reduce the possibility of such a limitation, the researcher tried to "establish a comprehensive communications plan that engages participants throughout the life of the 
project" (p. 54). As mentioned in Chapter 3, a communications plan was developed: five emails were sent and phone connections were made to help the female participants engage in the CM/PM process more effectively. However, using videoconference might not establish the same level of trust with a facilitator as when doing it face to face. Doing CMPM in this manner, one might get different results when facilitating brainstorming online than when doing it face to face. The researcher anticipates that despite making every attempt to present the same information face-to-face and online, differences in results might occur regardless.

6. Although the researcher informed all participants in both groups to express their insights/ideas freely and spontaneously, due to a cultural consideration, some participants believed that speaking out about the PYP might be considered a type of negative criticism. This might have resulted in a limitation; however, the researcher made considerable effort to make participants feel comfortable and ensured them that no judgment or negative effect would result from their participation in this study. A recommendation may be to repeat this study sometime in the future with separate student and faculty groups to encourage participants to speak more spontaneously and thus, increase the number of responses received.

7. Since the groups of stakeholders, both male and female, consisted of participants of widely differing ages and stages of life, e.g. students, faculty, parents, etc., limitations were encountered in terms of scheduling suitable times to meet, and allowing participants enough time to understand, discuss, and respond to the prompt questions. This may have affected the participants' ability to generate more response statements. 
8. Some limitations regarding survey items that were generated by the CM/PM outcomes have already been noted. In addition, the fact that the participants were required to respond to the survey's items, 48 statements for males and 36 statements for females, twice over - for importance and for efficacy ratings - may have caused a limitation in terms of accuracy of responses. However, the participants had a clear vision about the meaning of each item because the items were written verbatim as stated in the sessions. Moreover, the use of advanced statistical techniques, such as the Multidimensional Scaling (MDS) and Hierarchical Cluster Analysis (HCA) for data analysis, may also have reduced the effect of this limitation. The researcher gave participants enough time to respond, and space was provided on the survey itself for participants to add any insights/ideas or comments they thought could be added to the list of statements.

9. Although the sorting phase for each group involved clearly defined conditions and a specific process to sort the 36 (women) and 48 (men) statements into piles, this phase may have resulted in some errors or limitations. The reading and distribution of statements in piles may have caused limitations in cases where the researcher could not ensure that all the participants understood the criteria or sorted their statements according to these criteria. However, the researcher discussed every statement with each participant and got the participant's approval about its content before the sorting and rating phases took place.

10. One limitation of this study is that it does not address fully the breadth of politicization that occurs in organizations as complex as a university. The conceptualization from $\mathrm{CM} / \mathrm{PM}$ provides only a single representation (i.e. conceptualization) of phenomenon, when in reality; there may be multiple conceptualizations truly at play. This study did 
explore differences between males and females, but only because the cultural context demanded to explore them separately. However, gender was not the only factor related to "politicization." Manifestations of power occur in many ways. Power differentials occur also across: levels of management; academic disciplines; role as student, faculty or staff; and even within certain groups, their relative rank (e.g. Assistant, Associate \& Full Professors). Admittedly CM/PM limits to account fully for the rich complexity of power differentials that occur throughout the organization. Fully analyzing how power manifests throughout KSU, regardless of whether it relates to gender or academic rank of faculty, is well beyond the scope of this study. Furthermore, albeit imperfect, CM/PM, by providing a single conceptualization, allows an organization to conceptualize a single strategic plan, as opposed to unrealistically pursuing multiple strategic plans at the same time, many of which might be conflicting. In other words, this study purposely focused on the PYP program's consensus as a whole, rather than focusing specifically on multiple, conflicting points of interest.

11. For any university, retention is a complex phenomenon that is driven by both student development concerns as well as fiscal concerns for the institution. This study did not attempt to explain how these seemingly conflicting interests combine to inform PYP efforts.

12. Since the researcher used the Student's Guidebook as a guideline to describe the PYP model, this may be considered a limitation of the study. The Student's Guidebook only reported the PYP practical activities and described the program's explicit aspects; thus, some implicit dimensions might not have been included, which may constitute a further 
limitation. For example, the program's underlying philosophy and pedagogical base were not directly mentioned in the Guide.

13. As an ethical consideration regarding KSU's policies, the researcher avoided including any political or cultural dimensions or deliberation of governmental practices in the PYP. The researcher respected ethical values that may be inherent in the body of the first-year field experience without a negative critique of the current practices. This may limit the validity of results, but may make this study more culturally acceptable and, ultimately, more useful.

14. It should be noted that the results of this study may be limited to developmental purposes only; therefore, using the study's results for evaluative purposes may not be appropriate.

15. Finally, the CM/PM literature exposed several general limitations regarding the $\mathrm{CM} / \mathrm{PM}$ methodology illustrated by Kolb and Shepherd (1997) in their study, Concept Mapping Organizational Cultures. Four main themes may cause limitations for CM/PM reporting as follows: (1) concern about reliability of the CM/PM outcomes when repeating the study with different groups of stakeholders, (2) validity of the CM/PM for theory tests or for comparative studies, (3) as CM/PM has several processes, the sorting and rating phases may cause confusion for participants, and (4) arranging the CM/PM process, particularly brainstorming session, plus the sorting, rating, and interpretation phases, is considered a difficult challenge, especially with a large sample. However, Michalskia and Cousins (2000) state, "From a wider perspective, none of these limitations should be construed as fatal flaws." 


\section{Chapter Five}

\section{Summary, Discussion, Implications, and Future Research}

Chapter five offers an overview of the study, a summary of the study's finding, discussion of the potential implications, and recommendations for future research regarding First-Year Experiences and the Preparatory Year Program development.

\section{Overview of Study}

First-year experience is critical for developing a foundation for successfully transitioning into college, and students' success is largely based on first-year experiences (Ben-Avie, Kennedy,Unson, Li, Riccardi \& Mugno, 2012; Clark, 2005; Frazier, 2007; Mutch, 2005; Noel, Levitz, \& Saluri, 1985; Tinto \& Pusser, 2006; Upcraft, Gardner \& Barefoot, 2004).

Several issues and challenges related to students' transition into postsecondary education still exist in the majority of higher education institutions, whether it be in the United States of America or on the international level, some challenges include: (a) Culture barriers, (b) Personal change, (c) Increase in emotional and mental health disorders among new students, (d) Family background, (e) Increase in university cost and decrease in financial aid, (f) Number of students with disabilities, (g) students' diversity, and (h) the trend of postsecondary institutions to develop specific employment related skills, especially those that want to shift toward a knowledge society or knowledge based-economy (Astin, Oseguera, Sax, \& Korn, 2002; Bauer \& Liang, 2003; Johnston, 2010; Crissman \& Ishler, 2005; Gordon \& Steele, 2003; Howe \& Strauss, 2000; Pryor, Hurtado, Saenz, Lindholm, Korn \& Mahoney, 2005).

In the Saudi higher education context, first-year experience is considered a new phenomenon in the majority of Saudi's universities, where most of them started the Preparatory Year Program (PYP) in 2007 or beyond, including King Saud University (KSU). The current 
working model of the PYP at KSU has several challenges including: 1) the program's capability to meet students' actual needs and to prepare them to achieve the university's vision and mission; 2) the quality of learning and teaching cause concern with its relation to the business sector, which is currently responsible for the operation of the Preparatory Year Program; 3) the economic problems related to the high operational budget for the program, since it will cause the program to have instability in the future; 4) the lack of governing philosophy, theoretical, and pedagogical base of the program; and 5) challenges encountered by the female education reform movement, which has a goal to achieve equality of educational opportunities and achieve a knowledge society (Jamjoom \& Kelly, 2013; Smith \& Abouammoh, 2013). These challenges and others led this study's purpose and objective to develop the future ideal functions of the Preparatory Year Program to help first-year students successfully transition into college/university at King Saud University and to positively contribute to the achievement of KSU's vision, "To be a world class university and a leader in building the knowledge society" (Plan, 2014, p. 14).

As this study used the Concept Mapping/Pattern Matching (CM/PM) methodology, the $\mathrm{CM} / \mathrm{PM}$ approach offers a practical method to program planning and evaluation, which can help a researcher to extract the necessary information from multiple stakeholders for development or assessment purposes. This makes it ideal to use in educational sectors either for public or higher education to gather data and provide solutions (Streeter, Franklin, Kim, \& Tripodi, 2011). Furthermore, in the educational sectors, the CM/PM methodology can be used for two main purposes: 1) that related to student learning and curriculum development; and 2) program evaluation and planning (Sutherland, \& Katz, 2005, p. 258). 
This study's goal was developmental and to avoid mismatch between the reality of the PYP, institution's mission and vision, stakeholders' needs, and desire to develop; two separate groups of participants, one male and one female, were created to meet the study's goals. Each group involved members from different backgrounds, including KSU and the PYP's faculty, students, parents, representative of the business sector, student affairs, academic affairs, and KSU and the PYP's administrators, all of which have an interest and a direct relationship with the PYP at KSU.

The creation of two groups of participants was for the study of male-only educational context versus female-only educational context, which shows that gender is not the focus of the study. Therefore, the following research questions guided this study:

RQ1: Using the Concept Mapping/Pattern Matching methodology, how do Saudi male and female postsecondary stakeholders conceptualize the future ideal functions of the Preparatory Year Deanship to help students successfully transition into their first year of college/university?

a: Does this Concept Mapping/Pattern Matching conceptualization compare and contrast with the current working model of the Preparatory Year Program at King Saud University?

b: Does this Concept Mapping/Pattern Matching conceptualization compare and contrast with King Saud University's explicit strategic plan?

RQ2: When conducting a Concept Mapping/Pattern Matching conceptualization, how do the results for males compare and contrast with the results for females?

To address these research questions, the researcher first got the Institutional Review Board's (IRB) approval to conduct the study, along with permission from the Preparatory Year Deanship to apply the study to the PYP at King Saud University (see Appendix A \& J). Further, 
the researcher developed a communication plan to identify potential participants in each group, then defined the research problem to the confirmed participants, and scheduled brainstorming sessions at their convenience.

Following, the researcher applied the six steps of the Concept Mapping/Pattern Matching (CM/PM) methodology, which was advanced by William Trochim (1989a, 1989b) and Kane and Trochim (2007). Post preparation phase, two brainstorming sessions were conducted, one faceface with the male group and one remotely for the female group, using the focus prompt question "What programs, services, and activities should guide the functions of the Preparatory Year Program?" The total of males $(\mathrm{n}=14)$ and females $(\mathrm{n}=9)$ that participated in the brainstorming sessions had two main activities: 1) generating statements; and 2) statement sorting (statement restructuring). One week later, the participants responded to a survey designed on Qualtrics Software (Internet Based-Survey tool) to rate the separately created statements, 48 from the male group and 36 from female group, on a 5-point Ordinal Scale to measure how important the items are for King Saud University and the efficacy of KSU to facilitate the item for its first-year students. Using advanced statistical techniques involving Multidimensional Scaling (MDS) and Hierarchical Cluster Analysis (HCA) the data was analyzed and reported.

\section{Summary of Finding}

Summary of Results for Research Question 1. "Using the Concept Mapping/Pattern Matching methodology, how do Saudi male and female postsecondary stakeholders conceptualize the future ideal functions of the Preparatory Year Deanship to help students successfully transition into their first year of college/university?" The data collected from the two brainstorming sessions using the $\mathrm{CM} / \mathrm{PM}$, six phases were loaded and treated separately for 
each group using advanced statistical methods, Multidimensional Scaling (MDS) and Hierarchical Cluster Analysis (HCA).

The MDS method was used to create similarity and dissimilarity matrix and to "locate each statement as a separate point on a two-dimensional (X,Y) map" (Kane \& Trochim, 2007, p. 87). The HCA analysis produced a cluster tree or Dendogram graph with possible solutions arranged between 3-10 possible clusters for each group. Upon closer examination for all possible solutions, the decision was made to select seven clusters for the male group and six clusters for the female group. The 13 clusters expressed the main possible developmental themes of the Preparatory Year Program at King Saud University as conceptualized from the stakeholders' perceptions. For the male group, the seven clusters were defined as follows:

- Program Regulation Cluster (4 statements): Developing program rules for more flexibility for the PY's student to make decisions about course registration, granting PYP certification, and review faculty performance and capacity to teach first-year students.

- Program Assessment Mechanism and Curriculum Structure Cluster (10 statements): Developing students' learning assessment methods to foster student's movement to higher levels of study, and restructuring curriculums' content, syllabus, and applications through coordination with the university's colleges to meet their academic requirements and prospective students' needs.

- Program Philosophy, Planning, and Operational Mechanism Cluster (7 statements): Developing the PY's philosophy, purpose, goals, and application concurrently with improving the overall learning environments and starting self-operation for the program. 
- Program Academic Design (8 statements): Identifying, developing, and organizing the essential skills that first-year student's need with more concentration on note taking, professional ethics, values, volunteer work, and responsible autonomy skills.

- Program Services: Prior to and During Cluster (9 statements): Providing prospective students services prior to and during the first-year to connect students with the university environment and help them to engage in the learning process through an orientation program, counseling services, cooperation with beneficiary, colleges, and high schools, and conducting awareness programs and workshops.

- Supporting Student Learning Cluster (4 statements): Developing extra academic programs and services to foster student learning and to improve critical thinking skills and creativity.

- Program Applications Policy Cluster (6 statements): Developing a program policy and design to be part of colleges academic programs, to support students who cannot pass the PYP, and to address student's departure issue during or after the PYP (see Tables 6, 8, $10,11,12,13,14,15$, and 17).

Furthermore, the Pattern Matching examination (see Table 17 and Figure 15) revealed that all seven clusters yielded importance means above 4.00. The Program Regulation and Program Applications Policy Clusters recorded the highest importance mean respectively, $(M=4.48)$ and $(M=4.42)$, which indicates that these two clusters were the most important for the Preparatory Year Program's development domains. Moreover, the Program Applications Policy Cluster rated in the lowest level of efficacy, which indicates that King Saud University (KSU) performed ineffectively in this domain. 
On the contrary, the Supporting Student Learning Cluster rated on the lowest level of importance at $(M=4.04)$ and on the highest level of efficacy at $(M=3.79)$. Despite the importance of this cluster, the result showed that KSU performed effectively comparing to the other clusters on supporting student's learning through student activities and environment facilitations more than academic domains.

Moreover, the Program Philosophy, Planning, and Operational Mechanism Cluster recorded $(M=4.19)$ for importance and $(M=3.36)$ for efficacy, which put this cluster in the second lowest level of efficacy in the male group. This result described the participants concern about the ambiguity of the PYP's purpose and philosophy. In general, all seven clusters yielded efficacy mean scores below 4.00, which indicates the need to develop the program.

The survey results indicated that the participants believed that the majority of the 48 statements were very important. 43 statements were rated at or above 4.00 , five statements rated between 3.00 and 4.00. Additionally, the counted participants' responses on each statement showed that the total of all responses was 672 responses (48 statements x 14 participants): 325 responses (48.36\%) were very important, 246 responses $(36.61 \%)$ were important, 81 responses $(12.05 \%)$ were neutral, $14(2.08 \%)$ were unimportant, and 6 responses $(0.89 \%)$ were very unimportant. The very important and important ratings represented 571 responses $(84.97 \%)$ of the 672 total responses (see Appendix K).

For efficacy, the survey outcomes concluded that 196 responses $(29.17 \%)$ were very effective, 157 (23.36\%) were effective, 150 (22.32\%) were neutral, 77 (11.46\%) were ineffective, and 92 (13.69\%) were very ineffective. The very effective and effective results recorded 353 responses $(52.53 \%)$, while the ineffective and very ineffective recorded 169 (25.149\%). The undecided (neutral) recorded 150 responses $(22.32 \%)$ (see Appendix K). 
For the female group, the 36 statements were separated into the defining six clusters:

- Program Assessment Mechanism and Curriculum Structure Cluster (7 statements): Developing students' learning assessment approaches to foster student's learning, restructuring the PYP's curriculum content, syllabus, and comparing/contrasting with public education curriculums.

- Program Academic Design Cluster (10 statements): Identifying, developing, organizing, and emerging some of the program courses with concentrating on practices, extracurricular, and applied skills more than theory.

- Teaching Quality Cluster (3 statements): Ensuring the quality and capability of faculty at the PYP to deal with first-year students.

- Program Regulation Cluster (8 statements): Developing program rules to make the academic/college placement for all students on specific track/major before the PYP rather than after the PY's completion, and do not count the PYP's GPA to determine the future college or major.

- Program Services: Prior to and During Cluster (4 statements): Developing the orientation program and counseling services to educate first-year students about their rights and duties and the university's regulations.

- Promoting Student Learning Cluster (4 statements): Developing activities and academic programs that promote and stimulate student learning and raise student's engagement in the local and global contexts. (see Tables 7, 9, 18, 19, 20, 21, 22, and 23).

Furthermore, the pattern matching examination (see Table 24 and Figure 16) exposed that all six clusters yielded importance mean scores above 4.00. The Program Regulation and Teaching Quality Clusters recorded the highest importance mean respectively at $(M=4.54)$ and 
$(M=4.52)$, which indicates that these two clusters are considered the most important domains for the Preparatory Year Program development. Moreover, the Program Regulation Cluster rated in the lowest level of efficacy at $(\mathrm{M}=2.85)$, which indicates that King Saud University (KSU) performed ineffectively on reforming the program regulation. In fact, this cluster is the only one that rated below 3.00 among all 13 clusters for both groups.

Promoting Student Learning and Program Academic Design Clusters rated on the lowest level of importance respectively at $(\mathrm{M}=4.22)$ and $(\mathrm{M}=4.29)$. Additionally, the Program Academic Design Cluster fell to the second lowest level of efficacy at $(M=3.19)$. The Program Assessment Mechanism and Curriculum Structure and Program Services: Prior to and During Clusters recorded respectively at $(\mathrm{M}=4.46)$ and $(\mathrm{M}=4.33)$ for importance. In general, all six clusters yielded efficacy mean scores below 4.00, which indicates a desire for development of the program.

The survey results indicated that the majority of the 36 statements were very important and important, where one statement rated at $(\mathrm{M}=5.00), 30$ statements above 4.00 , five statements rated between 3.00 and 4.00. Additionally, the total of all responses was 324 responses (36 statements x 9 participants): 204 responses (62.96\%) were very important, 67 responses (20.68\%) were important, 39 (12.04\%) were neutral, 5 (1.54\%) were unimportant, and $9(2.78 \%)$ were very unimportant. The very important and important ratings represented 271 responses (83.64\%) out of the 324 total responses (see Appendix L).

For efficacy, the survey outcomes presented that 104 responses $(32.10 \%)$ were very effective, 49 (15.12\%) were effective, 73 (22.53\%) were neutral, 36 (11.11\%) were ineffective, and $62(19.14 \%)$ were very ineffective. The very effective and effective results recorded 153 
responses (47.22\%), while ineffective and very ineffective recorded 98 (30.25\%). The undecided (neutral) recorded 73 responses (22.53\%) (see Appendix L).

Summary of Results for Research Question 1a. Does this Concept Mapping/Pattern Matching conceptualization compare and contrast with the current working model of the Preparatory Year Program at King Saud University? The researcher performed a document analysis to compare and contrast the Concept Mapping/Pattern Matching (CM/PM) outcomes separately for the male and female groups, with the current working model of the Preparatory Year Program (PYP). The comparison involved the 48 statements and 7 clusters for the male group and the 36 statements and 6 clusters for the female group. The researcher used the official Student's Guidebook developed by the PY Deanship in 2016 as a primary source for comparison. The decision to use the Student's Guidebook was made because it is considered the only official source released that cites the PYP's mission, goals, policy, academic aspects, service, and functions (see Table 25).

The Student's Guidebook released two versions, one for males and one for females, the researcher set criteria to identify to what extent these two versions corresponded: 1) text alignment in meaning, despite the differences in some words that pertain to gender (male or female); and 2) the alignment of projects, initiatives, activities, and curriculums placed under each chapter in both documents. Examining and matching the two versions revealed a correspondence at $94.45 \%$ in terms of text, content, services, activities, policy, curriculums, and functions between the two versions (see Table 26). Out of 14 chapters, only 11 chapters were used for comparison purposes and the remaining three chapters were discarded.

The comparison of the CM/PM results and the current working model of the PYP were performed on two separate main levels, the clusters level and the statements level; the statements 
level has two sub-levels of comparisons, the similarity level and the differences level. The researcher set two criteria for comparison to ensure the validity and integrity of the results: 1) Each statement is paired with only one chapter in the Student's Guidebook that relates the closest conceptually, in meaning or function; and 2) The document analysis performed was based on the researcher's subjective perception of the conceptual sense of each cluster/statement, either in the male or female group.

For the male group, on the cluster level, the purpose of comparison was to explore the relationship between themes generated by the CM/PM and from the Student's Guidebook chapters. The analysis revealed that all 11 chapters aligned with five clusters of $\mathrm{CM} / \mathrm{PM}$ : Cluster 5 Program Services: Prior to and During matched Chapters 6, 8, 9, 10, and 11, which represents $45.45 \%$ as the highest percentage of alignment, Cluster 2 Program Assessment Mechanism \& Curriculum Structure paired with Chapters 2, 3, and 4. Cluster 3 aligned with Chapter 1 PY's Strategic Plan. Clusters 4 and 6 matched Chapter 7 Student Activities and Chapter 5 Learning Resources. Cluster 1 Program Regulation and Cluster 7 Program Applications Policy did not match any chapter in the Student's Guidebook. The results indicate that the male group's perceptions were not compatible with the chapters' content.

On the statements level, for similarity analysis 19 statements (39.58\%) aligned with a specific chapter. The similarity means that the PYP already applied these statements or ideas within the current working model. Out of 19 , only five statements $(26.32 \%)$, S6, S7, S22, S24, and S43, matched Chapter 7 Student Activities. These five statements belong to Cluster 4 Program Academic Design. The result indicates that the PYP performed effectively in developing student activities. Chapter 3 Curriculum and Student's Placement aligned with 4 statements (21.05\%). Chapter 8 Student Counseling Service involved three statements, S20, S47, 
and S12. Chapters 1, 5, and 9 recorded two statements in each chapter as follows: Chapter 1 PY's Strategic Plan has statements 35 and 46; Chapter 5 Learning Resources recorded statements 10 and 42; and Chapters 6 and 10 recorded one statement for each, statements 44 and 8 respectively.

A close examination to this outcome revealed that the statements in Cluster 5 Program Services: Prior to and During appeared frequently in Chapters 3, 5, 6, 8, 9, and 10 with seven statements: S8, S9, S10, S12, S13, S23, and S44. Cluster 5 had importance rated $(\mathrm{M}=4.33)$ and efficacy $(M=3.51)$, which placed this cluster in the fourth level of importance and second level of efficacy. The results concluded that the PYP program performed effectively in terms of student services, activities, and learning resources than regulation, policy, curriculum, and assessment (see Table 28).

For the male groups differences, the researcher could not align 29 statements $(60.42 \%)$ with any chapter in the Student's Guidebook. Cluster 1Program Regulation did not match any chapters in the Student's Guidebook. Cluster 3 Program Philosophy, Planning, and Operational Mechanism, reported 6 statements $(85.71 \%)$ with nonalignment. Cluster 2 Program Assessment Mechanism and Curriculum Structure, was placed in the third level, in terms of retaining ratio of 8 statements (80\%). Cluster 7 Program Applications Policy was placed in the fourth level of dissimilarity, with 4 statements $(66.67 \%)$ in nonalignment with the Student's Guidebook chapters. Clusters 4 Program Academic Design, 5 Program Services: Prior to and During, and 6 Supporting Student Learning recorded low levels of nonalignment and fell below 50\%.

The male group results indicate that the difference in some of the statements in these clusters and the majority of its statements are compatible with the current working model of the PYP. The results indicate that developing the program regulation, assessment methodology, and 
application policy are considered the most important domains from participants' perceptions (see Table 29).

For the female group, with one exception for Chapter 1 PY's Strategic Plan, all other 10 chapters aligned with existing clusters in the female group. Further, Cluster 4 Program Regulation, and Cluster 3 Teaching Quality were in nonalignment with any chapter in the Student's Guidebook. Cluster 1 Program Assessment Mechanism and Curriculum Structure aligned with Chapter 4 Student's Assessment. Cluster 2 Program Academic Design aligned with Chapters 2 and 3. Similar to the male group comparison, Cluster 5 Program Services: Prior to and During aligned with Chapters 6, 8, 9, 10, and 11 that represented (45.45\%) of the matches. Finally, Cluster 6 Promoting Student Learning paired with two chapters, 5 and 7 . This result reveals that the PYP's interests focus on providing student's service rather than focusing on teaching quality, assessment, academic, and program regulation (see Table 30).

Furthermore, for similarity, only $5(13.89 \%)$ of the female statements aligned into specific a chapter, while 31 statements $(86.11 \%)$ represented new ideas or suggestions for PYP's development. Chapter 3 Curriculum and Student's Placement involved one statement, S22 that belongs to Cluster 1 Program Assessment Mechanism and Curriculum Structure. Chapter 6 Students Affairs aligned with one statement, S13. Chapter 7 Student Activities aligns with two statements, S27 and S34. Finally, Chapter 10 Student's Rights and Duties aligned with statement S36. These statements aligned with Chapters 3, 6, 7, and 10, which means that there are seven chapters in nonalignment with any statements. The result supports the idea that the current working model of the PYP tends to be a service model rather than an academic model for firstyear students (see Table 31 ). For differences in the female group, 31 statements $(86.11 \%)$ are in nonalignment with any part of the current working model of the PYP. Upon closer examination, 
the outcomes of the document analysis revealed that statements from Cluster 3 Teaching Quality and Cluster 4 Program Regulation did not match any part of the current working model of the PYP.

For Cluster 2 Program Academic Design, nine statements (88.89\%) are in nonalignment with any chapter of the Student's Guidebook. Cluster 1 Program Assessment Mechanism and Curriculum Structure recorded $85.71 \%$ of nonalignment with six statements. Cluster 6 Promoting Student Learning, has (75\%) nonalignment for its statements. Cluster 5 Program Services: Prior to and During recorded 50\% nonalignment. The program services that reported high similarity and low differences in the male group were also reported in the female group; this outcome stresses the fact that the current working model of the PYP performed more effectively on student services than on an academic domain (see Table 32).

Summary of Results for Research Question 1b. Does this Concept Mapping/Pattern Matching conceptualization compare and contrast with King Saud University's explicit strategic plan? The document analysis of KSU's Strategic Plan KSU2030-Version-2 (2014) was performed to explore the association of the CM/PM outcomes for both groups of stakeholders with the university's plan. An in-depth review for the plan was accomplished to create a comparison matrix that involved KSU's vision, mission, values, strategic objectives, and any implication to the phrase "Preparatory Year Program". The document mentioned the phrase "Preparatory year" 11 times, but only in the primary section, including in the matrix (see Appendix O). The final set of matrix is comprised of nine themes (see Table 33).

The comparison was achieved on the statements level. The researcher decided to only compare and contrast the clusters seeking more accuracy; also, performing a comparison on the clusters level did not reveal valuable information for this study. The document analysis 
performed was based on the researcher's subjective perception of the conceptual sense of each statement. The researcher was aware that another researcher performing a documents analysis may result in different outcomes. The comparison involved the 48 statements from the male group and the 36 statements from the female group.

KSU's plan states the importance of continuing development of the PYP, “The Preparatory year program seeks to strengthen the effectiveness and build capabilities in H.R., infrastructure, students etc. This would include review of Preparatory year program capabilities such a H.R., system, faculty, curriculum, infrastructure, collaboration with industry, NGO's, private sector [sic]" (Plan, 2014, p. 222). The researcher took this comprehensive statement into account, since it may allow alignment with all 48 and 36 statements generated by both stakeholder groups. The researcher was also aware that some statements could be placed under different themes in the plan, thus, the researcher decided to place the statements under conceptually related theme. However, the document analysis revealed that 19 statements $(39.58 \%)$ from the male group and 10 statements $(27.78 \%)$ from the female group aligned with KSU's strategic plan.

From the male group, two statements, S24 (M=4.00) and S35 (M=4.21) aligned with KSU's mission. S22, S23, and S45 appeared under the Leadership and Teamwork topic that belonged to KSU's value theme. Additionally, S7, Teaching students the basics of professional ethics and linking them to Islamic values was paired with KSU's value of fairness and integrity. S16, Hiring faculty members from colleges who have experience in teaching first-year university students, and S33, Reviewing the performance of faculty members in the Preparatory Year, aligned with the second strategic objective of KSU, "Distinctive faculty (Attract and develop 
distinctive faculty)”. S6 and S23 were respectively placed under the fourth and fifth strategic goals of KSU.

S42 aligned with the sixth strategic objective of KSU that states, "Supportive learning environment”. S36 aligned with the PYP's task. S48, Intensifying/Enhancing the English language program, paired with KSU's strategic implication to improve English skills for all KSU's students. S3, S4, S18, S19, S21, and S31 aligned with KSU's recommendation to apply continuous development for the PYP. In the male group, the majority of statements aligned with KSU's strategic plan belong to Cluster 2 Program Assessment Mechanism and Curriculum Structure with five statements, Cluster 3 Program Philosophy, Planning, and Operational Mechanism with four statements, and Cluster 7 Program Applications Policy with three statements. These results indicate that the PYP may not have enough support to achieve KSU's mission, values, teaching quality, coordination between KSU's colleges, and services deanships and the PYP. Thus, the PYP may have performed ineffectively in the development of three domains of the PYP, including program assessment, program philosophy and purpose, and program application policy and regulations.

From the female group, S26, Engaging students in international conferences to gain experience and contact with elites, and S28, Partnering with leading universities in adopting outstanding students, recorded similar importance means at $(M=4.33)$ and efficacy means at $(M=3.78)$ and $(M=3.22)$ respectively. Both statements aligned with KSU's value of fairness and integrity that mentions "equal opportunity". S9, Emphasizing practical, applied, and skill aspects not just a compilation of grades for academic placement, S15, All offered skills are important and should not be specific for the Preparatory Year, S24, Focusing on the practical aspects that ensure students will maintain skills, such as the English language, and S30, Implementing 
independent learning more than lectures" all paired with KSU's value of lifelong learning. This result shows that the PYP's academic approach tends to be more theoretical than practical in the female section. S12, Ensuring that faculty members have the necessary capability to deal with students at this age, aligned with the strategic objective, "Distinctive faculty (Attract and develop distinctive faculty)". S22 aligned with KSU's strategic implication that suggests intensifying the English program for all students. S2 and S17 exposed the need for comparing the PYP's curriculum with public education curriculum and assessing some of the PYP's courses. Both S2 and S17 aligned with KSU's strategic implication that suggests developing a comprehensive teaching and learning plan with a concentration on curriculum development to meet student's needs.

For the female group, the majority of statements belonged to Cluster 2 Program Academic Design with four statements and Cluster 1 Program Assessment Mechanism and Curriculum with three statements. Two clusters were placed in the fourth and fifth levels of efficacy, which are considered poor despite its importance. This result raised a question about the PYP's current working model's capability to achieve KSU's strategic plan objectives in the female section.

For dissimilarity, 29 statements $(60.42 \%)$ from the male group and 26 statements $(72.22 \%)$ from the female group were in nonalignment with any theme in KSU's strategic plan, which indicates that KSU might need to reassess their PY model, strategic plan, and stakeholders' suggestions to develop the program in the future. The majority of statements from the male group did not pair with KSU's plan belonged to Cluster 5 Program Services: Prior to and During, Cluster 4 Program Academic Design, and Cluster 2 Program Assessment Mechanism and Curriculum Structure. On the other hand, the majority of statements from the 
female group belonged to Cluster 2 Program Academic Design, Cluster 3 Teaching Quality, Cluster 4 Program Regulation, and Cluster 5 Program Services: Prior to and During. In fact, Cluster 4 and 5's statements have no matching with KSU's strategic plan; further, Cluster 4's statements are the complete opposite of KSU's regulation plan that places students into their colleges after the completion of the PYP.

Summary of Results for Research Question 2. When conducting a Concept Mapping/Pattern Matching conceptualization, how do the results for males compare and contrast with the results for females? 14 participants contributed to the male groups brainstorming sessions and produced 48 statements that were placed into seven clusters. Nine individuals participated in the female brainstorming session and produced 36 statements that were distributed among six clusters. Of the 13 total cluster from both groups, eight yielded similar themes.

- The Program Regulation name assigned for the males Cluster 1 with 4-statements, and the females Cluster 4 with 8-statements; both clusters recorded the highest importance mean at $(M=4.48)$ and $(M=4.54)$ respectively. Furthermore, Cluster 4 rated the lowest in efficacy at $(\mathrm{M}=2.85)$ among all 13 clusters.

- The Program Assessment Mechanism and Curriculum Structure was allocated to the males Cluster 2 with 10 statements, and the females Cluster 1 with 7 statements. Both clusters rated above 4.00 for importance and efficacy at $(\mathrm{M}=3.38)$ and $(\mathrm{M}=3.37)$ respectively.

- The Program Services: Prior to and During name was given for both groups Cluster 5's. The two clusters reported similar importance means at $(\mathrm{M}=4.33)$ and both recorded high mean efficacy scores above 3.50 . 
- The Program Academic Design name was allocated for the males Cluster 4 with 8 statements, and the females Cluster 2 with 10 statements. Both clusters yielded importance means above 4.00 .

The remaining clusters suggested new themes about the PYP's future development. For the male group, Cluster 3 Program Philosophy, Planning, and Operational Mechanism, and Cluster 7 Program Applications Policy recorded average importance means above 4.00 on a 5point Ordinal Scale; both clusters were placed on the lowest level of efficacy at $(M=3.36)$ and $(\mathrm{M}=3.23)$ respectively. Cluster 3 Teaching Quality rated in the second level of importance and efficacy. Finally, Cluster 6 Supporting Student Learning in the male group, and Cluster 6 Promoting Student Learning in the female group have four statements each (see Tables 34 and 35 and Figure 16).

On the statements level, 43 statements $(89.58 \%)$ from the male group rated above 4.00 , and five (10.42\%) rated between 3.00 and 4.00 for importance. For efficacy, three statements $(6.25 \%)$ rated at or above $4.00,30$ statement $(83.33 \%)$ fell between 3.00 and 4.00 , and five statement $(10.42 \%)$ rated below 3.00 on a 5-point Ordinal Scale. For the female group, one statement $(2.78 \%)$ recorded the highest mean scores among all statements in both groups at 5.00. Further, 30 statements $(83.33 \%)$ rated above 4.00 , and five $(13.89 \%)$ below 3.00 . For the efficacy rating, five statements $(13.89 \%)$ rated at or above $4.00,20$ statements $(55.56 \%)$ rated between 3.00 and 4.00, and 11 statement (30.56\%) rated below 3.00 on a 5-point Ordinal Scale. Although the researcher decided not to include all statements for comparison purposes, the statements yielded an importance mean at or above 4.50 and efficacy mean at or below 3.00 were selected for comparison. 
For males, 13 statements $(27.08 \%)$ yielded an importance mean at or above 4.50 . One statement rated at $(M=4.64)$, seven statements at $(M=4.57)$, and five statements at $(M=4.50)$. S25, S36, S37, and S39 belong to Cluster 7 Program Applications Policy. S8, S9, and S10 fit into Cluster 5 Program Services: Prior to and During. S31, S32, and S40 tailor to Cluster 2 Program Assessment Mechanism and Curriculum Structure. S33 and S45 belong to Cluster 1 Program Regulation, and S43 fits into Cluster 4 Program Academic Design. No statements align with Clusters 3 Program Philosophy, Planning, and Operational Mechanism, and 6 Supporting Student Learning for importance.

For the male groups efficacy, nine statements $(18.75 \%)$ rated at or below 3.00. S1, S17, $\mathrm{S} 6$, and $\mathrm{S} 5$ rated at $(\mathrm{M}=3.00), \mathrm{S} 15$ and $\mathrm{S} 34$ at $(\mathrm{M}=2.93), \mathrm{S} 38$ at $(\mathrm{M}=2.86), \mathrm{S} 2$ at $(\mathrm{M}=2.79)$, and $\mathrm{S} 29$ at $(\mathrm{M}=2.64)$. The matching revealed that $\mathrm{S} 2, \mathrm{~S} 5$, and $\mathrm{S} 17$ belong to Cluster 2, $\mathrm{S} 1$ and S38 belong to Cluster 1, S34 to Cluster 3, S6 to Cluster 4, S1 5 to Cluster 5, S29 to Cluster 7, and finally, no statements paired with Cluster 6. The results exposed that Cluster 7 Program Applications Policy and its statements have the majority of importance, while Cluster 2 Program Assessment Mechanism and Curriculum Structure and its statements have the majority of the lowest efficacy (see Figure 17, and Table 36).

For the female group, 16 statements $(44.44 \%)$ yielded importance at or above 4.50. S17 rated at $(\mathrm{M}=5.00), \mathrm{S} 24$ at $(\mathrm{M}=4.89) ; \mathrm{S} 1, \mathrm{~S} 6, \mathrm{~S} 9, \mathrm{~S} 19, \mathrm{~S} 23$, and $\mathrm{S} 31$ rated at $(\mathrm{M}=4.78) ; \mathrm{S} 4, \mathrm{~S} 16$, and $\mathrm{S} 18$ at $(\mathrm{M}=4.67)$; and $\mathrm{S} 11, \mathrm{~S} 12, \mathrm{~S} 13, \mathrm{~S} 14$, and $\mathrm{S} 30$ at $(\mathrm{M}=4.56) . \mathrm{S} 1, \mathrm{~S} 11$, and $\mathrm{S} 17$ belong to Cluster 1 Program Assessment Mechanism and Curriculum Structure, S4, S9, S30, and S24 fit in Cluster 2 Program Academic Design, S12 and S16 paired with Cluster 3 Teaching Quality, S18, S19, S23, and S31 fit into Cluster 4 Program Regulation, S13 and S14 match Cluster 5 Program 
Services: Prior to and During, and finally, Cluster 6 Promoting Student Learning did not pair with any statements in this comparison.

For the female groups efficacy, 13 statements (36.11\%) rated at or below 3.00. S5 and $\mathrm{S} 25$ rated at $(\mathrm{M}=3.00), \mathrm{S} 7, \mathrm{~S} 21, \mathrm{~S} 31$, and $\mathrm{S} 35$ at $(\mathrm{M}=2.89), \mathrm{S} 2, \mathrm{~S} 6$, and $\mathrm{S} 18$ at $(\mathrm{M}=2.78), \mathrm{S} 23$ rated at $(\mathrm{M}=2.67)$, and $\mathrm{S} 29, \mathrm{~S} 32$, and $\mathrm{S} 33$ at $(\mathrm{M}=2.56)$. Further, S6, S7, S18, S21, S23, S29, and S31 belong to Cluster 4, S32, S33, and S35 fit into Cluster 2, S2 to Cluster 1, S5 to Cluster 3, S25 to Cluster 6, and Cluster 5 has no matching. Table 37 shows the most important and fewest efficacy statements. Finally, the outcomes show that Cluster 4 Program Regulation recorded the majority of statements for importance and efficacy. Figure 18 displays the statements that were rated as the most important and fewest efficacies for the female group.

Further, a comparison was performed between both groups to explore similarities and differences among the most important and fewest efficacy statements. The similar statements means show a similar theme or context based on the researcher's subjective perception. For the most important statements on the similarity level, 16 statements $(100 \%)$ in the female group aligned with 11 statements $(84.62 \%)$ of the 13 statements in the male group. In detail, S17, S24, S9, S4, and S30 from the female group matched S31, S36, S40, S45, S25, and S43 in male group respectively. These statements show suggestions regarding the PYP's academic and curriculum designs. Further, S1, S6, S19, S23, S31, S18, and S11 in the female group and S32 in the male group focus on student's learning assessment methods. Besides, S16 and S12 in the female group match the male groups S33 and provides insight about developing teaching practices at the PYP. Lastly, S13 and S14 in the female group match S8, S9, and S10 in the male group, and both suggest some ideas regarding student orientation programs and its components. For differences, there were two remaining statements in the male group that did not pair with any in the female 
group; S37 and S39 both recommend studying student dropouts from the PYP or KSU (see Table $38)$.

For comparison of the majority of fewest efficacy statements on the similarity level; 12 statements $(92.31 \%)$ of the 13 fewest efficacies statements in the female group pairs with 7 statements $(77.78 \%)$ of the 9 statements in the male group. S5 in the female group pairs with S34 in the male group, and describe the PYP's operational mechanism. Furthermore, S18, S21, S7, S23, S6, and S31 in the female group align with S1 and S2 in the male group, and discuss student's learning assessment methods. Also, S35, S2, S32, and S33 in the female group fit with S17, S5, and S6 in the male group and highlight the academic and curriculum designs in the PYP. Lastly, both the male's and female's S29 represent ideas regarding the implementation and structuring of the program. For the differences on the level of the fewest efficacies statements, the female group retains S25 and the male group has two statements that were retained, S15 and S38, and all represent ideas regarding the administration and organization of the program (see Table 39).

\section{Discussion}

Students' success in postsecondary institutions is largely based on their first-year college experiences (Ben-Avie, Kennedy, Unson, Li, Riccardi \& Mugno, 2012; Clark, 2005; Frazier, 2007: Mutch, 2005; Noel, Levitz, \& Saluri, 1985; Tinto \& Pusser, 2006; Upcraft, Gardner \& Barefoot, 2004). Based on 84 total statements produced by two groups of stakeholders, male and female, including KSU and PYP's faculty, students, parents, representative of the business sector, student's affair, academic affairs, and KSU and PYP's administrators, this study proposed a set of developmental outcomes for Preparatory Year Program (PYP) to King Saud University 
(KSU) that could support their efforts to achieve program goals, stakeholders' needs, and university's future trend as related to the four research questions.

\section{A Comprehensive Set to Develop a Conceptual Framework of the Preparatory Year}

Program. Currently, King Saud University (KSU) applies one model of the Preparatory Year Program (PYP) for male and female students. The current model of PYP has four main challenges: 1) the program's capability to meet students' actual needs and to prepare them to achieve the university's vision and mission; 2) concerns regarding learning and teaching quality related to the business sector, which is currently responsible for operating the PYP; 3 ) the economic challenge related to the high operational budget of the program, which will cause instability in the program in the future; and 4) lacking of governing philosophy, theoretical, and pedagogical base of the program.

As a response to these challenges the current study was conducted to identify the future ideal functions of the Preparatory Year Program (PYP) that could help first-year students successfully transition into college/university at King Saud University. Furthermore, some underlying goals were met by comparing the conceptualization schema outcomes to the current working model of the PYP and to KSU's explicit strategic plan. Finally, this study examined the consensus of two conceptualization map outcomes for the male and female groups. The prompt question used for the brainstorming sessions was What programs, services, and activities should guide the functions of the Preparatory Year Program?

Once again, this study's main focus was not gender issues. Instead, its purpose was to examine both female education and male education within the PYP at KSU. Furthermore, the male and female segregation in Saudi Arabian postsecondary education is a sociopolitical reality, not an intellectual divide. Creating two separate groups of stakeholders provided better 
understanding for the programs developmental dimensions and gave a chance for each group's voices to be heard about the program. In her book In a Different Voice, Gilligan (1982) states:

The different voice I describe is characterized not by gender but theme...this association [with women's voice] is not absolute, and the contrasts between male and female are presented here to highlight distinctions between two modes of thought and to focus a problem of interpretation rather than to represent a generalization about either sex (as reported by Skipper, 2005, p. 61).

Moreover, involvement of two different stakeholder groups allowed shifting from an institution standpoint (the current model of the PYP) to a more agreeable one, based on participants' viewpoints. "Organizations use concept mapping to plan actions that will move the organization from a current state to a desired future state" (Kane \& Trochim, 2007, p. 135).

The Concept Mapping/Pattern Matching (CM/PM) process used in this study allowed determining the dimensions that may need to be developed in the PYP based on stakeholders' perceptions. The total of 84 developmental statements and 13 clusters, combined from both groups of stakeholders' perceptions, male and female, plus the statements rating for importance and efficacy, allowed identifying the most important aspect of development and the fewest efficacies domains that the PYP's policymaker may need to work on improving for the future. The list of statements and clusters of this study are valid to use for development purposes, but could not be appropriate for evaluation purposes. To make the CM/PM more practical and usable, Kane and Trochim state:

Concept mapping gives a natural order for action planning groups because it is a framework for dividing the planning effort into more manageable subtopics or tasks to be examined by a specific task group responsible for their topic of interest. (p. 135-136) 
Consequently, the researcher divided the cluster map into regions to find a meaning and to move from theoretical perspective to action. Trochim (1989) states, "A region on the map represents clusters that can be meaning-fully grouped together more tightly than they are with other regional groups of clusters...decision about regional distinctions can be driven by theoretical preconceptions or simply through discussion." (Jackson \& Trochim, 2002, p. 327328). However, a closer examination on cluster maps created by the CM/PM, the researcher divided each cluster maps, reported in Chapter 4 (see Figures $13 \& 14$ ) that were created by the groups of stakeholders, into three regions that expressed the main themes that could be used as a base for development of the conceptual framework of the PYP, and may inform educational policymakers about areas that need to address, as appears in Figure 19 and 20 below.

\section{Pedagogical Functionality Issues}

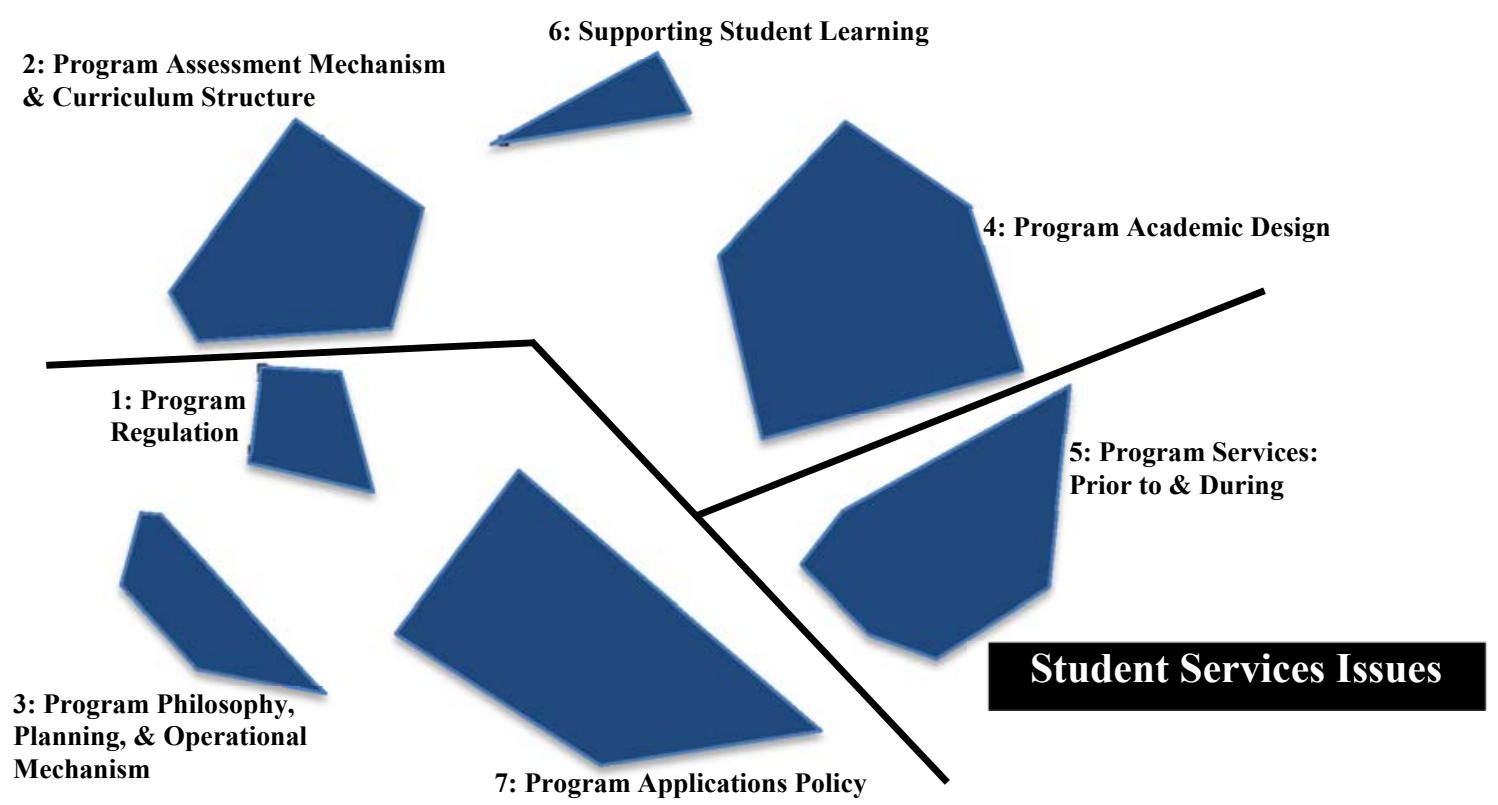

\section{Organizational Design and Structure Issues}

Figure 19: Final Map for the Male Group with Clusters Labels and Theoretical Interpretation. 


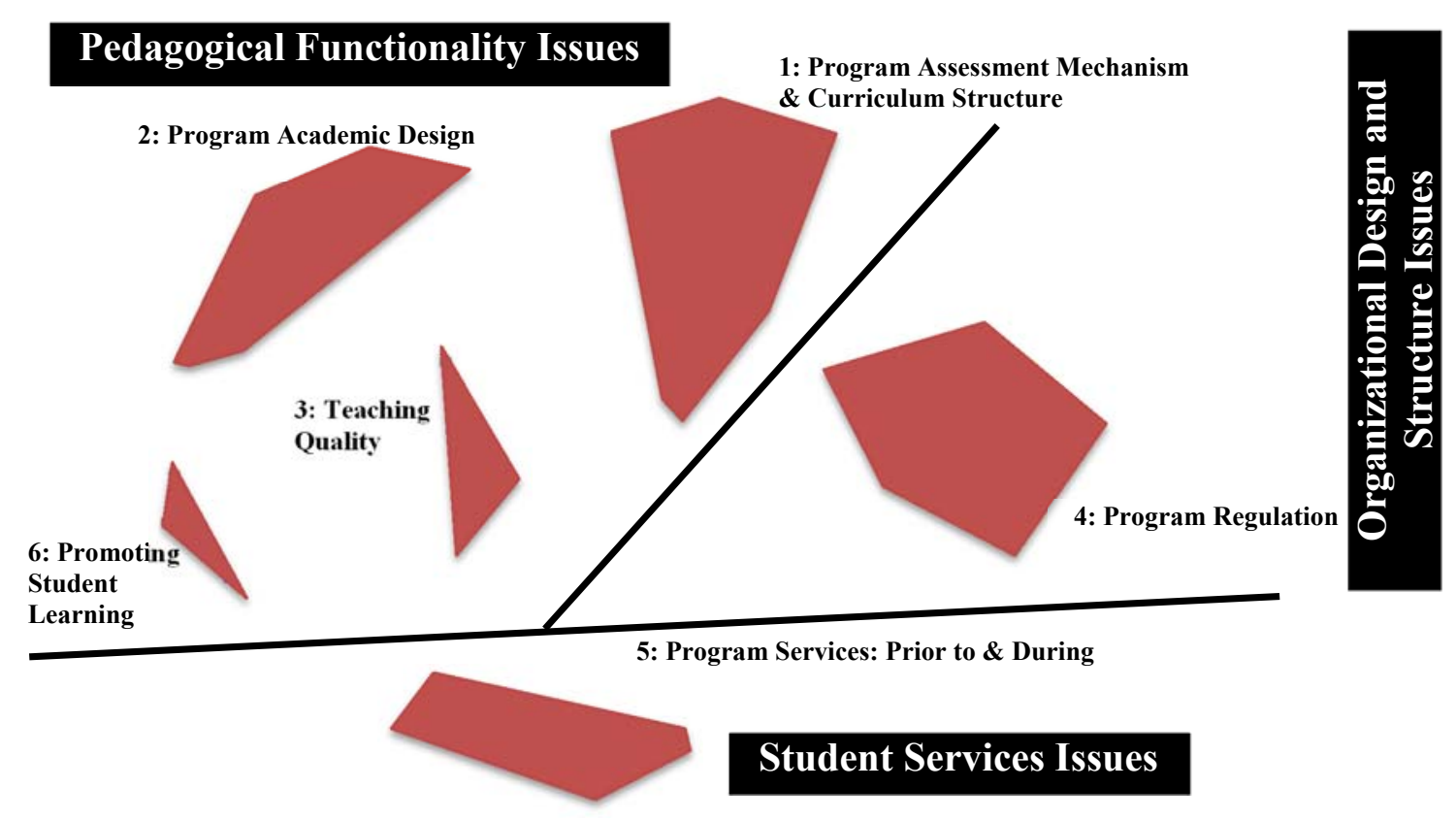

Figure 20: Final Map for the Female Group with Clusters Labels and Theoretical Interpretation. The solid lines overlaid on Figure 19 and 20 represent one interpretation of how the stakeholder groups criteria might be conceptualized on the theoretical and practical levels. For the male group, the upper region regrouped Clusters, 2 Program Assessment Mechanism and Curriculum Structure, 4 Program Academic Design, and 6 Supporting Student Learning. Its statements articulated the need for learning assessment strategies, developing and organizing the PYP's curriculum, including knowledge and skills offered for students, and evolving cocurricular activities and training on specific skills based on students' needs.

These statements and clusters represent Pedagogical Functionality Issues that need to be addressed in the PYP. For example, S4, Reviewing student assessment mechanisms (student's acceleration/promotion) during the program for all courses, S32, Developing student assessment methods, S22, Developing the skills of responsible autonomy, S24, Providing activities that encourage students to participate in community service, S11, Adding course activities that 
promote and motivate students' learning, and S47, Developing tutoring programs according to students' needs.

The left bottom region comprised from Cluster 1 Program Regulation, 3 Program Philosophy, Planning, and Operational Mechanism, and 7 Program Applications Policy). Its statements referred to the program's purpose, organizational structure, regulation and application policy's, operation approaches, and the relationship with KSU's colleges and programs. These clusters and its statements represent Organizational Design and Structure Issues regarding the current model of the PYP, including the program's purpose, regulation, policy, strategic plan, etc. Some examples include, S1, Enabling students in fulfilling certain criteria to enroll in major-specific courses, S14, Involving all preparatory year beneficiaries/stakeholders in the development of its plan, S21, Reviewing the philosophy of the preparatory year and its purpose, S34, Developing the preparatory year self-operation mechanisms and phasing out of outsourcing to private companies, S29, Implementing the preparatory year program within colleges in accordance with major tracks, and S39, Developing programs to address student dropout in the preparatory year or beyond.

The last division located on the right bottom level. This division contains only one cluster, Cluster 5 Program Services: Prior to and During. This cluster has several statements that concentrate on facilitating and providing first-year student services and information that may help them engage in the university's environment. This division represents Student Services Issues. Separating this cluster is due to the nature of tasks that may be done through the orientation program or through other departments or deanships in KSU, such as Student Affairs or Student Services. However, the stakeholders' perceptions seemed satisfied about the PYP's performance on this clusters elements since they rated the highest for efficacy scores. 
For example, S8 Educating students about the university regulations and their rights, S15 Organizing workshops for high school students to identify and address weaknesses of preparatory year students, S44 Assigning students to visit their future colleges in coordination with them to learn closely about the offered majors, S10 Educating students about libraries and research resources, and S30 Providing academic counseling services for high school students before the Preparatory Year.

For the female group, the cluster map was also divided into the same three regions as the male group. The region of Pedagogical Functionality Issues is located on the upper level of the map. The division consists of four clusters, Cluster 1 Program Assessment Mechanism and Curriculum Structure, 2 Program Academic Design, 3 Teaching Quality, and 6 Promoting Student Learning. These clusters exposed the importance of reassessing the student's placement procedure. In other words, developing student's assessment methods and giving students more freedom to select the courses they need. Furthermore, these clusters mentioned the necessity of reviewing the PYP's curriculum and activities. It also suggested merging or cancelling some courses that they believed unnecessary for them and focus more on practice than theory.

Additionally, the term "promoting" was used to describe female perceptions when asking for more educational opportunities and permission to participate in local or international educational activities. The female group also raised concern about the teaching quality, which may need more attention in the future. Some examples include, S2, Reassessing the importance of teaching (some) courses in the Preparatory Year, for example, health and fitness courses, S20, Determining the course timeline based on students' needs, S8, Canceling some of the redundant courses or merging them into a single course, for example, math skills, S9, Emphasizing practical, applied, and skill aspects not just a compilation of grades for academic placement, 
S12, Ensuring that faculty members have the necessary capability to deal with students at this age, S25, Organizing academic trips for distinguished students to study English language courses in international institutes, and S26, Engaging students in international conferences to gain experience and contact with elites.

The second division represents Organizational Design and Structure Issues; this partition is located on the upper right. This region has one cluster, Cluster 4 Program Regulation. This cluster concentrates on one issue that relates to the student placement rule, which determines what college they are placed in. The female voice stressed applying student's academic placement at the beginning, not end, of the PYP. Some statements that apply to this position include, S6, Applying the academic/college placement at the beginning of the Preparatory Year, S19, "Identifying academic track/major from the first day of study, S21, The Preparatory Year's GPA should not affect choosing the future college of study, and S36, Increasing student awareness about university laws and regulations through a specialist department whenever they need advice.

The final division refers to Student Services Issues. Like the male group, this region consists of one cluster, Cluster 5 Program Services: Prior to and During. The main theme in this cluster was emphasized on the importance of orientation programs and its benefit. For example, S14 from the female group, The importance of the orientation program for students before starting the study plan, S23 from the male group, Providing services needed by students through workshops and through the cooperation between colleges and the Preparatory Year Deanship, and S30, from the male group, Providing academic counseling services for high school students before the Preparatory Year. Theoretically, the three main themes: Pedagogical Functionality Issues, Organizational Design and Structure Issues, and Student's Services Issues, have been 
addressed by several researchers and studies in the postsecondary education field, both generally and in the first-year student experience, and student's development theory in particular.

First, the Pedagogical Functionality Issues, the concept of pedagogy has several definitions and is used within an educational context. This study's focus was on the concept meaning and the concept classification at the same time. In other words, the concept's philosophy and components. For instance, the program's philosophy and theory, learning and teaching strategies, assessment methods, course integration, extra-curricular activities, student activities, team teaching, and the use of several teaching models in the class (Erickson, Peters, \& Strommer, 2006 as cited in Greenfield, Keup, \& Gardner, 2013). Thus, the Pedagogical Functionality is considered the skeleton and central challenge of the PYP. "Universities must provide faculty with the pedagogical and assessment skills they need to establish conditions in their classrooms that promote student involvement, learning, and retention" (Tinto, 2002, p. 7). Kuh, Kinzie, Buckley, Bridges, and Hayek (2006) articulate that: Institutions that adopt educational philosophies that value undergraduate student learning also tend to encourage the use of such engaging pedagogies as active and collaborative learning, classroom-based problem solving, peer teaching, service-learning, and various forms of electronic technologies. Other promising instructional practices are supplemental instruction, peer tutoring, reciprocal teaching, attributional retraining, concept-knowledge maps, and 1-minute papers (p. 67).

The stakeholders' perceptions and the CM/PM statistical outcomes, including Program Assessment Mechanism and Curriculum Structure, Program Academic Design, Teaching Quality, and Promoting Student Learning, are compatible with the pedagogical aspects previously mentioned. Based on the data, we now know that KSU and the PYP may need to 
redefine its pedagogical philosophy and develop its practices to meet student's needs and the institution's goals. The stakeholders' statements, in both groups, connected to these aspects, specifically the aspects of Pedagogical Functionality: curriculum, teaching, and assessments, which should be rooted in student's needs. However, the groups of stakeholders' conceptualizations matched most of the first-year literature regarding Pedagogical Functionality components, especially the characteristics regarding teaching and curriculums.

Another concern regarding Pedagogical Functionality Issues is about female education. The data revealed that the female voice specified the need for more educational opportunities, more attention to improving teaching quality, and to participate in local and global learning activities. This finding is consistent with Smith and Abouammoh's (2013) comments on Saudi postsecondary education where they highly recommended "maximizing opportunities and achievements for women in higher education" (p. 181). Jamjoom and Kelly (2013) mentioned that Saudi postsecondary education requires taking gender related issues into account. For example, providing equal access to library materials and online research facilities for both women and men, where in some cases the libraries provide services to males only. Furthermore, this study observed that the female section did not mention the program's philosophy or purpose or theory as a concern for them and this may due to the lack of knowledge about the first-year experience or student's development theories. They also did not comment on the program's policy issues, such as retention or dropout; instead they believe that the current program's practices may require too much from them academically.

Moreover, both groups did not point out student diversity, although the program includes domestic and international students. In fact, the issues exposed and illustrated in this section gave the impression that there is a major lack of understanding about the first-year experience and 
student development theory as previously mentioned. This conclusion completely matched the First National Conference for Preparatory Year in Saudi Universities' recommendations that took place April 22-23, 2015, which stresses: 1) working on consistency of the PYP's goals with the university's vision, mission, and objectives; and 2) taking the student's needs (psychology, social, and knowledge) into account when building the PYP's curriculum.

Second, for the Organizational Design and Structure Issues, the two terminologies must be interdependent. It "refers to the formal configuration between individuals and groups regarding the allocation of tasks, responsibilities, and authority within the organization (Galbraith, 1987; Greenberg, 2011 as reported by Lunenburg, 2012, p. 1). Further, Gutterman (2009) states:

The organizational design is more than simply organizational structure the boxes and lines that are normally found on a traditional organization chart and extends outward to include a variety of other factors including information and reward systems; management and decision making processes; organizational culture, including mission, vision, values and norms; strategy, including the goals or purposes for which the organization exists; and the human resources who will do the work necessary for the organization to operate, survive and thrive (para, 1).

Furthermore, Corkindale (2011) articulates that:

Poor organizational design and structure results in a bewildering morass of contradictions: confusion within roles, a lack of co-ordination among functions, failure to share ideas, and slow decision-making bring managers unnecessary complexity, stress, and conflict. Often those at the top of an organization are oblivious to these problems or, 
worse, pass them off as or challenges to overcome or opportunities to develop. [sic] (para. 8)

Consequently, Cichocki and Irwin (2014) believe that redesigning the organizing design is essential when the organization would like to work on or are faced with: 1) define or redefine the organizational purpose; 2) the organization's reason for being; 3) establish or re-establish the organization's strategy; 4) significant changes to operations; 5) sustained evolution; and 6) the organization is not performing as expected (p. 21). The groups of male and female stakeholders suggested developing the current philosophy, regulations, policy, and functions of the Preparatory Year Program (PYP) to increase student's possibility of success in their first-year and to help students engage and transfer successfully into university; their recommendation was consistent with Kuh, Kinzie, Buckley, Bridges, \& Hayek’s (2006) perspective:

A student's beliefs are affected by experiences with the institution, which then evolve into attitudes about the institution, which ultimately determine a student's sense of belonging or "fit" with the institution. Thus, students' perceptions of the fairness of institutional policies and the responsiveness of faculty and staff presumably affect decisions to persist or leave the institution (p. 13).

Moreover, from an organizational perspective, "effective communication of rules and regulations positively impacts student integration and persistence, how new students perceive and interact with the bureaucratic elements of the institution may well affect student success" (Braxton and McClendon 2001-02 as reported by Kuh, Kinzie, Buckley, Bridges, \& Hayek, 2006, p. 55). The CM/PM outcomes were not only an expression about participations' perceptions, but also a warning alarm for the educational policymaker to reconsider the current practices of the PYP to make university attractive for all its students, and not just for a specific 
body of students. In other words, the PYP program may need to embrace a talent development philosophy that takes into account students' diversity, background, characteristics, and actual needs. (Kuh, Kinzie, Buckley, Bridges, \& Hayek, 2006)

Furthermore, Cutright (2002), determined several themes which influence research universities in developing the first-year program's design and structure: 1) diffusion of first-year programs on the university level; 2) housing first-year initiatives on the colleges' level or in departments; 3) adoption of varied strategies or approaches for first-year programs; 4) adoption of learning communities as a main strategy for first-year programs; 5) assess and develop learning and teaching strategies of first-year programs; 6) develop the relationship between academic and student affairs, especially in terms of the admission policy; and 7) use benchmark and assessment tools to evaluate the first-year experience. The majority of higher education institutions develop their first-year program design and structure to gain positive common characteristics of new first-year students, including skills and knowledge to use technology, which is a trend toward social work and team activity, the ability to access and acquire information, focus less on school work and emphasize a future career plan, improve familial/parental involvement, and create a passion to learn more with higher expectations (Keeling, 2003; Newton, 2000).

The document analysis exposed that KSU and the PYP's desires of their students drives the PYP's strategies and practices. The current structure of the program is built on the assumption that high school graduates are not ready for university, and intensive preparation is required for them before they begin their study (Plan, 2014). This judgment is reflected on the current practices of the PYP, strategic plan, regulation, application policy, and practices that were not taken into account, such as student's differences, needs, and readiness level for 
university. The organizational design and structure, including all functions mentioned above, is not just a description of tasks or jobs, but is a place where all meet student's success and needs along with institutional goals.

The last dimension is Student Services Issues. The CM/PM outcomes and rating results revealed that KSU performed above average on a 5-point Ordinal Scale on providing first-year students high quality services. Despite this fact, the PYP may need to reconsider the nature and methods of delivering service to first-year students. Some ideas raised in the CM/PM outcomes suggest expanding the PYP's service before and after the PYP. For example, organizing workshops for high school students to educate them about the university's majors, programs, and policy. With this, more coordination between the PYP and university's deanships and departments may make students' services more effective. For example, coordinating with Student Affairs in terms of planning and managing extra-curricular activities. In this context, for improving student services, Chickering and Reisser (1993) suggest a collaborative effort between academics and student affairs to design ideal service programs to fit students' needs. As this recommendation consensus with this study outcomes, Dwyer (1989) identified two services that can help universities or colleges provide support to first-year students as they transition to postsecondary education: 1) consular system; and 2) orientation programs.

In summary, this study's purpose was to develop a conceptualization model of the Preparatory Year Program based on male/female stakeholders' perspectives and the Concept Mapping/Pattern Matching (CM/PM) outcomes. The 13 clusters generated by participants were regrouped into three main dimensions: Pedagogical Functionality, Organizational Design and Structure, and Student Services. The conceptualization model developed by this study could be used as a guideline for future development of the PYP. More details about this conceptualization 
model are provided later in the implications sections of this chapter. Figure 20 clarifies the general conceptualization model of the PYP generated by CM/PM.

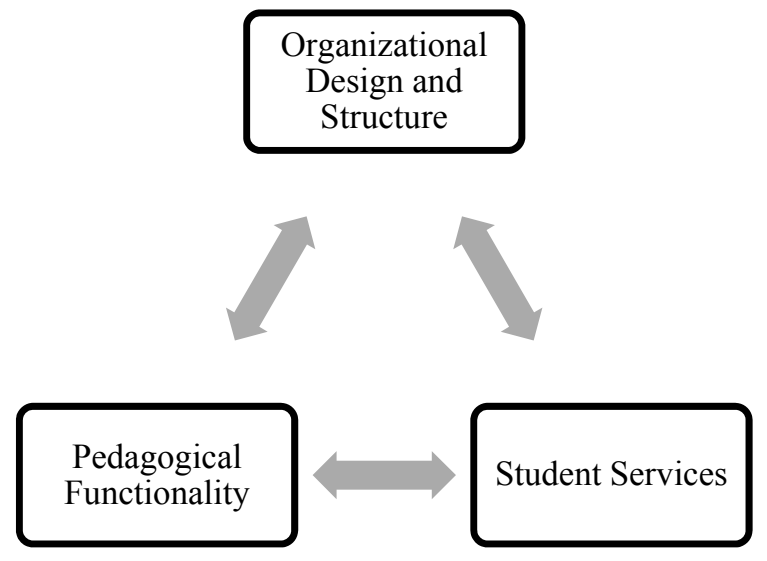

Figure 21: The Main Dimensions of General Conceptualization Framework of the PYP as Generated by $C M / P M$.

\section{Relevance of CM/PM on the Organizational Design and Structure, Pedagogical}

Functionality, and Student Services themes to the First-Year Experience Theory. This

study's aim was to identify the future ideal functions and to develop a conceptual framework of the Preparatory Year Program (PYP) at King Saud University (KSU). Student development and first-year experience theories usually use these as fundamental information to build first-year programs and to also understand, explain, clarify, predict, and/or develop student's needs.

Exploring the applicability of the stakeholders' perceptions (CM/PM) to a general theory or model of first-year experience was an underlying goal for this study; therefore, the researcher consulted the literature review of first-year experience and students' development theory and conducted a wide search to find an appropriate theory or model that can meet stakeholders' perceptions. As this study's concentration was not to explore topics such as Psychosocial or Cognitive-Structural, but was for developing the PYP's functions the First-year FocusFoundational Dimensions ${ }^{\circledR}$ for Four-Year College established the Foundations of Excellence ${ }^{\circledR}$ in 
the First College Year Institute was an appropriate and useful study of the association of CM/PM with the first-year theory and model.

The Foundational Dimensions was established to guide and help postsecondary institutions develop their First-Year Program. Nine dimensions of normative statements represent issues related to postsecondary institution cultures, policy, mission, structure, activities, and programs that shape student learning and success in their first-year (Terenzini, 2005).

The organizational design and structure represented by stakeholder groups aligned with three dimensions, specifically dimension one, two, and eight, which provides institutions with means to evaluate and improve the first-year structure and functions. These three dimensions reflect the stakeholders' perceptions regarding the program development aspect. For example, the CM/PM perceptions reported concerns about the program's purpose and goals, and the program's internal and external relationship with the university's colleges and other programs.

Furthermore, the outcomes of CM/PM exposed a challenge regarding the PYP's capability to achieve KSU's mission. A closer examination to these dimensions and comparing them to the Organizational Design and Structure statements may help in knowing where the PYP's standpoint is. However, this conclusion was not used for evaluation purposes, but gave insights or indicators about the program's reality. Thus, the dimensions that paired with Organizational Design and Structure are:

1- Foundations Institutions approach the first-year in ways that are intentional and based on a philosophy/rationale of the first-year that informs relevant institutional policies and practices (Philosophy).

2- Foundations Institutions create organizational structures and policies that provide a comprehensive, integrated, and coordinated approach to the first-year (Organization). 
3- Foundations Institutions promote student understanding of the various roles and purposes of higher education, both for the individual and society (Roles and Purposes).

The Pedagogical Functionality theme is considered the skeleton of the PYP. The Pedagogical Functionality theme involves curriculum design and course planning, faculty performance and teaching strategies, student assessment methods, learning environment, and learning activities. The size and variety of learning issues reported by the stakeholders no doubt indicted the necessity of reconsideration about the program's academic design and pedagogy. However, the Pedagogical Functionality aligned with the third, fourth, fifth, seventh, and ninth dimensions of the Foundations of Excellence ${ }^{\circledR}$ in the First College Year Institute:

1- Foundations Institutions deliver intentional curricular and co-curricular learning experiences that engage students in order to develop knowledge, skills, attitudes, and behaviors consistent with the desired outcomes of higher education and the institution's philosophy and mission (Learning).

2- Foundations Institutions make the first college year a high priority for the faculty (Faculty).

3- Foundations Institutions facilitate appropriate student transitions through policies and practices that are intentional and aligned with the institutional mission (Transitions).

4- Foundations Institutions ensure that all first-year students experience diverse ideas, worldviews, and cultures as a means of enhancing their learning and preparing them to become members of pluralistic communities (Diversity).

5- Foundations Institutions conduct assessments and maintain associations with other institutions and relevant professional organizations in order to achieve ongoing first-year improvement (Improvement). 
For the student services theme, the CM/PM outcomes indicated that the PYP performed more effectively on this dimension than the academic dimension, such as curriculum development, student's assessment, teaching strategies, etc. However, student services provided by the PYP involve an orientation program, educating new students about their rights and university' regulation and policy, and may organize a workshop for high school students about the PYP and KSU's programs. This study's outcome supports that such services are important; but at the same time raised a question about who is responsible to provide new students these services. Does the Preparatory Year Program take responsibility to develop such services or maybe there is another division or department at King Saud University that could do this work? What is the role of Student Affairs and Academic Affairs for first-year students?

Based on the CM/PM suggestions, the current model design of the PYP seems to provide all first-year services and academic programs in isolation from the university's community, which may affect student's engagement or involvement in the learning environment. Centralizing student services for all KSU students may support KSU's mission to improve services quality and find new ways to help first-year students engage and explore university life in a better way. Also, reorganizing student services under another department or deanship, such as Student Affairs or Admission and Registration Deanships with cooperation with the PYP, may benefit KSU economically and academically.

However, this theme for student services aligned with the sixth dimension of the Foundations of Excellence ${ }^{\circledR}$ in the First College Year Institute:

1- Foundations Institutions serve all first-year students according to their varied needs (All Students). 
In general, the three themes created by the CM/PM conceptualizations are associated with the first-year experience theory represented by the Foundations of Excellence ${ }^{\circledR}$ in the First College Year Institute, which established the First-year Focus - Foundational Dimensions ${ }^{\circledR}$ for four-year colleges.

\section{Concerns regarding the Preparatory Year Program philosophy, pedagogy, and}

guiding theory. As mentioned in Chapter 4, the Student's Guidebook of the Preparatory Year Program was used as a guideline to compare and contrast the current working model of PYP with stakeholders' perceptions. In the ideal world, the PYP would have something more than just the Student's Guidebook as a source for outlining what the philosophy of the program or guiding theory is. In other words, the researcher did not find any documentation regarding the philosophy or guiding theory of the PYP.

However, the comparison of the Student's Guidebook themes and the CM/PM outcomes revealed that only 19 of the 48 statements (39.58\%) in the male group and 5 statements $(13.89 \%)$ in the female group align with the Student's Guidebook chapters. Further, 29 statements $(60.42 \%)$ from the male group and 31 statements $(86.11 \%)$ from the female group could not be matched with any parts in the current Student's Guidebook of the PYP. The results illustrate that Clusters Program Regulation (male/female) and Teaching Quality (female) did not match any chapter of the Student's Guidebook. Further, the majority of clusters reported diverse matching percentages as follows: Program Assessment Mechanism and Curriculum Structure (20\% male, 14.29\% female), Program Academic Design (62.50\% male, 14.11\%female), Program Applications Policy (33.33\% male), Promoting Student Learning (25\% female), Supporting Student Learning (75\% male), and finally Program Services: Prior to and During (77.78\% male, $50 \%$ female). 
The outcomes exposed the fact that the program's philosophy focused on providing student services more than academic or psychosocial development. For example, S8 for the males Educating students about the university regulations and their rights, S13 for males Educating students about the majors' requirements, S36 for females Increasing student awareness about university laws and regulations through a specialist department whenever they need advice, and S14 for females The importance of the orientation program for students before starting the study plan.

Furthermore, the generated statements from both groups support the indication of ambiguity of the PYP's purpose and philosophy. For instance, male statements: S21, Reviewing the philosophy of the Preparatory Year and its purpose", S3, Reformulating and defining the Preparatory Year's objectives, S34, Developing the Preparatory Year's self-operation mechanisms and phasing out of outsourcing to private companies, and female statements: S2, Reassessing the importance of teaching (some) courses in the Preparatory Year, for example, health and fitness courses, S17, Reviewing the Preparatory Year's curriculum and comparing/contrasting them with public education curriculum, S9, Emphasizing practical, applied, and skill aspects, not just a compilation of grades for academic placement, and S29, To be a Preparatory Program not a Preparatory Year. However, upon reflection of these statements, both groups of stakeholders believed that the PYP needs to develop its purpose and philosophy, but at the same time, they did not suggest a specific purpose or philosophy for the program; this may be due to the lack of knowledge about the first-year experience theory and the universal trend of the program or because they felt that the program is not necessary for students somewhere. 
Furthermore, the data revealed that Chapter 1 of the Student's Guidebook involves the PY's vision, mission, and strategic objective, which matched with only two statements from the male group, S35, Emphasizing critical thinking skills and creativity and S46, Developing a partnership with charitable and voluntary organizations and invite them to be present and represented in the Preparatory Year; while the female groups statements did not match any part of the PY's vision, mission, and strategic objective, which raised concern regarding the stakeholders' knowledge about the program's mission. Moreover, the first-year experience literature considers the ambiguity of the PYP's purpose, philosophy, and guided theory as a universal challenge to the majority of higher education institutions. For example, Upcraft, Gardner, and Barefoot (2005) mentioned some challenges they encountered in the first-year experience movements:

1. There is no consensus about a clear sense of purpose in the first-year.

2. Building first-year initiatives that are responsive to today's increasingly diverse students is still a challenge.

3. The link from research and assessment to policy and practice is still weak.

4. Institutional efforts to help first-year students succeed are still not sufficiently integrated.

5. Efforts to help first-year students succeed are too often focused on retention rather than student's learning.

6. First-year students' out-of-class experiences are still a double-edged sword. (p. 2-7) In fact, these results were expected due to the newest form of the program in Saudi higher education's context. As mentioned in Chapter 1, the majority of Saudi universities started their PYP in 2007 or beyond, including KSU. King Saud University (KSU) and the majority of Saudi universities apply similar approaches where new students are required to study one academic 
year with a concentration on math, English, self-development, and technology skills before entering their colleges (Yushau \& Omar, 2007), in spite of differences among these institutions in terms of size, mission, and operational capacity. Higher education institutions should take into account two questions while developing their first-year programs: "How do we distinguish between wants and needs? How do we know if what we offer fits with entering students?" (Upcraft, 2005, p. 476)

Furthermore, since its establishment in 2007, the PYP model retaining one approach in terms of curriculum, policy, and learning style, despite the dramatic changes occurring within a new generation of students (millennium students) or the changes happening in the educational context in Saudi Arabia. For example, merging higher education and public education ministries into one ministry, the Education Ministry, in January 29, 2015. Therefore, the stakeholder groups suggested reviewing the Preparatory Year's philosophy, purpose, curriculum, and policy within the educational context, both locally and internationally, also due to the drastic changes happening for students due to the change in learning nature and methods. Pascarella and Terenzini $(1991,2005)$ admitted that "the important lesson is to understand what the constraints are on any approach and to bear in mind that reliance on developmental models may lead to misspecification of the origins of student change and growth" (p. 49-50). Further, Tinto (1993) stresses that postsecondary institutes are obligated to plan a long-term process to develop and adjust these programs to meet students' needs and the institution's mission. Pascarella and Terenzini state:

Ironically, just as analysis of the experiences of college students reached an apex in terms of quantitative technique and vigor, the population of interest began shifting. Now at the end of the 2 decades, our college campuses are no longer predominantly populated by the 
students described in this book. (Educational Research, Stage 1993, p. 22 as cited in Pascarella and Terenzini, 1997, p. 2)

\section{Alignment of the CM/PM Outcomes and King Saud University's Vision and}

Mission. KSU's educational policymakers believe that the Preparatory Year Program (PYP) plays an essential role in achieving KSU2030 vision "to be a world class university and a leader in building the knowledge society" and KSU's mission "to provide distinctive education, produce creative research, serve society and contribute in building the knowledge economy and community through learning, creative thinking environment, the optimal use of technology and effective international partnership" (Plan, 2014, p. 14).

The comparison of the CM/PM outcomes and KSU's strategic plan (KSU2030) revealed that the phrase "Preparatory Year" appears 11 times in the document. The document analysis revealed that 19 statements $(39.58 \%)$ from the male group and 10 statements $(27.78 \%)$ from the female group aligned with KSU's strategic plan, while 29 statements $(60.42 \%)$ from the male group and 26 statements $(72.22 \%)$ from the female group did not align with any theme in KSU's strategic plan. Only two statements in the male group aligned with KSU's mission: S24, Providing activities that encourage students to participate in community service and S35, Emphasizing critical thinking skills and creativity.

On the other hand, the $\mathrm{CM} / \mathrm{PM}$ outcomes exposed vital implementation issues regarding the PYP's current practices that may affect KSU's movement to achieve its vision to be a knowledge society. For example, the data disclosed that the PYP performed ineffectively on providing high quality teaching appropriate for first-year students' characteristics. For instance, male statements: S16, Hiring faculty members from colleges who have experience in teaching first-year university students, S33, Reviewing the performance of faculty members in the 
Preparatory Year, and female statement: S12, Ensuring that faculty members have the necessary capability to deal with students at this age. This result contradicts the second strategic objective of KSU's plan, “Distinctive faculty (Attract and develop distinctive faculty).” (Plan, 2014, p.

Organizational theory suggests that institutional mission, which is generally denoted by sector difference or institutional type, is related to student success because colleges and universities that align their mission with their educational policies and programs generally are more effective and efficient. (Birnbaum 1991; Bolman and Deal 1991;

Ewell 1989 as reported by Kuh, Kinzie, Buckley, Bridges, \& Hayek, 2006, p. 55).

This conclusion presented a serious problem regarding the first-year pedagogical functionality and its ability to meet knowledge society requirements. University leaders, faculty, and administration staff should be aware of the changing roles within teaching, learning, and preparing students for a knowledge society (Rowley, 2000). The PYP's faculties should have enough experience to not just teach first-year students, but to also prepare KSU's students for the knowledge society era and its requirements. The teaching for a knowledge society is different from teaching for traditional society. KSU may have to work hard to ensure its faculty, administration staff, and curriculum have the knowledge and skills content that can contribute to build a knowledge society.

Furthermore, the rating results indicated that the PYP may need to put in more effort in improving its program to meet the fifth strategic goal of KSU "Building bridges (Build bridges among KSU constituencies and externally with local and international groups).” For example, male statements 23 and 25. S23, Providing services needed by students through workshops and through the cooperation between colleges and the Preparatory Year Deanship, and S25, 
Coordinating with beneficiary colleges to choose the knowledge topics and skills that serve their majors. The stakeholders' perceptions suggested more coordination between the PYP and university's beneficiary colleges to select and build the PYP's curriculum and identify required knowledge and skills for first-year students. For example, a student in the humanities track or science track should receive the same dosage of skills and knowledge, although there will be differences between them in the future. The group of stakeholders suggested including knowledge and skills that can assist colleges achieve their goals. In other words, the current model of the PYP works in isolation from other colleges and departments at KSU, which may affect KSU's mission to achieve a knowledge society. So, creating a flexible model of the PYP may help to solve such a problem.

Two statements from the female group, S26, Engaging students in international conferences to gain experience and contact with elites and S28, Partnering with leading universities in adopting outstanding students, reflected the female voice that calls for more opportunities in participating in building a knowledge society. These suggestions run against KSU's value of fairness and integrity that mentions "equal opportunity". Essentially, offering equal opportunity is considered fundamental for building a knowledge based-economy or knowledge society (Johnston, 2010). This result raised a question about women's contribution in building a knowledge society. Are what we offer in the PYP support KSU's movement towards a knowledge society? Smith \& Abouammoh (2013) called for "maximizing opportunities and achievements for women in higher education.” (p. 181)

Finally, the following statements from the female group indicate ineffective performance for the PYP, which contradict KSU's value of lifelong learning that is considered the soul of a knowledge society: S9 Emphasizing practical, applied, and skill aspects, not just a compilation 
of grades for academic placement, S15, All offered skills are important and should not be specific for the Preparatory Year, S24, Focusing on the practical aspects that ensure students will maintain skills, such as the English language, and S30, Implementing independent learning more than lectures.

Lifelong learning is becoming a necessity in many countries. It is more than just education and training beyond formal schooling. A lifelong learning framework encompasses learning throughout the lifecycle, from early childhood to retirement, and in different learning environments, formal, non-formal, and informal. Opportunities for learning throughout one's lifetime are becoming increasingly critical for countries to be competitive in the global knowledge economy. Lifelong learning is education for the knowledge economy... Learners should be able to enter and leave the system at different points. The learning system needs to include a multitude of players, such as learners, families, employers, providers, and the state. (World Bank, 2003, p. xiii)

With the World Bank's comment, Weert (2004) suggests that founding a philosophy of learning and pedagogy is the key component of success in developing the university's, colleges, or school's mission towards a knowledge society. In this context, the PYP's role in a knowledge society may require a flexible structure, which can respond to economic, social, and individual needs. Flexibility involves policy change, continuing development of faculty and curriculum, and the ability to redesign programs based on the market's needs. In contrast, university, colleges, or schools with firm structures will encounter some challenges in a knowledge society in the future, possibly causing isolation from the world. Thus, this study believes that relying on one static model, such as the current model of the PYP may result in unfavorable outcomes. This includes a consideration of the nature, purpose, and philosophy of the first-year experience, along with 
preparing for students for the job market, changes to assessment methods, responding to student's needs, and research-teaching associations (Moir, 2010). Further, Moir states, "If we wish to engage and empower students in the first-year then one way we can do this is through personal development planning (PDP) and an associated personalization of the curriculum" (p. $6)$.

Recently, the Saudi government launched a new strategic plan, Vision2030 that focuses on transferring the government's dependence on oil to relying on the intellectual capital. Saudi postsecondary education plays an important role in achieving Vision2030. As Saudi universities, including King Saud University, are working to develop and adjust their strategic plans to meet Vision2030, this study assumes that the current model of the Preparatory Year Program may need to reform in order to meet the university’s mission and positively contribute to achieve Vision2030. Although the large effort has been made by PYP policymakers and staff at KSU, the CM/PM perceptions present concerns about achieving KSU's mission, due to the challenges that encounter in the current model of the PYP mentioned in Chapter 1. As mentioned in the Preparatory Year Program Philosophy, Pedagogy, and Guiding Theory section, the PYP may need to develop a flexible approach not just to respond to the diversity of its students and their needs, but also to achieve KSU's mission to build a knowledge society. It is also important that any program wanting long-term viability ensure that their purpose and mission are integrated into the overall strategic plan. Johnston (2010) suggested that postsecondary institutions need to create flexible solutions that can respond to the diversity of students, to promote their learning, and to make their transition experience successful, while improving persistence and retention through systemic efforts with an appropriate pedagogy fitting local culture and supporting international trends. 


\section{Relevance of the CM/PM Outcomes from the Male and Female Groups. As}

mentioned throughout all chapters, gender was not the main focus of this study. Creating two separate stakeholder groups, male and female, was to compare and contrast the male education versus the female education at the Preparatory Year Program. As King Saud University applies one model of the PYP for both groups, this study attempted to explore each group's perceptions to develop the program in the future in way that fits each students' needs. Nine females produced 36 statements that were placed into six clusters and 14 males created 48 statements that were divided into seven clusters. Statistically, each female produced 4 statements and each male produced 3.43 statements.

Four clusters from the male group aligned with four clusters from the female group, according to their names, although there were slight differences among their statements/ideas: for instance, Cluster 1 Program Regulation, e.g. males S38, Granting a certificate for students who pass the Preparatory Year Program and females S18, Students academic placement to be before the Preparatory Year. The main theme that appeared in both groups concentrated on changing the student academic placement regulation to be before the PYP, not after the program's completion. The groups of stakeholders believe that placing students after the program's completion could make them psychologically unstable. Furthermore, placing students into their colleges based on the PYP's GPA may result in an undesirable college or major placement, which may affect student achievement or cause the student to dropout or effect student retention at KSU. Also, granting PYP certification for those who could not complete the PYP may help them engage in the labor market. However, both males and females have a sizeable lack of overlap, with females being more inconsistent than males. 
Being respectful of KSU's regulations and desires to ensure student's quality and the capability of graduates to find a place in the labor market, the current practice may be a double edged sword, especially for those who complete high school and passed standardize tests (Tahsil and Qiyas) with high mean scores, but they could not make it into their dream college. For example, some students apply to study at Business College but their final GPA did not meet the college's requirements, which resulted in transferring to different colleges or majors that was not in their plan. This result may affect student's decision about their study and raise the dropout rate or influence the student's performance.

Furthermore, some colleges have extra criteria for admission, such as the Medical College that applies rigorous admission criteria, including "weight of grades and examinations 40\% Tahsil, 30\% Qiyas, 30\% Thanawiya, and Placement exam after preparatory year” (Plan, 2014, p. 98). As observed, the placement exam after the PYP is considered a secondary condition because it not weighted. The question is, Can Medical College students succeed in their study if they do not study one year at the PYP? The idea here is that if KSU raised its admission criteria to ensure student's quality, how will the PYP respond to the prospective students needs if it applies a model that cannot be adjusted/modified. In other words, why should ready students complete one year of the PYP if they already meet the program's criteria and admission standards? The idea here is to make the first-year of college more attractive and acceptable for first-year students, which can make their engagements to the learning environment and transition to university successful. In its strategic plan, KSU states: KSU should review its admission criteria and raise its admission bar, using the available Qiyas, Thanawiyas and Tahseely scores, heavily favoring to provide students not accepted to KSU with a viable, tailored alternative that 
suits their skills. The accreditation report also recommends that more clarity be introduced in the setting of student criteria and enrollment (Plan, 2014, p. 98).

A second consensus between both groups was on the Program Assessment Mechanism and Curriculum Structure. Both groups agreed that the PYP should develop an assessments methodology that can identify the student's learning background, progression, and can inform the curriculum developer and policymaker about the program's performance. In fact, it could be the essential reason for the lack or absence of an effective assessment mechanism for clear theories and philosophies that can evaluate the student's learning and evolution. Pascarella and Terenzini (1991) and Tinto (1993) stress the important existence of theories to provide a better understanding of students' characteristics, assessment and development tools of the first-year, and more approaches to help students to transition into colleges successfully. Further, as KSU's plan uses the best international practices to develop its programs, including the PYP, Pascarella and Terenzini (2005) observed the lack of assessment studies that explore the weaknesses and strengths of the first-year intervention programs, and studies that evaluated some of these intervention programs did not mention program characteristics, which creates difficulties predicting whether these programs can work in different environments or not. However, the current strategic plan of the Preparatory Year states that its fourth strategic goal is "Adopting a rigorous system for student assessment" (Deanship, 2014), and mentioned that the PYP achieved (77\%) of this system so far. Existence of an effective assessment mechanism should result in an integrative approach that will eventually modify the postsecondary curriculum to include knowledge society skills in the Preparatory Year Program.

A third agreement between the two groups was on the Program Services: Prior to and During, the result indicated that the PYP concentrated more on developing infrastructure and 
student services than academic aspects. In other words, the PYP performed effectively in student services.

The KSU Rector issued a decree to establish the PY Vice-Deanship for Student Services in the academic year 2014/2015. It is a service entity concerned with providing different services to students in the areas of student affairs, student advising, and student activities. The Vice-Deanship is keen on developing its services to enhance the students' skills and talents while they are starting their university life. This will help them to complete their education successfully (PYP's website, 2016, para. 1).

As stated in Chapter 1, the PYP encounters economic challenges that may affect program academic responsibilities in the future; therefore, the PYP and KSU's policymaker may consider transferring student services tasks to the original department or deanship to provide such services at KSU. For example, Deanship of Student Affairs, Deanship of Admissions and Registration, and Deanship of e-Transactions and Communication.

The last consensus was Program Academic Design. The main themes shared between the two groups were identifying, developing, organizing, and emerging student's skills and activities within specific academic designs. The stakeholder groups believed that some courses would be better if the PYP integrated them into one course. For example, the Learning, Thinking and Research Skills and Communication Skills courses. Although there are differences in its contents, the beneficiary thinks that both courses could be combined into one course titled Learning Skills. In fact, some of the stakeholders argued that both courses are different, but as this study's purpose was not to judge courses content, but to report the stakeholders' perceptions. However, the PYP's curriculum may need more evaluation to ensure its compatibility with KSU's mission and the first-year philosophy. 
The remaining clusters for both groups represented new themes about the PYP's future. The male group included Cluster 3 Program Philosophy, Planning, and Operational Mechanism, Cluster 6 Supporting Student Learning, and Cluster 7 Program Applications Policy, while the female group involved Cluster 2 Teaching Quality and Cluster 6 Promoting Student Learning. This study noted that the male group took the issues of program philosophy, purpose, planning, and program design into account. In other words, the male group's perceptions looked at the program holistically, starting from theory to practices, while the female group tended to report program challenges and their perceptions to address specific issues in the program, such as student academic placement. In other words, the female group was not interested in developing or discussing program theory or purpose. Although the male group mentioned the program theory and philosophy, and the female group did not. The fact that both groups of stakeholders did not mention student development theories or first-year experience concepts or practices was surprising.

This result gave the researcher an idea regarding student's development theory and firstyear student science and its application in Saudi higher education, as a new domain for research and investigation in the future. The majority of educational research in educational policy studies and higher education administration focuses on leadership theories or on assessment of some of the educational administration models or practices or aspects, while the student development domain suffers from nonexistence research studies in the Saudi postsecondary education context.

In fact, this conclusion exposes why the PYP launched in Saudi higher education is based on best practices, not on theory-based information that can inform educational decision-makers about the program's reality and the potential dimensions of development. 


\section{Importance of Involving Stakeholder Group in Developing the Preparatory Year}

Program. This study represented several segments of stakeholders with firm interest in the Preparatory Year Program (PYP), such students, parents, faculty, administrators, and representative of student affairs, academic affairs, colleges, educational companies, and the private sector. Both stakeholder groups' inputs provided better understanding for the PYP and the potential development aspects in the future. The 84 statements generated by the Concept Mapping/Pattern Matching (CM/PM) methodology agreed that developing the current working model of the PYP is important, but the program performs ineffectively on some domains that connect students' needs and King Saud University's mission.

Following, the Hierarchical Cluster Analysis (HCA), the male groups 48 statements were separated into seven clusters and the female groups 36 statements into six clusters. Interestingly, both groups of stakeholders, male and female, rated the Program Regulation clusters as the highest importance clusters respectively at, $(\mathrm{M}=4.48)$ and $(\mathrm{M}=4.54)$ on a 5-point Ordinal Scale. This conclusion given by all various participants to the Program Regulation clusters supported the notion that regulation may be the main obstacle in developing the PYP. The key stakeholder groups believed that the current regulation restricted program has some benefits. In other words, the current regulation forces all students to be involved in one line of learning, with no consideration to their background or pervious knowledge or skills. The students' academic placement regulation makes the PYP's students unstable, academically or psychologically, since future college identification is based on the PYP's GPA at the end of year. Policymakers at KSU believe that the current regulation may raise selection criteria for admission at KSU for some colleges, such as the Medical or Engineering colleges, but the regulation may not be suitable for the Humanity or Science colleges. It also contradicts the first-year universal philosophy that aims 
to develop student's learning, characteristics, and help them become involved in the university's environment. The current practice may cause "suffer high attrition between freshman and sophomore year.” (Bratton \& Shushok, 2006, p.16)

Furthermore, as mentioned earlier in this chapter, since the PYP's establishment in 2007, the program expanded and added some courses, such Arabic Writing Skills, Computer Skills, Entrepreneurship Skills, Statistics, and Mathematics. All PYP students should study most of these courses, although there are many aspects of similarity between them and high school courses. For example, mathematics courses. The female participant group stated S17, Reviewing the Preparatory Year curriculum and comparing/contrasting them with public education curriculum. Recently, public education works to improve high schoolers performance and most of these problems are addressed through public education curriculum. In other words, filling knowledge and skills gap between high school outcomes and university requirements is not just the university's responsibility. More coordination between public and higher education is essential to find better solutions that can improve student's performance, accomplish both sectors goals, and meet the national objective of building a knowledge society.

A new notion was introduced by the stakeholder groups that may change the PYP's mission to be beyond the first-year. The female group suggested S15, All offered skills are important and should not be specific for the Preparatory Year, and the male group suggested S40, Developing the Preparatory Year to become a package of educational and skills programs and then colleges and departments dictate the programs that are required from their students. In fact, developing communication, research, IT skills, etc. could happen in the first-year of study, but what may happen in the next four years of study at university? A knowledge society or labor market requires high skills and continuous development, so the PYP may develop its programs 
for all KSU students not only for the PYP's students. In other words, developing programs for freshmen, sophomores, juniors, and seniors to support the university's mission. Developing the PYP beyond its current responsibilities may benefit improving students' performance and student retention at KSU, and to establish a new culture about student development in Saudi postsecondary education. "We have now reached the stage where universities must recognize the need for institution-wide approaches to enhancing the first-year experience" (Krause et al, 2005, at 8.8.6 as cited in Kift, 2008, p. 1).

\section{Implications of Finding}

"Where do we go from here with concept mapping?” (Kane \& Trochim, 2007, p. 175) The outcomes of this study reported several applicable implications to the Preparatory Year Program at King Saud University.

\section{Implication to Develop the Preparatory Year Program: A Conceptual Framework}

Proposed to the Policymakers at KSU. Kane and Trochim (2007) state, "Using the organization of the map and the contents of each cluster, groups can make tasks concrete by assigning specific responsibilities or actions to specific people” (p. 136). The Concept Mapping/Pattern Matching outcomes generated by the stakeholder groups revealed 48 statements placed into seven clusters and 36 statements placed in six clusters for males/females respectively. The most important and fewest efficacies statements developed by the stakeholder groups were identified. The rating phase of the CM/PM reported 29 statements as most important and 22 statements as fewest efficacies in both groups.

To create the PYP's Developmental Conceptual Framework, the 29 and 22 statements placed under the three main dimensions of development created in the maps interpretation stage, mentioned in the Discussion section of this chapter, included Organizational Design and 
Structure, Pedagogical Functionality, and Student Services. The three dimensions mentioned above used the 29 and 22 statements as a guideline for the proposed Conceptual Framework of the PYP (see Figure 22). The Developmental Conceptual Framework suggested by this study, was established based on seven foundational principles as proposed by the study' outcomes as follows: 1) adopting a talent philosophy of the program that can first meet student's needs and then the institution's mission; 2) develop a flexible PYP model, which can individually meet student's needs and may expand beyond the first-year of university; 3) embracing an appropriate pedagogy established on theory-based to assist the developer designing and improving the program's curriculum, teaching, and assessment of student's learning methodology; 4) reorganizing the PYP's tasks to focus more on academic dimensions than Student Services and may centralize student services for all KSU students; 5) Involving KSU's colleges to identify the knowledge and skills required for its first-year students; 6) making the PYP a supportive year, not a filtering year, which may require changing the program's name to First-Year, instead of PYP, and to develop the program's design, practices, and policy; and 7) adopting self-operation.

Astin (1984) supports such a trend in developing the first-year experience program where he says, "individualized (or eclectic) theories: each student can get an appropriate education according to his/her capacity." (p. 520-521) Furthermore, Johnston (2010) suggested that postsecondary institutions need to create flexible solutions that can respond to the diversity of students, to promote their learning, and to make their transition experience successful, while improving persistence and retention through systemic efforts with an appropriate pedagogy fitting the local culture and supporting international trends. Cubarrubia and Schoen (2010) state, “intentionally using student development theory to develop and deliver new students programs is critical to ensure that the needs of diverse students populations are addressed." (p. 167). Lastly, 
one disadvantage of relying on the business sector to operate the Preparatory Year Program is known as the "Commodification of Higher Education" (Alaqeeli, Abouammoh, \& Alghamdi, 2014), which leads to learning and teaching quality problems.

The male and female stakeholder groups reported that the PYP should take this topic into account. The male groups suggest, S34, Developing the Preparatory Year self-operation mechanisms and phasing out of outsourcing to private companies and the female group, S5, Assigning a stable educational entity to run the courses (with low possibility of management change). These two statements, in fact, raised several questions regarding the PYP's future; if KSU's policymakers decide to operate the PYP and not rely on the private sector to teach firstyear students, due to economic issues or to improve teaching quality or for any other reasons, could KSU continue to operate the program based on the current design and structure, learning methodology, and services offered in the program? Thinking about first-year students' futures is a required action to avoid any interruption in the future.

The policymaker of the Preparatory Year Program may need to work closely with KSU's colleges and deanships to discuss the possibility of transferring some of the PYP's responsibility to their original houses and make the PYP focus more on developing their curriculum, teaching practice, and assessment methods, and preparing KSU's faculty and department to participate in teaching first-year students based on the first-year experience perspective. Moreover, make KSU's policymakers think about transferring student services responsibilities from the PYP to the Student Affairs Deanship, in order to centralize student services, which can improve student's engagement and reduce program operational costs. Also, make taking responsibility of planning and managing, e.g. the orientation program in coordination with the PYP. 
The group of stakeholders, especially the females, stressed on the necessity of changing the PYP's regulation regarding student's academic placement. The participants believed that this is a serious issue that makes first-year students struggle to achieve the colleges' requirements and gain a high GPA to enter their desired colleges. In fact, change this regulation to make student's transition into postsecondary education easier. KSU may raise its selection criteria or admission requirements of prospective students, instead of filtering them and deciding their future after one academic year in the program. The first-year's purpose is to support prospective students not make them struggle in the program.

Finally, this study suggests developing the PYP to not only be for first-year students, but extend the program's mission for all KSU students from their freshman year to their senior year. Such an idea may support KSU's mission to prepare its students for a knowledge society or for the labor market. In this regard, the participant groups suggested changing the PY from the Preparatory Year Program to a Preparatory Program. Figure 22 displays the proposed conceptual framework of the PYP in detail. 


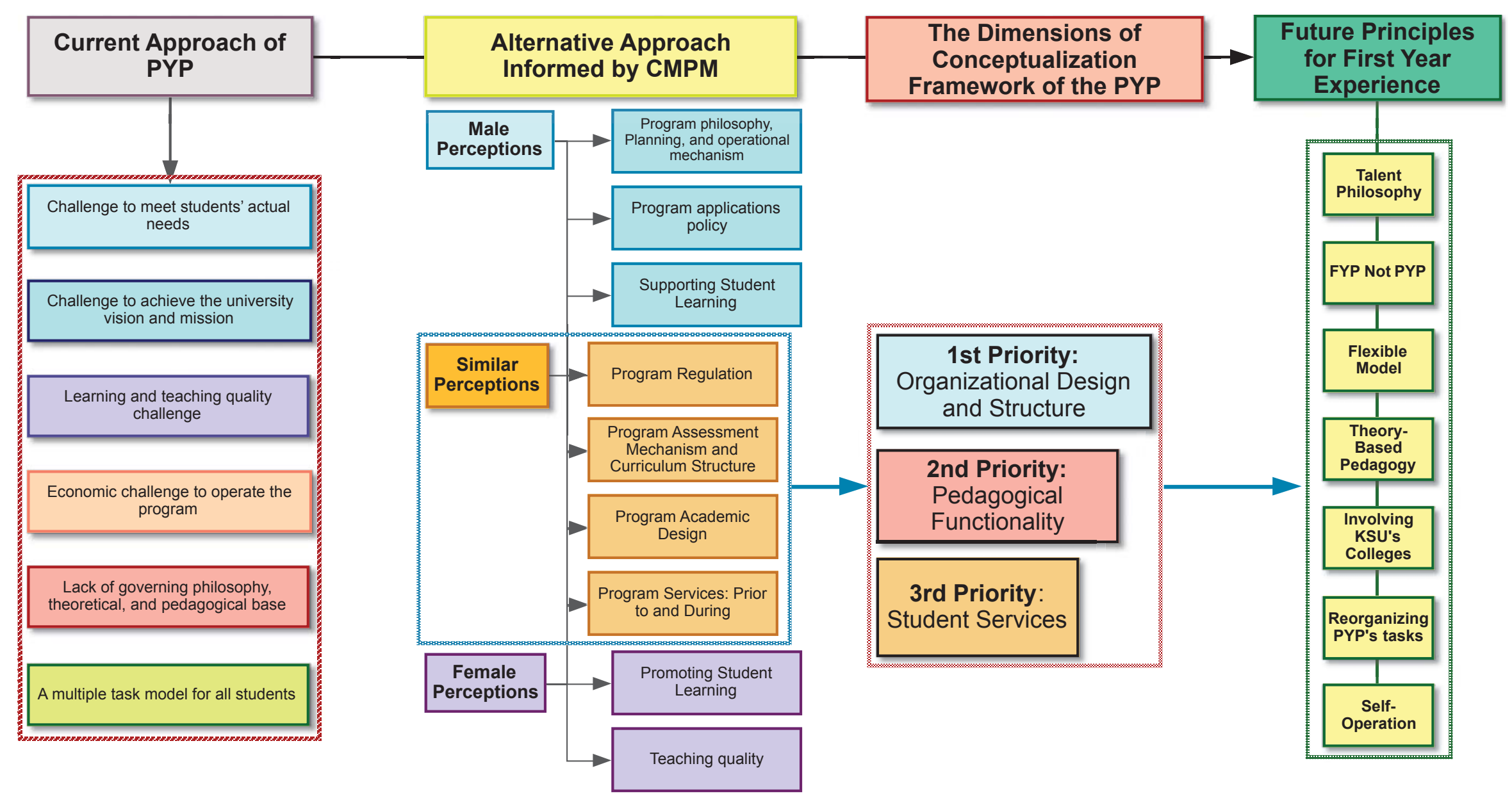

Figure 22: The Proposed Conceptual Framework Generated by the CM/PM. 
Implication to Raise the Benefit of the PYP Investment on the Program. This

study exposed that the success of the Preparatory Year Program should be created to meet individuals and the institution's needs. These challenges raised a critical concern about the program's benefit compared to its cost. In other words, the external and internal efficiency of the program.

The PYP should revise these challenges separately and study the students' needs carefully to have a full understanding of the problems before launching such initiatives. Each of these challenges may work as an overarching framework to measure the PYP's performance in the future. Applying the best international practices on the Saudi education context without research, this study can inform on the fitting of such experiences to Saudi culture, or with no customization, it is considered a double-edged sword, which may cause educational problems instead of improving students' learning. Studying Saudi's educational culture is essential before applying western theory to ensure its suitability to use in a new context, also, to recognize the ability of a new culture to adopt the philosophy.

Further, this study exposed concern regarding the teaching quality in the female section in particular and for the PYP in general. Some thoughtful implications may be applied to improve or reduce problems effect on students. First, the PYP may activate on-line or blended-learning and develop some of its courses standards-based for the female section to improve teaching and curriculum quality. Second, the PYP may raise selection criteria for faculty or may apply some standardized tests to ensure faculty quality to teach first-year students or may provide a professional development initiative for them. Additionally, for the PYP's curriculum, this study reported concerns about the PYP's curriculum design and content. The PYP may need to re-assess and compare its curriculum with selection theory or with first-year curriculum standards to confirm its appropriateness. Furthermore, the PYP may think to develop a basket of skills and knowledge courses, and activities in cooperation 
with all KSU colleges, and then each student can select a course or activity based on his/her need or based on a placement test.

Finally, implication regarding the PYP's vision and mission statements. As mentioned in Chapters 3 and 4, the PYP's vision statement is "To achieve leadership and excellence in providing knowledge generation" and its mission statement is "To provide a quality education in an environment incentive to learning and creativity supported by optimal utilization of state-of-the-art technologies and excellent partnerships". With respect to these statements, the $\mathrm{CM} / \mathrm{PM}$ outcomes for both groups focused on students learning and facilitating students transition to university more than providing an educational environment or creating excellent partnership. This study's outcomes support the fact that the PYP performed effectively on student services, but more attention and action are required to develop the PYP academically. This study thought that the PYP may need to re-state its vision and mission to place more emphasis on students' success than providing technology or building partnerships or developing the infrastructure of the program, although these areas are also important.

Implication to King Saud University Policymakers. The CM/PM results reported that respectively $29(60.42 \%)$ and $26(72.22 \%)$ statements of the stakeholders' perceptions, male and female, did not align with KSU's strategic plan themes, including KSU's vision, mission, strategic goals, etc. The high percentage of dissimilarity indicated that the group of stakeholders might have little to no experience or knowledge about KSU2030 strategic plan's vision, mission, and objectives.

In this context, how can KSU's faculty, administration, and students contribute to achieve KSU's vision if they limit knowledge about it or about its applications? KSU may need to give more attention to its entire staff including faculty, students, administrators, community, etc. to involve them in the planning process and incorporating its vision. KSU 
may also need to provide its entire staff with the necessary skills that could help them achieve the institution's vision. For example, KSU intends to create a knowledge society so, the question is, what is the nature of teaching, curriculum, policy, knowledge, skills, students, and faculty's characteristics that are required for a knowledge society? Also, how should the academic design of the PYP be to achieve KSU's vision?

Implication for Educational Planning at Saudi Ministry of Education. On January

29, 2015, Saudi higher education and public education ministries became one ministry, named Educational Ministry, and assigned one minister for both sectors. Historically, both sectors were separate since their establishment date. However, combining both sectors into one makes this study's outcomes more important to bridge the gap between public education outcomes and university requirements. Originally, the PYP's idea was borne to fill knowledge and skill gaps between public education outcomes and higher education requirements.

However, the female group suggested S17, Reviewing the Preparatory Year curriculum and comparing/contrasting them with public education curriculum. This suggestion provides an implication to the educational planners in both sectors to reconsider the possibility of developing some curriculums in the middle of high school to prepare students for university. For example, developing students'skills, e.g. communication, research, using the library, and preparing them for the labor market to some extent before university.

Furthermore, the Saudi Ministry of Education established the National Center for Assessment in Higher Education. The National Center applies several tests for all high school graduates every year. For example, 1) General Aptitude Test (GAT); 2) General Aptitude Test in E_GAT; 3) Scholastic Achievement Admission Test (Science); and 4) Scholastic Achievement Admission Test (Arts/Females). These standardized test results could be used 
to help educational planning identify the knowledge and skill gaps and then support the PYP's planners to develop the program on a research-based.

\section{Recommendations for Future Research}

Using the Concept Mapping/Pattern Matching methodology advanced by Trochim (1989a, 1989b) and Kane and Trochim (2007) in this study revealed a conceptual framework for developing the Preparatory Year Program at King Saud University.

Concept mapping can be considered a structured methodology for organizing the ideas of a group or organization, to bring together diverse groups of stakeholders and help them rapidly form a common framework that can be used for planning, evaluation, or both. (Kane \& Trochim, 2007, p. 1)

In this context, the researcher recommends several future research studies for further investigation and to refine and evaluate the conceptual framework of the PYP, as well as to inform broader concerns regarding curriculum development in postsecondary education.

First: Recommendations Regarding the PYP's Conceptual Framework and

\section{CM/PM Methodology:}

1. Replicate this study for students, faculty, parents, and high school students; then compare and contrast the original study outcomes to these new research outcomes.

2. Future studies might use CM/PM to compare and contrast subgroups within a university that might reasonably have conflicting perspectives.

3. The generated statements for both groups were compared and contrasted to the current working model of PYP and to KSU's strategic plan (KSU2030), revealing a high percentage of dissimilarity between groups' perceptions and explicit documents. Further research should involve the PYP's policymakers, educational planning, students, and KSU colleges to identify the PYP components that could 
achieve KSU's vision and mission. In other words, how should the PYP's academic curriculum be designed to achieve KSU's mission?

4. The generated statements for both groups were compared and contrasted to explore differences and similarities between males and females. Each group rated and sorted its statements individually. Further research could ask female participants to rate male statements and males to rate female statements for further comparison of the two groups' perceptions.

5. The outcomes of this study revealed several areas of development at the PYP. For example, program pedagogy and philosophy, curriculum, teaching, program regulation and policy, and assessment methodology. Further research should be conducted with different groups to address each domain separately. For instance, study the PYP's pedagogy, philosophy, or purpose. The participants may ask to articulate the PYP's purpose and philosophy or to create curriculum matrixes for the PYP, including required knowledge and skills.

6. More research is needed in which $\mathrm{CM} / \mathrm{PM}$ is conducted before a particular curriculum is developed. Future research can leverage CM/PM as a planning tool before a curriculum is actually implemented.

7. This study focused on the PYP's conceptual framework. Further research should help develop metrics for measuring progress on the PYP's domains identified through this study.

8. $\mathrm{CM} / \mathrm{PM}$ is a vital methodology for evaluation and refining organizational purposes. Further research studies should be conducted at the national level in Saudi Arabia or at other universities to assess and develop the PYP in the future.

9. Moreover, a thorough literature review reveals this study may be the first study utilizing the CM/PM methodology within a Saudi higher education context along 
with being conducted in the Arabic language. Further research is needed to evaluate the CM/PM's validity and reliability in the Arabic context.

\section{Second: Recommendations Regarding the First-Year Experience within Saudi}

\section{Education Context.}

1. This study exposed a paucity of research studies on the first-year theory in Saudi higher education. The researcher plans to develop a roadmap for first-year experience research studies disseminated to universities throughout Saudi Arabia. This plan will include, but is not limited to student development theories, first-year experience theories, models and initiatives locally or internationally, policy, curriculums, and possibly establishing first-year experience research networks among Saudi universities.

2. The $\mathrm{CM} / \mathrm{PM}$ results revealed an absence of coordination between higher education institutions represented by KSU and public education represented by high schools. Incorporating research studies on high schoolers can help assess their readiness for postsecondary education and to identify the potential dimensions of development within Saudi high schools.

3. In the workforce development research, this study revealed that more research is needed to inform the role of females for the future Knowledge Economy workforce in Saudi Arabia.

\section{Summary of the Study}

To create a successful Preparatory Year Program (PYP), it is important to link program policy, structure, and practices with the university's mission (Koch and Gardner, 2014). King Saud University (KSU) established its PYP in 2007, for males and females, which is considered a relatively new phenomenon within Saudi's higher education context. The PYP is a fundamental requirement for prospective students in $\mathrm{KSU}$, regardless of major 
or readiness levels. The Preparatory Year is designed to address the knowledge and skill gaps between high school outcomes and university requirements. The program encountered several challenges, including: a) the program's capability to meet students' needs and the university's mission; b) learning and teaching quality concerns; c) economic challenges related to the operational budget of the program; and d) lacking a governing philosophy, theoretical, and pedagogical base of the program.

This study attempted to advance a conceptual framework to develop the future ideal functions of the Preparatory Year Program to help first-year students successfully transition into college. The six phases of Concept Mapping/Pattern Matching (CM/PM) developed by (Trochim, 1989a \& 1989b; Kane \& Trochim, 2007) were utilized to achieve this study's goal and to answer the articulated four research questions.

Fourteen males and nine females participated in two separate brainstorming sessions to generate developmental statements that were used to create the similarity matrix, point maps, clusters maps, and items to be rated. The focus prompt used for the both sessions was "What programs, services, and activities should guide the functions of the Preparatory Year Program?" Using robust statistical approaches, like Multidimensional Scaling (MDS) and Hierarchical Cluster Analysis (HCA), the CM/PM process generated 84 total statements, the males created 48 statements that were then placed into seven clusters, and the females created 36 statements that were then positioned into six clusters.

The seven clusters created by the male group were: 1) Program Regulation; 2) Program Assessment Mechanism and Curriculum Structure; 3) Program Philosophy, Planning, and Operational Mechanism; 4) Program Academic Design; 5) Program Services: Prior to and During; 6) Supporting Student Learning; and 7) Program Applications Policy.

Furthermore, the six clusters created by the female group were: 1) Program Assessment Mechanism and Curriculum Structure; 2) Program Academic Design; 3) 
Teaching Quality; 4) Program Regulation; 5) Program Services: Prior to and During; and 6) Prompting Student Learning.

The results revealed that four clusters were similar for both groups: Program Regulation, Program Assessment Mechanism and Curriculum Structure, Program Academic Design, and Program Services: Prior to and During. The Program Regulation Cluster was rated as the most important cluster for both groups. Further, for the efficacy rating, this cluster was rated in the lowest level for the female group and in the third lowest level for the male group. Additionally, the Program Services: Prior to and During Cluster was rated at the fourth level of importance, and the Program Academic Design Clusters rated in the fifth level of importance in both groups.

This study also examined the similarities and differences between both groups' perceptions on the statements level. The most important statements and the most fewest efficacy statements in both groups were identified. The main themes that appeared in the comparison regarded the development of academic and curriculum design, teaching quality, orientation program, operational mechanism, and structuring the program's regulation and policy.

This study compared the stakeholders' perceptions and the current working model of the Preparatory Year Program (PYP) in-depth. The document analysis of the Student's Guidebook indicated that the PYP performed more effectively in developing student services, activities, and learning resources than in regulation, policy, curriculum, and assessment methodology of the program. The current model of the PYP focuses more on student services than on academic dimensions.

This study also compared and contrasted the CM/PM outcomes generated by both stakeholder groups with the explicit strategic plan of King Saud University, KSU2030. The comparison revealed that the degree of consensus between the CM/PM results and KSU's 
plan was low, where only $10(27.78 \%)$ statements in the female group and $19(39.58 \%)$ statements in the male group aligned with KSU2030's plan. The result indicated a mismatch between the CM/PM outcomes and KSU's plan, which showed ineffective performance in achieving KSU's mission on the PYP level. However, using Concept Mapping/Pattern Matching (CM/PM) features and after regrouping the clusters generated by participants in both groups, three main dimensions of the PYP's developmental conceptual framework were identified: Organizational Design and Structure, Pedagogical Functionality, and Student Services.

To develop the Preparatory Year Program at King Saud University, based on three dimensions mentioned previously, the educational policymaker, planner, and developer must be required to take the seven principles of the PYP's development models created by this study into account as follows: 1) adopting a talent philosophy of the program that can first meet student's needs and then the institution's mission; 2) develop a flexible PYP model, which can individually meet student's need; 3) embracing an appropriate pedagogy created on theory-base to assist developing program curriculum, teaching, and assessment of student's learning; 4) reorganizing the PYP's tasks to focus more on academic dimensions than on Student Services and may centralizing student services for all KSU students; (5) coordinating with KSU's colleges; (6) making the PYP a supportive year, not a filtering year through program regulation and policy; and 7) adopting self-operation. 


\section{References}

(AAFAQ), P. M. (2013). The future plan of higher education in saudi arabia. Riyadh: Ministry of Higher Education.

About the center. (n. d.). The national resource center for the first-year experience and students in transition at the university of south carolina. Retrieved January 20, 2015, from http://sc.edu/fye/center/index.html.

Activities, Student. (n. d.). Objectives. In the about the unit. Retrieved September 21, 2016, from http://py.ksu.edu.sa/male/en/node/1315

Affaires, Student. (n. d.). Duties and responsibilities. In the about the unit. Retrieved September 21, 2016, from http://py.ksu.edu.sa/male/en/node/1291

Ahmad, J. (2011). Pronunciation problems among saudi learners: A case study at the preparatory year program of najran university in saudi arabia. Language In India, 11(7), 22-36.

Al Awsat, Asharq (2013, June, 24). Saudi universities are ready to recive 376,000 high school gradute. Asharq Al Awsat Newspaper , 12627. Alriyadh, Saudi Arabia: Saudi Research and Marketing LTD (In Arabic).

Al Kathiri , S. N. (2014). Preparatory year (first-year experience). The Saudi Journal of Higher Education (11), 65-70.

Al-Eisa, E. S., \& Smith, L. (2013). Governance in saudi higher education. In Higher Education in Saudi Arabia (pp. 27-35). Springer Netherlands.

Al-jarallah, A. (2014, August, 18). Saudi universities and the preparatory year dilemma. AlJazerah Newspaper, 15299. Riyadh, Saudi Arabia: Al-Jazerah .

Al-Swailem, O., \& Elliott, G. (2013). The learning experiences of saudi arabian higher education leadership: Characteristics for global success. In Higher Education in Saudi Arabia (pp. 37-47). Springer Netherlands.

Alaqeeli, A. S. (2014). The preparatory year: Global perspectives and local practices. The Saudi Journal of Higher Education (11), 45-64.

Alaqeeli, A., Abouammoh, A., \& Alghamdi, S. (2014). International experiences in the preparatory year: Highlight on the 33rd annual conference on the first-year experience in the United State of America. Riyadh: Ministry of Higher Education (In Arabic).

Alatas, A. (2012, November, 4). An ambitious action plan at shqra university to improve the educational outcomes and provide better academic and training services to students: 
Preparatory year investing on minds of young people to promote knowledge-based society. Al-Riyadh Newspaper, 16204. Riyadh, Saudi Arabia: Alyamama Press Est (In Arabic).

Aldana, U. S. (2014). Moving beyond the college-preparatory high school model to a college-going culture in urban catholic high schools. Catholic Education: A Journal of Inquiry and Practice, 17 (2). Retrieved from http://digitalcommons.lmu.edu/ce/vol17/iss2/9

Alexander, B. C., García, V., González, L., Grimes, G., \& O'Brien, D. (2007). Barriers in the transfer process for hispanic and hispanic immigrant students. Journal of Hispanic Higher Education, 6(2), 174-184.

Alghamdi, A. (2013). Pedagogical implications of using discussion board to improve student learning in higher education. Higher Education Studies, 3(5), 68-80.

Alhosin, M. (2010, January, 9). Preparatory year works to raise the level of academic preparation of graduates to achieve the developmental requirements and to meet labor market demand. Al-Riyadh Newspaper, 15174. Riyadh, Saudi Arabia: Alyamama Press Est (In Arabic). .

Alhosini, K. (2012, April, 14). The preparatory year frustration. Al-Riyadh Newspaper, 16000. Riyadh, Saudi Arabia: Alyamama Press Est (In Arabic).

Alkhazim, M. (2007, July, 26). Preparatory year or the year of guillotine? Al-riyadh Newspaper, 14276. Riyadh, Saudi Arabia: Alyamama Press Est (In Arabic). .

Alkhazim, M. (2013, October, 6). Preparatory year and king fahd university of petroleum and minerals. Al-Jazirah Newspaper, 14983. Riyadh, Saudi Arabia: Al-Jazirah (In Arabic).

Almaliki, S. (2011, December, 13). Al-shura council board tends to abolish the preparatory year in Saudi universities. Sabq Electronic Newspaper. Riyadh, Saudi Arabia: Sabq (In Arabic).

Alnahdi, G. H. (2013). Educational change in saudi arabia. Journal of International Education Research (JIER), 10(1), 1-6.

Alnassar, S. A., \& Dow, K. L. (2013). Delivering high-quality teaching and learning for university students in Saudi Arabia. Higher Education in Saudi Arabia (pp. 49-60). Springer Netherlands.

Alnofaie, H. (2013). A framework for implementing critical thinking as a language pedagogy in EFL preparatory programs. Thinking Skills and Creativity, 10, 154-158. 
Alqahtani, M. (2010, March, 30). Preparatory year function [powerpoint]. The fourth periodic meeting for academic affairs deputy of Saudi universities. Riyadh: King Saud University.

Alqassim, U. (2010, March, 31). Highlight on the preparatory year program at the university of qassim: Challenges and experience. The fourth periodic meeting for academic affairs deputy of Saudi universities. Riyadh: King Saud University.

Alsalim, H. (2012, March, 10). Dilemma of public education outputs need to solutions better than disablement: Fourth of secondary school or preparatory year. Al-Riyadh Newspaper, 15965. Riyadh, Saudi Arabia: Alyamama Press Est (In Arabic).

Alshaghdali, N., Greener, S., \& Loveless, A. (2014). Quality of women's learning experiences in the digital age in higher education in saudi arabia. Proceedings of The European Conference on E-Learning, 607-617.

Alshamri, T. (2010, March, 31). Highlight on the preparatory year program at Al-jouf university. The fourth periodic meeting for academic affairs deputy of Saudi universities. Riyadh: King Saud University.

Alsoltan, A. (2012, April, 17). Preparatory year hinder educational reform. Al-Jazirah Newspaper, 14446. Riyadh, Saudi Arabia: Al-Jazirah (In Arabic).

Altowjry, A. (2005). Reforming higher education in Saudi Arabia: The use of telecommunications technology.

Alyahya, S., \& Irfan, M. A. (2016). Role of saudi universities in achieving the solar potential 2030 Target. Energy Policy, 91325-328. doi:http://dx.doi.org.www.libproxy.wvu.edu/10.1016/j.enpol.2016.01.019

Amanatides, J., Armour, M. H., Bellissimo, L., Conrad, M., Dupuis, J., Gaukel, A. L., ... \& Parna, J. (2013). A Case for change: A first year experience framework at york university.

Amaral, A. and A. Magalhães (2002). The emergent role of external stakeholders in european higher education governance. In A. Amaral, G.A. Jones and B. Karseth (eds.) Governing Higher Education: National Perspectives on Institutional Governance, Higher Education Dynamics 2, Dodrecht, Boston and London, Luwer Academic Publishers, pp. 279-298.

Andrade, M. (2005). International students and the first-year of college. Journal of the FirstYear Experience \& Students in Transition, 17(1), 101-129.

Arnold, K. D., Lu, E. C., \& Armstrong, K. J. (2012). The ecology of college readiness, ASHE Higher Education Report Volume 38, Number 5. John Wiley \& Sons. 
Astin, A. W. (1977). Four critical years. Effects of college on beliefs, attitudes, and knowledge.

Astin, A. W. (1984). Student involvement: A developmental theory for higher education. Journal of college student personnel, 25(4), 297-308.

Astin, A. W. (1985). Achieving educational excellence: A critical assessment of priorities and practices in higher education. Jossey-Bass.

Astin, A. W. (1993). What matters in college?: Four critical years revisited (Vol. 1). San Francisco: Jossey-Bass.

Astin, A. W. (1999). Student involvement: A developmental theory for higher education. Journal of College Student Development, 40(5), 518-29.

Astin, A. W., \& Panos, R. J. (1969). The educational and vocational development of college students. Washington: American Council on Education.

Astin, A. W., Oseguera, L., Sax, L.J., Korn, W.S. (2002).The american freshman: Thirty-five year trends, Los Angeles: Higher Education Research Institute, UCLA.

Bagazi, A. (2010, June, 28). King saud university treat the inadequacy of educational outcomes for the labor market by preparatory year. Asharq Al-Awsat Newspaper, 11535. Al-Riyadh, Saudi Arabia: Saudi Research and Marketing LTD (In Arabic).

Bailey, T. R., \& Alfonso, M. (2005). Paths to persistence: An analysis of research on program effectiveness at community colleges. Indianapolis, IN: Lumina Foundation for Education.

Baker, L., Meyer, K., \& Hunt, S. (2005). First-year students' perception of power and use of persuasive techniques: A comparison of learning community versus traditional classes. Journal of the First-Year Experience \& Students in Transition, 17(2), 23-48.

Bakry, S. H., \& Al-Ghamdi, A. (2008). A framework for the knowledge society ecosystem: A tool for development in the open knowledge society. A Computer Science and Information Systems Manifesto (pp. 32-44). Springer Berlin Heidelberg.

Barefoot, B. (1998). A brief introduction to student development theory; Special issues pertaining to the first-year. Paper presented at the Annual Conference on The FirstYear Experience, Columbia SC.

Barefoot, B. (2004). Foundations of excellence: A new model for first-year assessment. Assessment update, 16(2), 5-7.

Barefoot, B. O. (1992). Helping first-year college students climb the academic ladder. Report of a national survey of freshman seminar programming in American higher education. Unpublished doctoral dissertation, College of William and Mary, Williamsburg, VA. 
Barefoot, B. O. (2000). The first-year experience. About Campus, 4(6), 12-18.

Barefoot, B. O. (2005). Achieving and sustaining institutional excellence for the first-year of college. San Francisco, CA: Jossey-Bass.

Barefoot, B. O. (2005). Current institutional practices in the first college year. In M. L. Upcraft, J. N. Gardner, \& B. O. Barefoot (Eds.), Challenging and supporting the firstyear student: A handbook for improving the first-year of college, 47-63. San Francisco: Jossey-Bass.

Barefoot, B. O., \& Fidler, P. P. (1992). 1991 National survey of freshman seminar programming. (Monograph No. 10). Columbia, SC: University of South Carolina, National Resource Center for The Freshman Year Experience.

Barefoot, B. O., Gardner, J. N., Cutright, M., Morris, L. V., Schroeder, C. C., Schwartz, S. W., Siegel, M. L., \& Swing, R. L. (2010). Achieving and sustaining institutional excellence for the first-year of college. John Wiley \& Sons.

Barrows, S., \& Goodfellow, M. (2005). Learning effect on first-year students success in a general chemistry course. The Journal of the First-Year Experience \& Students' in Transition, 17(2), 11-22.

Bartley, J. L. (2015). Touchstones of connection: A concept mapping study of therapist factors that contribute to relational depth. Retrieved from http://search.proquest.com/docview/1696289263?accountid=2837

Bauer, K. W., \& Liang, Q. (2003). The effect of personality and precollege characteristics on first-year activities and academic performance. Journal of College Student Development, 44(3), 277-290.

Beerkens, E. (2008). University policies for the knowledge society: Global standardization, local reinvention. Perspectives on global development and technology, 7(1), 15-36.

Beers, R. E. (1998). The first-year university experience: An international student perspective. Retrieved from http://search.proquest.com/docview/304490691?accountid=2837

Behling, O, \& Law, K. (2000). Translating questionnaires and other research instruments: Problems and solutions. London: Sage Publications.

Ben-Avie, M., Kennedy, M., Unson, C., Li, J., Riccardi, R. L., \& Mugno, R. (2012). Firstyear experience: A comparison study. Journal of Assessment and Institutional Effectiveness, 2(2), 143-170.

Bess, J. L., \& Dee, J. R. (2008). Understanding college and university organization: Dynamics of the system (Vol. 2). Stylus Publishing, LLC. 
Bindé, J., \& Matsuura, K. (2005). Towards knowledge societies (Vol. 1). UNESCO.

Birnbaum, R. (1992). How academic leadership works: Understanding success and failure in the college presidency. San Francisco: Jossey-Bass.

Blackhurst, A., Akey, L., \& Bobilya, A. (2003). A qualitative investigation of student outcomes in a residential learning community. Journal of the First-Year Experience \& Students in Transition, 15(2), 35-59.

Bogard, M., Helbig, T., Huff, G., \& James, C. (2011). A comparison of empirical models for predicting student retention. White paper. Office of Institutional Research, Western Kentucky University.

Bolman, L. G., \& Deal, T. E. (2008). Reframing organizations: Artistry, choice, and leadership, fourth edition Jossey-Bass.

Borsky, A. E. (2014). Promoting prosocial behaviors to prevent dating violence among college students: Evaluation of a bystander intervention. Retrieved from http://search.proquest.com/docview/1524282734?accountid=2837

Bosse, S., Duncan, K., Gapp, S., \& Newland, L. (2011). Supporting american indian students in the transition to postsecondary education. Journal of the First-Year Experience \& Students in Transition, 23(2), 33-51.

Boylan, H. R., Bonham, B. S., \& White, S. R. (1999). Developmental and remedial education in postsecondary education. New Directions for Higher Education, 108, 87-101.

Bratton, S., \& Shushok, F. (2006). Engaging undergraduate learners: Strengthening the firstyear experience and research mentoring: A sacs quality enhancement plan white paper proposal. Baylor University.

Braxton, J. M. (2000). Reworking the student departure puzzle. Nashville: Vanderbilt University Press.

Braxton, J. M., \& McClendon, S. A. (2001). The fostering of social integration and retention through institutional practice. Journal of College Student Retention: Research, Theory \& Practice, 3(1), 57-71.

Braxton, J. M., Hirschy, A. S., \& McClendon, S. A. (2011). Understanding and reducing college student departure. ASHE-ERIC higher education report, volume 30, number 3. Hoboken: Jossey-Bass.

Brislin, R. W. (1970). Back-translation for cross-cultural research. Journal of cross-cultural psychology, 1(3), 185-216. 
Brooman, S., \& Darwent, S. (2012). 'Yes, as the articles suggest, I have considered dropping out self-awareness literature and the first-year student. Studies in Higher Education, 37(1), 19-31.

Cacy, J. R. (1995). The reality of stakeholder groups: A study of the validity and reliability of concept maps. Retrieved from http://search.proquest.com/docview/304202034?accountid=2837

Cetinavci, U. R., \& Topkaya, E. Z. (2012). A contrastive qualitative evaluation of two different sequential programs launched at the school of foreign languages of a turkish university. Online Submission, 3(3), 82-101.

Chickering, A. W., \& Gamson, Z. F. (1987). Seven principles for good practice in undergraduate education. AAHE bulletin, 3, 7.

Chickering, A. W., \& Reisser, L. (1993). Education and identity. San Francisco: Jossey-Bass Publishers.

Chiu, K. (2012). Concept mapping for planning and evaluation of a community-based initiative. Retrieved from http://search.proquest.com/docview/1284159171?accountid=2837

Chomey, L. (1994). Concept mapping and the role of the elementary school counsellor. University of Alberta.

Chun, J. (2004). Stress and coping strategies in runaway youths: An application of concept mapping. Retrieved from http://search.proquest.com/docview/305127911 ?accountid=2837

Cichocki, P., \& Irwin, C. (2014). Organization design : A guide to building effective organizations. London, GB: Kogan Page. Retrieved from http://www.ebrary.com

Clark, M. R. (2005). Negotiating the freshman year: Challenges and strategies among firstyear college students. Journal of College Student Development, 46(3), 296-316.

Clayton, L. B. (2002). The use of concept mapping to evaluate the isomorphism of the hierarchical leisure constraint typology. Retrieved from http://search.proquest.com/docview/276289705?accountid=2837

Cohen, M. D., March, J. G., \& Olsen, J. P. (1972). A garbage can model of organizational choice. Administrative science quarterly, 1-25.

College of Applied Medical Sciences. (n. d.). Home. In the college of applied medical sciences. Retrieved March 18, 2015, from http://cams.ksu.edu.sa/en.

College of Business administration. (n. d.). Vision. In the college of business administration. Retrieved March 18, 2015, from http://cba.ksu.edu.sa/en/content/vision\#. 
College of Education. (n. d.). Vision. In the college of education. Retrieved March 18, 2015, from http://education.ksu.edu.sa/en.

College of Engineering. (n. d.). Vision. in college of engineering. Retrieved March 18, 2015, from http://engineering.ksu.edu.sa/Arabic/en/Pages/default.aspx.

Comeaux, E., \& Harrison, C. K. (2011). A conceptual model of academic success for student-athletes. Educational Researcher, 40(5), 235-245.

Comeaux, E., \& Harrison, C. K. (2011). A conceptual model of academic success for student-athletes. Educational Researcher, 40(5), 235-245.

Commander, N., Valeri-Gold, M., \& Darnell, K. (2004). The strategic thinking and learning community: An innovative model for providing academic assistance. Journal of the First-Year Experience \& Students in Transition, 16(1), 61-76.

Conley, D. T. (2008). Rethinking college readiness. New directions for higher education, 2008(144), 3-13. doi:10.1002/he.321.

Conley, D. T. (2010). College and career ready: Helping all students succeed beyond high school. John Wiley \& Sons.

Conley, D. T. (2013). Getting ready for college, careers, and the common core: What every educator needs to know. John Wiley \& Sons.

Corkindale, G. (2011, February). The importance of organizational design and structure. Retrieved October 30, 2016, from https://hbr.org/2011/02/the-importance-oforganization

Corneo, G. (2011). Stakeholding as a new development strategy for saudi arabia. Review of Middle East Economics and Finance, 7(1), 1-19.

Counseling, Student. (n. d.). Objectives. In the about the unit. Retrieved September 21, 2016, from http://py.ksu.edu.sa/male/en/node/1337

Crissman Ishler, J. L. (2005). Today’s first-year students. In M. L. Upcraft, J. N. Gardner, \& B. O. Barefoot (Eds.), Challenging and supporting the first-year student: A handbook for improving the first-year of college, 15-26. San Francisco: Jossey-Bass.

Crissman, J. (2001). Clustered and non-clustered first-year seminars: New students' firstsemester experiences. Journal of the First-Year Experience \& Students in Transition, 13(1), 69-88.

Crosling, G., Thomas, L., \& Heagney, M. (2008). Introduction: Student success and retention.

Cubarrubia, A. P. \& J. C. Schoen (2010). Creating a developmental framework for new student orientation to address the needs of diverse population. In J. A. Ward-Roof 
(Ed), Designing successful transitions: A guide for orienting students to college. (Monograph No. 13, $3^{\text {rd }}$ ed.). Columbia, SC: University of South Carolina, National Resource Center for The First-Year Experience and Students in Transition.

Curtis, S. M., \& Harte, J. (1991). A freshman retention project at borough of Manhattan community college.

Cuseo, J. (2014). Student success: Definition, outcomes, principles and practices. The Big Picture: Esource for College Transitions.

Cuseo, J. (n. d.). The first-year experience and students-in-transition movement: What is its appeal? what are its ideals?.

Cuseo, J. B. (2008). Assessment of the first-year experience: Six significant questions. Proving and Improving: Strategies for Assessing the First College Year (Monograph No. 33), 27-34.

Cutright, M. (2002). What are research universities doing for first-year students?. About Campus, 7(4), 16-20.

Cutright, M., \& Rodems, M. (2003). Annotated bibliography on assessment of the first college year. Policy Center on the First-year of College.

Daif-Allah, A. S., \& Albesher, K. (2013). The use of discourse markers in paragraph writings: The case of preparatory year program students in Al-qassim university. English Language Teaching, 6(9), 217-227.

Daif-Allah, A. S., \& Alsamani, A. S. (2014). Motivators for demotivators affecting english language acquisition of Saudi preparatory year program. English Language Teaching, $7(1), 120-127$.

Deanship, P. Y. (2014). Student handbook 2014-2015. Riyadh: King Saud University.

Deanship, Preparatory Year (2016, October). Home. Deputy deanships: Student services. Retrieved from http://py.ksu.edu.sa/male/en/node/1263

Deanship, Preparatory Year (2016, November). Home, About py: Organizational Chart. Retrieved from http://py.ksu.edu.sa/male/en/Oraganizational_Chart.

Demetriou, C., \& Schmitz-Sciborski, A. (2011). Integration, motivation, strengths and optimism: Retention theories past, present and future. In the 7th National Symposium on Student Retention, Charleston, Norman, OK: The University of Oklahoma.

DeVilbiss, Samantha E. (2014). The transition experience: Understanding the transition from high school to college for conditionally-admitted students using the lens of Schlossberg's transition theory. University of Nebraska - Lincoln. 
DeWitz, S. J., Woolsey, M. L., \& Walsh, W. B. (2009). College student retention: An exploration of the relationship between self-efficacy beliefs and purpose in life among college students. Journal of College Student Development, 50(1), 19-34. doi:10.1353/csd.0.0049

Dillon, J. J. (2003). Bringing counseling to the classroom and the residence hall: The university learning community. The Journal of Humanistic Counseling, Education and Development, 42(2), 194-208.

DiRamio, D., \& Jarvis, K. (2011). Transition 2.0: Using Tinto's model to understand studentveteran persistence. ASHE Higher Education Report, 37(3), 35-49.

Division of Public Administration, \& Development Management. (2005). Understanding Knowledge Societies: In twenty questions and answers with the index of knowledge societies. United Nations Publications.

Draper, S. (2005). Tinto's model of student retention.

Driscoll, D. P. (2010). Higher education planning for a strategic goal with a concept mapping process at a small private college. Retrieved from http://search.proquest.com/docview/497092721 ?accountid=2837

Drucker, P. (2012). Managing in the next society. Routledge.

Drucker, P. F. (1969). The age of discontinuity: Guidelines to our changing society. New York: Harper \& Row.

Drucker, P. F. (1993). The rise of the knowledge society. The Wilson Quarterly (1976-), $17(2), 52-71$.

Drucker, P. F. (1999). Management challenges for the 21st century. New York: HarperBusiness.

Drucker, P. F., \& Drucker, P. F. (1994). Post-capitalist society. Routledge.

Drucker, P. F., \& Wartzman, R. (2010). The drucker lectures: Essential lessons on management, society and economy: Part VI: 1990s: Chapter 22: Manage yourself and then your company 1996. Sebastopol: Safari Books Online LLC

Duderstadt, J. J., \& Weber, L. E. (2006). Universities and business: Partnering for the knowledge society. Economica.

Dwyer, J. O. (1989). A historical look at the freshman year experience. In Upcraft, M. L., \& Gardner, J. N. The freshman year experience: Helping students survive and succeed in college. San Francisco, Calif: Jossey-Bass Publishers.

Eddie, C., \& C, K. H. (2011, June, 1). A conceptual model of academic success for studentathletes. Educational Researcher, 40, 5, 235-245. 
El-Tantawi, M., Al-Ansari, A., Sadaf, S., \& AlHumaid, J. (2016). Evaluating the english language scientific writing skills of saudi dental students at entry level. Eastern Mediterranean Health Journal, 22(2), 148-153.

Elyas, T., \& Picard, M. (2013). Critiquing of higher education policy in saudi arabia: Towards a new neoliberalism. Education, Business and Society: Contemporary Middle Eastern Issues, 6(1), 31-41.

Erickson, B. L., \& Strommer, D. W. (2005). In M. L. Upcraft, J. N. Gardner, \& B. O. Barefoot (Eds.), Challenging and supporting the first-year student: A handbook for improving the first-year of college, 241-256. San Francisco: Jossey-Bass.

Ernest T. Pascarella, \& Patrick T. Terenzini. (2005). How college affects students: A third decade of research. Jossey-Bass.

Evans, N. J., Forney, D. S., \& Guido-DiBrito, F. (1998). Student development in college: Theory, research, and practice. San Francisco: Jossey-Bass Publishers.

Evenbeck, S. E., Jackson, B., Smith, M., Ward, D., \& Associates. (2010). Organizing for student success: The university college model (Monograph No. 53). Columbia, SC: University of South Carolina, National Resource Center for the First-Year Experience $\&$ Students in Transition,

Fashola, O. S., \& Slavin, R. E. (1998). Effective dropout prevention and college attendance programs for students placed at risk. Journal of Education for Students Placed at Risk, 3, 159-183.

Feldman, R. S. (Ed.). (2005). Improving the first-year of college: Research and practice. Psychology Press.

Feldman, R. S., \& Zimbler, M. S. (2011). Engendering college student success: Improving the first year and beyond. Massachusetts: The McGraw-Hill Research Foundation.

Female Student Campus. (n. d.). Home. in female student campus. Retrieved March 18, 2015, from http://womencampus.ksu.edu.sa/en.

Fielstein, L., \& Bush, L. (1998). Remedial students' perceptions: Pre-college decisionmaking, satisfaction with the freshman year, and self-perceptions of academic abilities. Journal of the First-Year Experience \& Students in Transition, 10(2), 41-55.

Fitzpatrick, S. J. (2012). Using concept mapping to identify action steps for physical activity promotion in cancer treatment. Retrieved from http://search.proquest.com/docview/1113335366?accountid=2837

Foot, S. M., Hinkle, S. E., Kranzow, J., Pistilli, M. D., Rease Miles, L., \& Simmons, J. G. (2013). College students in transition: An annotated bibliography. Columbia, SC: 
University of South Carolina, National Resource Center for the First-Year Experience and Students in Transition.

Franklin, K. (2000). Shared and connected learning in a freshman learning community. Journal of the First-Year Experience \& Students in Transition, 12(2), 3360.

Fraser, K. M. (1993). Theory based use of concept mapping in organization development: creating shared understanding as a basis for the cooperative design of work changes and changes in working relationships. Cornell University.

Frazier, K. G. (2007). First-year experience collaboration among academic affairs and student affairs at public state university. Georgia State University.

Fullan, M. (1993).Change forces: Probing the depths of educational reform. School Development and the Management of Change Series 10. London: Falmer.

Fuller, S. (2003). Can universities solve the problem of knowledge in society without succumbing to the knowledge society? Policy Futures in Education, 1(1), 106-124.

Gallarotti, G. M., Filali, A., \& Yahia, I. (2013). Smart Development: Saudi Arabia's Quest for a Knowledge Economy. International Studies.

Gardner, J. (2007). An interview with John Gardner: Student success. The Newsletter for Higher Education Professionals, November 2007. (2007).

Gardner, J. N., \& Barefoot, B. O. (2011). Your college experience: Strategies for success. Macmillan.

Gardner, J. N., \& Koch, A. K. (2014). A history of the first-year experience in the united states during the twentieth and twenty-first centuries: Past practices, current approches, and future directions. The Saudi Journal of Higher Education (11), 11-44.

Gardner, J.N. (1998, February). Current trends in the first college year. Faculty House Dinner Workshop conducted at the National Conference on the Freshman Year Experience, Columbia, South Carolina.

General Department for Planning Statistics. (2011). Higher education and building knowledge society: An international evaluation. Riyadh: Education, Ministry of Higher. Retrieved December 1, 2014, from http://www.mohe.gov.sa

General Department for Planning Statistics. (2013). Higher education and building knowledge society: An international evaluation. Riyadh: Ministry of Higher Education. Retrieved December 1, 2014, from http://www.mohe.gov.sa

Gengler-Dunn, D. (2007). A narrative inquiry of four female first-year, first-generation student perspectives of the university experience. 
Giles, C., \& Hargreaves, A. (2006). The sustainability of innovative schools as learning organizations and professional learning communities during standardized reform. Educational Administration Quarterly, 42(1), 124-156.

Gold, J., Miller, M., \& Rotholz, J. (2001). Grief experiences of first-year women students in the transition to college: Implications for individual and systemic interventions. Journal of the First-Year Experience \& Students in Transition, 13(2), 37-54.

Golde, C. M., \& Pribbenow, D. A. (2000). Understanding faculty involvement in residential learning communities. Journal of College Student Development, 41(1), 27-40.

Gordon, V., \& Steele, G. (2003). Undecided first-year students: A 25-year longitudinal study. Journal of the First-Year Experience and Students in Transition, 15(1), 19-38.

Gore, P. A., Jr., \& Carter, L. P. (Eds.). (2011). Students in transition: Research and practice in career development (Monograph No. 55). Columbia, SC: University of South Carolina, National Resource Center for the First-Year Experience and Students in Transition.

Greenfield, G. M., Keup, J. R., \& Gardner, J. N. (2013). Developing and sustaining successful first-year programs: A guide for practitioners. John Wiley \& Sons.

Guidebook, Student's (2016). Student's guidebook 2016. Riyadh: King Saud University.

Gutterman, A. (2009). Organizational design: De nition and introduction. Retrieved October 31, 2016, from http://alangutterman.typepad.com/files/odm_11.07.2011.pdf

Habib, H. (2010, September, 21). Preparatory year is a transition phase for student: Its benefits exceed on just academic chance. Al-Riyadh Newspaper, 15429. Riyadh, Saudi Arabia: Alyamama Press Est (In Arabic).

Halvorsen, T., \& Skauge, T. (2004). Constructing knowledge societies? The world bank and the new lending policy for tertiary education. Journal of Higher Education in Africa, $2(3), 140$.

Hamdan, A. (2005). Women and education in Saudi Arabia: Challenges and achievements. International Education Journal, 6(1), 42-64.

Hamdan, A. K. (2014). The road to culturally relevant pedagogy: Expatriate teachers' pedagogical practices in the cultural context of saudi arabian higher education. Mcgill Journal of Education, 49(1), 201-226.

Hanley, G., \& Olson, S. (1996). Preparing incoming students for the university educational process: From the students' perspective and retrospective. Journal of the First-Year Experience \& Students in Transition, 8(1), 47-77. 
Hargreaves, A. (2003). Teaching in the knowledge society: Education in the age of insecurity. Teachers College Press.

Haring, M. J. (2005). Preparing for college: Nine elements of effective outreach. Middletown: American Library Association CHOICE.

Hensheid, J. M., \& Keup, J. R. (2011). Crafting and conducting research on student transitions. National Resource Center for the First-Year Experience and Students in Transition, University of South Carolina.

Higgins, M. (2010). The first-year experinec. Kansas State University, Department of Counseling and Student Development. Manhattan: College of Education.

Higher education statistics in details (2015, January 10). Retrieved from https:/he.moe.gov.sa/ar/Ministry/Deputy-Ministry-for-Planning-and-Informationaffairs/HESC/Ehsaat/Pages/default.aspx (In Arabic).

Hilal, K. T. (2013). Between the fears and hopes for a different future for the nation-states: Scholarship programs in saudi arabia and united arab emirates from a public policy standpoint. International Journal Of Higher Education, 2(2), 195-210.

Hill, M., \& Sedlacek, W. (1995). Freshman counseling interests. In M. L. Upcraft, J. N. Gardner, \& B. O. Barefoot (Eds), Challenging and supporting the first-year student: A handbook for improving the first-year of college, 27-38. San Francisco: JosseyBass.

Hollands, A. L. C. (2012). Fostering hope and closing the academic gap: An examination of college retention for African-American and Latino students who participate in the louis stokes alliance minority participation program (learning community) while enrolled in a predominately white institution.

Hornidge, A. K. (2011). Knowledge society as academic concept and stage of development: A conceptual and historical review. World Scientific Publishing.

Hossler, D., Kuh, G. D., \& Olsen, D. (2001). Finding (more) fruit on the vines: Using higher education research and institutional research to guide institutional policies and strategies (Part II). Research in Higher Education, 42(2), 223-235.

Hunter, M. S. (2006). Fostering student learning and success through first-year programs. Peer Review, 8(3).

Information Technology unit. (2014). Internal statistical report of preparatory year. Preparatory year deanship. Riyadh, King Saud University.

Information, D. f. (2010). Ministry of higher education's plan to achieve excellence in science and technology. Riyadh: Ministry of Higher Education. 
Information, M. D. (2013). The current status of higher education in the kingdom of saudi arabia. General Department for Planning and Statistics . Riyadh: Ministry of Higher Education.

Int J FYHE. (n. d.). In the International Journal of the First-year in Higher Education. Retrieved January 20, 2015, from https://fyhejournal.com.

Jabareen, Y. (2009). Building a conceptual framework: Philosophy, definitions, and procedure. International Journal of Qualitative Methods, 8(4), 49-62.

Jackson, C. K. (2014). Do college-preparatory programs improve long-term outcomes?. Economic Inquiry, 52(1), 72-99.

Jackson, K. M., \& Trochim, W. M. (2002). Concept mapping as an alternative approach for the analysis of open-ended survey responses. Organizational Research Methods, 5(4), 307-336.

Jacob, M. (2000). "Mode 2' in context: The contract researcher, the university and the knowledge society", in M. Jacob and T. Hellström (eds) The Future of Knowledge Production in the Academy, Buckingham, SRHE and Open University Press, pp. 1127.

Jamelske, E. (2009). Measuring the impact of a university first-year experience program on student GPA and retention. Higher Education, 57(3), 373-391.

Jamjoom, F. B., \& Kelly, P. (2013). Higher education for women in the kingdom of Saudi Arabia. In Higher Education in Saudi Arabia (pp. 117-125). Springer Netherlands.

Jamjoom, Y. (2012). Understanding private higher education in saudi arabia-emergence, development and perceptions. University of London.

Javid, C. Z. (2016). Teaching effectiveness of native and non-native EFL teachers as perceived by preparatory year students in Saudi context. Language in India, 16(1), 98-121.

Jazan, U. (2010, March, 31). Preparatory year program (pyp) at jazan university. The fourth periodic meeting for academic affairs deputy of Saudi universities. Riyadh: King Saud University.

John N. Gardner Institute for Excellence in Undergraduate Education. (n. d.). First-year focus - foundational dimensions ${ }^{\circledR}$. In John N. Gardner Institute for Excellence in Undergraduate Education. Retrieved March 12, 2015, from http://www.jngi.org/foeprogram/foundational-dimensions/four-year-first-year-focus/. 
Johnson, J. L. (2000). Learning communities and special efforts in the retention of university students: What works, what doesn't, and is the return worth the investment. Journal of college student retention, 2(3), 219-238.

Johnson, M. A. (2012). United states evaluation policy: A theoretical taxonomy. Retrieved from http://search.proquest.com/docview/1513556541?accountid=2837

Johnston, B. (2010). The first-year at university: Teaching students in transition. McGrawHill International.

Joseph, D. D. (2004). Hispanic dropouts speak out: A study of hispanic youth and their experiences in the public school system. Retrieved from http://search.proquest.com/docview/305126398?accountid=2837

Kaliyadan, F., Thalamkandathil, N., Parupalli, S. R., Amin, T. T., Balaha, M. H., \& Al Bu Ali, W. H. (2015). English language proficiency and academic performance: A study of a medical preparatory year program in saudi arabia. Avicenna Journal of Medicine, 5(4), 140-144. doi:10.4103/2231-0770.165126

Kane, M., \& Trochim, W. M. K. (2007). Concept mapping for planning and evaluation. Thousand Oaks, CA: Sage.

Kearns, P. (2004). Education research in the knowledge society: Key trends in Europe and North America. National Centre for Vocational Education Research Ltd. PO Box 8288, Stational Arcade, Adelaide, SA 5000, Australia.

Keeling, S. (2003). Advising the millennial generation. NACADA Journal, 23(1-2), 30-36.

Kelly, J. T., Kendrick, M. M., Newgent, R. A., \& Lucas, C. J. (2007). Strategies for student transition to college: A proactive approach. College Student Journal, 41(4), 1021.

Kelly, L. J. (1996). Implementing Astin's I-E-O model in the study of student retention: A multivariate time dependent approach. New London, CT: U.S. Coast Guard Academy, Center for Advanced Studies.

Keup, J. (2013). Twenty-five years of scholarship on students in transition: Celebrations and reflections. Journal of the First-Year Experience \& Students in Transition, 25(1), 911.

Kezar, A. (2001). Understanding and facilitating organizational change in the 21 st century. ASHE-ERIC higher education report, 28(4), 147.

Kift, S. (2004, July). Organizing first year engagement around learning: Formal and informal curriculum intervention. In 8th Pacific Rim First Year in Higher Education Conference, Dealing with Diversity, Queensland University of Technology in conjunction with Monash University, Melbourne, Australia. 
Kift, S. (2009). Articulating a transition pedagogy to scaffold and to enhance the first-year student learning experience in Australian higher education: Final report for ALTC senior fellowship program. Strawberry Hills, NSW: Australian Learning and Teaching Council.

Kift, S. M. (2008). The next, great first year challenge: Sustaining, coordinating and embedding coherent institution-wide approaches to enact the fye as" everybody's business".

King Abdulaziz City for Science and Technology (2014). Transition to knowledge society in saudi arabia: Tracing the rise of the knowledge economy in the kingdom of saudi arabia in 2014. Riyadh: Alani, D. I., Mrayati M., Al Kamil, A. K., \& M. Alghamdi, M.

Kirby, R. M. S. (2001). The impact of an educational initiative for at-risk urban African American males: An evaluation of a boarding school program. Retrieved from http://search.proquest.com/docview/304727170?accountid=2837

Kirst, M. W., \& Venezia, A. (2004). From high school to college: Improving opportunities for success in postsecondary education. San Francisco, CA: Jossey-Bass

Koch, A. K., Foote, S. M., Hinkle, S. E., Keup, J., \& Pistilli, M. D. (Eds). (2007). The firstyear experience in american higher education: An annotated bibliography ( $4^{\text {th }} \mathrm{ed}$.). Columbia, SC: University of South Carolina, National Resource Center for the FirstYear Experience and Students in Transition.

Kolb, D. G., \& Shepherd, D. M. (1997). Concept mapping organizational cultures. Journal of Management Inquiry, 6(4), 282-295.

Krahenbuhl, K. (2012). Analysis of social and academic integration in a public university's first-year experience seminar. Northern Arizona University.

Krause, K. (2006, October). On being strategic about the first-year. In keynote presentation, Queensland University of Technology First-year Forum (Vol. 5).

Kronour, J. P. (2004). Preservice teaching standards: What skills should first-year teachers possess as they enter the field. Retrieved from: http://search.proquest.com/docview/305093604?accountid=2837

KSUnews (n. d.). King Saud Univeristy Portal. Retrieved Feburuary 12, 2015, from http://ksu.edu.sa.

Kuh, G. D., Kinzie, J., Buckley, J. A., Bridges, B. K., \& Hayek, J. C. (2006, July). What matters to student success: A review of the literature commissioned report for the 
national symposium on postsecondary student success: Spearheading a dialog on student success. Washington DC: National Postsecondary Education Cooperative.

Kuh, G. D., Kinzie, J., Schuh, J. H., \& Whitt, E. J. (2005). Assessing conditions to enhance educational effectiveness: The inventory for student engagement and success. San Francisco: Jossey-Bass.

Kuh, G. D., Kinzie, J., Schuh, J. H., \& Whitt, E. J. (2011). Student success in college: Creating conditions that matter. John Wiley \& Sons.

Kumar, S., \& Phrommathed, P. (2005). Research methodology (pp. 43-50). Springer US.

Kutnowski, M. (2005). In practice-this is why we teach: Igniting a passion for learning in linked courses. About Campus, 10(1), 23-26.

Lane, R. E. (1966). The decline of politics and ideology in a knowledgeable society. American Sociological Review, 5(31): 649-62.

Larmar, S. \& Lodge, J. (2014). Making sense of how I learn: Metacognitive capital and the first-year university student. The International Journal of the First-year in Higher Education, 5(1). 93-105. doi: 10.5204/intjfyhe.v5i1.193

Le Ha, P., \& Barnawi, O. Z. (2015). Where english, neoliberalism, desire and internationalization are alive and kicking: Higher education in saudi arabia today. Language and Education, 29(6), 545-565. doi:10.1080/09500782.2015.1059436

Lindstrom Johnson, S. R. (2009). Using concept mapping to structure students' views of the school environment's contribution to school violence: Providing suggestions for school environment intervention. Retrieved from http://search.proquest.com/docview/304914411 ?accountid=2837

Linton, R. (1989). Conceptualizing feminism: Clarifying social science concepts.

Long, D. (2012). Theories and models of student development.

Loza, P. P. (2003). A system at risk: College outreach programs and the educational neglect of underachieving Latino high school students. Urban Review, 35, 43-57.

Ludwig, S. R. (1996). Abused women's experience with the justice system: Concept mapping. Retrieved from http://search.proquest.com/docview/193484835?accountid=2837

Lunenburg, F. C. (2012). Organizational structure: Mintzberg's framework. International journal of scholarly, academic, intellectual diversity, 14(1), 1-8.

MacGregor, J., \& Leigh Smith, B. (2005). Where are learning communities now? National leaders take stock. About Campus, 10(2), 2-8. 
Mahmood, A. (2010, March, 30). Preparatory year's students' problems in some of saudi universities [powerpoint]. The fourth periodic meeting for academic affairs deputy of Saudi universities. Riyadh: King Saud University.

Malawi, A. (2010, March, 30). Preparatory year system at the university of the northern border between reality and expectations. The fourth periodic meeting for academic affairs deputy of saudi universities. Riyadh: King Saud University.

Marifh, F. (2013, June, 29). The preparatory year: Proposals and solutions. Al-Riyadh Newspaper, 16441. Riyadh, Saudi Arabia: Alyamama Press Est (In Arabic). .

Marina, B., \& McGuire, M. (2008). First-year-experience: Reform in college freshmen programs for first year students. Educational Planning, 17(3), 19-27.

Mayhew, M. J., Vanderlinden, K., \& Kim, E. K. (2010). A multi-level assessment of the impact of orientation programs on student learning. Research in Higher Education, $51(4), 320-345$.

McCubbin, I. (2003). An examination of criticisms made of Tinto's 1975 student integration model of attrition. Retrieved July 2, 2008.

Menkhoff, T., Evers, H. D., \& Wah, C. Y. (Eds.). (2011). Beyond the knowledge trap: Developing asia's knowledge-based economies. World Scientific.

Mertes, S. (2013). Exploring the construct of social integration in a community college environment. University of Nebraska - Lincoln.

Messman-Mandicott, E. M. (2012). The use of concept mapping/pattern matching to determine the content domain for information literacy in baccalaureate education. West Virginia University Libraries.

Michalski, G. V. (1999). Stakeholder variation in perceptions about training program evaluation. Retrieved from http://search.proquest.com/docview/304565041 accountid=2837

Michalski, G. V., \& Cousins, J. B. (2000). Differences in stakeholder perceptions about training evaluation: A concept mapping/pattern matching investigation. Evaluation and Program Planning, 23(2), 211-230.

Miller, C. E. (2011). Choosing foundations of excellence: Three profiles in institutional change and first-year student success. University of Georgia.

Ministry of Higher Education, Kingdom of Saudi Arabia. (2014). The king abdullah scholarship program. Retrieved December 1, 2014, from http://www.mohe.gov.sa 
Ministry, H. E. (2015, January, 28). Higher education news. Retrieved 4 22, 2015, from Selfoperating of preparatory year is a priority for Saudi universities: http://he.moe.gov.sa/ar/news/Pages/28-01-2015.aspx

Moir, J. (2010). Graduate attributes and the knowledge society: Developments in scottish higher education. In SGIR 7th Pan-European Conference 2010, Politics in Hard Times: International Relations Responses to the Financial Crisis. ECPR-Standing Group on international relations.

Moon, B., Hoffman, R. R., Novak, J., \& Canas, A. (Eds.). (2011). Applied concept mapping: Capturing, analyzing, and organizing knowledge. CRC Press.

Moon, S., Sullivan, E., Hershey, J., Walker, S., Bosangue, M., Filowitz, M., Fernandez, Unnikrishnan \& Delgado, V. (2013). High-impact educational practices as promoting student retention and success.

Mullendore, R., \& Banahan, L. (2005). Designing orientation programs. In M. L. Upcraft, J. N. Gardner, \& B. O. Barefoot (Eds), Challenging and supporting the first-year student: A handbook for improving the first-year of college, 391-409. San Francisco: Jossey-Bass.

Mutch, C., (2005). The transition from high school to university: An analysis of advice for students, faculty and administration. 名古屋高等教育研究第 5 号, pp. 143-66.

Nelson, K. J., Creagh, T., Kift, S. M., \& Clarke, J. A. (2014). Transition pedagogy handbook: A good practice guide for policy and practice in the first year experience at QUT.

Newcomb, T. M. (1979). Four critical years: Effects of college on beliefs, attitudes, and knowledge. The American Association for Higher Education, the Ohio State University Press.

Newton, F. B. (2000). The new student. About Campus, 5(5), 8-15.

Noel, L., Levitz, R., \& Saluri, D. (1985). Increasing student retention: Effective programs and practices for reducing the dropout rate. San Francisco, CA: Jossey- Bass.

Norwani, N. M. (2005). Learning outcomes at higher learning institutions: Do institutional environments matter?. Forum of the Australasian Association for Institutional Research, Australia.

Novak, J. D., \& Cañas, A. J. (2006). The origins of the concept mapping tool and the continuing evolution of the tool. Information Visualization, 5(3), 175-184. 
Novak, J. D., \& Cañas, A. J. (2008). The theory underlying concept maps and how to construct and use them. Florida Institute for Human and Machine Cognition Pensacola, 284, 16.

Nutt, D., \& Calderon, D. (2009). The First-year experience: An international perspective. University of South Carolina/University of Teeside: National Resource Centre.

Oates, K. K., \& Leavitt, L. H. (2003). Service-learning and learning communities: Tools for integration and assessment. Association of American Colleges and Universities. Washington, DC 20009-1604.

Okasha, M. A., \& Hamdi, S. A. (2014). Using strategic writing techniques for promoting efl writing skills and attitudes. Journal of Language Teaching \& Research, 5(3), 674681. doi:10.4304/jltr.5.3.674-681

Onsman, A. (2010). Dismantling the perceived barriers to the implementation of national higher education accreditation guidelines in the kingdom of saudi arabia. Journal of Higher Education Policy \& Management, 32(5), 511-519.

doi:10.1080/1360080X.2010.511123

Orsi, R. (2011). Using concept mapping as tool for program theory development. Retrieved from http://search.proquest.com/docview/889091487?accountid=2837

Palinkas, L. A., Horwitz, S. M., Green, C. A., Wisdom, J. P., Duan, N., \& Hoagwood, K. (2015). Purposeful sampling for qualitative data collection and analysis in mixed method implementation research. Administration and Policy in Mental Health and Mental Health Services Research, 42(5), 533-544.

Pascarella, E. T. (1985). College environmental influences on learning and cognitive development: A critical review and synthesis. Higher education: Handbook of theory and research, 1(1), 1-61.

Pascarella, E. T. (2006). How college affects students: Ten directions for future research. Journal of College Student Development, 47(5), 508-520.

Pascarella, E. T., \& Chapman, D. W. (1983). Validation of a theoretical model of college withdrawal: Interaction effects in a multi-institutional sample. Research in Higher Education, 19(1), 25-48. doi:10.1007/BF00977337

Pascarella, E. T., \& Terenzini, P. T. (1991). How college affects students: Findings and insights from twenty years of research. San Francisco: Jossey-Bass Publishers.

Pascarella, E. T., \& Terenzini, P. T. (1997). Studying college students in the 21 st century: Meeting new challenges. The Review of Higher Education, 21(2), 151-165. 
Pascarella, E. T., \& Terenzini, P. T. (2005). How college affects students: A third decade of research. San Francisco: Jossey-Bass.

Pavan, A. (2013). A new perspective on the quest for education: The saudi arabian way to knowledge society. Higher Education Studies, 3(6), 25-34.

Pavan, A. (2014). The new saudi educational renaissance: In between the "capacity to aspire" and the "capacity to remember". Higher Education Studies, 4(5), p37.

Perrine, R. (2001). College stress and persistence as a function of attachment and support. Journal of the First-Year Experience \& Students in Transition, 13(1), 7-22.

Peters, M. A. (2007). Knowledge economy, development and the future of higher education. Rotterdam: Sense Publishers.

Peterson, M. W. (2007). The study of colleges and universities as organizations. Sociology of Higher Education. Contributions and Their Contexts, 147-188.

Pikoff-Mirwis, E. (2011). A concept mapping study of ethical alignment in professional psychology. Retrieved from http://search.proquest.com/docview/854507898?accountid=2837

Plan, M. O. (2014). KSU strategic plan 2030. Riyadh: King Saud University.

Planning, M. o. (2010). The ninth development plan. Retrieved 1 16, 2015, from http://www.mep.gov.sa/themes/GoldenCarpet/\#1429708335943

Plybon, L. E. (2001). Ethnic identity by any other name...: A longitudinal analysis of the measurement of ethnic identity in an urban African American early adolescent sample. Retrieved from http://search.proquest.com/docview/304786018?accountid=2837

Poisel, M. A., \& Joseph, S. (Eds.). (2011). Transfer students in higher education: Building foundations for policies, programs, and services that foster student success (Monograph No. 54). Columbia, SC: University of South Carolina, National Resource Center for the First-Year Experience and Students in Transition.

Preparatory Year Strategic Plan 2011-2016 (2011). Preparatory year deanship. King saud university. www.py.ksu.edu.sa

Prosser, M., \& Pitkethly, A. (2001). The first-year experience project: A model for university-wide change. Higher Education Research \& Development, 20(2), 185-198. doi:10.1080/758483470

Pryor, J. H., Hurtado, S., Saenz, V. B., Lindholm, J. A., Korn, W. S., \& Mahoney, K. M. (2005). The american freshman: National Norms for Fall 2005. Los Angeles: Higher Education Research Institute, UCLA. 
Raymond, L., \& Napoli, R. (1998). An explanation of the impact of a freshman seminar course on student academic outcomes. Journal of Applied Research in the Community College, Vol. 6, n 1, p. 27-34.

Reason, R. D. (2009). An examination of persistence research through the lens of a comprehensive conceptual framework. Journal of College Student Development, 50(6), 659-682. doi:10.1353/csd.0.0098

Rendón, L. I., Jalomo, R. E., \& Nora, A. (2000). Part II: New theoretical directions: Theoretical considerations in the study of minority student retention in higher education. In, Reworking the Student Departure Puzzle (pp. 125-156). Nashville, TN: Vanderbilt University Press.

Resalh, U. (2011, May, 21). King saud university portal. Retrieved 4 22, 2015, from university launches its strategic plan KSU 2030: http://rs.ksu.edu.sa/48796.html

Riley, R. W. (1998). It's time to “GEAR UP'” for college! Schools in the middle, 8, 39-41.

Riyadh Valley Company. (n. d.). Home. In riyadh valley company. Retrieved March 18, 2015, from http://rvc.com.sa/.

Rizzo Michelin, L.,L. (1998). Concept mapping in evaluation practice and theory: A synthesis of current empirical research. Retrieved from http://search.proquest.com/docview/304488106?accountid=2837

Rode, L, Denise \& Cawthon Tony W., (2010). Theoretical perspective on orientation. In J. A. Ward-Roof(Ed). Designing successful transitions: A guide for orienting students to college. (Monograph No. 13, $3^{\text {rd }}$ ed.). Columbia, SC: University of South Carolina, National Resource Center for The First-Year Experience and Students in Transition.

Roe Clark, M. (2005). Negotiating the freshman year: Challenges and strategies among firstyear college students. Journal of College Student Development, 46, 296-316.

Rogers, M., \& Stypka, A. (2013). A case for change: A first year experience framework at York university.

Roos, R. D. (2012). Relationship between first-year student retention, noncognitive risk factors, and student advising. Logan, Utah: Utah State University.

Rosas, S. R. (2002). Linking concept to outcome: A pattern matching approach for the evaluation of family support and parent empowerment programming. Retrieved from http://search.proquest.com/docview/304800671 accountid=2837

Rowley, J. (2000). Is higher education ready for knowledge management? The International Journal of Educational Management, Vol. 14, No. 7, pp. 325-333. 
Saleh, M. A. (1986). Development of higher education in saudi arabia. Higher Education, 15(1-2), 17-23.

Salmi, J. (2003). Constructing knowledge societies: New challenges for tertiary education. Higher Education in Europe, 28(1), 65-69. San Francisco, CA: Jossey-Bass.

Sanwidi, J. B. (2015). The use of concept mapping/pattern matching to conceptualize the desired domain of student learning in the first year of college. Retrieved from http://search.proquest.com/docview/1708653628?accountid=2837

Schlossberg, J., Waters, R., \& Goodman, P. (1995). Counseling adults in transition (2 ${ }^{\text {nd }}$ ed.). New York: Springer.

Schlossberg, N. K., \& Nicolay, R. C. (1984). Counseling adults in transition.

Schmoch, U. u., Fardoun, H., \& Mashat, A. (2016). Establishing a world-class university in Saudi Arabia: Intended and unintended effects. Scientometrics, 109(2), 1191-1207.

Schrader, P. G., \& Brown, S. W. (2008). Evaluating the first-year experience: Students' knowledge, attitudes, and behaviors. Journal of Advanced Academics, 19(2), 310-343.

Schreiner, L. A., Louis, M. C., \& Nelson, D. D. (Eds.). (2012). Thriving in transitions: A research-based approach to college student success. University of South Carolina, National Resource Center for the First-Year Experience and Students in Transition.

Schroeder, C. C. (1998). Developing collaborative partnerships that enhance student learning and educational attainment. ACPA Senior Scholars Trend Analysis Draft Essays.

Shin, J. Y. (2013). Improving first-year intervention strategies at universities by focusing on meaning and purpose in life. Colorado State University.

Skipper, T. L. (2005). Student development in the first college year: A primer for college educators. National Resource Center for the First-Year Experience and Students in Transition, University of South Carolina.

Smith, B., Gahagan, J., McQuillin, S., Haywood, B., Cole, C., Bolton, C., \& Wampler, M. (2011). The development of a service-learning program for first-year students based on the hallmarks of high quality service-learning and rigorous program evaluation. Innovative Higher Education, 36(5), 317-329. doi:10.1007/s10755-011-9177-9

Smith, L., \& Abouammoh, A. (2013). Higher education in saudi arabia: Reforms, challenges and priorities. In Higher Education in Saudi Arabia (pp. 1-12). Springer Netherlands.

Smith, L., \& Abouammoh, A. (2013). Higher education in saudi arabia: Conclusions. In Higher Education in Saudi Arabia (pp. 181-190). Springer Netherlands.

Soldner, L., Lee, Y., \& Duby, P. (1999). Welcome to the block: Developing freshman learning communities that work. Journal of College Student Retention, 1(2), 115-129. 
Sörlin, S., \& Vessuri, H. (2007). Knowledge society vs. knowledge economy: Knowledge, power, and politics.

Sperber, A. D., Devellis, R. F., \& Boehlecke, B. (1994). Cross-cultural translation methodology and validation. Journal of cross-cultural psychology, 25(4), 501-524.

Squires, A., Aiken, L. H., van den Heede, K., Sermeus, W., Bruyneel, L., Lindqvist, R., ... \& Ensio, A. (2013). A systematic survey instrument translation process for multicountry, comparative health workforce studies. International journal of nursing studies, 50(2), 264-273.

Stanford, N. (2007). Guide to organization design: Creating high-performing and adaptable enterprises. London: Profile Books Ltd.

Stehr, N. (1994). Knowledge societies. London: Sage.

Stevens, C. P. (2002). Evaluating the effectiveness of concept mapping as a strategy for developing a knowledge management model for an urban technical institute's digital campus. Retrieved from http://search.proquest.com/docview/305512482?accountid=2837

Stone, J. R., \& Lewis, M. V. (2012). College and career ready in the 21st century: Making high school matter. Teachers College Press.

Storey, K. L. (2010). Bridging the gap: Linking co-curricular activities to student learning outcomes in community college students.

Stovall, M. (2000). Using success courses for promoting persistence and completion. New Directions for Community Colleges, (112), 45-54.

Strauss, W., \& Howe, N. (2000). Millennials rising: The next great generation. New York: Vintage Books.

Streeter, C. L., Franklin, C., Kim, J. S., \& Tripodi, S. J. (2011). Concept mapping: An approach for evaluating a public alternative school program. Children \& Schools, 33(4), 197-214.

Stuart, G. R., Rios-Aguilar, C., \& Deil-Amen, R. (2014). How much economic value does my credential have?: Reformulating Tinto's model to study students' persistence in community colleges. Community College Review, 42(4), 327-341.

Stuart, J. M. (2002). Client perceptions of emotional experience in counselling. Retrieved from http://search.proquest.com/docview/305472405?accountid=2837 
Studdert, T. P. (2013). The development of a comprehensive first-year experience program for the university of southern California: Using an innovation gap analysis model. University of Southern California.

Student Success: The newsletter for higher education professionals, November (2007).

Suciu, M. C., Drăgulănescu, I. V., Ghiţiu-Brătescu, A., Picioruş, L., Imbrişcă, C., Şerbu, V. M., \& Grigore, C. (2011). Universities role in knowledge-based economy and society: Implications for romanian economics higher education. The Economic Amphitheater, 13, 420-437.

Sutherland, S., \& Katz, S. (2005). Concept mapping methodology: A catalyst for organizational learning. Evaluation and Program Planning, 28(3), 257-269.

Swail, W. S. (2000). Preparing america's disadvantaged for college: Programs that increase college opportunity. New Directions for Institutional Research, 107, 85-101.

Swing, R.L. \& Alexander-Hamilton, J.H. (2010). University colleges: Flexible structures for serving undergraduate students. In S. E. Evenbeck, B. Jackson, M. Smith, D. Ward, \& Associates, Organizing for student success: The university college model (Monograph No. 53, pp. 1-23). Columbia, SC: University of South Carolina, National Resource Center for the First-Year Experience \& Students in Transition.

Tabuk, U. (2010, March 31). The application mechanism of preparatory year: Tabuk university model. The fourth periodic meeting for academic affairs deputy of Saudi universities. Riyadh: King Saud University.

Talafha, F. (2015). A reciprocal model of psychographic attributes related to their learning among preparatory year of undergraduate students in west of saudi arabia. International Education Studies, 8(2), 70-77.

Terenzini, P. T., \& Reason, R. D. (2005, November). Parsing the first-year of college: A conceptual framework for studying college impacts. In annual meeting of the association for the study of higher education, Philadelphia, PA.

Tinto, V. (1975). Dropout from higher education: A theoretical synthesis of recent research. Review of Educational Research, 45(1), 89-125. Doi: 10.3102/00346543045001089

Tinto, V. (1987). Leaving college: Rethinking the causes and cures of student attrition. Chicago, IL: University of Chicago Press.

Tinto, V. (1988). Stages of student departure: Reflections on the longitudinal character of student leaving. The Journal of Higher Education, 438-455.

Tinto, V. (1993). Leaving college: Rethinking the causes and cures of student attrition (2nd ed.). Chicago, IL: University of Chicago Press. 
Tinto, V. (1996). Reconstructing the first-year of college. Planning for higher education, 25(1), 1-6.

Tinto, V. (2000). Linking learning and leaving: Exploring the role of the college classroom in student departure. In J. M. Braxton (Ed.), Reworking the student departure puzzle (81-94). Nashville, TN: Vanderbilt University Press.

Tinto, V. (2002). Establishing conditions for student success: Lessons learned in the United States. Under-Privileged but Not Under-Achieving.

Tinto, V. (2006). Research and practice of student retention: what next?. Journal of College Student Retention: Research, Theory and Practice, 8(1), 1-19.

Tinto, V. (2006). The assessment of student retention programs. Faculty Convocation at Maricopa College, Phoenix, AZ. Retrieved September, 22, 2009.

Tinto, V. (2007). Taking student retention seriously. Syracuse University.

Tinto, V. (2010). From theory to action: Exploring the institutional conditions for student retention. In Smart, J. C. (2010). Higher education: Handbook of theory and research (pp. 51-89). Springer Netherlands.

Tinto, V. (July 01, 1988). Stages of student departure: Reflections on the longitudinal character of student leaving. Journal of Higher Education, 59, 4, 438-55.

Tinto, V., \& Pusser, B. (2006). Moving from theory to action: Building a model of institutional action for student success. National Postsecondary Education Cooperative, 1-51.

Torres, V., \& LePeau, L. (2013). Making the connection: The use of student development theory in first-year and transition programs. Journal of the First-Year Experience \& Students in Transition, 25(2), 13-26.

Transition (n. d.). In S. Abbott (Ed.), the glossary of education reform. Retrieved March 17, 2015, from http://edglossary.org/transition/

Trilling, B. (2007). Toward learning societies and the global challenges for learning with ICT. Australian Educational Computing, 22(1), 10-16.

Trochim, W. M. (1989). Concept mapping: Soft science or hard art?. Evaluation and program planning, 12(1), 87-110.

Trochim, W. M. K. (1985). Pattern matching, validity, and conceptualization in program evaluation. Evaluation Review, 9(5), 575-604. doi:10.1177/0193841X8500900503

Trochim, W. M. K. (1989). Concept mapping. evaluation and program planning, 12(1), 87110. doi:10.1016/0149-7189(89)90027-X 
Trochim, W. M. K. (1989a). Concept mapping: Soft science or hard art? Evaluation and Program Planning, 12(1), 87-110. Retrieved from http://www.socialresearchmethods.net/research/epp2/epp2.htm

Trochim, W. M. K. (1989b). An introduction to concept mapping for planning and evaluation. Evaluation and Program Planning, 12(1), 1-16. doi:10.1016/01497189(89)90016-5

Troxel, W. G., \& Cuttright, M. (Eds.). (2008). Exploring the evidence: initiatives in the first college year (Monograph No. 49). Columbia, SC: University of South Carolina, National Resource Center for the First-Year Experience and Students in Transition.

University of Dammam. (n. d.). Conference themes. In First national conference for preparatory year in Saudi Arabia. Retrieved January 20, 2015, from http://prep1 sa.uod.edu.sa/common/article.aspx?articleId=2.

Upcraft M. Lee. (2005). Assessing the first-year of college. In M. L. Upcraft, J. N. Gardner, \& B. O. Barefoot (Eds), Challenging and supporting the first-year student: A handbook for improving the first-year of college, 469-485. San Francisco: JosseyBass.

Upcraft, M. L., \& Gardner, J. N. (1989). A comprehensive approach to enhancing freshman success. In M. L. Upcraft \& J. N. Gardner (Eds.), the freshman year experience (pp. 1-12). San Francisco, CA: Jossey-Bass.

Upcraft, M. L., \& Gardner, J. N. (1989). The freshman year experience: Helping students survive and succeed in college. San Francisco, Calif: Jossey-Bass Publishers.

Upcraft, M. L., Gardner, J. N., \& Barefoot, B. O. (2004). Meeting challenges and building support: Creating campus climates for first-year student success. San Francisco: Jossey-Bass.

Upcraft, M. L., Gardner, J. N., \& Barefoot, B. O. (2005). Challenging and supporting the first-year student: A handbook for improving the first-year of college. San Francisco: Jossey-Bass.

Välimaa, J., \& Hoffman, D. (2008). Knowledge society discourse and higher education. Higher Education, 56(3), 265-285.

van Weert, T. (2005). Lifelong learning in the knowledge society. In Education and the Knowledge Society (pp. 15-25). Springer US.

van Weert, T. J. (Ed.). (2004). Education and the knowledge society: Information technology supporting human development. Springer Science \& Business Media (Vol. 161). 
Varela-Petito, G. (2012). System and Policy in the Planning of Higher Education in Mexico. Creative Education, 3(06), 980.

Vaughan, A., Parra, J., \& Lalonde, T. (2014). First-generation college student achievement and the first-year seminar: A quasi-experimental design. Journal of the First-Year Experience \& Students in Transition, 26(2), 51-67.

Walker, A. (2003). Learning communities and their effect on students' cognitive abilities. Journal of the First-Year Experience \& Students in Transition, 15(2), 11-33.

Ward-Roof, J. A. (2010). Designing successful transitions: A guide for orienting students to college. (Monograph No. 13, $3^{\text {rd }}$ ed.). Columbia, SC: University of South Carolina, National Resource Center for the First-Year Experience and Students in Transition.

Watt, K. M., Huerta, J., \& Lozano, A. (2007). A comparison study of AVID and GEAR UP 10th grade students in two high schools in the Rio Grande Valley of Texas. Journal of Education for Students Placed at Risk, 12, 185-212.

Watts, W. (n. d.). The power of words: A guide to the latest terminology in student affairs.

Weber, L. E., \& Duderstadt, J. J. (2006). Universities and business: Partnering for the knowledge society. London: Economica.

White, J., \& Weathersby, R. (2005). Can universities become true learning organizations? The Learning Organization: An International Journal, 12(3), 292-298.

William M. K. Trochim, Cook, J. A., \& Setze, R. J. (1994). Using concept mapping to develop a conceptual framework of staff's views of a supported employment program for individuals with severe mental illness. Journal of Consulting and Clinical Psychology, 62(4), 766. doi:10.1037/0022-006X.62.4.766.

Wilson, M. E., \& Association for the Study of Higher Education. (2011). College student development theory. Boston, MA: Pearson Learning Solutions.

Winit-Watjana, W., Baraka, M. A., Mostafa, A., \& Aljaizani, R. A. (2015). Assessment of motivation, learning styles and programme selections of Saudi pharmacy and nonpharmacy candidates during the preparatory year. Pharmacy Education: An International Journal of Pharmaceutical Education, 15(1), 281-289.

Wisner, B. L. (2008). The impact of meditation as a cognitive-behavioral practice for alternative high school students. Retrieved from http://search.proquest.com/docview/287978623 accountid=2837

Wolf-Wendel, L., Tuttle, K., \& Keller-Wolff, C. (1999). Assessment of a freshman summer transition program in an open-admissions institution. Journal of the First-Year Experience \& Students in Transition, 11(2), 7-32. 
World Bank. (2003). Lifelong learning in the global knowledge economy: Challenges for developing countries. (World Bank e-Library.) Washington, DC: World Bank.

World Economic Forum. 2004. "Towards an Arab renaissance”. Presented at the annual meeting, 2004.

Yanto, H., Mula, J. M., \& Kavanagh, M. H. (2011, November). Developing student's accounting competencies using Astin's I-E-O model: an identification of key educational inputs based on Indonesian student perspectives. In Proceedings of the RMIT Accounting Educators' Conference, 2011: Accounting Education or Educating Accountants?. University of Southern Queensland.

Young, D. G., \& Hopp, J. M. (2014). 2012-2013 National survey of first-year seminars: Exploring high-impact practices in the first college year (Research Report No. 4). Columbia, SC: University of South Carolina, National Resource Center for the FirstYear Experience and Students in Transition.

Yushau, B., \& Omar, M. H. (2007). Preparatory year program courses as predictors of first calculus course grade. Mathematics \& Computer Education, 41(2), 92-108.

Zafft, C., Kallenbach, S., \& Spohn, J. (2006). Transitioning adults to college: Adult basic education program models. National Center for the Study of Adult Learning and Literacy, Harvard Graduate School of Education 


\section{Appendices}

\section{Appendix A: PY's Dean Permission to Conduct the Study at PYP at KSU}

\begin{tabular}{|c|c|}
\hline 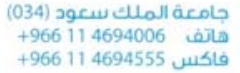 & 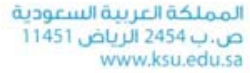 \\
\hline
\end{tabular}

\section{å $\Omega$ \\ النملك سعودة \\ King Saud University}

السنة التحضيرية

Date: July 6, 2015

West Virginia University Review Board for the Protection of Human Research (IRB)

886 Chestnut Ridge Road,

PO Box 6845 Morgantown,

WV 26506-6845

Dear Members of the West Virginia University Institutional Review Board,

The Preparatory Year Deanship at King Saud University is responsible for all aspects of students' first year experiences.

This letter is to provide support for Mr. Atiyah Alghamdi (Student ID conduct his doctoral dissertation research at the Preparatory Year Deanship as part of his $\mathrm{Ph} . \mathrm{D}$. program in the College of Education and Human Services at West Virginia University. Mr. Alghamdi is proposing to conduct a research study entitled: Using Concept Mapping/Pattern Matching to Develop a Conceptual Framework for Successful Transition of First Year Saudi Students into Postsecondary Education. The purpose of study is to identify the ideal future functions of the first year program at King Saud University.

We fully support Mr. Alghamdi's research and we assure that the research will not affect the cultural mores of participants. Furthermore we believe the outcome of the study will be highly valuable to the Preparatory Year.

For further information please do not hesitate to contact me via email at dean@py.ksu.edu.sa or call office number +966114694000 or mobile +966506544275
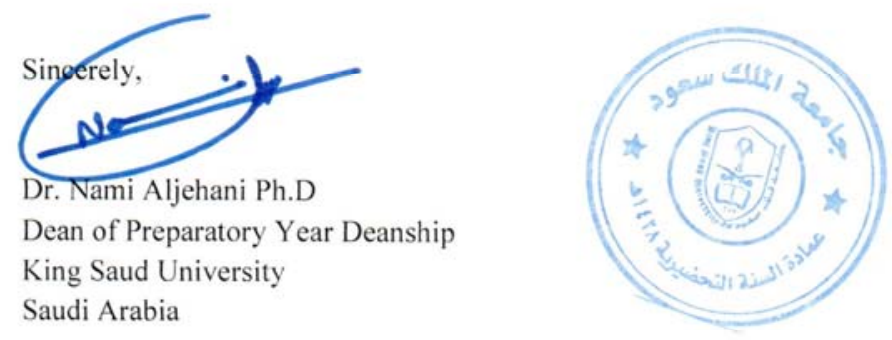
Appendix B: List of 48 Outcomes Formatted for the Importance and Efficacy Rating

\section{Using Qualtrics for Male Group}

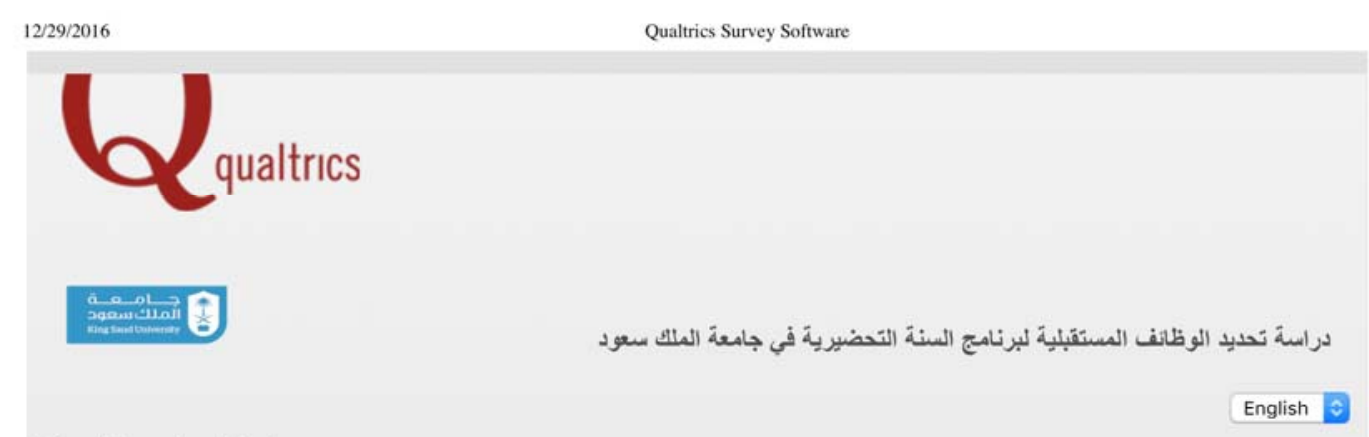

Default Question Block

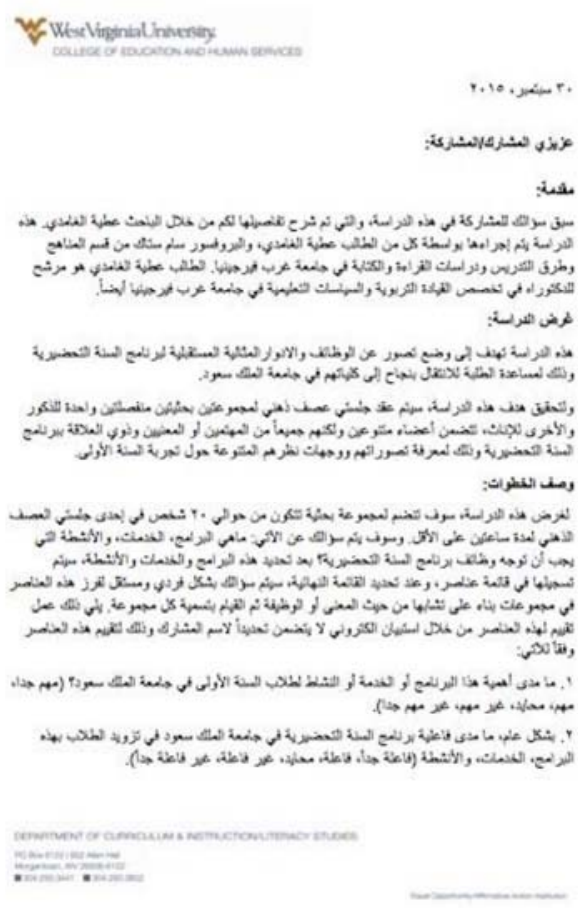




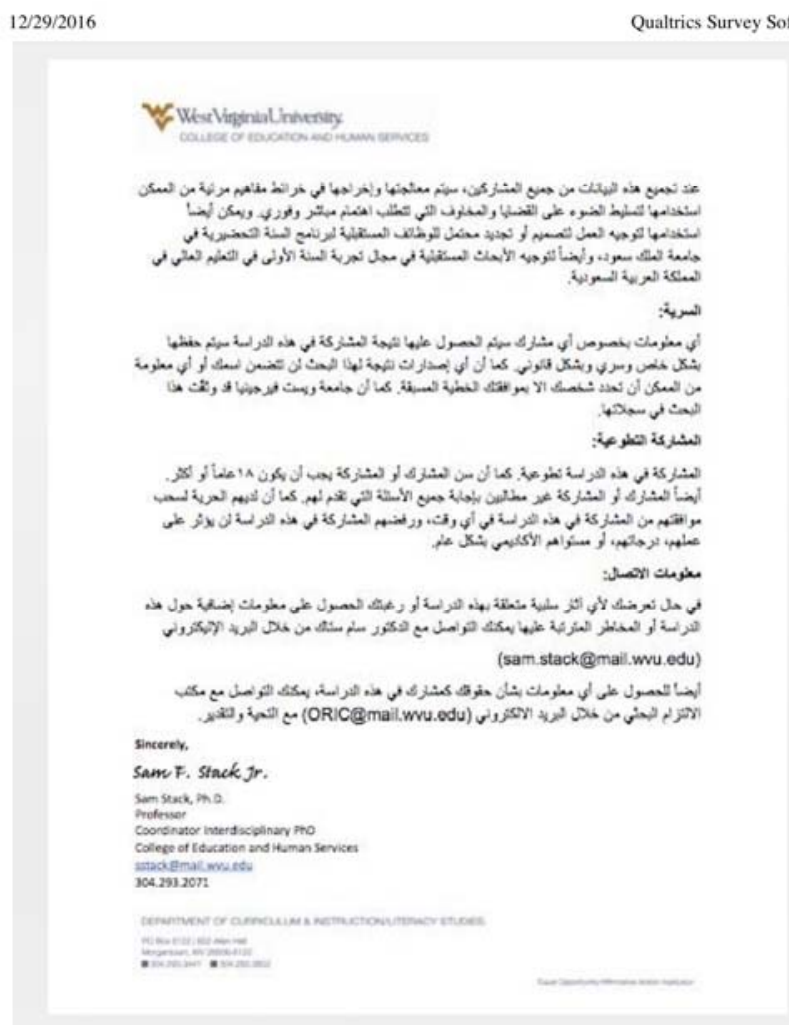

Q1. How important is this program, service or activity for first year students at King Saud University?

\begin{tabular}{|c|c|c|c|c|c|}
\hline & $\begin{array}{c}\text { Very } \\
\text { Important }\end{array}$ & Important & Neutral & Unimportant & $\begin{array}{c}\text { Very } \\
\text { Unimportant }\end{array}$ \\
\hline $\begin{array}{l}\text { Enable students fulfilling certain criteria to } \\
\text { enroll in major-specific courses }\end{array}$ & 0 & 0 & 0 & 0 & 0 \\
\hline $\begin{array}{l}\text { Availability of accelerated tracks in the } \\
\text { Preparatory Year. }\end{array}$ & 0 & 0 & 0 & 0 & 0 \\
\hline $\begin{array}{l}\text { Reformulating and defining the preparatory } \\
\text { year's objectives. }\end{array}$ & 0 & 0 & 0 & 0 & 0 \\
\hline $\begin{array}{l}\text { Revising the student assessment mechanisms } \\
\text { (students acceleration - upgrade) during the } \\
\text { program for all courses. }\end{array}$ & 0 & 0 & 0 & 0 & 0 \\
\hline $\begin{array}{l}\text { Merging some of PY's similar courses after } \\
\text { reviewing their syllabi. }\end{array}$ & 0 & 0 & 0 & 0 & 0 \\
\hline Developing note taking skills during the lecture. & 0 & 0 & 0 & 0 & 0 \\
\hline $\begin{array}{l}\text { Teaching students the basics of professional } \\
\text { ethics and linking them to Islamic values. }\end{array}$ & 0 & 0 & 0 & 0 & 0 \\
\hline $\begin{array}{l}\text { Educating students about the university } \\
\text { regulations and their rights. }\end{array}$ & 0 & 0 & 0 & 0 & 0 \\
\hline
\end{tabular}




\begin{tabular}{|c|c|c|c|c|c|}
\hline \multirow[t]{2}{*}{$12 / 29 / 2016$} & \multicolumn{5}{|c|}{ Qualtrics Survey Software } \\
\hline & $\begin{array}{l}\text { Very } \\
\text { Important }\end{array}$ & Important & Neutral & Unimportant & $\begin{array}{c}\text { Very } \\
\text { Unimportan }\end{array}$ \\
\hline $\begin{array}{l}\text { Introducing the university's facilities and } \\
\text { services for students to take its advantage } \\
\text { (orientation program). }\end{array}$ & O & 0 & 0 & O & O \\
\hline $\begin{array}{l}\text { Educating students about libraries and } \\
\text { scientific research containers. }\end{array}$ & & 0 & & & 0 \\
\hline $\begin{array}{l}\text { Include preparatory year's courses activities } \\
\text { that promote and motivate students' learning. }\end{array}$ & & & & O & O \\
\hline $\begin{array}{l}\text { Include activities and guidance programs to } \\
\text { help students make a decision about their } \\
\text { majors. }\end{array}$ & & & & O & O \\
\hline $\begin{array}{l}\text { Educating students about majors' } \\
\text { requirements. }\end{array}$ & & & & $\mathrm{O}$ & O \\
\hline $\begin{array}{l}\text { Involving all preparatory year beneficiaries in } \\
\text { development of its plan. }\end{array}$ & & & & O & O \\
\hline $\begin{array}{l}\text { Developing workshops for high school students } \\
\text { to identify and address the weaknesses of the } \\
\text { them through the preparatory year. }\end{array}$ & & & & & 0 \\
\hline $\begin{array}{l}\text { Hiring faculty members from colleges who have } \\
\text { experience in teaching first-year university } \\
\text { students. }\end{array}$ & & & & & O \\
\hline $\begin{array}{l}\text { Reconsidering the students' timetables and } \\
\text { credit hours. }\end{array}$ & & & & & 0 \\
\hline $\begin{array}{l}\text { Review the medical track courses plan ( the } \\
\text { study plan). }\end{array}$ & & & & & O \\
\hline $\begin{array}{l}\text { Reducing or revising courses content or } \\
\text { eliminating some of them. }\end{array}$ & & & & & 0 \\
\hline $\begin{array}{l}\text { Provide extra training hours do not conflict with } \\
\text { the current hours of study. }\end{array}$ & & & & & $\mathrm{O}$ \\
\hline $\begin{array}{l}\text { Revise on the philosophy of the preparatory } \\
\text { year and its purpose. }\end{array}$ & & $\cap$ & & & O \\
\hline Developing the skills of responsible autonomy. & O & $\mathrm{O}$ & $\mathrm{O}$ & O & O \\
\hline $\begin{array}{l}\text { Provide services needed by students through } \\
\text { workshops and by cooperation between } \\
\text { colleges and Preparatory Year deanship. }\end{array}$ & & & & & O \\
\hline $\begin{array}{l}\text { Conduct activities to encourage students to } \\
\text { participate in community service. }\end{array}$ & & C & & & O \\
\hline $\begin{array}{l}\text { Coordination with beneficiary colleges to } \\
\text { choose knowledge and skills that serve its } \\
\text { majors. }\end{array}$ & & & & & \\
\hline The PY is not an academic placement program. & O & $\mathrm{O}$ & O & O & 0 \\
\hline $\begin{array}{l}\text { Include activities into the preparatory year } \\
\text { program that are not offered by other colleges } \\
\text { (Do not provide extracurricular activities that } \\
\text { will offer after preparatory year in colleges). }\end{array}$ & & D & & & 0 \\
\hline Overwhelm, campus on-going activities. & 0 & O & & O & O \\
\hline $\begin{array}{l}\text { Implementation of the preparatory year program } \\
\text { within colleges' programs in accordance with } \\
\text { major selection. }\end{array}$ & & O & & & O \\
\hline $\begin{array}{l}\text { Provide counseling services for high school } \\
\text { students before the preparatory year. }\end{array}$ & & & & & O \\
\hline $\begin{array}{l}\text { Ongoing review for the preparatory year } \\
\text { curriculum. }\end{array}$ & & O & & O & O \\
\hline
\end{tabular}




\begin{tabular}{|c|c|c|c|c|c|}
\hline \multicolumn{6}{|c|}{ Qualtrics Survey Software } \\
\hline & $\begin{array}{l}\text { Very } \\
\text { Important }\end{array}$ & Important & Neutral & Unimportant & $\begin{array}{c}\text { Very } \\
\text { Unimportant }\end{array}$ \\
\hline Develop students' assessment instruments. & O & O & O & O & \\
\hline $\begin{array}{l}\text { Review the performance of faculty members in } \\
\text { the preparatory year. }\end{array}$ & & & & $\mathrm{O}$ & \\
\hline $\begin{array}{l}\text { Develop the preparatory year self-operation } \\
\text { mechanisms and phasing out commerical } \\
\text { assistance. }\end{array}$ & & & O & & \\
\hline $\begin{array}{l}\text { Attention to the critical thinking skills and } \\
\text { creativity. }\end{array}$ & & & & & \\
\hline $\begin{array}{l}\text { Students rehabilitation for subsequent } \\
\text { university study. }\end{array}$ & & & & & \\
\hline $\begin{array}{l}\text { Set clear and specific options in advance for } \\
\text { students who did not pass the preparatory year. }\end{array}$ & & & & C & \\
\hline $\begin{array}{l}\text { Granting a certificate for students who pass the } \\
\text { preparatory year program. }\end{array}$ & & & & & \\
\hline $\begin{array}{l}\text { Develop programs to address students dropout } \\
\text { in the preparatory year or beyond. }\end{array}$ & & & & & \\
\hline $\begin{array}{l}\text { Develop Preparatory Year to become a package } \\
\text { of educational programs and skills, and then } \\
\text { colleges and departments dictate the programs } \\
\text { that required for students. }\end{array}$ & & & & & \\
\hline $\begin{array}{l}\text { Assess student's Knowledge and skills before } \\
\text { and after the preparatory year program. }\end{array}$ & & & & C & \\
\hline $\begin{array}{l}\text { Develop and improve the educational halls and } \\
\text { learning environment. }\end{array}$ & & & & C & \\
\hline $\begin{array}{l}\text { Include gifted programs within the preparatory } \\
\text { year program to discover and take care of them. }\end{array}$ & & & & & \\
\hline $\begin{array}{l}\text { Assigning students to visit their future colleges } \\
\text { in coordination with colleges to learn about the } \\
\text { majors closely. }\end{array}$ & & & & & \\
\hline $\begin{array}{l}\text { Introduce the preparatory year program as a } \\
\text { university program that makes students take } \\
\text { the responsibility and self-reliant. }\end{array}$ & & & O & C & \\
\hline $\begin{array}{l}\text { Develop a partnership work with charitable and } \\
\text { voluntary organizations to attend and } \\
\text { representation in the preparatory year. }\end{array}$ & & & & $\mathrm{O}$ & \\
\hline $\begin{array}{l}\text { Develop a strengthening program according to } \\
\text { students' needs. }\end{array}$ & & & C & & \\
\hline Intensification of the English language program. & & & O & $\mathrm{O}$ & \\
\hline \multicolumn{6}{|c|}{$\begin{array}{l}\text { Q2. Overall, how effectively does King Saud University's Preparatory Year Program facilitate this program, service } \\
\text { or activity? }\end{array}$} \\
\hline & $\begin{array}{l}\text { Very } \\
\text { Effective }\end{array}$ & Effective & Neutral & Ineffective & $\begin{array}{c}\text { Very } \\
\text { Ineffective }\end{array}$ \\
\hline $\begin{array}{l}\text { Enable students fulfilling certain criteria to enroll } \\
\text { in major-specific courses }\end{array}$ & & & & & $\mathrm{O}$ \\
\hline $\begin{array}{l}\text { Availability of accelerated tracks in the } \\
\text { Preparatory Year. }\end{array}$ & & & & & \\
\hline $\begin{array}{l}\text { Reformulating and defining the preparatory year's } \\
\text { objectives. }\end{array}$ & & & & & \\
\hline
\end{tabular}




\begin{tabular}{|c|c|c|c|c|c|}
\hline \multirow[t]{2}{*}{ /29/2016 } & \multicolumn{5}{|c|}{ Qualtrics Survey Software } \\
\hline & $\begin{array}{c}\text { Very } \\
\text { Effective }\end{array}$ & Effective & Neutral & Ineffective & $\begin{array}{c}\text { Very } \\
\text { Ineffective }\end{array}$ \\
\hline $\begin{array}{l}\text { Revising the student assessment mechanisms } \\
\text { (students acceleration - upgrade) during the } \\
\text { program for all courses. }\end{array}$ & 0 & 0 & 0 & O & $\mathrm{O}$ \\
\hline $\begin{array}{l}\text { Merging some of PY's similar courses after } \\
\text { reviewing their syllabi. }\end{array}$ & $\mathrm{O}$ & $\mathrm{O}$ & $\mathrm{O}$ & 0 & $\mathrm{O}$ \\
\hline Developing note taking skills during the lecture. & 0 & 0 & $\mathrm{O}$ & 0 & 0 \\
\hline $\begin{array}{l}\text { Teaching students the basics of professional } \\
\text { ethics and linking them to Islamic values. }\end{array}$ & 0 & 0 & 0 & 0 & 0 \\
\hline $\begin{array}{l}\text { Educating students about the university } \\
\text { regulations and their rights. }\end{array}$ & 0 & $\mathrm{O}$ & 0 & 0 & 0 \\
\hline $\begin{array}{l}\text { Introducing the university's facilities and services } \\
\text { for students to take its advantage (orientation } \\
\text { program). }\end{array}$ & 0 & 0 & 0 & $\mathrm{O}$ & 0 \\
\hline $\begin{array}{l}\text { Educating students about libraries and scientific } \\
\text { research containers. }\end{array}$ & $\mathrm{O}$ & $\mathrm{O}$ & 0 & 0 & $\mathrm{O}$ \\
\hline $\begin{array}{l}\text { Include preparatory year's courses activities that } \\
\text { promote and motivate students' learning. }\end{array}$ & $\mathrm{O}$ & $\mathrm{O}$ & $\mathrm{O}$ & $\mathrm{O}$ & $\mathrm{O}$ \\
\hline $\begin{array}{l}\text { Include activities and guidance programs to help } \\
\text { students make a decision about their majors. }\end{array}$ & $\mathrm{O}$ & 0 & 0 & 0 & $\mathrm{O}$ \\
\hline Educating students about majors' requirements. & $\mathrm{O}$ & $\mathrm{O}$ & 0 & 0 & 0 \\
\hline $\begin{array}{l}\text { Involving all preparatory year beneficiaries in } \\
\text { development of its plan. }\end{array}$ & 0 & 0 & 0 & 0 & 0 \\
\hline $\begin{array}{l}\text { Developing workshops for high school students } \\
\text { to identify and address the weaknesses of the } \\
\text { them through the preparatory year. }\end{array}$ & $\mathrm{O}$ & 0 & 0 & 0 & 0 \\
\hline $\begin{array}{l}\text { Hiring faculty members from colleges who have } \\
\text { experience in teaching first-year university } \\
\text { students. }\end{array}$ & $\mathrm{O}$ & 0 & $\mathrm{O}$ & 0 & $\mathrm{O}$ \\
\hline $\begin{array}{l}\text { Reconsidering the students' timetables and credit } \\
\text { hours. }\end{array}$ & 0 & 0 & 0 & O & O \\
\hline $\begin{array}{l}\text { Review the medical track courses plan ( the study } \\
\text { plan). }\end{array}$ & 0 & 0 & 0 & 0 & 0 \\
\hline $\begin{array}{l}\text { Reducing or revising courses content or } \\
\text { eliminating some of them. }\end{array}$ & 0 & 0 & 0 & 0 & 0 \\
\hline $\begin{array}{l}\text { Provide extra training hours do not conflict with } \\
\text { the current hours of study. }\end{array}$ & 0 & 0 & 0 & 0 & 0 \\
\hline $\begin{array}{l}\text { Revise on the philosophy of the preparatory year } \\
\text { and its purpose. }\end{array}$ & 0 & 0 & 0 & 0 & 0 \\
\hline Developing the skills of responsible autonomy. & 0 & 0 & $\mathrm{O}$ & 0 & $\mathrm{O}$ \\
\hline $\begin{array}{l}\text { Provide services needed by students through } \\
\text { workshops and by cooperation between colleges } \\
\text { and Preparatory Year deanship. }\end{array}$ & O & 0 & 0 & 0 & 0 \\
\hline $\begin{array}{l}\text { Conduct activities to encourage students to } \\
\text { participate in community service. }\end{array}$ & 0 & 0 & 0 & 0 & $\mathrm{O}$ \\
\hline $\begin{array}{l}\text { Coordination with beneficiary colleges to choose } \\
\text { knowledge and skills that serve its majors. }\end{array}$ & 0 & 0 & 0 & 0 & 0 \\
\hline The PY is not an academic placement program. & 0 & 0 & $\mathrm{O}$ & 0 & $\mathrm{O}$ \\
\hline $\begin{array}{l}\text { Include activities into the preparatory year } \\
\text { program that are not offered by other colleges } \\
\text { (Do not provide extracurricular activities that will } \\
\text { offer after preparatory year in colleges). }\end{array}$ & $\mathrm{O}$ & 0 & $\mathrm{O}$ & $\mathrm{O}$ & 0 \\
\hline
\end{tabular}




\begin{tabular}{|c|c|c|c|c|c|}
\hline 9/2016 & ualtrics Survey & oftware & & & \\
\hline & $\begin{array}{c}\text { Very } \\
\text { Effective }\end{array}$ & Effective & Neutral & Ineffective & $\begin{array}{l}\text { Very } \\
\text { Ineffective }\end{array}$ \\
\hline Overwhelm, campus on-going activities. & O & O & O & O & \\
\hline $\begin{array}{l}\text { Implementation of the preparatory year program } \\
\text { within colleges' programs in accordance with } \\
\text { major selection. }\end{array}$ & & & & O & \\
\hline $\begin{array}{l}\text { Provide counseling services for high school } \\
\text { students before the preparatory year. }\end{array}$ & & & & & \\
\hline $\begin{array}{l}\text { Ongoing review for the preparatory year } \\
\text { curriculum. }\end{array}$ & & & & & \\
\hline Develop students' assessment instruments. & & & & & \\
\hline $\begin{array}{l}\text { Review the performance of faculty members in } \\
\text { the preparatory year. }\end{array}$ & & & & & \\
\hline $\begin{array}{l}\text { Develop the preparatory year self-operation } \\
\text { mechanisms and phasing out commerical } \\
\text { assistance. }\end{array}$ & & & & & \\
\hline $\begin{array}{l}\text { Attention to the critical thinking skills and } \\
\text { creativity. }\end{array}$ & & & & O & \\
\hline $\begin{array}{l}\text { Students rehabilitation for subsequent university } \\
\text { study. }\end{array}$ & & & & & \\
\hline $\begin{array}{l}\text { Set clear and specific options in advance for } \\
\text { students who did not pass the preparatory year. }\end{array}$ & & & & & \\
\hline $\begin{array}{l}\text { Granting a certificate for students who pass the } \\
\text { preparatory year program. }\end{array}$ & & & & O & \\
\hline $\begin{array}{l}\text { Develop programs to address students dropout in } \\
\text { the preparatory year or beyond. }\end{array}$ & & & & & \\
\hline $\begin{array}{l}\text { Develop Preparatory Year to become a package of } \\
\text { educational programs and skills, and then } \\
\text { colleges and departments dictate the programs } \\
\text { that required for students. }\end{array}$ & & & & & \\
\hline $\begin{array}{l}\text { Assess student's Knowledge and skills before } \\
\text { and after the preparatory year program. }\end{array}$ & & & & & \\
\hline $\begin{array}{l}\text { Develop and improve the educational halls and } \\
\text { learning environment. }\end{array}$ & & & & & \\
\hline $\begin{array}{l}\text { Include gifted programs within the preparatory } \\
\text { year program to discover and take care of them. }\end{array}$ & & & & & \\
\hline $\begin{array}{l}\text { Assigning students to visit their future colleges in } \\
\text { coordination with colleges to learn about the } \\
\text { majors closely. }\end{array}$ & & & & & \\
\hline $\begin{array}{l}\text { Introduce the preparatory year program as a } \\
\text { university program that makes students take the } \\
\text { responsibility and self-reliant. }\end{array}$ & & & & & \\
\hline $\begin{array}{l}\text { Develop a partnership work with charitable and } \\
\text { voluntary organizations to attend and } \\
\text { representation in the preparatory year. }\end{array}$ & & & & & \\
\hline $\begin{array}{l}\text { Develop a strengthening program according to } \\
\text { students' needs. }\end{array}$ & & & & & \\
\hline Intensification of the English language program. & O & O & O & O & O \\
\hline Q3. & & & & & \\
\hline
\end{tabular}

https://azl .qualtrics.com/ControlPanel/Ajax.php?action=GetSurveyPrintPreview 


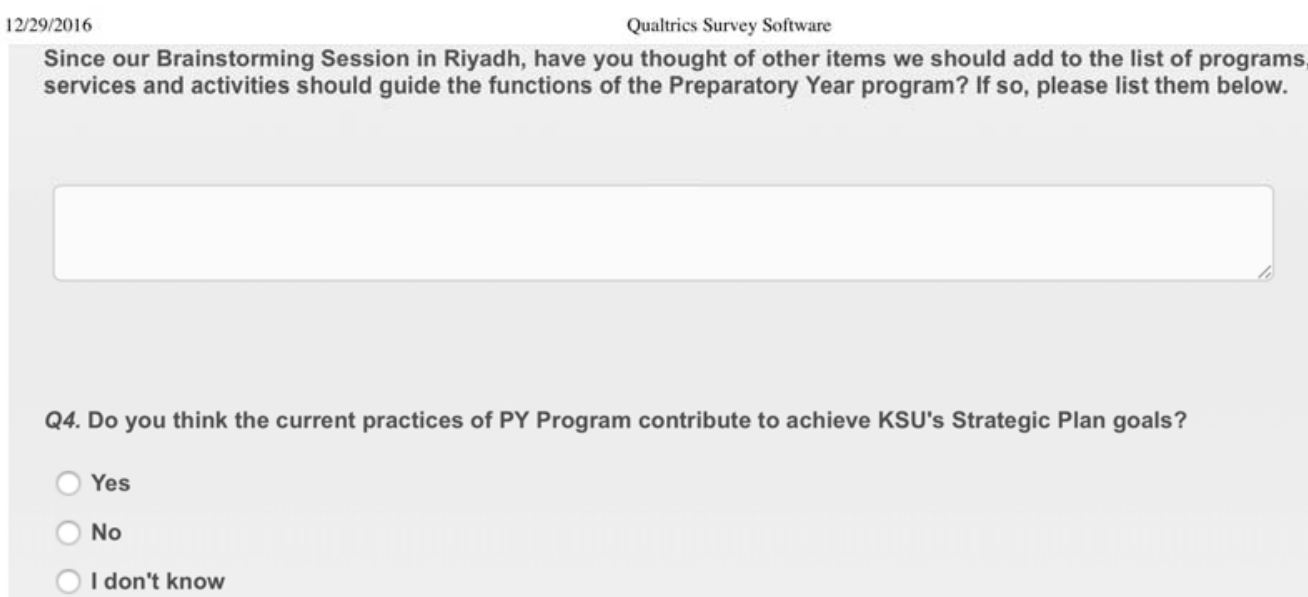


Appendix C: List of 36 Outcomes Formatted for the Importance and Efficacy Rating

\section{Using Qualtrics for Female Group}

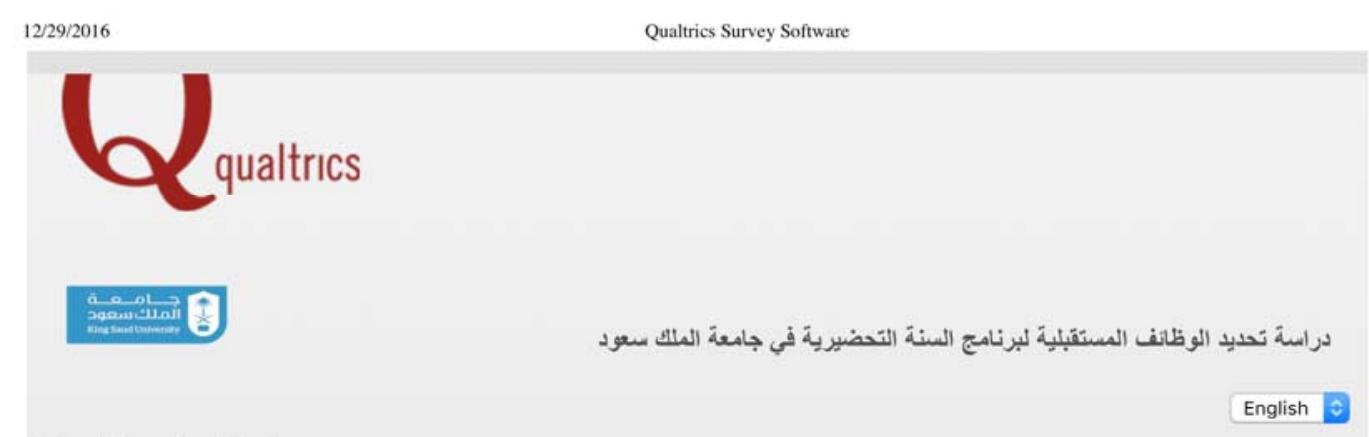

Default Question Block

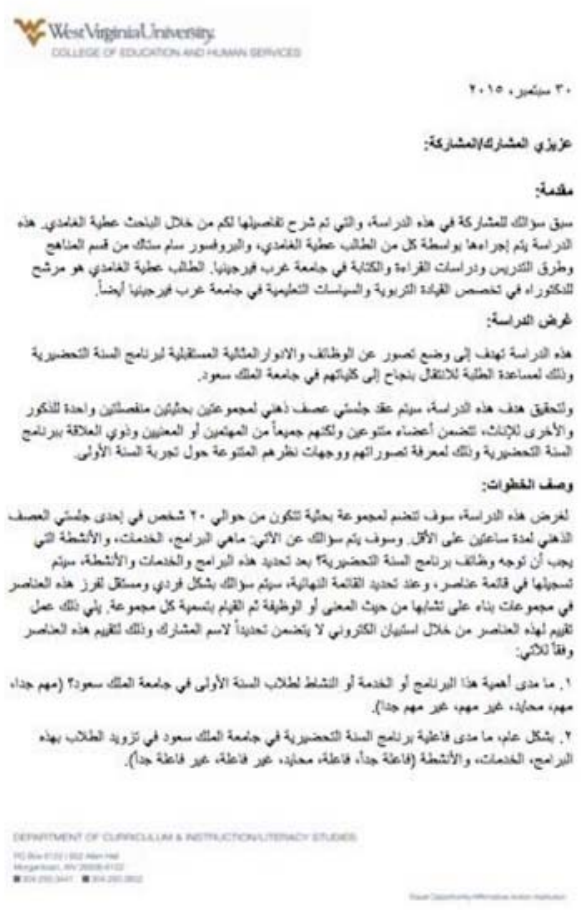




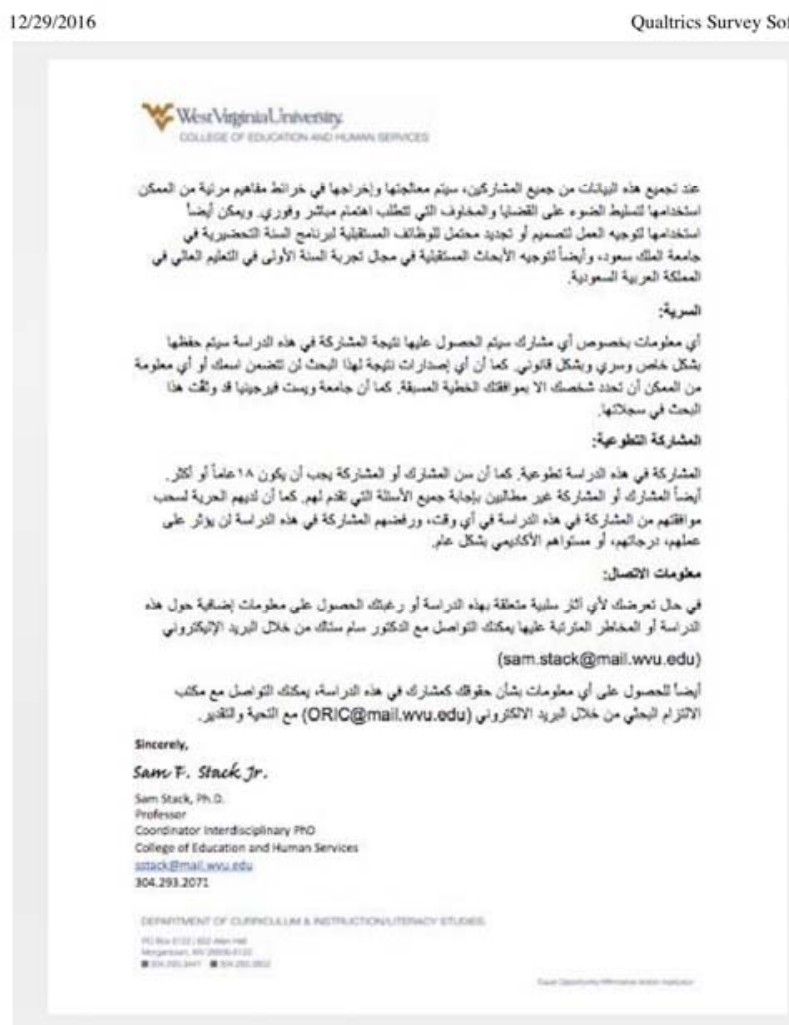

Q1. How important is this program, service or activity for first year students at King Saud University?

\begin{tabular}{|c|c|c|c|c|c|}
\hline & $\begin{array}{c}\text { Very } \\
\text { Important }\end{array}$ & Important & Neutral & Unimportant & $\begin{array}{c}\text { Very } \\
\text { Unimportant }\end{array}$ \\
\hline $\begin{array}{l}\text { Develop an instrument to measure the level of } \\
\text { the student, for example, English language } \\
\text { skills. }\end{array}$ & 0 & 0 & 0 & 0 & 0 \\
\hline $\begin{array}{l}\text { Revise the importance of some teaching } \\
\text { courses in the preparatory year, for example, } \\
\text { health and fitness course. }\end{array}$ & 0 & 0 & 0 & 0 & 0 \\
\hline $\begin{array}{l}\text { Passing the placement test of preparatory year } \\
\text { courses. }\end{array}$ & 0 & 0 & 0 & 0 & 0 \\
\hline $\begin{array}{l}\text { Reduce theoretical courses' hours that require } \\
\text { practical application such as communication } \\
\text { and computer skills. }\end{array}$ & 0 & 0 & 0 & 0 & 0 \\
\hline $\begin{array}{l}\text { Assign a stable educational entity to run the } \\
\text { courses (with low possibility of management } \\
\text { change) }\end{array}$ & 0 & 0 & 0 & 0 & 0 \\
\hline $\begin{array}{l}\text { Apply the academic placement at the beginning } \\
\text { of preparatory year. }\end{array}$ & 0 & 0 & 0 & 0 & 0 \\
\hline
\end{tabular}




\begin{tabular}{|c|c|c|c|c|c|}
\hline \multirow[t]{2}{*}{ 29/2016 } & \multicolumn{5}{|c|}{ Qualtrics Survey Software } \\
\hline & $\begin{array}{c}\text { Very } \\
\text { Important }\end{array}$ & Important & Neutral & Unimportant & $\begin{array}{c}\text { Very } \\
\text { Unimportant }\end{array}$ \\
\hline $\begin{array}{l}\text { Achieve the most benefit from preparatory year } \\
\text { by deleting the academic placement policy after } \\
\text { preparatory year. }\end{array}$ & 0 & 0 & 0 & 0 & 0 \\
\hline $\begin{array}{l}\text { Cancel some of the repetitive courses or merge } \\
\text { them into a single course, for example math } \\
\text { skills. }\end{array}$ & 0 & 0 & 0 & 0 & 0 \\
\hline $\begin{array}{l}\text { Attention should be on practical, applied, and } \\
\text { skills aspects not just a compilation of the } \\
\text { grades for academic placement. }\end{array}$ & 0 & 0 & 0 & 0 & 0 \\
\hline $\begin{array}{l}\text { The preparatory year regulation should be from } \\
\text { the vice dean of preparatory year. }\end{array}$ & 0 & 0 & 0 & 0 & 0 \\
\hline $\begin{array}{l}\text { Students can pass some of preparatory year } \\
\text { courses directly. }\end{array}$ & 0 & 0 & 0 & 0 & 0 \\
\hline $\begin{array}{l}\text { Make sure that the faculty member own the } \\
\text { necessary capability to deal with students at } \\
\text { this age. }\end{array}$ & 0 & 0 & 0 & 0 & O \\
\hline $\begin{array}{l}\text { The necessity of educating students about their } \\
\text { rights and duties. }\end{array}$ & 0 & 0 & 0 & 0 & 0 \\
\hline $\begin{array}{l}\text { The importance of the orientation program for } \\
\text { students before starting the study plan }\end{array}$ & 0 & 0 & 0 & 0 & 0 \\
\hline $\begin{array}{l}\text { All skills are important and should not just be in } \\
\text { the preparatory year. }\end{array}$ & 0 & 0 & 0 & 0 & 0 \\
\hline $\begin{array}{l}\text { Diversify of the teaching strategies to shorten } \\
\text { the time. }\end{array}$ & 0 & 0 & 0 & 0 & 0 \\
\hline $\begin{array}{l}\text { Review the preparatory year curriculums and } \\
\text { compare and contrast with the public education } \\
\text { curriculums. }\end{array}$ & 0 & 0 & 0 & 0 & 0 \\
\hline $\begin{array}{l}\text { Students academic placement to be before the } \\
\text { preparatory year. }\end{array}$ & 0 & 0 & 0 & 0 & 0 \\
\hline $\begin{array}{l}\text { Identify the academic majore since the first day } \\
\text { of study. }\end{array}$ & $\mathrm{O}$ & 0 & 0 & 0 & 0 \\
\hline $\begin{array}{l}\text { Determine the course timeline based on } \\
\text { student's need. }\end{array}$ & 0 & 0 & 0 & 0 & 0 \\
\hline $\begin{array}{l}\text { The preparatory year's GPA should not effect } \\
\text { the future college of study. }\end{array}$ & 0 & 0 & 0 & 0 & 0 \\
\hline $\begin{array}{l}\text { The inclusion of some courses for all study } \\
\text { tracks such as English. }\end{array}$ & 0 & 0 & 0 & 0 & 0 \\
\hline $\begin{array}{l}\text { Apply academic placment for all students } \\
\text { before entering the preparatory year to make } \\
\text { student's focus on academic achievement. } \\
\text { more. }\end{array}$ & 0 & 0 & 0 & 0 & 0 \\
\hline $\begin{array}{l}\text { Focus on the practical aspects that ensure } \\
\text { student will maintain skills such as English } \\
\text { language. }\end{array}$ & 0 & 0 & 0 & 0 & 0 \\
\hline $\begin{array}{l}\text { Organize an academic trip for distinct students } \\
\text { to study the English language courses in } \\
\text { international institutes. }\end{array}$ & 0 & 0 & 0 & 0 & 0 \\
\hline $\begin{array}{l}\text { Engage students in international conferences to } \\
\text { gain experience and contact with elites. }\end{array}$ & 0 & 0 & 0 & 0 & 0 \\
\hline $\begin{array}{l}\text { publish the outstanding research and media } \\
\text { produced by students. }\end{array}$ & 0 & 0 & 0 & 0 & 0 \\
\hline $\begin{array}{l}\text { Partnership with leading universities that adopt } \\
\text { outstanding students. }\end{array}$ & 0 & 0 & 0 & 0 & 0 \\
\hline
\end{tabular}




\begin{tabular}{l|l} 
12/29/2016 & $\begin{array}{c}\text { Very } \\
\text { Important Important }\end{array}$ \\
\hline $\begin{array}{l}\text { To be a preparatory program not a preparatory } \\
\text { year. }\end{array}$ \\
Implementation of self-learning more than \\
lectures. \\
Implementation of academic placement from the \\
beginning. \\
Merging some courses to gether such as \\
research skills and communication skills under \\
one course named the skills course. \\
Self-development skills can be acquired during \\
the study through workshops and courses that \\
are offered by the Deanship of Student Affairs. \\
Extra-curricular activities play important role in \\
the refinement of students' skills. \\
Integration of some skills such as speech skill \\
and scientific research during the study of \\
language. \\
Increase students awareness about university \\
laws and regulations throughout spicialist \\
department if they need advice.
\end{tabular}

Q2. Overall, how effectively does King Saud University's Preparatory Year Program facilitate this program, service or activity?

\begin{tabular}{|c|c|c|c|c|c|}
\hline & $\begin{array}{c}\text { Very } \\
\text { Effective }\end{array}$ & Effective & Neutral & Ineffective & $\begin{array}{c}\text { Very } \\
\text { Ineffective }\end{array}$ \\
\hline $\begin{array}{l}\text { Develop an instrument to measure the level of the } \\
\text { student, for example, English language skills. }\end{array}$ & 0 & 0 & 0 & 0 & 0 \\
\hline $\begin{array}{l}\text { Revise the importance of some teaching courses } \\
\text { in the preparatory year, for example, health and } \\
\text { fitness course. }\end{array}$ & 0 & 0 & 0 & 0 & 0 \\
\hline $\begin{array}{l}\text { Passing the placement test of preparatory year } \\
\text { courses. }\end{array}$ & 0 & 0 & 0 & 0 & 0 \\
\hline $\begin{array}{l}\text { Reduce theoretical courses' hours that require } \\
\text { practical application such as communication and } \\
\text { computer skills. }\end{array}$ & 0 & 0 & 0 & 0 & 0 \\
\hline $\begin{array}{l}\text { Assign a stable educational entity to run the } \\
\text { courses (with low possibility of management } \\
\text { change) }\end{array}$ & 0 & 0 & 0 & 0 & 0 \\
\hline $\begin{array}{l}\text { Apply the academic placement at the beginning of } \\
\text { preparatory year. }\end{array}$ & 0 & 0 & 0 & 0 & 0 \\
\hline $\begin{array}{l}\text { Achieve the most benefit from preparatory year } \\
\text { by deleting the academic placement policy after } \\
\text { preparatory year. }\end{array}$ & 0 & 0 & 0 & 0 & 0 \\
\hline $\begin{array}{l}\text { Cancel some of the repetitive courses or merge } \\
\text { them into a single course, for example math } \\
\text { skills. }\end{array}$ & 0 & 0 & 0 & 0 & 0 \\
\hline $\begin{array}{l}\text { Attention should be on practical, applied, and } \\
\text { skills aspects not just a compilation of the grades } \\
\text { for academic placement. }\end{array}$ & 0 & 0 & 0 & 0 & 0 \\
\hline
\end{tabular}




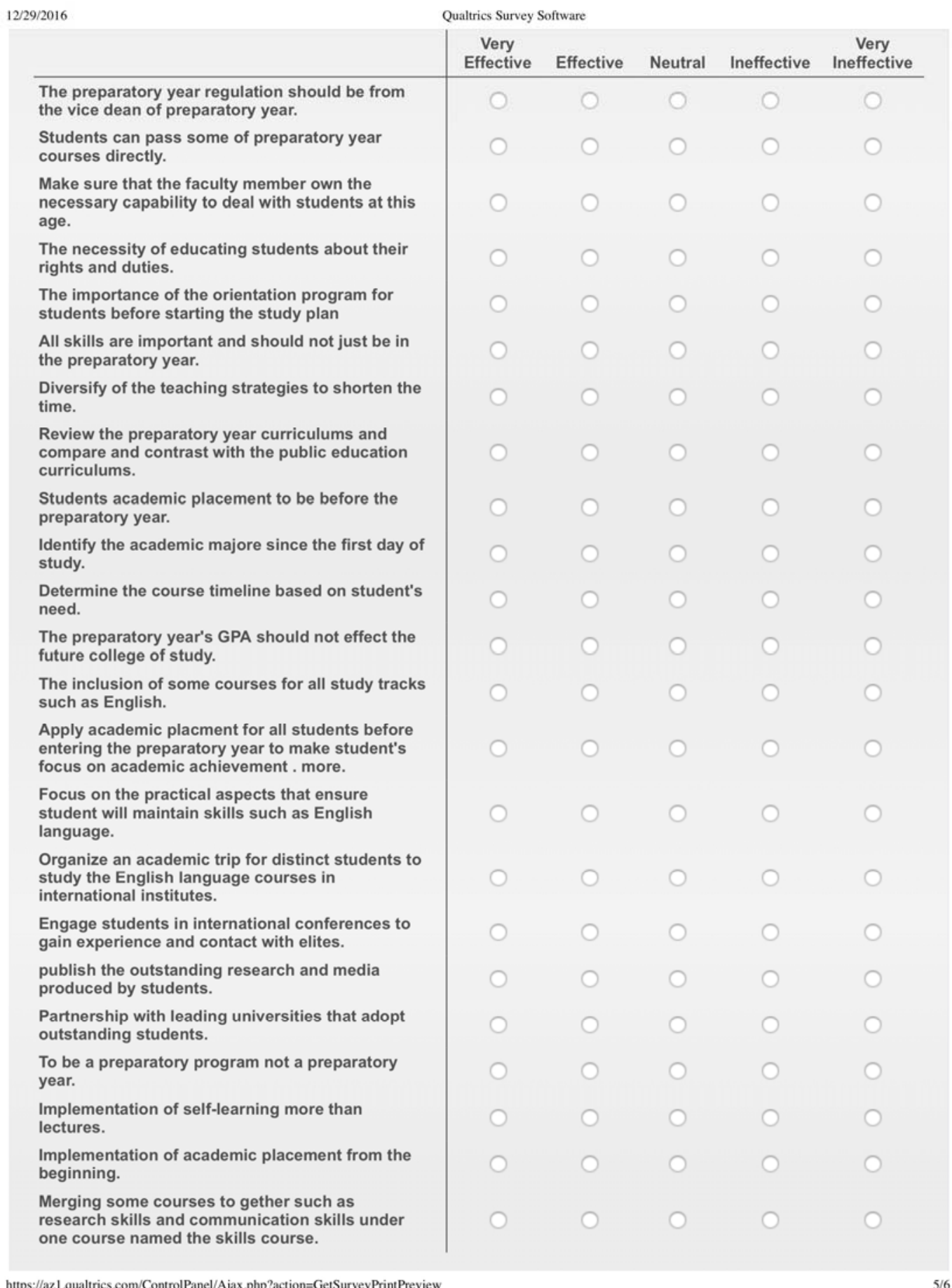




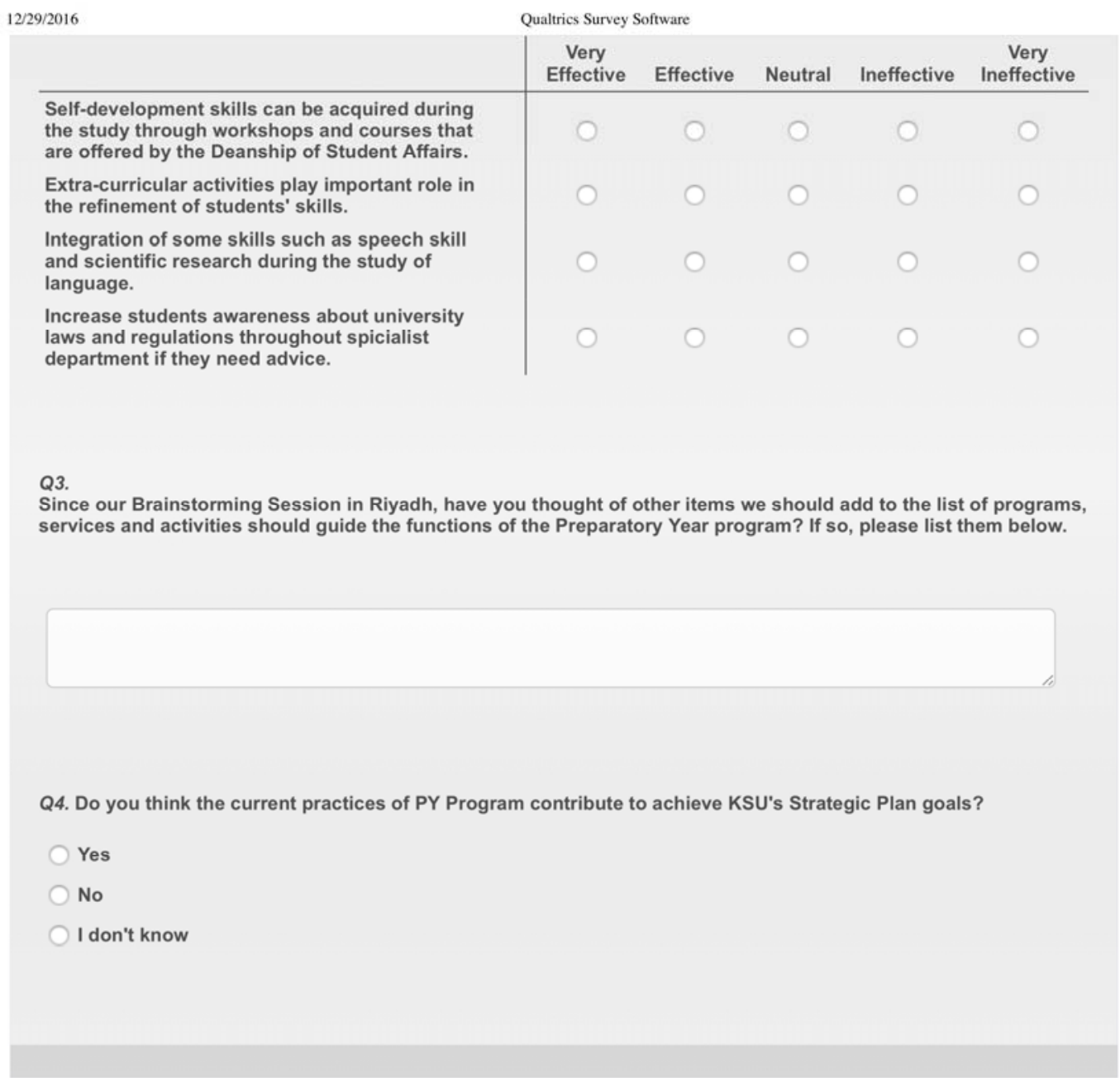


Appendix D: Dendrogram or Hierarchical Cluster Tree Acquired from the Hierarchical

\section{Cluster Analysis Showing Cluster Membership for Each Item in the Male Group}

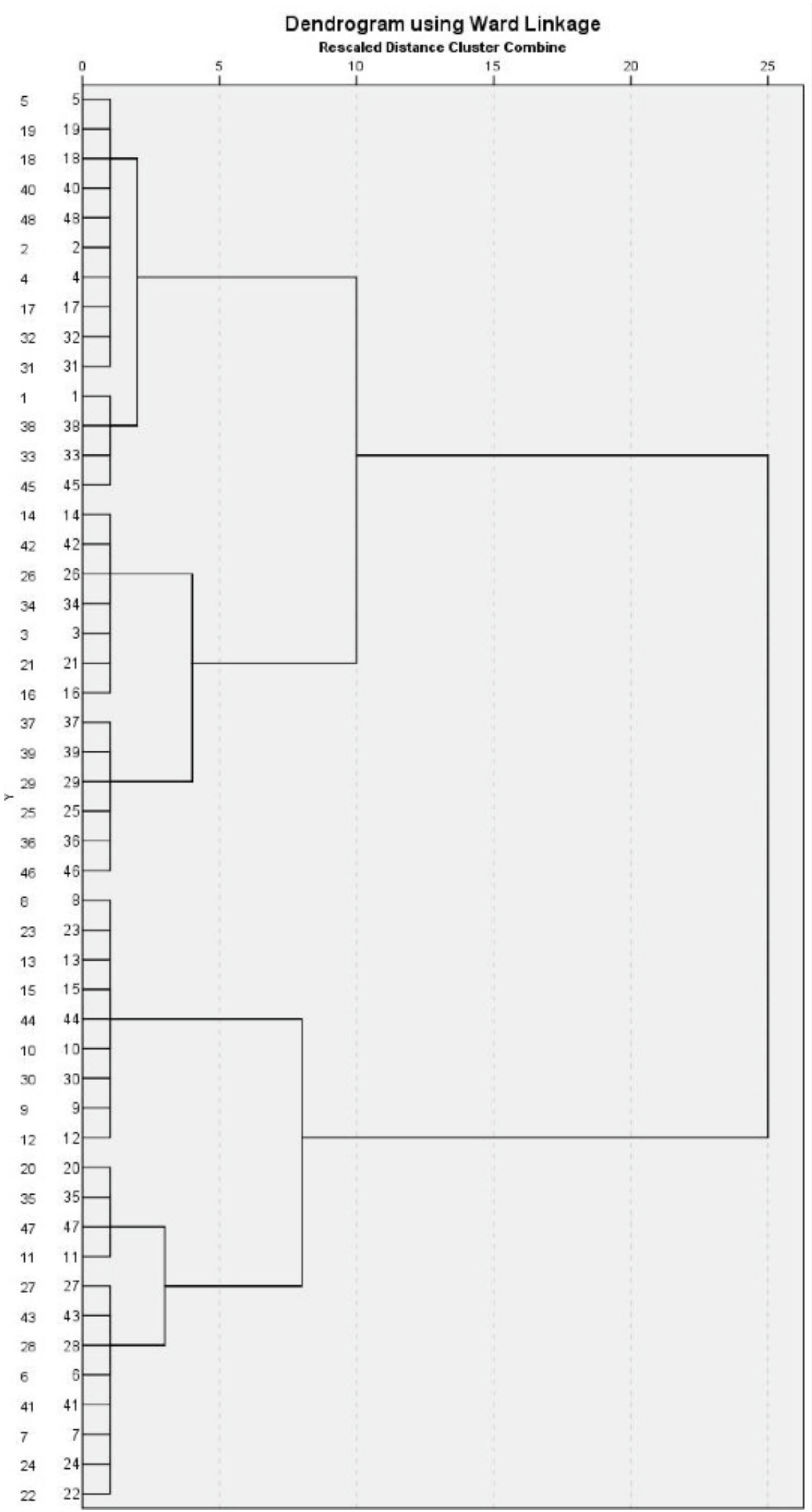


Appendix E: Dendrogram or Hierarchical Cluster Tree Acquired from the Hierarchical Cluster Analysis Showing Cluster Membership for Each Item in the Female Group

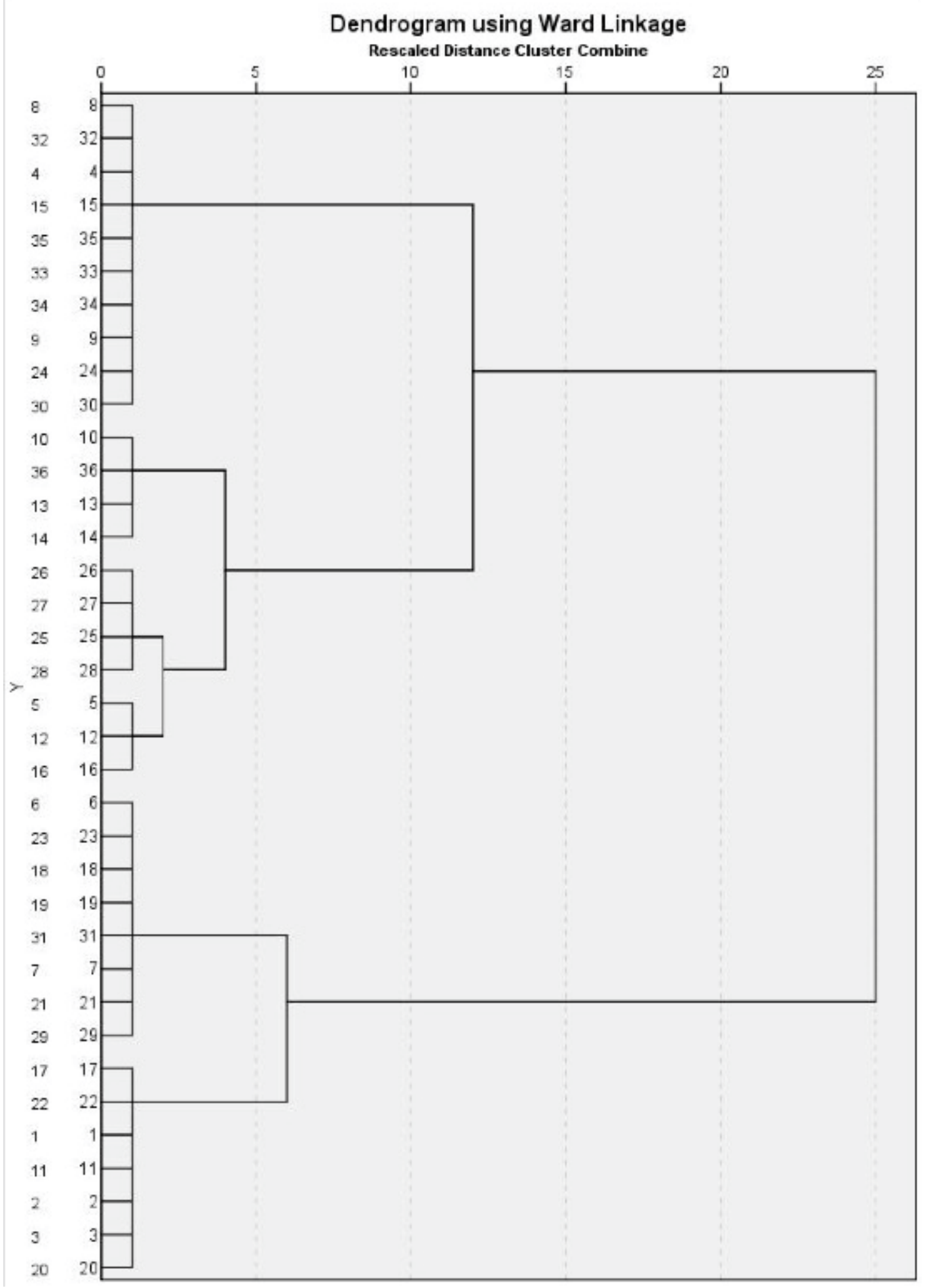




\section{Appendix F_1: Verification of the Translation Process}

\begin{tabular}{|c|c|}
\hline 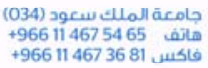 & 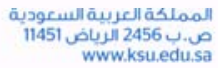 \\
\hline
\end{tabular}

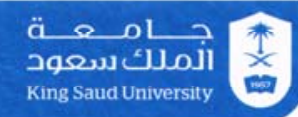

May 29, 2016

Dear Committee Members of Atiyah Alghamdi's Dissertation in Educational Leadership \& Policy Studies at West Virginia University

I am writing this letter to assert that Mr. Atiyah Alghamdi has correctly translated all research documents, written in both English and Arabic, for the purpose of his dissertation research.

1 have read the items generated by participants for both groups of participants (female and male) after the brainstorming sessions that were conducted on 10/27-28/2015 at King Saud University. I certify that Mr. Alghamdi's translation is correct and all the items are correctly translated from Arabic into English in both versions, being fluent in both English and Arabic languages.

For further questions please do not hesitate to contact me.

Sincerely,

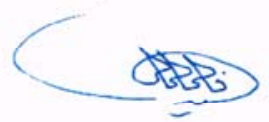

Fayez Alghamdi, Ph.D.

Assistant Professor of English

Department of English Language and Literature

College of Arts

King Saud University

P.O. Box 2456

Riyadh 11451

Kingdom of Saudi Arabia

Office: +966114948895

Mobile: +966553383373

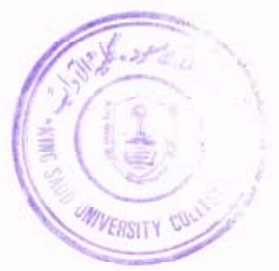




\section{Appendix F_2: Verification of the Translation Process}

July 5,2015

West Virginia University Review Board for the Protection of Human Research (IRB) 886 Chestnut Ridge Road,

PO Box 6845 Morgantown,

WV 26506-6845

Dear Members of the West Virginia University Institutional Review Board,

I am writing this letter to assert that Mr. Atiyah Alghamdi has correctly translated all research documents, written in both English and Arabic, for the purposes of his dissertation research.

I have read the cover letter, translated from English to Arabic. Being fluent in both English and Arabic, I certify that Mr. Alghamdi's translation is correct.

In addition, once Mr. Alghamdi collects data as part of his research, I will also work with him to ensure that items generated by participants during the brainstorming process are correctly translated from Arabic to English.

Sincerely,

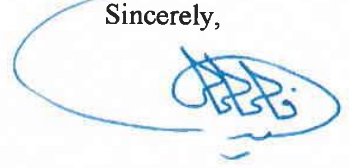

Fayez Alghamdi, Ph.D

Assistant Professor of English

Department of English Language and Literature

College of Arts

King Saud University

P.O. Box, 2456

Riyadh 11451

Kingdom of Saudi Arabia

Office: +966112899625

Mobile: +966553383373 


\section{Appendix G: List of the 48 Statements with Mean Scores for Importance and Efficacy and Cluster Membership from 3-10 for Male}

\section{Group}

\begin{tabular}{|c|c|c|c|c|c|c|c|c|c|c|c|c|c|c|c|c|c|c|c|c|c|c|c|c|c|c|c|c|}
\hline \multirow{2}{*}{ Arabic ltems } & \multirow{2}{*}{ English Items } & \multicolumn{9}{|c|}{$\begin{array}{l}\text { How important is this program, service or activity for first year students at King Saud } \\
\text { University? }\end{array}$} & \multicolumn{9}{|c|}{ 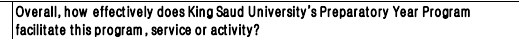 } & \multicolumn{9}{|c|}{ Cluster Membership } \\
\hline & & & & & & & & & $\begin{array}{l}\text { Vely } \\
\text { Unimmortan }\end{array}$ & |Total & & & & & & & & & & & & & & & & & & \\
\hline 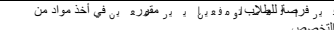 & Give sudents who meet riteria of spedific cours an opportunity to register & $50.00 \%$ & 7 & $42.86 \%$ & 67 & $7.14 \%$ & $0.00 \%$ & & $0.00 \%$ & 14 & $28.57 \%$ & 4 & $21.43 \%$ [ & \begin{tabular}{l|l}
3 & 0 \\
0
\end{tabular} & $0.00 \% / 0$ & $21.43 \%$ & \begin{tabular}{|l|l|}
3 & $28.57 \%$ \\
\end{tabular} & & 14 & 1 & 1 & 1 & 1 & 1 & & & & \\
\hline 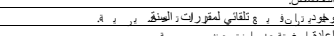 & mechanisisns for the Prepar atory Yyear courses & $\frac{50.0 \% \%}{57.14 \%}$ & $\frac{7}{8}$ & $\frac{4286 \%}{1.2296}$ & \begin{tabular}{|l|l}
67 \\
22 \\
2
\end{tabular} & $\frac{7.14 \%}{2143 \%}$ & $0.00 \%$ & & $0.00 \%$ & $\frac{14}{14}$ & $\frac{1429 \%}{285 \%}$ & $\frac{2}{4}$ & $\frac{28.5 \% \%}{285.6 \%}$ & \begin{tabular}{|l|l}
$4 \frac{7}{4}$ \\
442
\end{tabular} & 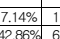 & 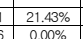 & $28.5 \%$ & & $\frac{14}{14}$ & $\frac{2}{3}$ & $\frac{2}{3}$ & 2 & 2 & 1 & 1 & & $\frac{1}{2}$ & 1 \\
\hline 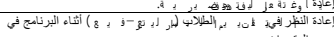 & Feoronulater & & $\left|\frac{8}{4}\right|$ & & 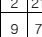 & & $0.00 \%$ & & & $\begin{array}{ll}0 & 14 \\
0 & 14 \\
\end{array}$ & & $\frac{4}{4}$ & & & & 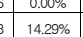 & $21.43 \%$ & & $\frac{14}{14}$ & $\frac{3}{2}$ & $\frac{3}{2}$ & $\frac{3}{2}$ & $\frac{3}{2}$ & & $\frac{2}{1}$ & & & \\
\hline 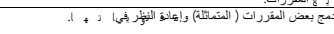 & Integating & $35.71 \%$ & 5 & $57.14 \%$ & \begin{tabular}{|l|l|l|l}
8 & 7 \\
\end{tabular} & $7.14 \%$ & $0.00 \%$ & & $0.00 \%$ & 14 & $21.43 \%$ & 3 & $14,29 \%$ & & $28.57 \%$ & $1422 \% \%$ & $21.43 \%$ & & 14 & 2 & 2 & 2 & 2 & 1 & & & & \\
\hline 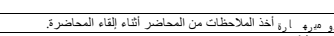 & 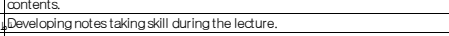 & $35.71 \%$ & & $42.86 \%$ & & $14.29 \%$ & $7.14 \%$ & & $0.00 \%$ & 14 & $21.43 \%$ & & $21.43 \%$ & & & $21.43 \%$ & $21.43 \%$ & & 14 & $\frac{4}{4}$ & $\frac{4}{4}$ & & & & & & & \\
\hline 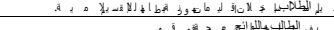 & is the basicso of profession: & $\frac{50.00 \%}{50.00 \%}$ & $\frac{7}{7}$ & \begin{tabular}{|l}
$35.71 \%$ \\
$50.00 \%$
\end{tabular} & 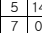 & $14.29 \% \%$ & $0.00 \%$ & & $0.00 \%$ & $\begin{array}{ll}0 & 14 \\
0 & 14 \\
\end{array}$ & $28.5 \% \%$ & $\frac{4}{6}$ & $\frac{14.29 \%}{2.85 \%}$ & 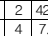 & & $\frac{7.14 \%}{1420 \%}$ & $\frac{7.14 \%}{7.14 \%}$ & & $\frac{14}{14}$ & $\frac{4}{5}$ & $\frac{4}{5}$ & $\frac{4}{5}$ & $\frac{4}{5}$ & $\frac{3}{4}$ & $\frac{3}{4}$ & & $\frac{3}{4}$ & 3 \\
\hline 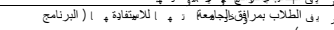 & 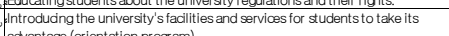 & $64.29 \%$ & 9 & $28.57 \%$ & \begin{tabular}{|l|l}
47 & 7 \\
\end{tabular} & $7.14 \%$ & $0.00 \%$ & & $0.00 \%$ & $\begin{array}{ll}0 & 14 \\
0 & 14 \\
\end{array}$ & $35.71 \%$ & 5 & $35.71 \%$ & \begin{tabular}{|l|l|l|l}
4 & 7 \\
\end{tabular} & 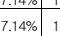 & $7.14 \%$ & $14.29 \%$ & & 14 & $\frac{5}{6}$ & $\frac{5}{6}$ & $\frac{5}{5}$ & $\frac{5}{5}$ & $\frac{4}{4}$ & 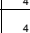 & & $\frac{4}{4}$ & $\frac{3}{3}$ \\
\hline & & & & & & & & & & & & & & & & & & & & & & & & & & & & \\
\hline 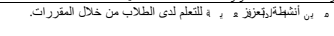 & 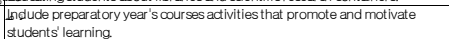 & $50.00 \%$ & 7 & $35.71 \%$ & \begin{tabular}{|l|l}
5 & 7 \\
\end{tabular} & $7.14 \%$ & $7.14 \%$ & & $0.00 \%$ & $\begin{array}{ll}0 & 14 \\
\end{array}$ & $35.71 \%$ & 5 & $28.57 \%$ & 428 & $28.57 \% / 4$ & $0.00 \%$ & $7.14 \%$ & & 14 & 7 & 7 & 6 & 6 & 5 & & & & \\
\hline 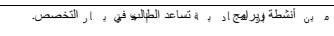 & sand guidance progorams to help sudents make a dedision & $50.00 \%$ & 7 & $42.86 \%$ & \begin{tabular}{|c|c|c|c|}
6 & 7 \\
\end{tabular} & $7.14 \%$ & $0.00 \%$ & & $0.00 \%$ & 014 & $35.71 \%$ & 5 & $21.43 \%$ & 3 & $28.57 \%$ & $7.14 \%$ & $7.14 \%$ & & 14 & 6 & 6 & 5 & 5 & & & & & \\
\hline 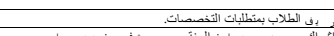 & about majors' requirements. & $50.0 \% \%$ & 7 & $42.86 \%$ & 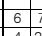 & $7.14 \%$ & $0.00 \%$ & & $0.00 \%$ & 0 14 & $28.5 \%$ & 4 & $28.57 \%$ & $\frac{14}{12}$ & & $21.43 \%$ & $7.14 \%$ & & 14 & 5 & 5 & 5 & 5 & 4 & & & & \\
\hline 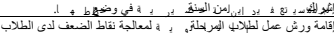 & 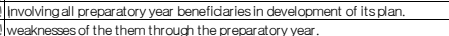 & $\begin{array}{l}50.0 \% \% \\
35.7 \% \\
\end{array}$ & 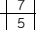 & \begin{tabular}{|l|l|l|l|l}
$35.71 \%$ \\
\end{tabular} & 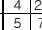 & $\frac{21.43 \%}{7.13 \%}$ & $\frac{0.02 \%}{1429 \%}$ & & $0.0 .0 \%$ & $\begin{array}{ll}0 & 14 \\
1 & 14\end{array}$ & $\frac{21.43 \%}{28.5 \%}$ & $\frac{3}{4}$ & $\frac{21.43 \%}{21.3 \% \%}$ & \begin{tabular}{|l|l|l|l|l|l|l|}
3 & 28 \\
\end{tabular} & $\begin{array}{ll}8.57 \% & 4 \\
7.14 \% & 1\end{array}$ & \begin{tabular}{|l|l|l|l}
$.00 \%$ \\
$0.0 \%$
\end{tabular} & $21.43 \% \%$ & & $\frac{14}{14}$ & $\frac{3}{5}$ & $\frac{3}{5}$ & $\frac{3}{5}$ & $\frac{3}{5}$ & $\frac{2}{4}$ & $\frac{2}{4}$ & & & $\frac{2}{3}$ \\
\hline 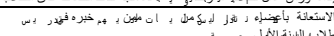 & 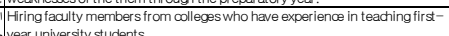 & $21.43 \%$ & 3 & $42.86 \%$ & \begin{tabular}{|l|l|l|l}
6 & 3 \\
\end{tabular} & $35.71 \% 5$ & $0.00 \%$ & & $0.00 \%$ & 014 & $28.5 \%$ & 4 & $21.43 \%$ & 30 & $0.00 \%$ & $28.5 \%$ & $21.43 \%$ & & 14 & 3 & 3 & 3 & 3 & 2 & & & & \\
\hline 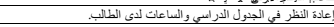 & of timetable and students's schedule. & $35.71 \%$ & & $50.00 \%$ & & $14.29 \% 22$ & $0.00 \%$ & & $0.00 \%$ & 14 & $21.43 \% \%$ & & & & & $7.14 \%$ & $28.5 \%$ & & 14 & 2 & $=$ & $=$ & $=$ & & & & & \\
\hline & & $35.71 \%$ & & $21.43 \%$ & & $42.86 \%$ & $0.00 \%$ & & $0.00 \%$ & 14 & $\frac{21.43 \%}{2.190 \%}$ & & 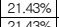 & & & $\frac{14.29}{21.35}$ & $0.00 \%$ & & $\frac{14}{14}$ & $\frac{2}{2}$ & & $\frac{2}{2}$ & & & & & & \\
\hline 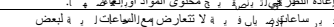 & 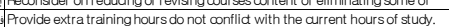 & $\frac{30.0 \% \%}{21.43 \%}$ & & 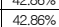 & $\frac{10}{62}$ & 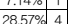 & $\frac{0.00 \%}{7.14 \%}$ & & $0.00 \%$ & $\frac{14}{14}$ & $\frac{21.45 \%}{28.57 \%}$ & $\frac{3}{4}$ & $\begin{array}{l}2.255 \% \\
2857 \%\end{array}$ & 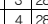 & 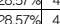 & $\frac{21.43 \%}{714 \%}$ & $\frac{7.14 \%}{7.14 \%}$ & & $\frac{14}{14}$ & 2 & 2 & $\frac{2}{6}$ & & $\frac{1}{5}$ & 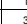 & & & 1 \\
\hline 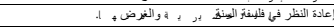 & Feconsider on the philososphy of the preparatory year andits purpose. & $57.14 \%$ & & $28.57 \%$ & & $7.14 \%$ & $7.14 \%$ & & 0.009 & 14 & $21.43 \%$ & 3 & $21.43 \%$ & $\sqrt{328}-250$ & $28.57 \% 4$ & $0.00 \%$ & $28.57 \%$ & & 14 & & 3 & & & & & & & \\
\hline 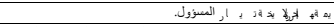 & Deverthoing the skills of responsible choice freedom. & $42.86 \%$ & 6 & $35.71 \%$ & 52 & $21.43 \% 3$ & $0.00 \%$ & & $0.00 \%$ & $\begin{array}{l}0.14 \\
\end{array}$ & $21.43 \%$ & 3 & $21.43 \%$ & 335 & $35.71 \%$ - 5 & $14.29 \%$ & $7.14 \%$ & & 14 & 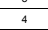 & $\frac{4}{4}$ & 4 & $e_{4}$ & 3 & & & & 3 \\
\hline 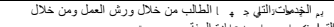 & 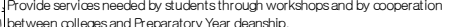 & $35.71 \%$ & 5 & $50.00 \%$ & 777 & $7.14 \% \mid 1$ & $7.14 \%$ & & $0.00 \%$ & 0 & $21.43 \%$ & 3 & $28.5 \% \%$ & 428 & $28.57 \%$ & $14.29 \%$ & $7.14 \%$ & & 14 & 5 & 5 & 5 & 5 & & & & & 3 \\
\hline is & 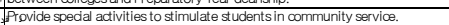 & $35.71 \%$ \% & 5 & $42.86 \%$ & & $7.14 \%$ & $14.29 \%$ & & 0.00 & 14 & $42.80 \%$ & 6 & $14.29 \%$ & & $28.57 \% 4$ & 14.2. & 0.00 & & 14 & & & & & & & & & \\
\hline 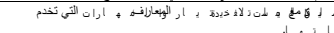 & beneficiary to choose knowledge & $50.00 \%$ & 7 & $50.00 \%$ & 70 & $0.00 \%$ & $0.00 \%$ & & $0.00 \%$ & 14 & $35.71 \%$ & 5 & $7.14 \%$ & & $21.43 \% 3$ & $21.43 \%$ & $14.29 \%$ & & 14 & 8 & 8 & 7 & 7 & 6 & 5 & & & 2 \\
\hline & EPeparatory Year with ace & & & & & 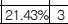 & & & & 14 & & & $7.14 \%$ & & & & & & 14 & & & & & & & & & \\
\hline 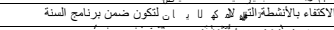 & other oolleges (10 not provide extra & & 6 & & 42 & & $0.00 \%$ & & & 14 & & 4 & $14.29 \%$ & 235 & & & & & 14 & & & ${ }^{4}$ & & & & & & 3 \\
\hline 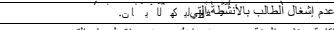 & . & $42.8 \%$ & 6 & $35.71 \%$ & 522 & $21.43 \% \mathrm{f}^{3}$ & $0.00 \%$ & & $0.00 \%$ & 14 & $21.43 \%$ & 3 & $21.43 \%$ & 328 & $28.57 \%$ / 4 & \begin{tabular}{l|l|}
4 & $28.57 \%$ \\
\end{tabular} & $0.00 \%$ & & 14 & 9 & ${ }^{4}$ & ${ }^{4}$ & ${ }^{4}$ & 3 & & & & 3 \\
\hline 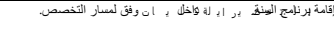 & 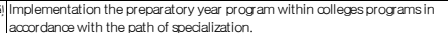 & $42.86 \%$ & 6 & $35.71 \%$ & 5 5 7 & $7.14 \%$ & $7.14 \%$ & & $7.14 \%$ & 14 & $7.14 \%$ & 1 & $28.57 \%$ & \begin{tabular}{|l|l|l|l|l|l}
4 & 14
\end{tabular} & $14.29 \% 2$ & $21.43 \%$ & $28.57 \%$ & & 14 & 10 & 9 & 8 & 7 & 6 & & & & 2 \\
\hline 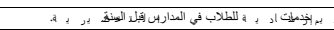 & earatotory & $57.14 \%$ & 8 & $28.57 \%$ & 47 & $7.14 \%$ & $0.00 \%$ & & 7.149 & 14 & 35.71 & 5 & $14.29 \%$ & & $21.43 \% 3$ & $7.14 \%$ & 21.4: & & 14 & 6 & 6 & 5 & 5 & ${ }^{4}$ & & & & 3 \\
\hline 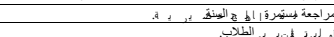 & 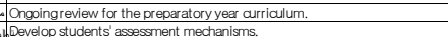 & $\frac{64.29 \%}{50.0 \% \%}$ & $\begin{array}{ll}9 \\
7\end{array}$ & $\begin{array}{l}35.71 \% \\
50.00 \% \\
\end{array}$ & $\begin{array}{ll}5 \\
79\end{array}$ & $0.00 \%$ & $0.00 \%$ & & $\frac{0.009}{0.098}$ & \begin{tabular}{|c|c|}
14 \\
14
\end{tabular} & $\frac{42.86}{21.43}$ & \begin{tabular}{|c|c|c|}
6 \\
3
\end{tabular} & $28.5 \%$ & 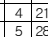 & 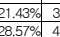 & $\frac{0.00 \%}{14.29 \%}$ & $\frac{7.144}{0.00}$ & & $\frac{14}{14}$ & $\frac{2}{2}$ & $\frac{2}{2}$ & $\frac{2}{2}$ & & 1 & & & & $\frac{1}{1}$ \\
\hline 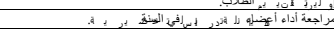 & efformance of faulity members & $57.14 \%$ & 8 & 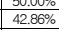 & \begin{tabular}{|l|l|l}
6 & 0 \\
& 0
\end{tabular} & $0.00 \%$ & $0.00 \%$ & & $0.00 \%$ & $\frac{14}{14}$ & $\frac{-42.45 \%}{42.8 \%}$ & $\frac{3}{6}$ & 21.43\% & \begin{tabular}{|l|l|l|l|l|l|}
328 \\
228 \\
\end{tabular} & $88.57 \% 6 / 4$ & $\frac{14.29 \%}{0.00 \%}$ & 7.148 & & $\frac{14}{14}$ & & & & & & & & & $\frac{1}{1}$ \\
\hline شركاتك. & 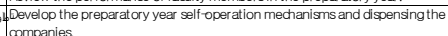 & $42.86 \%$ & 6 & $42.86 \%$ & 6 & $7.14 \%$ & $7.14 \%$ & & $0.00 \%$ & 14 & $21.43 \%$ & 3 & $14.29 \%$ & 228 & $28.57 \% 4$ & $7.14 \%$ & $28.5 \%$ & & 14 & 3 & 3 & 3 & 3 & 2 & & & 2 & 2 \\
\hline 年 & 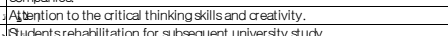 & $35.71 \%$ & $\frac{5}{9}$ & \begin{tabular}{|l|l|l}
$50.00 \%$ \\
25.576
\end{tabular} & $\begin{array}{lll}7 & 1 \\
4 & \end{array}$ & $\frac{14.29 \% 2}{7.140 \% 1}$ & $0.00 \%$ & & $0.00 \%$ & 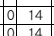 & $28.5 \% \%$ & \begin{tabular}{l|l}
4 \\
4
\end{tabular} & $\begin{array}{l}35.71 \% \\
21.4 \% 6\end{array}$ & \begin{tabular}{|l|l|l|l|l|}
5221 \\
3221
\end{tabular} & 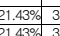 & $\frac{7.14 \%}{7.20 \%}$ & $\frac{7.14 \%}{1.2206}$ & & $\frac{14}{14}$ & $\frac{7}{8}$ & $\frac{7}{8}$ & $\frac{6}{7}$ & 6 & 5 & 3 & & 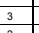 & 3 \\
\hline 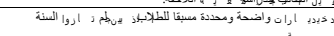 & 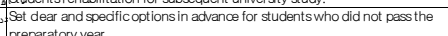 & $71.43 \%$ & 10 & $14.29 \%$ & 21 & $14.29 \% 2$ & $0.00 \%$ & & $0.00 \%$ & o. 14 & $28.5 \%$ & 4 & $21.43 \%$ & $\begin{array}{ll}37 & 7 \\
\end{array}$ & $7.14 \% / 1$ & $14,29 \%$ & $28.5 \%$ & & 14 & ${ }_{10}$ & 9 & 8 & 7 & 6 & & & & \\
\hline تونئي & & $50.00 \%$ & & $35.71 \%$ & & $14.29 \% 2$ & $0.00 \%$ & & $0.00 \%$ & 14 & $21.43 \%$ & & $21.43 \%$ & & $14.29 \% / 2$ & $7.14 \%$ & $35.71 \%$ & & 14 & & & & 1 & & & & & 1 \\
\hline 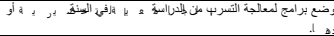 & $\begin{array}{l}\text { Devell } \\
\text { beyon }\end{array}$ & $64.29 \%$ & 9 & $21.43 \%$ & 31 & $14.299 \% 2$ & $0.00 \%$ & & $0.00 \%$ & 14 & $35.71 \%$ & 5 & $7.14 \%$ & & $28.57 \%$ & \begin{tabular}{|l|l|}
4 & $0.00 \%$ \\
\end{tabular} & $28.5 \%$ & & 14 & 10 & 9 & 8 & 7 & 6 & 5 & & & 2 \\
\hline 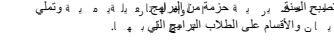 & 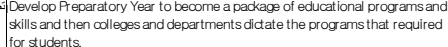 & $71.43 \%$ & 10 & $14.29 \%$ & 2 & $14.299 \% 2$ & $0.00 \%$ & & $0.00 \%$ & 14 & $28.5 \%$ & 4 & $21.43 \%$ & 328 & $28.57 \%$ & 4 & $7.14 \%$ & & 14 & 2 & ${ }^{2}$ & 2 & 2 & & & & & 1 \\
\hline 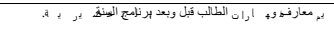 & dent's Krowledge and skills before and after the preparatory year & $57.14 \%$ & 8 & $21.43 \%$ & 3 & $7.14 \%$ | 1 & $7.14 \%$ & & $7.14 \%$ & 14 & $21.43 \%$ & 3 & $21.43 \%$ & \begin{tabular}{|l|l}
3 & 14 \\
\end{tabular} & $14.29 \% 2$ & $28.5 \%$ & $14.29 \%$ & & 14 & 4 & 4 & ${ }^{4}$ & ${ }^{4}$ & 3 & 3 & & 3 & 3 \\
\hline 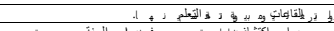 & tepevelop & & 5 & & 62 & & & & & & & 6 & 35.7 & 5 & 2.4.45\% & & & & & 3 & 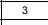 & & 3 & & & & & \\
\hline 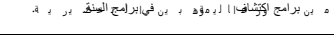 & lindudiog and take & $64.29 \%$ & 9 & $21.43 \%$ & 3 & $14.29 \% 2$ & $0.00 \%$ & & $0.00 \%$ & 14 & $42.86 \%$ & 6 & $21.43 \%$ & & $28.57 \%$ & $7.14 \%$ & $0.00 \%$ & & 14 & 9 & 4 & 4 & 4 & 3 & & & & 3 \\
\hline 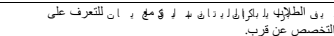 & 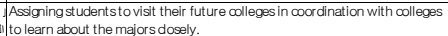 & $57.14 \%$ & 8 & $21.43 \%$ & 3 & $14.29 \% 2$ & $7.14 \%$ & & $0.00 \%$ & 14 & $28.5 \%$ & 4 & $28.57 \%$ & \begin{tabular}{|l|l|l|l|l|l}
4 & 14 \\
\end{tabular} & $14.29 \% 2$ & $21.43 \%$ & $7.14 \%$ & & 14 & 5 & 5 & 5 & 5 & ${ }^{4}$ & 4 & & & 3 \\
\hline 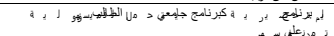 & $\begin{array}{l}\text { introod } \\
\text { suden }\end{array}$ & $64.29 \%$ & 9 & $28.57 \%$ & 4 & 7.14\% & $0.00 \%$ & & $0.00 \%$ & 14 & $28.57 \%$ & 4 & $28.57 \%$ & 435 & $35.71 \% 5$ & $7.14 \%$ & $0.00 \%$ & & 14 & 1 & 1 & 1 & 1 & 1 & 1 & & 1 & 1 \\
\hline 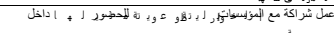 & 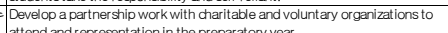 & $42.86 \%$ & 6 & $50.00 \%$ & 7 & |7.14\% & $0.00 \%$ & & $0.00 \%$ & o 14 & $28.5 \%$ & 4 & $35.71 \%$ & & $21.43 \%$ ] 3 & $14.29 \%$ & $0.00 \%$ & & 14 & 8 & 8 & 7 & 7 & 6 & $s$ & & 2 & 2 \\
\hline 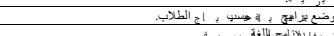 & ingprog am acoordingto students' needs & $35.71 \%$ & & $42.86 \%$ & & $7.14 \%$ & $0.00 \%$ & & 14.29\% & & $42.86 \%$ & & 28.57 & & & 7.14\% & $7.140 \%$ & & & $\frac{7}{2}$ & $\frac{7}{2}$ & $\frac{6}{2}$ & $\frac{6}{2}$ & 5 & & & 3 & 3 \\
\hline
\end{tabular}




\section{Appendix H: List of the 48 Statements with Mean Scores for Importance and Efficacy and Cluster Membership from 3-10 for Female}

\section{Group}

\begin{tabular}{|c|c|c|c|c|c|c|c|c|c|c|c|c|c|c|c|c|c|c|c|c|c|c|c|c|c|}
\hline \multirow{2}{*}{ Arabic ltems } & \multirow{2}{*}{ English Items } & \multicolumn{7}{|c|}{\begin{tabular}{|l|}
$\begin{array}{l}\text { How im portant is this program, service or activity for first year students at King Saud } \\
\text { university? }\end{array}$ \\
\end{tabular}} & \multicolumn{9}{|c|}{$\begin{array}{l}\text { Ooverall, how effectively does King Saud University's Preparatotory Year Program } \\
\text { facilitate this program, sevvice or activity? }\end{array}$} & \multicolumn{8}{|c|}{ Cluster M embership } \\
\hline & & & & & & & & & & & & & & & & & & & & & & & & \begin{tabular}{|ccc}
4 \\
Cluster
\end{tabular} & \\
\hline 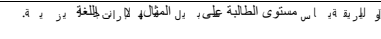 & 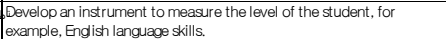 & $77.78 \%$ & 7 & $22.22 \%$ & \begin{tabular}{|c|c|c|c|c|}
2 & $0.00 \%$ & 0 \\
\end{tabular} & $0.00 \%$ & \begin{tabular}{l|l|}
0 & $0.00 \%$ \\
\end{tabular} & 9 & $55.56 \%$ & 5 & $0.00 \%$ & 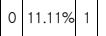 & $33.33 \%$ & & $0.00 \%$ & 0 & 9 & 1 & 1 & 1 & 1 & 1 & 1 & 1 & 1 \\
\hline 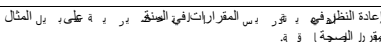 & 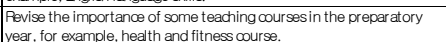 & $44.44 \%$ & 4 & $33.33 \%$ & $311.11 \%$ & $0.00 \%$ & $11.11 \%$ & 9 & $11.11 \%$ & 1 & $22.22 \%$ & $222.22 \% 2$ & $22.22 \%$ & & $22.22 \%$ & 2 & 9 & 1 & 1 & 1 & 1 & 1 & 1 & 1 & \\
\hline 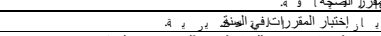 & 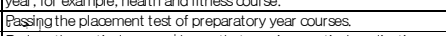 & $55.56 \%$ & 5 & $33.33 \%$ & $11.11 \% 1$ & $0.00 \%$ & $0.00 \%$ & 9 & $22.22 \%$ & 2 & $33.33 \%$ & $311.11 \% 1$ & $0.00 \%$ & & $33.33 \%$ & 3 & 9 & 1 & 1 & 1 & 1 & 1 & 1 & 1 & 1 \\
\hline 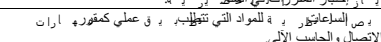 & 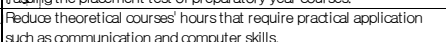 & $77.78 \%$ & 7 & $11.11 \%$ & $11.11 \% 1$ & $0.00 \%$ & $0.00 \%$ & 9 & $44.44 \%$ & 4 & $0.00 \%$ & $0 \mid 11.11 \% 1$ & $22.22 \%$ & & $22.22 \%$ & 2 & 9 & 2 & 2 & 2 & 2 & 2 & 2 & 2 & 2 \\
\hline 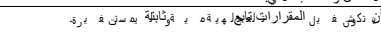 & 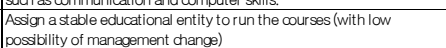 & $66.67 \%$ & 6 & $11.11 \%$ & $11.111 \%$ & $11.11 \%$ & $0.00 \%$ & 9 & $11.11 \%$ & 1 & $22.22 \%$ & $2 \mid 44.44 \%$ | 4 & $0.00 \%$ & & $22.22 \%$ & 2 & 9 & 3 & 3 & 3 & 3 & 3 & 3 & 3 & 3 \\
\hline A & Apply the cacademic placement at the beginning of prepar atory year. & $88.89 \%$ & 8 & $0.00 \%$ & $11.11 \% 1$ & $0.00 \%$ & $0.00 \%$ & 9 & $44.44 \%$ & 4 & $0.00 \%$ & $00.00 \%$ & $0.00 \%$ & & $55.56 \%$ & 5 & 9 & 4 & 4 & 4 & 4 & 4 & 4 & & 1 \\
\hline a & 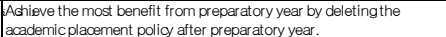 & $66.67 \%$ & 6 & $11.11 \%$ & $22.22 \% 2$ & $0.00 \%$ & $0.00 \%$ & 9 & $33.33 \%$ & 3 & $11.11 \%$ & 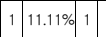 & $0.00 \%$ & 0 & $44.44 \%$ & 4 & 9 & 5 & 4 & 4 & 4 & 4 & 4 & 4 & 1 \\
\hline 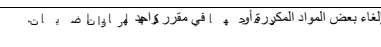 & $\begin{array}{l}\text { Canoves some of the repetitive o oursess or merge them into a single } \\
\text { course, for example math skills. }\end{array}$ & $55.56 \%$ & 5 & $33.33 \%$ & $0.00 \%|0|$ & $0.00 \%$ & $11.11 \%$ & 9 & $44.44 \%$ & 4 & $0.00 \%$ & \begin{tabular}{|l|l|l|l|l|l|l|l|l|l|l}
0 & $11.11 \%$ & 1
\end{tabular} & $11.11 \%$ & & $33.33 \%$ & 3 & 9 & 2 & 2 & 2 & 2 & 2 & 2 & 2 & 2 \\
\hline 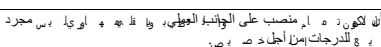 & 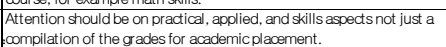 & $77.78 \%$ & 7 & $22.22 \%$ & \begin{tabular}{l|l|l|l|l|l|l|l|l}
2 & $0.00 \%$ & 0
\end{tabular} & $0.00 \%$ & $0.00 \%$ & 9 & $44.44 \%$ & 4 & $0.00 \%$ & 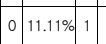 & $22.22 \%$ & & $22.22 \%$ & 2 & 9 & 6 & 5 & 5 & 5 & 2 & 2 & 2 & 2 \\
\hline 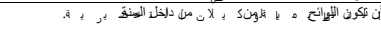 & 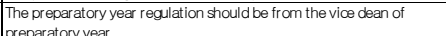 & $55.56 \%$ & 5 & $0.00 \%$ & $33.33 \% 3$ & $0.00 \%$ & $11.11 \%$ & 9 & $22.22 \%$ & 2 & $22.22 \%$ & \begin{tabular}{|c|c|c|c|c|} 
& $44.44 \%$ & 4 \\
\end{tabular} & $11.11 \%$ & & $0.00 \%$ & 0 & 9 & 7 & 6 & 6 & 6 & 5 & 5 & 3 & 3 \\
\hline 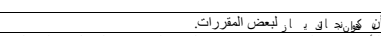 & $\begin{array}{l}\text { pereparatory year. } \\
\text { Sudents can pass some of preparatory y year courses diredly. }\end{array}$ & $66.67 \%$ & 6 & $22.22 \%$ & $211.11 \% 1$ & $0.00 \%$ & $0.00 \%$ & 9 & $33.33 \%$ & 3 & $0.00 \%$ & $033.33 \%$ & $22.22 \%$ & & $11.11 \%$ & 1 & 9 & 1 & 1 & 1 & 1 & 1 & 1 & 1 & 1 \\
\hline 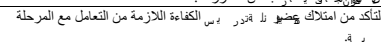 & 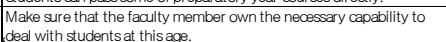 & $77.78 \%$ & 7 & $11.11 \%$ & $0.00 \%$ & $11.11 \%$ & $0.00 \%$ & 9 & $55.56 \%$ & 5 & $0.00 \%$ & $0.33 .33 \%$ & $11.11 \%$ & & $0.00 \%$ & 0 & 9 & 3 & 3 & 3 & 3 & 3 & 3 & 3 & 3 \\
\hline & incosidents about their rights and duties. & $55.56 \%$ & 5 & $44.44 \%$ & $0.00 \% 0$ & $0.00 \%$ & $0.00 \%$ & 9 & $33.33 \%$ & 3 & $33.33 \%$ & $333.33 \%$ & $0.00 \%$ & & $0.00 \%$ & 0 & 9 & 8 & 7 & 6 & 6 & 5 & 5 & 3 & 3 \\
\hline & eorientation prog am for students befóre & $66.67 \%$ & 6 & $22.22 \%$ & $11.11 \% 1$ & $0.00 \%$ & $0.00 \%$ & 9 & $55.56 \%$ & 5 & $22.22 \%$ & \begin{tabular}{|l|l|}
2 & $22.22 \%$ \\
2
\end{tabular} & $0.00 \%$ & & $0.00 \%$ & 0 & 9 & 8 & 7 & 6 & 6 & 5 & 5 & 3 & 3 \\
\hline 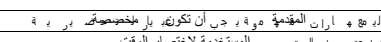 & Allskills are important and should not just be in $t$ & $33.33 \%$ & & $44.44 \%$ & $422.22 \% 2$ & $0.00 \%$ & $0.00 \%$ & 9 & $22.22 \%$ & 2 & $22.22 \%$ & $244.44 \% 4$ & $0.00 \%$ & & $11.11 \%$ & & 9 & 2 & 2 & 2 & 2 & 2 & 2 & 2 & 2 \\
\hline 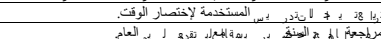 & 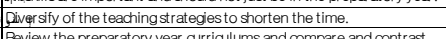 & $66.67 \%$ & 6 & $33.33 \%$ & $\begin{array}{lll}30.00 \% & 0 \\
\end{array}$ & $0.00 \%$ & 0.00 & 9 & $33.33 \%$ & 3 & $22.22 \%$ & $244.44 \% 4$ & $0.00 \%$ & & $0.00 \%$ & & & & & & & & & & \\
\hline 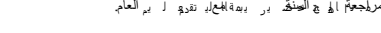 & 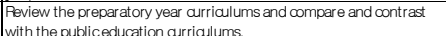 & $100.00 \%$ & 9 & $0.00 \%$ & $0.00 \%$ & $0.00 \%$ & $0.00 \%$ & 9 & $33.33 \%$ & 3 & $11.11 \%$ & $122.22 \% 2$ & $22.22 \%$ & & $11.11 \%$ & & 9 & 9 & 8 & 7 & 1 & 1 & 1 & 1 & 1 \\
\hline 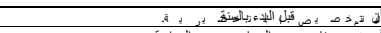 & Siludent & $77.78 \%$ & 7 & $11.11 \%$ & $11.11 \% 1$ & 0.009 & 0.00 & & $33.33 \%$ & & $11.11 \%$ & \begin{tabular}{|l|l|l|l|l}
1 & $0.00 \%$ & 0 \\
\end{tabular} & $11.11 \%$ & & 44,44 & & & & & & & & & & 1 \\
\hline 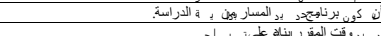 & iajore since the first day of tsudy. & $88.89 \%$ & $\frac{8}{5}$ & $0.00 \%$ & $11.11 \% / 1$ & 0.009 & 0.00 & 9 & 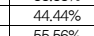 & $\frac{4}{5}$ & $11.11 \%$ & 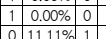 & $\frac{22.22 \%}{2020 \%}$ & & $\frac{22.22}{1.11}$ & & $\frac{9}{9}$ & 4 & 4 & 4 & 4 & 4 & 4 & & 1 \\
\hline 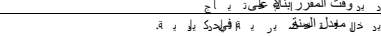 & 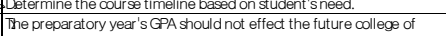 & $\frac{55.5 \% \%}{44.44 \%}$ & $\frac{5}{4}$ & $\frac{3.33 \%}{44.44 \%}$ & 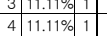 & $0.00 \%$ & 0.00 & $\frac{9}{9}$ & $\frac{5.56}{22.22}$ & $\frac{5}{2}$ & $\mid 0.00 \%$ & $\mid \begin{array}{ll}\mid 011.119 \% \\
133.33 \% \\
\end{array}$ & $2.22 \% \%$ & & $1.11 .3 \%$ & $\frac{1}{3}$ & $\frac{9}{9}$ & & $\frac{1}{4}$ & $\frac{1}{4}$ & $\frac{1}{4}$ & $\frac{1}{4}$ & $\frac{1}{4}$ & & $\frac{1}{1}$ \\
\hline 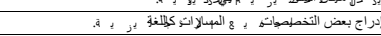 & oks such as English. & $44.44 \%$ & 4 & $11.11 \%$ & $44.44 \% 4$ & $0.00 \%$ & $0.00 \%$ & 9 & $22.22 \%$ & & $22.22 \%$ & 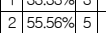 & $0.00 \%$ & & $0.00 \%$ & & 9 & & 8 & & & & 1 & & 1 \\
\hline 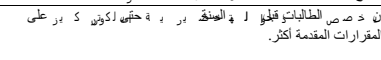 & $\begin{array}{l}\text { Apply academic plaament for all students before entering the } \\
\text { prepparatory year to make student's focaus on academic achieverement. } \\
\text { more }\end{array}$ & $88.89 \%$ & 8 & $0.00 \%$ & $11.11 \%$ & $0.00 \%$ & $0.00 \%$ & 9 & $22.22 \%$ & 2 & $22.22 \%$ & \begin{tabular}{|c|c|c|c|c|}
2 & $0.00 \%$ & 0 \\
\end{tabular} & $11.11 \%$ & & $44.44 \%$ & 4 & 9 & 4 & 4 & 4 & 4 & 4 & 4 & 4 & 1 \\
\hline 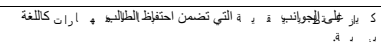 & 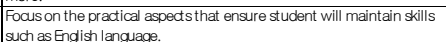 & $88.89 \%$ & 8 & $11.11 \%$ & $0.00 \%$ & $0.00 \%$ & $0.00 \%$ & 9 & $22.22 \%$ & 2 & 33.33\% & \begin{tabular}{|l|l|l|} 
& $22.22 \%$ & 2 \\
\end{tabular} & $11.11 \%$ & & $11.11 \%$ & 1 & 9 & 6 & 5 & 5 & 5 & 2 & 2 & 2 & 2 \\
\hline 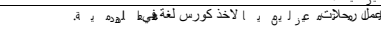 & it for distind students to study the English & $44.44 \%$ & 4 & $11.11 \%$ & $22.22 \% 2$ & $22.22 \%$ & $0.00 \%$ & 9 & $33.33 \%$ & 3 & $\mid 11.11 \%$ | & 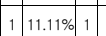 & $11.11 \%$ & & $33.33 \%$ & 3 & 9 & 10 & 9 & 8 & 7 & 6 & 3 & 3 & 3 \\
\hline 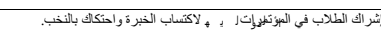 & 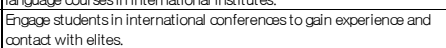 & $55.56 \%$ & 5 & $22.22 \%$ & $22.22 \% 2$ & $0.00 \%$ & $0.00 \%$ & 9 & $44.44 \%$ & 4 & $11.11 \%$ & \begin{tabular}{|l|l|l} 
& $33.33 \%$ & 3 \\
\end{tabular} & $0.00 \%$ & & $11.11 \%$ & & 9 & 10 & 9 & 8 & 7 & 6 & 3 & 3 & 3 \\
\hline (ل) & & $55.56 \%$ & 5 & $33.33 \%$ & $311.11 \% 1$ & 0.0 & & 9 & 33.33 & 3 & $22.22 \%$ & \begin{tabular}{|l|l|}
$233.33 \% 3$ \\
3
\end{tabular} & $11.11 \%$ & & $0.00 \%$ & & 9 & 10 & 9 & 8 & 7 & 6 & 3 & & 3 \\
\hline 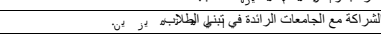 & Partnershit & & 6 & $11.11 \%$ & 111.1 & $\frac{11.11}{111}$ & & $\frac{9}{9}$ & 22.2 & 2 & 22.2 .2 & & $22.22 \%$ & & $11.11 \%$ & & 9 & 10 & 9 & 8 & 7 & 6 & 3 & & 3 \\
\hline & To be apt & 44. & 4 & & 133.339 & & & & 11.11 & & $11.11 \%$ & $133.33 \%$ & $11.11 \%$ & & 33.33 & & & & 4 & & 4 & & & & \\
\hline 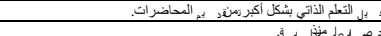 & 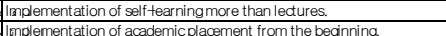 & $55.56 \%$ & $\begin{array}{l}5 \\
8 \\
\end{array}$ & $44.44 \%$ & 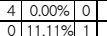 & $0.00 \%$ & $0.00 \%$ & \begin{tabular}{c|c}
9 \\
9
\end{tabular} & $\frac{11.11 \%}{44.44 \%}$ & $\frac{1}{4}$ & $\begin{array}{ll}33.33 \% \\
0.00 \%\end{array}$ & 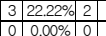 & $33.33 \%$ & & $0.00 \%$ & $\frac{0}{4}$ & $\begin{array}{l}9 \\
\end{array}$ & $\frac{6}{4}$ & $\frac{5}{4}$ & $\frac{5}{4}$ & $\frac{5}{4}$ & $\frac{2}{4}$ & $\frac{2}{4}$ & $\frac{2}{4}$ & $\frac{2}{1}$ \\
\hline 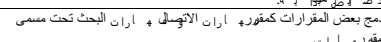 & 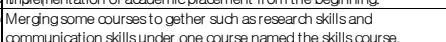 & $44.44 \%$ & 4 & $3.33 \%$ & $3111.11 \% 1$ & $0.00 \%$ & $11.11 \%$ & 9 & $22.22 \%$ & 2 & $11.11 \%$ & \begin{tabular}{|c|c|}
1 & $11.11 \%$ \\
\end{tabular} & $11.11 \%$ & & $44.44 \%$ & & 9 & 2 & 2 & 2 & 2 & 2 & 2 & 2 & 2 \\
\hline 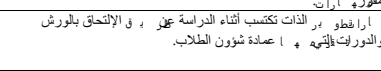 & 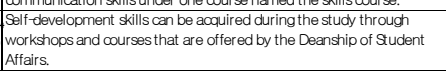 & $44.44 \%$ & 4 & $11.11 \%$ & $11.11 \%$ & $0.00 \%$ & $33.33 \%$ & 9 & $22.22 \%$ & 2 & $0.00 \%$ & $022.22 \%$ & $22.22 \%$ & & 33.33\% & 3 & 9 & 6 & 5 & 5 & 5 & 2 & 2 & 2 & 2 \\
\hline 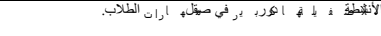 & Ia advivities slay important role in the refinement of & $55.56 \%$ & 5 & $33.33 \%$ & $\begin{array}{ll}3 & 11.11 \% \\
1\end{array}$ & $0.00 \%$ & $0.00 \%$ & 9 & $44.44 \%$ & 4 & $33.33 \%$ & $322.22 \% 2$ & $0.00 \%$ & & $0.00 \%$ & 0 & 9 & 6 & 5 & 5 & 5 & 2 & 2 & 2 & 2 \\
\hline 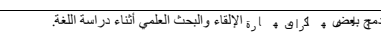 & 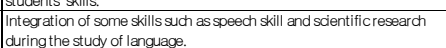 & $44.44 \%$ & 4 & $22.22 \%$ & $22.22 \% 2$ & $0.00 \%$ & $11.11 \%$ & 9 & $22.22 \%$ & 2 & $0.00 \%$ & $44.44 \% \%$ & $11.11 \%$ & & $22.22 \%$ & $2^{2}-20$ & 9 & 2 & 2 & 2 & 2 & 2 & 2 & 2 & 2 \\
\hline 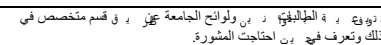 & $\begin{array}{l}\text { Inceases studutents swarenenss about university laws and } \\
\text { throughout spicalist department if they need advice. }\end{array}$ & $44.44 \%$ & 4 & 44.44\% & $4 \mid 11.11 \%$ & $0.00 \%$ & $0.00 \%$ & 9 & $22.22 \%$ & 2 & 55.56\% & $5222.22 \% 2$ & $0.00 \%$ & & $0.00 \%$ & & 9 & 7 & 6 & 6 & 6 & 5 & 5 & 3 & 3 \\
\hline
\end{tabular}


WestVirginiaUniversity.

COLLEGE OF EDUCATION AND HUMAN SERVICES

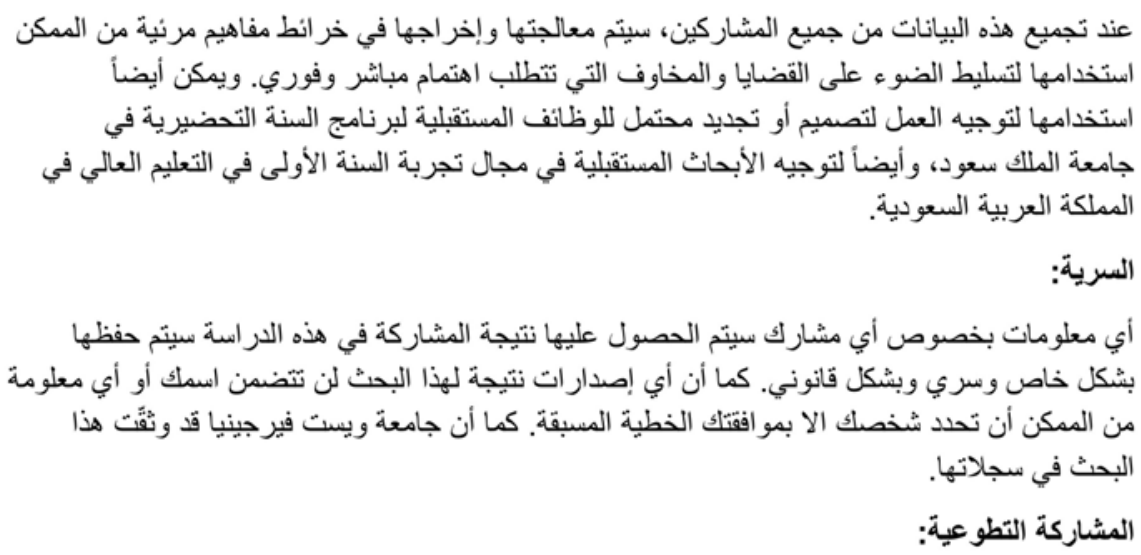

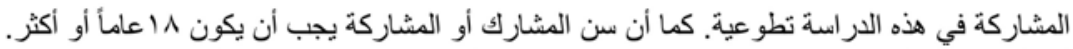

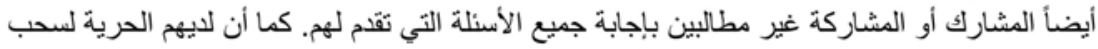

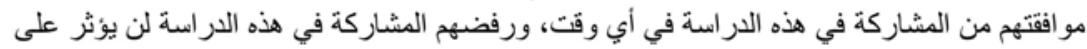

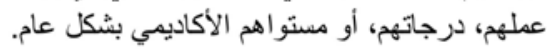

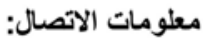

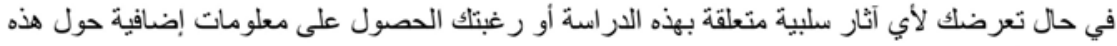

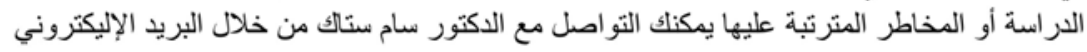

(sam.stack@mail.wvu.edu)

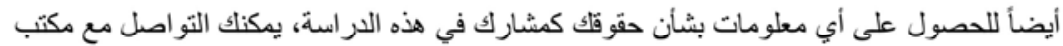
الالتزام البحثي من خلال البريد الالكتروني (ORIC@mail.wvu.edu) مع التحية والثقدير.

Sincerely,

sam F. stack Jr.

Sam Stack, Ph.D.

Professor

Coordinator Interdisciplinary PhD

College of Education and Human Services

sstack@mail.wvu.edu

304.293.2071

DEPARTMENT OF CURRICULUM \& INSTRUCTION/ITERACY STUDIES

PO Box 6122 | 602 Allen Hall

Morgantown, WW 26506-6122

ब $304.293 .3441 \quad \mathbf{\square} 304.293 .3802$ 


\title{
Appendix I_2: IRB Cover and Recruitment Script Letter (English Version)
}

\author{
W.WestVirginiaUniversity. \\ COLLEGE OF EDUCATION AND HUMAN SERVICES
}

Sep 30, 2015

\section{Dear participant:}

Introduction

You have been asked to participate in this research study, which has been explained to you Mr. Atiyah Alghamdi. This study is being conducted by Mr. Alghamdi and Dr. Sam Stack, Professor in the Department of Curriculum and Instruction/Literacy Studies at West Virginia University (WVU) in the United States. Mr. Atiyah Alghamdi is a Ph.D candidate in Educational Leadership and Policy Studies at West Virginia University.

\section{Purpose of the study}

The purpose of this study is to conceptualize the future ideal functions of the Preparatory Year Program to help first year students successfully transition into of college/university at King Saud University. To accomplish this goal, two diverse groups of stakeholders, male and female, representing different perspectives on the topic of First Year Experience, will be convened separately for brainstorming sessions to help conceptualize this domain.

\section{Description of procedures}

For this study, you will join a group of about 20 individuals for a brainstorming session that will last approximately 2 hours. You will be asked to identify What programs, services and activities should guide the functions of the Preparatory Year program? As these programs, services and activities are identified, they will be recorded as a list of items. Once the final list of items is determined, you will asked to work independently to sort the items into groups of meaningfully related piles and label the piles. You will then be instructed to rate the items, using an anonymous online survey, by addressing:

1. How important is this program, service or activity for first year students at King Saud University? (Very Unimportant; Unimportant; Neutral; Important; Very Important)

2. Overall, how effectively does King Saud University's Preparatory Year Program facilitate this program, service or activity? (Very Ineffective; Ineffective; Neutral; Effective; Very Effective).

Once these data is collected from all participants, the information will be constructed into visual concept maps that can be used to pinpoint issues and concerns needing more immediate attention. Additionally, this information can be used to design potential innovations for the King Saud University, and guide the future functions of the Preparatory Year Program and future research into first year experience in Saudi higher education context. 
WestVirginiaUniversity.

COLLEGE OF EDUCATION AND HUMAN SERVICES

\section{Confidentiality}

Any information about you that is obtained as a result of your participation in this study will be kept as confidential as legally possible. In any publications that result from this research, neither your name nor any information from which you might be identified will be published without your consent. Additionally, the West Virginia University IRB has acknowledgement of this research on file.

\section{Voluntary Participation}

Participation in this study is voluntary and participants must be of 18 years or older. You do not have to answer any of the questions presented to you. You are free to withdraw your consent to participate in this study at any time, and your refusal to participate in this study will not affect your job status, grades, or class standing.

\section{Contact Persons}

In the event you experience any consequences related to this research, or for more information about this research and about research-related risk or injury, you can contact Dr. Sam Stack at (sam.stack@mail.wvu.edu). For information regarding your rights as a research subject, you may contact the office of Research Compliance at (ORIC@mail.wvu.edu).

\section{Sincerely,}

sam F. Stack Jr.

Sam Stack, Ph.D.

Professor

Coordinator Interdisciplinary $\mathrm{PhD}$

College of Education and Human Services

sstack@mail.wvu.edu

304.293.2071 


\section{Appendix J: IRB Approval Letter}

\section{WestVirginiaUniversity. \\ Office of Research Integrity and Compliance as6 CHESNUt RLGE ROAD MORGANTOWN, WV 25606}

Acknowledgement Letter Exempt Initial Protocol Review

$\begin{array}{ll}\text { Action Date } & 10 / 09 / 2015 \\ \text { To } & \text { Samuel Stack } \\ \text { From } & \text { WVU Office of Research Integrity and Compliance } \\ \text { Approval Date } & 10 / 09 / 2015 \\ \text { Expiration Date } & 10 / 08 / 2018 \\ \text { Subject } & \text { Acknowledgement Letter Exempt Initial Protocol Review } \\ \text { Protocol Number } & 1506708861 \\ \text { Title } & \text { Using Concept Mapping/Pattern Matching to Develop a Conceptual Framework } \\ & \text { for Successful Transition of First Year Saudi Students into Postsecondary } \\ & \text { Education. }\end{array}$

The above-referenced study was reviewed by the West Virginia University Institutional Review Board IRB and was granted exemption in accordance with 45 CFR 46.101 .

- This research study was granted an exemption because the Research involves educational tests, survey procedures, interview procedures or observation of public behavior and (i) information obtained is recorded in such a manner that human subjects cannot be identified, directly or through identifiers linked to the subjects; and (ii) any disclosure of the human subjects responses outside the research could not reasonably place the subjects at risk of criminal or civil liability or be damaging to the subjects financial standing, employability, or reputation [45 CFR 46.101(2)]. All exemptions are only good for three years. If this research extends more than three years beyond the approved date, then the researcher will have to request another exemption. The following documents have been acknowledged for use in this study and are available in the WVU+kc system:

Documents reviewed and/or approved as part of this submission:

Cover Letter English Version IRB Updating-signed.pdf: 2015-10-01-04:00

Cover Letter Arabic Version IRB Updating-signed.pdf: 2015-10-01-04:00

PY's Dean Letter jpeg: 2015-09-08-04:00 
Translation Letter.PDF: 2015-09-08-04:00

Cover Letter English Version 2-signed.pdf: 2015-09-09-04:00

Cover Letter Arabic Version 2-signed.pdf: 2015-09-09-04:00

Documents for use in this study have been acknowledged and are available in the WVUkc system in the Notes and Attachments section of your protocol.

The Office of Research Integrity and Compliance is here to provide assistance to you from the initial submission of an IRB protocol and all subsequent activity. Please feel free to contact us by phone at 304.293 .7073 with any question you may have. Thank you.

WVU Office of Research Integrity and Compliance

Date: 10/09/2015

Signed:

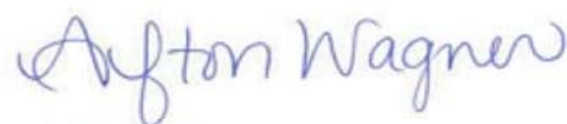

Afton Wagner

IRB Administrator 


\section{Appendix K: List of the 48 Outcomes with Mean Scores for Importance and Efficacy}

\section{for Male Group}

\begin{tabular}{|c|c|c|c|c|c|c|}
\hline No & x Coordinate & y Coordinate & Item & Cluster Membership & Importanc Mean & Efficacy Mean \\
\hline 1 & -0.86807 & 0.14889 & $\begin{array}{l}\text { Enable students fulfilling certain criteria to enroll in major- } \\
\text { specific courses }\end{array}$ & 1 & 4.43 & 3.00 \\
\hline 2 & -1.41193 & 0.551 & Availability of accelerated tracks in the Preparatory Year. & 2 & 4.43 & 2.79 \\
\hline 3 & -1.14631 & -1.01828 & $\begin{array}{l}\text { Reformulating and defining the preparatory year's } \\
\text { objectives. }\end{array}$ & 3 & 4.21 & 3.86 \\
\hline 4 & -1.31768 & 0.39715 & $\begin{array}{l}\text { Revising the student assessment mechanisms (students } \\
\text { acceleration - upgrade) during the program for all courses. }\end{array}$ & 2 & 4.21 & 3.14 \\
\hline 5 & -0.90328 & 1.29177 & $\begin{array}{l}\text { Merging some of PY's similar courses after reviewing their } \\
\text { syllabi. }\end{array}$ & 2 & 4.29 & 3.00 \\
\hline 6 & 0.78255 & 0.96867 & Developing note taking skills during the lecture. & 4 & 4.07 & 3.00 \\
\hline 7 & 1.34476 & 0.55804 & $\begin{array}{l}\text { Teaching students the basics of professional ethics and } \\
\text { linking them to Islamic values. }\end{array}$ & 4 & 4.36 & 3.50 \\
\hline 8 & 1.37697 & -1.04955 & $\begin{array}{l}\text { Educating students about the university regulations and } \\
\text { their rights. }\end{array}$ & 5 & 4.50 & 3.86 \\
\hline 9 & 1.75497 & -0.68931 & $\begin{array}{l}\text { Introducing the university's facilities and services for } \\
\text { students to take its advantage (orientation program). }\end{array}$ & 5 & 4.57 & 3.71 \\
\hline 10 & 1.68384 & -0.3356 & $\begin{array}{l}\text { Educating students about libraries and scientific research } \\
\text { containers. }\end{array}$ & 5 & 4.57 & 3.57 \\
\hline 11 & -0.21238 & 1.29048 & $\begin{array}{l}\text { Include preparatory year's courses activities that promote } \\
\text { and motivate students' learning. }\end{array}$ & 6 & 4.29 & 3.86 \\
\hline 12 & 1.86142 & 0.07629 & $\begin{array}{l}\text { Include activities and guidance programs to help students } \\
\text { make a decision about their majors. }\end{array}$ & 5 & 4.43 & 3.71 \\
\hline 13 & 0.95594 & -0.68399 & Educating students about majors' requirements. & 5 & 4.43 & 3.50 \\
\hline 14 & -1.60344 & -0.84255 & $\begin{array}{l}\text { Involving all preparatory year beneficiaries in development } \\
\text { of its plan. }\end{array}$ & 3 & 4.29 & 3.14 \\
\hline 15 & 1.06502 & -0.52951 & $\begin{array}{l}\text { Developing workshops for high school students to identify } \\
\text { and address the weaknesses of the them through the } \\
\text { preparatory year. }\end{array}$ & 5 & 3.79 & 2.93 \\
\hline 16 & -0.94746 & -1.28946 & $\begin{array}{l}\text { Hiring faculty members from colleges who have experience } \\
\text { in teaching first-year university students. }\end{array}$ & 3 & 3.86 & 3.07 \\
\hline 17 & -0.96556 & 0.85875 & Reconsidering the students' timetables and credit hours. & 2 & 4.21 & 3.00 \\
\hline 18 & -0.81256 & 0.64898 & Review the medical track courses plan ( the study plan). & 2 & 3.93 & 3.50 \\
\hline 19 & -0.98366 & 1.31987 & $\begin{array}{l}\text { Reducing or revising courses content or eliminating some of } \\
\text { them. }\end{array}$ & 2 & 4.43 & 3.29 \\
\hline 20 & 0.42662 & 1.50055 & $\begin{array}{l}\text { Provide extra training hours do not conflict with the current } \\
\text { hours of study. }\end{array}$ & 6 & 3.79 & 3.64 \\
\hline 21 & -1.34708 & -1.17714 & $\begin{array}{l}\text { Revise on the philosophy of the preparatory year and its } \\
\text { purpose. }\end{array}$ & 3 & 4.36 & 3.07 \\
\hline 22 & 1.43925 & 0.96572 & Developing the skills of responsible autonomy. & 4 & 4.21 & 3.36 \\
\hline 23 & 1.16273 & -0.93116 & $\begin{array}{l}\text { Provide services needed by students through workshops } \\
\text { and by cooperation between colleges and Preparatory Year } \\
\text { deanship. }\end{array}$ & 5 & 4.14 & 3.43 \\
\hline 24 & 1.57472 & 0.39135 & $\begin{array}{l}\text { Conduct activities to encourage students to participate in } \\
\text { community service. }\end{array}$ & 4 & 4.00 & 3.86 \\
\hline 25 & 0.15617 & -1.57206 & $\begin{array}{l}\text { Coordination with beneficiary colleges to choose } \\
\text { knowledge and skills that serve its majors. }\end{array}$ & 7 & 4.50 & 3.29 \\
\hline 26 & -1.11234 & -1.10567 & The PY is not an academic placement program. & 3 & 4.29 & 3.21 \\
\hline 27 & 1.18882 & 0.14111 & $\begin{array}{l}\text { Include activities into the preparatory year program that } \\
\text { are not offered by other colleges (Do not provide } \\
\text { extracurricular activities that will offer after preparatory } \\
\text { year in colleges). }\end{array}$ & 4 & 4.14 & 3.50 \\
\hline 28 & 0.67256 & 0.51913 & Overwhelm, campus on-going activities. & 4 & 4.21 & 3.36 \\
\hline
\end{tabular}




\begin{tabular}{|c|c|c|c|c|c|c|}
\hline 29 & -0.56007 & -1.01828 & $\begin{array}{l}\text { Implementation of the preparatory year program within } \\
\text { colleges' programs in accordance with major selection. }\end{array}$ & 7 & 4.00 & 2.64 \\
\hline 30 & 1.59942 & -0.30814 & $\begin{array}{l}\text { Provide counseling services for high school students before } \\
\text { the preparatory year. }\end{array}$ & 5 & 4.29 & 3.36 \\
\hline 31 & -1.23589 & 0.71498 & Ongoing review for the preparatory year curriculum. & 2 & 4.64 & 4.00 \\
\hline 32 & -1.00459 & 0.71319 & Develop students' assessment instruments. & 2 & 4.50 & 3.64 \\
\hline 33 & -1.15171 & -0.17711 & $\begin{array}{l}\text { Review the performance of faculty members in the } \\
\text { preparatory year. }\end{array}$ & 1 & 4.57 & 3.93 \\
\hline 34 & -1.18195 & -1.15809 & $\begin{array}{l}\text { Develop the preparatory year self-operation mechanisms } \\
\text { and phasing out commerical assistance. }\end{array}$ & 3 & 4.21 & 2.93 \\
\hline 35 & 0.34123 & 1.59743 & Attention to the critical thinking skills and creativity. & 6 & 4.21 & 3.71 \\
\hline 36 & 0.24991 & -1.03062 & Students rehabilitation for subsequent university study. & 7 & 4.57 & 3.36 \\
\hline 37 & -0.07779 & -0.73205 & $\begin{array}{l}\text { Set clear and specific options in advance for students who } \\
\text { did not pass the preparatory year. }\end{array}$ & 7 & 4.57 & 3.07 \\
\hline 38 & -1.11557 & 0.21392 & $\begin{array}{l}\text { Granting a certificate for students who pass the } \\
\text { preparatory year program. }\end{array}$ & 1 & 4.36 & 2.86 \\
\hline 39 & -0.18238 & -0.35665 & $\begin{array}{l}\text { Develop programs to address students dropout in the } \\
\text { preparatory year or beyond. }\end{array}$ & 7 & 4.50 & 3.21 \\
\hline 40 & -0.68749 & 0.43722 & $\begin{array}{l}\text { Develop Preparatory Year to become a package of } \\
\text { educational programs and skills, and then colleges and } \\
\text { departments dictate the programs that required for } \\
\text { students. }\end{array}$ & 2 & 4.57 & 3.50 \\
\hline 41 & 1.04772 & 1.31834 & $\begin{array}{l}\text { Assess student's Knowledge and skills before and after the } \\
\text { preparatory year program. }\end{array}$ & 4 & 4.14 & 3.07 \\
\hline 42 & -1.53676 & -0.57063 & $\begin{array}{l}\text { Develop and improve the educational halls and learning } \\
\text { environment. }\end{array}$ & 3 & 4.14 & 4.21 \\
\hline 43 & 0.78489 & 0.01246 & $\begin{array}{l}\text { Include gifted programs within the preparatory year } \\
\text { program to discover and take care of them. }\end{array}$ & 4 & 4.50 & 4.00 \\
\hline 44 & 1.27472 & -0.68535 & $\begin{array}{l}\text { Assigning students to visit their future colleges in } \\
\text { coordination with colleges to learn about the majors } \\
\text { closely. }\end{array}$ & 5 & 4.29 & 3.50 \\
\hline 45 & -0.75999 & -0.29818 & $\begin{array}{l}\text { Introduce the preparatory year program as a university } \\
\text { program that makes students take the responsibility and } \\
\text { self-reliant. }\end{array}$ & 1 & 4.57 & 3.79 \\
\hline 46 & 0.86083 & -1.44294 & $\begin{array}{l}\text { Develop a partnership work with charitable and voluntary } \\
\text { organizations to attend and representation in the } \\
\text { preparatory year. }\end{array}$ & 7 & 4.36 & 3.79 \\
\hline 47 & 0.12292 & 1.44669 & $\begin{array}{l}\text { Develop a strengthening program according to students' } \\
\text { needs. }\end{array}$ & 6 & 3.86 & 3.93 \\
\hline 48 & -0.60203 & 0.92036 & Intensification of the English language program. & 2 & 4.36 & 3.93 \\
\hline
\end{tabular}




\section{Appendix L: List of the 36 Outcomes with Mean Scores for Importance and Efficacy for}

\section{Female Group}

\begin{tabular}{|c|c|c|c|c|c|c|}
\hline No & x Coordinate & y Coordinate & Item & Cluster Membership & Importanc Mean & Efficacy Mean \\
\hline 1 & 0.93123 & 1.16147 & $\begin{array}{l}\text { Developing an instrument to measure student level, for } \\
\text { example, English language skills. }\end{array}$ & 1 & 4.78 & 3.78 \\
\hline 2 & 0.75238 & 0.70751 & $\begin{array}{l}\text { Reassessing the importance of teaching (some) courses } \\
\text { in the preparatory year, for example, health and fitness } \\
\text { course. }\end{array}$ & 1 & 4 & 2.78 \\
\hline 3 & 0.4375 & 0.83075 & Passing the placment tests for preparatory year courses. & 1 & 4.44 & 3.11 \\
\hline 4 & -0.99354 & 0.96887 & $\begin{array}{l}\text { Reducing theoretical hours for the courses that require } \\
\text { practical application such as communication and } \\
\text { computer skills. }\end{array}$ & 2 & 4.67 & 3.22 \\
\hline 5 & -0.2366 & -0.50529 & $\begin{array}{l}\text { Assigning a stable educational entity to run the courses } \\
\text { (with low possibility of management change) }\end{array}$ & 3 & 4.33 & 3 \\
\hline 6 & 1.82683 & -0.07427 & $\begin{array}{l}\text { Applying the academic/college placement at the } \\
\text { beginning of preparatory year. }\end{array}$ & 4 & 4.78 & 2.78 \\
\hline 7 & 1.05547 & -0.02403 & $\begin{array}{l}\text { Achieving the most benefit from preparatory year (skills) } \\
\text { by abolishing the academic placement policy after } \\
\text { preparatory year. }\end{array}$ & 4 & 4.44 & 2.89 \\
\hline 8 & -0.48812 & 0.99282 & $\begin{array}{l}\text { Canceling some of the redundant courses or merging } \\
\text { them into a single course, for example, math skills. }\end{array}$ & 2 & 4.22 & 3.11 \\
\hline 9 & -1.07164 & 0.74874 & $\begin{array}{l}\text { Emphasizing practical, applied, and skills aspects not just } \\
\text { a compilation of grades for academic placement. }\end{array}$ & 2 & 4.78 & 3.22 \\
\hline 10 & -0.47794 & -1.51784 & $\begin{array}{l}\text { The preparatory year regulations should be issued by } \\
\text { the vice dean of preparatory year. }\end{array}$ & 5 & 3.89 & 3.56 \\
\hline 11 & 0.62968 & 1.28421 & $\begin{array}{l}\text { Students can pass some of preparatory year courses } \\
\text { directly. }\end{array}$ & 1 & 4.56 & 3.22 \\
\hline 12 & -0.41088 & -0.75861 & $\begin{array}{l}\text { Ensuring that faculty members have the necessary } \\
\text { capability to deal with students at this age. }\end{array}$ & 3 & 4.56 & 4 \\
\hline 13 & 0.13505 & -1.93226 & $\begin{array}{l}\text { The necessity of educating students about their rights } \\
\text { and duties. }\end{array}$ & 5 & 4.56 & 4 \\
\hline 14 & 0.4002 & -1.77142 & $\begin{array}{l}\text { The importance of the orientation program for students } \\
\text { before starting the study plan }\end{array}$ & 5 & 4.56 & 4.33 \\
\hline 15 & -0.73653 & 1.01985 & $\begin{array}{l}\text { All offered skills are important and should not be specific } \\
\text { for the preparatory year. }\end{array}$ & 2 & 4.11 & 3.44 \\
\hline 16 & -0.46616 & 0.07039 & Diversifying teaching strategies to shorten time. & 3 & 4.67 & 3.89 \\
\hline 17 & 0.70298 & 0.32202 & $\begin{array}{l}\text { Reviewing the preparatory year curriculums and } \\
\text { comparing/contrasting them with public education } \\
\text { curriculums. }\end{array}$ & 1 & 5 & 3.33 \\
\hline 18 & 1.82683 & -0.07429 & $\begin{array}{l}\text { Students academic placement to be before the } \\
\text { preparatory year. }\end{array}$ & 4 & 4.67 & 2.78 \\
\hline 19 & 1.80242 & -0.2407 & $\begin{array}{l}\text { Identifying academic track/major from the first day of } \\
\text { study. }\end{array}$ & 4 & 4.78 & 3.33 \\
\hline 20 & 0.23859 & 1.15546 & $\begin{array}{l}\text { Determining the course timeline based on students' } \\
\text { needs. }\end{array}$ & 1 & 4.44 & 3.67 \\
\hline 21 & 1.26762 & -0.46389 & $\begin{array}{l}\text { The preparatory year's GPA should not affect choosing } \\
\text { the future college of study. }\end{array}$ & 4 & 4.33 & 2.89 \\
\hline 22 & 0.43016 & -0.08755 & $\begin{array}{l}\text { The inclusion of some courses for all study tracks such as } \\
\text { English. }\end{array}$ & 1 & 4 & 3.67 \\
\hline 23 & 1.82684 & -0.07426 & $\begin{array}{l}\text { Applying academic placement for all students before } \\
\text { entering the preparatory year to make students focus } \\
\text { more on academic achievement. }\end{array}$ & 4 & 4.78 & 2.67 \\
\hline 24 & -1.16813 & 0.75872 & $\begin{array}{l}\text { Focusing on the practical aspects that ensure students } \\
\text { will maintain skills such as English language. }\end{array}$ & 2 & 4.89 & 3.44 \\
\hline
\end{tabular}




\begin{tabular}{|c|c|c|c|c|c|c|}
\hline 25 & -1.51097 & -0.48047 & $\begin{array}{l}\text { Organizing academic trips for distinguished students to } \\
\text { study English language courses in international institutes. }\end{array}$ & 6 & 3.78 & 3 \\
\hline 26 & -1.4584 & -0.7503 & $\begin{array}{l}\text { Engaging students in international conferences to gain } \\
\text { experience and contact with elites. }\end{array}$ & 6 & 4.33 & 3.78 \\
\hline 27 & -1.54163 & -0.71279 & $\begin{array}{l}\text { Publishing the outstanding research and media } \\
\text { produced by students. }\end{array}$ & 6 & 4.44 & 3.78 \\
\hline 28 & -1.30021 & -0.98192 & $\begin{array}{l}\text { Partnering with leading universities in adopting } \\
\text { outstanding students. }\end{array}$ & 6 & 4.33 & 3.22 \\
\hline 29 & 1.70519 & -0.76284 & To be a preparatory program not a preparatory year. & 4 & 3.78 & 2.56 \\
\hline 30 & -1.1298 & 0.5915 & Implementing independent learning more than lectures. & 2 & 4.56 & 3.22 \\
\hline 31 & 1.65233 & 0.18697 & Implementing academic placement from the beginning. & 4 & 4.78 & 2.89 \\
\hline 32 & -0.48812 & 0.99281 & $\begin{array}{l}\text { Merging some courses together such as research skills } \\
\text { and communication skills under one course named the } \\
\text { skills course. }\end{array}$ & 2 & 4 & 2.56 \\
\hline 33 & -1.31806 & 0.19218 & $\begin{array}{l}\text { Self-development skills can be acquired during the study } \\
\text { through workshops and courses that are offered by the } \\
\text { Deanship of Student Affairs. }\end{array}$ & 2 & 3.33 & 2.56 \\
\hline 34 & -1.43805 & 0.14501 & $\begin{array}{l}\text { Extra-curricular activities play an important role in the } \\
\text { refinement of students' skills. }\end{array}$ & 2 & 4.44 & 4.22 \\
\hline 35 & -0.81125 & 0.76099 & $\begin{array}{l}\text { Integrating some skills such as speech skill and scientific } \\
\text { research during the study of language. }\end{array}$ & 2 & 3.89 & 2.89 \\
\hline 36 & -0.57528 & -1.67757 & $\begin{array}{l}\text { Increasing student awareness about university laws and } \\
\text { regulations through a specialist department whenever } \\
\text { they need advice. }\end{array}$ & 5 & 4.33 & 4 \\
\hline
\end{tabular}


Appendix M_1: Student's Guidebook Cover for Boys Section

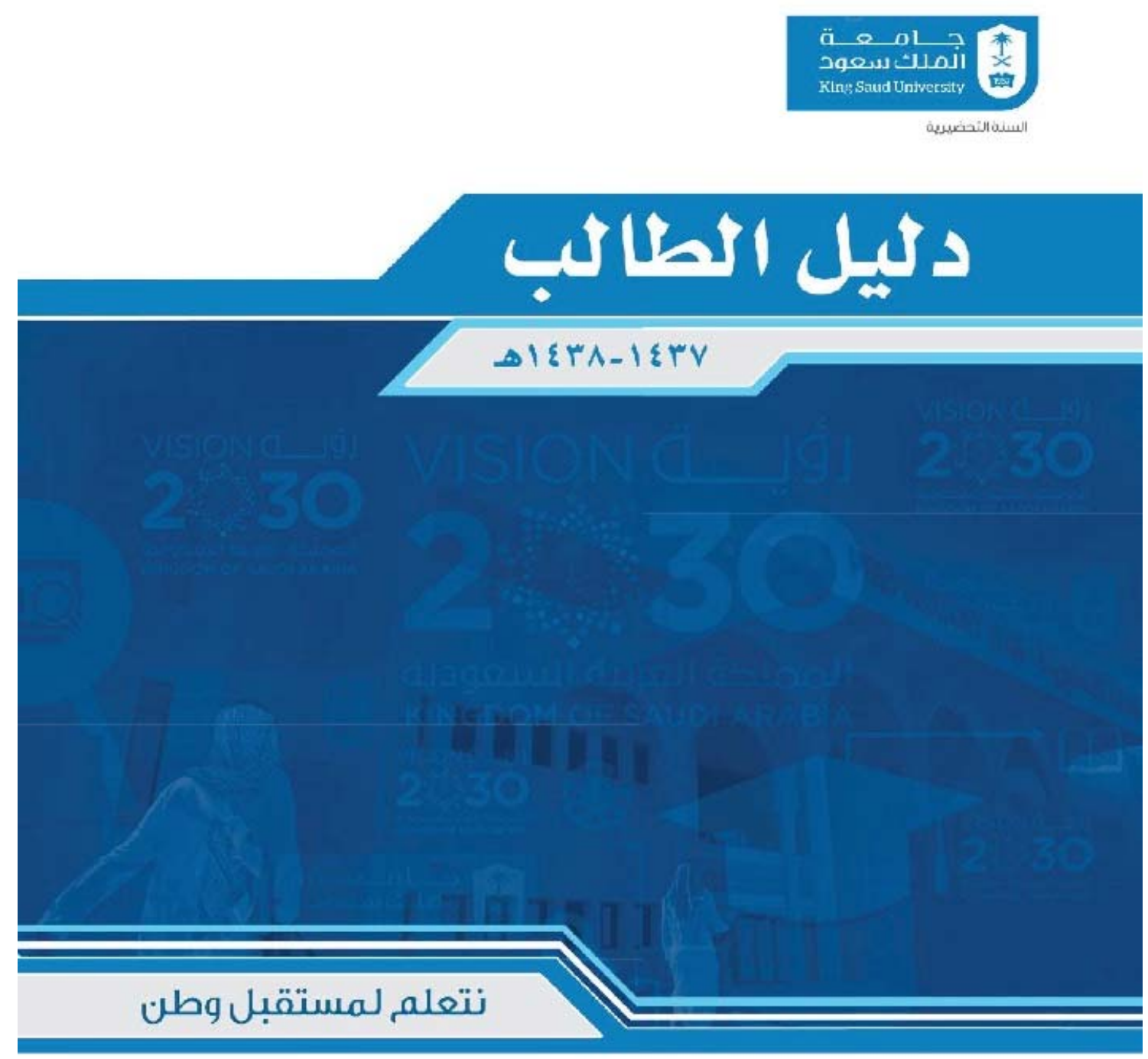


Appendix M_2: Student's Guidebook Cover for Girls Section

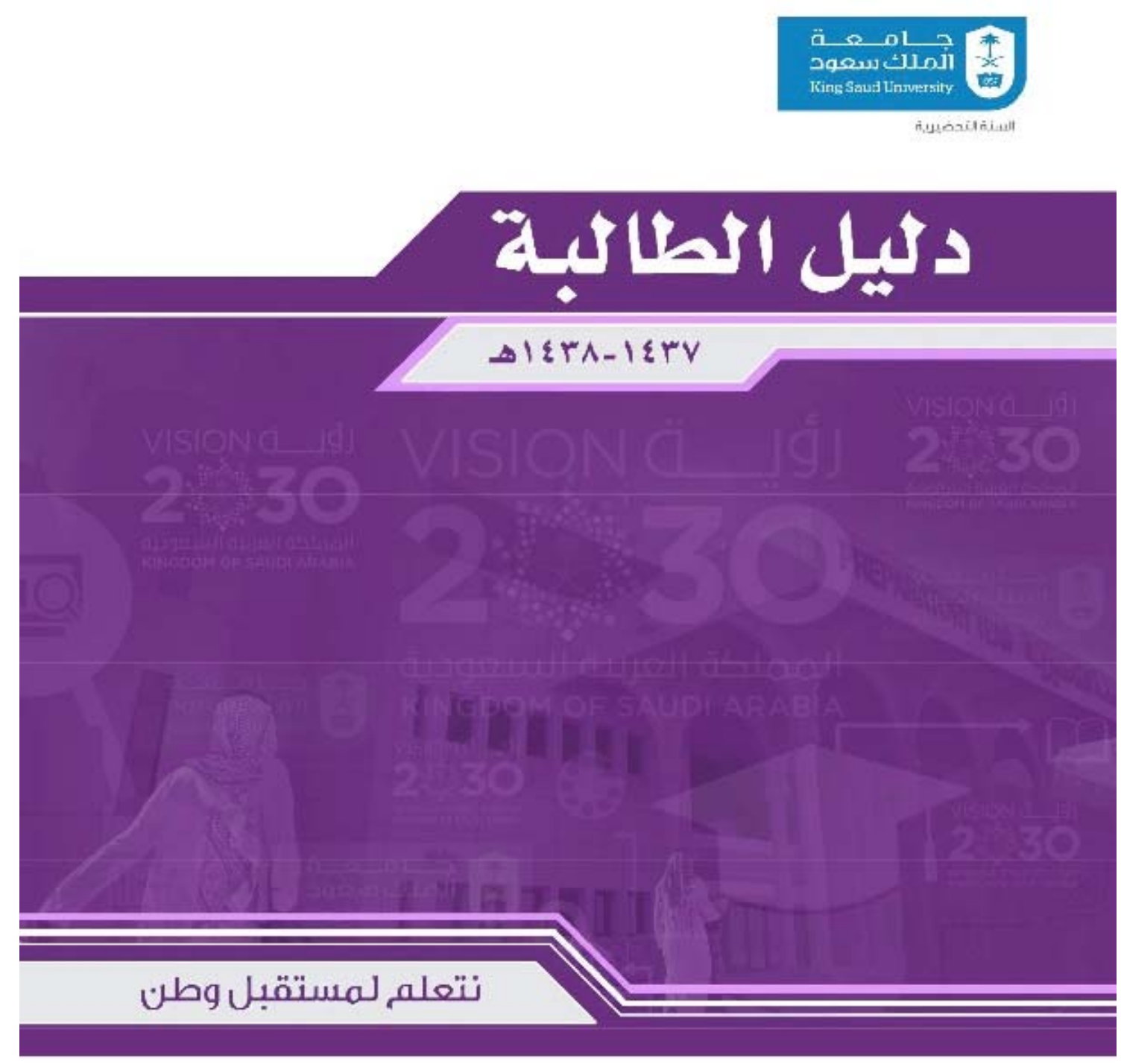


Appendix N: Student's King Saud University's Strategic Plan (KSU2030) Cover

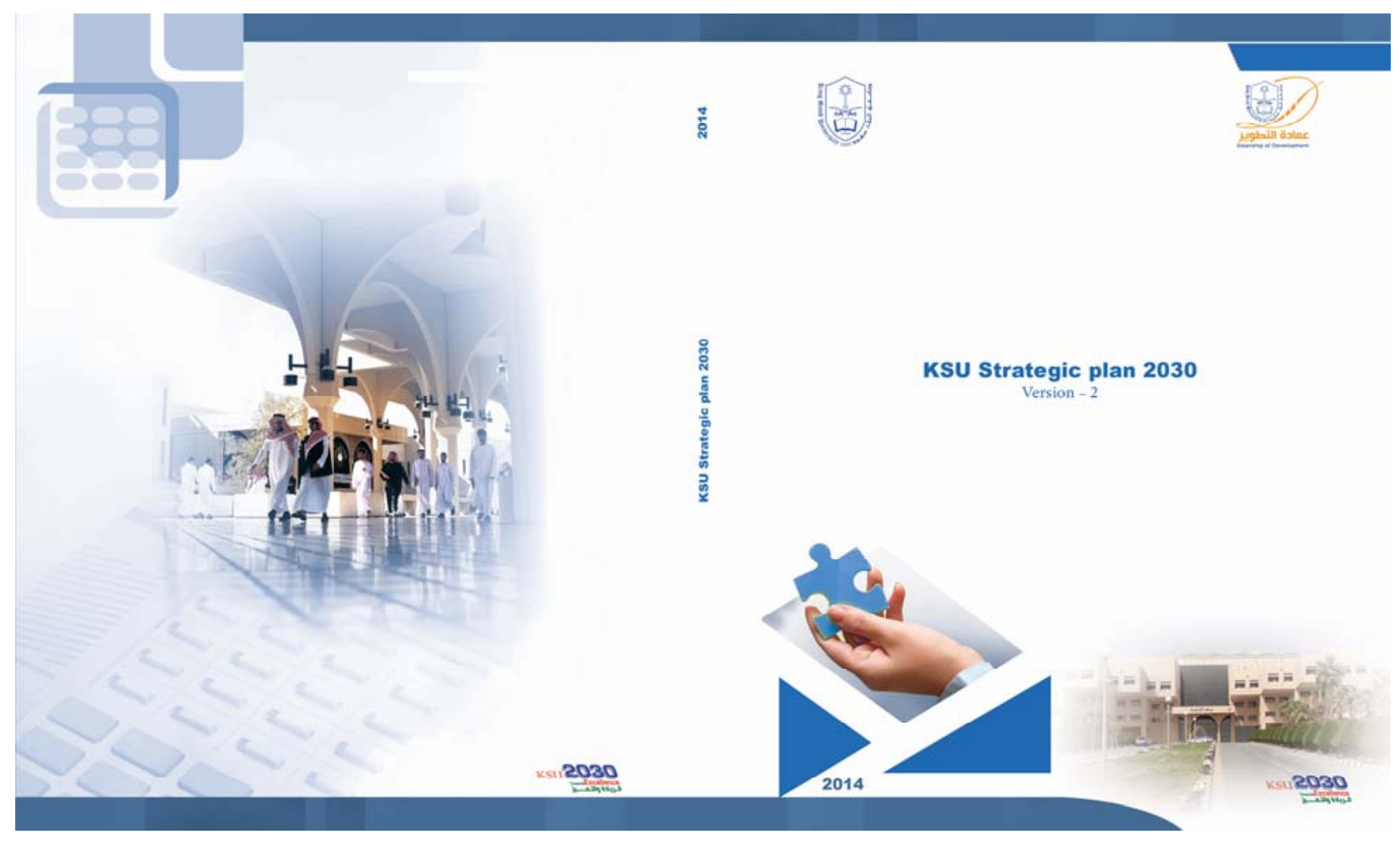




\section{Appendix O: The Comparison Matrix of KSU's Strategic Plan}

\begin{tabular}{ll}
\hline No & \multicolumn{1}{c}{ Item } \\
\hline 1 & $\begin{array}{l}\text { Mission: To provide distinctive education, produce } \\
\text { creative research, serve society and contribute in } \\
\text { building the knowledge economy and community } \\
\text { through learning, creative thinking environment, the } \\
\\
\text { optimal use of technology and effective international } \\
\text { partnership }\end{array}$
\end{tabular}

2 Vision: To be a world class university and a leader in building the knowledge society

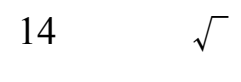

$3 \quad$ Value:

14-15 $\sqrt{ }$

7- Quality and excellence: We measure ourselves according to challenging criteria, honoring high ambitions and the pursuit of distinctiveness through our commitment to the highest intellectual standards in teaching, learning and innovation

8- Leadership and teamwork: Were main committed to promoting individual and institutional leadership roles that drive social development upholding professionalism, responsibility, and innovation.

9- Freedom of inquiry: Rigorous and honest intellectual exploration is dimensions of our scholarly activities.

10- Fairness and integrity: We abide by the principles of social justice, equal opportunity and cultural diversity, consequently holding the members of our community to the highest standards of honesty, respect, and professional ethics.

11- Transparency and accountability: We remain committed to expose our thinking and ideas for society and scholars to judge our contributions to global knowledge, and we hold accountable everybody in our community for respecting and upholding our values in all forms of their scholarly activities.

12- Lifelong learning: We are committed to lifelong learning inside and outside the KSU community, enhancing continued intellectual growth and welfare of the society. 
$4 \quad$ Strategic objective:

$156-$

10- Good everywhere; Great in focus areas

159

(Strengthen our comprehensive university with academic areas of research and teaching excellence)

11- Distinctive faculty (Attract and develop distinctive faculty)

12- Less is more (Reduce KSU's volume, increase the share of graduate students and raise entry requirements)

13- $\quad$ Stronger graduates (Enable KSU students to learn hard and soft skills throughout their academic life)

14- $\quad$ Building bridges (Build bridges among KSU constituencies and externally with local and international groups)

15- Supportive learning environment (Create an engaging environment at KSU for faculty, students, and staff)

16- Sustainable future (Build KSU's endowment and diversify sources of funding)

17- Flexibility and Accountability (Create a performance contract between KSU and the government)

18- Organizing for purpose (Establishing an organization and governance model that support KSU's mission)

5 Placement exam after preparatory year (The medical school admissions criteria)

$6 \quad$ KSU's recent introduction of the preparatory year 103 (whereby students are given foundation courses in core hard and soft skills before beginning their universitylevel studies) has started to address these gaps--64\% faculty and $55 \%$ of students agree that the preparatory year has helped improve the quality of students

$7 \quad$ Faculty and students feel that preparatory year is 104 helping improve the quality of students 
$10 \quad 55 \%$ agree; 30\% Indifferent; $15 \%$ Disagree. Percentage 104

$104 \sqrt{ }$

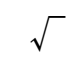
of students agreeing that the preparatory year has improved the quality of incoming students

11 Strategic implication for KSU: KSU should create a 3- 104 track preparatory year program, with a mandatory placement exam for entering undergraduate school

12 Strategic implication for KSU: KSU should ensure that 106 the skills taught during the preparatory year (English, soft skills) are developed further through the curriculum of all its academic programs. The accreditation further recommends the development of a comprehensive Learning and Teaching plan to support transition points for students, and skill-building for faculty

13 Dean of Preparatory Year program (Organization Structure)

14 Dean of Preparatory Year program (Organization Structure)

15 Recommendation 4.1: Strengthen preparatory year 222 capabilities: all students who take admission in KSU have to choose a track e.g. humanities track, Science \& Engineering, Health track etc. The installation of PY Tracks has been a huge success at the university. It is equally important to have a lasting effect on students as their one year is invested in their capabilities. The Preparatory year program seeks to strengthen the effectiveness and build capabilities in H.R., infrastructure, students etc. This would include review of Preparatory year program capabilities such a H.R., system, faculty, curriculum, infrastructure, collaboration with industry, NGO's, private sectors

16 Dean of Preparatory Year program (Organization 